\title{
Konsequente Traditionsgeschichte: Festschrift für Klaus Baltzer zum 65. Geburtstag
}

Edited by: Bartelmus, Rüdiger ; Krüger, Thomas ; Utzschneider, Helmut

\begin{abstract}
Der vorliegende Band ist Klaus Baltzer zum 65. Geburtstag gewidmet. Der Titel, „Konsequente Traditionsgeschichte", ist Klaus Baltzers Programm. Es zielt auf eine Exegese des Alten Testaments, die dessen Texte und Konzepte über Grenzen hinweg verfolgt. In Baltzers Forschung haben altorientalische wie griechische Geschichte und Literatur einen hohen Stellenwert. Die Gegenwartsbedeutung alttestamentlicher Texte und Konzepte liegt ihm am Herzen. Dem gemäß enthält dieser Band neben alttestamentlichen Artikeln Beiträge aus dem Bereich des Neuen Testaments, der griechischhellenistischen Antike sowie zur Rezeptionsgeschichte des Alten Testamens in der Neuzeit. Auch der praktisch-theologische Aspekt ist vertreten. Mitgearbeitet haben u.a.: Dieter Georgi, Manfred Görg, Baruch Halpern, Jörg Jeremias, Helmut Koester, Norbert Lohfink und Josef Scharbert.
\end{abstract}

Posted at the Zurich Open Repository and Archive, University of Zurich

ZORA URL: https://doi.org/10.5167/uzh-151422

Edited Scientific Work

Published Version

Originally published at:

Konsequente Traditionsgeschichte: Festschrift für Klaus Baltzer zum 65. Geburtstag. Edited by: Bartelmus, Rüdiger; Krüger, Thomas; Utzschneider, Helmut (1993). Freiburg, Switzerland / Göttingen, Germany: Universitätsverlag / Vandenhoeck Ruprecht. 


\section{ORBIS BIBLICUS ET ORIENTALIS}

Im Auftrag des Biblischen Instituts

der Universität Freiburg Schweiz,

des Seminars für Biblische Zeitgeschichte

der Universität Münster i. W.

und der Schweizerischen Gesellschaft

für orientalische Altertumswissenschaft

herausgegeben von

Othmar Keel

unter Mitarbeit von Erich Zenger und Albert de Pury 


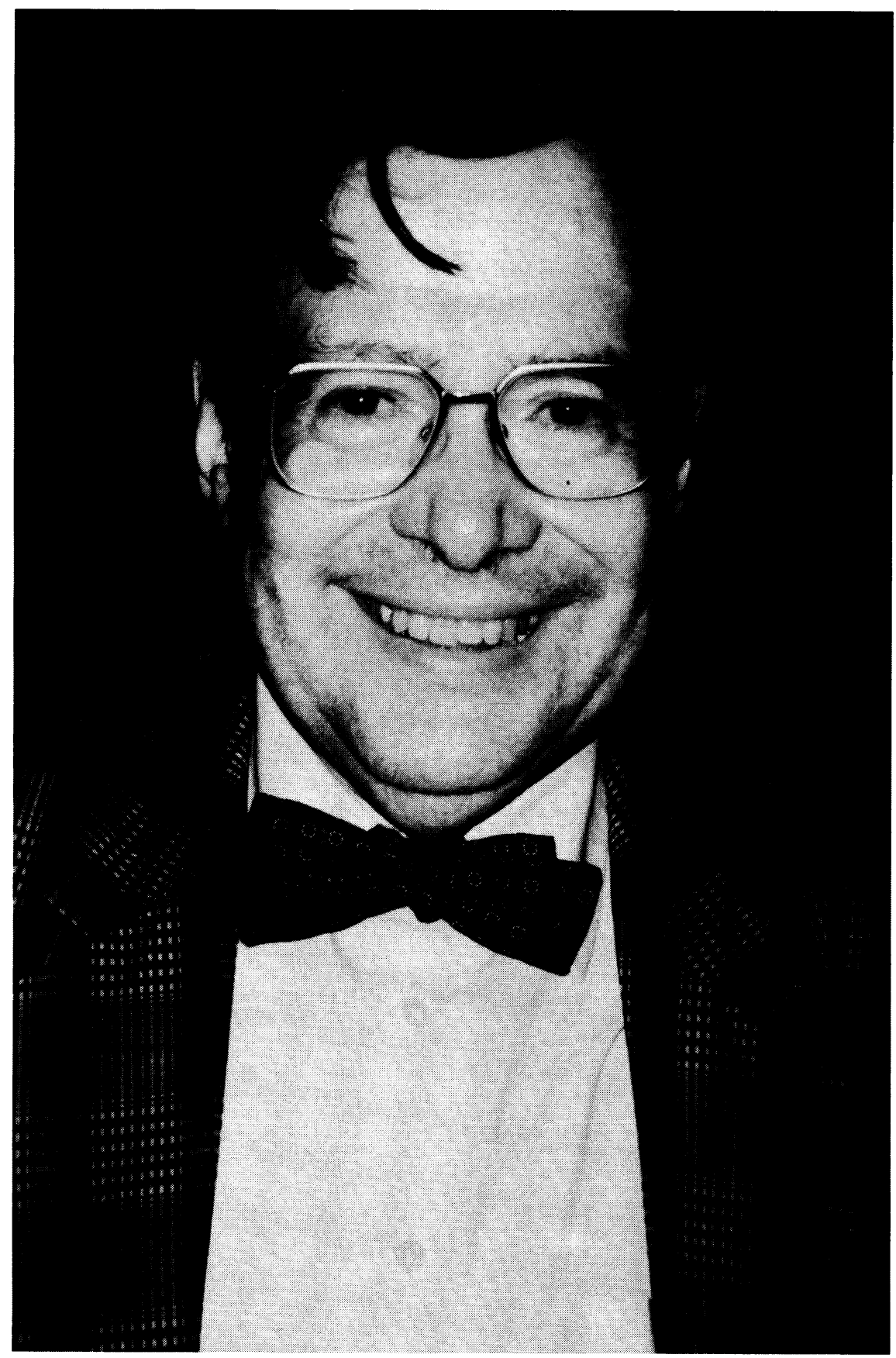




\section{Orbis Biblicus et Orientalis 126}

\section{Konsequente \\ Traditionsgeschichte}

Festschrift für Klaus Baltzer

zum 65. Geburtstag

Herausgegeben

von Rüdiger Bartelmus, Thomas Krüger und Helmut Utzschneider

Universitätsverlag Freiburg Schweiz

Vandenhoeck \& Ruprecht Göttingen 
Die Deutsche Bibliothek - CIP-Einheitsaufnahme

Konsequente Traditionsgeschichte: Festschrift für Klaus Baltzer zu seinem 65. Geburtstag / hrsg. von Rüdiger Bartelmus... - Freiburg, Schweiz: Univ.Verl.; Göttingen: Vandenhoeck und Ruprecht, 1993.

(Orbis biblicus et orientalis; 126)

ISBN 3-525-53761-1 (Vandenhoeck und Ruprecht)

ISBN 3-7278-0871-3 (Univ.-Verl.)

NE: Bartelmus, Rüdiger [Hrsg.]; GT

Die Druckvorlagen wurden vom Verfasser als reprofertige Dokumente zur Verfügung gestellt

(C) 1993 by Universitätsverlag Freiburg Schweiz Vandenhoeck \& Ruprecht Göttingen

Paulusdruckerei Freiburg Schweiz

ISBN 3-7278-0871-3 (Universitätsverlag) ISBN 3-525-53761-1 (Vandenhoeck \& Ruprecht)

Digitalisat erstellt durch Florian Lippke, Departement für Biblische Studien, Universität Freiburg Schweiz 


\section{VORWORT}

Klaus Baltzer steht für engagiertes, unkonventionelles und dabei konsequentes theologisches Denken. Seine Freunde hat er damit in unzähligen Gesprächen bereichert, seine Kollegen bisweilen überrascht. Seine Schülerinnen und Schüler hat er stets dazu ermutigt.

"Konsequente Traditionsgeschichte" ist Klaus Baltzers Programm. Es zielt auf eine Exegese des Alten Testaments, die dessen Texte und Konzepte über Grenzen hinweg verfolgt. "Konsequent" ist Traditionsgeschichte im Sinne Klaus Baltzers erst dann, wenn sie auch die Traditionen in den Blick nimmt, die bei der Exegetin oder beim Exegeten die Interpretation alttestamentlicher Texte mit bestimmen - und wenn sie die geschichtliche Bedingtheit auch dieser Traditionen deutlich macht.

Klaus Baltzer hat eine solche "grenzüberschreitende" Exegese stets selbst geübt. In seiner Forschung haben altorientalische wie griechische Geschichte und Literatur einen hohen Stellenwert. Die Gegenwartsbedeutung alttestamentlicher Texte und Konzepte liegt ihm am Herzen. Insbesondere hat er Grenzen nie anerkannt, die durch die Konventionen des alttestamentlichen Forschungs- oder Lehrbetriebs gezogen werden. Interdisziplinarität ist seit jeher ein Markenzeichen seiner akademischen Tätigkeit. "Leisten wir uns ein bißchen Universität!"- mit diesem Satz pflegt er seine interdiszplinären Seminare zu eröffnen.

Die vorliegende Festschrift will Klaus Baltzer zu seinem 65. Geburtstag am 3. März 1993 grüßen. Sie ist ein Spiegelbild und z.T. auch eine Frucht der Eigenart seines Wirkens als Theologe an der Universität: Neben alttestamentlichen Beiträgen steht eine Reihe von Artikeln, die die Grenzen des Alten Testaments überschreiten. Sie sind allesamt Zeichen des Dankes an den Jubilar. Sie mögen ihm Freude machen und den Lesern Anreiz sein, das Alte Testament grenzüberschreitend zu lesen.

Die Herausgeber danken Othmar Keel für seine Bereitschaft, den Band in die Reihe "Orbis Biblicus et Orientalis" aufzunehmen, dem Landeskirchenrat der Evangelisch-Lutherischen Kirche in Bayern für einen namhaften Druckkostenzuschuß sowie Frau Barbara Bonham, Geltendorf, Frau Andrea Siebert, Neuendettelsau und Herrn Gerhard Büsing, Bethel, für manche Hilfe beim Schreiben und Korrigieren.

München, im September 1992 


\section{INHALTSVERZEICHNIS}

\section{RUDIGER BARTELMUS}

J.S. Bach als Interpret des Alten Testaments und als "biblischer Theologe". Exegetisch-musikalische Beobachtungen zu der Motette:

"Fürchte dich nicht, ich bin bei dir" (BWV 228)

KAI BRODERSEN

Salomon in Alexandria ? Der weise Richter in 1 Könige 3, antiker Bildtradition und P. Oxy. 2944

RUSSELL FULLER

The Blessing of Levi in Dtn 33, Mal 2, and Qumran

DIETER GEORGI

Die Aristoteles- und Theophrastausgabe des Andronikus

von Rhodus. Ein Beitrag zur Kanonsproblematik

MANFRED GORG

Juda - Namensdeutung in Tradition und Etymologie

INGRID GRILL-AHOLLINGER

Biblische Gattungen als didaktische Impulse im Religionsunterricht

BARUCH HALPERN

The Baal (and the Asherah) in Seventh-Century Judah:

Yhwh's Retainers Retired

JORG JEREMIAS

Das unzugängliche Heiligtum. Zur letzten Vision des Amos (Am 9,1-4)

\section{KENICHI KIDA}

The Sovereignty of God and the Destiny of the Nations in the Prophecies of Amos, Isaiah and Jeremiah

HANS KLEIN

Zur Wirkungsgeschichte von Psalm 8

HELMUT KOESTER

Jesu Leiden und Tod als Erzählung 
THOMAS KRÜGER

Genesis 38 - ein "Lehrstück" alttestamentlicher Ethik

HEINZ-WOLFGANG KUHN

Die drei wichtigsten Qumranparallelen zum Galaterbrief.

Unbekannte Wege der Tradition

NORBERT LOHFINK

Zur Fabel in Dtn 31-32

PETER MARINKOVIC

Was wissen wir über den zweiten Tempel aus Sach 1-8?

ECKHARD VON NORDHEIM

Das Gottesurteil als Schutzordal für die Frau nach Numeri 5

ROBERT B. ROBINSON

The Coherence of the Jericho Narrative: A Literary Reading of Joshua 6

JOSEF SCHARBERT

Die Landverheissung an die Väter als einfache Zusage, als Eid und als "Bund"

EBERHARD SCHWARZ

"Ziehet aus Ihrer Mitte und sondert euch ab!"

Abgrenzung als Ursprungssituation paulinischer

Gemeindebildung. Beobachtungen zu 2 Kor 6,14 - 7,1

CHRISTOPHER R. SEITZ

The Patience of Job in the Epistle of James

HELMUT UTZSCHNEIDER

Zur vierfachen Lektüre des Alten Testaments. Bibelrezeption als Erfahrung von Diskrepanz und Perspektive 


\section{J.S. BACH ALS INTERPRET DES ALTEN TESTAMENTS UND ALS "BIBLISCHER THEOLOGE"}

Exegetisch-musikalische Beobachtungen zu der Motette: "Fürchte dich nicht, ich bin bei dir" (BWV 228)

von

Rüdiger Bartelmus

Evang.-Theol. Fakultät, Ludwig-Maximilians-Universität München

Es mag auf den ersten Blick seltsam anmuten, in einer Festschrift mit dem Titel "Konsequente Traditionsgeschichte", die einem Alttestamentler gewidmet ist, als ersten Beitrag eine Studie zu finden, die man eher in einer musikwissenschaftlichen Zeitschrift, dem Begleitheft zu einer Compactdisc oder im Programmheft zu einem Konzert erwarten würde als in einer exegetischen Publikation. Für diejenigen, die Klaus BALTZER näher kennen, erklärt sich die scheinbar exotische Themenwahl indes leicht. Neben dem Umstand, daß interdisziplinäre Seminare mit Kollegen aus höchst unterschiedlichen Fakultäten einen besonderen Schwerpunkt seines Wirkens in München gebildet haben, liegt ein wichtiger Grund für sie in dem lebhaften Interesse des Jubilars für das Sachgebiet, das seine Ehefrau einst professionell betrieben hat, und in dessen praktischer Ausübung sich Adressat und Autor vor mehr als zwanzig Jahren näher kennengelernt haben - lange bevor letzterer von Klaus BALTZER als Mitarbeiter an sein Münchner Institut geholt und bei ihm promoviert und habilitiert wurde. Die Entscheidung für dieses spezielle Thema lag allerdings nicht nur von solchen eher subjektiv-emotionalen Beweggründen her nahe - es gibt vielmehr auch eine Reihe von theologisch-sachlichen Gründen:

Bei der im folgenden unter exegetisch-musikalischen Gesichtspunkten untersuchten Motette geht es zum einen um die Vertonung von zentralen Sätzen aus dem biblischen Textbereich, mit dem sich der Jubilar seit mehr als zwanzig Jahren intensiv beschäftigt hat, und zu dem - aller Voraussicht nach zeitgleich mit der Publikation der Festschrift zu seinem 65. Geburtstag - endlich sein lange erwarteter Kommentar erscheinen wird. Zum anderen hat Klaus BALTZER "Traditionsgeschichte" nie so eng verstanden, daß er angenommen hätte, daß das mit diesem Stichwort umschriebene prozesshafte hermeneutische $\mathrm{Ge}-$ schehen der lebendigen Auseinandersetzung mit theologisch relevanten "Topen" bzw. "Konzepten"1 mit dem Abschluß des Kanons zum

1 "Konzept" stellt ein Schlüsselbegriff im hermeneutischen System von K. BALTZER dar, das davon geprägt ist, daß er sprachlich in der alten wie in der neuen Welt zuhause ist. Es handelt sich dabei um die Ausweitung eines deutschen Begriffs: Der mit dem ame- 
Stillstand gekommen sein könnte. Ein unverkennbares Markenzeichen seiner Arbeit im Seminar ist ja stets die positive Einbeziehung dessen gewesen, was von den Vertretern einer schulmäßigen historisch-kritischen Exegese, die ausschließlich an der Erhebung der (vermeintlich) ursprünglichen Wahrheit interessiert sind, als "Rezeptionsgeschichte" klassifiziert - und damit letzlich als "Adiaphoron" abqualifiziert wird. Wo auch immer die Einführungstagungen zu seinen Hauptseminaren stattfanden, stets wurde eine Besichtigung der jeweils in der Nähe befindlichen oberbayerischen (Barock-) Kirche(n) mit ihren reichen Bildprogrammen in das Seminargeschehen integriert. Daß den Seminarteilnehmern dabei zugleich immer - lange bevor daraus eine theologische Mode wurde - "biblische Theologie" in ihrer praktischen Dimension nahegebracht wurde, hat Klaus BALTZER indes nie eigens thematisiert große programmatische Worte waren und sind nicht seine Art. Die Aufnahme dieses Anliegens des aus der Gemeindepraxis kommenden und für die Praxis in Gemeinde und Schule ausbildenden Hochschullehrers bildet das dritte Motiv für die Themenwahl. In der derzeitigen wissenschaftsgeschichtlichen Phase, in der systematisch durchkonstruierte (gesamt-) biblische theologische Entwürfe gewissermaßen als der "letzte Schrei" gelten, kann es nicht schaden, das Augenmerk darauf zu richten, daß "Biblische Theologie" nur an das anknüpft, was bis zur Aufklärung das allein im Glauben begründete $A$ und $O$ aller christlichen Theologie war: Wenn seinerzeit theologische "Laien" wie J.S. BACH oder G.F. HÄNDEL ihren Kompositionen alt- oder neutestamentliche Texte zugrundelegten, bedienten sie sich - wie im folgenden an dem Beispiel der BACHschen Motette "Fürchte dich nicht" (BWV 228) gezeigt werden soll - ganz selbstverständlich des glaubensmäßig, d.h. affektiv internalisierten ${ }^{2}$ Grundgedankens, daß AT und NT als eine organische Einheit zu betrachten sind. Des hegelianischen "Überbaus" der Tübinger Schule, die einen in sich stringenten, ontologisch zu interpretierenden Traditionsprozeß vom Sinaiereignis bis zur Auferstehung Jesu aufweisen zu können mein $t^{3}$, bedurften sie dazu nicht. Ja, aller Wahrscheinlichkeit nach hätte sie diese formallogische "Beweisführung" sogar dar-

rikanischen Terminus "concept" verbundene semantische Horizont ist auf das deutsche Wort übertragen, das somit intersubjektiv-institutionell relevante Vorstellungszusammenhänge zur Deutung von Wirklichkeit bezeichnet. Topen sind demgegenüber Teilelemente von Konzepten.

$2 \mathrm{DaB}$ Religion primär im affektiven Bereich beheimatet ist, hat F. SCHLEIERMACHER in seiner zweiten Rede "Über die Religion" in Auseinandersetzung mit den Theologen der Aufklärungszeit hinreichend deutlich gemacht - durchgesetzt hat er sich damit allerdings nicht, zumal er von dieser richtigen Erkenntnis später wieder abgerückt ist.

3 Vgl. dazu deren Darstellung bei H. SEEBASS, Biblische Theologie, VuF 27 (1982) 34. $\mathrm{DaB}$ der Sinnlinie "vom Sinai zum Zion" (und weiter nach Golgatha) keine innere Logik eignet, ergibt sich schon daraus, daß Juden und Moslems zu einer anderen Sicht der Dinge gekommen sind. Kann man ihnen deshalb unterstellen, daß sie nicht denken können? 
an gehindert, ihre Kompositionen so sinnenfällig zu gestalten, wie wir sie heute kennen - was rational beweisbar und damit unmittelbar einsichtig ist, bedarf nicht der affektiven Ausgestaltung auf der Ebene der "Kundgabe", sondern läßt sich rein argumentativ auf der Ebene der "Darstellung" entwickeln ${ }^{4}$ und widersetzt sich von daher der Umsetzung in "Klangrede", die ihrem Wesen nach affektbezogen ist $t^{5}$. In diesem Zusammenhang wäre noch ein viertes Motiv der Themenwahl zu nennen, das in gewisser Weise zum subjektiv-emotionalen Anfang zurückweist: Als Exeget hat man es immer nur mit "schriftlichen Texten" zu tun - mit Texten also, denen die eben erwähnte wichtige sprachliche Dimension des Ausdrucks, der Kundgabe so gut wie vollkommen fehlt. Damit sind und bleiben sie "leer", sofern sie nicht von seiten des sie Interpretierenden bzw. Rezipierenden entsprechend gefüllt werden. Diese affektive Füllung der Texte erfordert vom Exegeten besonderes Fingerspitzengefühl, wird aber angesichts der Fixierung der Fachwissenschaft auf Sachprobleme, d.h. auf die Darstellungsebene, oft nicht genügend wahrgenommen: Wenn überhaupt, erfolgen Eintragungen im Bereich des Ausdrucks zumeist unbewußt und damit unkontrolliert, im schlimmsten Fall gar nicht, was die entsprechenden Elaborate für theologische Normalverbraucher ungenießbar macht. Im erwarteten Deuterojesajakommentar des Jubilars, dessen Grundkonzeption er mit seinen Schülern seit Jahren diskutiert hat, wird dieses Problem explizit aufgenommen. Klaus BALTZER geht darin davon aus, daß sich die von Deuterojesaja intendierte Art der "Kundgabe" aus strukturellen, phonetischen und sonstigen Elementen so rekonstruieren läßt, daß man eine dramatische Dichtung wahrnehmen kann, mit der Israel in schwerer Zeit Zuversicht vermittelt werden sollte ${ }^{6}$. - Hier nun soll das Problem der "Kundgabe" im Bereich der Rezeptions- bzw. Wirkungsgeschichte weiter verfolgt werden: Hat BACH in seiner Aktualisierung der Sätze aus Deuterojesaja die Sinndimensionen des ursprünglichen Textes theologisch sachgerecht wahrgenommen und weitergeführt, mit welchen Mitteln hat er sie seinen Hörern "kundgetan", d.h. affektiv erfahrbar gemacht, und inwiefern hat er durch seine musikalische Gestaltung die

\footnotetext{
${ }^{4}$ Mit diesen Stichworten nehme ich Bezug auf die Terminologie des großen Sprachwissenschaftlers K. BÜHLER, der Sprache folgendermaßen definiert hat: "Dreifach ist die Leistung der menschlichen Sprache, Kundgabe, Auslösung und Darstellung" bzw. in den von ihm später bevorzugten Termini ausgedrückt: "Ausdruck, Appell und Darstellung". Vgl. dazu K. BÜHLER, Sprachtheorie, Stuttgart 21965, 28.

5 Vgl. dazu N. HARNONCOURT, Musik als Klangrede. Wege zu einem neuen Musikverständnis, dtv 10500, München und Kassel-Basel-London ${ }^{3} 1987$. Nicht umsonst kennt die Musikgeschichte Tausende von Mess-Kompositionen, aber keine Vertonung etwa einer altlutherischen oder katholischen Dogmatik: Was zu vertonen ist, sind Glaubenssätze wie das Credo oder das Kyrie, nicht aber Argumente, die Glaubenssätze zu beweisen suchen.

${ }^{6}$ Mit Worten der aristotelischen Tragödientheorie: Es geht um kóoapors.
} 
"Verständlichkeit" des Textes gefördert? Diesen Fragen soll im folgenden nachgegangen werden.

I.

Vor alledem muß allerdings noch ein Aspekt der Themenwahl angesprochen werden, der weniger mit dem Adressaten, wohl aber einiges mit dem Objekt der Untersuchung zu tun hat: Warum ausgerechnet eine Spruchmotette J.S. BACHs und nicht ein alttestamentliches Oratorium aus der Feder G.F. HÄNDELs, so etwa dessen Belsazar, der ja thematisch und strukturell ${ }^{7}$ unmittelbare Beziehungen zu Deuterojesaja aufweist und ausgesprochen auf- bzw. anregende Interpretationselemente enthält ${ }^{8}$ ? Wird doch ohnehin HÄNDEL gewöhnlich als der "Alttestamentler" und BACH als der "Neutestamentler" unter den großen Komponisten der Barockzeit angesehen, was primär wohl damit zusammenhängt, daß HÄNDEL rein numerisch gesehen weit mehr alt- als neutestamentliche Stoffe vertont hat, während bei $\mathrm{BACH}$ die Dinge umgekehrt liegen: In den geistlichen Werken BACHs stehen - bedingt durch die konkrete (gottesdienstliche) Funktion derselben und die pietistische Tradition seiner Umgebung - Jesus und die neutestamentlichen Traditionen im Vordergrund'; von HÄNDELs für ein eher säkulares Publikum konzipierten Oratorien sind dagegen rund zwei Drittel alttestamentlichen Gestalten bzw. Themen gewidmet ${ }^{10}$.

Ausschlaggebend war angesichts des begrenzten Rahmens einer Festschrift allein der Umfang der zu diskutierenden Komposition, zumal die eben angesprochene Klassifikation der beiden großen Barockkomponisten ein äußerst problematisches Vorurteil darstellt ${ }^{11}: \mathrm{BACH}$

7 Dabei setze ich mit K. BALTZER voraus, daß es sich beim Buch Deuterojesaja um ein Drama handelt.

8 Theologisch besonders wichtig erscheint mir der Umstand, daß HÄNDEL die in ihrem Schwarz-Weiß-Denken eher chauvinistisch wirkende biblische Tradition so weitergestaltet hat, da $B$ deren eigentlicher theologischer Hintergrund - die allgemein-menschliche Problematik der Hybris - wieder kenntlich wird.

9 In den Titeln der 208 geistlichen Kantaten erscheint der Name Jesus bzw. Christus zwar nur 24mal, aber ganz ohne textlichen Bezug auf Jesus bzw. das NT sind nur ganz wenige Kantaten, sowie die Motetten "Singet dem Herrn" (BWV 225; Text: Ps 149,1-3; Jer 15,15 [s.u. A.18]; 150,2.6) und "Lobet den Herrn alle Heiden" (BWV 230; Text: Ps 117).

10 In Zahlen ausgedrückt: 14 von 20. Wieviele Kompositionen HÄNDELs sicher der Gattung "Oratorium" zuzuweisen sind, ist allerdings umstritten; die angegebene Zahl stellt einen Mittelwert dar. Die Stoffe aus den Apokryphen (Alexander Balus, Judas Makkabäus, Susanna) sind dabei dem AT zugerechnet.

11 Parallel zu der in Rede stehenden Klassifikation wird BACH zumeist auch noch als der theologisch tiefgründigere von beiden eingestuft, während man in HÄNDEL den oberflächlichen, weltzugewandten Komponisten sieht: Die aus einem latenten Antisemitismus gespeiste Ablehnung der "weltlichen" Texte des AT wird dabei in ein Werturteil über HÄNDELs kompositorische Fähigkeiten umfunktioniert, obwohl schon allein ein Hineinhören in den Anfang des "Messias" derartige Fehlurteile verhindern könnte. Daß 
stand dem AT keineswegs fremd gegenüber, sondern war in ihm besser zuhause als mancher Theologe, wie sich z.B. an gewissen ausgesprochen entlegenen alttestamentlichen Zitaten in der Matthäuspassion zeigen läßt ${ }^{12}$, und umgekehrt hat HÄNDEL - sofern er nur dafür ein Publikum hatte - durchaus neutestamentliche Stoffe verarbeitet ${ }^{13}$. Die Auswahl der Sujets stellt ohnehin nur ein - für einen Komponisten sicher nicht einmal das entscheidende - Kriterium zur Beurteilung seiner theologischen Aussageintention dar. Wichtig ist in der Barockzeit mit ihrer von der antiken Rhetorik her geprägten "Affektkultur" vor allem, welche geprägten Stilfiguren bzw. rhetorischen Mittel ein Komponist einsetzt ${ }^{14}$ und welche Bezüge er mit diesen Mitteln herstellt, denn erst von ihnen aus lassen sich sichere Rückschlüsse auf das religiös-affektive Anliegen des Komponisten ziehen. Auf dieser Ebene unterscheiden sich nun aber BACH und HÄNDEL letztlich nur wenig: Beide verwenden die gleichen Stilmittel und beide greifen, wenn sie alttestamentliche Texte vertonen, an den Stellen, wo es ihnen theologisch notwendig erscheint, zu musikalischen Figuren, die eindeutig auf neutestamentliche Sachverhalte verweisen, womit die alttestamentlichen Aussagen für den mit diesen Figuren vertrauten Hörer in einen gesamtbiblischen Horizont gestellt werden. So bringt etwa HÄNDEL im Rezitativ des Jephtha am Ende des zweiten Aktes des gleichnamigen Oratoriums in wenigen Tönen die ganze paulinische Sünden- und Gnadenlehre unter, um von ihr her die - aus historistischer Sicht illegitime - Anfügung des Iphigenien-Schlusses an die Jephtha-Tradition theologisch zu rechtfertigen ${ }^{15}$, und (methodisch) entsprechend verfährt BACH am Ende der hier in Rede stehenden Motette, wie am Ende dieser Untersuchung deutlich wer-

übrigens BACH selbst seinen Hallenser Kollegen durchaus hoch schätzte, ergibt sich daraus, daß er sich z.B. im Rahmen der Arbeit an der Matthäuspassion dessen Brockespassion besorgte, eigenhändig kopierte und ein Stück daraus in die Matthäuspassion übernahm; vgl. dazu R. BARTELMUS, Die Matthäuspassion J.S. Bachs als Symbol. Gedanken zu einem unerschöpflichen musikalisch-theologischen Werk, ThZ 47 (1991) 22.

12 Vgl. dazu R. BARTELMUS [A.11] 41f.

13 Daß HÄNDEL nicht nur im "Messias" neutestamentliche Gedanken aufgenommen hat, sondern auch zwei Passionen komponiert hat (eine Johannespassion und die sog. "Brockespassion" - die Komposition einer Nachdichtung der Passionsgeschichte aus der Feder des Hamburger Ratsherren B.H. BROCKES), ist außerhalb von Spezialistenkreisen weitgehend unbeachtet geblieben.

14 Einen guten Überblick über diese lange Zeit viel zu wenig beachteten Elemente barocker Kompositionspraxis bietet D. BARTEL, Handbuch der musikalischen Figurenlehre, Laaber 1985.

15 Ich hoffe, die entsprechende ausführliche Analyse, die ich am 20.12.1990 im Rahmen eines Vortrags vor der Theologischen Fakultät der Universität Heidelberg erstmals einer breiteren Öffentlichkeit vorgestellt habe, demnächst an anderem Orte publizieren zu können. 
den wird. Doch zunächst zum Text, den BACH verarbeitet hat, und zum konkreten Anlaß seiner Komposition.

II.

Die beiden Verse aus Deuterojesaja, die den Kern der Motette bilden, hat BACH nicht selbst ausgewählt bzw. aufeinander bezogen. Sie waren ihm vielmehr als Text der Trauerpredigt für eine gewisse, im Januar 1726 verstorbene, "Frau Stadthauptmann Winkler" im Wortlaut der Lutherbibel vorgegeben ${ }^{16}$ :

Fürchte dich nicht, ich bin bei dir; weiche nicht, denn ich bin dein Gott! Ich stärke dich, ich helfe dir auch, ich erhalte dich durch die rechte Hand meiner Gerechtigkeit. (Jes 41,10)

Fürchte dich nicht, denn ich habe dich erlöset; ich habe dich bei deinem Namen gerufen, du bist mein! (Jes 43,1b)

Was BACH selbst damit verband, waren die beiden letzten Verse des Paul-Gerhard-Liedes "Warum sollt ich mich denn grämen" (EKG 297, V. 11 und 12)17:

Herr, mein Hirt, Brunn aller Freuden, du bist mein, ich bin dein, niemand kann uns scheiden.

Ich bin dein, weil du dein Leben und dein Blut mir zu gut in den Tod gegeben;

du bist mein, weil ich dich fasse und dich nicht, o mein Licht, aus dem Herzen lasse.

Laß mich, laß mich hingelangen, da du mich und ich dich leiblich werd umfangen.

Der Grund für die Wahl dieser Choralverse ist unschwer zu erkennen: BACH hat offenbar die assoziative Nähe der Paul-Gerhard-Verse zum Bibeltext wahrgenommen und diesen Umstand dazu genutzt, den alttestamentlichen Sätzen eine christologisch "weitergedachte" Variante gewissermaßen als Kommentar der gläubigen Gemeinde gegenüberzustellen. Das dabei angewandte theologische Argumentationsmuster, auf das $\mathrm{BACH}$ übrigens ausgesprochen häufig zurückgegriffen hat ${ }^{18}$, steht

16 Vgl. dazu W. SCHMIEDER, Thematisch-systematisches Verzeichnis der musikalischen Werke von Johann Sebastian Bach [BWV], Leipzig 1986, 306 bzw. H.J. MARX, Die Motetten Bachs, in: Begleitheft zur Einspielung der Motetten durch den Bachchor Stockholm und den Concentus musicus Wien unter der Leitung von N. HARNONCOURT, TELDEC 8.42663, 6.

17 Möglicherweise hatte ihm der Trauerprediger allerdings auch das Lied als ganzes (für den Gemeindegesang?) vorgegeben.

18 Es findet sich schon in den beiden ersten Kirchenkantaten BACHs aus der Mühlhausener Zeit - so im 2. und 4. Satz der Kantate : "Aus der Tiefe rufe ich Herr zu dir" (BWV 131) und im 3 Satz des "Actus tragicus" (BWV 106). Dort ist jeweils eine "Aria" bzw. ein "Duetto" im Stile des seit der Zeit H. SCHÜTZs geläufigen Typs des kleinen "Geistlichen Konzerts" mit einem Choral verbunden. Das wohl bekannteste Beispiel für diese Technik stellt die (dort allerdings wohl auf Picander zurückgehende) Kombination des Chorals 
faktisch - was m.E. viel zu wenig beachtet wird - in der Tradition des musikalischen "Quodlibet"s, das seinerseits auf die akademischen "disputationes de quodlibet" des 14. und 15. Jahrhunderts zurückgeht ${ }^{19}$. In derartigen Quodlibets werden, um überraschende - lustige oder nachdenklich machende - Wirkungen zu erzielen, Liedfragmente bzw. ganze Lieder entweder sukzessive aneinander gereiht ${ }^{20}$ oder aber simultan übereinander geschichtet ${ }^{21}$; im Extremfall kann beides sogar miteinander kombiniert sein 22 .

Mag es nun Zufall oder Absicht gewesen sein: BACH hat mit der Wahl dieses - auch von der Kürze des Textes her naheliegenden - Argumentationsmusters jedenfalls die literarische Struktur seiner Vorlage kongenial erfaßt. Denn gleichgültig, ob man mit dem Jubilar annimmt,

"O Lamm Gottes unschuldig" mit den Worten des Hohenliedes: "Kommt ihr Töchter, helft mir klagen" im Eingangschor der Matthäuspassion dar; vgl. dazu R. BARTELMUS [A.11] 55f. Das für diesen Zusammenhang nächstliegendste Beispiel dürfte aus der Motette "Singet dem Herm ein neues Lied" (BWV 225) stammen: Der weder aus Ps 149,1-3; 150,2.6 noch aus EKG 188 stammende und im zweiten Teil der Motette parallel zu V. 3 des genannten Liedes von Chor I stereotyp wiederholte liturgische Ruf: "Gott nimm dich (ferner) unser an" dürfte ein Zitat aus Jer 15,15 darstellen. Es wurde allerdings m.W. bisher nicht erkannt (vgl. BWV), wohl weil die Revision der Lutherübersetzung - historisch-kritisch gesehen zu Recht - die von Luther vorgenommene eigenmächtige Setzung des Plurals ausgemerzt hat. Vgl. demgegenüber die Fassung der letzten zu Luthers Lebzeiten erschienen Ausgabe, Wittenberg 1545, in der V.15ff als "Jeremie Gebet" vom vorhergehenden Kontext abgehoben und pluralisch formuliert ist.

19 Derartige "disputationes" sind seit Beginn des 14. Jhs. an der Sorbonne nachweisbar, wurden von dort nach Deutschland übernommen, dort aber im 16. Jh. wieder abgeschafft, weil das derb-humoristische Element zu sehr in den Vordergrund gerückt war; vgl. dazu und zum folgenden K. GUDEWILL, Art. Quodlibet, MGG 10, 1822-1832. - Daß BACH unmittelbar an die Tradition der mehrtextigen Motetten des Mittelalters (vgl. dazu L. FINSCHER, Art. Motette, MGG 9, 638-649) angeknüpft haben könnte, scheint mir demgegenüber weniger wahrscheinlich.

20 So bei weltlich-humoristischen Quodlibets. Als triviales Beispiel sei wenigstens der Anfang eines bis in die jüngste Zeit hinein auch in kirchlichen Jugendgruppen beliebten Quodlibets erwähnt: "Der Mai ist gekommen, die Bäume schlagen $\rightarrow$ Aus der Jugendzeit, aus der Jugendzeit, klingt es $\rightarrow$ Kling, Glöckchen, klingeling, kling, Glöckchen, kling. Macht mir auf $\rightarrow$ Ihr Kinderlein, kommet, o kommet doch $\rightarrow$ Alle meine Entchen" u.s.w.

21 So bei weltlich-humoristischen wie bei polyphonen geistlichen Quodlibets aus verschiedenen Kirchenliedern, wie sie erstmals bei M. PRAETORIUS im Syntagma musicum von 1619 nachweisbar sind. Als Beispiel für ersteres sei ein Quodlibet von L. SENFL erwähnt, das zeigt, daß die Zuordnung der Lieder auch im weltlichen Bereich durchaus nicht so beliebig war, wie der Name der Gattung erwarten läßt. In ihm singt der Sopran quasi als Cantus firmus - das Lied: "So man lang macht, betracht't und ach't, viel Kurzweil treibt, in Freuden bleibt, ist gwohnlich das und allweg was ...", was die drei Unterstimmen mit dem Lied konterkarieren: "Ich armer Mann, was hab' ich g'tan, daß ich ein Weib hab' g'nommen! Hätt' ich es unterwegen lan, ich wär' sein wohl bekommen ...".

22 So in einer Reihe von dreistimmigen Quodlibets, die als "Cantus firmus" das Lied "O rosa bella" von J. DUNSTABLE verwenden, während die Unterstimmen verschiedene Liedanfänge hintereinander reihen. 
daß die auf den ersten Blick ausgesprochen heterogen wirkenden kurzen Teileinheiten des Deuterojesajabuches von einem Autor absichtsvoll als Äußerungen verschiedener Protagonisten in einem Drama nebeneinander gestellt wurden, oder im Einklang mit dem gegenwärtigen Forschungstrend mit einem sukzessiven Wachstums- bzw. Redaktionsprozeß im Buche rechnet ${ }^{23}$, oder aber mit der älteren literarkritischen Schule bei der Beobachtung der sekundären Herkunft gewisser Teile des Buches stehenbleibt ${ }^{24}$ - daß im Deuterojesajabuch heterogene Gedanken(reihen) neben- bzw. nacheinander angeordnet, aber dennoch aufeinander bezogen sind, steht außer Zweifel. Und eben diese Struktur hat $\mathrm{BACH}$ in seiner am Vorbild des Quodlibets orientierten Ausdeutung der beiden Verse positiv aufgenommen.

Doch damit nicht genug, bis in den Bereich der literarischen Gattungen hinein reicht das BACHsche Einfühlungsvermögen: So hat man schon seit langem erkannt, daß an den "Schlüsselstellen" des Buches "Hymnen" bzw. "(eschatologische) Loblieder" eingeschoben sind 25 , die als Antwort Israels auf die Heilsorakel, aus denen die beiden Verse 41,10 und $43,1 \mathrm{~b}$ entnommen sind, und deren als sicher vorausgesetzte Verwirklichung $\mathrm{zu}$ verstehen sind ${ }^{26}$ - und just mit dem dieser alttestamentlichen Gattung unmittelbar entsprechenden Mittel des Chorals antwortet der gläubige Christ BACH auf den in zwei verschiedenen Fassungen zitierten "Heilszuspruch": "Fürchte dich nicht".

Nun könnte man immerhin einwenden, daß zumindest die $\mathrm{BACH}$ vorgegebene - Applikation des an das exilierte Israel als Kollektiv gerichteten "Heilszuspruchs" auf einen individuellen Trauerfall nicht mehr durch den Gedankenduktus des ursprünglichen Textes abgedeckt, und somit exegetisch nicht zu verantworten ist. Dieser Einwand läßt sich indes relativieren - zumal bereits bei Deuterojesaja selbst keine säuberliche Unterscheidung von Kollektiv (resp. "corporate personality") und Individuum wahrzunehmen ist: Der uralte Streit, ob z.B. die "Gottesknechtslieder" individuell oder kollektiv zu deuten seien, hat ja seine Wurzel in der diesbezüglichen Ambivalenz der Texte27. - Aber auch

23 Vgl. dazu neuerdings etwa R.G. KRATZ, Kyros im Deuterojesajabuch. Redaktionsgeschichtliche Untersuchungen zu Entstehung und Theologie von Jes 40-55, FzAT 1, Tübingen 1991.

24 So etwa bei B. DUHM, Das Buch Jesaja, HK, Göttingen ${ }^{4} 1922=51968$, 14f, wo - neben anderem - die Ebed-Jahwe-Lieder als sekundär ausgeschieden werden, oder - in neuerer Zeit - bei G. FOHRER, Das Buch Jesaja. Kapitel 40-66, ZBK, Zürich 1964, der 40,18-20; 41,$7 ; 44,9-20 ; 46,5-8$ einem Weisheitslehrer, 42,8-9; 45,8; 45,18-19; 48,1-11; 51,11-16; 52,16 anderen nicht näher bestimmten Verfassern zuweist.

25 Vgl. dazu den Forschungsbericht von C. WESTERMANN, Sprache und Struktur der Prophetie Deuterojesajas, ThB 24, München 1964, 94f; 157-163. Geht man von der Dramentheorie K. BALTZERs aus, handelt es sich dabei um Chorlieder entsprechend den das dramatische Geschehen kommentierenden Chorliedern der griechischen Tragödie.

26 Vgl. ebd. 118-120; $164 f$.

27 So besonders deutlich in Jes 49,1-6. 
die dahinter stehende eigentliche hermeneutische Frage, ob die Übertragung des bei Deuterojesaja auf die irdische (konkret-politische) Restitution des Kollektivs Israel bezogenen "Heilszuspruchs" auf die christliche individuelle Auferstehungshoffnung theologisch legitim ist, läßt sich aufgrund der inneralttestamentlichen (wie frühjüdischen und frühchristlichen) Fortentwicklung der entsprechenden Gedanken positiv beantworten, wie z.B. ein Blick auf die Redaktionsgeschichte von Ez 37,1-14 lehrt 28, wo die gleiche Problematik - wenn auch mit anderen Mitteln theologischer Sprache - diskutiert wird.

BACHs außermusikalischer Umgang mit dem Bibeltext ist insoweit aus exegetischer Sicht nicht zu hinterfragen. Was noch offen bleibt, ist die Frage, welche religiösen Anschauungen hinter der Auswahl zweier in ihrer Grundaussage identischer, in der Fortführung indes durchaus unterschiedlicher "Heilszusprüche" stehen. Da diese konkrete textliche Auswahl jedoch nicht von BACH getroffen wurde, können wir, um den Rahmen unserer Fragestellung nicht zu sprengen, die Antwort auf diese Frage erst im Rahmen der Analyse der musikalischen Interpretamente suchen, geht es uns hier doch allein um BACH als Ausleger der Bibel, also um seine Interpretation dieser Textauswahl, und nicht darum, was der uns unbekannte Trauerprediger mit den Versen verbunden hat.

III.

Einen der sichersten Indikatoren für das Textverständnis barocker Komponisten bildet die Wahl der Grund-Tonart ${ }^{29}$. Im Falle der Motette "Fürchte dich nicht" ist das $A$-Dur ${ }^{30}$ - die zur Textaussage passende Tonart der Rettung, der Energie, der Klarheit, des Gottvertrauens, des Frühlings, die nicht umsonst im Zenit des Quintenzirkels zu stehen kommt. Von daher könnte man versucht sein, sich mit dem ReclamChormusikführer damit zu bescheiden, daß man in der Motette einen "Trostgesang" sieht, "dessen heitere Stimmung sich schon in der lichten Tonart A-Dur ausspricht"31. Damit wäre zwar die letztliche praktisch-theologische Intention BACHs - gewissermaßen der pragmatische "Skopus" - zweifellos richtig erkannt, aber zugleich der Zugang zu dem im musikalischen Aufbau des Werks verborgenen theologischen Programm gründlich verbaut. Überdies kann man selbst bei oberflächlichem Hören unschwer wahrnehmen, daß diese Charakterisierung, was die konkrete Durchführung der Komposition betrifft, in keiner Weise zutrifft. Erst am Schluß - und dort beinahe überraschend - lösen sich die

28 Vgl. dazu R. BARTELMUS, Ez 37,1-14, die Verbform weqatal und die Anfänge der Auferstehungshoffnung, ZAW 97 (1985) 366-389.

${ }^{29} \mathrm{Vgl}$. dazu und zum folgenden R. BARTELMUS [A.11] 33-35.65.

${ }^{30} \mathrm{Im}$ folgenden werden Dur-Tonarten nur mehr durch kursiv gesetzte Großbuchstaben, Moll-Tonarten durch kursiv gesetzte Kleinbuchstaben bezeichnet.

31 So W. OEHLMANN, Chormusikführer, Stuttgart 1965, 78. 
gelegentlich fast unerträglich wirkenden Spannungen in ein strahlendes $A$ auf; was vorher zu hören ist, klingt - abgesehen vom Anfang häufig eher klagend oder doch zumindest nie wirklich tröstlich, ja der Halbschluß am Ende des ersten Teils der Motette (T. 73,1) sogar ausgesprochen hart. Wie sind diese Spannungen zu erklären?

Bei BACH (wie bei allen großen Komponisten dieser Zeit) kommt zur Tonartwahl schon allein im Rahmen der Harmonik stets noch eine Reihe weiterer, den Charakter des Musikstücks prägender Faktoren hinzu. Dazu gehört die Breite der Modulationen ${ }^{32}$, die Wahl der Tonschrittfolgen (diatonisch vs. chromatisch) bzw. der Akkorde auf "Halbschlüssen" (konsonant vs. dissonant resp. "geschlossen" vs. "offen"), die Zahl der zugelassenen dissonanten Akkorde u.v.a.m. - und das alles steht im Dienste der "Klangrede", d.h. im Falle der BACHschen religiösen Kompositionen nicht nur im Dienste der "Affektkultur", sondern auch und gerade der Theologie. Schon von daher erscheint es alles andere als sinnvoll, eine Komposition allein nach ihrer Grund-Tonart beurteilen zu wollen. Relevant sind daneben aber auch noch andere Kategorien wie Tonsprünge, Rhythmus, Stimmenwahl oder komplexere musikalisch-rhetorische Figuren, bei BACH zusätzlich noch Zahlenoder Buchstabensymbole und graphische Elemente wie das Kreuz, um nur einige wenige Faktoren zu nennen ${ }^{33}$. Hier alle diese Faktoren diskutieren zu wollen, würde allerdings den Rahmen dieses Beitrags ebenso sprengen, wie der Anspruch, eine vollständige musikalische Analyse durchzuführen. Im folgenden können nur die elementar sinnenfälligen Elemente der BACHschen Komposition andiskutiert werden und auf ihre theologische Relevanz hin überprüft werden.

Im Zentrum steht dabei zunächst die Frage, die sich auf der rein textlichen Ebene nicht klären ließ, die Frage also, wie BACH die Auswahl (und damit den Inhalt) der zwei in ihrer Grundaussage identischen, in der Fortführung durchaus unterschiedlichen "Heilszusprüche" verstanden hat. Welche Indikatoren auf der musikalischen Ebene lassen sich hier finden? Ich meine, daß man in diesem Fall schon auf der Ebene der Tonart zu einem relativ klaren Ergebnis kommen kann, das durch weitere Beobachtungen, v.a. am zweiten Teil, eindeutig bestätigt wird. - Spätestens hier zeigt sich übrigens zugleich, wie weit die oben zitierte simplifizierende Klassifizierung der Motette an den kompositorischen Gegebenheiten vorbeigeht - hat deren Autor doch nicht wahrgenommen, daß der Schluß des ersten Teils der Motette nicht in $A$, sondern in cis steht, d.h. in einer alles andere als "heiteren" oder "lich-

32 Im Falle des erwähnten hochemotionalen Recitativo accompagnato aus HÄNDELs Jephtha (vgl. dazu o. A.15) "irrt" der verzweifelte Jephtha z.B. durch insgesamt 14 Tonarten, womit die menschliche Extremsituation musikalisch überzeugend ausgedrückt wird. Das ganze stellt allerdings einen durch das Sujet bedingten Extremfall dar; üblicherweise wird die Grundtonart selten um mehr als drei Stufen verlassen!

33 Näheres dazu bei R. BARTELMUS [A.11] 30-48. 
ten" Tonart! Diese Tonart-Wahl impliziert nun aber, daß BACH Jes 41,10 , das dem ersten Teil zugrundeliegt, anders als Jes $43,1 \mathrm{~b}$ verstanden haben muß, sonst hätte er auch diesen Teil in $A$ oder - kompositionstechnisch gesehen richtiger - in $E$ abgeschlossen, und nicht ins Zentrum der Motette einen Moll-Akkord gesetzt.

Rein musikalisch gesehen, ist festzuhalten, daß es sich bei cis um eine mit $A$ harmonisch immerhin relativ nahe verwandte Tonart handelt - befindet es sich doch im Quintenzirkel in unmittelbarer Nachbarschaft zu $A$. Es liegt ein Abstand von einer Stufe - aber eben auch ein Wechsel im Grundcharakter (Dur-Moll) vor. Wie wichtig für BACH die v.a. durch den Moll-Charakter gegebene "Fremdheit" war, läßt sich recht eigentlich erst an der Reihe der unmittelbar folgenden Akkorde erkennen: $\mathrm{BACH}$ geht danach auffälligerweise noch einmal um drei Schritte weiter von der Grund-Tonart weg nach Fis, dann über eine Folge von Sept- und Sextakkorden zurück nach $A$ (T. 75,1) ${ }^{34}$, und anschließend leitet er in ähnlicher Weise erst auf dem "Umweg" über die Subdominante $D$ sowie nochmals $A$ nach $E$ - der Tonart, in der dann (regelhaft) die Fuge des zweiten Teiles beginnt (T. 77,3). Warum hat BACH hier nicht den gewöhnlichen Weg beschritten, d.h. den ersten Teil in der unmittelbaren "Nachbartonart" zu $A$, in $E$, beendet, warum entfernt er sich in der Überleitung zur Fuge des zweiten Teils noch weiter von der Grund-Tonart und warum gebraucht er so schmerzlich klingende Akkorde, obwohl der Text lautet: "Fürchte dich nicht"?

Das Rätsel löst sich, wenn man sich zum einen jeweils am Schluß der beiden vertonten Verse orientiert, zum anderen in Rechnung stellt, daß BACHs christliche Inkulturation nicht von der Bibel in ihrer hebräischen bzw. griechischen Urgestalt geprägt war, sondern von der LutherBibel, und von dieser wiederum nicht nur direkt, sondern v.a. auf dem Umweg über den spezifischen Blickwinkel von L. HUTTERs "Compendium locorum theologicorum ex scriptura sacra et libro Concordantiae collectum" (1610) - einem extrem orthodoxen Lehrbuch der lutherischen Dogmatik von großer Wirksamkeit ${ }^{35}$, und wenn man sich überdies vergegenwärtigt, daß er sich als Kirchenmusiker regelmäßig mit Liedern Luthers auseinandersetzen mußte ${ }^{36}$. Aller Wahrscheinlichkeit nach hörte er von daher aus dem Stichwort "Gerechtigkeit", mit dem das erste Deuterojesaja-Zitat endet, in erster Linie den entsprechenden dogmatischen locus heraus, und damit eine Assoziation an das AT als "Gesetz", während er das Stichwort "erlöset" im zweiten Zitat wohl so

\footnotetext{
34 Die dabei berührten Tonarten sind $H$ und $E$.

35 BACH begegnete diesem Werk erstmals im Rahmen seiner Schulbildung in Ohrdruf (1695-1700).

$36 \mathrm{DaB}$ BACH die ihm vorgegebenen Lieder nicht nur als musikalische Vorlagen verwendet hat, sondern v.a. ihre Inhalte emst genommen hat, hat als einer der ersten $A$. SCHWEITZER erkannt; vgl. dazu das Vorwort C.M. WIDORs zu A. SCHWEITZER, J.S. Bach, Leipzig ${ }^{3} 1920$.
} 
verstand, daß dieses auf das NT zielt, also als "Evangelium" verstanden sein will.

Dieser Umstand spricht übrigens nicht gegen die hier vertretene These, daß BACH ein kompetenter Ausleger biblischer Texte war - wirklich vorurteilsfrei gehen auch die Vertreter der historisch-kritischen Exegese nicht an die Texte. Und daß "Gerechtigkeit" (TRTY/PTY) im AT weit mehr meint als die mit dem Gesetz verbundene strafende Gerechtigkeit bzw. den Anspruch, den der Mensch (nach Paulus) ohnehin nicht einlösen kann, sondern daß die "rechte Hand meiner Gerechtigkeit" hier wohl das gemeinschaftstreue, heilsame Eingreifen Jahwes bedeutet ${ }^{37}$, konnte BACH rund 200 Jahre vor den Arbeiten von CREMER ${ }^{38}$, FAHLGREN ${ }^{39}$ oder REITERER ${ }^{40}$ schlicht noch nicht einmal ahnen. Ebenso wenig konnte er als Nicht-Hebraist wissen, daß der Begriff $\$$ w, den Luther mit "erlösen" übersetzt hatte, nicht in Opposition zu "Gerechtigkeit" steht, sondern gleichermaßen ein Terminus aus der umfassenden Sphäre des im AT rein relational bestimmten Rechts ist.

Stimmt diese Vermutung, dann mußte BACH die beiden Sätze, die - in der vorliegenden sekundären Zusammenstellung - gewissermaßen einen synonymen Parallelismus membrorum bilden, quasi als antithetischen Parallelismus membrorum verstehen - ganz im Sinne der im Lied "Nun freut euch lieben Christen g'mein" (EKG 239)41 so anschaulich zusammengefaßten Theologie Luthers, deren Grundlage die Annahme einer Opposition zwischen der im AT geforderten Gerechtigkeit und der im NT vollzogenen Erlösung 42 bildet. Von dieser theologischen Prämisse her war für BACH die Komposition dann aber musikalisch-theologisch eindeutig vorstrukturiert - es ging also einmal mehr darum, das Prinzip "Gesetz und Evangelium" musikalisch darzustellen, wie er das in überzeugender Weise erstmals schon im "Actus tragicus" versucht hatte ${ }^{43}$. Demzufolge gestaltete er den Satz, der bei Deuterojesaja positiv von der Erhaltung durch die göttliche Gerechtigkeit spricht, musikalisch-affektiv so, daß nunmehr die lutherische Anschauung von der altestamentlichen "Gerechtigkeit" zum Ausdruck kommt - und diese ist negativ. Als Tonart kam somit nur eine Moll-Tonart in Frage. Innerhalb der Moll-Tonarten lag dann angesichts der Thematik wiederum cis nahe, das die Parallel-Tonart zu $E$ darstellt, das seinerseits für den

37 Vgl. dazu B. JOHNSON, Art. PT\$ sadaq etc. II., ThWANT VI, 912f; K. KOCH, Art. pרצ gemeinschaftstreu / heilvoll sein, THAT II, 527.

$38 \mathrm{H}$. CREMER, Die paulinische Rechtfertigungslehre im Zusammenhang ihrer geschichtlichen Voraussetzungen, Gütersloh 21900.

${ }^{39} \mathrm{~K}$.H. FAHLGREN, sedrks, nahestehende und entgegengesetzte Begriffe im AT, Uppsala 1932.

40 F.V. REITERER, Gerechtigkeit als Heil, p $7 x$ bei Deuterojesaja, Graz 1976.

$41 \mathrm{Zu}$ den einschlägigen Versen s.u.; daß BACH dieses Lied gut kannte, ergibt sich daraus, daß er es insgesamt viermal bearbeitete (BWV 388; 734; 734a; 755).

42 In Anlehnung an den verhandelten Text spreche ich von "Erlösung", es geht natürlich um die "Rechtfertigung".

43 Vgl. dazu die Analyse bei A. DÜRR, Die Kantaten von Johann Sebastian Bach, Band 2, dtv WR 4081, 617. 
Weltenrichter Christus steht ${ }^{44}$. Doch damit nicht genug: Weil die von BACH internalisierte paulinisch-lutherische Lehre impliziert, daß der im AT angebotene Weg der Gerechtigkeit zum Tode führt, aus dem heraus einzig die göttliche Erlösung in Christus führen kann, mußte er auch noch diesen - in den vorgegebenen Versen in keiner Weise angedeuteten, jedoch vom situativen Kontext der Trauerfeier her naheliegenden - Gedanken unterbringen: Dafür steht das von rein musikalischen Gesichtspunkten her kaum zu erklärende schneidende $F$ is in T. 73,3 - ist doch Fis II Ges die Tonart des Todes! Damit erklären sich dann aber auch die vielen dissonanten - dem gesungenen Text scheinbar widersprechenden - Akkorde auf dem Wege zur "erlösenden" Fuge: Es geht BACH um nichts anderes als die Darstellung der Schrecken des Todes und der Hölle; die musikalischen Interpretamente dienen hier also gewissermaßen als Kontrastprogramm zur Vertiefung des gesungenen Wortes: Auch im Tod und in der Hölle gilt die Zusage: "Fürchte dich nicht"45.

Die abschließende Antwort auf die am Anfang dieses Abschnitts gestellten Fragen ist somit so einfach wie überraschend: BACH hat die beiden Verse aus Deuterojesaja im Sinne der geprägten dogmatischen Opposition "Gesetz" und "Evangelium" als Repräsentanten von AT und NT verstanden und von daher in die im Zentrum der Motette stehenden Takte 73-77 musikalisch nichts anderes hineingelegt als die Kurzfassung eines von genuin paulinischen Gedanken geprägten Kernstücks lutherischer Dogmatik - analog dem, was ihm von Luther selbst im eben erwähnten Lied verbal vorgegeben war:

Mein guten Werk', die galten nicht, es war mit ihn' verdorben;

der frei Will' haßte Gotts Gericht, er war zum Gut'n erstorben;

die Angst mich zu verzweifeln trieb, daß nichts denn Sterben bei mir blieb, zur Höllen muBt ich sinken. (EKG 239, V. 3)

Hat man diese Deutung des Zentrums der Motette einmal akzeptiert, und wendet den Gedanken, daß die beiden Teile der Motette für Gesetz und Evangelium, für AT und NT stehen, konsequent auf die gesamte musikalische Faktur an, erschließt sich eine ganze Reihe weiterer Aspekte, deren Bedeutung ebenso wenig aus rein musikalischer Sicht zu erklären ist, wie sie als unmittelbare Ausdeutung des vertonten Tex-

\footnotetext{
$44 \mathrm{Vgl}$. dazu H. PoOS, Kreuz und Krone sind verbunden. Sinnbild und Bildsinn im geistlichen Vokalwerk J.S.Bachs. Eine ikonografische Studie, Musik-Konzepte 50/51, München 1986, 77. Molltonarten stehen bei BACH für den menschlichen Bereich, Dur für Gott! 45 Insofern erweist sich BACH übrigens auch als guter Psychologe, der gewissermaßen eine musikalische Anleitung zur "Trauerarbeit" gibt: Er komponiert den Satz "Fürchte dich nicht" nicht nur als positive Zusage, sondern so, daß erst einmal die Furcht resp. "Angst" (so in EKG 239) hörbar wird. Ohne diesen Kontrast wäre kein echter Trost möglich, was W. OEHLMANN (A.31) offenbar entgangen ist. Nur wenn der Schmerz zugelassen, wenn er ernst genommen wird, kann der Trost wirken! Auf einer von A-Dur-Wellen umschmeichelten musikalischen "Insel der Seligen" kann es keinen Trost geben.
} 
tes verstanden werden können. Letzteres mag zwar nicht für für Phänomene wie die ruhige Baßlinie in den ersten vier Takten, für die lang ausgehaltenen Noten auf das Wort "erhalte"46 oder den positiven Schluß in $A$ gelten, durch den der Satz "Du bist mein" fast ins Überirdische verklärt wird, (was situationsspezifisch ja wohl auch beabsichtigt ist), aber selbst diese "einfachen", unmittelbar verständlichen Deutungen bekommen noch einmal eine andere Dimension, wenn man sie im Zusammenhang mit dem eben aufgewiesenen übergeordneten theologisch-musikalischen Strukturmuster betrachtet. - Dabei muß allerdings zugestanden werden, daß die folgenden Deutungen einen unterschiedlichen Wahrscheinlichkeitsgrad aufweisen: Was Teil 1 der Motette (IV.) betrifft, sind sie z.T. eher spekulativ, was Teil 2 (V.) betrifft, stehen sie auf ausgesprochen solidem Grund in der gemeinbarocken Lehre von den rhetorischen Figuren.

IV.

Kommt man von der allgemeinen Typik der Stimmen in der Barockzeit her, ist klar, daß der Umstand, daß die Bässe ganz alleine mit einer rhythmisch wie melodisch völlig eigenständigen, an Sprechgesang erinnernden Ausdeutung des Themasatzes beginnen, so zu verstehen ist, daß hier Gott selbst spricht - die väterliche Ruhe Gottes steht gegen die eher aufgeregte Stimmführung der übrigen, die menschliche Seite repräsentierenden Stimmen ${ }^{47}$.

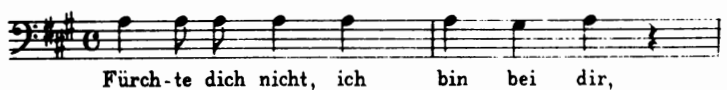

An dem, was hier gesagt wird, ist nicht zu zweifeln, wird der Satz doch im $B a B 2$ in identischer musikalischer Faktur in der Quint-Parallele $E$ wiederholt - gewissermaßen in freier Anwendung des Satzes: "Auf zweier Zeugen Mund sollst du ein Urteil sprechen"48. Der Gott, der hier spricht, ist indes nicht Christus, wie man zunächst aufgrund der standardtypischen Verwendung der Baßstimme in Kantaten und Passionen BACHs vermuten könnte, sondern Gott, der Vater ${ }^{49}$. Ja, es liegt

46 So durch alle Stimmen ab T. 36 (Sopran 1) - übersteigert in T. 55-59 (Baß 1).

47 Man möchte fast vermuten, daß BACH hier an den Anfang des Johannesevangeliums gedacht hat: "Im Anfang war das Wort, und das Wort war bei Gott, und Gott war das Wort".

48 Vgl. dazu R. BARTELMUS [A.11] 42 bzw. Dtn 17,6; 19,15. Das Prinzip der Doppelung zur Bekräftigung der Aussage ist sogar noch ein zweites Mal angewandt: Beim ersten Mal singen $B a B 1$ und $B a B 2$ unisono!

49 Wenn Christus bzw. Jesus gemeint ist, wird ein Solo-Baß eingesetzt: Der inkarnierte Gott ist ein Mensch! Vgl. dazu etwa allein die Jesus-Mystik in der Kantate "Wachet auf, 
nahe, an den nach Abschluß des Schöpfungswerkes ruhenden Gott von Gen 2,2-3 zu denken, der gesehen hat, daß alles "sehr gut" ist, und aus dieser Sicherheit heraus sagen kann: "Fürchte dich nicht". Dafür spricht jedenfalls der Umstand, daß BACH diese erste Version des Themasatzes - gegen alle musikalischen Regeln - an keiner einzigen Stelle in der Motette wörtlich oder sinngemäß wiederholt: Der damit gezeichnete $\mathrm{Zu}$ stand der noch nicht durch menschliches Eingreifen gestörten "angstfreien" Schöpfungsordnung ist einmalig, und somit selbst durch Gott nicht nach dem Fall in identischer Weise wiederherzustellen. Wenn ganz am Ende der Motette (T. 152) auf diese Version des Themasatzes immerhin noch einmal andeutungsweise angespielt wird, ist es nur mehr der Rhythmus der ersten drei Noten, der im Baß 2 in identischer Weise wiederkehrt ${ }^{50}$ - und nicht die ganze, fast statuarisch wirkende Figur von acht Noten. Das "Du bist mein", mit dem die Erlösungswirklichkeit ausgedrückt wird, ist eben eine völlig neue Wirklichkeit gegenüber dem, was prolapsarisch gegolten hat.

Die Beobachtungen zu den folgenden Takten liegen weniger im musikalischen Bereich als im Bereich der für BACH so wichtigen Zahlensymbolik. Zunächst fällt auf, daß der an das "Fürchte dich nicht" anschließende Folgesatz: "Ich bin bei dir", außerhalb des dem Baß vorbehaltenen, gewissermaßen außerhalb der irdischen Realität stehenden Themasatzes in insgesamt 9 voneinander abgesetzten "Blöcken" des Doppelchores erscheint (T. 2-9). BACH zitiert hier offenbar das AT, denn dort finden sich genau 9 Stellen, an denen Gott (bzw. Jahwe) zu einer Person sagt: "Ich bin bei dir"51. Daß dieses: "Ich bin bei dir", keine musikalisch feste Form hat, sondern - alternierend durch die verschiedenen Stimmen - einmal durch eine Abwärtsbewegung über den Tonraum einer Quart, dann durch eine Aufwärtsbewegung im gleichen Rahmen, dann wieder durch eine Art "Messanza"52 - also durch eine Figur aus teils "springenden", teils "ordentlich gehenden" Intervallen oder gar durch eine fast bewegungslose Figur dargestellt werden kann,

ruft uns die Stimme" (BWV 140), Satz 3, 5 und 6, bzw. dazu A. DÜRR [A.43] 534f. - Daß die Stimme Gottes, des Vaters, nicht durch einen Solisten wiedergegeben werden darf - es sei denn, Gott spricht durch einen Propheten -, ist noch bis in die Zeit MENDELSSOHNs hinein bewußt geblieben. MENDELSSOHN verwendet in seinem Paulus zur Verfremdung allerdings einen Frauenchor. Möglicherweise hat er dabei an Engel gedacht.

$50 \mathrm{Baß} 1$ (T. 151f) läßt sich insofern nicht unmittelbar vergleichen, als dort die Figur auf den 3. Schlag beginnt.

51 w in Gen 26,$24 ; 43,2.5 ;$ Jer $1,8.19 ; 15,20 ; 30,11 ; 46,28$ - in Jes $\underline{41,10}$ w sich hier an der LXX orientiert haben, denn die Luther-Bibel verwendet in Jes 43,2 (sinngemä $B$, aber gegen den hebräischen Wortlaut) das Futur, während LXX - wie an den

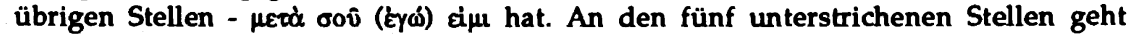
überdies der Beistandszusage ein "Fürchte dich nicht" voraus. Zur Frage der Zahlensymbolik vgl. o. A.12.

52 Vgl. dazu D. BARTEL [A.14] $203 f$. 
ist sicher so zu verstehen, daß die Zusage für alle (musikalisch darst baren) Lebenslagen gilt.
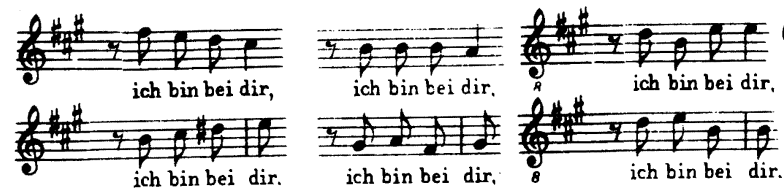

(T. 2f; Sopran 1/2;

Alt 1/2;

Tenor 1/2)

Zahlensymbolische Aspekte lassen sich auch beim nächsten Teilsatz feststellen. BACH argumentiert hier aus einem soliden bibelkundlichen Wissen heraus. Ihm ist das deuteronomistische Denkschema bekannt, nach dem Israel immer wieder von seinem Gott gewichen ist, und daß Gott nach 2 Kön 17,1353 alle Propheten gesandt hat, um Israel/Juda an solchem Abfall von seinem Gott zu hindern. Von daher deutet er den Satz: "Weiche nicht, denn ich bin dein Gott", rein numerisch. In 16 Stimm"blöcken" wird diese Aussage in der "variatio per choros" des ersten Teils wiederholt - und genau 16 Propheten kennt die Luther-Bibel 54 !

Wiederum auf rein musikalischer Ebene liegt demgegenüber das Phänomen, das erstmals in T. $29 \mathrm{f}$ im $B a ß 1$ und dann noch einmal in T. $33 \mathrm{f} \mathrm{im} \mathrm{BaB} 2$ erscheint ${ }^{55}$. Es handelt sich dabei um eine abwärtsgerichtete Figur über den Tonraum einer verminderte Oktave, die angesichts ihres Endes in einem Septakkord der ganz "entlegenen" Tonarten Cis bzw. Gis ${ }^{56}$ besonders "unvollkommen" klingt, was in krassem Gegensatz zur Textaussage: "Ich stärke dich", steht.

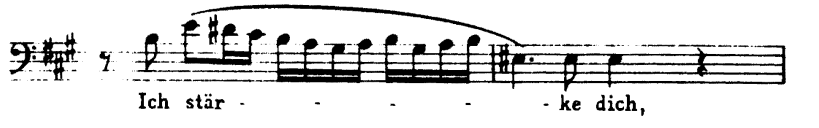

Was will BACH mit diesem befremdlichen Klang bewirken, worauf zielt die unbeholfen wirkende Koloratur, die durch ihre "katabatische" Struktur auf etwas Geringes, Verächtliches hinzuweisen scheint ${ }^{57}$ ? Wenn nicht alles täuscht, ist die Koloratur als Karikatur zu verstehen. BACH karikiert hier - damit übrigens weit über Paulus hinausgehend das Sinai-Geschehen, das ja mit der Gesetzesverkündigung endet. Des-

53 BACH muß speziell diese Stelle im Kopf gehabt haben, denn nur hier ist in dem hier in Rede stehenden Zusammenhang von allen Propheten die Rede; vgl. aber immerhin Ri 6,8-10; ähnlich auch $2 \mathrm{Chr} 36,15$.

54 Anders als in der hebräischen Bibel gehört das Buch Daniel in der Luther-Bibel bekanntlich zu den Propheten.

55 Minimal variiert auch noch in T. 30f (Alt 1) und T. $32 f$ (Sopran 2).

56 Im Falle der beiden in A.54 erwähnten Varianten in Fis bzw. H. Daß Cis und Gis keine gewöhnlichen Tonarten sind, ergibt sich daraus, daß beide im einfachen Quintenzirkel keinen Platz haben; vgl. dazu R. BARTELMUS [A.11] 45.

57 Vgl. dazu D. BARTEL [A.14] 115f. 
halb fährt er in cis als der Tonart der menschlichen Gerechtigkeit weiter und verwendet in T. 40 auf "Gerechtigkeit" den schon am Ende von III. analysierten cis-Akkord: Gott läßt sich in fast theatralischer Weise unter Blitz und Donner auf dem Sinai nieder - aber was dabei herauskommt, ist keine echte Stärkung Israels, sondern nur das Gesetz, das auf menschliche Gerechtigkeit zielt, und damit faktisch zum Tode führt, weshalb Gott immer wieder selbst helfend eingreifen muß. Das "Ich helfe dir auch" wirkt denn auch ausgesprochen hektisch, vor allem wenn man es neben den langgezogenen Noten auf "Ich erhalte dich" hört, die im Rahmen der hier vorgeschlagenen Deutung kaum anders als als Hinweise auf Gottes Langmut zu verstehen sind. Auch wenn diese letzten Gedanken, wie bereits angedeutet, ausgesprochen spekulativ sind als Bindeglied zwischen den relativ sicheren Beobachtungen zum Anfang bzw. zu der von EKG 239 her zu verstehenden Mitte der Motette und dem zweiten Teil ergeben sie einen guten Sinn - sind doch die von $\mathrm{BACH}$ dort eingesetzten rhetorischen Figuren eindeutig auf das Erlösungsgeschehen des NT bezogen, das für $\mathrm{BACH}$ als paulinisch-lutherisch geprägten Christen u.a. dadurch veranlaßt ist, daß der Weg des "Gesetzes" gescheitert ist.

V.

Das in Teil III. zitierte und eben wieder erwähnte Lutherlied als ganzes enthält nun nicht nur die biblisch-dogmatischen Grundelemente für die glaubensbedingten Entscheidungen BACHs im Blick auf die Interpretation der beiden Texthälften, sondern zugleich auch wichtige Topen, die für das Verständnis der musikalischen Faktur des zweiten Teils der Motette wichtig sind. Daher seien als Einleitung zur Analyse dieses Teils noch zwei weitere Verse aus diesem Lied in Erinnerung gerufen:

Der Sohn dem Vater g'horsam ward, er kam zu mir auf Erden von einer Jungfrau rein und zart; er sollt mein Bruder werden.

Gar heimlich führt' er sein Gewalt, er ging in meiner armen G'stalt, den Teufel ${ }^{+}$wollt er fangen.

Vergießen wird er ${ }^{+}$mir mein Blut, dazu mein Leben rauben;

das leid ich alles dir zu gut, das halt mit festem Glauben.

Den Tod verschlingt das Leben mein, mein Unschuld trägt die Sünde dein, da bist du selig worden. (EKG 239, V. 6 und 8)

Zur Erlösung - und von ihr redet der Text von Jes 43,1b explizit gehört danach zum einen das Inkarnationsgeschehen, zum anderen das Leiden am Kreuz und der descensus ad inferos. Beides ist im Notentext BACHs unmittelbar nachvollziehbar. Der Satz: "Denn ich habe dich erlöset", wird durch einen doppelten, abwärtsgerichteten "passus duriuscu- 
lus"58 artikuliert - seit MONTEVERDI die rhetorische Figur für Erniedrigung bzw. Leiden.

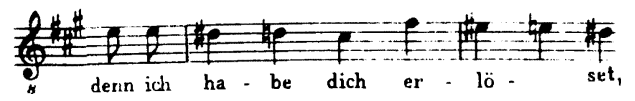

(T. 77-79; Tenor)

Er bildet das Thema der Fuge, in dem somit der "doppelte" Abstieg Christi und sein Leiden in Noten gefaßt erscheinen. Von daher erklärt sich also die eher gedrückt-traurige Stimmung dieses Teils, die in scheinbarem Gegensatz zum Text steht. - Auffälligerweise reiht BACH die beiden chromatischen Skalen nun aber nicht linear absteigend aneinander, sondern läßt den zweiten "passus duriusculus" einen Ton höher als den ersten beginnen, so daß die Abwärtsbewegung durch einen Quart-Sprung nach oben unterbrochen wird. Daß BACH damit schon mitten in der Darstellung des Erden- bzw. Höllenwegs Christi andeutet, daß Inkarnation und Leiden Heil bringen, ist m.E. klar - ist doch der Quartsprung nach oben ein Standardtopos für "Aufbruch", "Sieg" etc. und steht er doch genau bei der ersten Silbe des Wortes "erlöset"59.

Neben dieses "Subjekt" der Fuge hat BACH nun aber ein diatonisch um eine Quart aufsteigendes "Kontrasubjekt" gesetzt, das ihn vollends als biblischen Theologen von hohen Graden ausweist - läßt sich doch die dadurch entstandene musikalische Struktur des "crux-gloria-Topos"60 im Zusammenhang dieser Motette und ihres Anlasses als Begräbnismusik am besten von Röm 6,1-11 verstehen:

Oder wißt ihr nicht, daß alle, die wir auf Christus Jesus getauft sind, die sind in seinen Tod getauft? So sind wir ja mit ihm begraben durch die Taufe in den Tod, damit, wie Christus auferweckt ist von den Toten durch die Herrlichkeit des Vaters, auch wir in einem neuen Leben wandeln. Denn wenn wir mit ihm verbunden und ihm gleichgeworden sind in seinem Tod, so werden wir ihm auch in der Auferstehung gleich sein.

Sind wir aber mit Christus gestorben, so glauben wir, daß wir auch mit ihm leben werden, und wissen, da B Christus, von den Toten erweckt, hinfort nicht stirbt; der Tod kann hinfort über ihn nicht herrschen. (Röm 6,3-5.8-9)

Das "Ich habe dich bei deinem Namen gerufen" hat BACH offenbar an die Taufliturgie erinnert, und so interpretiert er die beiden bei Deuterojesaja hintereinander artikulierten Sätze konsequent parallel zueinander, daß dahinter neben einer dramatischen Darstellung der Menschwerdung und der Leidensgeschichte die paulinische Tauflehre, und durch sie hindurch - in der aufsteigenden diatonischen Figur - die Auferstehung Jesu erkennbar wird.

58 Vgl. dazu D. BARTEL [A.14] 234 bzw. R. BARTELMUS [A.11] 48.

59 Von dieser Aussageabsicht her erklärt sich vermutlich der Umstand, daß der "passus duriusculus" hier nur aus einer chromatischen Skala von 4 Tönen besteht, und nicht - wie sonst üblich - 5 Töne umfaßt.

60 Vgl. dazu N. POOS [A.44]. 


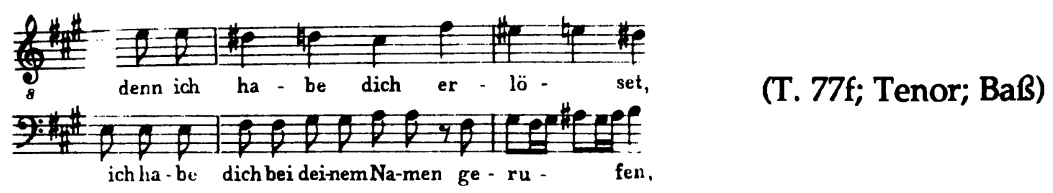

Von daher gewinnt indes die bereits oben (II.) erwähnte Einbeziehung der beiden letzten Verse von EKG 297 in der Sopranstimme noch einen über die rein verbalen Bezüge hinausreichenden Sinn - konnte $\mathrm{BACH}$ doch durch die Einbeziehung der Choralmelodie als drittes Thema der Fuge den zweiten Teil der Motette dreistimmig, und damit als trinitarisches Zeugnis gestalten, was angesichts der Erinnerung an die Taufe theologisch ja mehr als naheliegend ist.

Wie so oft in seinen Werken, beläßt es BACH ganz zum Schluß nicht bei einer theologisch schlüssigen, aber doch unpersönlichen Aussage, sondern fügt sich selbst als $B a B 1$ in den Chor ein: In T. 151f erscheint unverkennbar das Strukturmuster B-A-C-H, wenn auch tonartspezifisch um eine kleine Terz nach unten versetzt. Inmitten der noch einmal alle Schrecken des Todes ausmalenden Akkorde - in T. 152 findet sich etwa ein verminderter Septimen-Akkord, in dem der Tritonus, der "diabolus in musica", gleich mehrfach übereinander erscheint stimmt BACH in den Chor derer ein, die angesichts des Erlösungswerkes Christi sagen können: "Fürchte dich nicht".

Rückblickend läßt sich also feststellen, daß es BACH in der Motette "Fürchte dich nicht" nicht um eine oberflächlich appellative Auslegung der wenigen Worte aus Jes 41 und 43 geht. BACH hat vielmehr die vorgegebenen Worte zu einem heilsgeschichtlichen Entwurf, ja zu einem biblisch-theologischen Drama in nuce, genutzt. Der Trost, um den es natürlich auch ihm geht, baut nicht auf fader Affirmation sattsam bekannter theologischer Gedanken auf. BACH nimmt - und hier schließt sich der Kreis hin zur eingangs erwähnten Deutung des DeuterojesajaBuches durch den Jubilar - den Hörer vielmehr hinein in ein dramatisches Geschehen, von dem er affektiv so elementar berührt wird, daß $\operatorname{der} A$-Dur-Akkord am Ende als echte kó̈apors, als "Angeld" auf die erhoffte Erlösung, wahrgenommen werden kann. 



\title{
SALOMON IN ALEXANDRIA?
}

\section{Der weise Richter in 1 Könige 3, antiker Bildtradition und P. Oxy. 2944}

\author{
von
}

Kai Brodersen

Institut für Alte Geschichte, Ludwig-Maximilians-Universität München

In die halbverfallene Pyramiden-Nekropole der nubischen Könige im oberägyptischen Meroe war ein antiker Grabräuber eingedrungen und fündig geworden: Einen prächtigen vergoldeten alexandrinischen Silberbecher aus augusteischer Zeit mit der Relief-Darstellung einer Gerichtsszene hatte er entdeckt. Doch als wollte es der auf dem Becher dargestellte Richter, fiel dem Dieb die wertvolle Beute so unglücklich in einen Spalt zwischen herabgestürzten Pyramidensteinen, daß er sie nicht mehr erreichen konnte - die modernen Ausgräber fanden den Becher deshalb kaum beschädigt und konnten das Relief beschreiben':

Vor einem auf einem hohen Tribunal sitzenden Herrscher kniet bittflehend eine Frau mit zwei Kindern; hinter ihr steht ein wild gestikulierender Mann. Ein mit einem Beil bewaffneter Henker und eine hinter dem Tribunal aufgestellte Hackbank weisen auf das mögliche Urteil.

Als Richter ist der Herrscher Ägyptens dargestellt; "die gedankliche Parallele zur Figur Salomons liegt nahe und war zumindest einem orientalischen Publikum geläufig"2. Kannte man also Salomon in Alexandria?

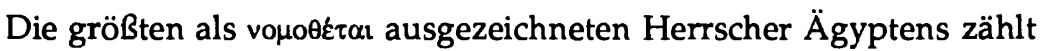
der griechische Historiker Diodor in seiner "Bibliothek der Geschichte" auf: Mneues, Sasychis, Sesoösis, Bokchoris, Amasis und Dareios ${ }^{3}$. Ist diese Liste schon als solche bemerkenswert - sie nennt ja mit Dareios einen Perserkönig -, sind es insbesondere die Erläuterungen zu den einzelnen Gesetzgebern:

So heißt es zu dem erstgenannten König, dem Begründer der ersten Dynastie Ägyptens, auf die erst nach über tausend Jahren die zwei-

\footnotetext{
1 Vgl. D. DUNHAM, The Egyptian Department and its excavation. Boston 1958, 126 und fig. 100. - Abkürzungen hier nach S. SCHWERTNER, Internationales Abkürzungsverzeichnis für Theologie und Grenzgebiete. Berlin-New York 1974.

2 E. KÜNZL, Eine Silberkanne mit Kentauromachie aus Pompeji. Jahrbuch des römischgermanischen Zentralmuseums 22 (1975) 62-80. 73.

3 Diodor I 94. Den Mneues nennt Diodor andernorts Menas: vgl. zuletzt R. LAQUEUR, Diodors Geschichtswerk - Die Überlieferung von Buch I-V, hg. v. K. BRODERSEN (Studien zur Klassischen Philologie 71 ) Frankfurt/Main 1992, 49.
} 
te, von Busiris begründete, folgte ${ }^{4}$, er habe seine Aufzeichnung von Gesetzen auf Hermes zurückgeführt wie Minos in Kreta auf Zeus, Lykurgos in Sparta auf Apollon, Zarathustra in Areia auf den Agathos Daimon, Zalmoxis in Getien auf Hestia und Moses ${ }^{5}$ bei den Juden auf

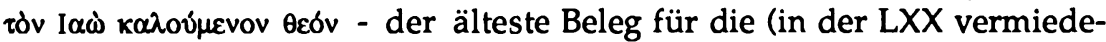
ne) Gottesbezeichnung ידה in der griechischen Literatur.

Beim letzten König, den Diodor in seiner Liste anführt, stellt er dessen $\phi_{\imath} \lambda \delta_{\theta} \theta \varepsilon \circ \varsigma$ Verhalten dem Wüten des Vorgängers Kambyses gegen die Heiligtümer Ägyptens gegenüber - eine dem Alttestamentler (etwa aus Esr 5f) geläufige Einschätzung dieses Perserkönigs, den der Althistoriker vor allem als Urheber des erst in der Schlacht bei Marathon zurückgeworfenen persischen Angriffs auf Hellas kennt.

Und einzig zu Bokchoris ${ }^{6}$ wird betont, seine kpiбeıs seien so weise gewesen, daß man sich an viele wegen ihrer Verständigkeit "noch in unserer Zeit" erinnere; man hat deshalb auch in der Darstellung auf dem Silberbecher aus Meroe den Bokchoris dargestellt gesehen?.

Bokchoris, dem der hellenistische Dichter Pankrates aus Arkadien ein mehrere Bücher umfassendes, für uns aber bis auf den Titel Borøwpric und ein Distichon verlorenes Werk gewidmet hat ${ }^{8}$, begegnet uns in der antiken Literatur sonst zum einen als der König, in dessen Herrschaftszeit der Exodus der Juden aus Ägypten stattfand ${ }^{9}$, zum anderen als bedeutender Gesetzgeber ${ }^{10}$ (seine Gesetze sollen sogar ein Vorbild für Solons Reformen gewesen sein) ${ }^{11}$, vor allem aber als überaus gerechter Mann 12:

Auf eine offenbar sprichwörtlich bekannte Entscheidung des Bok-

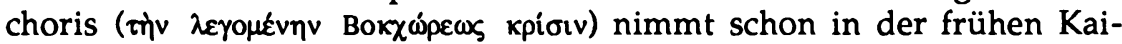
serzeit Plutarch Bezug ${ }^{13}$, und noch gut ein Jahrhundert später bezeich-

\footnotetext{
4 Diodor I 45.

5 Vgl. D. TIMPE, Moses als Gesetzgeber. Saec. 31 (1980) 66-77.

6 Bokchoris (Bekanref), Sohn des Tefnachte, herrschte am Ende des 8.Jh.s v.Chr. (24. Dynastie).

7 W.S. SMITH, Ancient Egypt as represented in the Museum of Fine Arts. Boston 1960, $184 f$.

${ }^{8}$ H. LLOYD-JONES, P. PARSONS, Supplementum Hellenisticum. (Texte und Kommentare 11) Berlin-New York 1983, 287f nr. 602 (bei Athenaios XI 478a).

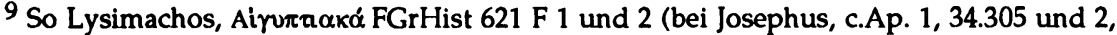
2.16) und Tacitus, Historien V 3. Andere Datierungen erörtert Georgios Synkellos, chron. p.69ff Mossh.

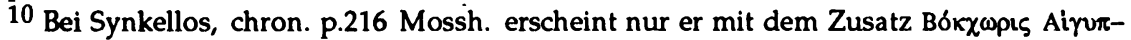
tiots Evouotétr.

11 Diodor I 79.

12 Vgl. die Zusammenstellung bei A. MORET, De Bocchori rege. Diss. Paris 1903, $50 \mathrm{ff}$.

13 Plutarch, Demetrios 27, 11; vgl. auch ders., De vitioso pudore 3 mor. p.529 e-f: Isis

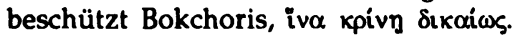


net Aelian, der Bokchoris in anderer Sache kritisiert, ihn als "vielbe-

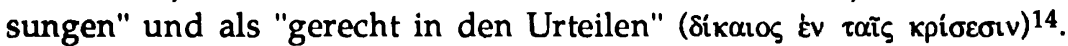

Dabei war Bokchoris' Ruhm als weiser Richter auch außerhalb der "hohen" Literatur verbreitet. So heißt es etwa im kaiserzeitlichen Liebesroman des Iamblichos, daß von den drei Töchtern einer Aphroditepriesterin, Euphrat, Tigris und Mesopotamia, die letztere drei aufeinander eifersüchtige Verehrer gehabt habe - und die kpioı dem Bokchoris

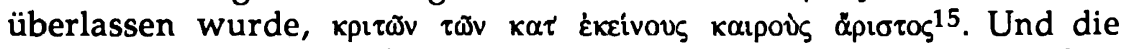
Sammlung griechischer Sprichwörter, die Zenobios etwa in Aelians Zeit zusammengestellt hat, gibt an, man nenne ein besonders gerechtes und verständiges Urteil gewöhnlich "Bokchoris' Urteil"16 - also was wir mit

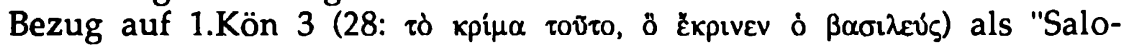
monisches Urteil" bezeichnen.

Als einzig erhaltene literarische Parallele zur biblischen Geschichte von Salomons Urteil in der heidnisch-antiken Literatur hat man eine Anspielung im "Satyrika"-Roman des Petron (79,9ff) angesehen 17:

Gerade vom Gastmahl bei Trimalchio heimgekehrt, geraten die Romanhelden Encolpius und Ascyltus über den von beiden begehrten Knaben Giton in Streit; Ascyltus schlägt daraufhin vor, den Knaben zu zerteilen und erhebt sein Schwert. Der Knabe fleht um Schonung, woraufhin schließlich ihm selbst die Entscheidung überlassen wird.

Diese Geschichte wirkt besonders komisch - und dadurch dem Ton des Romans angemessen -, wenn gleichsam als Gegenbild ein "Salomonisches" Urteil bekannt ist: bei jenem sind die Streitenden Frauen, hier Männer, dort ist der Knabe ein Sohn, hier ein Geliebter, und dort fällt das Urteil ein weiser König, hier das Opfer selbst.

Man hat deshalb gemeint, daß Petron 1 Kön 3 während der Zeit seiner Statthalterschaft im Osten kennengelernt habe - eine kaum plausible Vermutung, denn der Spaß beruht ja gerade darauf, daß auch das Lesepublikum die Geschichte kennt - oder aber daß die Geschichte durch Juden, die ja im 79 n.Chr. verschütteten Pompeji belegt ${ }^{18}$ und

\footnotetext{
14 Aelian, nat. an. 12, 3 bzw. 11, 11.

15 Iamblichi Babyloniacarum reliquiae, ed. E. HABRICH. Leipzig: Teubner 1960, 24 (aus Photios, bibl. 94 p.75a-b [II 39 Henry]); vgl. T. HÄGG, Eros und Tyche. Der Roman in der antiken Welt. (Kulturgeschichte der antiken Welt 36) Mainz 1987, 49 ff.

16 Zenobios, Centuria II 60 (ed. E. LEUTSCH, F.G. SCHNEIDEWIN, Corpus Paroemiographorum Graecorum. I Göttingen 1839, 48).

17 H. GRESSMANN, Das salomonische Urteil. Deutsche Rundschau 130 (1907) 212-228. 225.

18 Vgl. J.B. FREY, Les Juifs a Pompéi. RBi 42 (1933) 365-384.
} 
vielleicht auch durch Apg 28,13 (Paulus habe im nahen Puteoli "Brüder" getroffen) bezeugt sind, in Italien verbreitet worden sei ${ }^{19}$.

Doch stünde eine solche Bekanntheit einer biblischen Geschichte in der frühen römischen Kaiserzeit völlig allein; Salomon wird von keinem heidnisch antiken Autor genannt. Vielmehr ist für die - ohnehin zu den "Wanderanekdoten" gehörende und wohl auch als solche ins Königsbuch gekommene 20 - Geschichte in der Antike der Bezug auf einen anderen Richter wahrscheinlicher: Petrons Lesepublikum kannte wohl eher "Bokchoris' Urteil" als das Salomons" - kurz: Die antiken Texte wissen nichts von Salomon.

In mehreren antiken Bildern hat man hingegen mit größerer Bestimmtheit Bezüge auf Salomons Urteil gesehen, am deutlichsten auf einem Wandgemälde, das in Pompeji in der sog. Casa del gallo (Regio VIII, Insula 6, Nr. 6) gefunden wurde und heute im Nationalmuseum in Neapel aufbewahrt wird22. Dargestellt ist eine Szene, deren Beteiligte "Pygmäen" sind, also zwergenwüchsige "ägyptische" Gestalten mit auffallend groß abgebildeten Köpfen:

Auf einem hohen Podium sitzen drei Männer, von denen einer eine Lanze hält; hinter ihnen stehen drei Bewaffnete. Vor dem Podium liegt auf einem dreibeinigen Tisch ein Kleinkind. Ein Bewaffneter schickt sich an, es mit einem Hackmesser durchzuhauen. Ihm zur Seite steht eine Frau, eine zweite kniet vor dem Podium. Auf der linken Bildseite beobachtet eine Menge das Geschehen, rechts ist ein Zeltdach zu sehen ${ }^{23}$.

19 Vgl. H.C. SCHNUR, Petron, Satyricon, Ein römischer Schelmenroman. Stuttgart 1968, 224f. Auf Juden bezieht sich Petron sat. 68, 1 ff und 104, 13f sowie fr. 37.

20 Zahlreiche, vor allem orientalische Versionen haben etwa H. GAIDOZ, Le Jugement de Salomon. Mélusine 4 (1888/89) 313-316. 337-341. 366f. 385-387. 414f. 446. 457-460 und H. GRESSMANN [A.17] zusammengestellt. - Die ältere Auffassung, die indischen Versionen ahmten den Bibeltext nach (so noch J.G. FRAZER, Folk-Lore in the Old Testament. II London 1918, 570f), ist überholt: H. GRESSMANN, Die älteste Geschichtsschreibung und Prophetie Israels. SAT II/1, Göttingen 21921, 198 und H. GUNKEL, Das Märchen im Alten Testament. (RV II 23/26) Tübingen 1921, 145f. suchen den Ursprung der in 1 Kön 3 ohne Nennung Salomons wiedergegebenen Geschichte in einer polygamen Gesellschaft wie der indischen, in der beiden Frauen am Erbanspruch ihres Sohnes gelegen ist.

$21 \mathrm{Vgl}$. H. LuCAS, Ein Märchen bei Petron. In: Beiträge zur Alten Geschichte und griechisch-römischen Alterthumskunde Otto Hirschfeld ... gewidmet. Berlin 1903, 257-269. $262 f$.

22 Abbildungen z.B. in G.E. RIZzO, La Pittura ellenistico-romana. Mailand 1929, tav. CLI; O. ELIA, Pitture murali e mosaici nel museo nazionale di Napoli. Rom 1932, 58f (Nr.100) Fig.18.

23 Manches Detail ist dabei umstritten: T. GESZTELYI, Zur Frage der Darstellungen des sog. Salomourteils. Acta Classica Univ. Scient. Debrecensis 25 (1989) 73-84. 82 meint drei Richter erkennen zu können, doch scheint nur einer durch die Lanze hervorgehoben; $K$. SCHEFOLD, Lachendes Pompeji. Gym. 67 (1960) 90-102. 98 deutet die stehende Frau als Helferin des Kindes, die kniende für unterwürfig ergeben. 
Die gleiche Tradition kann einem Wandbild im Columbarium der Villa Pamphili zugrundeliegen, das der erste Interpret nicht zu deuten vermochte ${ }^{24}$ :

Ein mit einer Tunika bekleideter Mann ist im Begriff, ein vor ihm auf einem Tisch liegendes Kind mit einem Hackmesser durchzuhauen; vor ihm kniet eine bittflehende Frau.

Man hat aber schon bald auch diese Darstellung auf Salomons Urteil bezogen ${ }^{25}$; daß sie unvollständig ist, führte man auf einen mechanischen Verlust zurück oder deutete man als Mißverständnis der bildlichen oder auch mündlichen, jedenfalls auf Salomon bezogenen und aus Alexandria stammenden Tradition; dort nämlich sei "die biblische Geschichte bekannt genug" gewesen ${ }^{26}$.

Auch im Grab der Nasonier hat man auf einem Wandgemälde eine vergleichbare Szene rekonstruieren wollen ${ }^{27}$; da die Originalbefunde fast völlig verloren und die im 17.Jh. angefertigen Abzeichnungen durch P.S. BARTOLI notorisch ungenau sind, bleibt diese Deutung freilich umstritten 28 :

Vor einem auf einem Podest sitzenden bekränzten Mann stehen ein diesem zugewandter junger Mann sowie zwei um einen Tisch gruppierte gestikulierende Frauen; ein Mann richtet ein Beil (BARTOLI: Stab) auf ein auf dem Tisch liegendes Kind (BARTOLI: Krug).

Sicherer ist die Deutung einer der pompejanischen ähnlichen Darstellung auf einer in zwei Bildfeldern gestalteten, wohl spätkaiserzeitlichen Gemme in der Sammlung des Ungarischen Nationalmuseums in Budapest, die jüngst publiziert wurde ${ }^{29}$ :

24 O. JAHN, Die Wandgemälde des Columbariums in der Villa Pamfili. AHKBAW 8 (1858) 229-284. 249f ("mythologische Scene"); vgl. G. BENDINELLI, Le pitture del colombario di Villa Pamphili. (Monumenti della Pittura antica scoperti in Italia III, Roma V) Rom 1941, tav. agg. 2 b.

25 E. PETERSEN, Zusatz zu O. KELLER, Wandbild der Villa Pamfili. MDAI.R 5 (1890) 160.

${ }^{26}$ A. SAMTER, (Vortrag vor der Archäologischen Gesellschaft). JdI 13 (1898) AA 47-50. 49.

27 R. ENGELMANN, Ein neues "Urtheil Salomonis" und die Friesbilder der Casa Tiberina. Hermes 39 (1904) 146-154. 148ff; diese Deutung erwähnt B. ANDREAE, Studien zur römischen Grabkunst. (MDAI.RE 9) Heidelberg 1963, 124 nicht.

28 R. EISLER, Orphisch-dionysische Mysteriengedanken in der christlichen Antike. Leipzig-Berlin 1925, 160f deutet diese Szene als Antigone vor Kreon, doch da in jenem Grab auch das Urteil des Paris und Oidipus' weise Antwort auf das Rätsel der Sphinx dargestellt sind, scheint eine Bezugnahme auf ein weises Urteil durchaus möglich.

${ }^{29}$ T. GESZTELYI [A.23] 78ff; die beste Abbildung bei DEMS., Zur Frage der Darstellungen und Salomon-Urteils. Akten des XIII. Internationalen Kongresses für Klassische Archäologie Berlin 1988. Mainz 1990, 532f mit Taf. 84.1f. 
Auf dem Bildfeld thront ein lorbeerbekränzter Mann zwischen drei Speerträgern und wendet sich einer knienden Frau zu. Unten wird ein Kind an der einen Hand von einer gestikulierenden Frau gehalten, an der anderen von einem Schwertträger. Auf der einen Seite dieser Gruppe steht ein weiterer Bewaffneter, auf der anderen bewegt ein Mann seinen Kahn.

Dieser Darstellung wiederum ähnelt die auf einer anderen spätkaiserzeitlichen Gemme in Bukarester Privatbesitz ${ }^{30}$ :

Ein thronender, hinten durch einen Leibwächter beschützter Mann hält ein Kind an den Füßen hoch; vor ihm kniet eine Frau, eine zweite Frau steht, und ein Bewaffneter erhebt sein Schwert zu Schlag gegen das Kind.

Und ähnlich ist auch die Darstellung auf einem Fresko im sog. schwarzen Saal (triclinium) der augusteischen Villa Tiberina bei der Villa Farnesina ${ }^{31}$ :

Vor einem thronenden Richter hält ein junger Mann ein Kind an den Füßen über ein Becken; ihm leistet eine Frau Hilfe, eine andere wendet sich gestikulierend ab.

Alle diese Darstellungen hat man auf das Urteil Salomons bezogen. Daß - anders als in den neuzeitlichen Bildern der Szene, die meist zwei Kinder zeigen ${ }^{32}$ - jeweils nur ein Kind dargestellt wird, darf dabei nicht verwundern, da erst die Lucianische Rezension der Septuaginta und Josephus ant. VIII 2.31 (vielleicht wegen Ex 21,35) angeben, der König habe das lebende und das tote Kind zu teilen befohlen.

Vor allem das am längsten bekannte und am sichersten gedeutete Wandgemälde aus Pompeji gilt vielen als Darstellung von Salomons Urteil. Diese Deutung vorausgesetzt, wurde gefragt: Kannte der Künstler den Bibeltext oder gar eine Bibel-Illustration ${ }^{33}$ oder aber - was die als Masken deutbaren großen Köpfe der Pygmäen nahelegen ${ }^{34}$ - ein "biblical play" 35 von Salomons Urteil?

Unter derselben Voraussetzung des Bezugs auf 1 Kön 3 wurde aber auch die entgegengesetzte Deutung der Szene als einer antisemitischen Parodie der biblischen Geschichte vertreten ${ }^{36}$.

30 A. DE LONGPÉRIER, Une intaille antique inédite. CRAI 4.S.8 (1880) 275-80 (und RAr N.S. 40 [1880] 242-245), wieder in DERS., Euvres complètes. III Paris 1883, 378-383.

31 Vgl. I. BRAGANTINI, M. DE VOS, Le decorazioni della villa romana della Farnesina (Museo Nazionale Romana, Le Pitture II 1) Rom 1982, 236 zu nr. 1080 C 5 und tav. 153ff.

32 Vgl. B. KERBER, "Salomon", LCI IV, Freiburg 1970, 15-24. 20.

33 K. SCHEFOLD [A.23] 98. Vgl. allg. K. WEITZMANN, Die Illustrationen der Septuaginta. Münchner Jahrbuch der bildenden Kunst 3.F. 3/4 (1952/3) 96-120; vgl. aber J. GUTMANN, The Illustrated Jewish Manuscripts in Antiquity. Gesta 5 (1966) 39-44.

34 An Theateraufführungen denkt etwa R. ENGELMANN [A.27] 147.

35 So J. GUTMANN, Was there biblical art at Pompeii? AK 15 (1972) 122-124, u.a. mit Hinweis auf das Exodus-Drama des Ezechiel tragicus (dazu E. VOGT, Tragiker Ezechiel. JSHRZ IV/3 Gütersloh 1983, 115ff).

36 SO K. SCHEFOLD [A.23] 98. 
Und immer noch unter derselben Voraussetzung wurde diskutiert, ob es überhaupt Juden in Pompeji gab, die mit dieser Darstellung in Verbindung gebracht werden können, oder ob nicht vielmehr auch die Thematik des Gemäldes eher auf eine Vorlage in Alexandria mit seiner jüdischen Gemeinde hinweise. Noch der letzte Interpret betont, "da $B$ die bildliche Formulierung der Geschichte ... aus Alexandrien stammt und von dort aus nach Italien gekommen ist"37. Hatte die Antike also zumindest ein Bild von Salomon in Alexandria?

Die zunehmende Bekanntschaft mit anderen Texten mit weiteren Versionen des "Salomonischen" Urteils hat die Voraussetzung, die Bildtradition müsse sich auf 1 Kön 3 beziehen, erschüttert: Für das Gemälde in der Villa Pamphili hat man - freilich ohne stichhaltige Gründe - indische Vorlagen bemüht ${ }^{38}$, wie sie ja auch für die biblische Geschichte vorausgesetzt werden dürfen (s.o.). Die Gemälde in der Villa Tiberina hat man aus seinem Kontext - die anderen Gemälde im Raum stellen weitere auf Rechtsfälle beziehbare Szenen dar - auf Bokchoris gedeutet $^{39}$, ja als Illustrationen zu einer epischen "Bokchoreis" aufge$\mathrm{faBt}^{\mathbf{4 0}}$, ferner auch an Bilder $\mathrm{zu}$ Themen der Rhetorenschule ${ }^{\mathbf{4}}$ oder $\mathrm{zu}$ einem Roman ${ }^{42}$ gedacht. Vor allem aber hat man das pompejanische Gemälde, dem weitere ägyptisierende Darstellungen im selben Raum zur Seite stehen, überzeugend auf einen ägyptischen König bezogen, ja sogar die Bildtradition zu epichorisch ägyptischen Darstellungen in Beziehung zu setzen gesucht $t^{43}$. Es liegt dann nahe, in dem dargestellten Richter den weisen ägyptischen König Bokchoris zu sehen: Sollten wir also gleichsam nicht Salomon, sondern Bokchoris in Alexandria vermuten?

Vor zwanzig Jahren wurde ein - noch vom letzten Interpreten der Bildtradition nicht berücksichtigter - Papyrus aus Oxyrhynchos publiziert, dessen geradezu kalligraphische Schrift des späten 1. oder frühen 2. Jahrhunderts n.Chr. und dessen ungewöhnlich handliches Format

${ }^{37}$ T. GESZTELYI [A.23] 84.

38 G. LIGNANA, Pompei, e le novelle indiane. Actes du sixième congrès international des orientalistes. III 2 Leiden 1885, 121-132.

39 A. MAU, Bibliografia Pompeiana. MDAI(R) 10 (1895) 314-335. $321 f$.

40 E. LOEWY, Aneddoti giudiziari dipinti in un fregio antico. Rendiconti della Classe di Scienze morali ... dell' Accademia dei Lincei (Rom) 5.S. 6 (1897) 27 - 45; A. MORET [A.12] 62ff; A. MAIURI, La peinture romaine. Genf 1953, 30.

41 R. ENGELMANN bei A. SAMTER [A.26] 50 (vgl. DERS. in E. GUHL, W. KONER, Leben der Griechen und Römer. Berlin $61893,679 \mathrm{ff})$.

42 C. ROBERT, Archaeologische Nachlese. Hermes 36 (1901) 364-404. 364ff.

43 W.B. MCDANIEL, A Fresco Picturing Pygmies. AJA 36 (1932) 260-271. 267. 
auf ein "coffee-table book" mit "light literature" weisen. Die erhaltene Partie lautet ${ }^{44}$ :

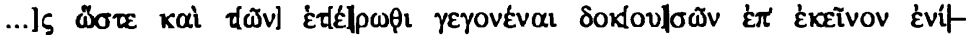

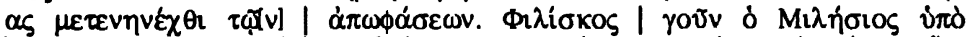

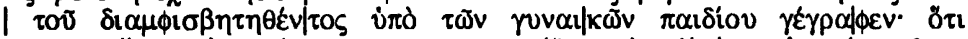

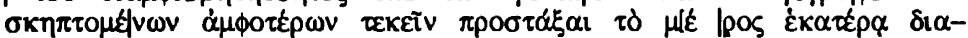

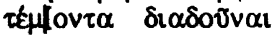

... so daß sogar von den Entscheidungen, die anderswo (oder: ein andermal) getroffen worden sind, einige auf jenen übertragen wurden. Zum Beispiel hat Philiskos von Milet von dem Kind geschrieben, das seitens der Frauen umstritten war, daß er, als beide vorgaben, es geboren zu haben, befohlen habe, es durchzuschneiden, um jeder einen Teil zu geben ...

Der im Text genannte Philiskos von Milet ist uns bekannt als ह̇ंõ̃pos des bedeutenden athenischen Redners Lysias (445-380); wenn Plutarch, dem wir diese Information verdanken, hinzufügt, daraus gehe dessen Alter hervor, so bezieht er sich wohl auf die päderastische Beziehung des älteren Lysias zum jungen Philiskos, der auch ein rvwipıнs des athenischen Politikers und Rhetors Isokrates (436/5 - 338) gewesen sei45; als Isokratesschüler wird Philiskos auch sonst bezeichnet ${ }^{46}$. Über einen anderen Schüler dieses Meisters, den athenischen Staatsmann Lykurgos (um 390 - um 324) schrieb Philiskos eine Biographie 47; als

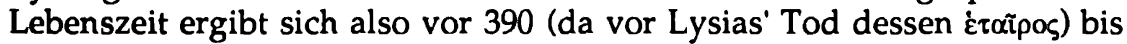
nach 324 (da Biograph des Lykurgos) ${ }^{48}$ : Das Erblühen Alexandrias unter den Ptolemäern hat Philiskos nicht mehr erlebt.

Der Herausgeber des Textes hat die Angaben des Papyrus auf 1 Kön 3 bezogen und betont, eine vergleichbare Geschichte finde sich nicht in "any classical author", weshalb es überhaupt "no Greek or Roman analogy" dazu gebe ${ }^{49}$ (er übersieht dabei die Bildtradition ebenso wie deren Interpreten den Papyrus). Kannte man also Salomon nicht erst im hellenistischen Alexandria, sondern schon im 4.Jh. v. Chr. in Athen?

44 P. Oxy. 2944, ed. E.G. TURNER, in: G.M. BROWNE u.a., The Oxyrhynchus Papyri XLI London 1972, 4ff; vgl. DERS., The Papyrologist at Work. (GRBS Monogr. 6) Durham NC 1973, 7ff.

45 Plutarch, vita Lysiae (vitae decem oratorum, mor. p.836c).

46 Dionysios von Halikarnaß, de Isaeo 19 und ad Ammaeum 2; Cicero, de oratore II 94 (Philistus); Vita Isocratis (in G. BAITTER/H. SAUPPE, Oratores Attici. II Zürich 1850, 4 b 26); Suda s.v. Philiskos.

47 Olympiodor, In Platonis Gorgiam commentaria 41, 10 p.125 WESTERINK (FGrHist 337 bis); dazu R.F. RENEHAN, The Platonism of Lycurgus. GRBS 11 (1970) 219-231. $229 f$.

48 Dazu paßt, daß zu Isokrates' Lebzeiten der Historiker Timaios und der Rhetor Neanthes von Kyzikos wohl dessen Schüler geworden wären, so aber wurden sie Schüler des Philiskos: s. jeweils SUDA s.v.

49 E.G. TURNER [A.44] (1973) 5. 
Man kann spekulieren, in welchem Zusammenhang Philiskos' Angabe stand, und da der Papyrus den Begriff ánoфáбeıs verwendet, liegt

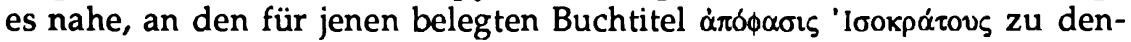
ken, der freilich unterschiedliche Deutungen zuläßt: Man hat ihn als "Absagebrief an Isokrates"50, als "Memorabilien über Isokrates"51, als "Apophthegmata von Isokrates" 52 oder - im Zusammenhang mit dem Papyrustext - als "imaginäres Urteil des Isokrates" verstanden; Philiskos habe also das "Salomonische" Urteil seinem Lehrer in den Mund gelegt ${ }^{53}$. Doch ist der Bezug auf den Buchtitel kaum gerechtfertigt: Der Papyrus spricht ja nicht im Singular von einem Urteil, sondern im Plu-

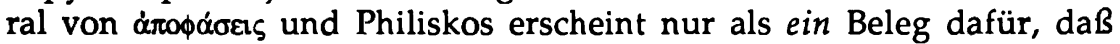
diese Geschichte aus einem anderen Zusammenhang auf "jenen" übertragen wurde. Könnte nicht vielmehr der sprichwörtlich gerechte ägyptische König Bokchoris gemeint sein, über den Philiskos hier ebenso spricht wie sein Lehrer Isokrates über einen Vorgänger des Bokchoris, den eingangs genannten Busiris? Lernen wir also durch den Papyrustext gar nicht Salomon, sondern Bokchoris in Athen kennen?

Salomon in Alexandria, Bokchoris in Alexandria, Salomon in Athen, Bokchoris in Athen - wir fassen zusammen: Während die ältere Forschung in der antiken Bildtradition des Urteils eines weisen Richters einen Bezug auf Salomon sah und der "Nöthigung" unterlag, "alexandrinischen Ursprung ohne weiteres als selbstverständlich anzunehmen und von dieser Basis aus die Deutung zu versuchen"54, weist die gerade auch außerhalb der hohen Literatur - im Roman des Iamblichos (und wohl auch des Petron), im Sprichwort, in einem "coffee-table book" aus Oxyrhynchos - vorausgesetzte Tradition von den weisen Urteilen des Bokchoris auf diesen als in Texten wie Bildern gemeinten weisen Richter, und der im Papyrus genannte Philiskos legt eine Bekanntheit der Geschichte bereits vor dem Erblühen Alexandrias nahe - kurz: Die antike literarische und ikonographische Tradition kennt eher Bokchoris in Athen als Salomon in Alexandria.

Wir könnten unsere Überlegungen hier abbrechen - wäre die Identifizierung des Herrschers auf dem Silberbecher aus Meroe mit Bokcho-

50 Th. BERGK, Fünf Abhandlungen zur Geschichte der griechischen Philosophie und Astronomie. Leipzig 1883, 24 Anm. 1.

51 P. SANNEG, De schola Isocratea. Diss. Halle 1867, 32.

52 F. BLASS, Die Attische Beredsamkeit. II ${ }^{2}$ Leipzig 1892, 454.

53 A. MOMIGLIANO bei E.G. TURNER [A.44] (1972) 5 bzw. (1973) 12.

54 R. ENGELMANN [A.27] 147. 
ris die einzig mögliche. Der dargestellte Richter trägt nämlich eine römische Toga, ja mehr noch: Seine Züge gleichen denen auf im griechischen Osten kursierenden augusteischen Münzen ${ }^{55}$. Wie die weise Urteilskraft des Bokchoris den Ägyptern (und - ihm folgend - die des Solon den Athenern, aber auch die des Salomon den Juden) genützt hat, so ist es nun die des - Diodor noch nicht bekannten - neuen und größten vouootems Ägyptens, des römischen Kaisers Augustus ${ }^{56}$.

55 C. VERMEULE, Augustan and Julio-Claudian Court Silver. AK 6.1 (1963) 33-40. 33 erwägt als Vorlage ein "monumental work, perhaps a painting, with political implications"; vgl. H. GABELMANN, Antike Tribunalszenen. Darmstadt 1984, 127f.

$56 \mathrm{Zu}$ Augustus als Richter vgl. Phaedrus 3, 10. - Die von C. VERMEULE [A.55] 38 gebotene Überlegung, der Künstler habe den Richter lächerlich machen wollen, indem er ihn "presiding over the squabbles of two women about one or more children" darstellte, über-

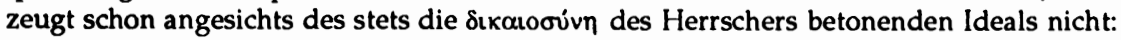
vgl. nur H.H. SCHMITT, "Herrscherideal", in: DERS./E. VOGT, Kleines Wörterbuch des Hellenismus. Wiesbaden 1988, 232-238. $236 \mathrm{f}$ und die von F. MILLAR, The Emperor in the Roman World. London 1977, 3f hervorgehobene Anekdote bei Cassius Dio 69, 6, 3: Als eine Frau Kaiser Hadrian um etwas bat, dieser aber nur sagte, "ich habe keine Zeit", rief

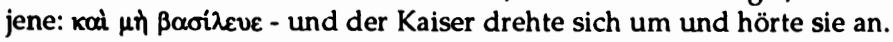


THE BLESSING OF LEVI IN DTN 33, MAL 2, AND QUMRAN 1

\author{
von \\ Russell Fuller \\ University of San Diego, CA, USA
}

\title{
I. Deuteronomy 33:8-11, The Blessing of Levi
}

In working with any ancient document which has been preserved in multiple copies we immediately confront the problem of method and priority of method in analysis. In the case of a biblical text the problem is especially acute since a passage may have been preserved, at least partially, in various contexts and these contexts may have affected the form of the text. The first pressing question which then arises is: "What text does one analyze? Does the received text have priority over another version of the same passage when they differ?"

This is not a new problem, but it has become more pressing in the study of the text of the Hebrew Bible with the increasing availability to scholars of the materials recovered from the Judean Desert, from the community at Qumran and elsewhere. This material, some biblical manuscripts, some non-biblical, commentaries, and "sectarian" compositions preserves, cites and alludes to biblical passages. From a text-critical perspective this at first glance seems like a welcome situation indeed. The more data we have the better off we are. But the textual critic quickly becomes aware of an important issue. Are the biblical citations which are found in the pesharim, for example, to be accepted at face value as simply a biblical text which has been cited for its apparent relevance to the purpose(s) of the author of the pesher, or is the citation rather a conscious revision (or rereading) of the lemma in question to suit the purpose of the interpreter? The question then becomes for the textual critic of the Hebrew Bible: "How do we evaluate these cited texts which exist in a unique context when they differ from the 'received' text? Should they be considered to reflect a singular textual tradition or idiomatic variants due to the context?" This is also not a new issue in the history of textual criticism. The use of citations of New Testament passages in the church fathers is one which has divided New Testament textual critics. It is also an issue in the production of critical editions of biblical materials.

This paper is an attempt to examine the history of the use of the composition known as the Blessing of Levi found in Dtn 33:8-11. This

1 I would like to dedicate this small paper to Prof. Klaus BALTZER in sincere graditude for his friendship and learning. 
text, which is not without some interesting textual problems to which I will allude in passing, is cited or alluded to in other biblical and non-biblical literature from the pre-Christian period. Dtn 33:8-11 is utilized along with other traditions in Mal 2:4-9. Dtn 33:8-11 is cited in two nonbiblical compositions found in the library of the community at Qumran. In $4 \mathrm{Q} 174(=4 \mathrm{Q}$ Florilegium now renamed $4 \mathrm{Q}$ Midrash on Eschatology)2, and in 4 Q175 ( $=4 \mathrm{Q}$ Testimonia).

In this paper I will begin with observations on the primary text, Dtn 33:8-11, in its context then move to an examination of the use made of this text in Mal 2:4-9, and end with a discussion of the citation of Dtn 33:8-11 in the two non-biblical compositions from Qumran.

II.

Dtn 33:8-11:

8 And of Levi he said:

Give to Levi your Thummim

and your Urim to your loyal one,

whom you tested at Massah,

with whom you contended

at the waters of Meribah;

9 who said of his father and mother,

"I regard them not";

he ignored his kin,

and did not acknowledge his children.

For they observed your word,

and kept your covenant.

10 They teach Jacob your ordinances,

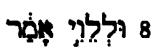

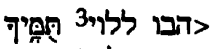

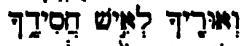

政

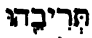

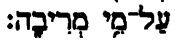

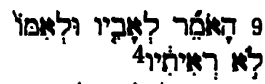

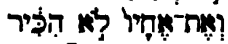

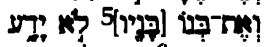

ד

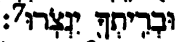

10

2 See the excellent paper A. STEUDEL, "4QMidrEschat: 'A Midrash on Eschatology' (4Q174 + 4Q177) forthcoming in Proceedings of Manuscritos Mar Muerto Madrid, Congresso Internacional (17-22 Marzo - 1991). Leiden 1991.

$34 \mathrm{QDt}$, $, 4 \mathrm{QTest}, \mathrm{LXX}$. For the biblical manuscripts of Deuteronomy from Qumran, Cave IV see J.A. DUNCAN, A Critical Edition of Deuteronomy Manuscripts from Qumran, Cave IV: $4 Q^{2} t^{b}, 4 Q D t^{e}, 4 Q D t^{h}, 4 Q D t^{j}, 4 Q D t^{k}, 4 Q D t^{l}$. Harvard Dissertation 1989. I would like to thank Prof. DUNCAN for sharing her insights on this material.

4 Note the reading of $4 \mathrm{QDt} \mathrm{t}^{\mathrm{h}} \mathrm{j}^{\mathrm{r}} \mathrm{n}$ and the clause which seems to have dropped out see 4Q175 and J.A. DUNCAN,[A.3] 71.

5 Ketiv; Qere iq.

$64 \mathrm{QDt}^{\mathrm{h}} \mathrm{LXX}$ רax.

$74 \mathrm{QDt}^{\mathrm{h}}$ ינר but the reading is uncertain, compare J.A. DUNCAN [A.3] figure 16.

$84 \mathrm{QDt} \mathrm{h}^{\mathrm{h}} \mathrm{n}$. Contrast the reading of $4 \mathrm{QTestamonia}$ inserted above the line by the original scribe. No suggested explanation for this reading has yet commanded widespread acceptance. This reading has no known parallels among textual witnesses. The usage of $17 \times$ is not so different graphically from the reading of the Masoretic Text reflecting only a difference of two letters, another yod and an alep. Could the reading of 
and Israel your law;

they place incense before you,

and whole burnt offerings on your altar.

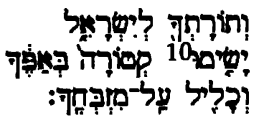

11 Bless, $\mathrm{O}$ Lord, his substance,

11

and accept the work of his hands;

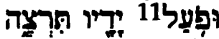

crush the loins of his adversaries,

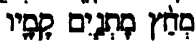

of those that hate him,

1

so that they do not rise again?

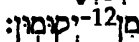

The prehistory of Dtn 33 is unclear. Ch. 33 is presented as the final blessing of Moses given beyond the Jordan river before his death. The composition begins with a poem briefly describing the theophany of Yahweh; the choice of Israel; the giving of the Torah; and the march through the wilderness; culminating with the rise of a king in Jeshurun, the poetic designation for Israel. This may be Yahweh as king, or it may indicate the development of kingship in Israel. ${ }^{13}$ The composition is a composite one. The poetic introduction (vv. 2-5) and the closing section (vv. 26-29) were probably originally a single composition which was split into two by an editor. This Exordium in vv. $2-5$ is completed by the poetic conclusion in vv. 26-29. Indeed the use of Jeshurun ${ }^{14}$ in vv. 5

$4 \mathrm{QTest}$ be the result of a playful interpretation of the majority reading nir on the part of the composer of this composition? The reading of $4 \mathrm{QTest}$ (n' found in Testament of Levi 4:3, "The light of knowledge you shall make shine in Jacob, and you shall be as the sun for all the posterity of Israel." (

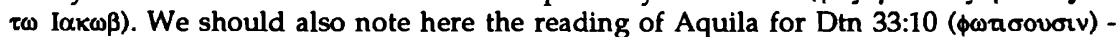
on which see M. SMITH, Bib. 48 (1967) -, which is quite curious since Aquila normally reflects very faithfully the reading of the Masoretic Text. Compare the LXX reading,

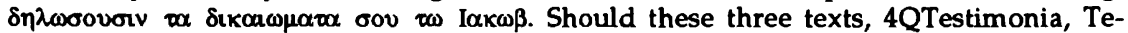
stament of Levi, and Aquila, be understood to reflect an interpretive tradition based on nir of Dtn 33:10? - For information on the Aramaic Testament of Levi material see the article of J.C. GREENFIELD and M.E. STONE, Remarks on the Aramaic Testament of Levi from the Geniza, RB 86 (1979) 223-24.

9 The English version given above is taken from the New Revised Standard Version and reflects the textual decisions of that committee of translators.

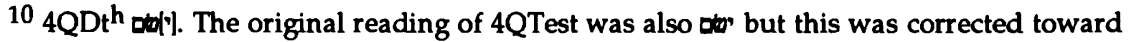
the reading preserved in the Masoretic Text. See J. STRUGNELL, Notes en marge du volume V des 'Discoveries in the Judean Desert of Jordan', RdQ 7 (1970) 225.

$114 \mathrm{QDt}{ }^{\mathrm{h}}$ פעלת. Compare $4 \mathrm{QT}$ Test where taw has been erased. Since LXX reads $\tau \alpha \varepsilon p \gamma \alpha$, here J.A. DUNCAN [A.3] 72 suggests that the Qumran manuscripts may have read the plural construct.

12 Contrast $4 \mathrm{QDt} \mathrm{t}^{\mathrm{h}}$ and $4 \mathrm{QTest}$ both of which read בל which makes much better sense in this context.

13 If the development of Kingship in Israel is meant, then this composition might be traceable to the time of Saul, or approximately the 11th century BCE.

14 Jeshurun (pret) occurs only in Dtn 32:15; 33:5.26; Isa 44:2. 
\& 26 is one indication that these two pieces were originally one composition which was split and used as a frame for the blessings. ${ }^{15}$

With the exception of the first blessing, that for Reuben, the individual blessings for the tribes are each introduced by the narrator who is also responsible for 33:1 which connects ch. 33 to what preceeds. There is widespread agreement that ch. 33 , as well as $32-34$ are a sort of appendix to the book. 16

The blessing of Levi in vv. 8-11 is second only to the blessing of Joseph in length. It is introduced by the narrator based on the pattern used to introduce the other blessings. As in Gen 49, so also here in Dtn 33, each of the tribes seems to be blessed in the person of their ancestor at the beginning of the blessing. In the blessing of Levi there is a marked shift from the singular to the plural in the midst of v. 9. This shift in number may mark a shift in the perspective of the writer as we shall see. The blessing may be divided into three sections as follows:
1. Section 1: vv. 8-9b
Yahweh is addressed directly using injunctive forms.
2. Section 2: vv. $9 c \& 10$
the past/current or ongoing actions of Levi (the tribe) are described.
3. Section 3: v. 11
Yahweh is addressed directly again using injunctive forms.

In sections $1 \& 3$ Yahweh is addressed directly. This is evident in v. 11 from the masculine singular imperative forms as well as the appeal to Yahweh by name. Verse 8 is less clear, but the Thummim and Urim are

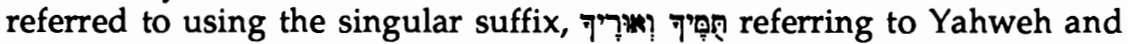
the singular suffix is also used on only problem with this understanding comes if we restore the phrase הבו ללוי textual tradition and Qumran manuscripts ${ }^{18}$. The use of the plural imperative form with Yahweh as the antecedent is unparalleled in this composition. However there is precedent outside of Dtn 33 for using

15 I.L. SEeligmanN, A Psalm from Pre-Regal Times. VT 14 (1964) 75-92, and A.D.H. MAYES, Deuteronomy. London 1979, 396.

16 Note the treatment of MAYES. Contrast the view of B.S. CHILDS, Introduction to the Old Testament as Scripture. Philadelphia 1979, 219-221.

17 So S.R. DRIVER, A Critical and Exegetical Commentary on Deuteronomy, ICC, Edinburgh 1902, 398ff.

18 is the reading found in the Qumran manuscripts (4QTest $14 ; 4 Q D t^{\text {h }}$ frag 9 line

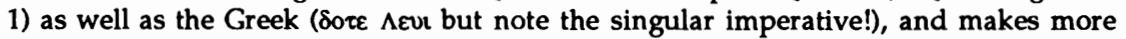
sense in context than the reading preserved in the Masoretic Text. which omits this phrase. The omission may be due to a haplography, but this is difficult to justify. Note also that while the Hebrew witnesses preserve the plural imperative, the Greek tradition has the singular. This may be due to the translator's attempt at smoothing. See J.A. DUNCAN [A.3] 71f. 
with a singular. ${ }^{19}$ The incidents referred to in the remainder of v. 8, the testing at Massah and the contending at Meribah, are unclear ${ }^{20}$. What seems clear is that v. 8 draws on the Massah/Meribah traditions and in conjunction with v. 9a-b combines them with a tradition similar to, although not necessarily identical with the action of the Levites during the episode of the golden calf in Ex 32:25. MAYES suggests that Ex 15:25 may contain the background for 33:9a-b. A study of the vocabulary shared by Dtn 33:8-9b and texts which mention the Massah/Meribah incident shows that Ex 17:1-7 and 15:25 share more of the vocabulary which is applied to Levi in Dtn 33:8-10 than any other passages. Although it is not conclusive, this does reinforce the suggestion of MAYES.21

In section 2, the shift from singular to plural forms in vv. 9c-10 has long been recognized as problematic. In most of the remainder of Dtn 33 singular forms seem to be used with collective force to indicate the actions of the collection of individuals which make up the tribe. An exception to this usage occurs in vv. 18-19, the blessing of Zebulun. V. 18 begins by

19 הכו with a singular antecedent is found only twice (2 Sam 11:15; 16:20).

20 Compare the discussion in S.R. DRIVER [A.17] 399-400.

21 Passages connected with the Massah/Meribah traditions are: Ex 15:25; 17:1-7; Dtn 32:51; Pss $81: 8 ; 106: 32$. These texts indicate a certain variety in the form of these traditions.

Ex 15:25

ריב

Ex 17:1-7

Dtn 32:51

Ps 81:8

Ps 95:8-9

$x$

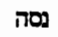

$\mathbf{x}$

$x$

$x / x$

Ps 106:32

$x$

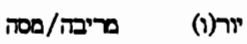

$x$

(x)

(x)
The table shows that Ex 15:25 and Ex 17:1-7 share more of the selected vocabulary that has to do with the Levites in Dtn 33:8-10 than the other passages. It is only Ex 15:25, however, which also uses the vocabulary which pertains to the roles which the Levites fill after the incident which is used in Dtn 33. Note also that Ex 32:25f. contains none of this vocabulary but does use some of the kinship terms which are used in Dtn 33:9, $\mathrm{m} x$ and p. Thus it seems likely that Dtn 33;8-10 draws upon these two passages (or their antecedant traditions) in forming this version of the incident and its results. Note that only Ex 17:7, Dtn 33:8 and Ps 95:8 join Massah and Meribah together. In Deuteronomy, Massah by itself is mentioned more frequently, i.e., Dtn 6:16; 9:22 (also in Ex 17:7). Meribah is mentioned only in Dtn 32:51 (alone) and 33:8. Outside Deuteronomy, Meribah is mentioned by itself in Num 20:13,24; Pss 81:8; 106:32. These data would seem to indicate separate traditions perhaps centered around the two names which are also certainly the result of word plays. These traditions were combined at some point in the three texts where both are mentioned together. 
addressing Zebulun in the singular: "Rejoice, Zebulun, in your going out ...". But v. 19 has plural forms, "they call, they offer, they suck", referring to the actions of the tribe as a collection of individuals. The shift

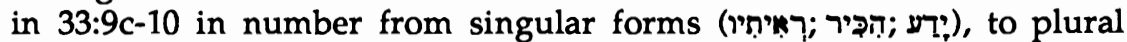

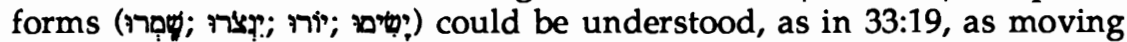
from Levi, an historical person, to Levites as a collection of individuals and their functions or at least their idealized functions in the writer's own time. That is the interpretation if we view the shift as intentional. The textual evidence on the shift in number is uneven. Both 4QDt ${ }^{\mathrm{h}}$ and 4QTestamonia consistantly read singular forms throughout this material. Another, and perhaps older, model within scholarship for understanding this shift would be to view the plural verb forms in $9 c-10$ as secondary developments from singular forms which were collective in force. The only evidence which could be cited for this view are the readings of $4 \mathrm{QD} \mathrm{t}^{\mathrm{h}}$ which consistantly reads singular verb forms in this section where the other witnesses (including the MT) have plural forms. (and in v.9c the Greek also).22 Although the evidence of the Qumran material is significant for the textual criticism of Deuteronomy, I am inclined to favor the view that the shifts in person are intentional. This need not be the case each time it occurs in Deuteronomy. Each case should be reviewed on a pericope by pericope basis.

Although what may be said about the original setting of this composition is limited, some conclusions may be offered. The figure of Le$\mathrm{vi} /$ the Levites fulfill three functions: (1) they observe the covenant, presumably the covenant between God and Israel not the special covenant with Levi; (2) they teach the ordinances and the Torah; and (3) they offer incense and sacrifices to God. Concerning vv. 8-10, it is clear that they were composed at a time when the teaching and sacrificial functions of the Levites had been established. This need not mean that they had been long established. Verses 8-10 could either come from a setting in which the Levites as a group had long been practicing these functions and thus the composition only describes the usual practice, or they could come from a setting in which this role was just being established and serve as a sort of charter document legitimizing the new role. This latter possibility might fit in better with the view of the Levites in Deuteronomy.

Second, if MAYES and others are correct in seeing v. 11 as a secondary addition to vv. 8-10 which was originally part of the blessing of Judah, then v. 11 can be used as information about this time period. The Levites may have been under some sort of threat (v.11b) while the language of v.11a has connections to some post-exilic literature concerned with the priests and Levites. For example, in the Book of Malachi a form of the root רצו is used four times in reference to accepting the offering from the hands of the priests (in three of those occurances the forms

22 J.A. DUNCAN [A.3] 71. 
מידכה מחה are also present). To a tradent of the second temple period

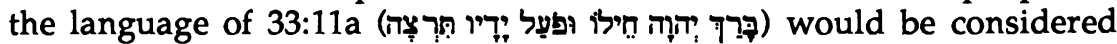
quite appropriate for discussion of priestly or levitical functions. The second temple period might provide a reasonable period in which to set the shifting of v.11 from the blessing of Judah to the blessing of Levi.

\section{III.}

\section{Mal 2:4-9:}

4 Know, then, that I have sent

this command to you,

that my covenant with Levi may hold, says the Lord of hosts.

5 My covenant with him was a covenant of life and well-being,

which I gave him; this called for reverence, and he revered me and stood in awe of my name.

6 True instruction was in his mouth, and no wrong was found on his lips. He walked with me in integrity and uprightness, and he turned many from iniquity.

7 For the lips of a priest should guard knowledge, and the people should seek instruction from his mouth, for he is the messenger of the Lord of hosts.

8 But you have turned aside from the way; you have caused many to stumble by your instruction; you have corrupted the covenant of Levi, says the Lord of hosts, 9 and so I make you despised and abased before all the people, inasmuch as you have not kept my ways but have shown partiallity in your instruction.
4

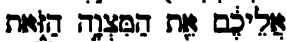

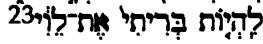

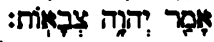
5 החיטים ורד i़ מิ

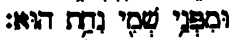
6

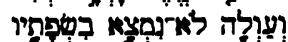

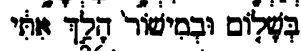

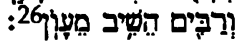
7

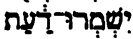

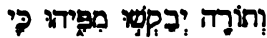

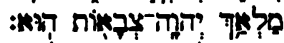
8

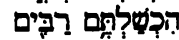

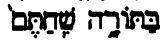

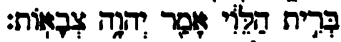
9

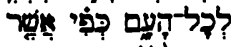

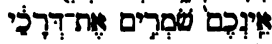

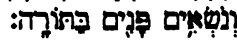

In the fifth century BCE when this short composition is usually dated, the writer expresses a great deal of dissatisfaction with the current practice of the cult of sacrifice in the Jerusalem temple as well as with

\footnotetext{
23 Dtn 33.
}

24 Num 25.

25 NRSV "this called for reverence and he revered me..."; GLAZIER-MCDONALD, "I gave these to him and reverence (I asked from him) and he revered me ...". ZIEGLER re-

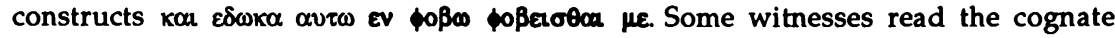
accusative plus inf. which simply means "to fear" for the Old Greek. - I would suspect that a reasonable translation might be: "and I gave (them) to him to fear me (so that he would/might fear me), and (so that he would/might) ... my name." The meaning of oted$\lambda \omega$ here is problematic. The Vulgate follows the MT.

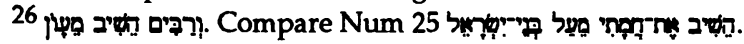


other areas where he sees priestly responsibilities. This is a complex composition which utilizes two pentateuchal passages in developing the idea of a covenant with Levi27 Dtn 33:8-11 forms part of the background for this passage in Malachi which focuses on a covenant with Levi. The other important text in this connection is Num 25:10-13. In an excellent study $H$. UTZSCHNEIDER has discussed the linguistic and thematic connections between these texts. ${ }^{28}$ I will examine this passage in order to make clear the use of Dtn 33 in the composition of this passage. We must first examine the entire passage.

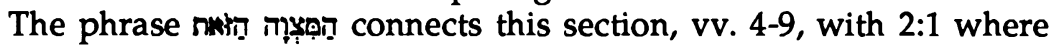
the phrase first occurs, which introduces the larger section on the priesthood and the misbehavior of the priests. To elucidate this misbehavior, the writer has chosen to contrast the ideal role of the priest with that of his contemporaries. In order to do this, he uses both Dtn 33:8-11 which presents the functions of the priest, as well as Num 25:10-1329, the story of Phinehas at Baal-Peor. As I will attempt to show, the writer has skillfully interwoven reference to these two stories, especially through the reuse of key terms from both passages, with his own commentary on those passages and the behavior of his contemporaries.

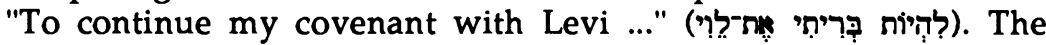
writer works with the figure of Levi the son of Jacob, an individual, which is clear from the pronominal forms in the text. There is mention of a covenant in Dtn 33:9c, which seems to refer to the covenant between Yahweh and Israel, not a special covenant with Levi. However even though it is reasonably clear that in Dtn 33 there is no special covenant with Levi, the idea may have begun quite early and in the fifth century, Dtn 33 may have been read in this light. In Num 25 a covenant (פִּר) of priesthood is mentioned specifically given to the descendents of

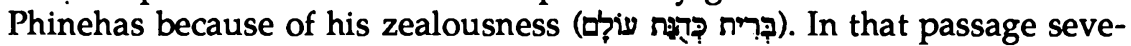
ral key terms occur which are also utilized in this passage such as also remainds of the function which Phinehas served to turn the wrath of the Lord from the people. In fact this function along with the use of the key term "zealous" is later used by the writer of Malachi to begin linking the northern figure of Elijah and the figure of an ideal priest such as Phinehas and Levi. As UTZSCHNEIDER points out, Phinehas is a good model for the fifth century be-

27 This idea of a covenant or at least a special relationship between Levi and God is also assumed in the Testament of Levi (4:2-6).

28 H. UTZSCHNEIDER, Künder oder Schreiber? Eine These zum Problem der 'Schriftprophetie' auf Grund von Maleachi 1,7-2,9. Frankfurt 1989. See also J.M. O'BRIEN, Priest and Levite in Malachi. Atlanta 1990.

29 Num 25:10-13

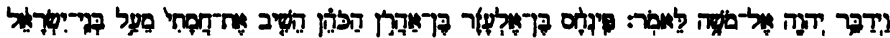

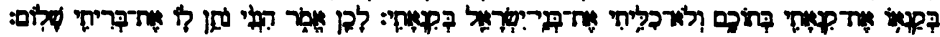

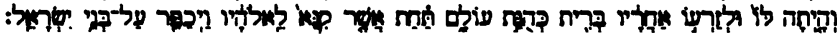


cause he prevents the joining of Israelites and foreign women from continuing (Num 25). Levi, however, is an even better model because along with his brother Simeon he prevents any contact of this sort between Israelites and foreigners from happening at all (Gen 34 ). ${ }^{30}$

V. 4 serves as an introduction to this section on Levi. In v. $4 \mathrm{~b}$ Levi is introduced as an individual. In vv. $5 \& 6$ the individual actions and virtues of Levi are extolled in language reminiscent of Phinehas in Num 25,7-9 shift the focus from the mythical ancestor of perfect virtue to the contemporary situation. V. 7 moves from the past, the situation of the ideal ancestor, to the present and this marked by the use of durative verb forms; "the lips of the priest do guard knowledge"; "they do seek Torah from his mouth".31 In v. 7 using two consecutive and related $k \hat{\imath}$ clauses the writer introduces the idea that the priest is the source of knowledge and Torah, an idea easily extrapolated from Dtn 33:8-11. But the second $k \hat{i}$ clause introduces an entirely new idea. The priest is the messenger of Yahweh. With this phrase the writer has moved to place the priest on the same level with the prophet. ${ }^{32}$ In contrast to vv. 5-7 which described the faithfulness and personal integrity of Levi, vv. 8-9 describe the faithless actions of the contemporary priesthood. The contrast is deliberately marked by placing the second masculine plural pronoun in the first position in v. 8 an! . This is followed by three verb forms in the second plural perfect emphasizing through assonance with the pronoun at the beginning of v. 8 the fault of the priests; "you turned aside"; "you caused many to stumble"; "you have corrupted the covenant of Levi." V. 9 moves to the first person and thus returns the reader once again to the beginning of the section where Yahweh threatened the priests and sent them "this commandment". V. 9 further links up with some elements in ch. 1 in the use of the forms "despise" (גבוּים), and

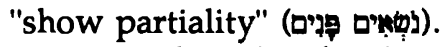

It is clear that for the writer of Malachi, the figure of Levi is of interest primarily as an ideal and as a foil. The writer is interested in the contemporary situation and uses Levi as a contrast both in terms of behavior, but also as a way of contrasting the past and the writer's present. This writer seems very interested in figures from the past and certainly makes extensive use of several in this small booklet. In ch. 1 he uses Jacob and Esau, in ch. 2 he uses Levi, and in ch. 3 he uses not only Moses, but also Elijah who recieves the place of emphasis at the very end of the composition. ${ }^{33}$ The figure of Levi serves as the ideal priest from the di-

\footnotetext{
${ }^{30}$ H. UTZSCHNEIDER [A.28] 67.

31 The form wp: could be understood as an impersonal passive, "knowledge is sought from ...".

32 J.M. O'BRIEN [A.28] 42-44.

33 It seems possible that this composition marks the beginning point not only of an eschatological function for the prophet Elijah, but also the application of priestly characteristics to him by means of a comparison with Levi and especially Phinehas.
} 
stant past who models proper behavior as well as priestly responsibilities.

\section{Qumran Material}

There are two non-biblical compositions from Qumran which quote Dtn 33:8-11 along with other biblical texts.

4Q174 Florilegium is a document which contains a selection or anthology of scriptural citations with their interpretations. It is known to interpret 2 Sam 7:10-14, Ex 15:17-18, Am 9:11, Ps 1:1, Is 8:11, Ez 37:23, Ps 2:1, etc. It has recently been proposed by A. STEUDEL that 4 QFlorilegium $(=4 \mathrm{Q} 174)$ actually preserves part of a copy of much longer composition. STEUDEL has proposed that another copy of the second half of the same composition is preserved in $4 \mathrm{Q} 177$ previously named Catena A. ${ }^{34}$ 4 QFlor also cites Dtn 33:8-11. In contrast to 4QTest, the text of Dtn 33 which is cited conforms, for the most part, to the text preserved in the Masoretic Text. Dtn 33:8-11 is quoted in an uncertain context toward the beginning of the composition. Only a small part of the following section is preserved, enough to know that a pesher on the text cited apparently followed. The overall concern of this composition seems to be the 'end of days' or 'the last days' (הים הים הים ). The structure of the document ran as follows: after a thematic section with selected biblical texts, the document may have continued with a commentary on selected psalms in the order found in the Hebrew canon. This structure is not apparent from 4Q174 alone, but emerges clearly if we follow STEUDEL's suggested reconstruction. She has convincingly proposed that $4 Q 174$ and $4 Q 177$ (Catena A) actually contain roughly the first half and the second half respectively of a single composition now extant in two copies. $4 \mathrm{Q} 177$ continues the midrash on psalms with a short gap where $4 \mathrm{Q} 174$ leaves off. If STEUDEL's suggested reconstruction is correct, then the community at Qumran had composed several compositions on their beliefs about the 'last days' incorporating some of their 'messianic' beliefs. Because of the topic of this composition STEUDEL has suggested renaming it $4 \mathrm{Q}$ Midrash on Eschatology $(=4 \mathrm{Q} 174+177)$.

4 QFlor or 4 QMidrEschat utilizes Dtn 33:8-11 in the context of a composition devoted to eschatology. Given this context, it is reasonable to conclude, and probable, that Dtn 33:8-11 refered to the group's expectation of an eschatological priestly figure. This is clearly not certain, since almost nothing is preserved of the pesher on this section. Nor is it clear when the priest fell in the history of the community. Was this a figure from the past or one for the future? In addition, we have seen

\footnotetext{
34 A. STEUDEL [A.3]. See also J. STRUGNELL, [A.10] 163-276 for notes on the text of these manuscripts and the interpretation of the readings. I will not reproduce the text of these documents here. For a usable rerpoduction see the edition of E. LOHSE, Die Texte aus Qumran. Hebräisch und Deutsch, München 21971.
} 
above in regard to Am 9:11a that in different compositions the same biblical passage could be interpreted differently. This is nevertheless the most likely scenario.

4Q175 called Testimonia is a unique text which contains citations of five biblical passages plus an apocryphal composition and the beginning of a pesher. The texts cited are: Dtn 5:28-29; 18:18-19; Num 24:15-17; Dtn 33:8-11; Jos 6:26; and a citation from the Psalms of Joshua known from cave IV at Qumran. ${ }^{35}$

The citation of Dtn 5:28b-29, and most likely Dtn 18:18-19 also, seems to be excerpted from a biblical manuscript of the proto-samaritan tradition. In that tradition both of these texts are cited together following Ex 20:21 which shares the beginning of the first part of the verse in $4 \mathrm{QTest}$. So that it is likely that these citations come not from a manuscript of Deuteronomy, but from a manuscript of the Book of Exodus. Dtn 5:28-29 follows on Moses' reporting to God of the Israelites request that he become the mediator or "go-between" between God and the people. VV. 28-29 record God's affirmative response to the people's request and the homiletical comment regretting that the people did not have a similar strength of will to follow the commandments of the Torah. In their "original setting", both of these comments are important. The first sets the stage for the appointment of Moses, and the second is a moralizing comment on the people's lack of ability to follow the commandments of the Torah which has parallels in material from Qumran.

The citation of Dtn 18:18-19 records the promise to raise up a prophet like Moses. This is followed by the citation of Num 24:15-17, which has most frequently been understood to refer to the community's expectation of a royal or Davidic messiah. This may be the case since in other texts from Qumran a "messiah of Israel" is clearly expected. ${ }^{36}$ However we should note that in CD A 7:18-19, Num 24:17 is cited in the 'Amos Numbers midrash' and is not interpreted as referring to a davidic messiah. In CD, the passages from Amos (5:26-27; 9:11a) are read in the light of the history of the community itself.

CD (A) 7:12-21

"...When the two houses of Israel separated, 13 it was Ephraim who broke away from Judah. All the apostates were delivered up to the sword, but those who held fast ${ }^{14}$ escaped to the land of the north, as he said: 'I will exile the Sikkuth of your king ${ }^{15}$ and the Kiyyun of your images from my tent to Damascus. ${ }^{37}$ The books of the law are the booth ${ }^{38} 16$ of the king, as

35 J.M. ALLEGRO, Qumran Cave 4, I (4Q158-4Q186), DJD 5, Oxford 1968, 57-60 and plate XXI; and JBL 75 (1956) 182-187. See J. STRUGNELL [A.10] 225-229.

36 See for example, 1QS9.11; CD 7.20; 1QSb 5.20; etc.

$37 \mathrm{Am}$ 5:26 in a version with some paralles to the LXX form of the text. The Masoretic text may be translated, " 26 You shall take up Sakkuth your king, and Kaiwan your stargod, your images/star-god, which you made for yourselves; 27 therefore I will take you into exile beyond Damascus, says the Lord, whose name is the God of hosts." In the use of 
he said: 'I will raise up the booth of David which is fallen.' ${ }^{39}$ The king 17 is the assembly. And the bases of the images $<\ldots .$. are the books of the prophets ${ }^{18}$ whose words Israel despised. The star ${ }^{40}$ is the interpreter of the law ${ }^{19}$ who will come ${ }^{41}$ to Damascus, as it is written: 'A star shall come forth out of Jacob, and a comet shall rise 20 out of Israel. ${ }^{42}$ The comet is the prince of the whole congregation, and when he appears he shall beat down 21 all the sons of Seth. ..."

In lines 18-21 above, the 'star' is understood to refer to the 'interpreter of the law'. This was an enigmatic figure, but by no means could this figure have refered to the 'messiah of Israel' or a davidic messiah. The 'interpreter of the law' was probably a priestly figure. Hence, although the citation of Num 24:17 was frequently understood elsewhere in this period to refer to a royal or davidic messiah, we must exercise caution concerning the function of this citation in $4 \mathrm{Q}$ Testimonia where the context is so limited. This is contrary to $4 \mathrm{Q}$ Florilegium. ${ }^{43}$

We actually do not know much about the purpose/use of this composition. The citation of Dtn 33:8-11 in $4 \mathrm{Q}$ Testimonia seemingly implies the belief in a priestly eschatological figure, a priestly messiah. In 1QS 9:11 this figure is called the "messiah of Aaron" and is apparently identical with the figure in $4 \mathrm{Q}$ Florilegium called "the interpreter of the law" (4Q174 I.11).44 The role implied by this title fits well with the teaching function of the Levites in Dtn 33. In the community rule both the messiah of Aaron and the messiah of Israel fulfill necessary roles, especially at the eschatological banquet. There the messiah of Aaron has precedence over the messiah of Israel. It is to be noted that neither of these two figures seems to function in such a way as to bring about the new era for which the community prepared itself. Rather both figures are presented as functioning after the beginning of the new era. The functions which we know of are projected into the new era and were apparently reflected in the community's organization proleptically.

4 QTestimonia closes with the citation of 4 QPsalms of Joshua which is partially based on a quotation of Jos 6:26 following the Septuagint text.

this passage in $C D$, not only does the writer quote another version of the text, but use is made of variants in the terms Sakkuth and Katwan. In CD Sakkuth is understood as sukkath or sukkoth, 'booth(s)'.

38 Reading sukkath instead of sikkuth.

39 Am 9:11a.

40 The 'star' is taken from Am 5:26. The Masoretic text has טכב הלדיכם.

41 Or "who has come". It is unclear whether or not this is a figure of the past or of the future or perhaps both. The text has 1 , although the biblical citation has the verb in the past tense.

42 Num 24:17.

43 See M. KNIBB, The Qumran Community. Cambridge 1987, 261.

44 M. KNIBB [A.43] 263-266. See also CD 5.7-8. 
This composition is known from other manuscripts from cave IV and the text of 4QTest is partially reconstructed on the basis of those manuscripts. The Septuagint text of Jos 6:26 does not refer to Jericho as does the Masoretic text. It instead refers to 'the city'. This apparently allowed the writer of this composition to interpret 'the city' as Jerusalem and to read the recent history of that city and the community at Qumran into the text. The passage in 4QTest also quotes from Gen 49:5, the phrase 'weapons of violence' which is from the section on Simeon and Levi. This reference is certainly not accidental and if this section of 4QTest does refer to the recent history of the sect, it could be an oblique reference to the combination of secular and priestly powers by the Hasmonean rulers.

The overall purpose/function of 4QTest is uncertain. Most scholars have seen it as a compilation of biblical and non-biblical passages which the sect used as a basis for their messianic expectations. Thus Dtn 5 and 18 support the idea of a prophet like Moses who might have been expected to return at or during the eschaton. In Num 24:15-17, the royal or davidic or 'messiah of Israel' is refered to. And in Dtn 33:8-11, the priestly messiah is mentioned. The only problem in this scenario is raised by the presence of the Psalms of Joshua at the end of the composition. No expectation for an eschatological figure is expressed in this section. However, if the citation of 4QPssJos is intended as the beginning of a section which sketches the history of the community incorporating their eschatological expectations, then perhaps $4 \mathrm{QPss} J o s$ makes a bit more sense in this context.

$$
\text { V. }
$$

In this brief study I have attempted to examine the figure of Levi in four texts from different time periods and communities. The common thread to the study was not only the figure of Levi but also the use of Dtn 33:8-11. In Deuteronomy Levi was refered to both as an individual, but also as a group and there was a marked shift in usage, singulars versus plurals to signal this shift in emphasis. In Dtn 33, Levi was an ideal figure and this composition could be seen as a foundation document of sorts which spells out the legitimate areas of the involvement of the Levites. This may be the case, but it is difficult to be certain of the background of this text.

In Malachi, Levi is a figure of the past. He is an ideal priest and person of virtue who serves as the perfect contrast to the priesthood of the writer's time. Dtn 33:8-11 provides background for Mal 2:4-9 and is not explicitly cited in this passage. In terms of Levi the writer is interested only in his own situation and Levi is used only as an ideal figure of the past. 
In contrast to both Dtn 33 and Mal 2, in the two Qumran compositions Levi is not simply a figure of the remote past. In both 4 Q175 Testimonia, and 4Q177 Florilegium Levi is most likely a figure of the end times, the last days. Although the evidence for the use of these texts is ambiguous, it is probable that scholarly opinion is correct which sees the citation of Dtn 33:8-11 in these two manuscripts as an indication that the Qumran community expected a priestly messiah or eschatological figure. That this expectation existed should be no surprise since the pattern for a diarchic eschatology was established early on in the Persian period in the restoration community. This expectation of a priestly eschatological figure also develops further in the Testament of Levi and the Testament of Judah the traditions of which are possibly also from this period. It is to be noted though that unlike the later traditions involving Levi as an active priestly and eschatological being, the material from Qumran does not intimate, thus far, that the priestly figure would play an active role in introducing the end time. 


\title{
DIE ARISTOTELES- UND THEOPHRASTAUSGABE DES ANDRONIKUS VON
}

\section{RHODUS}

\author{
Ein Beitrag zur Kanonsproblematik
}

von

Dieter Georgi

Johann Wolfgang Goethe-Universität, Frankfurt a.M.

I.

Die gegenwärtige Diskussion über eine biblische Theologie erweckt den Eindruck, als sei die Debatte über Charakter und Umfang des Kanons im wesentlichen abgeschlossen. Das wird dann unterstrichen durch Thesen wie die, die G. WANKE seinem Artikel "Bibel I. die Entstehung des Alten Testaments als Kanon", TRE 6 (1980) 1-8, seine historischen Aufstellungen konkludierend, beigibt:

\begin{abstract}
"Das Alte Testament ist nicht entstanden aufgrund einer Reihe autoritativer Entscheidungen, sondern es hat sich selbst in seinen Teilen unabhängig von Institutionen in solchen Kreisen als Autorität durchgesetzt, die in Krisensituationen die Identität des Volkes Israel durch die Tradition bewahren wollten. Die im Rahmen der Identitätsfindung ausgetragenen theologischen Auseinandersetzungen führten zu unterschiedlicher Abgrenzung der verbindlichen Tradition, wobei sich endgültig die Position im Judentum durchsetzte, die offenbar die praktikabelste Anwendung der Heiligen Schriften anbot (pharisäischer Kompromiß)".
\end{abstract}

Hier wird ein Erstaunen vorgeführt, das scheinbar geschichtlich begründet ist. Der moderne Historiker gibt sich verwundert, daß ein geschichtliches Phänomen, der Kanon, sich in einem geradezu von selbst laufenden und dabei zu allem noch sinnhaften Prozeß herausbildet. Hier wird der historische Bericht zur Wundererzählung, zur Darstellung von so etwas wie einem historisch-kritisch ojektivierbaren 'concursus dei': providentielle Sinnhaftigkeit und Zielgerichtetheit in Sachen Kanon historisch nachgewiesen!

Dieses Erstaunen des modernen Historikers - das sich in der ntl. Kanonsforschung wiederholt - ist aber nicht neu, sondern Wiederholung eines alten Phänomens in der christlichen Kanonsdiskussion. Es findet sich bereits bei Irenäus. Es lebt aber bis zum heutigen Tage von einer wesentlichen Reduktion der relevanten Daten und Faktoren. Daß z.B. der von WANKE im Eingang seines Artikels als prototypisch zitierte Josephus unter dem Mäzenat des Caesar in Rom schrieb, spielt für seine weiteren Überlegungen genauso wenig eine Rolle wie die Tatsache, daß die sich während des Romaufenthaltes von Josephus in Palästina durchsetzende pharisäisch-rabbinische Position unter der Duldung und 
Gunst der römischen Besatzungsmacht stand. In dieser Wundergeschichte interessiert auch nicht, daß nach dem Exil Esra und Nehemia als persische Beamte in Judäa tätig gewesen waren und die Restauration dieser persischen Provinz im Rahmen der rechtlichen, institutionellen und funktionalen Interessen der Besatzungsmacht betrieben hatten. Die Torah war ein Geschenk des persischen Großkönigs.

Ich möchte diese Andeutungen durch Thesen ergänzen, die nicht auf Vollständigkeit bedacht sind, sondern eine Reihe der offenen Probleme in der Kanonsdiskussion und -forschung anreißen wollen ${ }^{1}$ :

1. Die Fragen von Kanonsentstehung und Kanoncharakter sind sowohl auf dem Feld des Alten wie des Neuen Testaments, erst recht aber hinsichtlich des Verhältnisses beider Testamente zueinander heute offener und mehr im Fluß als je zuvor.

2. Die Bibel Alten und Neuen Testaments ist eine Fragmentensammlung. Die Mehrheit der israelitischen, jüdischen, frühkirchlichen und dann auch der frühchristlichen Überlieferung ist verloren gegangen. Die Kanonisierung von Schriften im Alten und Neuen Testament hat zwar diese für die Nachwelt gerettet, andererseits aber zu Verschwinden und Vernichtung der übrigen Überlieferung mit beigetragen.

3. Die auch heute noch in wissenschaftlichen Äußerungen zu findende Feststellung, daß an dem verschwundenen israelitischen, jüdischen und christlichen Schrifttum nicht viel verloren sei, wirkt angesichts der gestiegenen Sensibilität gegenüber Menschenrechtsverletzungen und dem Abscheu gegenüber Zensur und Bücherverbrennungen makaber und ist auch theologisch unverantwortlich.

4. Der gegenwärtige Optimismus hinsichtlich einer biblischen Theologie ist nur möglich, weil die LXX-Problematik ausgeblendet worden ist, obgleich die Entdeckungen der Bibelhandschriften von Qumran die Zuverlässigkeit der Textüberlieferung der LXX gegenüber der Masora in vielen Fällen erwiesen und dadurch der gängigen Marginalisierung der jüdischen Diasporapraxis und -überlieferung entgegenstehen sollten, wie sie in den gegenwärtigen Diskussionen über biblische Theologie üblich ist.

5. Neuere Erkenntnisse über Ausdehnung und Charakter des Diasporajudentums unterstützen die Notwendigkeit einer Vertiefung und Verbreiterung der LXX-Diskussion, nicht nur hinsichtlich des Textes, sondern auch hinsichtlich des Umfangs des biblischen Schrifttums.

6. Damit verbunden sind neue Erkenntnisse und Einsichten über die sogenannte zwischentestamentliche Literatur. Da ist die lebhafter

\footnotetext{
1 Zum Stand der gegenwärtigen Kanonsdiskussion s. die im o.g. Artikel angeführte Literatur. S. auch die folgenden Artikel von E. PLÜMACHER, W. SCHNEEMELCHER UND H. KARPP (Bibel II - IV) mit ihren jeweiligen Literaturangaben; außerdem zur ntl. Kanonsdiskussion noch W. SCHNEEMELCHER, in: E. HENNECKE - W. SCHNEEMELCHER, Neutestamentliche Apokryphen, Bd.1, Tübingen 51987, 1-40.
} 
werdende Diskussion über bereits bekannte Texte, die bislang in der Kanonsdebatte faktisch unberücksichtigt bleibt (z.B. Jesus Sirach, Henochschriften, Weisheit Salomos). Die Qumran- und die Nag-HammadiFunde haben der zwischentestamentlichen Literatur neue Texte hinzugefügt, die unsere Einsichten in Charakter und Umfang des Judentums vertieft und verbreitert und den Umfang des Eisbergs, den wir biblische Überlieferungsgeschichte nennen, um ein Vielfaches vergrößert haben.

7. Die Forderung der Religionsgeschichtlichen Schule nach einer stärkeren Berücksichtigung solcher marginalisierter Texte in einer Neufassung jüdischer und christlicher Religionsgeschichte ist ungehört geblieben; es herrscht immer noch eine harmonistische Stromlinienformung des Kanonsphänomens und seiner wissenschaftlichen Diskussion vor.

8. Nicht nur unökumenische Gesinnung, sondern häufig auch mehr oder weniger deutlicher Rassismus zeigen sich in der Mißachtung der von unseren kanonischen Schriftensammlungen unterschiedenen Kanons anderer christlicher Gruppen, die nicht nur das frühkirchliche Schrifttum betreffen, sondern gerade auch das israelitisch-jüdische.

9. Von Tag zu Tag wachsen unsere Erkenntnisse über die nicht nur bis zur Zeitenwende, sondern auch über Konstantin hinaus anhaltende Vielschichtigkeit und Mannigfaltigkeit des Judentums. Dazu gehört die wachsende Einsicht, daß das Neue Testament nicht dem Alten gegenübergestellt werden kann, sondern zunächst und vor allem Teil der jüdischen Überlieferungsgeschichte ist. Die Erforschung der neutestamentlichen Apokryphen unterstreicht die Offenheit dieser Fragestellung. Wie bereits die nur sehr bruchstückhaften Überreste der sogenannten judenchristlichen literarischen Tradition beweisen, existierte ein torah-treuer Flügel der Kirche mehrere Jahrhunderte, und sowohl die Überlieferungsgeschichte des Islam wie auch die der äthiopischen Kirche belegen, daß dieser Zweig der Kirche noch lange einflußreich geblieben sein muß, unbeachtet von dem, was der Westen dann völlig unzureichend Kirche nannte.

10. Die samaritanische Traditionsgeschichte ist mit der jüdischen Traditionsgeschichte dialogisch viel stärker verzahnt als gewöhnlich zugestanden, nicht nur was den Bibeltext angeht, sondern auch hinsichtlich religiöser Vorstellungen und Praktiken. Auch für sich selbst genommen ist die samaritanische Überlieferungsgeschichte recht bunt.

11. Spätestens die Qumranentdeckungen sollten gezeigt haben, daß die immer noch verwendeten Kategorien Orthodoxie und Heterodoxie für die historisch-kritische Diskussion von Judentum und Christentum völlig untauglich sind; auch der Begriff Orthopraxie ist für ein angemessenes Verständnis der Differenzierungen innerhalb des Judentums und in seinem Verhältnis zum Christentums eher hinderlich geworden. Es wird dabei z.B. übersehen, daß Philo von Alexandrien sehr viel von 
Theologie gehalten und der christlichen Theologie Geburtshelfer- und Patendienste geleistet hat.

12. Das verbietet es auch, dem Kanonsproblem mit Hilfe einer ebenso reduktionistischen wie harmonistischen Beschränkung des Judentums auf das pharisäisch-rabbinische beizukommen. Schon innerhalb dieser Form des Judentums erweisen sich die Unterschiede zunehmend größer als die Einheitlichkeit.

13. Von einem Abschluß des rabbinischen Kanons im 2. Jahrhundert unserer Zeitrechnung kann man immer weniger sprechen, und außerdem bleibt das Verhältnis des rabbinischen Kanons zum LXX-Kanon, zum samaritanischen Kanon, zum essenischen Kanon und zum apokalyptischen Kanon des 4. Esra weiterhin ungeklärt - um nur einige jüdische Beispiele zu nennen.

14. Daß es auch auf christlicher Seite nur zwei Teilkirchen gibt, die den Kanon abgeschlossen haben, die römisch-katholische und die presbyterianische, sollte weiter zu denken geben. Ein sich auf eine ausgegrenzte und beschränkte Anzahl von Dokumenten stützender Biblizismus oder gar Fundamentalismus sind außerhalb der römisch-katholischen oder der presbyterianischen Kirchen rechtlich und sachlich keine Traditionstreue, sondern 'per definitionem' Revisionismus und Modernismus. Die Schrift als literarisch genau fixiertes 'Fundamentum' gibt es in allen anderen als den genannten Kirchen nicht 'per legem'.

15. Eine Erforschung der religions-, sozial-, kultur- und machtpolitischen Aspekte der Kanonsfrage läßt sich nicht länger von der Hand weisen, ist aber erst in den Anfängen begriffen. Die Isolierung der Bemühungen um einen biblischen Kanon von dem Kontext der orientalischen und mediterranen Umwelt ist nicht mehr möglich, obgleich in der Bundesrepublik immer noch das gängige Verfahren. Die direkten Hinweise, die die jüdische und christliche Tradition über diese Beziehungen geben, lassen sich nicht länger übersehen ${ }^{2}$.

II.

Im Kontext der letzten These möchte ich einem Phänomen nachgehen, das neues Licht auch auf die in den anderen Thesen angesprochenen Probleme zu werfen vermag. Ich möchte Nachrichten über Geschick und Behandlung "kanonischer" - und das heißt doch wörtlich "maßgeblicher" - Texte untersuchen, die für die westliche Zivilisation grundlegend geworden sind, obgleich sie allem Anschein nach über

2 Ich habe bereits in der deutschen Fassung meines Buchs über "Die Gegner des Paulus im

2. Korintherbrief. Studien zur Religiösen Propaganda in der Spätantike", WMANT 13, Neukirchen-Vluyn 1964, auf diese Dimensionen des Kanonsproblems verwiesen und bin dem in dem Epilog zur englischen Fassung dieses Buchs (The Opponents of Paul in Second Corinthians, Philadelphia 1986) weiter nachgegangen, bes. auf den S. 422-445. Das im folgenden ausführlicher behandelte Phänomen wird S. 442-443, Anm. 192 andiskutiert. 
Hunderte von Jahren verloren schienen und so in Vergessenheit geraten waren, dann aber wieder auftauchten und - wie ich an den Berichten selbst zeigen möchte - nicht nur Überraschung, sondern auch Kritik und Polemik erzeugten. Diese Nachricht betrifft grundlegende Texte der peripatetischen, $\mathrm{dh}$ der aristotelischen und theophrastischen Schule, u.a. fast all das, was wir heute als Texte des Aristoteles und des Theophrast kennen und nutzen ${ }^{3}$. Für diese Nachrichten gibt es drei Fundstellen: einmal Strabos Geographikon $(13,1,54)$, dann Plutarchs Biographie des Sulla (26) und schließlich Porphyrius' Biographie des Plotin (24).

Strabo sagt in seiner Beschreibung der Stadt Skepsis in der Troas, also der heutigen Nordwesttürkei: Aus Skepsis kam Neleus,

"der Schüler des Aristoteles und des Theophrast, der die Bibliothek des Theophrast ererbt hatte, die auch die des Aristoteles enthielt. Aristoteles hatte ja seine eigene (Bibliothek) dem Theophrast vermacht, dem er auch die Schule überlassen hatte. Dieser ${ }^{4}$ war der erste, von dem wir wissen, daß

3 Über die im folgenden diskutierten Texte gibt es eine umfängliche Debatte und entsprechende Literatur. Ich gebe eine Auswahl wichtiger Darstellungen:

K.O. BRINK, Peripatos, PW Suppl. 7 (1940) 899-949; A.H. CHROUST, The Miraculous Disappearance and Recovery of the Corpus Aristotelicum, Classica et Mediaevalia 23 (1962) 50-67; DERS., The First Thirty Years of Modern Aristotelian Scholarship (19121942), Classica et Mediaevalia 24 (1963) 27-57; I. DÜRING, Aristotle in the Ancient Biographical Tradition, Göteborgs Universitets Årsskrift 63, Göteborg 1957; DERS., Aristoteles, Heidelberg 1966; DERS., Aristoteles, PW Suppl. 11 (1968) 159-336; A. GERCKE, Andronikos (von Rhodos), PW 2 (1894) 2164-2167; H.B. GoTTSCHALK, Aristotelian Philosophy in the Roman World from the Time of Cicero to the End of the Second Century AD, W. HAASE (Hg.), ANRW 2, Principat 36 (1987) 1079-1174; F. GRAYEFF, Aristotle and His School, London 1974; W. JAEGER, Aristoteles. Grundlegung einer Geschichte seiner Entwicklung, Berlin 1923, 2. ergänzte Auflage, Berlin 1955 (dieses Buch setzt W. JAEGERs früheres Werk "Studien zur Entstehungsgeschichte der Metaphysik des Aristoteles", 1912, fort); J.J. KEANEY, Two Notes on the Textual Tradition of Aristotle's School, AJP 84 (1963) 52-63; P. MORAUX (Hg.), Les listes anciennes d'Aristote, Louvain 1951; DERS., Aristoteles in der neueren Forschung, Darmstadt 1968 (hier vor allem die Aufsätze von MANSION, MORAUX, CHROUST und DIRLMEIER auf den S. 1-157, der Aufsatz von CHROUST hier ist die ergänzte Übersetzung des oben angegebenen "First Thirty Years"); O. REGENBOGEN, Theophrastos, PW Suppl 7 (1940) 1254-1562 (da vor allem 1363-1379 über das Schriftenverzeichnis und die Überlieferungsgeschichte); F. WEHRLI, Die Schule des Aristoteles. Texte und Kommentare, Basel 1969.

4 Das "dieser" bezieht sich syntaktisch zwar auf Theophrast, könnte aber sachlich auch und gerade auf Aristoteles gehen, der für seine Bibliothek als der größten Privatbibliothek seiner Zeit und für die entsprechenden bibliographischen und bibliothekarischen Kenntnisse und Fertigkeiten in seiner Zeit berühmt war. Die enge Verbindung der bibliothekarischen Beratung des Ptolemäerkönigs durch A. oder T. und der Übertragung der Bibliotheken der beiden Philosophen auf Neleus scheint von der Quelle des Athenaeus mißverstanden worden zu sein, aus der er in seinen Deipnosophistae 1,3a zitiert. Dort wird zwar ebenfalls von Neleus als dem Erben dieser Bibliotheken berichtet, dann aber behauptet, daß er diese Büchereien dem ägyptischen König Ptolemaeus Philadelphus verkauft hätte, der sie mit vielen anderen in Athen und Rhodus erworbenen Handschriften nach Alexandrien gebracht habe. Dies ist übrigens derselbe Ptolemaeus, den 
er Bücher gesammelt hatte; er hatte auch die Könige Ägyptens darin unterrichtet, eine Bibliothek zu arrangieren. Theophrast aber vermachte (sie, die Bibliothek,) dem Neleus. Der aber brachte (sie) nach Skepsis und vermachte (sie) seinen Nachkommen, Laienmenschen, die die Bücher weggeschlossen hielten, noch nicht einmal sorgfältig aufbewahrt. Aber als sie vernahmen, daß die Attalidischen Könige, denen die Stadt unterworfen war, nach Büchern für die Etablierung der Bibliothek in Pergamum suchten, da verbargen sie (sie) unter der Erde (und zwar) in so etwas wie einem Graben. Aber viel später, als (sie bereits) von Feuchtigkeit und Motten beschädigt waren, da verkauften die Nachkommen die Bücher des Aristoteles und des Theophrast dem Apellikon von Teos für eine große Menge von Silbergeld. Aber Apellikon war eher ein Bücher- als ein Weisheitsfreund. Deswegen (kam es) auch, daß er zwar die Rekonstruktion der durchfressenen Stellen versuchte (mit dem Ziel der Verfertigung) neuer Kopien, sie (die Lücken also) aber nicht korrekt ausfüllte und so die Bücher voller Fehler herausgab.

Es resultierte aber (einerseits), daß die ältere Schule der Peripatetiker nach Theophrast überhaupt keine Bücher (des Aristoteles und Theophrast) hatte außer wenigen, und am meisten exoterische (Werke), (also) nicht im Besitz (von etwas war, mit dem man) auf substantielle Weise (hätte) philosophieren (können), sondern (pure) Thesen, um leeres Stroh zu dreschen; (es resultierte aber andererseits,) daß die Späteren seit der Zeit, als diese Bücher erschienen waren, zwar besser als jene ( $\mathrm{dh}$ die früheren Peripatetiker) in der Lage waren zu philosophieren und zu aristotelisieren, (aber doch) gezwungen waren, die Mehrzahl (ihrer Aussagen) wegen der Menge der (Text-)Fehler für (pure) Wahrscheinlichkeiten zu erklären ${ }^{5}$.

Viel aber trug auch Rom dazu bei, denn bald nach dem Tod des Apellikon brachte Sulla, der Athen eingenommen hatte, die Bibliothek des Apellikon hierher (nach Rom), wo der Grammatiker Tyrannion die (hierher) gebrachte (Bibliothek) bearbeitete ${ }^{6}$, er, der ein Aristotelesverehrer war; er hatte dem über die Bibliothek (gesetzten) Aufseher geholfen7; (das taten) auch (auf ihre Weise) bestimmte Buchhändler, die schlechte Abschreiber

die Legende über die Entstehung der LXX im Aristeasbrief die Veranlassung der griechischen Übersetzung des Pentateuch zugunsten der Bibliothek in Alexandrien zuschreibt.

Die Quelle des Athenaeus scheint die im folgenden Teil des Strabotexts angeführte Nachricht über die Vorenthaltung der aristotelischen und theophrastischen Bibliothek gegenüber den anderen Peripatetikern durch Neleus und ihr späteres Wiederauftauchen mit der Notiz über Einwirkung des Theophrast auf die Entstehung der alexandrinischen Bibliothek zusammengezogen und die angeführte Behauptung daraus konstruiert und erfunden zu haben. Als Veranlassung werden bei Athenaeus - für die hellenistische Antike plausibel - Gewinnsucht des Neleus und Geltungssucht des Ptolemaeus Philadelphus unterstellt. Die dem Strabo (und dem Plutarch) vorliegende Tradition scheint älter und zuverlässiger zu sein als die des Athenaeus, denn die Strabo- (und die Plutarch-) Version läßt sich nicht aus und neben der des Athenaeus erklären, letztere wohl aber aus der ersteren.

${ }^{5} \mathrm{Dh}$ ohne feste aristotelische oder theophrastische Textgrundlage.

6 Zur Übersetzung s.u. Anm.23.

7 Das өeparevioac, das "assistieren" bedeuten könnte, muß wegen des folgenden kai auch die im weiteren genannten Buchhändler mit einbeziehen können. Das wird mit "helfen" erreicht, jeder halt auf seine Weise. 
benutzten und keine (textkritischen) Kollationen herstellten - was auch bei anderen Büchern geschieht, die um des Verkaufs willen kopiert werden, sowohl hier als auch in Alexandrien".

Dieser Bericht des Strabo wird durch den des Plutarch in seiner Biographie des Sulla bestätigt und ergänzt. Plutarch sagt (Sulla 26):

"Er (Sulla) ließ sich (in die Mysterien) einweihen, und er nahm die Bibliothek des Apellikon aus Teos für sich, (eine Bibliothek,) in der sich die Mehrzahl der Bücher des Aristoteles und des Theophrast befanden, damals der Öffentlichkeit noch nicht ausreichend bekannt. Aber es heißt, daß nach der Überbringung (der Bibliothek) nach Rom Tyrannion die Mehrzahl (der Bücher) einrichtete und Andronikus aus Rhodos von ihm mit Abschriften versorgt wurde; und der veröffentlichte sie und stellte die jetzt gültigen $\mathrm{Ka}$ taloge auf. Die älteren Peripatetiker waren offenbar begabte und vernunftbeflissene (Leute), aber sie besaßen weder viele Werke des Aristoteles und des Theophrast noch wußten sie genauen Bescheid, denn das Erbe des Neleus aus Skepsis, dem Theophrast die Bücher (des Aristoteles und Theophrast) vermacht hatte, war in die Hände von sorglosen und laienhaften Menschen geraten".

Der letzte Teil des Berichts des Plutarch wird bestätigt und ergänzt durch eine Bemerkung des Porphyrius in seiner Vita des Plotin. Dort heißt es in Kapitel 24:

"Er (Plotin) beauftragte uns mit der Organisation und der textkritischen Herausgabe der Bücher. Ich aber sagte dem (noch) Lebenden zu und versprach den anderen Genossen, dies zu tun. Zuerst hielt ich es nicht für richtig, die Bücher in Unordnung zu lassen hinsichtlich der Zeit, in der sie herausgegeben worden waren. Ich imitierte den Athener Apollodor und den Peripatetiker Andronikus, von denen der eine (die Werke des) Komödienschreibers Epimarchus in zehn Bänden sammelte, der andere aber die (Werke) des Aristoteles und des Theophrast".

III.

Die Aristoteles- und Theophrastphilologie hat diese, auf den ersten Blick wirklich abenteuerlich klingenden Nachrichten lange nicht ernstgenommen. Das änderte sich aber zusehends seit den angegebenen Arbeiten W. JAEGERs zu den Schriften und Schriftenlisten des Aristoteles, was dann durch Beobachtungen zu den Werken und Listen des Theophrast bestärkt und bestätigt wurde. JAEGER hat der philologischen und philosophischen Wissenschaft bewußt gemacht, daß ein wesentlicher Unterschied zwischen den der Antike bekannten veröffentlichten Schriften des Aristoteles und den uns bekannten aristotelischen Werken besteht. Bei den Schriften des Theophrast steht es ähnlich. Dies läßt sich an Hand der uns vollständig erhaltenen Texte und ihrem Vergleich mit den nur fragmentarisch überlieferten Texten zeigen. Dies wird weiterhin durch Vergleich verschiedener Listen der Schriften des Aristoteles und des Theophrast nachgewiesen. Schließlich wird es 
durch stilistische Beobachtungen unterstützt. Die für uns im wesentlichen verlorenen, dem Altertum aber per Veröffentlichung bekannten Texte waren kompositorisch und stilistisch ausgefeilt, häufig sogar brillant geschrieben. Die uns erhaltenen Dokumente dagegen sind eher stockend, häufig skizzenhaft, voller Wiederholungen und Widersprüche, die sich aber als Verbesserungen durch die Autoren selbst interpretieren lassen. JAEGER und andere haben plausibel gemacht, daß dieser Textbefund dafür spricht, daß das uns überlieferte Aristoteles- und Theophrastmaterial Vorlesungsmanuskripte sind, die häufig Entwurfcharakter tragen und von Aristoteles und Theophrast immer wieder korrigiert und ergänzt wurden ${ }^{8}$.

All diese Beobachtungen haben den durch Strabo9, Plutarch und Plotin mitgeteilten Informationen neuen Auftrieb gegeben und sich zu der immer wahrscheinlicher werdenden These verdichten lassen, daß die Vorlesungsmanuskripte von Aristoteles und Theophrast für längere Zeit verschwanden, dann wieder ans Licht traten und von Andronikus von Rhodus ediert und publiziert wurden. Die der Antike bekannten veröffentlichten Schriften der beiden Philosophen dagegen gingen mit dem Ausgang des Altertums verloren, endgültig verdrängt durch die für die eigentlich philosophisch gehaltenen Schriften der beiden Autoren, besonders des Aristoteles. Daneben hat es im Bereich der peripatetischen Schule sicher auch stilistisch und sachlich ausgeglichenere Schülernachschriften der Vorlesungen des Aristoteles und des Theophrast gegeben.

Es ist verständlich, daß die philosophische Öffentlichkeit die neu auftauchenden Manuskripte an dem bisher Bekannten maß. So war es nur natürlich, daß die Veröffentlichung dieser Vorlesungsmanuskripte wegen der erheblichen sprachlichen und sachlichen Unterschiede zu dem auf dem Buchmarkt vorhandenen und bekannten Material zu erheblichen Irritationen führte. Es war zu erwarten, daß die Rätselhaftigkeit der neuen alten Dokumente mit Überraschung, Zweifel, Kritik, ja Polemik begrüßt wurde. Bei dem Vergleich mit dem bisher veröffentlichten und bekannten Material mußten die "neuen Texte" als korrum-

8 Obgleich man das auch nach Werner JAEGERs Publikationen noch nicht überall voll zur Kenntnis genommen hat, scheint sich doch die Auffassung durchzusetzen, daß selbst die alexandrinische Bibliothek die Mehrheit der eigentlich philosophischen Arbeiten des Aristoteles, dh mehr oder weniger das, was wir heute von Aristoteles haben, bestenfalls bruchstückhaft (durch Schüler- und Schülerinnennachschriften) besa B.

${ }^{9}$ Zu Strabo F. LASSERRE, Strabon, Der kleine Pauly 5 (1975) 381-385. Zu Tyrannion C. WENDEL, Tyrannion 2, PW 7A2 (1948) 1811-1819. Strabo war Schüler des in dem zitierten Text erwähnten Tyrannion. Er wird die wiedergegebene Information von seinem Lehrer enthalten haben. Die Tatsache, daß von Tyrannion in der dritten Person berichtet wird, spricht dafür, daß es sich hier nicht um eine mündliche Mitteilung handelt, sondern um einen von Tyrannion verfaßten Text, am ehesten um einen wesentlichen Teil des Proömiums der von ihm begonnenen, aber anscheinend nicht fertiggestellten Ausgabe der wiedergefundenen Werke des Aristoteles und des Theophrast. 
piert erscheinen, wenn nicht überhaupt als inauthentisch. Die vermutete Korrumpierung wollte erklärt werden, um die Kritik an dem Neuaufgetauchten schlagkräftiger $\mathrm{zu}$ machen. Ich werde dem in einer tendenzkritischen Analyse der erhaltenen Nachrichten nachgehen und die darin enthaltenen kritischen Kommentare herauskristallisieren. Es wird aber auch notwendig sein, die sich meldenden kritischen Stimmen zu differenzieren und zu gewichten. Sie verfolgen nicht alle die gleiche Absicht.

Die Nachricht von der Vererbung der Bibliothek des Aristoteles an Theophrast und beider Bibliotheken an Neleus ${ }^{10}$ wird durch die bei Diogenes Laertius 5.11-16 und 5,51-57 zitierten Testamente des Aristoteles und des Theophrast bestätigt. Laut D.L. 5,12 vermachte Aristoteles dem Theophrast alle seine Hinterlassenschaften, also auch seine Bibliothek, dh alle Handschriften, die er besaß, und das schloß sicher und vor allem auch die Handexemplare seiner eigenen Vorlesungen mit ein. Nach D.L. 5,52 vererbte dann Theophrast seine ganze Bibliothek, die also dann auch die des Aristoteles und seine eigenen Manuskripte, einschließlich der seiner Vorlesungen, umfaßte, dem Neleus, einem Freund und Schüler schon des Aristoteles. Neleus sollte dann mit neun anderen Schülern des Theophrast eine philosophische Kommunität im engeren Sinne innerhalb der Gesamtschule bilden, so etwas wie ein Presbyterium oder Kuratorium. Ihr vordringlicher Aufenthaltsort sollte in dem bereits von Aristoteles gebildeten, dem Theophrast vererbten, von diesem erweiterten und diesen Zehn vermachten Land- und Gebäudekomplex sein. Wesentliche Reparaturen an den Gebäuden waren inzwischen notwendig geworden, und das Geld schien knapp zu sein beides durch die politischen und sozialen Verhältnisse verursacht ${ }^{11}$.

Das sogenannte Lykeion und die dortige peripatetische Schule waren nach der im Kontext gegebenen Beschreibung zu urteilen eindeutig nicht nur eine philosophische, sondern auch eine religiöse Institution, wie ja auch die testamentarische Regelung nicht nur eine juristische, gar nur privatrechtliche, sondern auch eine religiöse Angelegenheit war. Die Götter wachten sowohl über den privaten Verfügungen wie über den institutionellen, auch in eigenem Interesse, denn das gemeinsame Philosophieren in der Schule geschah nicht nur zur höheren Ehre des Schulgründers, sondern auch der in der Schule offiziell verehrten Gottheiten. Damit war aber die Überlieferung, die mündliche ebenso wie die schriftliche, nicht nur in das Schulerbe gestellt, sondern auch unter den Schutz der Götter. Theophrast verfügte, daß die Schule im engeren Sinn in dem Schulkomplex gemeinsam studieren und philosophieren und nichts von dem Ererbten - also gerade auch nicht die vor-

10 Über Neleus K. VON FRITZ, Neleus 4, PW 16,2 (1935) 2280-2281.

11 Darüber O. REGENBOGEN im Gefolge von U. V. WILAMOWITZ im Artikel Theophrastos, PW Suppl. 7 (1940) 1354-1562 und hier 1361-1363 (über das Testament des Theophrast); s. auch K.O. BRINK [A.3] 931-938, der den inneren Abstieg stärker betont. 
handene schriftliche Überlieferung - entfremden oder veräußern ( $\varepsilon_{\xi} \xi_{\alpha \lambda-}$

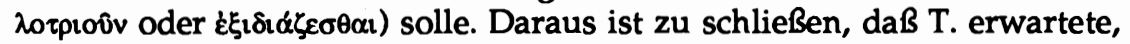
daß Neleus die von ihm geerbte Bibliothek den anderen zum gemeinsamen Forschen zur Verfügung stellen würde. Genau das aber scheint auf Dauer nicht geschehen $\mathrm{zu}$ sein.

Die Anm. 4 genannte Athenaeusquelle bestätigt die Straboquelle darin, daß Neleus die Bibliotheken des Aristoteles und des Theophrast ihrem weiteren Gebrauch in der peripatetischen Schule und der philosophischen Diskussion überhaupt entzog. Dies scheint zu der Zeit geschehen zu sein, als die peripatetische Schule einen Niedergang erlebte. Aus dem Testament des Theophrast geht hervor, daß dieser den Straton nur als nachgeordnete Persönlichkeit gesehen und ihm nicht die Schulleitung anvertraut hatte. Straton ist dann nach dem Tod des Theophrast von der Mehrheit des besagten Kuratoriums zum Scholiarchen gewählt worden. Das Testament des Straton selbst (D.L. 5.61-64) bestätigt indirekt, daß er die Bibliotheken des Aristoteles und des Theophrast nicht besaß, denn es schweigt darüber, daß zu seinen von ihm vererbten Büchern die des Aristoteles und Theophrast gehört hätten. Genauere Lektüre dieses Testaments offenbart, daß in der peripatetischen Schule damals alles andere als harmonische Verhältnisse herrschten, was die Entscheidung des Neleus, die Bibliotheken des Aristoteles und des Theophrast auszulagern, verständlicher macht. Die Vererbung an seine Nachkommen bedeutet dann, daß Neleus keine Besserung erwartete.

Weder Strabos Text noch der Schluß der Plutarchpassage zeigen eine hohe Meinung für die Nachkommen des Neleus, so auch indirekt ihn selbst kritisierend. Der Vorwurf mangelnder Sorgfalt wird ins Spiel gebracht, und die Kritik kann starten. Diese kritische, zunehmend polemischer werdende Tendenz hält sich bei Strabo durch. Die den Bericht durchziehenden Merkwürdigkeiten lassen sich eher als interpretative Verzerrungen deuten denn als Mitteilungen von Fakten. Es wird sich zeigen, daß die kritische Spitze sich vor allem auf die Form der in die Öffentlichkeit gebrachten Aristoteles- und Theophrastmanuskripte konzentrierte, diese vor allem den Verdacht der Korrumpierung erzeugte, der dann durch die kritischen Spitzen in Gestalt einzelner Diffamierungen begründet wurde.

In der Nachricht über die Zurückhaltung der Dokumente durch Neleus und seine Nachkommen liegt nicht nur der Vorwurf, daß diese Literatur der philosophischen Diskussion und Bildung entzogen wurde. Die weiter und tiefer gehende Kritik ist vielmehr die an der mangelhaften Fürsorge für die Manuskripte. Dieser Mangel, als Laienhaftigkeit beschrieben, bezieht sich weniger auf philosophische als auf bibliothekarische Fertigkeiten.

Manuskripte, das waren für die Antike noch sehr viel eindeutiger als für uns heute Handschriften mit der diesen naturgemäß gegebenen Hinfälligkeit des Beschriebenen und des Geschriebenen - und das blieb 
auch so hinsichtlich des veröffentlichten Materials. Es ist bezeichnend, $\mathrm{da} \beta$ den Erben des Neleus vorgeworfen wird, daß sie es nicht einmal verstanden, die Handschriften sorgfältig aufzubewahren. Dies war aber Grunderfordernis der Manuskriptpflege des Altertums ${ }^{12}$. Zu den bibliothekarischen Obliegenheiten gehörten Erfassung und angemessene Behandlung des Schreibmaterials, Fertigkeiten in der Textkritik und -restauration, philologisches Gespür, natürlich ebenso Fähigkeiten in der angemessenen $\mathrm{Zu}$ - und Anordnung der Manuskripte, in der Katalogisierung und in anderen Maßnahmen der Bestandsaufnahme und Bestandssicherung. Die Fertigkeit, authentisches Material von zweifelhaftem und unechtem Material zu trennen, war ebenfalls erwünscht. Geschick, mit dem Publikum umzugehen, nicht nur dem lesenden, sondern auch dem schreibenden, schenkenden, verkaufenden, kopierenden und kaufenden, war bei der besonderen Art des antiken Buchbestands, seiner Verfertigung, Bestandswahrung und -mehrung, von groBer Bedeutung.

Wenn festgestellt wird, daß die Erben der Manuskripte diese nicht den attalidischen Königen für ihre Bibliothek in Pergamum zur Verfügung stellten, dann lautet der implizite Vorwurf: wenn diese Ignoranten ihren Schatz wenigsten den Attaliden für ihre Bibliothek in Pergamum überlassen hätten, dann wäre er in sachkundige Hände geraten. Die Könige von Pergamum wollten nämlich die Ptolemäer nachahmen, ja sogar mit ihnen konkurrieren. Zur wirtschaftlichen und politischen Konkurrenz in der damaligen Markt- und Leistungsgesellschaft gehörten angemessene kulturelle Leistungen. Bibliotheken waren dafür wichtig. Die Errichtung einer Bibliothek bedeutete recht anschaulich die konzentrierte Aufbewahrung vergangener Leistungen.

Eigentlich wollten die Attaliden einem Peripatetiker die Leitung der neuen Bibliothek, dh die Etablierung und Organisation des Wissenschafts- und Büchereibetriebs anvertrauen. Es stellte sich ihnen aber keiner zur Verfügung. Deshalb wurde die Bibliothek einem Stoiker, Krates aus Mallos in Kilikien, übergeben ${ }^{13}$.

Sollte sich die polemische Tendenz des Berichts also aus stoischer Quelle herleiten? Man könnte sich vorstellen, daß die Stoiker aus Pergamum und anderswo durch den tatsächlichen Inhalt der Manuskripte des Aristoteles und Theophrast, die so spät an die Öffentlichkeit gerieten, irritiert wurden und sie deshalb diffamierende und diskreditierende Urteile unter Wissenschaftlern verbreiteten, die faktischen Irritationen des Inhalts auf die Fragwürdigkeit des Zustands nicht nur der dann

12 Zur antiken Bibliothek s. H. LECLERQ, Bibliothéqes, Dictionnaire d'Archéologie Chrétienne 2 (1925) 842-904; C. WENDEL, Bibliothek, RAC 2 (1954) 231-274; R. PFEIFFER, History of Classical Scholarship: From the Beginnings to the End of the Hellenistic Age, Oxford 1968.

13 S. R. PFEIFFER [A.12] 235; s. auch sein ganzes Kapitel "Pergamum: Scholarship and Philosophy. A New Antiquarianism", ebd., 234-251. 
in Zirkulation gebrachten Textes, sondern auch des dahinter liegenden Überlieferungsprozesses schoben, um mit dem Argument mehr oder weniger grundsätzlicher Unzuverlässigkeit die Bedeutung dieser Texte anzuzweifeln oder gar auszuschalten. Daß sich die mit den Peripatetikern konkurrierenden Stoiker durch diese "neuen" Texte besonders betroffen fühlen mußten, darf nicht wundern, denn spätestens seit dem Ende des zweiten vorchristlichen Jahrhunderts arbeiteten sie an der Symbiose von Stoa und Aristotelismus, ja fühlten sich zunehmend als die eigentlichen Erben und Fortsetzer der Philosophie des Stagiriten.

Aber Strabo hat wohl seine Gesamtinformation aus peripatetischer Hand erhalten, ich vermute der seines Lehrers Tyrannion, denn dieser taucht als letzter in dem Bericht des Strabo auf. Mir scheint der Bericht vor allem interne kritische Diskussionen unter den Peripatetikern wiederzugeben. Zunächst könnte man an die amtierenden und studierenden Peripatetiker als an die Urheber solcher Kritik denken. Sie konnten nicht darüber erfreut sein, daß die Aristoteles- und Theophrastüberlieferung, auf der sie fußten, Konkurrenz durch bisher nicht veröffentliche und auch nicht bekannte Dokumente erhielt. Tyrannion war anscheinend der erste Peripatetiker, der einen Eindruck über den Handschriftenfund insgesamt gewinnen konnte. $\mathrm{Er}$ hätte dann diese, mangels Kenntnis auf einzeln auftauchende Abschriften zielende, recht vage und abenteuerliche Kritik aufgenommen, sie gebündelt und zu einer apologetischen Rechtfertigung der eigenen Arbeit benutzte. Der Strabotext läßt sich am ehesten als ein Teil eines Proömiums versteht, das Tyrannion für die von ihm geplante, aber dann nicht verwirklichte Gesamtausgabe der aufgefundenen Handschriften geschrieben hatte. Das würde erklären, daß sein Name nur in der dritten Person vorkommt, obgleich er Strabos Quelle zu sein scheint und deshalb die erste Person in dem Zitat eines Augenzeugenberichts zu erwarten wäre.

Die Geschichte von der Vergrabung der Manuskripte ist der abenteuerlichste und gleichzeitig unwahrscheinlichste Teil des Ganzen. In der gegenwärtigen Formulierung wird die kritische Tendenz der Gesamtinformation hier am direktesten. Hätte man die fraglichen Manuskripte aus Papyrus, kaum Pergament, wirklich so behandelt wie behauptet, dann hätten die 60 oder 70 Jahre bis zum nächsten Akt des Dramas, der Übereignung an Apellikon ${ }^{14}$, sicher einen weit größeren Schaden angerichtet, als im folgenden angedeutet. Weitgehende Zerstörung wäre die Folge gewesen. In der Forschung versucht man der Unwahrscheinlichkeit des Berichts dadurch zu entgehen, daß man aus dem recht eindeutigen $\delta i \omega$ po $\xi$ des griechischen Texts, also aus einem von menschlicher Kraft hergestellten Graben, bestenfalls einem Kanal, eine Höhle macht. Dadurch verstellt man sich aber die kritische Tendenz der gesamten Erzählung.

14 Über Apellikon C. DZIATZKO, Apellikon, PW 1,2 (1894) 2693-2694. 
Es ist jedoch selbst bei einem Polemiker schwer vorstellbar, daß er ein solches abenteuerliches Detail wie die Vergrabung erfunden hätte. Dieser Zug der Erzählung wäre im Gegenteil plausibler, hätte er zunächst eine positive Pointe gehabt, wäre nämlich diese als solche phantastische Vergrabungsgeschichte als authentisierende Findungslegende geschaffen worden. Dabei wäre aus der Not eine Tugend gemacht worden. Man hätte ein altes und oft gebrauchtes Beglaubigungsmotiv für wesentliche Texte benutzt. Es ist uns u.a. aus der atl. Traditionsgeschichte, nämlich der Überlieferung des "Gesetzbuchs" bzw. des "Bundesbuchs" in 2 Kön 22 und 23 bekannt: ich meine das Motiv von der Verbergung und Wiederauffindung von 'hieroi logoi', eine Variation des Motivs vom Himmelsbrief ${ }^{15}$. Bereits die Version in 2 Kön zeigt, daß hier manipulative Techniken eingesetzt werden konnten, und zwar mit deutlich propagandistischen Intentionen. Das Vergraben oder das Verbergen war ja auch nicht so wichtig wie das (vorgebliche) Wiederauffinden. Ein sehr kurzer Zeitraum konnte leicht für einen sehr langen stehen, wenn man nur die frischen Spuren des Verbergens oder Vergrabens ausreichend verdeckte. Einem Hasardeur wie dem gleich noch näher zu beschreibenden Apellikon wäre bei seiner alles andere als der Wahrhaftigkeit verpflichteten Großspurigkeit auch solche Legendenbildung zuzutrauen ${ }^{16}$. Später hätten dann Kritiker die Findungslegende als Anlaß dafür genommen, der Episode ihre gegenwärtige negativ intendierte Wendung zu geben.

$\mathrm{Da}$ der Bericht an dieser Stelle alles andere als unmittelbar einleuchtend ist, zeigt sich auch an der widersprüchlichen Zeichnung der Nachfahren des Neleus: die früheren wollten nicht verkaufen, nämlich an die Attaliden; die späteren dagegen verkauften in Bausch und Bogen, und zwar an eine sehr viel weniger ehrenwerte Figur, nämlich den Apellikon. Der hier erwähnte Apellikon von Teos war ein reicher, bibliophiler Athener, der aber auch politisch engagiert war. Er hatte sich eine ansehnliche Bibliothek zusammengekauft und ergänzte sie im 1. Mithridatischen Krieg (88 - $84 \mathrm{v}$. Chr.) auf billige Weise, als er aus verschiedenen Archiven griechischer Städte Urkunden zusammenstahl. Man fragt sich, ob der Erwerb der aristotelischen und theophrastischen Büchereien von den Nachkommen des Neleus nicht auch eher eine

15 Was zunächst ein Nachteil zu sein schien - das Verschwundensein -, wäre auf diese Weise zum geradezu wunderbaren Vorteil gemacht worden, das Verschwinden und Wiederauffinden wäre durch das Vergrabungsmotiv dramatisiert worden. $\mathrm{Zu}$ dem Motiv der wunderbaren Findung von alten und/oder heiligen Schriften und ihrer ebenso legitimierenden wie propagandistischen Bedeutung s. D. GEORGI [A.2] Gegner, 200-205; Opponents, 160-164, 223-224; W. SPEYER, Fälschungen, literarische, RAC 7 (1969) 236-277, hier 239-240.

16 Völlig ohne textlichen und jeden hinreichenden anderen Grund, ja gegen den Test ist H.B. GOTTSCHALKs [A.3] Vermutung (1086), daB die von Neleus geerbten Bibliotheken nie Athen verlassen hätten, sondern nach seinem Tod in das Eigentum der Schule zurückgekehrt wären. 
Konfiskation als ein Kauf war. A. machte sich den Römern besonders verhaßt, weil er die Athener gegen die Römer aufwiegelte und so hauptsächlich hinter ihrem anhaltenden Widerstand gegen Sulla stand. A. muß während der Eroberung Athens umgekommen sein. Die Version des Plutarch bestätigt, daß Apellikon von Teos den wesentlichen Teil der Bibliotheken des Aristoteles und des Theophrast besessen und Sulla von daher die Sammlung genommen hatte.

Die Bemerkung, daß Apellikon Korrekturen der beschädigten Stellen versuchte, aber inkorrekt durchführte und die Bücher voller Fehler herausgab, ist ein tendenziöser Vorwurf; er ist nicht sehr substantiiert, und so keine zuverlässige Information. Die Unterstellung, daß der Fund wesentlich beschädigt war, wird vorausgesetzt. Der Vorwurf wird angeschlossen, daß Apellikon dies durch textkritisch verbessernde $\mathrm{Ab}$ schriften zu korrigieren gesucht hätte, ihm aber für eine angemessene Rekonstruktion die erforderlichen Sachkenntnisse gefehlt hätten. $\mathrm{Ob}$ Originale und Kopien weiter nebeneinander existierten, wird nicht gesagt. Impliziert wird, daß die Abschriften die Originale ersetzten. Es ist aber kaum anzunehmen, daß ein Büchernarr, ja ein Antiquitätenliebhaber wie Apellikon die Originale vernichtet haben sollte. Außerdem wäre es angesichts der zu vermutenden Anzahl von Manuskripten unmöglich gewesen, sie alle in der vorauszusetzenden relativ kurzen Zeit von allerhöchstens wenigen Jahren abzuschreiben - einschließlich der dabei doch angeblich mindestens versuchten textkritischen Arbeit.

$\mathrm{Da} \beta$ über das Wiederauftauchen der Manuskripte dieser nicht unwichtigen Persönlichkeiten Informationen an die Offentlichkeit gerieten, sogar auch einige Abschriften in Umlauf gebracht wurden, ist nur zu erwarten. Solche Mitteilungen mußten verwundern, ja bestürzen. Die zitierte Kritik beweist, daß die Reaktion zunächst vornehmlich negativ war. Aus der Darstellung der Apellikonphase des Texts läßt sich meines Erachtens der Grund für die negative Reaktion und damit auch für die zornige Form der Dramatisierung der nachlässigen Behandlung der Manuskripte erkennen: es ist die polemische Unterstellung, daß der tatsächliche Zustand der langsam an die Öffentlichkeit dringenden Abschriften - oder auch als Abschriften verdächtigten Originalmanuskripte - voller wesentlicher Fehler gewesen wäre.

Der nächste Satz des Strabo, der mit "es resultierte aber ..." beginnt, ist umständlich formuliert. Dies ist ein Hinweis darauf, daß hier die $\mathrm{Er}$ zählung sekundär unterbrochen wird, also eine spätere erklärende Reflexion grundsätzlicher Art vorliegt, die noch stärker den Fluß der Erzählung stört als die kommentierenden Glossen zuvor. Diese Parenthese steht an einer strategischen Stelle, nämlich dem Schnitt zwischen dem Zugriff des Apellikon und der Überbringung der Manuskripte nach Rom und damit dem Beginn ihrer endgültigen Rettung, für den Strabotext bzw. seine Quelle abgeschlossen durch die Aktivität des Tyrannion. Der Einschub verrät eine deutliche Kritik an früheren Peripa- 
tetikern, einmal den ersten Generationen der Schule nach Theophrast, dann aber auch späteren Vertretern vor Tyrannion, die die neugefundenen Texte übereilt benutzten und deshalb nicht zu vertretbaren philosophischen Resultaten kommen konnten.

Wenn den ersten Generationen der peripatetischen Schule unterstellt wird, daß sie "überhaupt keine Bücher (des Aristoteles und Theophrast) hatte(n) außer wenigen", so ist das sicher eine polemische Übertreibung. Die Behauptung kann schon deshalb nicht stimmen, weil beide Philosophen bereits zu ihren Lebzeiten eine reiche Literatur produziert hatten, nämlich die im folgenden als exoterisch bezeichneten $\mathrm{Ar}$ beiten, die auf den Büchermarkt gingen und auch ihren Weg mindestens in die Bibliothek von Alexandrien fanden, deren Verzeichnis von Aristotelestiteln nach der neueren Aristotelesphilologie wohl hinter der von Diogenes Laertius wiedergegebenen Liste steht ${ }^{17}$. Dazu kamen dann noch die Vorlesungsmitschriften der Schüler und Schülerinnen, die neben den veröffentlichten Schriften der Meister in den Schulen und im weiteren peripatetischen Umfeld benutzt und weiter vererbt wurden.

Die im Verlauf der Parenthese avisierte Unterscheidung zwischen exoterischer und esoterischer Überlieferung von Aristoteles und Theophrast hat die Aristotelesphilologie und die Aristotelesinterpretation bis heute beunruhigt. Die Mehrheit leugnet, daß diese Unterscheidung, buchstäblich verstanden, die Wirklichkeit träfe; vielmehr läge eine interpretierende Übertragung späterer Begrifflichkeit und Vorstellung (aus dem Philosophieverständnis des ersten vorchristlichen Jahrhunderts) vor. Eine Minderheit allerdings hält diese Dualität auch für die Lehr- und Schulpraxis schon des Aristoteles (und des Theophrast - wie auch des Plato) für relevant.

Für die antiken Leser assoziierte natürlich der Begriff "exoterisch" den Gegenbegriff "esoterisch", und diese Assoziation sollte wohl in unserem Text erzeugt werden. Aber es darf nicht übersehen werden, daß der Gegenbegriff nicht gebraucht wird, und dies, obgleich das Interesse des ganzen Berichts an dem Fund der nicht unter den exoterischen Werken befindlichen Arbeiten haftet. Warum werden sie nicht scheinbar ganz logisch - als esoterisch bezeichnet? Wohl weil sie es nicht waren. Die ihnen anhaftende Rätselhaftigkeit wird im Kontext späterer Verbergung, mangelnder Fürsorge, textlicher Korruption und schlechter oder fehlender textkritischer Arbeit gesucht, eben nicht in der von philosophischer Geheimlehre. Es geht es also nicht um den Gegensatz von "offenbar" und "geheim", sondern von "veröffentlicht" und "nicht-veröffentlicht." Die an anderen Stellen zu findende Differenzie-

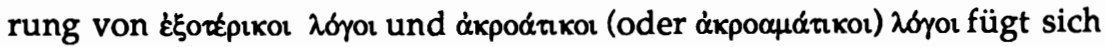

$17 \mathrm{Zu}$ diesen Schriftenverzeichnissen s. I. DÜRING [A.3] PW Suppl. 11, 184-190 und O. REGENBOGEN [A.3] 1363-1370; außerdem A. DIHLE, Der Platoniker Ptolemaios, Hermes 85 (1957) 314-325. 
hier gut ein ${ }^{18}$. Aber aus der folgenden Polemik wird klar, daß der Bericht der Erzeugung eines bestimmten Beigeschmacks dient, den man damals mit dem implizierten Begriff "esoterisch" verband, nämlich den von "eigentlich" oder "hauptsächlich". Solch eine Andeutung mußte den Wert des Gefundenen hervorheben.

Die Parenthese verfolgt die Absicht, die Peripatetiker des dritten und zweiten vorchristlichen Jahrhunderts von der neueren Phase der Schule abzusetzen und als philosophisch unzuverlässig, ja substanzlos zu disqualifizieren. Auch die ersten Vertreter der neueren Phase erhalten kein uneingeschränktes Lob. Der ältere Peripatos wird insgesamt als philosophisch hohl abqualifiziert. Demgegenüber steht die neue Phase, die mit dem neugefundenen Material wirklich $\mathrm{zu}$ arbeiten versucht. Hier scheint sich Tyrannion selbst als Wasserscheide zu sehen. Seine Arbeit, von der der folgende Text redet, setzt den Transfer der Handschriften nach Rom voraus und das heißt den Eingriff des Sulla ${ }^{19}$.

Das Interesse des sowohl in der Antike wie auch in der Moderne als Gewalt- und Genußmensch dargestellten Sulla an dieser Sammlung von philosophischen Manuskripten hat seine Biographen immer wieder erstaunt, und mehr als eine herrische Laune und Plünderungsabsichten hat man selten herauszulesen vermocht. Apellikon war für Sulla ein Aufrührer und sein Besitz, und das hieß vor allem seine Bibliothek, deshalb in den Augen des Römers seine legitime Beute. Man hat auch immer wieder auf das Beispiel des Aemilius Paulus und des Lukullus verwiesen, die beide - der eine vor Sulla, der andere danach je eine Bibliothek aus Griechenland als Kriegsbeute nach Rom verbracht hatten, wenngleich nicht von demselben kulturellen Wert.

Nun weiß der Strabobericht aber auch von einem Bibliothekar, der die Bücherschätze des inzwischen verstorbenen Sulla verwaltete und von dem späteren Kontakt des Tyrannion mit dieser Person. Daß erst der Sohn des Sulla, Faustus ${ }^{20}$, diese Bestallung eines Bibliothekars vorgenommen und entsprechendes Interesse an sorgfältiger Behandlung der Beute gezeigt haben sollte, ist nicht anzunehmen. Dieses intensive Interesse an den Manuskripten ist eher das des Sulla gewesen, der - wie schon die Reste seiner Memoiren beweisen - alles andere als ungebildet war. Die ersten Initiativen für den Wiederaufbau des Jupitertempels auf dem Capitol und des Tabulariums sowie der Wiederherstellung ihres

18 S. dazu I. DÜRING [A.3] PW Suppl. 11, 197-198; dort (197) auch der Beleg für das Verständnis des Andronikus von den nicht-exoterischen Werken des Aristoteles als $\lambda$ óyor

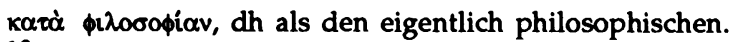

19 F. FRÖHLICH, Cornelius 3 (L. Cornelius. Sulla Felix), PW 4,1 (1900) 1522-1566; ebd. 1544; H. BERVE, Gestaltende Kräfte der Antike, 21966, 375ff; H. VOLKMANN, Sulla, Der kleine Pauly, 5 (1975) 416-420.

$20 \mathrm{Zu}$ Faustus (Cornelius Sulla) s. F. MÜNZER, Cornelius 377, PW 4,1 (1900) 1515-1517. Faustus war beim Tod seines Vaters 8 Jahre alt. Über die Versteigerung seiner Bibliothek aus Geldmangel s. Cicero, Att. 4,10; 9,11,4; Plutarch, Cicero 27,2. 
jeweiligen Archivbestands nach dem Brand von 83 scheinen auch auf Sulla zurückzugehen.

Die Plutarchversion über den Zugriff des Sulla auf die Bibliotheken des Aristoteles und Theophrast stellt ihn in unmittelbaren Zusammenhang mit der zuvor berichteten Einweihung in die (eleusinischen) Mysterien. Mindestens bei der Person, die für die Plutarchversion verantwortlich war, könnte sich hier die Absicht bekunden, in beidem, der Einweihung und dem Zugriff, gemeinsames Interesse am Mysterienhaften und damit Esoterischen zu assoziieren, wobei - nach zeitgenössischem Verständnis - damit natürlich auch der Eindruck des Wesentlichen und eigentlich Authentischen verknüpft wäre. Falls, wie anzunehmen, Andronikus von Rhodus für die Plutarchnachricht verantwortlich sein sollte, wäre damit eine wesentliche Zielansprache seiner Edition gegeben. Wie weit das auch Absichten des Sulla wiederspiegeln könnte, läßt sich nicht mehr sagen.

Der Grammatiker (Philologe) Tyrannion ${ }^{21}$ half besagtem Bibliothekar als Aristotelesspezialist ${ }^{22}$ wohl vor allem bei dem peripatetischen Material. Diese Vertrauensstellung erlaubte es ihm dann auch, eben diese Manuskripte zu "bearbeiten"23. Der Bericht des Strabo endet mit einer Bemerkung, die der Ausdruck extremer Frustration ist. Sie beschreibt eine Konkurrenz, die sich am ehesten aus den schlechten finanziellen Umständen erklärt, in denen sich Faustus und damit auch seine Bibliothek befanden, die dann auch zum Verkauf der Bibliothek führten. Buchhändler wurden nämlich zur Bibliothek zugelassen, die sich mit ihren Abschreibern über die Aristoteles- und Theophrasthandschriften hermachten, sie völlig unkritisch kopierten und auf den Markt brachten, um gute Geschäfte zu machen ${ }^{24}$. Es sieht so aus, als habe sich $T$. demgegenüber um eine philologisch und textkritisch saubere Ausgabe bemüht, ohne aber damit je fertiggeworden zu sein.

Aber hinter dieser offenkundigen Frustration scheint sich noch eine andere $z u$ verbergen, und diese zweite, tieferliegende Beunruhigung scheint sich der ersten, offenkundigen Irritation bedient zu haben. Strabos Gewährsmann, wohl Tyrannion, muß weiterhin an die Vergrabungsgeschichte und die dann daraus abgeleitete Behauptung der Verderbnis der Manuskripte geglaubt haben, denn sonst hätte er diese Abenteuerlichkeit nicht weiter erzählt. Das würde aber bedeuten, daß er

21 S.o. Anm. 8.

22 Das ist mit dem "Aristotelesliebhaber" gemeint.

23 O. REGENBOGEN meint in seinem PW-Artikel über Theophrast [A.3] 1376, daß hier mit dem griechischen Begriff nur ein "behandeln" im Sinn von "sich beschäftigen" gemeint sei. Das reicht aber als Charakterisierung nicht aus, denn nach der Plutarchstelle ist anzunehmen, daß Tyrannion den Andronikus mit Abschriften versorgte. Tyrannion muß also Verfügungsgewalt erhalten haben, ob durch Kenntnis oder Kauf oder - wie wahrscheinlich - nacheinander durch beides, bleibt dann im Grunde gleich.

24 Sicher nicht ohne dem Faustus Provision zu zahlen, ihre Form der "Hilfe". 
das ihm überkommene Material nicht nur für marginal, sondern für wesentlich korrumpiert hielt. Daraus kann man folgern, daß er den erratischen Textzustand selbst nicht für original, sondern für nachträglich, $\mathrm{dh}$ für durch falsche Eingriffe und vor allem durch von falschem Sachverstand verursachte Unordnung erzeugt, ansah.

Die dem Plutarch vorliegenden Tradition datiert später als die des Strabo. Auch sie setzt voraus, daß die Handschriften des Aristoteles und des Theophrast, die Neleus von Theophrast erbte, nicht mit den zu ihren Lebzeiten veröffentlichten und danach auf dem Büchermarkt und in den öffentlichen Bibliothen greifbaren Werken der beiden Philosophen identisch waren, der größere Teil des Schaffens der beiden Männer der Nachwelt also zunächst unbekannt geblieben war. Die beiden Traditionen korrespondieren auch in der Nachricht von der Überbringung der Manuskripte durch Neleus nach Skepsis und der Betonung ihrer laienhaften Betreuung durch Spätere. Der Plutarchversion fehlen aber die dramatischen Züge. Die Erwerbung der Handschriften durch Apellikon wird nur impliziert; Sulla konfisziert auch hier die Manuskripte und überbringt sie nach Rom. Tyrannion wird als aktiv an der Erhaltung des Fundes interessiert gezeigt. Zusätzlich wird dann die Übertragung der Manuskripte in die Hand des Andronikus berichtet, der in dieser Tradition die Endstation darstellt.

Beide Quellen sind unterschiedlich genug, hinsichtlich ihrer Sprache und der sachlichen Details. Der Plutarchbericht ist nicht nur kürzer, sondern es fehlen die meisten kritischen Spitzen. Der größte Unterschied ist der, daß Plutarch die Information über die Beziehungen zwischen Tyrannion und Andronikus und über die aktive Betreuung der Texte durch diesen bestätigt.

Der Plutarchbericht ist zwar nicht ohne kritischen $\mathrm{BiB}$, aber er hat nicht die gleich Tendenz wie der Bericht des Strabo, bzw. dessen Quelle. Zwar wird am Ende auch von "sorglosen und laienhaften Leuten" gesprochen. Aber sie werden hier nicht eindeutig als Nachkommen des Neleus definiert - obgleich der Begriff "Erbe" darauf deutet ${ }^{25}$. Sorglosigkeit muß hier keine wesentlichen Beschädigungen assoziieren, sondern nur Unordnung, wenngleich in ihren verschiedenen möglichen Varianten, wie sie bei einer fachlich unbetreuten Aufbewahrung von Manuskripten über längere Zeit eintreten: z.B. die Auflösung der inneren Ordnung der Einzelmanuskripte, deren Abnutzung und Beschädigung an den empfindlichen Stellen, versuchte amateurhafte Neuordnung und dilettantische textkritische Korrekturarbeit - aber die Bedeutung dieser Korrumpierung wird jetzt erheblich heruntergespielt.

25 Wenngleich der Vorwurf der Laienhaftigkeit beibehalten bleibt, so wird er nun nur noch als Postskriptum an das Ende der gesamten Nachricht gestellt und so in der Bedeutung stark herabgestuft - ein interessantes Beispiel für antike Traditionsgeschichte, vielleicht sogar Quellenkritik. 
Der Unterschied in der kritischen Tendenz der beiden Berichte erklärt sich am einfachsten daraus, daß sich inzwischen das Gesamturteil über Charakter und Zustand der Handschriften radikal geändert hatte. Das Resultat dieses Urteils liegt vor: die Textausgabe des Andronikus ${ }^{26}$. Er war im Gegensatz zu Tyrannion und anderen zu dem Schluß gekommen, daß die gefundenen Handschriften des Aristoteles und des Theophrast im wesentlichen nicht korrumpiert waren, sondern das, was darauf deuten konnte, die Sprünge im Text, die Korrekturbemerkungen und anderen Veränderungen und weiteres scheinbar Irreguläres nicht von späterer Hand war, sondern von den Autoren selbst herrührte, also Teil der Originale war. Diese Erkenntnis war die bedeutendste Errungenschaft des Andronikus.

$\mathrm{Zu}$ den Vorzügen der Andronikusausgabe gehörten ferner die eingebrachten erheblichen philologischen und bibliothekarischen Fertigkeiten, die der Herausgeber demonstrierte. Der Plutarchbericht faßt sie allzu knapp unter den Stichworten Veröffentlichung und Erstellung eines Katalogs zusammen. Porphyrius hat aus eigener Erfahrung ein wenig mehr Empfinden für die Anstrengungen und Entscheidungen, die damals mit der Arbeit an der Veröffentlichung solcher Handschriften verbunden waren. Dazu gehörten die Organisation bzw. Einteilung der Manuskripte insgesamt, Echtheitsentscheidungen und damit die angemessene Zuschreibung der Handschriften zu den einzelnen Autoren, die bibliothekarische Gesamtbearbeitung mit den Mitteln und im Sinn der damaligen Bibliothekswissenschaften, wozu die Erstellung von Einzel- und Gesamtkatalogen gehörte, was in vielen Fällen die Betitelung bisher unbetitelter Werke einschloß, außerdem die Gruppierung der Werke insgesamt und die Eingruppierung der Einzelstücke. Das setzte nicht nur eine enorme komparativische Arbeit innerhalb und zwischen den Einzelwerken voraus, sondern auch ihre Vergleiche mit externer Evidenz, so wie sie andere Bibliotheken und andere Manuskriptbestände boten. Die Tendenz des Plutarchberichts ist es, die Aristotelesausgabe des Andronikus und deren sachliche und didaktische Konsequenzen von der bisherigen Lehr- und Forschungspraxis der peripatetischen Schule abzusetzen, und dazu bestand sicher aller Anlaß, wie noch die späte Bewunderung durch Porphyrius bescheinigt. Ich möchte annehmen, daß der Plutarchtext aus der Einleitung der Ausgabe des Andronikus zitiert.

IV.

An den Nachrichten über das Verschwinden und das Wiederauftauchen der Schriften des Aristoteles und des Theophrast lassen sich

26 Zu Andronikus s. I. DÜRING [A.3] PW Suppl. 11, 195-200; O. REGENBOGEN [A.3] 13761379; O. REGENBOGEN, Pinax, PW 20.2 (1950) 1408-1482, hier 1442-1444; K.O. BRINK [A.3] 938-945; außerdem der ältere Artikel von A. GERCKE [A.3]. 
wesentliche Folgerungen für die Kanonsdiskussion ablesen. Ich habe sie im folgenden zusammengefaßt:

Die obige Analyse hat zutage gebracht, daß dem Einfluß pragmatischer und sogar auch politischer Überlegungen in den damaligen Entscheidungen und Vollzügen hinsichtlich der Bewahrung (und Zerstörung) von Dokumenten ein sehr viel größerer Platz eingeräumt und entsprechend in den theologischen Auswertungen und Urteilsbildungen bedacht werden muß27.

Das merkwürdige Geschick der Manuskripte des Aristoteles und des Theophrast, ihr Verschwinden und ihr Wiederauftauchen, rückt das Element der Zufälligkeit an die Spitze der Reflexion über Erhalt oder Verlust der sowohl nach antiken wie nach modernen Maßstäben für überlebenswichtig gehaltenen Literatur des Altertums. Für die archäologische und die historisch-kritische Wissenschaft überhaupt ist diese Erkenntnis geradezu konstitutiv.

Dies sollte zusätzlicher Ansporn für die Kanonsforschung sein, sich aus einer apologetischen Hilfswissenschaft zu einer die Theologie kritisch herausfordernden und bewegenden Disziplin zu werden. Die den archäologischen und historischen Disziplinen eigenen Überraschungen wollen viel stärker in den Diskurs eingebracht werden. Die Verbindung von Offenbarung und Geschichte in Judentum und Christentum und der damit verbundene rechtlich unabgeschlossene und offene Status des Umfangs der Heiligen Schriften in beiden Traditionen unterstützen das. Diese Offenheit kann nicht nur abstrakt deklamiert werden, sie will auch in der Praxis und der darauf fußenden theologischen Theorie ernstgenommen werden. Die Offenheit für Überraschungen ist für eine der Schrift als geschichtlicher Größe verpflichtete Theologie angemessener als die Beschwörung des Unveränderbaren oder auch des durchgehend greifbaren Sinns. Die Furcht vor Änderungen an der Basis hat weder historische noch theologische Berechtigung ${ }^{28}$.

Die diskutierten Berichte über den "Fund" des Apellikon und sein Schicksal haben an einem ebenso umfänglichen wie wichtigen Beispiel die Bedeutung von bibliothekarischen Rücksichten, Absichten und entsprechendem Können oder auch Nichtkönnen für die Frage von Bewahrung und Verlust von antiker Literatur sichtbar gemacht.

In der heutigen wissenschaftlichen Kanonsdiskussion wird aber die allgemeine Verfügbarkeit von vollständigen und lesbaren Handschriften bzw. Kopien für die Kanonisierungskandidatinnen des Alten

27 Der in diesem Aufsatz diskutierte Fall zeigt mit den angesprochenen Personennamen, Neleus, Apellikon, Sulla, Tyrannion und Andronikus, daB die Entscheidungen und auch Marotten von Einzelpersonen, besonders auch von reichen und mächtigen, dieses bibliothekarische Interesse initiieren, beflügeln, steuern oder auch verhindern konnten.

${ }^{28}$ Mit der Möglichkeit, daß bisher Gewußtes geändert, ja sogar umgestoßen werden kann, etwa durch das Wiederauftauchen im AT oder NT zitierter, verlorener Schriften, muß eine sich historisch orientierende Theologie grundsätzlich rechnen. 
und Neuen Testaments nie in Frage gestellt, im Gegenteil, die Präsenz all dieser Manuskripte in den jüdischen und christlichen Einzelgemeinden wird geradezu selbstverständlich angenommen, so als hätte - besonders da, wo man von allgemeiner Anerkennung redet - Meister Gutenberg bereits seine Erfindung gemacht ${ }^{29}$. Die Behauptungen der Rabbinen und der Kirchenväter über allgemeine Anerkennung bzw. Nichtanerkennung von Schriften werden auch heute noch für bare Münze genommen und unbewußt so behandelt, als habe es bereits damals in Judentum und Kirche so etwas wie die moderne interagierende Verwaltungspraxis oder gar die gegenwärtigen repräsentativen Meinungsumfragen gegeben. Es wird in den zeitgenössischen Arbeiten zum Kanon immer noch nicht nachgefragt, welche faktische Basis die Behauptungen der Rabbinen und der Kirchenväter hätten haben, wie die Evidenz denn technisch hätte beigebracht werden können. Die Behauptungen werden von den Rabbinen oder Kirchenvätern nie belegt, sondern sie stehen an Stelle des Nachweises, sind also im Sinn solider historischkritischer Diplomatik Tendenzbehauptungen, $\mathrm{dh}$ 'petitiones principii' ${ }^{30}$.

In Wirklichkeit war damals das erste wichtige Problem bei der Sammlung von Schriften, auch der biblischen, das der Erhaltung des Einzeldokuments, in den Zeiten vor der Erfindung des Buchdrucks um ein Vielfaches komplizierter und schwieriger als danach. Das Material brachte es mit sich, daß das nicht nur ein passives Phänomen des puren Überlebens war, sondern auch eines der aktiven Konservierung, entweder des Lesbar-haltens oder des Wieder-lesbar-machens. Motivation allein reichte dafür nicht aus. Können mußte hinzutreten. Der gute Wille für sich genommen, ohne Können, konnte sogar erheblichen Schaden anrichten. Im Unterschied zum gedruckten Buch mußte damals jede Kopie - auch in den Einzelgemeinden - als mögliche Vorlage für weitere Vervielfältigungen angesehen werden, $\mathrm{dh}$ aber eventuell auch als Ursache der Verbreitung von Korruptelen.

Die Integration einzelner Schriften in eine Sammlung bedurfte erhöhter Aufmerksamkeit beim Konservieren. Sie setzte noch größeres Können und anhaltendes Training voraus, was nicht allgemein zu finden war, erst recht nicht in der normalen jüdischen oder kirchlichen

29 Die Tatsache, daß sich Josephus von Titus eine Sammlung der heiligen Schriften aus der Beutemasse in Judäa schenken ließ (Vita 418), scheint darauf zu deuten, daß er, obgleich nicht unvermögend, bis dahin keine vollständige Sammlung der heiligen Schriften Israels zu besitzen schien.

30 Sie würden die Unmöglichkeit voraussetzen, daß die Einzelgemeinden über echte Vergleichsmöglichkeiten hätten verfügen können, dh im Besitz einer entsprechenden umfangreichen Handschriftensammlung gewesen wären oder mindestens leichten Zugang dazu gehabt hätten. Nur so hätten sie mit Ernst vergleichen und auswählen können. Es wird ihnen aber nur unterstellt. Sie sind nie gefragt worden, weder in der Synagoge noch in der Kirche. 
Ortsgemeinde. Der Wille, Texte zu sammeln und zu edieren, konzentrierte sich natürlicher Weise auf wenige Personen und wenige Orte. Selbst bei dem eingeschränkten Material, das wir heute kanonische Schriften nennen, läßt es sich nicht vorstellen, daß ein größere Anzahl jüdischer oder kirchlicher Gemeinden in der Lage gewesen wären, einen solchen Prozeß der Sammlung und Sichtung zu starten und über längere Zeit hinweg in Gang zu halten, noch weniger natürlich in einer die Mittelwelt, den Nahen und den Mittleren Osten umfassenden, flächendeckenden Weise.

Die antike Bibliothek ist oben auf mehrfache Weise in unseren Gesichtskreis getreten ${ }^{31}$. Sie war eine Besonderung des seit alters wichtigen Phänomens des Archivs. Die griechische und hellenistische Archivund Bibliothekskunst baute auf der vorderorientalischen auf. Die israelitischen und judäischen Könige hatten Archive, wie das im Vorderen Orient allgemein der Fall war. Dasselbe galt für ihre Tempel. Nach dem Exil hat der Jerusalemer Tempel sicher diese Funktion fortgeführt. Der Pentateuch wird nicht das einzige dort aufbewahrte Buch geblieben sein. $\mathrm{Ob}$ und inwieweit hier Material des alten königlichen Archivs fortlebte, ist schwer zu sagen. Die Anm. 28 mit gemeinten, vor allem in den Königs- und Chronikbüchern erwähnten Schriften, könnten dafür sprechen, daß der Tempel zur bibliothekarischen Sammelstelle für andere Schriften wurde.

Der Brief am Anfang des 2. Makkabäerbuchs weiß von einer Bibliothek des Nehemia und einer des Judas Makkabäus, beide in Jerusalem (2 Makk 2,13). Daß diese Notiz dem wahrscheinlich unechten Teil des das gegenwärtige 2. Makkabäerbuch einleitenden Briefs angehört, zerstört nicht unbedingt den Informationswert dieser Nachricht. 1 und 2 Makk und die dahinter stehende Tradition sprechen für eine ebenso intensive wie extensive Tätigkeit im Umkreis des aus Priesterkreisen stammenden hasmonäischen Hofs. Aus dem priesterlichen Umfeld stammt auch die für die Qumranbibliothek verantwortliche Gruppe, was immer ihre Denomination im einzelnen gewesen ist.

Natürlich war diese in Qumran gefundene Sammlung keine Bibliothek im wörtlichen Sinn. Sie war nicht im Betrieb, sondern die Folge einer Auslagerung, einer Notstandsmaßnahme also, bei der bibliothekarische Rücksichten in den Hintergrund traten. Was in den Krügen

31 Es wurde bereits angedeutet, daß der Besitz von Büchern, vor allem einer Büchersammlung, Macht bedeutete und Einfluß schuf und vermehrte. Bereits der Buchstabe, erst recht die Akkumulationen davon versprachen Anerkennung und Wirkung. Das Geschriebene konnte Leistung festhalten und vermehren, noch mehr die Sammlung von Schriften. Der durch ihre Nutzung ausgeübte literarische und kulturelle Einfluß, die dadurch ausgeübte Formung der Erinnerung und Gestaltung der Zukunft waren für die leistungsbesessene Gesellschaft des Mittelmeerraums von großer Wichtigkeit. In meinem Buch über "Die Gegner des Paulus" [A.2] bin ich dem nachgegangen, noch stärker in dem Epilog zu dessen englischer Ausgabe ("Gegner", 145-182; 200-205; "Opponents", 422-450). 
in die Höhlen gerettet werden konnte, atmet selbst also eine starke $\mathrm{Zu}$ fälligkeit. Aber trotzdem kann nicht übersehen werden, daß in Qumran der Fund von Manuskripten, die wir heute biblische nennen würden, minimal war. Die biblischen Handschriften waren auch nicht eindeutig von den vielen anderen Manuskripten getrennt und abgehoben. Eher läßt sich sagen, daß die auch in anderen mittelgroßen Bibliotheken der damaligen Zeit festzustellenden pragmatischen und ökonomischen Kategorien von Interesse und Vordringlichkeit selektiv gewirkt hatten.

Die drei Bemerkungen hinsichtlich der jüdischen Schriften, die der Enkel des Jesus Sirach im Vorwort zur Übersetzung des Werks seines Großvaters macht, haben keine sich selbst begrenzende, gar exklusive Sammlung jüdischer Schriften im Auge, sondern eine sich erweiternde. Nach dem Enkel zu urteilen wollte schon der Großvater zu den "anderen" oder "übrigen" Büchern und damit zur Vermehrung der Gelehrsamkeit (Weisheit, Bildung, Lernfreudigkeit) beitragen. Er setzt nicht voraus, daß seine Leserinnen und Leser diese Bücher selbst in Händen haben oder in ihrer lokalen Synagoge nachschlagen konnten. Er spricht hier ein typisches Bibliotheksphänomen an, was ihm in Jerusalem zur Verfügung stand, aber nicht in jeder Synagoge in Palästina. Das wird dann durch die vorliegende Intention des Enkels unterstrichen, der den griechischsprachigen Bücherschatz der Diaspora durch das eigene Werk ergänzen möchte. Auch der Enkel setzt damit eine relativ ansehnliche jüdische Bibliothek an seinem eigenen Arbeitsort, wohl in Alexandria, voraus ${ }^{32}$.

Christliche Bibliotheken hat es mindestens in Alexandrien, Caesarea, Jerusalem und Rom gegeben. Die Gnostiker Basilides, Marcion und Valentin, die Ketzerbestreiter Irenäus, Hippolyt und Epiphanius müssen alle Zugang zu Bibliotheken oder bibliotheksähnlichen Sammlungen mit jüdischem, heidnischem und kirchlichem Material gehabt haben. Bei Clemens von Alexandrien, Origenes und Euseb versteht sich das von selbst. Die kirchliche Bibliothek in Caesarea soll mehrere zehntausend Buchrollen besessen haben. Bei all diesen Bibliotheken muß es sich um Sammlungen gehandelt haben, die auch gegnerische Literatur enthielten, also keiner Zensur unterlagen, denn Gegner werden ja gerade ausführlich ausgeschrieben. Die in Nag Hammadi gefundene Bibliothek war wie auch die Qumranbibliothek eine mittelgroße ${ }^{33}$. Sie hatte

$32 \mathrm{DaB}$ die Juden in Jerusalem und in Alexandrien über Bibliotheken verfügen konnten, dürfen wir voraussetzen. Die literarische Produktion bereits des alten Israel, noch mehr aber die des biblischen und nachbiblischen Judentums waren erheblich, und die Kirche hat dem von Anfang an nicht nachgestanden, im Gegenteil. Es gab also genug zu sammeln. $\mathrm{Ob}$ aber hier oder dort je das Projekt einer allumfassenden Sammlung der israelitischen und jüdischen Literatur ins Auge gefaßt worden war, läßt sich nicht sagen.

33 Sowohl bei den für die Qumrandokumente wie bei den für die Nag-Hammadi-Texte verantwortlichen Kreisen handelt es sich um Gemeinschaften, die für die Entstehung und Bewahrung der Sammlungen verantwortlich waren, Gemeinschaften, die über längere 
neben christlichen auch vorchristlich-jüdische und heidnische Texte gesammelt, aber erstaunlicher Weise keine Schriften, die wir heute zu den sogenannten kanonischen zählen würden ${ }^{34}$.

Die großen Bibliotheken der Antike wie die in Alexandrien oder auch in Pergamum oder Rom konnten es sich leisten, nach der Sammlung aller Literatur mindestens in einer bestimmten Sprache zu streben ${ }^{35}$. Die Privatbibliotheken, obgleich 2.T. recht umfangreich, beschränkten sich dagegen verständlicher Weise in ihrer Auswahl. Die notwendige Selektivität wurde hier durch individuellen Geschmack gesteuert. Daneben aber gab es eine andere, mittlere Interessenebene, die der vielen kleineren öffentlichen Bibliotheken in den Städten des Mittelmeerraums. Eng mit ihnen verknüpft war der Bedarf des allgemeinen städtischen Schulunterrichts auf seinen verschiedenen Stufen. Auf größere private Büchereien konnte dieser in den wenigsten Fällen bauen.

Auf all diesen Ebenen schlossen philologische und bibliothekarische Arbeit von Anfang an Echtheitsfragen in ihre korrigierenden und ordnenden Verfahren mit ein, nicht aber als zensierende, sondern als organisierende Überlegungen hinsichtlich der Anordnung des Gesamtbestands. Die oben angeführte Plutarchstelle führt uns eine der wichtig-

Zeiträume existierten, wohl auch beide Außenkontakte hatten, aber bezeichnender Weise von den in der Kanonsdiskussion zitierten Instanzen überhaupt nicht erwähnt werden. Dabei ist es alles andere als wahrscheinlich, da $B$ die beiden genannten Bibliotheken extreme Ausnahmen waren, sondern sie wurden nur durch einen extremen Glücksfall ziemlich zur selben Zeit an die Oberfläche gebracht.

34 Die Versuche etwa, die mit dem Thomasevangelium gestellten Probleme durch eine Spätdatierung zu entschärfen, sind nicht gelungen. Inhaltliche Korrespondenzen mit unseren Evangelien lassen sich in keinem Fall als Zitat aus einem unserer sogenannten "kanonischen" Evangelien erweisen, sondern nur als Herkunft aus gemeinsamer mündlicher Tradition. Form- und traditionsgeschichtlich finden sich sowohl relativ späte wie umgekehrt auch relativ sehr frühe Stadien. Redaktionsgeschichtlich ist das Thomasevangelium im Vergleich zu unseren Evangelien sehr früh, am ehesten der Redenquelle vergleichbar (s. u.a. H. KÖSTER, Ancient Christian Gospels: Their History and Development, London-Philadelphia 1990; DERS., $Q$ and its Relatives, in: J.E. GOEHRING u.a. (Hg.), Gospel Origins and Christian Beginnings, FS James ROBINSON, Forum Fasc. I, Sonoma 1990, 49-63). Das Eigenmaterial ist im Vergleich zu den anderen Evangelien erstaunlich umfangreich. Wenn es in vielen Fällen einen gnostischen Einschlag hat, so kann dies nur für die ein Datierungshinweis sein, die die Gnosis für eine christliche und dazu noch relativ späte Schöpfung halten. Dafür, daß die Gnosis außer- und vorchristliche, jüdische Ursprünge hat, besteht erhebliche Evidenz, nicht zuletzt auch in Gestalt solcher in Nag Hammadi gefundener Dokumente, die entweder überhaupt keinen christlichen Einfluß zeigen, oder - wie in vielen in anderen Fällen - nur oberflächlich christianisiert sind.

35 Auch die literarische Produktion der diversen kirchlichen Gruppen war erheblich. Aber hier läßt sich nicht feststellen, ob vor Konstantin die Möglichkeit einer allumfassenden Sammlung kontempliert wurde. Caesarea scheint dem am nächsten gekommen zu sein. 
sten Errungenschaften dieses antiken Sammlungs- und Organisationsbedürfnisses vor Augen: den Katalog (Pinax), eine wohl differenzierte, rubrizierte, unter Umständen auch kommentierte Liste der in der jeweiligen Bibliothek vorhandenen Literatur ${ }^{36}$. Unerreichtes Vorbild in Umfang und Qualität war für die hellenistische Bibliothekskunde der Katalog des Kallimachus. Im Fall der Ausgabe des Andronikus steht vor allem der Pinax zu den Werken des Aristoteles zur Diskussion ${ }^{37}$. Freundliche und feindliche Fälschungen waren zahlreich und geschahen, wie das Beispiel Galens drastisch beweist, gelegentlich sogar bereits zu Lebzeiten der gefälschten Autoren ${ }^{38}$. Auch die bekannten öffentlichen Diskussionen über Anzahl und Namen der wichtigsten Vertreter der verschiedenen Literaturgattungen begannen in den großen Bibliotheken unter einem konkreten Sortierungsbedürfnis.

Hier muß nun auch über Marcion gesprochen werden. Nach 2000 Jahren christlichem Antijudaismus und vor allem nach dem Holocaust ist es schwer, ihm gegenüber fair zu sein ${ }^{39}$. Aber trotz all seiner Dämo-

36 Zu Pinax allgemein s. den ausführlichen Artikel "Pinax" von O. REGENBOGEN [A.26]. Größere Bibliotheken besaßen auch Unterkataloge.

37 O. REGENBOGEN, Pinax, 1442-1444, unterscheidet hier - jedenfalls hinsichtlich seiner Aristotelesausgabe - zwischen einem Katalog, also einer Pinax im eigentlichen Sinn und einer umfangreicheren Einführung in das Werk des Aristoteles. Von dem Katalog heißt es (unter Verweis auf die oben zitierte Plutarchstelle) bei R.: "Wir müssen annehmen, daß Andronikos die Gesamt-Indices, die er von Hermippos übernahm und überarbeitete, außerdem noch beigab" (gemeint ist: dem Einführungswerk). Von dem Einleitungswerk des Andronikus zu seiner Aristotelesausgabe sagt R.: "Die Schrift umfaßte fünf Bücher, war also verhältnismäßig umfangreich; er ordnete nach Pragmatien, also nach sachlichen Gesichtspunkten, und es ist anzunehmen, daß die erhaltenen Verzeichnisse in irgendeiner Weise auf ihn zurückgehen. Er hatte in seinem Werke auch eine Biographie gegeben und die Testamente der beiden Philosophen angeführt. ... Die systematische Einteilung ... ist ... ein eisagogisches Verzeichnis, nach dem systematische Aristoteles Lektüre und Interpretation betrieben werden soll". (O. REGENBOGEN [A.3] 1442-1443). Die bereits veröffentlichten Frühschriften des Aristoteles waren ausgeschlossen. Andronikus beschränkte sich also wesentlich, wenngleich nicht ausschließlich, auf den Fund selbst.

38 Er schrieb als alter Mann zwei relevante Traktate: "Über die Ordnung der eigenen Bücher" und "Über die eigenen Bücher" (s. dazu ausführlich O. REGENBOGEN [A.26] 1445-1446). Vor allem die zweite Schrift ist hier wichtig. "Sie beginnt mit einem Vorwort über die Veranlassung des Verzeichnisses, das vornehmlich beabsichtigt, den Leser in den Stand zu setzen, die untergeschobenen Schriften von den echten trennen zu können" (O. REGENBOGEN a.a.O. 1445). Wichtig ist auch die einzige aus dem Altertum erhaltene wissenschaftliche Schrift über das Fälschungsproblem, nämlich die des Dio von Halikarnass "Über Dinarchus"; s. G. MARENGHI, Dionisio di Alicarnasso: Dinarco ..., Milano. Hier diskutiert Dio ausführlich Echtheit und Unechtheit der dem Redner Dinarch zugeschriebenen Schriften und kommt nach der Erörtertung stilistischer, sachlicher und historisch-biographischer Argumente zu einer differenzierten Aufteilung der echten und der pseudepigraphischen Reden. Zum Gesamtproblem der antiken Fälschungen s. W. SPEYER [A.15] 239-244.

39 In seiner Einleitung zu "Gnosis und Politik", Religionstheorie und Politische Theologie 2, München-Paderborn 1984, hat mein inzwischen verstorbener jüdischer Freund J. TAUBES ein eindringliches Plädoyer für Fairness gegenüber Marcion geschrieben. Er hat 
nisierung des Judentums steht fest, daß er das jüdische Verständnis des AT, einschließlich seiner eschatologischen und messianischen Dimensionen ernster genommen hatte als seine Gegner. Marcions Auffassung des AT entsprach weitgehend etwa der historischen Sicht, wie sie Josephus in seinen Antiquitates vertritt. In seiner Ablehnung der allegorischen Exegese erwies sich $M$. gegenüber seinen Kritikern, Justin, Irenäus, Tertullian u.a., als der bessere Wissenschaftler. Auch seine Bevorzugung des Lukas war wissenschaftlicher Natur, nahm nämlich die Versicherung des Lukas ernst, daß er Quellen kritisch verglichen und sich für das Zuverlässigste entschieden habe. Überhaupt entsprach M.'s Interesse an einer zuverlässigen Textgrundlage philologischen Absichten und Methoden seiner Zeit, in die - trotz aller Dämonisierung und Radikalität - auch seine Korrekturen einzuordnen waren. Sie sollten auf eine methodisch ausgewiesene Weise Korruptelen aufdecken und zugunsten eines authentischeren Texts beseitigen.

Wie es sich für einen Wissenschaftler schon damals gehörte, legte Marcion über seine Kriterien Rechenschaft ab und lieferte einen Kommentar. Die Diskussion über den Fund der Aristoteles- und Theophrastfragmente, wie sie vor der Ausgabe des Andronikus geführt wurde, beweist, daß das Altertum durchaus die Möglichkeit weitgehender Korruption von Textüberlieferungen in Erwägung ziehen konnte, durchaus auch unter Erwägung dramatischer Aspekte, wenngleich nicht notwendiger Weise so mythisiert wie bei Marcion ${ }^{40}$.

Irenäus mußte überhaupt den Gnostikern im allgemeinen, wenngleich widerwillig, ihre wissenschaftlichen Aspirationen zugestehen. Sie entwickelten Überlegungen hinsichtlich Textkritik, Quellenkritik, Literarkritik, Edition und Kommentierung der benutzten Texte wie sie damals üblich waren. Der von I. mehrfach karikierte gnostische Wahrheitsbegriff bezog die besagten bibliothekarischen Aspekte mit ein, und I. und seine Gesinnungsgenossen bewiesen durch ihr Verhalten, daß sie diese Rücksichten auch in ihrer eigenen Praxis nicht übergehen konnten und wollten, sie im Gegenteil zu imitieren beabsichtigten, ohne allerdings den gnostischen Vorbildern den angemessenen Respekt zu zollen oder ihnen in wissenschaftlicher Qualität gleichzukommen. I. macht im Vorwort seines Ketzerbuchs und auch in seinen weiteren Ausführungen genügend Andeutungen, daß die Gnostiker diese An-

ihm den Titel gegeben "Das stählerne Gehäuse und der Exodus daraus oder ein Streit um Marcion, einst und heute", ebd. 9-15.

40 Natürlich war die philologische Qualität seiner Analysen und Urteile weit unterhalb des Standards der Wissenschaftler an den großen Bibliotheken. Aber es sollte nicht übersehen werden, daß auch die griechischen, hellenistischen und römischen Philologen nicht frei waren von Ideologie. Schon seit den Sophisten, aber gerade auch seit Aristoteles waren sie beeinflußt durch philosophische Theorien, am deutlichsten und folgenreichsten im Umkreis der Stoa. 
sprüche auch realisierten, daß sie nämlich kritische Arbeit am Text taten ${ }^{41}$. Der wissenschaftlich nicht sehr gebildete I. äußert sein Entsetzen darüber ${ }^{42}$. Aber nach allgemein antiken Rücksichten, die heute noch geteilt werden, wurde damals ein solcher wissenschaftlicher Zugang für selbstverständlich gehalten.

Die erwähnten kritischen Untersuchungen der hellenistisch-römischen Philologen und Bibliothekare und deren praktische Folgerungen brachten Vorzüge mit sich, die sich auf andere Gebiete übertragen lieBen. Sie etablierten nämlich Listen einer Standardliteratur, die den Bedürfnissen kleinerer örtlicher Bibliotheken und zusammen mit ihnen auch dem Schulunterricht und der öffentlichen Bildung zu gute kamen. Hier war der vornehmliche Sitz im Leben des "Klassischen," eines urspünglich sehr pragmatischen Phänomens.

Die Listen solcher Standardliteratur aus den Hellenismus werden heute häufig als Beispiele für antike 'canones' genannt. Das ist semantisch inkorrekt, denn auf diese Listen wurden damals der Begriff 'canon' noch nicht angewandt. Er ist in dieser Bedeutung erst in die fachwissenschaftlichen Diskussion unter Philologen und Historikern in den letzten 200 Jahren eingedrungen, sicher durch die christliche Verwendung des Kanonsbegriffs beeinfluß $\mathrm{A}^{43}$. Das Altertum verwandte für diese Auswahllisten denselben Begriff wie für die Gesamtkataloge, nämlich 'Pinax'.

Aber trotzdem scheint mir das beschriebene, recht pragmatische Verfahren mit Auswahlkatalogen für Anschaffung und Unterricht die einfachste Erklärung für die Anfänge dessen zu sein, was man später dann fälschlicher Weise Kanonisierung genannt hat ${ }^{44}$. Daß dies dem

41 M.E muß gefragt werden, ob nicht die uns erhaltenen guten biblischen Handschriften und Handschriftenfragmente auf das vor Origines nur in der Gnosis belegbare wissenschaftliche Interesse am Text zurückzuführen sind, jedenfalls was das NT angeht.

42 Adv.Haer. 3,2.2, s.a. 3.1.1 und 3.2.1, weiter 3.5.1; 3,11.9; 3,12.6 und 12; 3,14.4. Die von Irenäus den Gnostikern mehrfach vorgeworfene Verfälschung der Herrenworte wird wohl - 'in dubio pro reo' - den Versuch beschreiben, aus dem umfangreichen Angebot an dem Kyrios zugeschriebenen Logien die authentischen Herrenworte herauszufinden, ganz gleich, welche Kriterien im einzelnen für Echtheit angesetzt wurden. Verfälschung, wie I. es unterstellt, muß das nicht sein, in der Intention eher das Gegenteil.

Auch daß die Gnostiker die Herrenworte kommentierten, entsprach wissenschaftlicher Praxis der hellenistischen Umwelt, vor allem in den philosophischen Schulen hinsichtlich der schulgründenden und schulleitenden Texte, und die Bibliotheken versuchten, dem auch in ihren Sammlungen und deren differenzierter Organisation zu entsprechen dh die Kommentare zu integrieren.

43 S. dazu R. PFEIFFER [A.12] 207 (nach Vorarbeit von H. OPPEL, zitiert ebd.). O. REGENBOGEN [A.26] 1455-1462 handelt über das antike Material unter dem Untertitel "Wertende Listen".

44 Was die Information über die angemessene und empfehlenswerte Acquisition von Büchern als Zweck solcher Listen angeht, so erwähnt O. REGENBOGEN [A.26] 1456-1457, Werke des Artemon von Kassandrea und des Philo von Biblos, die von der Sammlung bzw. dem Erwerb von Büchern handeln und umfangreiche Kaufanleitungen in Listenform 
hohen Interesse von Machthabern an Kontrolle in die Hände spielte und deshalb von ihnen gefördert, häufig - wie bei Augustus - auch initiiert wurde, liegt auf der Hand ${ }^{45}$.

Die sogenannten Kanonslisten, die uns aus der alten Kirche erhalten sind, von dem sogenannten Kanon Muratori angefangen, geraten unter diesem Aspekt in ein ganz anderes Licht ${ }^{46}$. Sie zeigen, daß man den hellenistisch-römischen Bibliothekskatalogen nacheifern wollte, wenngleich auf der Ebene eines in den meisten Fällen viel bescheideneren Bibliotheksbestandes, eben auf dem der normalen städtischen Minimalerfordernisse, sowohl im synagogalen wie im kirchlichen Bereich. Das in solchen Listen demonstrierte Vorgehen erweist sich auch darin als dem hellenistisch-römischen Katalogisierungsverfahren analog, als man bestrebt war, allen Dokumenten einen Titel und einen Autornamen zuzuweisen, auch dies zunächst weniger aus theologischen als aus organisatorischen Gründen.

Wir müssen in diesen Auswahlbemühungen zunächst die Äußerung eines sehr konkreten, praktisch bestimmten Interesses an der Etablierung eines Minimalbestands relevanter Schriften auf Regional- und Gemeindeebene sowohl im Synagogal- wie im Kirchenverband sehen, nicht vordringlich die Absicht einer zensurartigen Minderung des Grundbestands. Dafür gab es viele praktische Gründe: einmal die Kosten von Gestehung und Erhaltung, zum anderen die leichtere Kontrollierbarkeit, die in erster Linie eine technische und erst in zweiter Hinsicht eine theologische war ${ }^{47}$.

Diese Annahme erhält durch die Sammlung der vier Evangelien mehr noch als durch die Sammlung des Pentateuch Unterstützung. Für die Kollektion der vier Evangelien gibt es nämlich trotz aller verzweifelten und eindeutig sekundären Bemühungen des Irenäus ${ }^{48}$ und anderer nach ihm keinen gescheiten theologischen oder sonstwie inhaltlichen Grund. Die Auskunft, daß es sich hier um einen Kompromiß handelt, um die Sammlung der an einem bestimmten Ort vor allem ge-

geben. - Der sich auf das Kopieren und Sammeln von Büchern ebenso wie auf Bibliothekarisches überhaupt verstehende Hieronymus konnte Altes und Neues Testament bezeichnender Weise zweimal als Bibliothek bezeichnen, als Kleinbibliothek natürlich. S. Epist. 5 ('sacra bibliotheca') und De vir. illustr. 75 ('bibliotheca divina').

$45 \mathrm{~S}$. dazu D. GEORGI [A.2] Opponents, 422-445.

46 Sie sind zusammen mit anderen für die Kanonentwicklung relevanten Texten gesammelt im 2. Teil von E. PREUSCHEN, Analecta, Sammlung ausgewählter kirchengeschichtlicher und dogmengeschichtlicher Quellenschriften $8,893,129-186$, z.T. auch in E. HENNECKE - W. SCHNEEMELCHER [A.1] 27-40.

$47 \mathrm{DaB}$ die Machtfrage dann hinzutreten konnte, habe ich bereits verschiedentlich erwähnt.

48 Adv.Haer. 3,11.6-9. 
nutzten Evangelien, die dann wegen der Bedeutung des Ortes auch von anderen nachgeahmt wurde, ist die plausibelste ${ }^{49}$.

Das Schicksal der Aristoteles- und Theophrastbibliotheken beleuchtet die enge Verbindung von bibliothekarischen Problemen und Lösungen mit den Stärken und Schwächen der Philosophenschulen der Antike und ihren Strukturen. Oft gab es sachliche und in vielen Fällen auch persönliche Überschneidungen. Philosophen trugen als Philologen viel zu den Sammel-, Abschreib- und Editionspraktiken bei und machten dadurch die Wichtigkeit von Schulen und schulähnlichen Gruppierungen für eben solche Tätigkeiten sichtbar. Im Fall des Andronikus konnten sich die Absichten des einzelnen und Schulintentionen treffen, hier wohl so, daß Edition und Veröffentlichung der Aristoteles- und Theophrasthandschriften wesentliche Elemente der Übernahme der Führung der peripatetischen Schule durch Andronikus waren.

Die Philosophentestamente, nicht zuletzt das oben ausführlicher behandelte des Theophrast, verdeutlichten das Interesse an einer ebenso religiösen wie rechtlichen Organisation der jeweiligen Philosophenschule. Die geregelte Nachfolge, die 'Diadoche', des Schulleiters spielte dabei eine wesentliche Rolle. Sie fand ihren Niederschlag in dem Instrument der Diadochenlisten.

Die bibliothekarische Praxis und Kritik hat diese Diadochenreihen bei ihrer Ein- und Zuordnung philosophischer Autoren genutzt und wohl auch kritisch korrigiert und ergänzt. Und diese Diadochenlisten konnten wieder zur Legitimierung und Authentisierung von Texten und Traditionen eingesetzt werden oder auch zur Bestimmung der Nichtauthentizität und einer entsprechend anderen Einordnung (in Schule und Bibliothek).

Die pharisäischen Rabbinen und die gnostischen Gruppen in der Kirche hatten die Institution der geregelten Nachfolge (Diadoche) von Schulhäuptern (Scholiarchen) und damit auch das Instrument der Diadochenliste aus den hellenistischen Philosophenschulen übernommen, wenngleich wohl nicht unmittelbar, sondern mittelbar auf dem Umweg über die der Gnosis und den Rabbinen gemeinsame weitverzweigte jüdische Weisheit, die sich ihrerseits in einigen ihrer Zweige den Philosophenschulen angeglichen hatte ${ }^{50}$. Bei dieser Übernahme spielte weniger interne Legitimierung eine Rolle als die Interessen kultureller Be-

49 A. VON HARNACK, Die Chronologie der altchristlichen Litteratur bis Eusebius, Leipzig 1897, hat dort 681-700 hierfür das westliche Kleinasien vorgeschlagen.

50 Die Pirqe Aboth deuten für den pharisäischen Rabbinat diese Verbindung zur Weisheit an, wenngleich in stilisierter Form. S. D. GEORGI, The Records of Jesus in Light of Ancient Accounts of Revered Men, SBL Seminar Papers, ed. L.C. MCGAUGHY, 1972, Missoula 1972, 527-542. Für die missionstheologisch orientierte Weisheit, die sogenannte Apologetik, lassen sich z.B. bei Philo Schultraditionen festmachen, die für die Existenz eines organisierten und kontinuierlichen Schulbetriebs sprechen. 
hauptung und auch reinen Überlebens, besonders angesichts des wachsenden staatlichen Drucks durch die Römer im ersten und zweiten nachchristlichen Jahrhundert. Besonders die Katastrophen der beiden jüdischen Kriege verlangten nach Vorsichtsmaßnahmen, die in der Sache kein Nachgeben bedeuteten, aber doch Schutz vor staatlichem Eingriff versprachen. Die Philosophenschulen waren von den Römern nicht nur geduldet, sondern sie waren wegen ihrer transparenten Struktur für die Behörden kontrollierbar und deshalb bevorzugt. Deshalb bestand auch keine durchgängige Berichtspflicht, und Verfolgung von Philosophen (besonders unter Domitian) war die Ausnahme ${ }^{51}$.

Dieses von den Philosophenschulen abgeschaute Interesse an kontinuierlicher Legitimierung von Schul- und Lehrautorität bewegte die pharisäischen Rabbinen und christlichen Gnostiker und Gnostikerinnen dazu, sich auch drei weitere für philosophische Schulstrukturen und philosophische Lehrautorität wichtige Faktoren zu bemühen: authentische Basistexte, methodisch strukturierte mündliche Lehre und autoritative Kommentierungen. Die gnostischen und die rabbinischen Gruppen bemühten sich um Auswahlen von besonders wichtigen Texten, denen man Basisfunktion und -autorität beimessen konnte, die also dem Rang nach den Texten der Schulgründer in den Philosophenschulen gleichzusetzen wären, auch dies eine weitere Demonstration gegenüber dem Staat, daß man sich durchsichtig halten wollte. Dabei spielten, wie in den Philosophenschulen, die Diadochenreihen eine hilfreiche Rolle 52 .

Als Basistexte wurden von Rabbinat und Gnosis Dokumente aus der Zahl derer ausgewählt, die nach Meinung der auswählenden GröBen als heilige Schriften Israels in Gebrauch waren. Dabei gab man sich aber zunächst keine große Mühe, diese Sammlung von anderen Texten genau abzugrenzen. Nur dies läßt sich feststellen, daß sich die Rabbinen auf hebräischsprachige Texte beschränkten, die christliche Gnosis dagegen der LXX-Tradition folgte, die ihrerseits auch keine exklusive Sammlung darstellte.

Die Gnostiker waren die ersten, bei denen wir neben enormer eigener Produktions- und Sammeltätigkeit ${ }^{53}$ die Tendenz feststellen können, andere als pragmatische Gründe für begrenzte Schriftensammlun-

$51 \mathrm{DaB}$ in dem nichtgnostischen Flügel der Kirche Didadochenreihen zuerst in Rom auftraten, bestätigt dies, denn die Jesusanhängerinnen und -anhänger in Rom waren besonders gefährdet. Die grundsätzliche Gefährdung durch die Ermöglichung des schnellen staatlichen Zugriffs auf die leitenden Persönlichkeiten der Gruppen bedeutete andererseits eine Minderung der konkreten Gefährdung der Gruppen in ihrem Normalbetrieb; denn da sich die staatlichen Behörden der grundsätzlichen schnellen Eingriffsmöglichkeit sicher waren, konnten sie im Tagesgeschäft toleranter sein.

52 K. WEGENAST, Das Verständnis der Tradition bei Paulus und in den Deuteropaulinen, WMANT 8, Neukirchen 1962, 121-130.

53 Irenäus kritisiert z.B. Adv.Haer. 1,20.1 ihre vielen Evangelien, gesammelte ebenso wie selbst geschaffene. 
gen einzuführen, sachliche Ausschlußkritieren zu diskutieren und damit in Richtung auf die Sammlung exklusiver Phänomene und deren Auflistung $\mathrm{zu}$ arbeiten ${ }^{54}$. Dahinter standen die erwähnten Schulbedürfnisse, aber auch ein bestimmtes Verständnis von den Grundsätzen wissenschaftlicher Zuverlässigkeit. Der erste, der konsequent eine exklusive Auswahl vornahm, war eindeutig Marcion. Er ist damit zum Vater des christlichen Kanons als Zensurphänomen und -instrument geworden - auch einer damit verbundenen schwerhändigen Ideologisierung von Textbestand und -gebrauch, der Vater auch des christlichen Fundamentalismus.

Die Geschichte der Überlieferung des Aristoteles und des Theophrast hat noch eine weitere für die Philosophenschulen und ihre Nachwirkung charakteristische Illustration erbracht, die sich dann auch bei den gnostischen Gruppen in der Kirche und bei den pharisäischen Rabbinen, vielleicht auch in der jüdischen Apokalyptik wiederfindet: die zunächst paradox erscheinende Beziehung zwischen Geschriebenem und Ungeschriebenem.

Es wird oft übersehen, daß in diesen Schulzusammenhängen das Geschriebene einerseits und das Ungeschriebene andererseits in einer komplexen Dialektik zueinanderstanden. Auf der schriftlichen, der ausdrücklich öffentlichen Seite standen neben den Veröffentlichungen der Schulhäupter die zur Abschrift freigegebenen Vorlesungsnachschriften der Schüler und Schülerinnen. Auf der mündlichen, der nicht-exoterischen oder auch esoterischen Seite standen die nicht-öffentliche bzw. nicht veröffentlichte Lehre des Meisters, seine mehr oder weniger mündliche Überlieferung (Paradosis)55 und dazu die mündliche Lehre der Schule, in der erstere lebendig gehalten wurde. Mündliche Lehre und Überlieferung waren methodisch strukturiert und inhaltlich offen, was sich in der lebendigen Beziehung von Vergangenheit und Gegenwart demonstrierte.

Als mündliches Gegengewicht zu den erwähnten Basistexten brachten die pharisäischen Rabbinen das, was im Anfang der Pirqe Aboth als mündliche Torah vom Sinai her vorgestellt wird. Diese weisheitliche Paradosis wurde dann in ein dialektisches Verhältnis zur lebendigen mündlichen Gesetzesinterpretation gesetz $t^{56}$. Auch die kirchliche Gnosis setzte das Geschriebene in ein dialektisches Verhältnis

\footnotetext{
54 Irenäus, Adv.Haer. 3,2.1 und öfter.

55 Die Forschung ist sich bis heute nicht darüber einig geworden, welche der einzelnen Philosophen und welche Schulen sich dieser besonderen Lehrform bedienten. Daß dies bei allen Schulen grundsätzlich im Blick stand, beweist die Tatsache, daß man durchweg die strukturelle Nähe zur Organisationsform der Mysterien aufrecht erhielt.

56 D. Georgi [A.50].
} 
zum Mündlichen und vernetzte im Bereich des letzteren mündliche Überlieferung mit der gegenwärtigen mündlichen Lehre ${ }^{57}$.

Eine aufmerksame Lektüre des Irenäus beweist, daß der nichtgnostische und nichtjüdische Teil der Kirche in all diesen Dingen die Gnosis nachahmte, indirekt auch den pharisäischen Rabbinat und die Philosophenschulen. I. behauptet zwar in Adv.Haer. 3,3,2 und 3, daß Diadochenlisten von Bischöfen in allen nichtgnostischen Gemeinden der Kirche geführt würden. Er kann sie aber noch nicht einmal für die eigene Diözese vorführen, sondern nur für den nichtgnostischen und nichtjüdischen Teil der Kirche in Rom. Die römische Bischofsliste wird demnach die einzige im von I. anerkannten Teil der Kirche vorhandene Diadochenliste gewesen sein. Sie war weder grundsätzlich noch von Anfang an mit Auswahl und Unterhaltung kirchlicher Basistexte verknüpft. I. bringt sie nur sehr gezwungen, also sekundär zueinander in Beziehung 58 .

Irenäus legt auch großen Wert auf mündliche Überlieferung/Paradosis in seinem Zweig der Kirche. Aber sie ist weder eng, noch wird sie dialektisch mit etablierter Texttradition verknüpft. Und auch die oben festgestellte interne Dialektik zwischen vergangener und gegenwärtiger mündlicher Lehre läßt sich nicht feststellen. Die faktische kirchliche Predigt spiegelt sich noch nicht einmal andeutungsweise bei I. wieder; erst recht spielt sie keine aktive Rolle in kirchlichem Leben und kirchlichem Aufbau, wie er sich diese wünscht. Der mündlichen Überlieferung, wie sie I. sich vorstellt, fehlt die methodische Struktur und Offenheit, wie sie ihr in den anderen vergleichbaren Größen selbstverständlich war. In seiner Vorstellung von Kirche will I. die mündliche Überlieferung kirchenamtlich reguliert und gleichförmig haben. Er will sie als "Kanon der Wahrheit", als "Kanon des Glaubens" einsetzen, also als Wahrheits- und als Glaubensnorm, als 'regula fidei'59. Hier steht die

$57 \mathrm{Zu}$ nennen wären hier vor allem Basilides und Valentinian. Das alles konnte dann wieder als autorisierte Kommentierung seinen schriftlichen Niederschlag finden, auf der rabbinischen Seite die Verschriftlichung der mündlichen Lehre in Mischna und Tosephta, auf der kirchlich-gnostischen Seite in Form von Herrenworten und apostolischen Schriften, also Kyrios und Apostolos, alles sich wieder in weiterer mündlicher Lehre verlebendigend.

58 Damit zeigte in gewisser Hinsicht die Entwicklung der von Irenäus positiv bewerteten Teile der Kirche Analogien zur Entwicklung des Peripatos, denn ausgerechnet diese Schule, die auf den ersten Blick die strengste Traditionssicherung durch Testament, Bestimmung des Schulhaupts, Nachfolgeregelung und weitere Formen der Schulorganisation besaß, hatte auf der Seite der schriftlichen Schulbasis die größte Lacuna aufzuweisen. Das bedeutete, daß man im Peripatos wie auch in der irenäischen Kirche zunächst sehr empfindlich auf neu auftauchende Texte reagierte. Aber im Endeffekt blieben auch beide Gruppen insofern vergleichbar, als der dann der von der Schule endgültig akzeptierte Basistext alle anderen verdrängte.

59 Adv.Haer. 1,22.1 und 27.1. Sicher spielte bei all dem eine Rolle, daß für Irenäus bei der oben erwähnten schulischen und bibliothekarischen Beschäftigung im Hintergrund der von ihm sehr geliebte Mysterienbegriff stand, den er mit Sakrament, Priestertum und 
philosophisch-moralische Bedeutung des Begriffs "Kanon" Pate, nun aber ins Juridische, ja ins Gesetzliche gedrängt. Die legalistische Bedeutung von "Kanon" blieb auch in der Zukunft in diesem Teil der Kirche, der später unter Konstantin die Macht erhielt, der beherrschende, wie vor allem der Sprachgebrauch der Synoden zeigt, wo die "Kanones" gesetzliche Bestimmungen waren. Die Wendungen "kanonisieren" und "kanonisiert" oder "als kanonisch anerkannt" meinten nun kirchenamtlich anerkannt - mit der Hoffnung auf reichsgesetzliche Bestätigung.

In 3,4 weist Irenäus darauf hin, daß in der - ihm aufgrund der Lage seines Bezirks nicht unvertrauten - Barbarenmission die Missionare sogar ganz auf den geschriebenen Text verzichten und sich auf die regulierte und regulierende Glaubensformel beschränken konnten. Der Aufriß der Ketzerbestreitung des I. beweist, daß Basistexte über weite Strekken in der Argumentation wegbleiben konnten. Sie treten erst später hinzu und dann nur als Argumentationsstütze. Sie beherrschen und bewegen die Argumentation nicht, im Gegenteil, die Basistexte werden häufig genug von der kirchenamtlichen Glaubensnorm und auf sie hin gebogen. Die 'regula fidei' ist und bleibt für I. der eigentliche Kanon, die 'norma normans', die Schrift ist 'norma normata'. Die Schrift als Kanon wurde zum Geschöpf der Kirche als Amtskirche.

Dies wurde dann von Athanasius in seinem berühmten 39. Festbrief festgemacht, wo er von den "kanonisierten, überlieferten und als göttlich beglaubigten Büchern" redet und dann eine exklusiv verstandene Liste alttestamentlicher und neutestamentlicher Schriften vorlegt. Er versteht sie aufgrund einer eisegetischen Mißdeutung des Lukasprologs als etwas, was "gemäß dem, was die ursprünglichen Augenzeugen und Diener des Wortes den Vätern überliefert haben", festgelegt worden ist. $\mathrm{Dh}$ auch hier ist es die als apostolische Überlieferung behauptete 'regula fidei', die die Norm darstellt, die die Schrift ebenso normiert wie sie sie etabliert ${ }^{60}$. Diese nun kirchenamtlich festgelegte, mit Regierungsunterstützung, vor allem auch in Form einer Massenproduktion von Bibelhandschriften, verbreitete und zensierend wirkende Heilige Schrift hat die 'regula fidei', den eigentlichen "Kanon" nicht verdrängt. Diese ist die eigentliche, die normierende Norm geblieben. Die $\pi \alpha p p \eta \sigma i \alpha$, die

Bischofsamt verknüpfte, wobei er letzteres durchaus auch als Lehramt verstehen konnte. Dadurch wurde die verhängnisvolle Verbindung ermöglicht und beschleunigt, von der oben die Rede ist.

60 Die bereits oben erwähnte Bedeutungsentwicklung zeigt sich auch in den 58 . und 59.

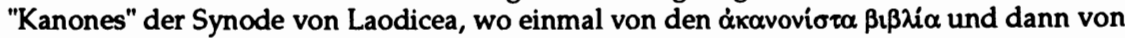

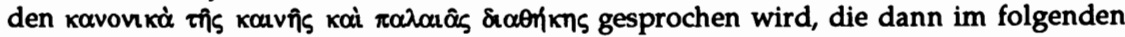
aufgezählt werden. S. F. LAUCHERT, Die Kanones der wichtigsten altkirchlichen Concilien, Sammlung ausgewählter kirchengeschichtlicher und dogmengeschichtlicher Quellenschriften 12 (1896) 78. Aber es sollte doch auch nicht übersehen werden, daß keine oekumenische Synode diesen Canones von Laodicea oder dem Athanasius gefolgt ist und den Umfang der Schrift endgültig exklusiv definiert hat. 
Redefreiheit der freien Bürger in der demokratischen Stadt, das Recht frei $\mathrm{zu}$ reden und frei $\mathrm{zu}$ handeln, die Paulus in 2 Kor 3 dem als Testament fixierten Text gegenüber kritisch gegenüberstellt und die von ihm sicher inklusiv verstanden worden ist, ist damit vom Tisch gewischt worden. 


\title{
JUDA - NAMENSDEUTUNG IN TRADITION UND ETYMOLOGIE
}

\author{
von \\ Manfred Görg \\ Kath.-Theol. Fakultät, Ludwig-Maximilians-Universität München
}

"Tradition" ist an Raum und Zeit gebunden. Die Weitergabe von grundlegenden Erfahrungen an Wendepunkten der Geschichte vollzieht sich gerade im Innenraum Israels auf eine unverwechselbare und zugleich paradigmatische Weise, zumal hier die gemeinschaftsstiftende Begegnung mit dem Gott der Geschichte die Wege zur Identitätsfindung des erwählten Volkes geöffnet hat. Die biblischen Überlieferungen zur Frühgeschichte der politischen Prozesse im südpalästinischen Raum konzentrieren sich auf Reflexionen zum Schicksal Judas, welcher Name zum Inbegriff der konstitutiven Erinnerungen Israels und des Judentums auf palästinischem Boden geworden ist. Im Weiterleben des Namens manifestiert sich die Kontinuität einer ortsbezogenen Bindung, die gerade auch mit der genuinen Entwicklung des Judentums in der Diaspora des hellenistisch-römischen Zeitraums, im Abendland und in der gegenwärtigen Welt zum Bestand einer grundlegenden Orientierung an dem auf palästinischem Boden gewachsenen Staat beigetragen hat 1 .

Für das Selbstverständnis des Judentums wird es daher von gleichbleibendem Interesse sein, wie sich der Name "Juda" im etymologischen und semantischen Bereich primär verstehen läßt. Die bislang ungelösten Schwierigkeiten bei der Namensdeutung setzen bereits bei der Beurteilung der Orthographie an. Hat die Forschung von einer Primärgestalt Yhuudd oder von Yrhưd auszugehen? Die naheliegende Berufung auf die biblischen Zitate ist keineswegs ein unumstrittenes Kriterium für ein höheres Alter der auf $-h$ endigenden Namensform, da trotz einschlägiger Ansetzung in den Publikationen der frühesten außerbiblischen Vorkommen des Namens in althebräischem Kontext keine ausreichende Gewißheit über die Schreibung des Namensauslauts zu gewinnen ist ${ }^{2}$. Obwohl die nichtbiblischen Belege erst vom 3. Jh. v.Chr. an sichere Schreibungen mit $-h$ im Auslaut erkennen lassen, besteht noch kein hinreichender Anlaß, daß man bei Ysuüdă von einer späten Bildung sprechen müßte, weil der "archäologische", d.h. vom Aspekt der Datierung von Originaltexten her bestimmte Ansatz eine ältere

1 Die biblischen Wurzeln jüdischer Identität reflektiert auf der Seite des Judentums zuletzt Rabbi J. MAGONET, The Biblical Roots of Jewish Identity: Exploring the Relativity of Exegesis, JSOT 54 (1992) 3-24.

2 Vgl. die Sammlung der Belege und die Konkordanz in G.I. DAVIES, Ancient Hebrew Inscriptions; Corpus and Concordance, Cambridge 1991, $364 f$. 
Festlegung dieser Orthographie nicht erlaube ${ }^{3}$. Stattdessen sollte der Kontinuität der Namenüberlieferung im orthographischen Bereich so viel Kredit gegeben werden, wie sie zu haben beansprucht. Nicht die Tradition einer bestimmten Namensgestalt trägt die Beweislast für ihre Anerkennung, sondern diejenigen, die ihr ein höheres Alter absprechen, so daß auch hier wie in zahllosen Fällen sonst zum mindesten von einem älteren, d.h. vor dem 3. Jh. v.Chr. anzusetzenden Nebeneinander von Namensbildungen mit und ohne Anzeige einer Namensendung auszugehen wäre.

Der Rekurs auf die vermeintlich ursprüngliche Orthographie YHWD ist denn auch bislang nicht Allgemeingut geworden; im Gegenteil, erst jüngst ist wiederum für die Originalität der Bildung YHWDH votiert worden 4 , freilich nicht unter Hinweis auf die Bringschuld dessen, der gegen die Tradition argumentiert, sondern aus etymologischen Gründen. Bevor diese Argumentation weiter verfolgt werden soll, möge ein Blick auf die keilschriftlichen Umschreibungen des Namens gestattet sein 5 .

Die assyrischen Wiedergaben ( $\left(a-u / u-d a-a-a\right.$ mit Varianten $\left.{ }^{6}\right)$ und auch die babylonischen Zitationen (la-a-bu-du mit Varianten ${ }^{7}$ ) unter Einschluß

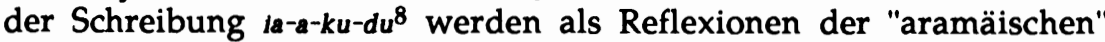
Namensform Yhd bzw. Yhud betrachtet ${ }^{9}$, was mir unter Betrachtung der vokalischen Auslautformen der Belegschreibungen nicht die einzige Erklärungsmöglichkeit zu sein scheint. Ich sehe kein grundsätzliches Hindernis, gerade für die keilschriftlichen Umschreibungen mit mindestens gleichem Recht die auf $-h$ auslautende Gestalt des Namens Juda supponieren zu dürfen.

\footnotetext{
${ }^{3}$ So B. DIEBNER, Erwägungen zur Namensform "Juda" Thr yadzh, DBAT 25 (1988) 49-73.

4 Vgl. E.A. KNAUF, Kritische Bemerkungen zu yehudsh und der "Göttin des Sohnes", DBAT 26 (1989/90; erschienen 1992) 198-200, 198.

5 Vgl. dazu die Zusammenstellung von M. WEIPPERT, Israel und Juda, RLA V (1976-1980) 200-208, 200f.

6 Vgl. die Belege bei S. PARPOLA, Neo-Assyrian Toponyms, AOAT 6 (1970) 182.

7 Vgl. die Belege bei R. ZADOK, Geographical Names According to New- and Late-Babylonian Texts, BTAVO B 7/8, Wiesbaden 1985, 186.

8 Zur keilschriftlichen Wiedergabe des hebräischen $h$ durch $k$ vgl. u.a. auch E. EDEL, Neue Deutungen keilschriftlicher Umschreibungen ägyptischer Wörter und Personennamen (Österreichische Akademie der Wissenschaften, Philosophisch-Historische Klasse, Sitzungsberichte, 375. Band), Wien 1980, 38.

9 Vgl. WEIPPERT [A.5] 200; E.A. KNAUF, Bemerkungen zur frühen Geschichte der arabischen Orthographie, Or 55 (1986) 452-453. DERS. [A.4] 198 notiert zu DIEBNERs [A.3] Ausführungen, er habe die keilschriftlichen Schreibungen nicht eigens diskutiert, obwohl sie seiner Vorstellung entgegenkämen, was DIEBNER im nachhinein als Stütze reklamiert (Zusatz 2 in eckigen Klammern). Es scheint mir dennoch noch nicht gesichert, $\mathrm{da} ß$ die keilschriftlichen Wiedergaben ausschließlich mit der Bildung Yhd bzw. YPhad zu verbinden seien, die natürlich nicht erst aramäischen Ursprungs ist.
} 
Die Annahme eines Nebeneinanders der Bildungen YHD/YHDH bzW. YHWD/YHWDH schon in vorexilischer Zeit stellt nun vor die Entscheidung, ob man für die Frühzeit der Geschichte des Namens der Kurzform oder der Langform die Präferenz geben sollte. Die Gretchenfrage dabei ist natürlich das Problem der Etymologie. Noch im Vorfeld der semantischen Klärungsversuche sollte diskutiert werden, ob eine Verbalform oder eine Nominalform zugrundeliegt, eine Alternative freilich, die wiederum nicht ohne Abstimmung mit dem zugänglichen Belegmaterial geprüft werden kann. Eine Grundform yhd bzw. yhwd ließe sich nun zweifellos als Präfixkonjugation einer Basis mit den tragenden Basismorphemen $H$ und $D$ verstehen, während eine Grundform yhdh bzw. yhwdh als Nominalbildung aufgefaßt werden müßte, die ihrerseits auf einer Basis mit den beiden Morphemen $\boldsymbol{H}$ und $\boldsymbol{D}$ beruhen sollte.

Wir beginnen mit der letztgenannten Möglichkeit, die in der Forschungsgeschichte bereits vorgeschlagen und erst jüngst wieder ins Gespräch gebracht worden ist. Es handelt sich um die These einer Rückführung des Namens auf ein Nomen vergleichbar mit dem arab. wahdah ${ }^{10}$, das in der Lexikographie unter den Bedeutungen "Bodensenkung" etc. geführt wird11. Mit diesem Nomen, das seinerseits mit einer Stammbildung wada'a "niederwerfen, ebnen" u.ä. zu verbinden wäre, sollte dann auf die geographischen Verhältnisse im südlichen Palästina angespielt, d.h. die Beschaffenheit des judäischen Berglandes bezeichnet worden sein, das dem Stamm als Wohnsitz gedient habe. Wie in zahlreichen Fällen sonst sei auch hier ein Landschaftsname konstitutiv für das Toponym und seine Bevölkerung geworden.

Diese zweifellos attraktive Rückführung des Namens Juda hat jedoch auch ihre Schwierigkeiten. Zunächst ist kein altwestsemitisches Nomen greifbar, das dem arabischen wahdah ohne weiteres zur Seite gestellt werden könnte ${ }^{12}$. Sodann wäre auch für ein solches Nomen keine Basis mit entsprechender Sembedeutung zur Hand, will man nicht zu YDH I im Sinne von "zu Boden werfen", "ebnen" u.ä. Zuflucht nehmen ${ }^{13}$. Vor allem aber wird man gerade das Territorium Judas gerade nicht als "Niederung" apostrophieren dürfen. Juda ist vielmehr als geo-

10 Vgl. E. LIPIŃSKI, L'Étymologie de "Juda", VT 23 (1973) 380-381 (unter Hinweis auf S. YEIVIN); E.A. KNAUF, Ehud, Neues Bibel-Lexikon (hg. von M. GÖRG - B. LANG), Zürich 1988ff, I, 487; DERS. [A.4] 198.

11 Vgl. u.a. A. WAHRMUND, Handwörterbuch der neu-arabischen und deutschen Sprache I/2, Gießen 1898, 1225; H. WEHR, Arabisches Wörterbuch für die Schriftsprache der Gegenwart, Leipzig 1956, 979.

12 Gewiß macht es sich H.-J. ZOBEL, ThWAT III, 516 mit seinem Einwand ein wenig zu leicht, wenn er bemerkt, daß "es dieses Nomen wahda nicht im $\mathrm{AT}^{\mathrm{T}}$ gebe, "so daß die vorgeschlagene Etymologie hypothetisch bleiben" müsse. Richtig ist jedoch, daß das AT keine Nominalbildung mit geographischer Sinngebung zu kennen scheint, die sich zwanglos mit dem Eigennamen Juda zusammenstellen ließe.

13 Zur Basis $Y D H(Y)$ "werfen" (G-St. und D-St.) in Verbindung mit arab. wada' vgl. u.a. HAL 372, auch schon E. MEIER, Hebräisches Wurzelwörterbuch, Mannheim 1845, 439. 
graphisches Gebilde mit Ackerland, Gebirge, Steppe und Wüste ausgewiesen ${ }^{14}$. Die ursprünglichen Wohngebiete des Stammes Juda dürften sich nicht in der kanaanäisch kontrollierten Niederung (vgl. u.a. Ri 1,19), sondern im südlichen Bereich des mittelpalästinischen Gebirges befunden haben ${ }^{15}$. Ob sich schließlich ein Stamm einen Namen zulegt, der nichts anderes als "das ausgewaschene, ausgehöhlte (Land)"16 bedeutet haben sollte, ist doch sehr problematisch. Eine Ableitung des Namens Juda von einem Nomen, dessen Sinngebung konstruiert werden müßte, wird man daher nicht bedenkenlos übernehmen dürfen ${ }^{17}$.

Wir stehen somit wohl wieder vor der Notwendigkeit, nach einer verbalen Grundlage für Yh(w)d als Bildung in Präfixkonjugation zu suchen, deren Subjekt zu ergänzen wäre. Dieser Auffassung ist denn auch in der Vergangenheit die größte Sympathie entgegengebracht worden. Am ehesten glaubte man, mit einer Hpass.-Form im Jussiv von der $\mathrm{Ba}$ sis YDH II "preisen"18 operieren zu können, um so mit El oder JHWH als fehlendem Subjekt die Bedeutung "El/JHWH möge gepriesen werden" zu gewinnen ${ }^{19}$. Doch auch hier kommt man nicht ohne hypothetische Voraussetzungen aus. Von einer sonstigen Bezeugung dieses Sprachgebrauchs im biblischen und außerbiblischen Hebräisch kann keine Rede sein ${ }^{20}$. Auch im Bereich der Namenbildung (Personen- oder Ortsnamen) findet sich kein direkt vergleichbares Gegenstück. Angesichts der Singularität prominenter Namensformen im AT muß dieses Argument jedoch nicht sonderlich gewichtet werden.

Immerhin scheint sich das AT selbst für eine Assoziation stark gemacht zu haben, die den Namen mit der Basis YDH(Y)"preisen" zusammenführt. Nach dem Beginn des Juda-Spruches im sogenannten Jakobssegen (Gen 49,8-12) ist dieser Zusammenhang wohl bewußt akzentuiert:

"Juda, du, dich preisen deine Brüder" $(49,8)$.

\footnotetext{
14 Vgl. ZOBEL, ThWAT III, 517f.

15 Vgl. dazu u.a. H. DONNER, Geschichte des Volkes Israel und seiner Nachbarn in Grundzügen (ATD Ergänzungsreihe 4/1), Göttingen 1984, 131.

16 Vgl. die Wiedergabe der Deutung LIPINSKIs bei ZOBEL, ThWAT III, 515.

17 E.A. KNAUF, NBL I [A.10] 487 und [A.4] 198 will den arab. Ausdruck wahdah auf "Schlucht, Senke, Gebirgsabfall" festlegen, um so eher eine kongeniale "Geländebezeichnung" für das Stammesgebiet Juda ausmachen zu können, was mir aus den oben genannten Gründen problematisch erscheint. Ich kann mich auch nicht entschließen, seiner Herleitung des Personennamens Ehud von der gleichen Nominalgrundlage meine ungeteilte Zustimmung zu geben. Vermutlich ist hier nach wie vor an eine Kombination mit dem Nomen hwd (dazu s.u.) zu denken (vgl. zuletzt GESENIUS, 18. Auflage, 20).

18 Vgl. dazu u.a. HAL 372; G. MAYER u.a., ThWAT III, 455-474.

19 Vgl. etwa W.F. ALBRIGHT, JBL 46 (1927) 168-178; zuletzt A.R. MILLARD, ZAW 86 (1974) 217.

20 Vgl. auch MILLARD [A.19] 217, der jedoch angesichts der verbreiteten Verwendung des H-Stammes von YDH(Y) die "possibility" nicht ausschließen will.
} 
Die Interpretation zielt hier freilich nicht auf Gott als Objekt der Preisung und stellt daher wohl eher eine Anspielung auf den Namen dar ${ }^{21}$. Ohne daß eine Etymologie vorliegt, haben wir jedenfalls einen Versuch wortspielartiger Bezugnahme vor uns, der allerdings im Schatten eines deutlicheren Interpretationsversuchs, nämlich in Gen 29,35, steht, wo der Mitteilung über den Vorgang der Namensnennung die Erklärung Leas vorangeht:

"Nunmehr will ich Jahwe preisen" (29,35).

Auch hier liegt keine strenge Etymologie vor, wohl aber eine "ausgedachte"22 Deutung, insofern vertretbar und sachgerecht, als man sich zu der Verbindung des Eigennamens mit der benannten Basis verstehen will.

Die innerbiblischen Bezugnahmen stellen freilich nur einen Versuch dar, ohne Anspruch auf philologische Gültigkeit erheben zu können. Sie haben ihre eigene Dignität und sind als Teil des Kontextes in dessen Gesamtintention verwoben, so daß ihnen keine sprachwissenschaftliche Intention unterschoben werden darf. So bleibt einerseits die Frage nach der Art und Weise der Einbindung der Namenszitation in einen anspielenden Textzusammenhang, andererseits die weitergehende Rückfrage nach der in diesem Kontext nicht erfaßten und ursprünglichen Etymologie, die nun keineswegs als eine höherwertige Auslegung betrachtet werden müßte, sondern lediglich den Anforderungen sprachwissenschaftlicher Lexemanalyse zu genügen hätte.

Der Aspekt der Theologisierung des Namens - besonders deutlich in Gen 29,35 - kann demzufolge in eine hilfreiche Spannung zur semiologischen Betrachtung treten, wenn man sich bewußt ist, daß die wie auch immer geartete Spiegelung eines Namens im Kontext dem Bemühen um eine erneuerte Integration und Vereinnahmung im positiven Sinn entspricht. In unserem Fall soll dem identitätsstiftenden Namen Juda eine Gottesbeziehung zugeteilt werden, die unabhängig von einer Ursprungsbedeutung als Landschaftname oder Personenname eine qualitative Verbindlichkeit beanspruchen darf.

Trotz des Vorbehalts gegenüber einer philologischen Relevanz innerbiblischer Deutungstradition soll in dieser Richtung jedoch noch weiter gefragt werden, um so vielleicht eine Brücke zu weiteren, auch wissenschaftlich komplikationsloser vertretbaren Lösungen des etymologischen Problems zu finden. Der Umgang mit einem Namen kann nämlich auf verschiedenen Ebenen erfolgen, die auch ein Spektrum von Assoziationen aufweisen können, an die dann das Interesse der morphologischen Sprachwissenschaft anknüpfen darf.

21 Vgl. dazu u.a. HAL 372. C. WESTERMANN, Genesis, BK I/3, Neukirchen-Vluyn 1982, $258 f$.

22 So mit Recht C. WESTERMANN, Genesis, BK I/2, Neukirchen-Vluyn 1981, 577. 
Der bereits zitierte Juda-Spruch des Jakobssegens enthält noch eine Reihe von bildhaften Aussagen und Vergleichen, deren Zusammenhang mit dem Eigennamen bisher nicht geprüft worden ist, weil er wohl in keiner Weise evident oder intendiert gewesen zu sein scheint. Die literarische Aufteilung des Gesamttextes Gen 49,8-12 in die Segmente V.8/V.9 und V.10-12 steht mit ihrer Orientierung noch zur Diskussion $^{23}$. Zuletzt ist die "Annahme eines Kunstgebildes" favorisiert worden, "das Gegenwart (V.8), Vergangenheit (V.9) und Zukunft (V.10-12) des Staates Juda beschreibt: ein Stück Jerusalemer Hoftheologie, ausmündend in die Erwartung des davidischen Messias"24.

Sollte V.9 die Vergangenheit Judas im Blick haben, dürfte es naheliegend sein, gerade hier eine weitere Anspielung auf den Namen zu erspüren. Es ist daher sinnvoll, gerade der Sequenz der Bildaussagen nachzugehen:

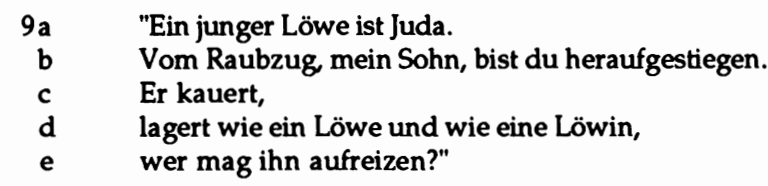

Formkritische Beobachtungen können die Variabilität der sprachlichen Gestalt im einzelnen aufweisen. Einem eröffnenden Nominalsatz (identifizierend) folgt eine konstatierende Erklärung ( $x+$ Suffixkonjugation). Zwei Suffixkonjugationsformen, die zweite mit Vergleichen angereichert, entsprechen einer auf Vergangenheit mit Auswirkung auf die Gegenwart zielenden Perspektive. Der rhetorische Fragesatz schließlich öffnet den Text unmittelbar für den Zeitgenossen. Der Struktur des Textes entnehmen wir eine Konzentration auf den Moment der Aggression, der formal im Satz der Mitte des Spruches zum Ausdruck kommt (9c). Es ist nach dieser Bildsequenz im Sinne des Spruches, Juda als herausfordernde Lebenswirklichkeit herauszustellen, wobei das Bild des Löwen in Analogie zur Symbolik der mächtigen und zugleich aggressiven Vitalität in der altorientalischen Bildsprache Verwendung findet ${ }^{25}$.

Unsere Fragestellung richtet sich auf eine mögliche Anspielung auf eine verborgene Konzeption zum Namen Judas, die bisher noch nicht erschlossen werden konnte. Vielleicht ist es gerade die gespannte Angriffshaltung, die hier einen semantischen Konnex erlaubt.

23 Vgl. dazu u.a. A. CAQUOT, La parole sur Juda dans le Testament lyrique de Jacob (Genèse 49,8-12), Semitica 26 (1976) 5-32.

24 H. DONNER [A.15] 133.

25 Vgl. dazu u.a. O. KEEL - M. KÜCHLER - C. UEHLINGER, Orte und Landschaften der Bibel. Ein Handbuch und Studienreiseführer zum Heiligen Land I, Zürich-Göttingen 1984, 143. Zur Bildsymbolik des Löwen vgl. jetzt O. KEEL - C. UEHLINGER, Göttinnen, Götter und Gottessymbole. Neue Erkenntnisse zur Religionsgeschichte Kanaans und Israels aufgrund bislang unerschlossener ikonographischer Quellen, QD 134 (1992) 24-28 u.ö. 
Unter den Basen, die mit den Grundmorphemen $H$ und $D$ ausgestattet sind, kann einmal auf die schon erwähnte Wurzel $Y D H(Y)$ II mit der Bedeutung "niederwerfen" u.ä. hingewiesen werden. Hier kann aber die Sequenz $D-H$ negativ ins Gewicht fallen, zumal der dritte Radikal nicht primär zu sein scheint. Ein Verb mit der Folge $H-D$ als starken Basismorphemen ist im biblischen Hebräisch offenbar nicht belegt.

Einer besonderen Betrachtung bedarf aber das Nomen HWD "Majestät", dessen Ableitung nach wie vor ein ungelöstes Problem darstellt ${ }^{26}$. Verwandte Morphemkonstellationen scheinen sich im biblischen Hebräisch mit den Nomen hd (hed "Donnerschlag (?)" (Ez 7,7) und dem Gottesnamen HDD (Hadad) ${ }^{27}$ zu ergeben. Der Gottesname, der im Ugaritischen als hd erscheint, wird wohl am ehesten mit der arab. Wurzel hadda "donnern", "mit starkem Geräusch einfallen" u.ä. zusammengestellt werden dürfen ${ }^{28}$. Damit liegt es nahe, nicht nur den Wettergott Hadad (Haddu) als "Donnerer" zu deuten, sondern auch das bekannte biblische Nomen hwd als Ausdruck für die naturmächtige Majestät, das "Tremendum" des heiligen Gottes zu verstehen. Für unseren Zusammenhang ergibt sich aus dieser Beobachtung, daß wir mit einer Basisgruppe $H-D$ rechnen dürfen, der semantisch die überlegene Majestät des triumphierenden Herrschers innewohnt.

Für diese aggressiv-vitale Dimension der Basis mit den Morphemen $H-D$ ist allem Anschein nach auch im Ägyptischen ein Anknüpfungspunkt zu finden. Das Verbum hd, seit dem Mittleren Reich belegt, findet seine spezifische Verwendung im Ausdrucksbereich für kämpferische Potenz und Initiative auf Seiten eines Königs oder einer Gottheit ${ }^{29}$. Es lohnt sich, das Augenmerk auf dieses Verbum zu richten, "pour lequel on admet une polysemie qui va de 'refouler' à 'vaincre', paradoxale en apparence, mais qui ne fait qu'exprimer deux poles de la confrontation"30. So heißt es etwa von Ramses II., er sei ein:

"Mächtiger Stier, der jedes Fremdland überwindet"31,

oder:

26 Vgl. u.a. HAL 231; G. WARMUTH, ThWAT II, 375-379, wo auch auf den Vorschlag einer Verbindung mit dem arab. 'awada "schwer sein" hingewiesen, aber keine hebräische Basis favorisiert wird.

$27 \mathrm{Zu}$ beiden Lexemen vgl. HAL 228f.

28 Vgl. dazu u.a. P.J. VAN ZIJL, Baal. A Study of Texts in Connexion with Baal in the Ugaritic Epics, AOAT 10 (1972) 350 mit Literatur (Anm. 7).

29 Vgl. die Angaben in: A. ERMAN - H. GRAPOW, Wörterbuch der ägyptischen Sprache II, $504 \mathrm{f}$.

30 N.-Chr. GRIMAL, Les Termes de la Propagande Royale Égyptienne de la XIXme Dynastie à la Conquete d'Alexandre (Mémoires de l'Académie des Inscriptions et Belles-Lettres, Nouvelle Série VI), Paris 1986, 674. Dort auch der Hinweis auf Belegstellen bei D. MEEKS, Année Lexicographique; Egypte Ancienne, III (1979), Paris 1982, 181 (Nr. 79. 1844).

31 Textbeispiel nach GRIMAL [A.30] 420 (n. 1436). 
"Vollkommener Gott ..., der alle Fremdländer überwindet"32.

Ramses III. kann erscheinen als:

"Horus, der Mächtige, der die Starken überwindet"33,

oder als:

"Tapfer im Streit, der die Masse überwindet"34.

Auch das Nomen hd steht für kämpferische Konfrontation ${ }^{35}$, so daß Ramses III. tituliert werden kann als:

"Stier in der Arena, wenn sein Angriff ansteht"36.

Für unseren Zusammenhang ist bemerkenswert, daß die Prädikationen mit dem Bild des kampfstarken Stiers aufwarten, wobei die damit gemeinte Rolle des Königs ebensogut auch mit dem Bild des Löwen ausgedrückt werden kann. So ist Ramses III.

"ein Löwe, wenn er ... die Fremdländer überwindet" 37.

Für die Morphemgruppe $H D$, sollte sie auch im hamitischen Bereich eine dem Semitischen entsprechende Sembedeutung haben ${ }^{38}$, kann nach allem eine Sinngebung veranschlagt werden, die auf eine majestätische Dominanz hindeutet. Sollte daher nicht auch unserem vieldiskutierten Eigennamen Juda eben diese semantische Orientierung innewohnen, die im rückschauenden Teil des Juda-Spruches Gen 49,9 ein Echo gefunden hätte?

Der Name Juda wäre demzufolge als yh(w)d (l/YHWH) "(Gott/JHWH) möge kämpfen bzw. seine Überlegenheit erweisen" o.ä. zu verstehen. Mit dieser Bedeutung stünde der Name dem nicht minder umstrittenen Namen "Israel" recht nahe, für den ja wohl auch mit guten Gründen eine entsprechende "streitbare" Etymologie eingebracht worden

32 Textbeispiel nach GRIMAL [A.30] 675 (n. 649).

33 Textbeispiel nach GRIMAL [A.30] 676 (n. 652).

34 Textbeispiel nach GRIMAL [A.30] 675 (n. 651).

35 Vgl. den Hinweis auf die Belegstellen bei MEEKS [A.30] 181 (Nr. 79. 1845).

36 Textbeispiel nach GRIMAL [A.30] 676 (n. 652).

37 Textbeispiel nach GRIMAL [A.30] 675 (n. 649).

38 Ein Vergleich des semitischen hd mit dem ägyptischen hd könnte freilich an der Schwierigkeit Anstoß nehmen, daß das ägyptische $d$ (Handhieroglyphe) nicht ohne weiteres mit dem semitischen $d$ kompatibel ist, da das Ägyptische keinen stimmhaften Dental kennt. Vgl. dazu E.A. KNAUF, Zur Etymologie der Handhieroglyphe, Göttinger Miszellen; Beiträge zur ägyptologischen Diskussion 59 (1982) 29-39. Dennoch besteht kein zwingender Anlaß, die phonetische Korrespondenz radikal auszuschließen, vgl. dazu auch die ihrerseits im einzelnen nicht immer überzeugenden Gegenargumente von W. VYCICHL, Das Zeichen für $d$ "Hand" in der Hieroglyphenschrift und die semitischen Entsprechungen des zugrunde liegenden Etymons, Zeitschrift für Ägyptische Sprache und Altertumskunde 112 (1985) 169-179. 
ist ${ }^{39}$. Die Frage, ob Juda von Haus aus ein Landschaftsname oder ein Personenname gewesen sei, bleibt von unseren etymologischen Erwägungen unberührt.

Für diese Position läßt sich vielleicht auf ein bedeutsames Gegenstück verweisen, nämlich auf den Gottesnamen YHWH. Dieser Name, ursprünglich allem Anschein nach ohne auslautendes -h geschrieben (!), scheint seiner Etymologie nach ursprünglich den Wettergott zu meinen, der "einherstürmt" und "einfällt", wie dies auch für den kanaanäischen Hadad charakteristisch ist ${ }^{40}$.

39 Dazu zuletzt P.R. DAVIES, Israel, Neues Bibel-Lexikon (hg. von M. GöRG und B. LANG), II, 246f und M. GöRG, Israelstele, ebd. 247-249.

40 Vgl. dazu v.a. E.A. KNAUF, Midian; Untersuchungen zur Geschichte Palästinas und Nordarabiens am Ende des 2. Jahrtausends v. Chr. (Abhandlungen des Deutschen Palästinavereins), Wiesbaden 1988, 43-63; M. GÖRG, Jahwe, Neues Bibel-Lexikon (hg. von M. GÖRG und B. LANG), II, 260-266. Nur anhangsweise und im Vorfeld weiterer Überlegungen sei hier auf den außerordentlich wichtigen Beitrag der ikonographischen Forschung zur Religionsgeschichte der frühen Eisenzeit in Palästina hingewiesen. Die besondere Skarabäendekoration zeigt die Verbreitung des Motivs eines triumphierenden "Pharao als Löwen", dessen symbolische Wirkkraft sich der Träger des Amuletts zu eigen machen will, vgl. dazu jetzt O. KEEL - C. UEHLINGER, Göttinnen ... [A.25] 134-138. Vielleicht muß gerade unter dem Eindruck dieser augenfälligen Befunde zu Beginn des Werdens Judas in Südpalästina mit einer Rezeption der Idee des streitbaren Herrschers gerechnet werden, die der Stamm Juda für seinen Gott JHWH und sich selbst unter der genuinen und schließlich unvergleichlichen Protektion JHWHs reklamiert. 



\section{BIBLISCHE GATTUNGEN ALS DIDAKTISCHE IMPULSE IM RELIGIONSUNTERRICHT ${ }^{1}$}

von

Ingrid Grill-Ahollinger

Feodor-Lynen-Gymnasium, München

\section{VORÜBERLEGUNGEN: RELIGIONSUNTERRICHT OHNE EXEGESE?}

Wenn in den letzten Jahrzehnten in der Religionspädagogik über Konzeptionen und Methoden debattiert wurde, dann ging es dabei immer auch um die Frage, welche Rolle die Bibel im Religionsunterricht spielen kann und soll. Im Moment will der Streit um "Bibelorientierung" und "Problemorientierung" niemanden mehr besonders aufregen; stattdessen erscheint auf der Bildfläche eine bunte Fülle von Möglichkeiten, mit der Bibel umzugehen, vom Bibel-Computerspiel bis hin zum Bibliodrama. Ganz deutlich wird der Wunsch nach unmittelbaren, erfahrungsorientierten Zugängen zur Bibel. Eher als hinderlich denn als erhellend wird dabei häufig die historisch-kritische Exegese empfunden, die in der gesamten Konzeptionsdebatte als Bezugswissenschaft überhaupt eine auffallend geringe Rolle spielt - ganz im Gegensatz etwa zur systematischen und praktischen Theologie, zu Pädagogik und Gesellschaftswissenschaften. Diejenigen, die in der Praxis stehen, beklagen, daß die universitäre Exegese jede unmittelbare Begegnung mit der Bibel durch einen Wust von "wissenschaftlichen" Verfahren und Techniken verstelle, die angeblich zum Verständnis der Bibel unbedingt nötig seien, und dies eben wirke auf Laien in Gemeinde und Schule als "Herrschaftswissen" der Studierten, die das Monopol für die Textauslegung beanspruchen. Die Systematiker unter ihren Kritikern werfen der Exegese vor, sie betreibe eigentlich keine Theologie, weil sie nur die Frage

1 Die Anregung zu dem Versuch, Religionsunterricht in einem traditionsgeschichtlichen Zusammenhang mit biblischer Überlieferung zu sehen, als ein Umsetzen biblischer Kommunikationssituationen in solche der SchülerInnen und LehrerInnen, verdanke ich der jahrelangen Arbeit bei Herrn Professor Dr. Klaus BALTZER, dem die folgenden Seiten gewidmet sein mögen, gleichsam auch als ein Stück "Traditionsgeschichte" zwischen Universität und Schulalltag.

Die folgenden Überlegungen, hier leicht überarbeitet, wurden 1988 als Einleitung zu einem didaktischen Modell für LehrerInnen (mit einem Schülerheft) in der Gymnasialpädagogischen Materialstelle der Evang.-Luth. Kirche in Bayern (Erlangen) abgedruckt (Themenfolge 84: Nicht einerlei Zunge noch Sprache. Alttestamentliche Gattungen im Unterricht der 5. Jahrgangsstufe). An einigen Stellen ist die Diskussion natürlich seitdem weitergegangen; dennoch hat sich nach meinem Eindruck kein grundsätzlich neues Bild v.a. auch der Rolle, die die Exegese im Unterricht spielt, ergeben, so daß m.E. die im folgenden wiedergegebene Diskussion durchaus "aktuell" ist. 
nach der ursprünglichen Textgestalt verfolge. Von Vertretern anderer Disziplinen schießlich hört man, die Exegese sei ins wissenschaftliche Abseits geraten, denn sie kümmere sich zu wenig um die Ergebnisse der modernen Nachbarwissenschaften, z.B. der Soziologie oder Linguistik. In der Tat war ausgerechnet aus der exegetischen Wissenschaft bemerkenswert wenig Echo auf die Konzeptionen "narrativer Theologie", um die es im folgenden gehen wird, zu hören.

Solche Distanz aufzubrechen, könnte m.E. gelingen in einem traditionsgeschichtlich - kommunikationsorientierten Unterricht, der Impulse aus einer ebenfalls traditionsgeschichtlich arbeitenden Exegese aufnimmt. Wenn man Exegese als eine Tätigkeit versteht, welche die in den biblischen Texten festgehaltenen Gesprächs- (Kommunikations-) Traditionen entdeckt und erschließt, wenn man andererseits den Religionsunterricht seinerseits als einen Kommunikationsprozeß im Kontext gegenwärtiger Gesellschaft begreift, so ist zu fragen, wie beide Kommunikationsprozesse so miteinander vermittelt, aufeinander bezogen werden können, daß die SchülerInnen ihre eigenen Fragen und Antwortversuche innerhalb jenes Gesprächsprozesses orten können, den wir "jüdisch-christliche Tradition" nennen.

Dieser Frage möchte ich hier am Beispiel des Erzählens biblischer Geschichten nachgehen, das ja wohl - allen religionspädagogischen Moden zum Trotz - seine Mittelpunktstellung im Religionsunterricht (zumindest der ersten sechs Schuljahre) nie verloren hat.

\section{ANNÄHERUNGEN AN DAS ERZÄHLEN}

\subsection{KINDER MÖGEN GESCHICHTEN}

Nicht nur Kinder lieben biblische (und andere!) Geschichten - auch LehrerInnen erleben Stunden, in denen eine Klasse gespannt ihren Erzählungen lauscht, gewöhnlich als "geglückt". Harald WEINRICH beschreibt die Situation des Erzählens sehr anschaulich:

"Der Prototyp des Erzählers ... ist eher alt als jung, beim Märchen ist er der Märchenonkel oder - als erzählende Frau - die Märchentante, oder die Großmutter. Er steht nicht, sondern sitzt, und zwar im Sessel, auf dem Sofa oder am Kamin. Seine Stunde ist der Abend, der Feierabend. Er unterbricht gerne seine Erzählung, um einen Zug aus der Pfeife oder Zigarre (selten an der Zigarette!) zu tun. Seine Bewegungen sind langsam: er nimmt sich Zeit, seine Zuschauer der Reihe nach anzuschauen, oder er blickt sinnierend zur Decke. Seine Gesten sind sparsam, sein Gesichtsausdruck eher versonnen als erregt. Er ist ganz entspannt"2.

2 H. WEINRICH, Tempus. Besprochene und erzählte Welt, Stuttgart 1964, 49. Das Zitat stammt aus dieser ersten Auflage, die 1971 vollständig überarbeitet wurde. 
Wenn auch diese Idealsituation im Unterricht wohl kaum erreicht wird, so kann doch auch hier Erzählen Entspannung und Konzentration schaffen. Die Rolle des Lehrers ändert sich: er beurteilt und diszipliniert nicht, sondern lädt seine SchülerInnen dazu ein, mit ihm gemeinsam in eine Geschichte einzutauchen, mit ihm gemeinsam Erfahrungen zu machen. Auch für die Kinder unterscheidet sich diese Situation vom gewohnten Fernsehkonsum. Erzählungen wecken Phantasie, fördern Kreativität. All dies erklärt wohl ein Stück weit, warum das Erzählen biblischer Geschichten alle methodischen Trends hartnäckig überdauert hat. Es ist aber auch nicht ganz ohne Gefahren: So wäre etwa zu fragen, ob bei häufigem Erzählen die SchülerInnen nicht doch in eine sehr passive Rolle schlüpfen, während andererseits ein begabter $\mathrm{Ge}$ schichtenerzähler ihre Gefühle und Bewertungen (bedenklich) fest "in den Griff" bekommen kann. Oft merken sich die Kinder spannende Details einer Geschichte, nicht aber deren (beabsichtigte) Pointe. Womöglich gibt es doch Situationen und Themen, die eine eher argumentative Behandlung nahelegen.

Jedenfalls scheint es, gerade um "gut" und "richtig" zu erzählen, wichtig, sich bewußt zu machen, was man eigentlich tut, wenn man erzählt, und worin die Leistungsfähigkeit des Erzählens im Blick auf biblische Texte besteht.

\subsection{DAS "PROPRIUM" DES ERZÄHLENS}

Häufig wird davon ausgegangen, Erzählen sei eine jedem bekannte, einheitlich definierte Größe. Doch in Wirklichkeit trägt gerade die Unschärfe des Begriffs, so brauchbar er in der Alltagssprache auch sein mag, in der theoretischen Diskussion erheblich zu Widersprüchlichkeiten, Mißverständnissen und Kontroversen bei. Wenn der Opa den Enkeln aus seinem Leben und dem Arzt seine Krankengeschichte "erzählt", wenn die Mutter eine Gutenachtgeschichte und der SPIEGEL die neuesten Affären erzählt - tun sie dann alle ein und dasselbe?

A.C. DANTO beantwortet diese Frage in seiner "Analytischen Philosophie der Geschichte" mit der inzwischen berühmt gewordenen Formel3: $^{3}$ :
(1) $\mathrm{x}$ is $\mathrm{F}$ at $\mathrm{t} 1$
(2) $H$ happens to $x$ at $t 2$
(3) $x$ is $G$ at $t 3$

Dieses Schema (bei dem $t$ time bedeutet), liegt seiner Ansicht nach allen narrativen Texten zugrunde und hat wohl seine kürzestmögliche Verwirklichung, bei dem $\mathrm{H}$ gleichsam zu einem Nichts zusammenschrumpft, in Cäsars Bonmot "veni, vidi, vici" bekommen. Das Schema liegt allerdings nicht schon - gleichsam naturgegeben - in den Ereignis-

${ }^{3}$ A.C. DANTO, Analytical Philosophy of History, Cambridge $21968,56$. 
sen selbst, sondern ist Produkt der geistigen Organisation durch den Geschichtsschreiber bzw. Erzähler. Da solche Organisation immer erst in der Rückschau möglich ist, die Rückschau sich aber je nach Standort und Interesse des Erzählers ändert, ist Geschichtsschreibung prinzipiell unabgeschlossen und hat als adäquates Erzähltempus die Vergangenheit.

Aus diesem sehr allgemeinen Modell, dessen Stellen im konkreten Erzähltext recht unterschiedlich besetzt sind ${ }^{4}$, lassen sich gleichwohl einige Gesichtspunkte zur Abgrenzung erzählender Texte von systematischen (Gesetzen, Lehrsätzen, Listen usw.) gewinnen, die vielleicht schon ahnen lassen, warum Erzählen für viele Theologen und Pädagogen so attraktiv ist:

1. Erzählungen sind subjektive Deutung von Wirklichkeit. Sie geben diffusen Erfahrungen Ordnung und Sinn, ohne sie jedoch in ein geschlossenes System zu zwängen.

2. Systematische Texte folgen einem zweiwertigen Wahrheitsbegriff: Oppositionen erscheinen als einander ausschließende Möglichkeiten (entweder - oder). Der narrative Text hingegen kann Oppositionen im Nacheinander aufführen (sowohl - als auch; erst so - dann anders). $\mathrm{Da}$ auf diese Weise auch ausgegrenzte Wirklichkeit integriert werden kann, ist der Erzähltext grundsätzlich offener und zu größerer Toleranz fähig als der systematische.

3. Die Kategorie der Zeit und damit der Veränderung spielt im narrativen Text eine große Rolle. Das ist für die Haltung des Rezipienten bedeutsam. Während der Leser des systematischen Textes entscheiden, bewerten, reflektieren soll, kann der des Erzähltextes einen Weg mitgehen, sich mit Figuren der Erzählung identifizieren und so Erfahrungen machen.

\section{ERZÄHLEN IN DER THEOLOGISCHEN UND RELIGIONSPÄDAGOGISCHEN DISKUSSION $^{5}$}

\subsection{ERZÄHLEN ALS SPRACHE DER NICHT-IDENTITÄT} (J.B. METZ UND K. BARTH)

Die Diskussion über die sogenannte "narrative Theologie", in der das Erzählen nicht nur in seinem Nutzen für die Praxis, sondern darüber hinaus als notwendige Redeweise der Theologie reflektiert wird,

\footnotetext{
4 Vgl. K. STIERLE, Geschichte als Exemplum - Exemplum als Geschichte. Zur Pragmatik und Poetik narrativer Texte, in: DERS., Text als Handlung, München 1975, 14-58; 21.

5 Im folgenden werde ich mich auf die Darstellung einiger weniger Positionen "narrativer Theologie" beschränken, die inzwischen zu "Klassikern" geworden sind und deren Argumente auch neueren Variationen und Ausdifferenzierungen des Themas zugrundeliegen. Eine Zusammenfassung der Positionen narrativer Theologie bietet: B. WACKER, Narrative Theologie, München 1977.
} 
haben in Deutschland der katholische Theologe Johann Baptist METZ und der Germanist Harald WEINRICH mit ihren 1973 erschienen Aufsätzen ausgelöst ${ }^{6}$.

Johann Baptist METZ will seine "Kleine Apologie des Erzählens" keinesfalls als "Ausdruck von theologischer Regression in ein vorkritisches Bewußtsein" verstanden wissen. Die Bemühung um Narrativität gehört vielmehr "in den Kontext einer gesellschaftlich bewußten kritischen Theologie"7. METZ sieht Theologie als kritisch emanzipatorische Theorie, die durch die "eschatologischen Verheißungen der Schrift wie Gerechtigkeit, Friede und Versöhnung ... immer wieder aufs neue in die gesellschaftliche Verantwortung und Bewährung (hineingerufen ist)" 8 .

Im Gegensatz zu einem blinden Fortschrittsglauben, der "über Leichen geht", hat die Theologie aber immer die Seite der Verlierer, der Übergangenen geltend zu machen: die Aspekte von Unterdrückung, Gewalt, aber auch Schuld, Endlichkeit und Tod. Sie tut das in Form der Erinnerung an vergangenes Leid, das kein Fortschritt ungeschehen machen kann; nur aus solcher Erinnerung kann Freiheit für alle erwachsen. Für Christen ist es in einmaliger Weise die Geschichte des Todes und der Auferstehung Jesu Christi, in der ihnen Erlösung verheißen ist. Daran zu glauben heißt, über Schuld und Negativität nicht hinweggehen zu müssen, sondern die "gefährliche Erinnerung" daran auszuhalten $^{9}$. METZ sieht das Defizit argumentativer Theologie darin, daß sie die Spannung zwischen verheißener Erlösung und immer noch erlebtem Leid logisch/begrifflich zudeckt oder spekulativ verschleiert und somit eine Identität vortäuscht, die noch aussteht. Die einzige Sprachform, die über Leiden nicht zynisch hinweggeht, sondern es als "gefährliche Erinnerung" angemessen zum Ausdruck bringt, ist die Erzählung.

"Eine Theologie des Heils, die weder die Heilsgeschichte konditioniert oder suspendiert noch die Nicht-Identität der Leidensgeschichte ignoriert bzw. dialektisch überfährt, kann nicht rein argumentativ, sie muß immer auch narrativ expliziert werden; sie ist in fundamentaler Weise memorativ-narrative Theologie"10.

So war denn auch das Christentum von Anfang an eine Erzählgemeinschaft, die die "gefährliche Erinnerung" an Jesus Christus nach-

\footnotetext{
6 J.B. METZ, Kleine Apologie des Erzählens, in: Concilium 9 (1973) 334-341; im selben Band erschien: H. WEINRICH, Narrative Theologie, 329-333.

7 J.B. METZ, Kirche und Volk - oder der Preis der Orthodoxie, StdZ 192 (1974) 797-811; 809.

8 B. WACKER [A.5] 17.

${ }^{9}$ Diese Gedankengänge sind ausgeführt in J.B. METZ, "Politische Theologie" in der Diskussion, in: H. PEUKERT (Hrsg.), Diskussion zur "politischen Theologie", Mainz-München 1969, 267-301 und DERS.: "Erlösung und Emanzipation", in: L. SCHEFFCZYK (Hrsg.), Erlösung und Emanzipation, Freiburg 1973, 120-140.

10 J.B. METZ [A.6] 339.
} 
und dabei immer auch neu erzählte. Als Autoren für "gefährliche" Geschichten jüngerer Zeit nennt METZ HEBEL, BRECHT, BLOCH und BUBER $^{11}$.

METZ will die argumentative Theologie dabei keinesfalls aufgeben 12; er erteilt ihr nur eine nachgeordnete Funktion, 2.B. eine apologetische und ideologiekritische. Dazu gehört bei ihm auch - anders als bei anderen "narrativen Theologen" - die Kritik an religiösen Symbolen, verstanden als Herrschaftskritik. Maßstab argumentierender Theologie bleibt jedoch die erzählende Erinnerung an das Leiden, den Tod und die Auferstehung Jesu Christi.

Von hier aus läßt sich eine Linie zurück zu der Theologie Karl BARTHs ziehen, der - lange vor "narrativen Trends" in der Theologie aus zwei Gründen für das Erzählen plädierte: Einmal entspreche die Erzählung in einzigartiger Weise dem Handlungs- und Begegnungscharakter der Offenbarung, die sich der Machbarkeit durch Menschen entziehe ${ }^{13}$. Zum anderen hält BARTH ein theologisches System für eine Entartung, weil es die "Gebrochenheit" alles theologischen Denkens verschleiere. Rede von Gott könne deshalb nicht vollständig und geschlossen sein, weil das Verhältnis zwischen Gott und den Menschen eben nicht heil sei. Was uns bleibe, sei schlicht das Bemühen, "alles recht zu erzählen"14.

Dieser Gedanke findet sich in jüngerer Zeit besonders auch bei Theologen, die an einer Theologie im christlich-jüdischen Dialog arbeiten. Auch hier wird programmatisch ein stärker fragender, suchender und eben auch erzählender (nach jüdischem Vorbild: haggadischer) Stil gepflegt $t^{15}$.

Die unbequeme Einsicht, daß das Erzählen uns nicht Gott näherbringt, sondern die Sprachform ist, die unserer Gottferne entspricht, wurde in vielen neueren Positionen nicht durchgehalten. METZ hat außerdem mit seinem Konzept der "gefährlichen Erinnerung" ein genuin biblisches Anliegen ins Gedächtnis zurückgerufen: Erzählen als Erinnerung, die Identität und Gemeinschaft stiftet und in der Spannung zwischen leidvoller Erfahrung und Verheißung steht.

Freilich wünscht sich vielleicht der Lehrer/die Lehrerin in der Praxis an manchen Stellen, METZ hätte seine bewußt fragmentarisch, in kurzen Aufsätzen dargelegten Überlegungen doch noch etwas weiter ausgeführt. So überzeugt es, auch im Anschluß an die Theorie DANTOs, $\mathrm{daß}$ er in der Erzählung wegen ihrer Unabgeschlossenheit und Offen-

\footnotetext{
11 J.B. METZ [A.6] 335.

12 J.B. METZ [A.9] 139.

13 K. BARTH, KD II,2, 206 und KD IV/1, 171.

$14 \mathrm{KD}$ III,3, 332ff.

15 Vgl. u.a. F.-W. MARQUARDT, "Rabbinische" und "dogmatische" Struktur theologischer Aussagen, in: M. STÖHR (Hrsg.) Jüdische Existenz und die Erneuerung der christlichen Theologie, München 1981, 163-181.
} 
heit die adäquate Form für Leidenserinnerung sieht. Nur: sie kann gerade wegen dieser strukturellen Eigenschaften auch das Gegenteil davon sein: Verschleierung, Ablenkung, Selbstzweck. Es bleibt eine ungelöste Aufgabe, Kriterien dafür zu gewinnen, wie man eine Geschichte "gefährlich" erzählt, obwohl das sicher schwieriger ist, als "schön" zu erzählen. METZ gibt zwar Hinweise auf moderne Erzähler von "gefährlichen Geschichten", aber BLOCH, BRECHT, BUBER und HEBEL haben eben keine Erinnerungen, sondern Kalendergeschichten, Parabeln und andere didaktische Kurzprosa geschrieben, die eher in den rhetorisch-argumentativen Bereich gehören und daher viel leicht pointiert, provokativ und gefährlich erzählt werden können. Die "gefährliche Erinnerung" bleibt demgegenüber die viel schwierigere Form, weil sie gern abgleitet in Erbaulichkeit, Unterhaltung oder allgemeine Lehrhaftigkeit. So erscheint METZ' Ansatz als eine wertvolle Aufgabenstellung für einen narrativen Unterricht, aber noch nicht als seine Lösung.

\subsection{DIE "NARRATIVE UNSCHULD" DER BIBEL (H.WEINRICH)}

Harald WEINRICHs Aufsatz "Narrative Theologie" erschien zusammen mit der "Kleinen Apologie" und wird seither in einem Atemzug mit ihr genannt. Während aber für METZ der - im Wortsinn - imperfekte Charakter der Erzählung sie als Sprachform für das Leiden in einer unerlösten Welt qualifiziert, stellt WEINRICH das Erzählen eher als die ursprünglichere und identischere Redeweise dar und fordert kategorisch ihre Vorrangstellung in der Theologie. Die Grundlage zu seinen Thesen legte Weinrich schon in seinem 1964 erstmals erschienenen Buch "Tempus. Besprochene und erzählte Welt", einem der klassischen Entwürfe der Erzähltheorie, der großen Einfluß auch im Bereich des Deutschunterrichts hat.

WEINRICH unterscheidet darin zwischen der "besprechenden" und der "erzählenden" Haltung. Erstere ist engagiert, fordernd, gespannt ("Paß auf, das geht dich unmittelbar an!"), letztere entspannt ("Du kannst jetzt etwas lässiger zuhören."). Die Situation des Erzählens ist an bestimmten sprachlichen Merkmalen, z.B. an den Zeitstufen der Vergangenheit, erkennbar. Weil hier Befreiung von unmittelbaren lebensweltlichen Zwängen geschehen kann, findet WEINRICH es wichtig, schon Kinder anhand von Märchen in die "erzählte Welt" einzuführen ${ }^{16}$. Von solchen Voraussetzungen her greift er nun in die theologische Diskussion ein. Er stellt fest, daß das Christentum von Anfang an eine Erzählgemeinschaft gewesen sei, denn die entscheidenden Texte im Alten und Neuen Testament seien Geschichten, die die Gemeinde weitererzählt habe. Das Kriterium für das rechte Weitererzählen sei nicht die historische Faktizität gewesen, sondern die Relevanz der Texte

${ }^{16}$ H. WEINRICH [A.2: Tempus ${ }^{2}$ 1971] $50 f$. 
für die Menschen. Weinrich wünscht sich darum auch heutige theologische Sprache als ein freies Neu- und Umerzählen biblischer Texte mit dem Ziel, Glauben zu wecken und Taten zu provozieren. Schließlich habe Jesus selbst "einen nicht geringen Teil seines öffentlichen Lebens damit zugebracht, Geschichten zu erzählen"17, gleichermaßen historische und fiktionale, in die Vergangenheit gerichtete oder Zukunft antizipierende.

Einen regelrechten "Sündenfall" in der Geschichte des Christentums sieht WEINRICH darin, daß durch die Begegnung mit der heidnisch-griechischen Welt ein Verlust der "narrative(n) Unschuld" des Redens von Gott eingetreten sei. Die biblischen Erzählungen seien "logisiert" worden, und es habe nun das "Räsonieren und Diskutieren, das Ergotieren und Theoretisieren"18 das erste Wort in der Theologie bekommen. In diesen Vorwurf bezieht Weinrich auch die moderne historisch-kritische Forschung ein. Zwar gibt er in "Tempus" zu, daß in altorientalischen Kulturen Erzählen und Besprechen noch nicht unverbunden nebeneinandergestanden hätten und daß die Weisheit damals noch "Blume und Frucht" des Erzählens gewesen sei ${ }^{19}$, doch auch hier gewährt er dem Erzählen deutlich den Vorrang.

Kritische Stimmen gegen WEINRICHs Unterscheidung wurden zunächst einmal in der Literaturwissenschaft selbst laut. So beanstandet K.H. STIERLE, daß WEINRICH von einer illusionären Einheit der Sprechsituation Erzählung als einer Art Urphänomen ausgehe, was den unterschiedlichen Erzählformen in keiner Weise gerecht werde ${ }^{20}$, besonders auch deshalb, weil er (bewußt!) keinen Unterschied zwischen fiktionalen Erzählungen und solchen mit praktischer Funktion mache. Die bessere Lösung wäre wohl eine Unterscheidung nach Erzählgattungen, von der noch die Rede sein wird.

Aus theologischer Sicht ist nachzufragen, was WEINRICH mit dem Verlust der narrativen "Unschuld" meint. Gibt es denn die richtige Rede von Gott, die Sprache der Identität und Unmittelbarkeit? Paulus, der Jude, sieht jedenfalls Juden und Griechen - und damit ja wohl auch ihre Sprache - als gleich "in Christus Jesus" (vgl. Gal 3,28; und er meint damit nicht als "unschuldig", sondern als "erlöste Sünder"). Entsprechend sind beider Sprachen in den Kanon aufgenommen worden.

Als Grund für den Primat des Erzählens nennt WEINRICH die Tatsache, daß Jesus selbst erzählt hat; doch scheint die tiefere Motivation in WEINRICHs Sicht vom Menschen zu liegen: Es wird deutlich, daß er das Erzählen für die unmittelbarere, ergreifendere, menschlichere Form der Mitteilung hält. Vorausgesetzt ist offensichtlich ein anthropologischer

17 H. WEINRICH [A.6] 329.

18 H. WEINRICH [A.6] 331.

${ }^{19}$ H. WEINRICH [A.2: Tempus $\left.{ }^{2} 1971\right] 137$.

20 K.H. STIERLE [A.4] 19. 
Dualismus (Gefühl gegen Logos, "Bauch" gegen "Kopf"), der nun allerdings hebräischem Denken nicht sehr nahesteht, wenn man denn die Fiktion "hebräisch" gegen "griechisch" überhaupt aufrechterhalten will:

"Die narrative - oder gar mythische Unschuld des Christentums (ist) doch wohl eher eine Legende. ... Die Spannung zwischen Christlich-Orientalischem und Hellenistisch-Abendländischem, zwischen Mythos und Logos, kann heute kaum mehr als völlige Polarität aufgefaßt werden"21.

Jedenfalls kennt das gepriesene "unsystematische" hebräische Denken - und hier ist es wirklich sehr unsystematisch! - nicht einmal einen Begriff für das Erzählen. Die Verben, die in Frage kommen, sind allesamt sehr vielschichtig, z.B.:

7. damit sind alle Schattierungen des Sprechens bezeichnet;

הִִּ heißt u.a.: erinnern an, gedenken, erwähnen, erzählen, preisen;

T⿱⺌⺝ heißt u.a.: anzeigen, Nachricht gegeben, erzählen, verkündigen, melden. offenbaren, Rätsel lösen ...

Auf der Ebene der Texte finden wir im Alten Testament auffällig oft argumentierendes und erzählendes Sprechen ineinander verschränkt:

- "Wenn dich dann künftig dein Sohn fragt: "Was sollen denn die Verordnungen, die Satzungen und Rechte, die euch Jahwe, unser Gott, geboten hat?«, so sollst du sagen: "Wir waren Sklaven des Pharao in Aggypten ...." (Dtn 6,20ff).

Der Sohn fragt also nach einer Erklärung und bekommt eine Erzählung zu hören.

- "Ich bin Jahwe, dein Gott, der ich dich aus dem Lande Ägypten, aus dem Sklavenhaus, herausgeführt habe. Du sollst (wirst) keine anderen Götter neben mir haben..." (Ex 20,2f.).

Hier wird von der Erzählung das Gesetz als zwingende, eigentlich, selbstverständliche Folge abgeleitet.

- "Ihr zwar gedachtet mir Böses zu tun, aber Gott hat es zum Guten gewendet." (Gen 50,20)

Die romanhafte, kunstvoll gestaltete Josefsgeschichte (Gen 37-50) wird immer wieder unterbrochen durch Sentenzen, die das Erzählte erklären, deuten und dabei der freien Phantasie Grenzen setzen.

In anderen Erzählungen haben oft Leitworte die Funktion theologischer Definition.

Diese Verschränkung von Erzählen und Besprechen setzt sich im Neuen Testament fort: Wir finden dort Evangelien und Briefe, Logien und Berichte, pointierte Streitgespräche und Gleichnisse, wobei letztere oft Teil einer Argumentation sind: Jesus hat nicht nur erzählt.

21 D. MIETH, Narrative Ethik, in: FZPhTh 22 (1975) 197-328; 301. 
Dabei erscheinen die unterschiedlichen sprachlichen Formen nicht im Nebeneinander und auch nicht einander untergeordnet, sondern sie erhellen und begrenzen sich gegenseitig. So hätte es z.B. schwerwiegende Folgen für die Theologie, wenn man aus der Verbindung Befreiungserzählung - Gesetz einen Teil ablösen wollte. Thematisiert wird die notwendige Vielfalt der Verkündigung in Psalm 78:

"Höre, mein Volk, mein Gesetz; neiget eure Ohren zu der Rede meines Mundes! Ich will meinen Mund auftun zu Sprüchen und alte Geschichten aussprechen, die wir gehört haben und wissen, und unsre Väter uns erzählet haben, daß wir's nicht verhalten sollten ihren Kindern, die hernach kommen, und verkündigten den Ruhm des Herrn und seine Macht und Wunder, die er getan hat."

Hier wird dargestellt, wie eine Generation der anderen, damit über Zeit und Raum Beziehungen stiftend, den Ruhm Jahwes weiterträgt. Um diesen Ruhm, um Gottes vorgängiges Handeln und Reden geht es, in bezug auf das jedes menschliche Sprechen nur sekundäre Antwort sein kann, weder erzählend noch besprechend jemals "richtig" und endgültig. Die Formen menschlicher Kommunikation werden in diesem kurzen Text - soviel zeigt auch schon Luthers Übersetzung - in nicht weniger als 13 Begriffen umschrieben. Was einem überzeugten "narrativen" Theologen, aber auch einem "Dogmatiker" als Redundanz erscheinen muß, bedeutet nichts Geringeres als die Polyphonie des Redens von Gott, wie sie den Menschen gemäß ist, die eben nicht mehr "mit einerlei Zunge und Sprache" (Gen 11,1) sprechen.

\subsection{SYMBOL UND MYTHOS - WEGE ZUR GANZHEITLICHKEIT (G. BAUDLER UND H. HALBFAS)}

Diejenige narrative Richtung, die sich am deutlichsten von der traditionellen und kritischen Hermeneutik abhebt, begründet Erzählen im Rahmen einer neuen Religiosität und Innerlichkeit ${ }^{22}$. In einer Radikalisierung des WEINRICHschen Ansatzes werden Betroffenheit sowie existentielle und religiöse Erfahrung durch das Erzählen erwartet, aber auch durch andere, die Fesseln der Rationalität sprengende Vermittlungsformen, z.B. Meditation oder Bildbetrachtung. Die Bibel hat in diesen Entwürfen eine sehr wichtige, aber keine normative Bedeutung. Auffallend häufig werden die Begriffe "Erzählung" und "Symbol" in

22 B. WACKER sieht das Entstehen "narrativer Theologie" im Zusammenhang mit dem Aufkommen der Alternativbewegung nach 1973/74. In einer Abkehr von der kapitalistisch-bürokratischen "Kolonialisierung der Lebenswelt" (HABERMAS) suche man wieder traditionelle Formen, primäre Möglichkeiten der Interaktion, Subjektivität, Innerlichkeit und Überschaubarkeit in allen Bereichen der Kunst und Wissenschaft (B. WACKER, Zehn Jahre "Narrative Theologie" - Versuch einer Bilanz, in: Erzählen für Kinder - Erzählen von Gott, hrsg. v. W. SANDERS und K. WEGENAST, Stuttgart-BerlinKöln-Mainz 1983, $17 f$. 
engem Zusammenhang, z.T. sogar bedeutungsgleich verwendet, wohl weil sie eine gewisse Strukturverwandtschaft aufweisen. Jedenfalls gilt das für Märchen und Mythos, mit denen in der Symboldidaktik vorrangig gearbeitet wird. So ist beiden, Erzählung und Symbol, eine gewisse Unschärfe und Bedeutungsvielfalt eigen. Beide überschreiten die engen Grenzen der Alltagssprache hin zu einer sehr aussagestarken Bildhaftigkeit und weisen damit über sich hinaus. Beide zielen auf ganzheitliche Erfahrung, auf Gefühl und Verstand (wobei aber tatsächlich von Vertretern der "Ganzheitlichkeit" meist vorrangig für das Gefühl plädiert wird!).

Aus der Fülle der Literatur sollen hier die Entwürfe der beiden katholischen Theologen Georg BAUDLER und Hubertus HALBFAS kurz erwähnt werden, weil beide in ganz unterschiedlicher Weise bedeutsam und beispielhaft für die religionspädagogische Diskussion geworden sind.

Für Georg BAUDLERS Konzept einer "symbolisch-erzählenden" Theologie ${ }^{23}$ gilt das zuvor Gesagte nur teilweise, denn er folgt ganz ausdrücklich J.B. METZ in der Überzeugung, Erzählen sei die der Leidensgeschichte adäquate Sprache. Die kommunikative Kraft der Erzählung liege außerdem darin, daß sie Leerstellen enthalte, die vom Leser erst zu besetzen seien, der sich auf diese Weise selbst in die Erzählung einbringen könne.

BAUDLER arbeitet die Gestaltung dieser Beziehung zwischen gegenwärtigem Rezipienten und christlicher Überlieferung in seiner "Korrelationsdidaktik" aus 24. Dabei hält er es für wichtig, den Bezug zwischen Lebenswirklichkeit und Glaubensüberlieferung nicht unmittelbar kurzzuschließen, sondern auf dem Weg über "repräsentative Symbole" herzustellen. Das heißt für den Religionsunterricht: Zunächst muß die konkrete Lebenswirklichkeit, die die Schüler einbringen, ihrer Vereinzelung und Zufälligkeit enthoben und zu einem "Lebenssymbol" verdichtet werden. Auf der anderen Seite ist der biblische Text daraufhin zu befragen, welches Glaubenssymbol in ihm entfaltet ist. Dieses Glaubenssymbol muß so ausgelegt werden, daß es auf das Fundament des Glaubens, die Geschichte von Kreuz und Auferstehung Jesu Christi, hinweist und es repräsentiert. Erst zwischen diesen Symbolen kann nun eine Korrelation hergestellt werden.

Dazu ein Beispiel: In seiner Jesuserzählung für Kinder wählt BAUDLER als repräsentatives Lebenssymbol für die kindliche Erfahrung

23 G. BAUDLER, Einführung in symbolisch-erzählende Theologie, Paderborn-MünchenWien-Zürich 1982.

24 G. BAUDLER [A.23] 49-68; Ich referiere hier im Sinne unserer Fragestellung BAUDLERs Ansatz nur in bezug auf biblische Texte. Er selbst geht auch sehr ausführlich auf kirchliche Symbole (Trinität, Sakramente, Mariologie etc.) ein. 
von Liebe und Vertrauen die Mutter. Darauf bezieht er die Gotteserfahrung Jesu, der Gott als die größere Mutter erlebt ${ }^{25}$.

BAUDLER betont, daß in einem öffentlichen Religionsunterricht, an dem auch nicht religiös oder christlich sozialisierte Schüler teilnehmen, unbedingt die unterschiedlichen Wirklichkeitsdeutungen gleichwertig und ungehindert zur Geltung kommen müssen ${ }^{26}$. Besonders seine Beispiele machen aber deutlich, daß es ihm dabei ein großes Anliegen ist, den Kindern die christlichen Symbole als die umfassenderen, tieferen, lebensmächtigeren $z u$ eröffnen ${ }^{27}$.

BAUDLERs Entwurf hält an der Vorläufigkeit und damit dem kritischen Potential der Erzählung fest. Mit Recht - und sehr realistisch - fordert er ein gleichberechtigtes Gespräch zwischen den unterschiedlichen Weltentwürfen. Es wäre allerdings zu fragen, ob dann nicht auch die Entscheidung für eine andere als die christliche Deutung möglich sein müßte, ob - und wie! - sich christliche Symbole wirklich evident als die tragfähigeren erweisen.

Die höhere Qualität christlicher Botschaft gegenüber anderen Weltentwürfen beschreibt BAUDLER gern in Kategorien der Überbietung und Vertiefung (die größere Mutter, der größere Vater, das "letzte Umgreifende", gegenüber dem andere Konzeptionen nur das "Vorletzte" sind) ${ }^{28}$. Demgegenüber tritt der Gedanke, daß die jüdisch-christliche Botschaft auch "quer" zu unseren Weltentwürfen stehen kann (ihr kritisches Potential mithin), ein wenig in den Hintergrund. Damit hat wohl auch die häufige Wiederkehr von Begriffen wie "Tiefe", "Fundament", "tragender Lebensgrund", "Mitte" bei BAUDLER zu tun, die eine große Affinität zur geschichtslosen Welt des Mythos haben.

Während jedoch diese Tendenz ausdrücklich nicht in BAUDLERs Absicht liegt, wird sie bei Hubertus HALBFAS zum Programm. Dieser hat sein symboldidaktisches Konzept in zahlreichen theoretischen und praktischen Entwürfen ausgearbeitet, von denen einige schon vor der "narrativen Wende" entstanden sind. Am grundsätzlichsten formuliert er sein Anliegen wohl in seinem 1982 erschienenen Buch "Das dritte Auge"29.

Den Ausgangspunkt seiner didaktischen Überlegungen bildet eine radikale Gesellschafts- und Kulturkritik. So beklagt er "die Entfremdung unserer Kultur mit ihrer in der Geschichte beispiellosen Egozentrik des christlich-europäischen Denkens, die Verwüstung unserer Erfahrung,

25 G. BAUDLER, Kindern heute GOTT erschließen. Theorie und Praxis einer Evangelisation durch Erzählen, Paderborn-München-Wien-Zürich 1986, 97f.

26 G. BAUDLER [A.23] $42 \mathrm{ff}$.

27 So sieht er in Gen $1 \mathrm{im}$ Gegensatz zu anderen orientalischen Mythen eine "grundsätzlich positive Lebensgrundstimmung" wirksam, für die er die Kinder aufschließen möchte; G. BAUDLER [A.26] 55f.

28 G. BAUDLER [A.26] 44.

${ }^{29}$ H. HALBFAS, Das dritte Auge. Religionsdidaktische Anstöße, Düsseldorf ${ }^{3} 1987$. 
das Zerstörerische unseres Verhaltens, das schließlich in Welt- und Selbstvernichtung enden mag"30. Diese Entfremdung habe auch vor dem Religionsunterricht nicht haltgemacht, der nicht mehr an Erfahrung, Verstehen und Spiritualität orientiert sei, sondern - sich der Hektik unserer Konsumgesellschaft anpassend - Probleme, Texte und Bilder nur verschleiße, ohne je zu ihrer Mitte zu gelangen ${ }^{31}$. Im Gegenzug dazu fordert HALBFAS vom Religionsunterricht eine Wiedergewinnung religiös-symbolischer Sprache, der "Sprache der Innenseite"32, denn "das Symbol ist die spezifische Ausdrucksgestalt religiöser Erfahrung, ohne deren Veständnis die Religionen in ihrer eigentlichen Mitte nicht erschlossen werden können" 33 . Er bestimmt das Symbol als archetypisch und zeitlos, zumindest seiner Struktur nach, denn die inhaltliche Füllung der Symbole sei eher geschichtlichem Wandel unterworfen. Auch räumt er die Notwendigkeit von Symbolkritik ein - etwa wenn ein Symbol zum Klischee erstarrt oder unlebendig geworden sei -, aber nicht im Religionsunterricht! Dieser solle vielmehr den Sinn für Symbolik - das "dritte Auge" - erst einmal wieder entdecken und entwickeln helfen. Dabei werde wahrscheinlich zunächst für die Lehrer selbst ein Lernprozeß nötig sein, bis sie sich auf eine Didaktik einlassen, "die durch das Nadelöhr führt, in eine Landschaft, die aller Menschen Heimat ist und dennoch den meisten fremd geworden" 34 .

In Entsprechung dazu fordert HALBFAS im Bereich des Erzählens eine "Rehabilitation der dem Symbol am meisten verwandten Form, des Mythos." Von ihm erwartet er Rettung vor dem Identitätsverlust in unserer verwissenschaftlichten, technisierten Wohlstandsgesellschaft und die "Zurückbindung an das, was die Welt im Innersten zusammenhält", an die alle menschlichen "Grenzen übergreifende, alles Begrenzte tragende Wirklichkeit" 35 .

Natürlich leben archetypische Symbole und Mythen nicht nur in christlicher Tradition, sondern in den Träumen und Phantasien aller Menschen, in den Kunstwerken, Märchen, Mythen und religiösen Überlieferungen aller Völker und Zeiten. Einen Einblick in diese farbige Vielfalt gibt uns HALBFAS in seinen bekannten Textsammlungen ${ }^{36}$.

${ }^{30} \mathrm{H}$. HALBFAS, Erfahrung und Sprache, Plädoyer für eine narrative Unterrichtskultur, in: H. HALBFAS u.a. (Hrsg.), Sprache, Umgang und Erziehung, Stuttgart 1975, 170-187; 176.

31 H. HALBFAS [A.29] 13-18.

32 H. HALBFAS [A.30] 180.

${ }^{33}$ H. HALBFAS [A.29] 15.

34 So das Motto auf der Titelseite des Buches "Das dritte Auge" [A.29].

35 H. HALBFAS [A.30] 177-183.

36 Vgl. H. HALBFAS, Das Menschenhaus, Stuttgart-Düsseldorf ${ }^{51976}$, Das Welthaus, Stuttgart-Düsseldorf 1983; H. HALBFAS hat inzwischen ein umfangreiches Unterrichtswerk vom 1. Schuljahr an vorgelegt (Patmos-Verlag), ferner geht er in "Wurzelwerk" (Patmos) auf "geschichtliche Dimensionen der Religionsdidaktik" ein; beides kann hier allerdings nicht berücksichtigt werden. 
Darin kommt zum Ausdruck, daß er im christlichen Glauben nur eine der möglichen Deutungen menschlicher Wirklichkeit sieht. Sie orientiert sich an der Existenzform Jesu aus der Perspektive des Glaubens der Gemeinde und läßt sich so zusammenfassen: "Gott ist Liebe und wird Mensch - will immer mehr Mensch werden!"37.

Es ist vielleicht deutlich geworden, welche Welten zwischen der Begründung des Erzählens etwa bei K. BARTH und der "Rehabilitierung des Mythos" bei H. HALBFAS liegen. Dieser gibt sicher eine treffende Analyse gegenwärtiger gesellschaftlicher und religionspädagogischer Defizite. Doch fällt es mir schwer, seinem Therapievorschlag zuzustimmen. Braucht es wirklich, um der großen Hektik und Oberflächlichkeit unserer Zeit, der "Sprachlosigkeit" vieler Jugendlicher entgegenzusteuern, mehr Mythen? Sind wir nicht - wenn wir unter Mythos nicht nur eine literarische Textsorte verstehen, sondern ein zeitlose Gültigkeit beanspruchendes Deutungsmuster von Wirklichkeit ("So ist die Welt ...") - mit einer Menge von Mythen konfrontiert: mit einem bunten Markt religiöser Angebote und darüber hinaus mit den in unserer Gesellschaft hochwirksamen Mythen von "Leistung" und "Wirtschaftswachstum", von "Schöner wohnen" und "Fitness", von "Jugend", "Männlichkeit" und "Weiblichkeit" u.v.a.?

Mögliche Gefahren von Symbol und Mythos lassen sich schon aus deren Struktur ableiten. Sie sind, wie oben erwähnt, offen, unscharf, vieldeutig, bildhaft und "selbstmächtig" 38 und (scheinen zumindest) der Zeitlichkeit enthoben. Das verleiht ihnen Einprägsamkeit und wirklichkeitsdeutende Kraft über Epochen und Erdteile hinweg, aber genau das macht sie auch zu willkommenen Werkzeugen jeder Ideologie. Hier ist nur an die inszenierte Religiosität des Dritten Reichs oder an die religiöse Symbolik der ehemaligen DDR zu erinnern ("Auferstanden aus Ruinen ...") oder - naheliegender - an den Umgang mit Symbolen in der Werbung. HALBFAS' Eingeständnis, Symbole könnten zu Klischees oder Zeichen absinken, wäre in diese Richtung zu verschärfen. M.E. sollten die SchülerInnen von Anfang an einen ideologiekritischen Umgang mit Symbolen und Mythen üben, sollten fragen lernen: Wer macht die Symbole? Wer gebraucht sie? Wer herrscht mit ihnen? Wer läßt sich durch sie beherrschen? Mit solchen Fragen aber werden Symbol und Mythos an die Geschichte zurückgebunden ${ }^{39}$.

Das ist ja wohl auch die Weise, wie die Bibel mit Symbolen umgeht: bei allem Reichtum an Bildern und Symbolen sind diese doch immer einem historischen Zusammenhang eingeordnet, ist ihnen ein kritischer Maßstab vor- und übergeordnet. So wird etwa im Alten Testament vom Glauben an den Jahwe des 1 . Gebots her das Symbol der gött-

37 H. HALBFAS, Das Menschenhaus [A.37] 232.

38 G. BAUDLER [A.26] 53 (im Anschluß an Paul TILLICH).

39 Ein Unterrichtskonzept, das Symboldidaktik mit Symbolkritik verbindet, verfolgt v.a. P. BIEHL. 
lichen Mutter samt den dazugehören Fruchtbarkeitsmythen strikt abgelehnt; gleichwohl kann Jahwe an anderer Stelle in anrührender Weise mit einer Mutter verglichen werden (Jes 66,13), weil klargestellt ist, daß der aus seinen Geschichtstaten bekannte Gott Israels gemeint ist.

So bereichernd der Umgang mit Symbolen und Mythen religionspädagogisch also sein kann, so wenig darf man doch erwarten, hier eine Lösung der bibeldidaktischen Probleme gefunden zu haben. Für mich kamen Anregungen aus zwei ganz anderen Richtungen: einmal aus den Anfängen der Formgeschichte, zum anderen aus der modernen Linguistik.

\section{DIE GATTUNGEN - SCHLÜSSEL ZUR WIRKLICHKEIT BIBLISCHER TEXTE}

\subsection{GATTUNGEN IN ALTTESTAMENTLICHER FORSCHUNG}

Es soll hier auf die eingangs formulierte Vermutung zurückgekommen werden, daß bei stärkerer Berücksichtigung der Exegese als Bezugswissenschaft ein differenzierteres Bild der Möglichkeiten biblischen Erzählens im Unterricht entstehen kann. Genaugenommen ist es der Begriff der biblischen Gattung, der hier weiterhelfen könnte.

Als erster hat zu Anfang unseres Jahrhunderts Hermann GUNKEL die Gattungsfrage als Frage nach Funktionstypen von Texten ins Zentrum alttestamentlicher Exegese gerückt. Sein Programm einer alttestamentlichen Literaturgeschichte, die er als Gattungsgeschichte konzipierte, suchte er v.a. in seinen bekannten Arbeiten über die Genesis, die Propheten und die Psalmen zu verwirklichen. Sein Ziel war es, über die herkömmlichen Methoden der Text- und Literarkritik, Grammatik und Archäologie hinaus Texte von ihrer Wirkung und damit von ihrer Form her zu erfassen. Von einer Gattung kann man nach Gunkel immer dort sprechen:

"wo wir zugleich gewahren: 1. einen bestimmten Schatz von Gedanken und Stimmungen 2. eine deutliche Formensprache, 3. einen Sitz im Leben, aus dem Inhalt und Form erst verstanden werden können"40.

Form ist demnach nichts "Äußerliches", sondern Ausdruck und Wirkungsbedingung des Inhalts. In Form und Inhalt wird soziale Wirklichkeit faßbar. Der Begriff "Sitz im Leben" steht dafür, daß innerhalb einer Gesellschaft Kommunikationssituationen, Institutionen und Rollen allemal vorgeprägt sind. Als "Gattungen" sind von daher diejenigen geprägten Formen zu bezeichnen, die aus einer typischen Kommunikationssituation hervorgehen und in denen Sprecher und Hörer feste

40 H. GUNKEL, Die israelitische Literatur, Darmstadt 1963, (Erstdruck Leipzig 1925), 57. 
Rollen innerhalb eines institutionellen Kontextes einnehmen. So ist Gattungstheorie letztlich Teil einer soziologischen Theorie ${ }^{41}$.

Leider ist dieser Ansatz, in dem über die Gattung der ganze Text erst erschlossen werden kann, in der wissenschaftlichen Exegese seitdem oft verflacht worden. Die Gattungsfrage wurde in die Einleitungswissenschaft verbannt und damit als Zusatz zur "eigentlichen" Exegese abgehandelt. Man ordnete auch immer mechanischer einer Gattung einen Sitz im Leben zu. In der Religionspädagogik hielt man es etwa für wichtig, daß 12jährige die Botschaft Jesu nach Gattungen sauber unterscheiden lernten (Parabel, Beispielgeschichte, Streitgespräch etc.) ${ }^{42}$. Daß es gerade die Gattungen sind, die von der unmittelbaren Lebendigkeit der Texte zeugen, nahm man oft nicht mehr wahr.

\subsection{GATTUNGEN ALS MUSTER TYPISCHER SPRECHHANDLUNGEN}

So kam die wirkungsvollste Verstärkung für GUNKEL nicht aus der Theologie, sondern aus der sprach- und literaturwissenschaftlichen Pragmatik jüngerer Zeit, vor allem aus der von AUSTIN begründeten und durch Dieter WUNDERLICH in Deutschland bekanntgemachten Sprechakt theorie.

Diese Theorie geht davon aus, daß das, was bei den sogenannten "performativen" Verben explizit geschieht (z.B. jemandem etwas "versprechen"), für jeden Text gilt: daß nämlich Sprechen Handeln ist, das sich in mehreren Dimensionen vollzieht:

1. Im lokutiven Akt werden Laute, Wörter und Sätze geäußert.

2. Im propositionalen Akt wird das Geäußerte auf Wirklichkeit bezogen.

3. Im illokutiven Akt handelt der Sprecher, geht er Beziehungen ein (z.B. fragen, auffordern, Vorwürfe machen usw.) Das kann explizit oder (häufiger) "zwischen den Zeilen" geschehen. Die Beschreibung dieses illkokutiven Akts ist die wichtigste Leistung der Sprechakktheorie; er wird auch als der eigentliche Sprechakt bezeichnet.

4. Der perlokutive Akt (besser: Effekt) bezeichnet die Wirkungen und Konsequenzen, die ein Text hat.

Wie anderes Handeln auch, folgt Sprechhandeln Regeln und Konventionen, die die Sprache, die aktuelle Situation und den institutionellen Kontext betreffen.

Das Zusammenspiel von Regeln, das einen Sprechakt ermöglicht, versucht S.J. SCHMIDT in seinem Modell des kommunikativen Handlungsspiels zu verdeutlichen ${ }^{43}$ :

41 K. KOCH, Was ist Formgeschichte?. Neukirchen ${ }^{3} 1974,34$.

42 Dieser Zugangsweg ist - m.E. glücklicherweise - im neuen, 1992 in Kraft getretetenen bayerischen Lehrplan aufgegeben worden.

43 S.J. SCHMIDT, Elemente einer Textpoetik, München 1974, 74. 


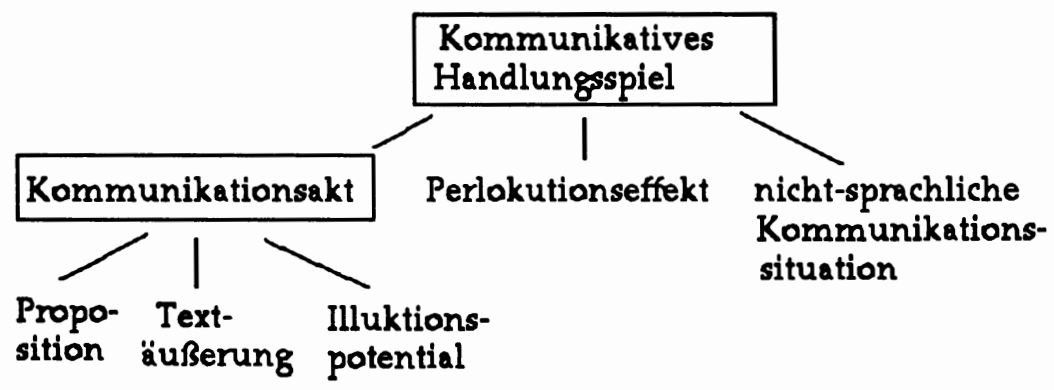

Trotz der für Theologen vielleicht ungewohnten Terminologie halte ich dieses Modell für wertvoll im Hinblick auf biblische Exegese, weil es den Textbegriff erweitert von dem, was "auf dem Papier steht", hin zu seinen außersprachlichen Bedingungen und Wirkungen, und weil es so die Notwendigkeit einer traditionsgeschichtlichen Bibelexegese offenlegt. Das, was herkömmlich als Text bezeichnet wird, ist hier nur die "Textäußerung". Sie ist lediglich ein Teil des Kommunikationsaktes. Dieser ist in ein Handlungsspiel eingebettet, das selbst wiederum einen Handlungstyp realisiert.

Gattungen sind in diesem Sinne als fixierte, typische kommunikative Handlungsspiele zu bezeichnen, erkennbar an typischen Formen, typischem kommunikativem Handeln und typischen Situationen (Sitz im Leben), alles gleichsam "eingefroren" und von uns zu erschließen. Dabei ist anzunehmen, daß die Geprägtheit eines Textes in der Antike noch weit größer war als heute. Dennoch hat es Konflikte zwischen einzelnen Regeln des kommunikativen Handlungsspiels gegeben (z.B. zwischen Einzelsituation und Normensystem). Das ist dann in Brechungen und Abwandlungen der Gattungen ersichtlich. Das Modell zeigt vielleicht auch - in leichter Korrektur zu GUNKEL -, daß ein Sitz im Leben nicht immer im historischen Rückschlußverfahren eindeutig zu bestimmen ist. Eine Gattung kann ja auch zitierend oder parodierend gebraucht sein, einen bestimmten Sitz im Leben nur thematisieren, ohne in ihm entstanden zu sein. Was wir aus einem Text erschließen können, ist immer nur sein impliziter Sitz im Leben.

Dieser Sprechakt- und Gattungstheorie wäre nun auch das Erzählen zu unterwerfen. Ist Erzählen ein Sprechakt, wie WEINRICH annimmt? Trotz vieler Strukturgleichheiten sicher nicht; das zeigt schon ein Blick auf die vielen unterschiedlichen möglichen Erzählsituationen. Hier ist nun André JOLLES' Unterscheidung der Einfachen Formen hilfreich. Auch dies ist eine "klassische" Position (1930), die dennoch in ihren Konsequenzen noch längst nicht ausgeschöpft worden ist. 


\section{3 "EINFACHE FORMEN" (A. JOLLES)}

André JOLLES bezeichnet als "Einfache Formen" solche, "die sich, sozusagen ohne Zutun eines Dichters, in der Sprache selbst ereignen"44, und greift damit die GRIMMsche Unterscheidung zwischen Natur- und Kunstpoesie wieder auf. Einfache Formen zeichnen sich durch eine besondere "Bündigkeit" aus und werden jeweils durch eine spezifische "Geistesbeschäftigung" hervorgebracht. Die Einfache Form ist dabei eine Art Schema, das die konkreten Formen hervorbringt, aber nicht mit ihnen identisch ist. Außer durch die jeweilige Geistesbeschäftigung ist jede Einfache Form noch durch einen bestimmten Gegenstand, ein Attribut, in dem sie sich verdichtet, charakterisiert. Es fällt auf, daß ein großer Teil dieser Formen narrative Texte hervorbringt, die JOLLES im Gegensatz zu WEINRICH sehr differenziert unterscheidet und auf verschiedene Geistesbeschäftigungen zurückführt ${ }^{45}$ :

\section{Einfache Form Geistesbeschäftigung}

1. Legende:

2. Sage:

3. Mythe:

4. Rätsel:

5. Spruch:

6. Kasus:

7. Memorabile:

8. Märchen:

9. Witz:

10. Fabel*:
Beschäftigung mit dem Heiligen, Imitatio $\rightarrow$ Befehl

Familie, Stamm, Blutsverwandtschaft $\rightarrow$ Aussage

Wissen und Wissenschaft als Wahrsage

$\rightarrow$ Frage und Antwort (Wissen wird erst errungen)

Wissen, Examen $\rightarrow$ Schweigen

(Wissen ist schon vorhanden)

Empirie, Erfahrung $\rightarrow$ Befehl

Welt wird als ein nach Normen Beurteilbares vorgestellt

$\rightarrow$ Frage, aber keine Antwort

\section{Das Tatsächliche $\rightarrow$ Aussage}

Die Welt, wie sie sein sollte $\rightarrow$ Wunsch

Entbindung eines unzulänglichen Gefüges, Lösung einer Spannung $\rightarrow$ Schweigen

Streben nach Einheit der Welt $\rightarrow$ Wunsch, Ruf

("von JOLLES geplant, aber nicht ausgeführt)

\section{Gegenstand}

Reliquie

Erbstück

Symbol

Rune

Emblem

Lohn

Dokument

verwandelte

Dinge

Karikatur

Maske

JOLLES' Ansatz wurde insofern durch die Sprechakttheorie überholt, als er von den Einfachen Formen immer wie von Urformen sprachlichen Verhaltens spricht. Diese ungeschichtliche Sichtweise wird heute durchweg kritisiert, denn

\footnotetext{
"erst die Lebenspraxis schafft Formen und daraus sich ergebende Konventionen. Auch bei den einfachen Formen handelt es sich um Konventionen, die im Laufe der Geschichte manifest (und typologisch greifbar) geworden sind, weil sie sich als praktikabel erwiesen und ihre Langzeitwirkung über diese Praktikabilität erreichten ..."46.
}

\footnotetext{
44 A. JOLLES, Einfache Formen, Tübingen 1974, Erstdruck 1930, 10.

45 Die nachstehende Zusammenfassung erfolgt nach K. KANZOG, Erzählstrategie, Heidelberg 1976, 33f.

46 K. KANZOG [A.45] 34.
} 
Was JOLLES' Konzept aber für eine traditionsgeschichtliche Bibelauslegung fruchtbar macht, ist sein Ansatz bei der "Geistesbeschäftigung". Er sieht nicht nur, daß - auch unter den Erzählungen - sehr verschiedene Formen möglich sind, sondern begründet diese Verschiedenheit aus verschiedenen Sprechsituationen, aus der Funktion der Texte.

Seine Überlegungen erhellen so manche Kontroverse innerhalb der Narrativik-Diskussion, die zweifellos daran krankt, daß alle vom "Erzählen" sprechen, aber nicht alle die gleiche Gattung meinen (METZ z.B. spricht im Grunde von Sagen, HALBFAS von Mythen, zwei Erzählgattungen mit völlig verschiedener Funktion).

\section{GATTUNGEN ALS DIDAKTISCHE VORGABEN IM BIBELUNTERRICHT}

\section{1 ÜBERLEGUNGEN ZU EINER HERMENEUTIK BIBLISCHER GATTUNGEN}

Aus den vorangegangenen Überlegungen ergibt sich für mich eine Konzeption des Bibelunterrichts, die sich zunächst noch ganz in den traditionellen Bahnen historischer Hermeneutik bewegt. Sie geht davon aus, daß man sich der Bibel als einem geschichtlichen Dokument, von dem uns Jahrtausende trennen, nähern kann, indem man unterschiedliche Verstehenshorizonte bewußtmacht, analysiert und miteinander vermittelt.

Was - nach christlichem Bekenntnis - die Bibel von anderen historischen Dokumenten unterscheidet, ist ihr "Vorsprung", der den "hermeneutischen Zirkel" gleichsam sprengt. Christen glauben, daß ihnen in der Bibel "Gottes Wort" begegnet. Biblische Hermeneutik ist darum kritische Hermeneutik, und zwar nach lutherischer Tradition in dem besonderen Sinne, daß die Bibel den Maßstab, an dem sich ihr Verstehen orientieren soll, in sich selbst trägt als das Evangelium von Jesus Christus. Mit diesem Kriterium entzieht Luther das Verständnis der Schrift unserer Verfügbarkeit, unseren "Interpretationstechniken".

M.E. ist es gerade für das unterrichtliche Gespräch mit Schülern sehr wichtig, das Bewußtsein dafür wachzuhalten, daß auch die Lehrer biblische Hermeneutik nicht "im Griff" haben. Das könnte etwa bedeuten, sich um einen eher fragenden, suchenden, "undogmatischen" Stil zu bemühen - eben aus diesem Grund bevorzugten ja K. BARTH und J.B. METZ die imperfekte Sprache des Erzählens. Aber es ist vielleicht schon deutlich geworden, daß dies eben nicht für alle Erzählungen gleichermaßen gilt, und vielleicht auch nicht nur für Erzählungen!

Ein Religionspädagoge, der mit dem "Vorsprung der Bibel" Ernst macht, ist Ingo BALDERMANN, der vorschlägt, man solle sich auch in Didaktik und Methode von der Bibel selbst leiten lassen, da diese auch "ihre didaktischen Möglichkeiten in sich selbst (trägt)"47. BALDERMANN

47 I. BALDERMANN, Biblische Didaktik, Hamburg ${ }^{3} 1966,26 f f$. 
sieht den Lehrer als einen Vermittler, der die Didaktik der biblischen Texte nur ungehindert zur Wirkung kommen lasse soll. Dazu brauche er lediglich der "sprachlichen Bewegung" eines Textes nachzuspüren, die sich in dessen "Form" verdichte.

Dieser etwas irrational anmutende und daher schwer vermittelbare Vorgang wird durchsichtiger und praktikabler, wenn man die angesprochene "Form" als "Gattung" definiert - mit all ihren zuvor beschriebenen Implikationen. Denn in der Gattung wird ja die Situation greifbar, in welcher der Text tatsächlich einmal kommuniziert wurde. So liegt es nahe, den Versuch zu machen, aus der damaligen Kommunikationssituation didaktische und methodische Anregungen für den Unterricht zu gewinnen. Das würde bedeuten, biblische Texte nicht zu "kürzen", sei es auf Symbole, sei es auf "Gehalte" ("Was hat der Text uns heute zu sagen?"), die dann jeweils zu unserer Gegenwart kurzgeschlossen werden, sondern das ganze kommunikative Handlungsspiel $\mathrm{zu}$ übersetzen, das in einem Text "eingefroren" ist und das wir über die Gattung versuchen können zu erschließen. Wie das aussehen kann, soll im folgenden an einem Beispiel gezeigt werden.

\subsection{DAVID UND GOLIAT IN DER 5. KLASSE - EIN VERSUCH}

\subsubsection{SCHRITTE DER ERSCHLIESSUNG}

An dieser - von SchülerInnen heißgeliebten - Geschichte läßt sich recht gut zeigen, wie eine solche "Übersetzung" aussehen könnte. Wichtiger als das "Ergebnis", die konkrete Unterrichtsstunde, die je nach Persönlichkeit, Überzeugung und Stil des/der Unterrichtenden ganz anders aussehen kann, sind die vorangehenden Erschließungsschritte, die sich auch auf andere Texte übertragen lassen:

\section{SCHRITT: KLÄRUNG DES VORVERSTÄNDNISSES:}

Die Geschichte gehört zu den bekanntesten der Bibel. Die Genugtuung darüber, daß der kleine David den übermächtigen Riesen besiegt, hat diese Gestalten zu Symbolen weit über kirchliche Grenzen hinaus werden lassen. In ähnlicher Weise wird auch im Religionsunterricht oft die Pointe der Erzählung darin gesehen, daß der kleine, schwache, wehrlose David im Kampf gegen den starken Feind Gottes Hilfe erfährt. Das erbaut, gibt Trost und Hoffnung, gerade für junge SchülerInnen, so wird oft argumentiert, die ja auch im Leben vielfach "Riesen" gegenüberstehen. (Die Kinder selbst bevorzugen übrigens oft die Deutung, daß der kleine David einfach cleverer ist als der plumpe Riese, und untergraben damit die angebliche "Moral" der Geschichte!) Unter dem Gesichtspunkt der Gattungen heißt das: "David und Goliat" ist als erbaulich-märchenhafte Geschichte mit zuweilen lehrhafter Tendenz bis in 
neueste Lehrbücher hinein geläufig. Diese Interpretation mag auch für Situationen hilfreich sein, in denen Trost und Stärkung nötig sind; wenn man sie aber als generelle Auslegunglinie betrachtet, provoziert sie (oft auch bei SchülerInnen) kritisches Nachfragen: "Was hat Goliat eigentlich verbrochen, außer daß er ein Riese ist?" möchten sie oft wissen. Ist das der Trost, den Gott für uns bereit hält, daß wir unsere Gegner niedermetzeln? Welches Interesse steckt hinter dieser Interpretation? Und wie geht es weiter, wenn das Märchen aufhört? Wie paßt es zur erbaulichen Pointe, daß David dann selber Machtträger, ein "Riese", wird?

\section{SCHRITT: HISTORISCHE KRITIK}

1 Sam 17 gehört zu dem Erzählkomplex von "Davids Aufstieg", der es insgesamt mit der Thematik der Legitimation des Königs zu tun hat. Die Exegese legt uns innerhalb der Geschichte von David und Goliat einen langen überlieferungsgeschichtlichen Proze $\beta$ frei ${ }^{48}$ : Es liegen Elemente einer (wohl in Hofkreisen propagierten) Heldensage zugrunde (das sind nicht zufällig die Motive, die die Schüler so lieben: die Stärke, Klugheit und Geschicklichkeit Davids schon in jungem Alter), die der Verherrlichung des Königs dienen würden, wenn sie nicht aus prophetischer Perspektive im Sinne der Konzeption des "Jahwekrieges" so überarbeitet worden wären, daß alle Stärke und Geschicklichkeit kompromißlos auf Jahwe zurückgeführt werden (vgl. 17,36ff; 17,45ff). Viel später schließlich (nach der Abfassung von LXX) wird der Text einer märchenhaft anmutenden, wohl weisheitlichen Überarbeitung unterzogen (v.a. V.12-31), die die Spannungen glättet und deren Konzept wohl am ehesten der oben dargestellten "erbaulichen" Absicht entspricht. Das Hauptthema bleibt aber die Macht des Königs. 1 Sam 17 macht also eine Konfliktsituation lebendig, in der die "Hauptrollen" vom König, seinen Höflingen (die "Heldensagen" über ihn erzählen) und kritischen Beobachtern (prophetische Kreise) gespielt werden (unerwähnt, aber gleichwohl wichtig: die Untertanen).

\section{SCHRITT: THEOLOGISCHE KRITIK}

Ich halte es für ein Mißverständnis, daß die von der historischen Exegese erschlossene "ursprüngliche Bedeutung" eines Textes immer die "richtige" sein soll (wenn sie natürlich auch eine kritische Funktion ausüben sollte). Gerade bei Texten mit jahrhundertelanger Überlieferungsgeschichte erübrigt sich ohnehin der Versuch, "Lösungen" durch historische Rückfrage zu gewinnen. Welche Fassung gilt? In Wahrheit finden wir in der Bibel Gesprächsprozesse, die durch die exegetischen

48 Vgl. dazu R. BARTELMUS, Heroentum in Israel und seiner Umwelt, AThANT 65, Zürich 1979, 31-77 (zur Gattung) und 128-140 (speziell zu 1 Sam 17). 
Methoden erschlossen werden können: spannende Auseinandersetzungen, immer neue Korrekturen, Erweiterungen und Neuinterpretationen kommen dabei ans Licht. Besonders komplexe Überlieferungsprozesse können ein Indikator dafür sein, daß hier besonders brennende Fragen auf dem Spiel stehen, Fragen, die vielleicht immer noch offen sind - offenbleiben müssen?

Dennoch wird der/die Unterrichtende innerhalb solcher Traditionsprozesse Schwerpunkte setzen, und solche Entscheidungen sollten pädagogisch und theologisch begründet sein. Eine pädagogische Entscheidung liegt etwa vor, wenn aus seelsorgerlichen Gründen 1 Sam 17 als märchenhafter "Trost für Schwache" erzählt wird. Theologisch und pädagogisch einleuchtend ist m.E. die Hervorhebung der Auseinandersetzung zwischen König und Prophet und der Thematik der Legitimation und Begrenzung der Königsmacht, also der Gattung der Heldensage samt ihrer prophetischen Kritik. Hier wird ein zentrales Anliegen biblischer Theologie berührt - die Bewährung des 1. Gebots angesichts der Gefährdung durch menschliche Herrschaftsansprüche -, und damit stellt sich zugleich die Frage, wie es um die Macht Gottes bestellt ist. Beide Aspekte, der Umgang mit "Menschenmacht" und die Frage nach der Spürbarkeit von Gottes Handeln in der Welt sind für 10-11jährige von elementarer Wichtigkeit.

\section{SCHRITT: ÜBERSETZUNG}

Das Schlichteste wäre, die SchülerInnen über die Gattung eines biblischen Textes einfach zu informieren, sie ihre Kennzeichen lernen zu lassen - eine im Blick auf das Verständnis von Kommunikationssituationen zweifelhafte Methode.

Eine andere Möglichkeit ist die Kontexterzählung, in der man die Situation, in der ein Text entstanden ist, gut anschaulich machen kann. Aber auch hier bleibt eine gewisse distanzierende, historisierende Tendenz: man spricht über die Gattung 49 .

Am unmittelbarsen und elementarsten kann der Schüler eine Gattung nachvollziehen, wenn ihm eine entsprechende Kommunikationssituation aus seiner Lebenswelt zur Übersetzung angeboten wird. Je aktueller und greifbarer eine solche Situation ist, desto besser.

Für die Heldensage, die die Basis der David-und-Goliat-Tradition bildet, habe ich mit dem Wahlkampf bewußt eine politische, aber dennoch auch Kindern vertraute Situation gewählt; denn die übliche privat-individualistische Engführung der David-und Goliat-Deutung verstellt die Sicht für die Dimensionen der Macht, die in diesem Text zur Sprache kommen.

49 Selbst die ungemein anregenden und spannenden Kontexterzählungen von W. HOLLENWEGER bleiben in gewisser Weise historisch-distanziert und eignen sich deshalb eher für ältere SchülerInnen und Erwachsene. 
Ein ganz wichtiger Aspekt der "Übersetzung" besteht darin, daß solche Vermittlung zwischen alttestamentlicher und gegenwärtiger Situation selbst wiederum in einer Kommunikationssituation, der des schulischen Religionsunterichts, geschieht. Wo immer es sinnvoll ist, sollte man diese in die "Übersetzung" miteinbeziehen, hier z.B. als einen Ort, an dem ebenfalls Machtkämpfe ausgetragen werden. Wenn das ein aktuelles Problem für die Klasse ist, würde ich es im Unterricht ganz in den Vordergrund stellen.

\section{SCHRITT: DIE BESETZUNG DER ROLLEN}

Wenn im Religionsuntericht ganze biblische Situationen übersetzt werden, so werden damit zugleich unterschiedliche Rollen zur Disposition gestellt. Welche Erfahrungen Schüler mit einem Text machen, hängt auch davon $a b$, mit welchen Rollen sie sich identifizieren. Wenn sie im Religionsunterricht den Freiraum bekommen, verschiedene Rollen des Textes auszuprobieren, kann ihnen das helfen, auch ihr eigenes Rollenverhalten $\mathrm{zu}$ durchschauen und eventuell neue Rollen zu entwerfen.

In unserem Beispiel identifizieren sich die Schüler zunächst mit denen, die Wahlkampfplakate sehen, mit denen also, die die Macht "zu spüren" bekommen. Danach übernehmen die Schüler die Rolle derer, die Wahlkampfgeschichten/Heldensagen machen; aus dieser Perspektive lernen sie, Techniken der Beeinflussung zu erkennen. Schließlich bleibt es ihnen in einem Gespräch über die Situation in der eigenen Klasse selbst überlassen, ihre Rolle zu bestimmen: Herrscher oder Beherrschte? Angeboten wird ihnen die Rolle des (kritischen) "Propheten".

\section{SCHRITT: WAHL DER METHODE}

Es wurde oben schon beschrieben, daß vor allem die Erzählung durch ihre Leerstellen dazu anregt, in den Text "einzusteigen" und sich mit den Rollen, die er anbietet, zu identifizieren. Der Autor/Erzähler wird durch Sympathielenkung zwar solche Identifikation zu steuern versuchen, doch letztlich bleibt sie nicht überprüfbar, und es wird in der Regel ein Gespräch darüber folgen müssen.

Eine vergleichsweise offenere und durchsichtigeres Methode, die überall naheliegt, wo Rollenverhalten durchschaut und Kommunikationsvorgänge verstanden werden sollen, ist das Spiel. Das muß keine abgeschlossene Szene sein, sondern kann auch darin bestehen, daß die Schüler Teile von Kommunikationssituationen nachvollziehen, so wie sie in diesem Beispiel die Aufgabe des Geschichtenerzählers übernehmen. 
Untergeordnet unter ein solches Rollenspiel im weitesten Sinn kann nun die ganze Bandbreite bekannter Methoden zur Anwendung kommen: Lehrervortrag, Unterrichtsgespräch und Textarbeit; Einzel-, Partner- und Gruppenarbeit; Singen, Malen, Dichten, Spielen; Schreiben, Hören, Sehen ... Wichtig ist nur, daß die Methoden von didaktischen Überlegungen, d.h. in diesem Zusammenhang von der zu übersetzenden Gattung abgeleitet sind. So wird man Methoden, die stärker die Phantasie anregen, vielleicht eher bei biblischen Texten anwenden, die selbst narrativ oder bildhaft gestaltet sind, während man Gesetze, wie überhaupt systematische Texte aller Art eher bespricht, analysiert, umformuliert, erklärt. Natürlich gibt es auch die Möglichkeit, es genau umgekehrt zu machen und die Gattung zu verfremden; diese Möglichkeit empfiehlt sich bei älteren Schülern, vor allem auch bei sehr bekannten Texten.

\subsubsection{UNTERRICHTSSKIZZE50:}

\section{WER SOLL REGIEREN? WAHLKAMPFGESCHICHTEN}

\section{Stunde:}

1. Der Lehrer/die Lehrerin bringt ein (möglichst aktuelles) Wahlkampfplakat mit; seine Gestaltung und sein Zweck werden kurz besprochen.

2. Überleitung und Aufgabenstellung durch den Lehrer/die Lehrerin: Anstatt (möglichst vorteilhafte) Bilder von einem Kandidaten im Wahlkampf aufzuhängen, könnte man auch Geschichten über ihn erzählen, die die Leute davon überzeugen, daß diese/r Kandidat/in der/die richtige Herrscher/in ist (so wie man es früher machen mußte, als es noch keine Plakate gab).

Jeder Schüler/jede Schülerin versetzt sich jetzt in die Rolle des Wahlkampfberaters und erfindet eine Wahlkampfgeschichte, die den/die betreffenden Kandidaten/-in möglichst gut darstellt.

3. Die Geschichten werden aufgeschrieben, vorgetragen und ausgewertet.

- Was hat der Kandidat/die Kandidatin getan?

- Auf welche Eigenschaften lassen diese Taten schließen?

- Das Ergebnis: Er/sie ist der/die größte, er/sie muß regieren.

4. Schriftlich festgehalten wird die linke Hälfte des Hefteintrags (s.u.); die rechte wird dann in der nächsten Stunde anhand der David-und-Goliatgeschichte ausgefüllt.

5. Spielwahl: Wen würden wir wählen? Warum? Abstimmen!

50 Das ist wörtlich zu nehmen: ich halte an diesem Ort wirklich nur eine "Skizze" zur Verdeutlichung des vorher Ausgeführten für sinnvoll, keinen ausgeführten Unterrichtsentwurf. 


\section{Stunde}

1. Vorstellung der Person König Davids, z.B. durch ein Bild (CHAGALL) oder durch ein Lied, z.B. das bekannte jüdische Volkslied "David melech Jisrael"51.

\section{2. Überleitung (Lehrererzählung, ungefähr so):}

"David ist für viele der wichtigste König Israels gewesen. Die jüdischen Kinder denken noch heute an ihn, wenn sie dies Lied singen. Aber als er König geworden war, fragten vielleicht auch manche: "Warum gerade er? Wäre nicht ein anderer besser gewesen? Wir kennen ihn doch gar nicht!" Nun gab es auch an Davids Hof Leute, deren Aufgabe es war, das Volk davon zu überzeugen, daß er der richtige Herrscher war. Plakate gab es natürlich damals noch nicht, aber Geschichten, ähnlich wie die, die ihr beim letzten Mal erfunden habt. Die Wahlkampfberater des Königs erzählten den Leuten folgende Geschichte:"

3. Der Lehrer/die Lehrerin erzählt nun die Geschichte von "David und Goliat" von 1 Sam 17,1 bis 1.Sam 17,37a ohne jede Erwähnung Gottes. Mit "und Saul sagte" bricht er/ sie $\mathrm{ab}$ und fordert die SchülerInnen auf, die Geschichte zu Ende zu erzählen.

4. Die SchülerInnen erzählen die Geschichte zu Ende, und sie tun das mit großer Sicherheit (auch wenn sie die Geschichte schon kennen), nach dem Muster der Heldensage, betonen also die Geschicklichkeit, Hilfsbereitschaft, Tüchtigkeit Davids.

5. Entsprechend den in der vorigen Stunde erzielten Ergebnissen werden Davids Taten und Eigenschaften in die rechte Spalte des Hefteintrags geschrieben.

6. Nun wird der biblische Schluß gelesen und der Unterschied festgestellt: in der Geschichte wird ganz besonders betont, daß Gott es war, mit dessen Hilfe David den Riesen nur überwinden konnte. Schränkt das den Ruhm Davids ein? Wie könnten die Leute damals darauf reagiert haben? Die SchülerInnen sollen verstehen, daß gerade ein König, der zwar Israel vor seinen Feinden rettet, sich aber dennoch nicht als (quasi-göttlichen) Helden sieht, sondern der seine Macht Gott unterordnet, für Israel vertrauenswürdig war. (Es sollte in den vorangegangenen Stunden schon über den Streit ums Königtum gesprochen worden sein). Vervollständigung des Hefteintrags: "Gott ist mit ihm! Er ist ein guter König für Israel".

7. Ein abschließendes kritisches Gespräch ist nötig:

a) Wo gibt es bei uns solche "großartigen Menschen" wie in den Wahlkampfgeschichten? (Stars, Anführer in der Klasse, Sportler ...)? Verehren wir sie? Möchten wir selbst so sein? Wie sieht das in unserer Klasse aus? Falls es einen "Star" gibt - wie geht es ihm selbst, wie den anderen damit?

b) Was ändert sich, wenn man bekennt: "Gott hat meinen Erfolg verursacht, nicht ich?" Hat man immer Erfolg, wenn Gott "mit einem" ist? Besiegt man dann die anderen? Vielleicht genügt ein Hinweis auf das Kreuz (das ja in vielen Klassenzimmern hängt), um daran zu erinnern, daß es in jüdisch-christlicher Tradition auch eine ganz andere Erfahrung des "Gott mit uns" gibt.

So etwa könnte (je nach Gesprächsverlauf) der Hefteintrag aussehen:

51 Zu finden u.a. bei G. ZIEGLER (Hrsg.) Shirú l'Adonai, Hänssler-Verlag, NeuhausenStuttgart, 7303. 


\section{Wer soll regieren? \\ Wahlkampfgeschichten}
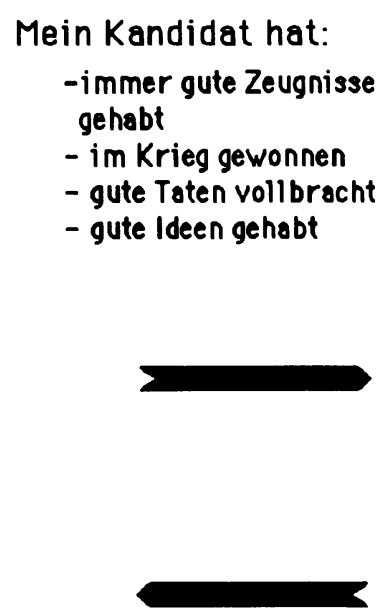

Er ist der Grösste!

Er muss regieren!
David hat:

- sich getrout, mit einem Riesen zU kämpfen

- inn mit der Hirtenschleuder besiegt

- Isroel vor den Philstern gerettet

ER IST

klug
mutig
geschickt
hilis bereit

Gott ist mit inm!

Er ist ein guter König für Israel 


\title{
THE BAAL (AND THE ASHERAH) IN SEVENTH-CENTURY JUDAH:
}

YHWH'S RETAINERS RETIRED

\author{
von \\ Baruch Halpern \\ Pennsylvania State University
}

Our canonical documents, particularly the books of the Former and the Latter Prophets, level an extensive polemic against Israelite devotion to "Baal" (bacal), or "the baal" (hab-bacal) or "the baals" (hab-bəa alm), among other gods imagined to be subordinate or even alien to the state god, Yhwh - the Host of Heaven, the Asherah/Asherim, the Ashtoret/ Ashtarot, the Queen of Heaven, to name a few. Modern scholars, for the most part, have taken the Biblical testimony at its word. They thus understand the cults of such gods as imports either from the nations Israel had defeated in Canaan (as Judg 1:1-3:5) or from the nations "around" Israel $^{1}$ : astral worship (the Host of Heaven, the Queen of Heaven), for example, is sometimes ascribed to Assyrian influence ${ }^{2}$; in origin, the gods were those of foreigners.

Yet this perspective, whatever its merits or defects, certainly cannot reflect the subjective experience of the Israelites who performed oblations to the "baals". Israel's public culture was given to fits of nativism: Jeroboam I's secession, for example, must have represented a reaction in part against the centralization of the state cult in Jerusalem under Solomon; Jeroboam thus consciously built his state shrines, at Dan and Bethel, not in the back yard of his palace at Tirzah, but distant from it. The notion of a separation of the cult from the kingship under Jeroboam and his successors reflects a popular concern about the usurpation of the national cult by the state. Interestingly, another nativist movement, that of Jehu ben-Nimshi, reacted against ostensibly foreign cults at a time when another temple had been erected in the Israelite capital: presumably, Ahab had adopted the Solomonic course. Even the programme implemented by Josiah to eradicate worship of the Host of Heaven and the baals clothed itself in the rhetoric of nativism - Josiah's history of Israel, the Deuteronomistic History, identifies the high places and the baals as remnants of the Canaanites whom Joshua had conquered ${ }^{3}$.

Such an appeal to "authentic" Israelite praxis in the past betrays a concern for identity: what is "authentic" is good, what is "foreign" is

\footnotetext{
1 As SPIECKERMANN 1982: 201-211.

2 See STÄHELIN 1843: 85-86; SPIECKERMANN 1982: 215-225; LEMAIRE 1986: 228; contrast KAUFMANN 1956: 3/2: 389- 90.

3 HALPERN 1988: 220-228.
} 
bad. To say, under the circumstances, that Israelite worshippers of "the baals" experienced those gods as foreign is to mistake the polemic against the baals for portrayal rather than caricature. It is at the same time to misunderstand how the polemic works: the baals are inappropriate objects of devotion - despite what their worshippers think because they are foreign. But if the worshippers already understood the baals to be foreign, this polemic can have had no persuasive effect. It is only by tracing the baals to foreign sources - to the Amorites and to Jezebel - in the remote, and forgotten, past that the polemicist can hope to show quondam adherents of the baals that they have been misguided. In other words, the votary of the baals and other gods must have understood those gods to be ancestral, those of his father, "authentic" Israelite deities.

This is indeed the understanding expressed in the only Biblical text in which the alleged apostates actually speak up for themselves. Jeremiah 44, an exilic text, preserves at least a reasonable version of their defense. It does so in the interest of attacking that defense, but the apostates' logic seems unimpeachable. Probably, the record of the episode survived only because it established a plausible rationale for why the Restoration community should come from Mesopotamia - it denied the possibility of a return from exile in Egypt.

In Egypt, Jeremiah announces that Yhwh had exiled Judah because of its worship of "other gods whom they didn't know - they, you and your fathers" (44:3)4. Continuation of these practices in Egypt precludes a restoration to Judah from the Judaean settlements there (44:7-14). Astonishingly, at this point the objects of Jeremiah's harangue are quoted:

There answered Jeremiah all the men who knew that their wives were burning incense to other gods, and all the women who were standing in (hd$8 m^{\circ}$ dot, LXX om.) a large congregation, and all the people who dwelt in the land of Egypt, in Patros, saying: "As to the word which you have spoken to us in the name of Yhwh, we will not listen to you. For we will do everything that came forth from our (LXX: your) mouth, burning incense to the Queen of the Heavens, and pouring libations to her, just as we have done, we and our fathers, our kings and our officials, in the towns of Judah and in the streets of Jerusalem, and we were sated with bread, and we were good, and evil we did not see. It was when we desisted from burning incense to the Queen of the Heavens, and from pouring out libations to her ( $L X X$ om.), that we lacked everything, and perished by the sword and by famine (Jer 44:15-18).

Jeremiah disputes this perfectly sensible interpretation of the Josianic reform and its aftermath - insisting that it was the cultic activity of the Judaean fugitives and their ancestors, their kings and their offi-

\footnotetext{
4 The last phrase of which has accrued from Dtn 13:3,7 and parallels in Deuteronomy: see DION 1991: 151, 182 \#38.
} 
cials, that had led Yhwh to devastate Judah. He prophesies the decimation of the Judaeans in Egypt, ostensibly by the Babylonians (44:20-30).

The critical aspect of this account is Jeremiah's admission (v 21) that the cult of "other gods" was indeed the ancestral and state practice that the Judaeans represent it as having been. Villagers are notoriously conservative, the more so in the realm of religion - and one of Mohammed's regular complaints was that the villagers preferred "to follow the way of our ancestors" rather than listen to his revelations from the heavens (Quran Sura 2.165; 43.20-23). The state, too (before Josiah), conducted such a cult - kings and officials $(44: 17,21)$, a phrase that does not stipulate Manasseh, or even Manasseh and Amon, as the only guilty parties. It is thus no coincidence that the Deuteronomistic History, and in particular Kings (1 Kgs 11:1-10; Judg 1:1-3:5), is careful to trace the introduction of such practices well beyond the bounds of living memory, and even beyond those of normal family tradition. For the Judahites of the late 7th and early 6th century, worship of these "other gods", including the Queen of Heaven, was indeed traditional practice, part of the folk- and traditional state religion of Judah.

Given these circumstances, the worship of the baals, principally attacked in the Josianic and post-Josianic era in such texts as Jeremiah (as 8:2; 19:13), Zephaniah (1:5) and the Deuteronomistic History (Dtn 4:19; $17: 3$ ), was probably equally traditional ${ }^{5}$. In the same period, the worship of the Host of Heaven came under attack, probably for the first time $e^{6}$ the first negative reference to the Host in Kings comes at $2 \mathrm{Kgs} \mathrm{17:16} \mathrm{in}$ connection with Israel, and in $2 \mathrm{Kgs} 21: 3,5$ in connection with Judah ${ }^{7}$. It is only in literature concentrated after the reign of Hezekiah, thus, that the Host seem to come under attack ${ }^{8}$.

\footnotetext{
5 Typically, Dtn 4 is dated quite late, but on the basis of a kulturgeschichtliche typology that is itself built on a literary assumption - mainly, that the language of the chapter is coordinate with or later than that of the exilic editors of DtrH (E[Dtr]x in the terminology of HALPERN 1988). Contrast FREEDMAN 1981: 16-22, excising only Dtn 4:25-32. Even these verses are consistent with the overall trajectory of Deuteronomistic thought in the period of the Josianic reform, such that if the language is exilic, the thinking is not. On the date of Dtn 17:3, note DION 1991, with the implication that the segment may well be part of the Josianic edition of Deuteronomy.

6 HALPERN and VANDERHOOFT 1992.

7 LEMAIRE 1986: 228.

8 This is of course the reason for assuming the astral cult was Assyrian. Thus, STÄHELIN 1843: 85-86 cites MOVERS as having analyzed the Host as an Assyrian import on the basis that it was first mentioned in Manasseh's regnal account as a problem. He asked whether the town name, Beth Shemesh, indicated earlier cultic activity and noted that human sacrifice (Molech) is first mentioned in connection with Ahaz and might therefore be an innovation of his time. STÄHELIN, operating without the data available today and in the framework of thought of his teacher, DE WETTE, adduced Ex 20:4 and Am 5:26 as contrary currents. In fact, Ex 20:4 is certainly Priestly and late, and Am 5:26 indicates nothing at all about concern with the astral cult in Judah, or under Assyrian influence. Note OLYAN 1988b.
} 
The coincidence of polemic against the baals in the 7th-century prophets and the Deuteronomistic History with polemic against the Host in the same prophets and the same history raises the question whether the two were substantially related. It has been the tendency among biblicists to assume that the term, Baal (bacal), referred to Haddu, the figure addressed as Baal in the Ugaritic mythological, liturgical and ritual texts ${ }^{9}$, to Melqart, or to Baal Shamem ${ }^{10}$. The confrontation between Yhwh and the baal - certainly an individual god held in opposition to Yhwh in 1 Kings 18:21,25-2711 - in the Elijah-Elisha cycle has conditioned this assumption. The phraseology "If the baal is the god, go after him" (18:21), and "for he is a god" (18:27) leaves no doubt that a single deity is under scrutiny (so, too, Judg 6:31). Yet the seventh-century polemicists regularly refer to baals, not just to a single Baal, and this is even true of Hosea, the lone literary prophet to complain about devotion to the baals in the 8th century. It is thus possible that the polemic against the baals in the seventh century is connected with the new assault on the cult of the Host. Indeed, it may be that the baals are partly identical with the Host of Heaven, who are represented, of course, by the stars.

For assessing the identity of the baals in 8th-7th century literature, it is important first to understand the morphosyntactical properties of the word, ba $\varsigma_{a l}$, itself. When basal in HB refers to immortals, it is without exception a determined noun. Where it occurs in the absolute state without a proclitic, it is always preceded by the definite article. Massoretic pointing carries this pattern through by vocalizing all cases where baal appears with a proclitic as determined. This pattern also characterizes occurrences in the plural. One might propose repointing in one or another case, but the ubiquity of the definite article where the orthography leaves it susceptible to observation contraindicates such a hypothesisi2.

The same pattern holds, as well, for the term, seserd, "Asherah", when this denotes a goddess, an object of devotion ${ }^{13}$. It does not hold, however, where the asherah is, or the asherim/ot are, objects dedicated to a goddess - and thus the object of a verb such as "build", "cut down"

\footnotetext{
${ }^{9}$ As SMITH 1990: 41- 64.

10 B. MAZAR 1986: 79-81; EISSFELDT 1962: 1-12.

11 But baals in 18:18, where the Lucianic recension corrects back to the singular.

12 So it is not significant - against SMITH 1990: 43 - that the object of worship in 1 Kgs $18: 19,22,25,26,40$ is called "the baal." Rather, "the" baal merely reflects the status of the lexeme in Hebrew usage, as "the" king does.

13 Singular in $1 \mathrm{Kgs} \mathrm{15:13//2} \mathrm{Chr} \mathrm{15:16} \mathrm{(Asa's} \mathrm{mother} \mathrm{made} \mathrm{a} \mathrm{mipleset} \mathrm{for} \mathrm{the} \mathrm{asherah);} 1$ Kgs 18:19 (O-LXX renders plural, then adds a singular in 18:22 - prophets of the asherah); $2 \mathrm{Kgs} 21: 7$ (the graven image of the asherah); 23:4 (the implements dedicated to the baal, and to the asherah, and to all the host of the heavens), 7 (where women wove 'houses' for the asherah); plural only in Judg 3:7, esterot (they did service to the baals and the asherahs).
} 
or "remove", or classified together with "stelae", "high places" or the like14. Not altogether dissimilar is usage in connection with the term *ohim: used with plural reference, as a common noun, it does not require a determinative; used with singular reference, it can serve as an effective substitute for a proper noun, a "divine name", in effect, but can also take the definite article, at which point it becomes a title, a common noun (similarly, 'el).

In the case of the term, castarot, "Ashtorets", a more interesting pattern arises. In three passages referring to the high places built by Solomon on the Mount of Olives, the singular, Ashtoret, appears without a definite article:

\begin{abstract}
Solomon went after Ashtoret, the god of Tyrians, and after Milcom, the abomination of Ammonites. ... Then Solomon built a high place for Chemosh, the abomination of Ammon, on the mountain which is opposite Jerusalem, and for Molech, the abomination of the children of Ammon. And so he did for all his foreign wives, who burned incense and sacrificed (D) to their gods (1 Kgs 11:5-8; MT).
\end{abstract}

Here, the Old Greek, which may have suffered a haplography ("David, his father" to "David, his father") and some revision, preserves the reading "Milcom" for the Ammonite abomination, and the idea that the high place was dedicated to Ashtoret as well as to Chemosh and Milcom.

A second passage in $1 \mathrm{Kgs}$ 11:33 refers to the first. Yhwh announces the division of the kingdom,

because they abandoned me and prostrated themselves to Ashtoret, the god of Sidonians, to Chemosh, the god of Moab, and to Milcom, the god of the children of Ammon ...

Finally, 2 Kgs 23:13 reports Josiah's demolition of the Solomonic high places, which, along with dedications to the Host and altars to the Host in Jerusalem, had survived Hezekiah's reform:

And the high places (LXX: singular, as in $1 \mathrm{Kgs} \mathrm{11:7)} \mathrm{which} \mathrm{are} \mathrm{opposite} \mathrm{Je-}$ rusalem, which are south of the Mount of the Vanguard (?), which Solomon, king of Israel, built for Ashtoret, the abomination of Sidonians, and for Chemosh, the abomination of Moab, and for Milcom, the vexation of the children of Ammon, the king defiled.

\footnotetext{
14 Singular in Dtn 16:21; Judg 6:25, 26, 28, 30; 1 Kgs 16:33; 2 Kgs 13:6; 17:16; 18:4; 21:3; 23:6, 15. Plural sentm in Ex 34:13; Dtn 7:5; 12:3 (these being three injunctions to destroy

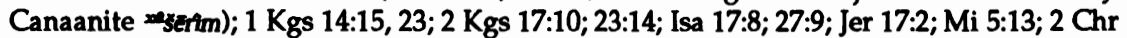
$14: 2 ; 17: 6 ; 19: 3$ (2nserot); $24: 18$ (an object of worship, but clearly an icon in the context of "idols", 'esabblm; Chr never otherwise refers to the goddess/goddesses with this term); 31:1 (// in $2 \mathrm{Kgs} \mathrm{18:4} \mathrm{singular);} \mathrm{33:3} \mathrm{(*terot} \mathrm{//} \mathrm{in} 2 \mathrm{Kgs} 21: 3$ singular), 19; 34:3,4 (typological

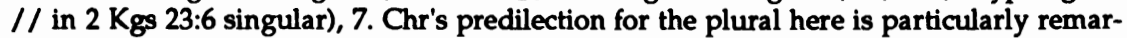
kable, and reflects an interpretation of the phenomenon that, while possibly erroneous because founded on contemporary examples from outside Jerusalem, understands the singular in Kings to function as a collective plural.
} 
In these passages, Ashtoret is a specific goddess (i.e., Astarte) particularly venerated in Sidon ${ }^{15}$. She is mentioned by name along with other national gods. None of the divine names in any of the passages, therefore, is marked with a definite article: the proper noun is definite in and of itself.

Contrast, however, the occurrences of the plural, ashtorets (castarot), where goddesses are the reference:

\footnotetext{
"They did service to the baal [singular] and to the ashtorets" (Judg 2:13).

"They did service to the baals and the astorets" (Judg 10:6).

"Put away the foreign gods from your midst and the ashtorets ... The children of Israel put away the baals and the ashtorets" (1 Sam 7:3-4).

"We have abandoned $\mathrm{Yhwh}$ and we have done service to the baals and the ashtorets" (1 Sam 12:10).
}

Each occurrence in which one specific goddess is not in point takes the definite article ${ }^{16}$. Notably, the Biblical place name formed from this term is itself in the plural: Ashtarot, and it is useful to compare to this the names Anathoth and Baaloth (as Jos 15:24; $1 \mathrm{Kgs} \mathrm{4:16).}$

The alternation between a determined plural and a non-determined singular status in the case of Ashtoret hinges on the semantic shift that occurs as one switches numbers. In the singular, in the texts adduced above, Ashtoret functions as a name. In the plural, however, it is not a name, but a common noun denoting a group of individual goddesses. It is immaterial here whether the various ashtorets to which the texts allude are all manifestations of a single deity ${ }^{17}$, though the usage would in that case be a trifle awkward: why would the authors of Judges and Samuel not say, "They did service to Ashtoret" if they recognized the identity of these gods? There is no evidence that Biblical usage distinguished the different local manifestations of a single god - rather, the tendency is the reverse, with El Elohe Israel identified with El Elyon and the like, all of them identified - already in JE - with Yhwh. In either case, however, the plural form functions solely as a common noun, which requires the definite article.

In the case of the term, asherah, the existence of a cult object of the same name somewhat obscures the situation. "Do not plant an asherah", warns Dtn 16:21, "any tree near the altar of Yhwh your god". Where the cult object is concerned, no definite article is required. However,

15 Cf., e.g., KAI 13-14, where "priest[ess] of Astarte" is the sinecure of kings and queenmothers.

16 For this reason, it is unlikely that 1 Sam 31:10 speaks of a "temple of ashtorets" (LXX Astarteion) because it lacks the definite article. More likely, it reports a place name that of Ashtarot in Transjordan, the b' strh (an apocopated byt 'strt? - MANDELKERN 1959: 1382) of Jos 21:27. Thus, the "temple of Ashtarot", or the toponym, Beth-Ashtarot, is placed into parallelism with the "city wall of Beth Shan".

17 So, e.g., SMITH 1990: 48. 
wherever a goddess may be called an asherah, the definite article consistently appears. The implication is that, singular or plural, the Hebrew term, asherah, is not a proper noun, not a name, but, like ashtorets in the plural, a common noun, denoting a female divinity.

Indeed, except for Judg 3:7, the term asherah does not occur in the plural with reference to a goddess. This occurrence, at the start of the Othniel story, is sometimes divorced from the (Josianic - i.e., H[Dtr]) stratum in Judges ${ }^{18}$, and the variation in usage - against ashtorets in Judg 2:13; 10:16 - may be taken to confirm that view ${ }^{19}$. In either case, the standard term in Biblical (Deuteronomistic) usage for "goddess" in the plural is ashtorets, which is not a common noun in the singular (in the singular, we should also expect iela, which occurs in the onomasticon, but not in the lexicon, despite 't on the Lachish ewer, as a reference to a goddess).

The implications for the term, baal, are stark. As designations of divine beings, baal, singular or plural, asherah in the singular, and ashtorets (plural) in HB usage are not proper nouns, but rather titles, like "king", that attach to particular figures. The definite article, or a genitive following baal in construct, indicates which particular god of this class is in point. That is why the term Baal Berith (Judg 8:33; 9:4) can freely take the alloform, El Berith (Judg 9:46): the "lord of the covenant" or the "god of the covenant" is equally nameless, but equally accurately described. By the same token, Phoenician adulation was directed toward no fewer than five "baals" - such as Baal Hammon (as KAI 24:16), Baal Lebanon (KAI 31:1-2), Baal Zaphon (KAI 50:2-3; 69:1), and, on the other hand, Baal Addir (KAI 9.B:5, distinct from Baal Hammon in KAI 162:1), Baal Semed (KAI 24:15, distinct from Baal Hammon), and Baal Shamem (distinct from Baal Hammon and Baal mgnm in KAI 78:2-4). Toponyms, such as Baal Hermon and Baal Rosh may also indicate the existence of local "baals"20; if so, the number of such local cults would be astronomical. Yet the identity of these gods with one another, let alone with actual divine proper names, is difficult to establish with anything approaching certainty.

It is worth observing that in connection with "baal", the pull of the plural is such that, formally, there is no 3 m.s. possessive suffix on the singular noun (ba $\left.{ }^{c a} / 8\right)$; the $3 \mathrm{~m}$.s. possessive suffix, even in reference to a singular baal, is appended to the plural stem (b2calayw - Ex 21:29 [bis],34,36; 22:10,11,13,14; Isa 1:3; Prov 1:19; 3:27; 16:22; 17:8; Eccl 8:8). This is not the case with comparable nouns, notably ma'al, of the pattern bilabial -cayin-

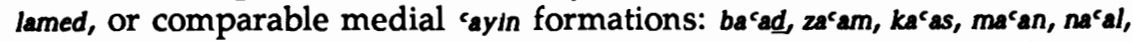
$n a^{2} a r$, sarad, serar, soral all occur in HB with a $3 \mathrm{~m}$.s. suffix on a singular no-

18 BUDDE 1890: 93; NOTH 1943: 50-51; RICHTER 1963; 1964: 23-26.

19 But HALPERN 1988: 142 n. 21.

20 See PECKHAM 1987: 80. 
minal base. In other words, substantive, rather than phonological, patterning has determined the suffix paradigm for basal. 21 .

"The baal", Hebrew hab-bac al, does not refer to a single god, Baal, by name, but is a title, specifically, "master, lord". It is sometimes applied to Yhwh, the high god (as in Isa 1:3; and in the onomasticon in the case of Saul's sons Ishbaal and Meribbaal or the judge Jerubbaal22). This is plain in the case of the name b'lyh, one of David's heroes in 1 Chr 12:6: the name should be construed, "Yhwh is my baal", or, with the MT, "Yhwh acts as master/baal". Hosea, moreover, claims that Yhwh instructs Israel, "Call me no more 'My baal"' (2:18), implying that such had indeed been the practice. As a term for "husband", this expression, applied to Yhwh, fathered Hosea's imagery portraying Israel's alleged apostasy as marital infidelity. Hosea's Yhwh, thus, counsels the use of the term $2 s$, "man", in its place. To this text, we will recur.

Isaiah's clever couplet, "An ox knows its owner, and (even) a donkey it's master's trough, but Israel do not know, my people do not understand" (1:3) identifies Yhwh as the owner and master of Israel. For the owner, the term is qoneh, "owner, purchaser, creator", a not too oblique reference to the epithet, qoneh samayim wa-ares, "creator of heaven and earth" (Gen 14:19), witnessed both in the second-millennium myth of Elqunirsa and in the godhead 'I qn 'rs, "El, creator of the earth", at Karatepe (KAI 26 A III 18), as well as in the epigraph, qn is from 8th-7th c. Jerusalem $^{23}$. For the master, Isaiah's term is bacal, another Yahwistic epithet. If we also equate Israel, "my people", with its animal counterparts here, the first, "bull/ox", is an El epithet at Ugarit, but the resonance in the Israelite context is with the name Israel or its synonym, Jeshurun ${ }^{24}$. The donkey is harder to connect to tradition, except to Hamor in Genesis 34. However, use of the term, "trough" ('bws), here is surely related to the root, bws, "trampling" - Israel should recognize that its trampling is Yhwh's doing, the point of the passage as a whole - a root deployed in Isaiah $14: 19,25 ; 18: 2,7 ; 22: 5$, in $31.25 \%$ of its occurrences. A layering of paronomasia is in point, and at its center is the use of the epithet, baal, to denote Yhwh.

Not coincidentally, a fragmentary plaster inscription at Kuntillet 'Ajrud, where Yhwh (and his asherah - below) was the primary object of veneration, runs: "When El shines forth [from Teman?] ... the mountains are melted ... To bless Baal in the day of batt[le] [...] For the name of

21 There is no pertinent parallel to the preposition $\mathrm{s}_{\mathrm{a}}$ in its bound forms, as these are uniformly attached to the plural stem due to the influence of the alloform case.

22 See CROSS 1973: 263-264.

23 AVIGAD 1983: 41; cf. KAI 129:1.

24 sor. yoseron / ytiratel ; cf. Hos 8:6, construed by WYATT [1990: 46] as my swr y- "who is the bull of $\mathrm{El}^{\text {"; }}$ though $\mathrm{MT}$ is comprehensible, the pun on the fathering of the "calf" may remain. 
$\mathrm{El}$ in the day of [his] batt[le]"25 - probably, El is the baal in this text, both being identical with Yhwh. Not coincidentally, the expression brk bcl (Baal bless) occurs at Kuntillet 'Ajrud ${ }^{26}$, again, given the distribution of divine names at the site, probably of $\mathrm{Yhwh}$, and if not, certainly of a subordinate.

In light of this data, Baal-theophorics in HB and in Hebrew seals are more probably to be connected with Yhwh, as "the baal", than with some alien god. The onomasticon is otherwise virtually without reference to other gods ${ }^{27}$. Most of the identifiable references to other gods include Egyptian names (Horus, Bes), quite possibly in historical, rather than devotional, use, especially among priestly families (Pashhur, etc.). The Tyrian baal of Jezebel is the one major exception, where "the baal" refers to a determinate god other than Yhwh with a distinctive identity (but also Judg 6:31); and, the name Adoram/Hadoram, of Rehoboam's tax collector, includes the divine name, Haddu (the name of Samson has the sun god as its theophoric; cf. Beth Shemesh, in the vicinity of his activity). Several names with baal-theophorics occur in the Samaria

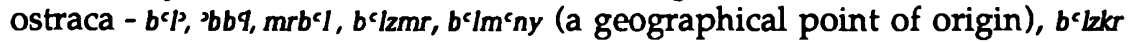
(see 39:3, not $b^{c} \mathcal{I}_{\mathbf{z}} \mathbf{k r}$ as 37:3)28. Notably, all other texts concerning foreign gods, especially of neighboring kingdoms, either name those gods explicitly (1 Kgs 11:1-3, e.g., with the names of the gods of the Transjordanian Hebrews; 2 Kgs 1:2,3,6,16 with Baal Zebub as the chief god of Eqron) or call them "other gods". A collection of names in Jerusalem at the start of the 6th c. contains no names with baal-theophorics; but this is in the aftermath of the era of reform, when the epithet was in patent disrepute ${ }^{29}$. The only late name with a baal-theophoric occurs in an ostracon at Mesad Hashavyahu ${ }^{30}$, and in light of the probable connection of the site with corvee may not represent a Judahite ${ }^{31}$.

In sum, until the seventh century, at least, Yhwh was probably "the baal" par excellence in the Israelite pantheon of baals (as Hos 2:18; cf. Jer 31:32): there is a parallel here to the usage, El Shadday, for Yhwh in P's

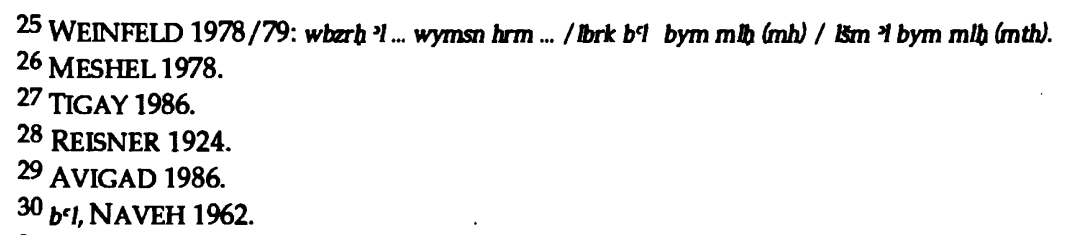

25 WEINFELD 1978/79: wbzrh ग... wymsn hrm ... / brk bq bym mlb (mh) / Lam 1 bym mlb (mth).

26 MESHEL 1978.

27 TIGAY 1986.

28 REISNER 1924.

29 AVIGAD 1986.

30 bel, NAVEH 1962.

31 See also NA'AMAN 1987: 7,12-14. - On br iplt at Tel Dan, and bintn on the Calah ostracon, cf. SMITH 1990: $65 \mathrm{n}$. 3. The latter can certainly be construed as Israelite, but could also be Transjordanian, or, for that matter, Sam'alian. It should be added that names citing Qaus are so far restricted to Negev ostraca of the late 7th century and later, and probably reflect Edomite activity rather than a change in onomastic patterns. A unprovenanced seal of the 9 th $/ 8$ th centuries containing the name $b^{c} r$ an, and stemming from a private collection, will be published shortly by $W$. AUFRECHT. For the suppression of the lexeme bacal in the 7th century, see further below, regarding Hos 2:18 and terms for "husband". 
protohistory, as a class of subordinate deities known as the sedm (Shaddayim) is known from the Deir Alla plasters and from Dtn 32:17; Ps 106:37 - Yhwh is again the archetype after whom the pantheon is denominated (and the Shaddayim are doubtless either the host/baals or the chthonic pantheon ${ }^{32}$ ).

An illuminating related phenomenon is the use of the $3 \mathrm{~m} . \mathrm{s}$. possessive suffix on the term, asherah (so, 3 rth), as at Kuntillet ' $A$ jrud ${ }^{33}$ and Khirbet el-Qom ${ }^{34}$. Asherah here cannot be a proper noun - proper nouns in Hebrew do not take possessive suffixes. Yet it surely denominates a goddess rather than a sanctuary or cult object (the Biblical asherah that is erected, planted or cut down) ${ }^{35}$ : S.M. OLYAN ${ }^{36}$ plausibly relates the inscription, lyhwh smrn w/3rth at Kuntillet 'Ajrud to the asherahicon Ahab is said to have "made" (1 Kgs 16:33; 2 Kgs 13:6), taking the epigraph as a dedication to Yhwh of Samaria and to Samaria's asherahicon. Still, the same reading does not apply convincingly to the parallel Kuntillet 'Ajrud dedication, lyhwh tmn w/strth - Teman is the south generally, not a specific site with a specific asherah-icon ${ }^{37}$. Moreover, the correct reading of the Khirbet el-Qom epigraph, "(blessed is Uriahu) to Yhwh and [...] to his asherah"38 leaves no doubt as to the referent of the $3 \mathrm{~m} . \mathrm{s}$. possessive suffix on the term, asherah: it is neither Samaria nor Teman, nor yet Uriah, but Yhwh. In this case there is absolutely no indication which particular asherah-icon is the source of blessing - is it the one (better, one of the ones) in Samaria? the one in the Jerusalem temple? the one in the Arad temple? the one at Bethel, or Dan, or Gilgal? Is it a hypostatized version of the icon, an idealized icon? Yet what is the icon except a representation (whether figurative or not) of the goddess, and thus what is the goddess herself but the idealization of the icon ${ }^{39}$ ?

In other words, Yhwh's asherah is indeed the goddess. Recent finds of direct dedications to Asherah ("sacred to [the?] Asherah", "to [the?] Asherah") in a 7th-century stratum (IB) at Tel Miqneh should put paid to the idea that asherah cannot function as a noun for or name for a

32 Cf. also KAI 15; 16, where sd qds is an epithet of Eshmun; the divine name Shad-rapa', parallel to Biblical El-Rapa', at Sarepta - PRITCHARD 1978: 100-102.

33 MESHEL 1978.

34 Esp. LEMAIRE 1977.

35 For the best treatment of asherah as a (hypostatized) sanctuary, see MCCARTER 1987). Note particularly KAI 222.B:11 (a treaty with Bit Agusi and its people, together with $*$ rthm, presumably their cult places) and KAI 277:1, *r, m., presumably as a cult place of Ashtoret; also, Akk. astirtu.

36 OLYAN 1988a: 23-33.

37 WEINFELD 1977: 284 compares Hab 3:3.

38 I take the intervening text between "Yhwh" and "and his asherah" to have been incised over the original blessing, along with much else in the epigraph. But see LEMAIRE 1977; cf. also DEVER 1984; ZEVIT 1984; HADLEY 1987.

${ }^{39}$ See MCCARTER 1987: 149. 
goddess. Here, she is no one's asherah but her own, and it is all but inconceivable that one should have agricultural goods "dedicated to the pole": such a notion regresses to the level of taking literally prophetic polemic against idolatry - assuming that the worshippers being accused of it could not distinguish at all between the sublime deity and the concrete representation standing in front of them. Indeed, in Biblical usage, "sacred to ..." can be completed only with the name of Yhwh, with the word "priest" or with a term denoting Israelites"0. "Asherah" in the Miqneh inscriptions therefore almost certainly functions as a name for or soubriquet of a goddess.

Recognizing that the asherah in the inscriptions is the goddess ${ }^{41}$, D.N. FREEDMAN42 proposes that the suffix implies the asherah is Asherah of Yhwh, much as Athiratu Yammi in Ugaritic can so be denominated (or is this an objective, rather than genitive, relationship - the Lady who treads the sea?). Ashtar Kemosh, the recipient of sacrificed captives, is the parallel in the Mesha inscription (KAI 181:17), the gods Atargatis (Astarte-Anat) and Anatyahu ${ }^{43}$ other examples of compounds. On this logic, the goddess is Asherat Yhwh. Against FREEDMAN's construction, however, there is no other case where a suffix is used as a substitute for the second component of a compounded theonym ${ }^{44}$.

$40 \mathrm{Cf}$. the ivory pomegranate, in the Israel Museum, inscribed, "sacred (thing) of the priests to the house of ...h" ( $q d s k$ knm lbyt ...h). This can be the house of Yhwh, of Asherah, or of some priestly lineage. There is no adjudicating among these alternatives, although the existence of a "house of Asherah" is not yet witnessed in any text.

"Sacred to Yhwh": Lev 19:8 (> Mal 2:11); 23:20; 27:14, 21, 23, 30, 32; Jos 6:19; Isa 23:18; Jer 2:3; 31:40; Ez 45:1; Zech 14:20,21; Ezra 8:28.

"Sacred to the priest(s)": Lev 23:20; Num 6:20; Ez 45:4.

"Sacred to you" (i.e., Israel): Lev 25:12; Num 18:10.

In DtrH, the term, qodzes occurs only in Dtn 26:13; 33:2; 1 Sam 21:5-7; 1 Kgs 7:51; 8:4,8,10 (the latter two reflecting the meaning, "adyton"); 15:15. The pattern of distribution in the Phoenician sphere is not dissimilar: gods are called "sacred", and the term is restricted to them alone.

41 See also DEVER 1984. For the Miqneh inscriptions see GITIN, forthcoming.

42 FREEDMAN 1987.

43 PORTEN and YARDENI 1989: B7.3:3.

44 SMITH 1990: 107 n. 52 cites KTU 2.31.39 (read 2.31.41), 'atrty and 1.43 .13 ' nth, neither of them in a transparent context, neither certainly the name of a goddess. He also cites EA 84:33 DA-MU-ia, "my Tammuz" and Ez 8:14, "the Tammuz", and suffixes on the Ugaritic गPib. The usage in Ezekiel conforms to other patterns in Hebrew explored here, and for that matter may take Tammuz to represent a common noun rather than a proper name. In the EA reference Rib-Addi is simply erecting a contrast, telling the pharaoh to send emissaries to take whatever belongs to his DA.MU to the pharaoh, but not to suffer the enemy taking what belongs to the pharaoh's god (= DA.MU): the cultic establishment, not the abstracted divinity, is at issue; the referent is probably the title, 'dn; and, in the contrast, "my god::your god(s)", it may be that the suffix is - semantically, if not formally - attached to the determinative, "god", rather than to the name itself. As to sprb, the very strong likelihood that it refers to an ancestral spirit (not, the god of the father, but the father's ghost - K. VAN DER TOORN, forthcoming) puts a strong dent in the value 
A preferable alternative, in the light of $\mathrm{HB}$ usage, where asherah, as a term for a god, like baal, is always determined, is to conclude that asherah denotes a class of deities (the Asherot or Ashtarot of HB), and that the suffix here stipulates precisely which member of the goddessclass, asherah, is meant. The text is a dedication to Yhwh of Samaria and his asherah, as opposed to any of the other asherahs/ashtorets, that is, goddesses. The usage of Akk. istar, istarate is parallel: the term does not denote only Ishtar, nor yet, when plural, the various cultic manifestations of Ishtar (as Ishtar of Nineveh and Ishtar of Arbela), but goddesses generally, just as $1 \| u, 1$ ant denotes gods generally (including ancestral spirits) ${ }^{45}$. Thus, in one text from the time of Esarhaddon, two distinct figures,

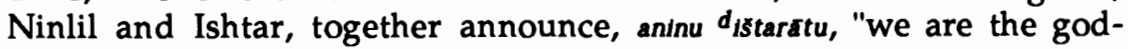
desses"46.

Given the fact that in Biblical usage, asherah in the singular is not the name of a goddess, but a common noun sometimes denoting a goddess, it is understandable that a possessive suffix might be employed - in place of a definite article - to indicate precisely which goddess is being mentioned. For the same reason, the definite article is attached to the term, baal, to stipulate which of the baals is under discussion. And Yhwh, for example, is distinguished with a possessive suffix when he appears as "my baal" in Hos 2:18: Yhwh, here, is the baal who presides over the other baals. Yet there is another dynamic at work as well in connection with the noun, baal, and probably with asherah as a term for goddess.

In 8th-century and later literature, hab-bacal, "the baal", appears alongside the plural, "the baals", "the gods of the class, baals". Hosea abjures the use of the term, "my baal" as an epithet of Yhwh, and speaks of

of the citation: it is common for ancestral spirits to be mentioned with possessive suffixes, at least in Akkadian, and apparently also in Ugaritic ("my ancestral spirits", etc.). 45 In a forthcoming study, K. VAN DER TOORN adduces a text mentioning DINGIR a-bi u dINNIN um-mI (MEIER 1941-44: 142: 36-37). As he demonstrates, this must be "the ghost of the father and the ghost of the mother" because there is no evidence that women had personal goddesses divorced from their husbands' or fathers' personal gods. A parallel to the locution, also adduced by VAN DER TOORN, is DINGIR E and dINNINE // dIstar bittim.

46 K12033 + 82-5-22, 527 I 1'-14', line 8': see WEIPPERT 1981. It is interesting to speculate on the possible appropriation of a Middle Assyrian term in Israel as well: esirtu in the Middle Assyrian Laws specifically denotes a concubine (pl. estate: DRIVER and MILES 1935: 41). The term is cognate with Heb. tr, Akk. eseru, with the meaning, "captive". However, the Assyrian sibilant will have been experienced as $/ s /$ in Israel (see MILLARD 1976), as it was in some Hittite texts, and the automatic association would have been with asherah. Since Hebrew seems to have borrowed its term for "concubine" from some other language family (pilegess // Gr. $\pi 0^{2} \lambda \alpha \alpha_{\text {, }}$ Lat. pellex), the possibility of a congeneric assimilation of the Assyrian term with the term asherah should not altogether be ruled out of court. 
dedications made to "the baal" $(2: 10)^{47}$ in the same breath as promising to wipe the name of the baals, plural, from Israel's tongue $(2: 15,19 ; 11: 2)$. His complaint about "the days of the baals" seems to be that devotion to them eclipsed the loyalty due Yhwh (2:15).

Later, Jeremiah speaks of the baals in the plural: in 2:23, he asks, "How can you say 'I am not profaned, I have not gone after the baals?' Look at your way in the Valley", just after denouncing prophets who prophesy "by the baal" (2:8, singular), then accusing his people of abandoning Yhwh, the (singular) "source of living waters to cut themselves cisterns [plural], broken cisterns that don't hold the water" (2:13). The cisterns and the baals are identical, and plural, yet the prophets prophesy by the formally singular baal. 2:23 is of special interest in that the prophet presupposes his audience would deny its allegiance to "the baals": the suggestion is that the term, baals, has an expanded semantic range in Jeremiah's rhetoric, including (ancestral?) elements that earlier would not have been covered by the same word.

Tying this polemic to the iconographic tradition in the cult, Jeremiah refers to those - including people, kings, officials, priests and prophets - "who say to a tree, 'You are my father,' and to a stone, 'You gave birth to me"' (2:27), where one might take the reference to be to a single pair of icons. ${ }^{48}$. Yet in the very next line, Jeremiah complains, "Where are your gods, which you made for yourself; let them rise up, they will not save you in your time of evil, for as numerous as your towns were your gods, Judah" (2:28: LXX adds: and as many as were the streets of Jerusalem they sacrificed to the baal). The multiple gods are identical to the cisterns and the baals in Jeremiah's rhetoric. Yet the references to the baal, and to the tree and stone, in the singular, accompany those in the plural.

In 7:9, in the context of a litany of wrongdoing reminiscent of Hos $4: 2$, Jeremiah introduces this interesting juxtaposition: the cultic offenses are two, "burning incense to the baal, and going after other gods whom you do not know". Again, the ritual act is oriented to the (singular) baal, the general accusation of apostasy is connected with gods (plural).

47 Against ANDERSEN and FREEDMAN 1980, the phrase ' $s w$ lbe $l$ is to be compared to 2 Kgs 23:4, "vessels 'wsym to the baal, and to the asherah, and to all the Host of the Heavens": clearly, these vessels have not been hammered into the form of a baal or an asherah, let alone of all the Host of Heaven. Rather, they have been made for or dedicated to those objects of devotion. As there is absolutely no indication in Hos 2 of any polemic against iconography, and as no identification of the baal(s) with icons until 11:2, it seems most likely that the locution in 2:10 refers to dedications as well.

48 The reference is probably to a stela, as in the Holy of Holies of the Arad shrine stelae remained an integral part of the cult at least until Josiah's reform not just on the literary evidence, but on that of the state shrine at Arad as well (see below on the Arad shrine). On the passage in question, and especially its polemical inversion of the meaning of the symbols, see OLYAN 1987. 
Some insight into the specific valences of this sort of rhetoric is to be had from Jer 7:18. Here, Yhwh accuses the children of gathering the firewood, the fathers of kindling the fire and the women of preparing the dough to make "cookies" (kawwantm) for the Queen of the Heavens, and "to pour out libations to other gods". Is it possible that the ritual discussed in Jeremiah 44 is generalized here, and that the accusation of cultic activity for other gods is triggered by devotion to one particular "other" deity? More likely, the cult of the Queen of Heaven involved invoking her (and Yhwh's) retinue - the Host of Heaven ${ }^{49}$. As Jer 9:13 remarks, "They went ... after the baals, whom their fathers had taught them". The plural other gods, as in 7:18; $2: 28$, and chap. 44 , are admittedly traditional deities (so, too, 11:10; 16:11,13; contrast 7:9; 19:4).

Even more important is Jeremiah's reiteration of the multiplicity of Judah's gods: he correlates this to the multiplicity of its "altars to burn incense to 'the baal"' (11:12-13). Clearly, the "gods to whom they burn incense" are the gods for whom they built "altars to burn incense to 'the baal"': again, the ritual act is oriented toward the (singular) baal; again, a multitude of actual gods is at issue. The same relation - of a ritual act - to a formally singular baal obtains in Jer 11:17 (sacrifice); 12:16 (invocation in oaths, cf. Hos 2:19); 19:5 (building altars, burning sons); 23:13 (prophesying by the baal), 27 (speaking in the name of the baal); 32:29 (sacrificing), 35 (building high places and sacrificing children). Yet Jeremiah plainly equates these activities with sacrifice and building high places for, prophesying in the name of and invoking "other gods" or "nongods" (2:11, devotion to non-gods; 5:7, oaths invoking non-gods; 7:9, incense burning for the baal//going after other gods; cf. 11:10; 13:10; 25:6; 35:15, going after other gods; 16:11, 13 bowing to and serving other gods; 1:16; $19: 4 ; 44: 3,5,8,15$, burning incense for other gods; $7: 18 ; 19: 13 ; 32: 29$, pouring out libations for other gods).

Particularly, Jeremiah identifies child sacrifice as a rite directed toward "the baal". In 7:32-8:3 he predicts that

"It will no longer be called, 'the Tophet' and 'the Valley of ben-Hinnom', but the Valley of Killing...".

When punishment is visited upon Jerusalem,

\begin{abstract}
"they will bring out the bones of the kings of Judah and the bones of its officials and the bones of the priests and the bones of the prophets and the bones of the inhabitants of Jerusalem from their graves. And they will slaughter them to the sun and to the moon and to all the Host of the Heavens whom they loved and whom they served and whom they went after and whom they sought and whom they bowed down to ...".
\end{abstract}

The beneficiaries of the human sacrifice, from Jeremiah's perspective, were "the sun and the moon and all the Host of Heaven".

49 PROPP suggests taking the $q^{2}$ re of 7:18; 44:17-25, mlkt, as "retinue" (so LXX to 7,18). 
The contrast is to Jer 19:5,11-13. Here, the prophet declaims, on site, the accusation that in the Valley of ben-Hinnom, the Judahites burned incense to other gods, whom their fathers did not know (19:4, cited above). They "built the high places of the baal to burn their children in fire as burnt offerings to the baal, which I did not command and did not speak and which never entered my mind" (19:5). In his peroration, Jeremiah observes that Yhwh will shatter the people like an unmendable pot,

"making this city like the Tophet. And the houses of Jerusalem and the houses of the kings of Judah will be like the profaned Tophet, all the houses where they burned incense on their roofs to all the Host of the Heavens and poured out libations to other gods" (19:11-13).

Against this background, the parallel text (32:29) which speaks of "the houses on the roofs of which they burned incense to the baal and poured out libations to other gods" is decisive, prose or not. The rituals of the Valley (cf. 2:23, cited above) are dedicated to the baal, to the Host, to other gods. Micah (6:6-7) portrays child sacrifice as the highest order of devotion to Yhwh, as does Genesis 22 (where adventitious substitution is legitimated, but where the intention to sacrifice the child is indispensable). Isaiah (30:33) speaks of Yhwh himself preparing a Tophet beside Jerusalem in which to slaughter the Assyrians. Yet Jeremiah identifies the Tophet, in a variety of passages, with the Host (including Sun and Moon), with other gods (plural), and with the baal (singular). He explicitly denies that the rite is oriented toward Yhwh (19:5): evidently, the worshippers claimed that it was, and denied, despite their activities in the Valley (i.e., the Tophet), that they followed the baals (plural, 2:23), as distinct from Yhwh. Jeremiah employs the term, baal, to denote a class of deities, the baals, which includes the Host of Heaven, and which, though subordinate to Yhwh in the traditional theology, are the beneficiaries of child sacrifice (compare Ashtar Kemosh in the Mesha stela; and cf. Dtn 4:19 where the astral cult is proscribed in identical language): in Jeremiah's mind, the "host" and "the baal" are identical. "The baal" is a collective noun.

Another constellation of texts buttresses this inference. Jer 3:17 enunciates a standing motif of the book of Jeremiah, and more particularly of chapters 1-25: the Israelites "go each after the srrwt (imagining?) of his own heart". This clause occurs again in 7:24, following an accusation of service to the Queen of the Heavens (7:18). It is succeeded by a judgment predicated on the accusation that the Israelites introduced abominations into the temple, "and built the high places of the Tophet in the Valley of ben-Hinnom to burn their sons and daughters in the fire, which I never commanded, and which never entered my mind" (Jer 7:30-8:3). The same passage, as noted above, links the Tophet to the Host of Heaven. 
The locution, "went after the imagining of their hearts", recurs in 9:13. Here, it is explicitly linked to worship of the baals. In 11:8, the same expression, in a generalized accusation of covenant violation, is immediately followed by the specific indictment of Israel for "going after other gods to serve them" (11:10). The same referent for the phrase appears in $13: 10$ and in 16:11-13. In 18:12; 23:17, where the phrase recurs, there is no further explanation of its meaning. Yet the valence, by now, is clear. Going after the imaginings of one's heart means abandoning Yhwh: what one abandons him for are other gods, baals, the Queen of Heaven and the Host. Jeremiah's equation of these terms may be a moral one, but the terms "baals", and "other gods" seem to include the Host, just as service to "the baal" seems to imply going after other gods, the baals, and the Host. Jeremiah's poetry accounts for 8 of 10 occurrences of "imaginings" in HB. Of the other two, Dtn 29:18 (cf. Jer 23:17) refers to "going after the gods of those nations" to which the Israelites had been exposed (v 17). Ps 81:13 (cf. Jer 7:24) speaks of more general apostasy, but is probably related.

"The baal", in sum, seems to be a collective plural. That this is the case, and that the noun in the singular can embrace a variety of gods, is reflected grammatically in several texts. $2 \mathrm{Kgs} 23: 5$ speaks of those "who burn incense lab-bacal (to the baal), to the sun and to the moon and to the constellations and to all the Host of Heaven". Here, hab-bacal is set into apposition with the succeeding objects of worship: the absence of the conjunction before the first element of the astral list is not inadvertent, anymore than its presence before each element succeeding the first in that list is inadvertent. This text, like Jeremiah, identifies the baal with the Host. Moreover, the baal is a collective noun: to burn incense to the baal is to adore the sun, the moon, the constellations and all the Host.

In the same period, and in the same setting, Zephaniah includes priests and worshippers of the Host of Heaven among the "remainder of hab-ba ' $a l$ ". This expression implies a collective plural (1:4-5) - elsewhere "remainder" ( 5 r r always implies plurality within an overarching unity the remainder of Israel, or a people (Isa 10:20-22; 11:11,16; 17:3; 28:5), of the trees of the forest (Isa 10:19), of the silver (2 Chr 24:14), and the like. On rare occasion, it refers to descendants (Isa 14:22), or, rather, to a surviving part of a lineage able to generate descendants, but for the most part this semantic function is fulfilled by the alloform, "remnant" (s'ryt, as Gen 45:7; 2 Kgs 21:14; Am 1:8; Mic 2:12 > Jer 23:3; Jer 11:23; 39:3; 44:7; $40: 15 ; 50: 26)^{50}$. One cannot thus take the passage to refer to some relict of

50 First Isaiah prefers the nominal form, $\xi^{\prime} r$, which otherwise apppears in preexilic materials only in Zeph 1:4. The other passages in which the term appears are: Isa $10: 19,20,21,22 ; 11: 11,16 ; 14: 22 ; 16: 14 ; 17: 3 ; 21: 17 ; 28: 5$. In none of these, except Isa $14: 22$, is the reference to anything but the remainder of a people, literally or metaphorically, who have survived disaster. In post-exilic materials, the term appears in Mal 2:15 (the rest of the spirit); Est 9:12 (in the rest of the states), 16 (the rest of the Jews); Ezra 3:8 
the baal, such as his (their) iconography: it is the survival of the baal(s), or of their memory, or the survival of some of the baals, in contradistinction to others, that is in point.

In light of the usage, one might choose to argue that the "remainder of the baal" in Zeph 1:4 are those who perpetuate the name of the baal, and thus conclude that it is the plural adherents who are under attack, while "the baal" is a single god. However, this violates the pattern of usage in that the "remainder of the baal" are, by the very argument, divorced from "the baal" (singular). More important, Zephaniah stipulates what the extirpation of the "rest of the baal" entails: "the name of the $k m r y m$ with (that of) the priests, and those who prostrate themselves on the roofs to the Host of the Heavens ...". SPIECKERMANN51 identifies the kmrym of Hos 10:5; Zeph 1:4; 2 Kgs 23:4 with the astral priests of KAI 225-226 (see KAI 2.275). That they are integral to the worship of "the baal" here is indisputable. Yet what is it that those who worship "the baal" devote themselves to? The Host of Heaven. Moreover, Zephaniah adds to his list of votaries of "the baal" "those who prostrate themselves 52 , who swear to Yhwh and who swear by Milcom"53 (1:5). Is it a coincidence that Milcom, like Ashtoret, is one of the baals to whom Solomon constructed a high place on the Mount of Olives? Rather, like Ashtoret and the Queen of Heaven, Milcom was probably regarded as an important astral underling of Yhwh, corresponding to one of the planets.

Under the circumstances, the context in which Jer 7:22 cites Am 5:25 - both deny the efficacy of sacrifice with an allusion to the absence of a sacrificial cultus during the wilderness era (contra $P$, and cf., significantly, 2 Sam 7:7) - may be significant. Jeremiah's citation comes in a segment sandwiched between his accusation about worship of the

(the rest of their brother priests and Levites); 4:3 (the rest of the clan chiefs of Israel), 7 (the rest of his cohorts); Neh 10:29; 11:1,20 (the rest of the people); $1 \mathrm{Chr} 11: 8$ (the rest of the city); 16:41 (the rest of the singers); $2 \mathrm{Chr} 9: 29$ (the rest of the affairs of Solomon); 24:14 (the rest of the silver). None of the post-exilic usage, except conceivably $1 \mathrm{Chr}$ $11: 8$, remotely implies survival of catastrophe, to which others have succumbed. In fact, the lexeme in postexilic texts where it governs a distributive term (Jews, states, cohorts, etc.) always has the meaning, "other", as distinct from those who have been named to this point.

Conversely, Deutero-Isaiah, Jeremiah, DtrH, Zephaniah, Amos, Micah, Zechariah, Ezra, Nehemiah, and Chronicles all prefer 3 ryt for the survivors of cataclysm. This form also appears in Isa 14:30; 15:9, and in Isa 37:4 (<2 Kgs 19:4). But its use is consistent across the other sources, although Haggai (alone) seems to deploy it as the post-exilic sources use $\operatorname{sit}(1: 12,14 ; 2: 2)$. It is frequently either affixed to or brought into equivalence with plyth (as Ezra 9:14, e.g.). It is always used of a people, with the single exception of 2 Sam 14:7, where the wise woman of Tekoa invokes it to plead for the provision of "name and remnant" (cf. Isa 14:22) for her deceased husband.

51 1982: 83-85.

52 So MT. LXX omits, and this is probably a double reading.

53 MT "their king", but read with Sinaiticus and the Lucianic recensions, Syriac, V. 
Queen of the Heavens and his prediction about the Tophet that was dedicated to the Host. The sourcetext in Amos succeeds a segment in which Yhwh is named, among other things, as the creator of the constellations. More important, it leads directly to a prediction of exile for the Israelites together with their astral images ${ }^{54}$. Amos's reference to "your king" ( $m / k k m)$ may even represent a pun on or error for (LXX: Molech) the name of Milkom $(\mathrm{m} / \mathrm{km})$. In that case, the god's astral connections would be confirmed. Such a reading draws some support from Hosea's reference to kmrym in connection with the exile of Samaria (10:5), supposing SPIECKERMANN's identification of these figures as astral priests (above) to be correct.

In Zephaniah's text, the identity of interest among the kmrym, the priests of "the baal" and the rooftop worshippers of the Host is organic: for reformationists of the Josianic period, the Host and the "baal" are identical. These and other texts suggest that the baals were included, at least in Josianic theology, among the Host of Heaven. They also indicate that hab-bacal, formally singular, could serve as a collective - not just grammatically, but for a multiplicity of gods such as composed the heavenly Host. Such a collective plural is also witnessed in Mesopotamia: Enuma Elish 6:116 speaks of mankind's DINGIR (var. 1-la-)-st-na [formally singular] istarsina [formally singular] - their gods and goddesses - who should bring tribute to Marduk. A text of Esarhaddon's speaks of messages for the gods and goddesses, nasparti DINGIR $d_{I S t a r} 55$. An inscription of Nabopolassar speaks of him "who in his mind has understood the worship due the gods and goddesses" (sa palah DINGIR u INNIN litmudu surrussu), where both "gods" and "goddesses" are formally singular56.

The equation of "other gods" with "baals" is not restricted to Jeremiah. Thus, in 1 Sam 7:3, Samuel urges the Israelites to remove the "foreign gods ... and the ashtorets ... So the Israelites removed the baals and the ashtorets". In the book of Judges, more particularly, whatever its editorial history 57 , a very revealing sequence occurs. Israel have failed to supplant the inhabitants of some of the tracts Joshua conquered. Yhwh therefore decrees his unwillingness to evict these peoples - leaving their gods in place as snares (2:3). The Israelites of the next generation, who had not witnessed the conquest, "did service to the baals". Specifically, "they went after other gods from the gods of the nations which were around them". "They did service to the baal [singular] and to the ashtorets" (2:11-13). Who is the baal Israel served? "The baal" represents the baals, the male gods of the nations of Israel's environs. These are the "other gods" to whom the nation's cultic attentions relapse even when

\footnotetext{
54 Latterly, ANDERSEN and FREEDMAN 1989.

55 Formally singular - BORGER 1956: 45 ii 6.

56 LANGDON 1912: 60: 17.

57 HALPERN 1988: 121-143, 220-228 for a Josianic date, with bibliography.
} 
"judges" arise (2:17,19): the other gods are the snares intentionally left by Yhwh. Intermarrying with the surrounding nations, the Israelites "did service to their gods" (3:6). After 2:13, "other gods" alone represents a term inclusive of the baals and ashtorets. Arguably, "baals" in 2:11, and, more certainly, "other gods" in 2:12, are also inclusive of the ashtorets. It is not to be assumed, on the basis of 1 Sam 7:3, that the ashtorets are identified by $\mathrm{H}(\mathrm{Dtr})$ as indigenous.

Judg 3:7, implementing the programmatic cycle of 2:11-19, stipulates that "The Israelites did what was evil in Yhwh's sight, and forgot Yhwh their god, and served the baals [plural] and the asherahs [plural]". This polytheistic apostasy is thus established as the referent for "The Israelites did what was evil..." at the start of the cycles of succeeding major judges $(3: 12 ; 4: 1 ; 6: 1 ; 13: 1) 58$. Two texts are more specific. Judg $8: 33$ states that on Gideon's death, the Israelites "whored after the baals, and made Baal Berit into their god". The particular figure of Baal Berit is drawn from the Abimelek story (Judg 9:4), but the editorial elaboration on that attestation deserves particular attention: service to Baal Berit implies service not just to one figure, but to many, to the baals generally. The editor's choice of the plural term here is a device to avoid the collective singular, and thus ambiguity in his formulation. Conversely, "the baal" with the altar in Judg 6:25-32 is understood to be a single figure (esp. 6:31-32).

Even more elaborate is the indictment in Judg 10:6-16. Here, the Israelite relapse explicitly involves service to "the baals and the ashtorets and the gods of Aram ${ }^{59}$ and the gods of Sidon and the gods of Moab and the gods of the children of Ammon and the gods of the Philistines" (10:6). From the formulation, one might expect that the baals and ashtorets were to be divorced, as the gods of aboriginal Canaanites, from the gods of the Iron-Age successor-nations - the Arameans, Phoenicians, Transjordanian Hebrews and Philistines. Yet the continuation belies such an inference: the Israelites confess, "We served the baals" (10:10), a text quoted at 1 Sam 12:10 as, "We served the baals and the ashtorets". The term "baals" here includes the various gods mentioned in Judg 10:6, as "the baals and the ashtorets" in 1 Sam 12:10 does. Yhwh's rebuttal then mentions "other gods" (10:13), so the Israelites remove "the fo-

584 Judga omits Judg 6:7-10, which is probably quite late. Nevertheless, in identifying "the gods of the Amorites" as the objects of Israelite apostasy, the author of this text has clearly understood the implications of Judges 1-3 that the baals and ashtorets were in origin Canaanite deities absorbed by Israel. This is also the perspective of Deuteronomy, which like the Former Prophets is interested in tracing both the Host and the high places to the supplanted Canaanites.

59 LXXA omits "and the gods of Aram", which is most likely a haplography by homoioarcton. That said, however, this is precisely the sort of list which is subject to scribal expansion over generations of transmission, and not all the present elements may belong to the first edition of DtrH. 
reign gods" (10:16). The "baal/baals" in Josianic usage, and the ashtorets, are all other gods, foreign gods, including the Host (17:3). The Host and the baal were in large measure congruent.

For the Host and the baal, a typical cult practice was to burn incense on rooftops - Jer 19:13 (cf. 8:2-3); 32:29 - where various cultic activities took place (1 Sam 9:25-26, the designation of Saul; 2 Sam 16:2 after 11:2, Absalom entering David's harem on the spot where David had spotted Bathsheba; Isa 22:1,13, sacrificial feasting in the face of Sennacherib's destruction of the countryside; Neh 8:16, tabernacles on the rooves; Isa 15:3; Jer 48:38, Moabite mourning on rooftops [and in streets and piazzas]; Judg 16:27, Philistines watching Samson from the temple roof; cf. Jos 2:6, Rahab's roof with psty h's spread out; Prov 21:9; 25:24). This is also identified as the locus of proskynesis to the Host in Zeph 1:5. It follows that Ahaz's "upper chamber" with the altars built by "the kings of Judah" was an astral installation on the rooftop outside of an interior upper chamber, possibly a throne room or a wing of the clerestory of the temple ${ }^{60}$ : as in the case of Solomon's high places on the Mount of Olives, the cult of the Host survived Hezekiah's measures unimpaired. The cultic activity attested for the Host is the same as that attested for the baals, chiefly burning incense and child sacrifice (Jeremiah, above, and Ps 106:28, 38, zbhw $\left.l^{\prime} s b y k^{c} n\right)$. Again, SPIECKERMANN's61 identification of the kmrym of Hos 10:5; Zeph 1:4; 2 Kgs 23:4 as priests of astral cults is central: it was "to burn incense on the high places in the towns of Judah and on the outskirts of Jerusalem" that "the kings of Judah" had appointed the kmrym - who led those "who burned incense to the baal: to the sun and to the moon and to the constellations and to all the Host of the Heavens". The collocation is not accidental, but essential. The suppression of Ahaz's upper chamber with the altars built by the kings of Judah (starting, one presumes, at least with Ahaz himself: contrast "the altar which Manasseh made" in the same verse), the suppression of the astral priests appointed by the kings of Judah - including in the vicinity of Jerusalem, where Solomon's high places continued in use - the devotion of the kings of Judah to the Queen of Heaven and to the Host/ baal(s) are all of a piece.

The restriction of the cult to incense offerings is of particular interest. Ex 22:19, zbh $l$ thym ybrm blty lyhwh lbdw, already proscribes animal sacrifice for any god but Yhwh. This rule may have been honored traditionally, though sometimes, no doubt, as with child sacrifice, in the breach as much as in the observance (contrast Hos 11:2, but note the MT vocalization, in D). By the same lights, no Catholic or traditional Jew or Muslim would imagine that a prohibition on sacrifice to any but the chief god precluded the dedication of candles, or like rites, to Mary, an-

\footnotetext{
60 HALPERN 1988: 43-54.

61 SPIECKERMANN 1982: 83-85.
} 
gels, saints or ancestors. Attention lavished on the high god's retainers, after all, was a mere corollary of the worship of the high god.

The noun, zbh, "sacrifice, sacrificial feast (involving meat)" is applied to "the baal" only in $2 \mathrm{Kgs}$ 10:19,24 in the Primary History, where Jehu announces such a feast as a trap. In 2 Kgs 5:17, Naaman declares that he will devote neither burnt offering nor meat sacrifice to other gods, but only to Yhwh: notably, he makes no such declaration in connection with other forms of offering, such as incense. As to the verb, zbh, $1 \mathrm{Kgs}$ 11:8 mentions sacrifice (D) by Solomon's foreign wives, along with incense burning, to their respective gods - it seems natural that these foreigners should in fact seek to dedicate meat sacrifices to their respective high gods (including Ashtoret). On the same principle, Judg 16:23 mentions a Philistine sacrifice (LXX with cognate accusative) to Dagon, Num 22:40 a sacrifice (LXX) by Balaq, king of Moab. $1 \mathrm{Kgs}$ 12:32 claims that Jeroboam sacrificed (D) to his calves. Ex 32:8 describes sacrifices (LXX, burnt and whole offerings in v 6) to the golden calf, and Dtn 32:17, sacrifices (LXX) to sedim - to be understood, in light of the Deir Alla plaster, as the subordinate gods of which Yhwh in P, El Shadday, is the chief (cf. Ps 106:37 [LXX] - child sacrifice to sed $m$ ). This material is plainly polemical, and does not represent the subjective experience of the alleged votaries. Ex 34:15 warns against sacrifice (LXX) to the gods of the Canaanites, Lev 17:7 against sacrifice (LXX) in the field to demons (?; s'rym; cf. the possible pun in Dtn 32:17, ścwm), Ex 22:19, as noted, against sacrifice (LXX) to any other god but Yhwh. Otherwise, in the Primary History, there is no reference to sacrifice to alien deities (but in the postexilic context, $2 \mathrm{Chr}$ 33:22, Amon sacrificed [D] to "icons", p's/nm, a term inserted in the parallel Hos 11:2 [D]; $2 \mathrm{Chr} 28: 23$, where Ahaz "sacrificed" [G] to the god[s] of Damascus, saying "Let me 'sacrifice' [D] to the gods of Aram" - those who were smiting him, in the hope of placation according to $\mathrm{Chr}$ - in the latter case, $\mathrm{Chr}$ deduces the act of meat sacrifice from the importation of an altar on a Damascene model).

Notably, the D stem of zbh is attached to sacrifice not just to foreign

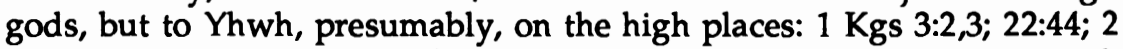
Kgs 12:4; 14:4; 15:4,35; 16:4//2 Chr 28:4 (also Hos 4:13-14; 12:12 at Gilgal; probably 13:2, at Adam, en route to Bethel from the Jordan, where the context condemns the calf iconography; contrast 2 Chr 33:17, LXX, in Chr's non-synoptic section after the rehabilitation of Manasseh; Ez 20:28, LXX); and, at the place of the ark rather than in the temple $-1 \mathrm{Kgs} 8: 5 / / 2$ $\mathrm{Chr} 5: 6$. The only place where the D-stem is used of sacrifice that earns an author's unreserved approbation is in $2 \mathrm{Chr} 30: 22$, where, however, it is the Levites, rather than the Aaronides, who conduct the ritual. All this suggests that the D form is applied to irregular activities, and, to judge from participial forms in which the orthography indicates the conjugation, in this matter the Massora merely follows the lead of the consonantal text. 
In Isa 57:7, as in Ps 106:28,38, the noun, zbh pertains to the funerary cult (at the highland bench-tomb) in connection with child sacrifice (57: 5-6; also 65:3-4, with "sacrifice on rooftops, burn incense on bricks [?]"). Ez 16:16-21; 20:28-31 likewise places child sacrifice on the high places, in connection with metal icons, but with no necessary connection to the funerary cult (Ps 106:37 connects it to $\mathbf{d e d m}$ ). $1 \mathrm{Kgs} 13: 2$ predicts, and $2 \mathrm{Kgs}$ 23:20 relates the sacrifice of priests of the high places by Josiah, but this to Yhwh, in the way of a ban. $2 \mathrm{Chr} 34: 4$ relates that Josiah's men "tore down the altars of the baals and chopped down the hmnym which were above them and broke up the sermm and the icons ( (pisinm) and the plating (of the icons - massekot)," where the altars of the baals and the hmnym that were above them occupy the place of the "high places" in $v 3$. In other words, as in Ez 16:16-21, where it is described at some length (cf. 20:28-31, and further below), the main specific activity connected with the baals, and with the Host of Heaven, other than child sacrifice, is incense burning, not meat sacrifice.

The cultic situation at Tell Miqneh/Eqron IB, ending in the mid-tolate 7th c. contributes substantially to our understanding of this circumstance. In connection with a huge boom in olive oil production - to 1.1 million litres/year, minimum, commanding at least 50,000 dunams of groves, and more probably over $100,000^{62}$ - there is a sudden explosion of incense altars. These are found both in the middle room of the processing workshops (where the pressed oil was presumably finished, possibly by the addition of aromatics) and in the elite area. The incense altars are of a type previously found in Israel and Judah, not Philistia, and may well indicate the socialization of Israelite folk religion at Eqron in the 7th century in both the elite and the industrial and perhaps in the domestic zones ${ }^{63}$. This would not be inconsistent with the occurrence of the Phoenician-type name, hmlk, (A)himelek (cf. [A]hiram), in an unpublished ostracon on the site (but written in Aramaic script!). Indeed, a deportation of Phoenicians (or of Israelites originating near Phoenicia) to Eqron in the 7th century might explain how the author of Kings came to identify Ashtoret particularly with Sidonians. However, if the incense altars found on the steps of the adyton of the Arad sanctuary are 7thcentury ${ }^{64}$, and thus absent from earlier levels in Judah, the influence at Eqron is probably strictly Israelite, as GITIN has suggested ${ }^{65}$.

As to gods at Eqron, an inscripton uncovered in 1990 reads "sacred (i.e., dedicated) to $h q . . s "(h-q-w$ ? $-r / d-s)$, a divine name or epithet possibly from a dialect related to that of the patronymics (?) found in the ostraca

\footnotetext{
62 EITAM and SHOMRONI 1987: 48-49; GITIN 1889; $1989 \mathrm{~b}$.

63 GITIN 1989.

64 USSISHKIN 1988.

65 GITIN 989. But the preservation of final $-t$ on suggests Phoenician influence on the local dialect. Contrast KAI 266.
} 
from Tel Jemme ${ }^{66}$. This would tend to sustain KEMPINSKI's view ${ }^{67}$ that the Jemme names are traditional ones of Philistine social groups: conceivably, the Eqron inscription even reflects a cult of a deified ancestor or cult founder. Asherah, however, appears in several inscriptions at Eqron (including twice, "sacred to Asherah") in the elite area, where further incense altars were uncovered in stratum IB.

Iconographically, Asherah was associated with trees ${ }^{68}$; it may be that as Asherah gives suck to the gods, she is naturally associated with the production of liquids. If she was the primary object of the incense offerings (or first fruits of the presses) in the industrial zone, we would have at Eqron the first reflex of the theology against which Israel's reformationist literature is railing. Since the burning of incense is regularly associated in Israelite (reformationist) literature with homage to gods inferior to Yhwh called baals and asherot/ashtarot, the generic names for Israelite gods and goddesses 69 , the connection seems a likely one. In any case, the situation at Philistine Eqron in the 7th century establishes the basis for later associations of Demeter with the Philistine coast.

Yhwh's asherah, similarly, is the principal candidate for the goddess called the Queen of Heaven in Jeremiah 44. This goddess is identified as the traditional recipient of incense, libations and fragrant cakes or cookies, shaped in her form (presumably the triangle, later the symbol of Tannit), in the female cult (44:15-19; 7:18). Yhwh's epithet in the Elephantine papyri, $m r^{2} s m y^{\prime}$ (also, $/ h s m y^{\nu}$ ), is not unrelated to this issue: that the Lord of the Heavens' consort should be the Queen of the Heavens seems most likely. The apparent association of an asherah with incense, and probably oil-based cakes, at Eqron considerably strengthens the case. At the same time, the erection of a high place outside Jerusalem for "Ashtoret the god(dess) of the Sidonians" - and the fact that this is the only proper name for a goddess (the scantily attested Anat aside) preserved in $\mathrm{HB}$, suggests that this was the personal name of Yhwh's asherah: the latter term, as noted, was a common noun in the singular, yet the standard 7th-century plural for "goddesses" was apparently "Ashtorets".

OLYAN ${ }^{70}$ has made a persuasive case, independent of these considerations, for the identity of the Queen of Heaven with Ashtoret - the "cookies", for example, used in her cult are denominated by a term cognate to kamanu, the cakes used in Ishtar's cult ${ }^{71}$; Ishtar's name is cognate with that of Ashtoret. It may be added, the association of cakes - of a sort

\footnotetext{
${ }^{66}$ NAVEH 1985. See GITIN forthcoming, for a link to the 7th-c. King of Eqron, Ikausu. 67 KEMPINSKI 1987.

68 Usually palms - see HESTRIN 1987: 222-223. GITIN (forthcoming) links leaf-decorated chalices at Eqron and elsewhere to the same motif. See also USSISHKIN, 1982: 77.4-5 register 2.

69 Styled foreign in Josianic literature, but see HALPERN 1987.

70 OLYAN 1988b, against which HESTRIN 1987.

71 HELD 1982.
} 
excluded from the cult of Yhwh in Lev 2:11 - - with the cult of Ashtoret is assured by an epigraph from Kition ${ }^{72}$ (KAI 37.A:10). First millennium inscriptions mentioning Ashtoret confirm her stature among Phoenicians across the Mediterranean. And there is no doubt that she is sometimes referred to as a heavenly deity, although it is by no means clear that the epithet "queen" attaches to her (as KAI 37.A:7,10) in contradistinction to the other major goddesses.

Thus, it may well be that Ashtoret as Queen of Heaven is identical with the asherah of the chief god, even that Ashtoret was somehow identified with Asherah proper: a Phoenician shrine in 7th-6th-century Egypt was dedicated to twin goddesses, and a similar shrine in 11th-10thc. Tel Qasile may reflect the early establishment of such a cult in Philistia73; in Carthage, there is evidence of a temple devoted in common to Astarte and Tannit of Lebanon (most likely, Asherah ${ }^{74}$ ). The temple of the Queen of Heaven referred to in Hermopolis Letter $4.1^{75}$ would presumably have been dedicated to the single figure that emerged from such a union: the goddess, Tannit-Astarte, of the Sareptah ivory plaque, furnishes such a figure, in Phoenicia already in the 7th century, and possibly associated with a wooden icon ${ }^{76}$. Peckham has explored the parallels between the cult of the Queen and Heaven and that of Astarte at Kition (KAI 37), including the mourning rite of cutting one's hair, possibly in connection with a dying god and child sacrifice 77 . The incense central to the cults of the asherah apparently at Eqron 78 , to the Queen of Heaven in Judah and to the worship of Ashtoret and Yhwh's asherah, as well as to the cult of the baals and the Host suggests that these cults stood on a level, and reinforces the possibility of their identity in 8th7th-century Judah. In this case, the Queen of Heaven is Ashtoret, identified with but not necessarily compounded with, Asherah.

Incense, used liberally in the cult of Yhwh, appears as an offering to other gods in a number of texts. atr ("burn incense") without explicit mention of a meat sacrifice, however, need not imply the absence of the

72 PECKHAM 1987: 96-97 n. 79.

73 See A. MAZAR, 1985.

74 CROSS 1973: 30, 31-43; OLYAN 1988a: 53-61.

75 OLYAN 1988b; MILIK 1967: 556-564.

76 PRITCHARD 1978: 104-108; see PECKHAM 1987: 80.

77 PECKHAM 1987: 84-87: the association of Astarte with the dying god, Eshmun, may well be related to child sacrifice, as PECKHAM; ROBERTSON 1982: 329. Given the parallel to Genesis 22, the tradition of Kronos sacrificing his only son as a part of the Phoenician cult looks to be related to the thriving business of infant sacrifice in Phoenician culture. The mourning ritual connected with Astarte in KAI 37 and elsewhere, and the tradition of "raising the god" (mgm 'm), identified as Astarte's bridegroom in KAI 44:2, in Phoenician epigraphs (cf. the Eqron epigraph, Imqm, in the seventh c., where other indications of Phoenician influence are present), suggest the importance of the cycle through the underworld in this cult.

78 See GITIN 1992. 
latter. This verb often refers to the practice of burning the fat for the gods. In fact, Ahaz in $2 \mathrm{Kgs} \mathrm{16:13}$ is said to have "burned his burnt offering and his meal offering as incense" (wyatr 't Itw w't mnhtw)79. The nouns, qtoret, $q$ tord and qtor refer to the substances employed as incense, to the odors thereby produced (also "pleasing odors"), and to the fumes respectively. In the last case, no implication of vegetarianism is present, and this is probably true in the other cases as well. The instances in HB are as follows:

In Kings: $1 \mathrm{Kgs} \mathrm{12:33;} \mathrm{13:1:} \mathrm{Jeroboam} \mathrm{standing} \mathrm{by} \mathrm{the} \mathrm{altar} \mathrm{to} \mathrm{burn}$ incense (C), allegedly to his calf - the referent may be burnt fat; $2 \mathrm{Kgs}$ 17:11: the Israelites on high places, to standing stones and asherim, worshipping glllanm forbidden by Yhwh, identified as Amorite gods, or as icons; 18:4: Israelites, to Nehushtan, the bronze serpent; 22:17//2 Chr 34:5: in Huldah's prophecy, to "other gods" (but on "their manufacture/ the deeds of their hands" cf. Jer 1:16//"other gods"); 23:5: Josiah "cashiered the kmrym [astral priests] whom the kings of Judah appointed to [with O-LXX] burn incense on the high places in the towns of Judah and in the environs of Jerusalem and those who burned incense to 'the baal': to the sun and to the moon and to the constellations and to all the Host of Heaven"; cf. 23:4, "implements donated to 'the baal' and 'the asherah' and to all the Host of Heaven"; 23:8, "the high places where the priests burned incense from Geba to Beersheva".

In Jeremiah:

11:12-13: "So the towns of Judah and the inhabitants of Jerusalem will go forth, and cry out to the gods to whom they burn incense. But these will never deliver them in their time of evil fate. For as the number of your towns were your gods, Judah, and as the number of Jerusalem's streets your made altars to 'Shame', altars to burn incense to nthe baale" (collective plural); 44:21-23: "is this not the incense-burning which you burned in the towns of Judah and in the streets of Jerusalem, you and your fathers and your kings and your officials and the people of the land, and Yhwh remembered and it entered his mind ... and your land became desolate, and a waste, and a curse for want of residents as on this day, because you burned incense and sinned against Yhwh ...";

19:13: "all the houses where they burned incense on their rooftops to all the Host of Heaven and poured out libations to other gods";

32:29: "and the houses where they burned incense on their rooftops to 'the baal' (collective plural) and poured out libations to other gods";

44:3,5,8,15,17-19,21,23,25: Jerusalem fell because Judahites angered Yhwh by burning incense "to other gods, whom they didn't know, they,

79 Note the reflex in $2 \mathrm{Chr}$ 28:3, which reflects Jeremiah's position on the baals and the Host in the Valley of ben-Hinnom. It should be noted, too, that $q t r, C$, outside of $P$ and Chronicles, seems chiefly to pertain to the burning of the fat. It can have the same valence within $P$, as at Ex 30:20; Lev 4:26; 8:21, 28; 9:13-20; 16:25; Num 18:17, for example, but this is far from being its only implication. 
you, and your fathers", so none of the Judahites in Egypt will return to Judah (a key to the theology of the return). tion:

As noted above, the popular response to Jeremiah's oracle is rejec-

"We will nevertheless do everything which issued from (y)our mouth, burning incense to the Queen of Heaven and pouring out libations to her, as we have done - we, and our fathers, our kings and our officials, in the towns of Judah and in the streets of Jerusalem - when we were sated with bread and it was well with us, and we saw no evil. It is only since we ceased to burn incense to the Queen of Heaven, and pour out libations to her, that we have lacked everything, and have been finished off by the sword and by famine ..." (Jer 44:17-18).

The devotions fulfill their vows (ndrynw ndrnw latr lmlkt hšmym, v 25):

"After robbing, murdering and committing adultery and uttering false oaths and burning incense to 'the baal' and going after other gods whom you don't know, you come and stand before me in this house...?" (Jer 7:9);

11:17: to 'the baal'; 18:5: $1 s w^{2}$, in Jeremiah's usage either "vainly" or "to a vain thing"; 1:16: "they burned incense to other gods, and prostrated themselves to their own manufacture"; 19:4-5: in the Valley of benHinnom,

"they left me and alienated this place and burned incense in it to other gods whom they didn't know - they and their fathers and the kings of Judah and filled this place with the blood of innocents, and built the high places of 'the baal' to burn their sons in fire as burnt offerings to 'the baal', which I did not command, nor did I say, nor did it enter my mind".

Here, in the background to the destruction of the rooftops in 19:13; 32:29, where "the baal" is collective, for the Host - the combination of burning incense at the Tophet in the Valley of ben-Hinnom with child

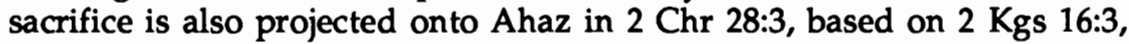
where incense does not appear; 48:35: by Moabites who build high places and burn incense to their god.

In Ezekiel: Ez 8:11: to gllanm, possibly representations of animals/ cherubim inscribed into a wall; 16:18: to male precious metal icons; effectively 23:41: to gillonm, v 37, recipients of child sacrifice, presumably congruent with Jeremiah's 'baal' and possibly even the active Host.

Note also these occurrences in Chronicles: 2 Chr 25:14: Amaziah bowed and burned incense before captured Edomite icons; 28:24-25: Ahaz multiplied altars all over Jerusalem and Judah to burn incense to other gods; 30:14: Hezekiah removed the altars and the mqtrwt, possibly incense altars in the context.

Aside from the previous texts, incense burning is described as the

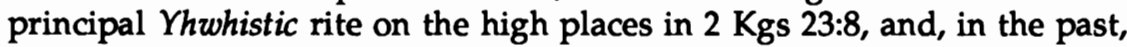
Isa $65: 7$ on the mountains and hills (but Isa $65: 3$ with sacrifice on roof- 
tops, incense on bricks[?]; cf. 66:3). Even $1 \mathrm{Kgs} 13: 2$ predicts a sacrifice on the Bethel altar of "the priests of the high places who burn incense upon you", rather than those who sacrifice meat. Hos 4:13 speaks of sacrifice and incense burning on the hills, where the prostitutes and sacred prostitutes practice. But the object of the sacrifice forecast in $1 \mathrm{Kgs} \mathrm{13:2} \mathrm{is} \mathrm{in}$ fact Yhwh, and the same may be true in the case of the meat sacrifices mocked by Hosea. Hos 2:15 speaks of "the days of the baals, when she [Israel] burned incense to them". And Hos 11:2 states, "They called to them, thus they went from my presence. They sacrificed to the baals, and burned incense to the carved icons". In context, this might refer to almost any incident of apostasy in the tradition, or to all of them. However, it likely reflects contemporary practice. Hosea's main complaint is that attention to the baals entailed forgetfulness about Yhwh's being the one who really - behind the scenes - promoted welfare. That is, the baals are real enough, but Yhwh is the director of their actions.

Incense burning with sacrifice occurs in $1 \mathrm{Kgs} 3: 3$, where the activity (vv 2-4) is surely Yhwhistic; 11:8, where it is not; 22:44; $2 \mathrm{Kgs} \mathrm{12:4;}$ $14: 4 ; 15: 4,35 ; 16: 4 / / 2$ Chr 28:4; but here, though it is on the high places, the assumption is the worship is of Yhwh, or at least of Yhwh along with other deities 80 .

Overall, incense burning appears to be the ritual characteristic of the baals-cult, and is related to infant sacrifice by Jeremiah and Chronicles. In some contexts, mention of incense burning alone can stand in for a larger sacrificial complex, as, in connection with $\mathrm{Yhwh}$, in $2 \mathrm{Chr}$ 32:12 (where an Assyrian official equates Yhwh, in the Chronicler's rhetoric, with a lesser god by suggesting that centralization involved restriction of incense burning to the temple in Jerusalem). However, this is not the case with regard to Yhwh in Kings, nor is it transparently the case in Jeremiah, Hosea or Ezekiel. Thus the incense burning to 'the baal', identified by Jeremiah, Kings and Zephaniah with the Host of Heaven, and with the Queen of Heaven in Jer 7:18; 44, and probably with the asherah at Eqron, represent part of the same cultural matrix.

Nevertheless, the literary evidence implies a cultural transition. Hosea, from the mid-eighth century, mentions meat sacrifices to the baals, and other eighth-century sources, such as E, have similar implications $(1 \mathrm{Kgs} 12$ and Exodus 32 are mutually referential, the former perhaps part of the first edition of DtrH). When one sacrificed, in the distributed clan sacrificial cult of the traditional social organization of Israel, one typically invited Yhwh's subordinates, along with Yhwh, to the repast. The seventh-sixth-century sources, however, including Jeremiah, Ezekiel and the Josianic stratum of the books of Kings, basically do not describe Israelite meat sacrifices to the baals. One nexus for the transition may have been - with the increasing availability of spices in the pe-

80 See HALPERN 1988: 220-228. 
riod as documented at Miqneh and in the resettlement pattern of the seventh century ${ }^{81}$ - a changing semantic weighting of the term, qtr. In Judah, at least, a transition from meat to incense and meal offerings for deities subordinate to Yhwh may well have been one outcropping of Hezekiah's reform. Interestingly, a large altar went out of use at Beersheba in this reform, before the destruction of Beersheba II.

At Arad, AHARON ${ }^{82}$ held that the main, earth-and-fieldstone altar for burnt offerings went out of use after stratum VIII, as a result of Hezekiah's reform (and remained out of use until Josiah ruined the sanctuary): he reports an intact floor of stratum VII, with an oven, on the spot where the altar stood, with the altar's last phase belonging to stratum VIII. AHARONI held that, probably in the same phase, two "incense altars" 83 were buried in the steps of the holy of holies, and two stelae plastered over inside the holy of holies 84 .

AHARONI also reported that Josiah subsequently buried the holy of holies under a casemate wall ${ }^{85}$. But this wall has proven to derive from the Hellenistic period, not the 7th century ${ }^{86}$. Nevertheless, there may be signs of Josiah's reform in some Iron-Age partition walls above the holy of holies ${ }^{87}$, which would imply that the temple was in disuse. USSISHKIN ${ }^{88}$, however, has shown that the incense altars may have been discarded only at the final destruction of the shrine in stratum VI. This in turn implies that only the covering over of the large, courtyard altar, and the plastering over of the pillars inside the Holy of Holies could possibly antedate Josiah; it seems unlikely that the latter will have occurred without the discarding of the incense altars. In short, it now seems most likely that the incense altars and the pillars survived Hezekiah's reform, and it is even possible that they survived Josiah's.

Should the two (small) incense altars be correlated to the two stelae, and associated with oblations to male and female classes of intermediate divinities - the baals and ashtorets - chiefly served through the burning of incense, according to our contemporary texts? The huge altar of burnt-offering would then pertain to Yhwh, the main object of meat sacrifices. It may be that the larger stela in fact represents the presence of

\footnotetext{
81 See GITN 1992; HALPERN 1991.

82 AHARONI 1968: 26-27.

83 See generally GITIN 1989: 52-67, esp. n. 4 where an association with "meal offerings" is suggested.

84 The removal of the incense altars was originally attributed to stratum IX, but it is now clear that the sanctuary cannot have been built before stratum IX, sometime in the 8th century - USSISHKIN 1988.

85 Further HERZOG, AHARONI, RAINEY and MOSHKOVITZ 1984.

86 MAZAR and NETZER 1986; cf. HERZOG 1987.

87 MAZAR and NETZER 1986.

88 USSISHKIN 1988.
} 
Yhwh himself, and that the smaller represents that of the baals: the ashtorets seem to have had poles or trees as their icons, rather than stones.

In any event, Hezekiah certainly left the temple standing as a functional structure, and probably even built it. This is consonant with the general character of Hezekiah's reform: it was his strategy to abandon the countryside to the Assyrians, and concentrate the rural population inside fortresses to protract the campaign in the hope of Egyptian or other intervention (the Egyptian intervention did, as it happens, prove decisive). As a corollary of this strategy, state shrines had to be renewed in the fortresses, and the population and priesthoods had to be registered ${ }^{89}$. It is improbable, however, that Hezekiah left the priesthoods at Arad intact or enrolled additional rural priests there, as part of his centralization of the population to state fortresses, without some provision for cultic activity. Yet it is incontrovertible that cultic activity at Arad inside the fortress itself, which was closely linked to Jerusalem - survived Hezekiah's period. It follows that at least incense burning, and possibly even animal sacrifice, continued at least until Josiah's day.

Some of the ambiguities in the interpretation of the data will be clarified with the final publication of the site, which HERZOG promises $^{90}$. For the interim, it seems most conservative to suggest that any marked reform of the temple at Arad be associated with Josiah, or the Babylonians. However, if a floor of stratum VII did indeed overlie the altar, it is a sign that sometime between 725 and about 610 the cult at Arad shifted away from meat offerings toward meal and incense offerings, as a residue of Hezekiah's reform.

A parallel development later occurs at the Elephantine temple, which before its destruction conducted meat and meal (and incense) offerings, but which after its reconstruction was licensed from Jerusalem to conduct the latter only ${ }^{91}$. Whatever remained of the "solar temple" at

89 See HALPERN 1991 for the reconstruction of the reform in its strategic valence.

90 HERZOG 1987: 77-79.

91 PORTEN and YARDENI 1986: A4.7:21,25-26,27-28; A4.8:20-21,24-25,26-27; A4.9: 9-11.

The actual history of the Yeb temple controversy is probably a bit more intricate than is usually indicated. Having failed, during the troubles of 410 , to extract any sign of support from Jerusalem itself (or the high priest Yohanan) - very likely because of opposition to the existence of any functioning temple outside of Jerusalem - Yedaniah in 407 turned instead to the governor of Samaria and to Bagoas, who was the person responsible for the governance of the province of Yehud (PORTEN and YARDENI 1986: A4.7:1). Yet the response to this inquiry came from Bagoas and Delaiah, son of Sanballat, then the governor of Samaria (PORTEN and YARDENI 1986: A4.9, but also attested in the Wadi Daliyeh papyri). Josephus's tradition (Ant. IX.7.1-2) of a Bagoses who came into conflict with a high priest, John (Yohanan), and with Jerusalem generally, in conjunction with a governor of Samaria, Sanballat, presumably telescopes the Elephantine contretemps with the recognition of a subsequent Sanballat by Alexander.

The conclusion to be drawn is that the Jerusalem establishment rejected Elephantine's bona fides, and was perhaps more sympathetic to the rebel, Vidranga, than not. Yet the Judaeans of Yeb found willing ears in Samaria and in the "general" Josephus identifies 
Lachish, too, at its apparent end-use in 701, divulged incense burners and an "incense altar" but no large meat altar" ${ }^{92}$ The Elephantine situation, at least, reflects fundamentally the notion of reform presented in Deuteronomy (and this in turn reflects seventh-century state practice): Dtn 12 regulates all sorts of behaviors, but the explicit injunction is against meat sacrifice (12:13-14) outside the "chosen" (i.e., central) place. There is an injunction on enjoying meal offerings for first fruits and vows at home, too (12:17-18). But the central issue is that of meat sacrifices, for which reason the question of profane slaughter is treated at great length (12:15-16, 21-25; 15:22-23). Implicitly, the injunction distinguishes meat sacrifice - for any meat derived from domestic herds from other forms of nourishment whose preparation did not necessarily involve cultic activity. There is no explicit injunction against the oblique devotion of such foodstuffs to subordinate gods in one's pantheon. This is illicit, surely. But it falls into a different category from that into which meat offerings fall. Indeed, on bringing the tithe of the third year to the gate for the indigent to enjoy, the lawcode lays an obligation on the Israelite pilgrim to declare, "before Yhwh", that he gave none of it to the ancestors. Again, not surprisingly, there is no such interdict on the rest of the agricultural produce of the land.

What is interesting in the late 7th century is that even incense burning - and meal-offerings in Jeremiah 44 - to subordinate gods in the pantheon now attract opposition, from Jeremiah, Ezekiel, Deuteronomy, Kings and Zephaniah. Thus, Jeremiah, as noted, identifies the Host of Heaven as baals, as does Zephaniah and $2 \mathrm{Kgs}$ 23:4-5. Early texts (Judg 5:20) and texts coming from certain traditions into Kings ( $1 \mathrm{Kgs} 22: 19 / / 2$ Chr 18:18)93 and the Deuteronomistic History even reflect favorably on the "Host" (Jos 5:14-15, with Joshua prostrating himself to the captain of the "Host"; 10:10-13, substantively parallel to Judg 5:20 in that the heavenly bodies conspire with the Israelites against the Canaanites).

Other positive or neutral references to the Host occur both in preexilic and in post-exilic materials. In Isa 13:4-6, the Host are Yhwh's army, just as in Judg 5:20. In Isa 14:13, ascendancy among the "stars of El"

him as an officer serving Artaxerxes, but Josephus is not altogether reliable on the identities of Persian kings at moments when their activities intersect with his history - a great deal of his information concerning the Achaemenids derives from reconstruction, and, in this case, the book of Esther interferes). The conflict between Bagoses and Jerusalem is reflected in that between Yeb and Jerusalem. Both the Samarian establishment and the anti-Jerusalemite general/governor had an interest in subsidizing the temple at Yeb.

92 AHARONI 1975: 26-32. Further HOLLADAY 1987: 254. For possible cultic elements (bronze censors) in the Lachish reliefs, see USSISHKIN 1982: 77.4-5 register 2. In ligth of these, and of the historical data, it seems likely that the level III "high place" posited by AHARONI was in fact a going concern.

93 On the redactional history of which see HALPERN and VANDERHOOFT 1992. 
is the mark of the master of the heavens. Ps $148: 3$ portrays the sun, moon and stars, among the Host, praising Yhwh - in a topos connected with the "sons of gods" in Ps 29:1-2. In Job 38:7, the stars, understood to represent the sons of Yhwh, cheer Yhwh's foundation of the universe. It is not irrelevant that Israel is compared in number or otherwise to the stars (as Gen 15:5; 22:17; 26:4; 37:9; Ex 32:13; Num 24:17), a metaphor that reflects positively on the host of stars (residual in Jer 33:22). The title, Yhwh of Hosts94, also reflects positively on the Host of Heaven in sources that construe that body to consist of animate beings under Yhwh's control (as above, and including J, E, most of Samuel, Amos [3:13; 6:14; 9:5]; Hosea [12:6, interpreting Ex 3:15, after 12:4-5]; proto-Isaiah, Micah [4:4], Nahum, Habakkuk, parts of Psalms, etc.; probably Zechariah). Unsurprisingly, in light of all this, Sargon's report of the sack of Samaria includes a reference to "the gods on whom they relied"95. The references to astral deities connected with Samarian exile, noted above, find confirmation in this report.

However, in some texts, the "Host" or the "Host of Heaven" is a demythologized cliche. P, for example, identifies Israel as the "hosts" of Yhwh of Hosts. In Ex 7:4, Yhwh vows to withdraw "my hosts, my people, the children of Israel from the land of Egypt". In Ex 12:17, Yhwh commemorates the day on which "I withdrew your hosts from the land of Egypt". And, in Ex 12:41 (similarly, Ps 103:21), "all the hosts of Yhwh withdrew from the land of Egypt" (cf. also 12:51). The identification of Israel as the Host is the logical corollary of earlier promises (JE) that Israel will be as numerous as the stars: the stars now become, instead of the counterparts of the gods, those of the Israelites, Yhwh's adopted children.

As to the stars themselves, identified as the Host, these reach the cusp of inanimacy in P at Gen 2:1, where the heavenly Host is depersonalized, along with the other aspects of nature. In Isa 40:26; 45:12; Ps 33:6, where the creation of the stars (host) is witness to Yhwh's puissance, no personality or function is attributed to the host. In some texts, actual hostility against the host is present: in Isa $24: 21 ; 34: 2-4$, violence visited on the host reflects violence against mundane foes with whom the Host is identified (more metaphorically, Dan 8:10)96. Not all texts share this hostility. Zech 4:10b identifies the seven branches of an oil lamp (inscribed on the lintel of the Second Temple, but received as a vision in 4:2) as "the eyes of Yhwh, they scout out all the earth". The "eyes" and the lamps figure the seven planets. Similarly, the "eyes" filling the backs of Ezekiel's fiery beasts or the wheels beneath them $(1: 18 ; 10: 12)$ must re-

94 Possibly, "he summons Hosts into being", parallel to Yhwh Elohim: HALPERN 1987: 85; but cf. METTINGER 1987: 30-32; and the Carian Zeus Stratios in Herodotus 5.120.

95 GADD 1954: 179.iv.32.

96 Contrast Ps 82 , where the judgement on the Host comes in a context that assumes the benevolent functioning of that body. 
present the Host, again as Yhwh's scouts. It may be that the concept of "wheels within wheels" (Ez 1:16), intended to afford mobility in all directions to the chariot of Yhwh (which is itself modelled on the basin stands of Solomon's temple, removed by Ahaz), reflects the "Egyptian" astronomy on which Herakleides' system was allegedly based - with Mercury and Venus circling the sun, a wheel within the wheel of the sun's circling the earth. Still, even where the stars or planets are Yhwh's eyes, they lack individuality, are mere organs of his senses.

The background of this alienation of the Host from Yhwh and from Israel - its depersonalization, its rejection, can be summarized in a word: the Host is foreign, in Josianic theory. In Dtn 4:19-20 (cf. Jer 10:2), the Host is explicitly identified as that body of manifestations which Yhwh had assigned to the "nations", not Israel. In the traditional cosmology, the Host is at least potentially identical with those subordinate deities responsible for administering foreign nations. Thus, Dtn 32:8-9 affirm (with LXX) that Yhwh determined the territories of the nations "according to the numbers of the sons of El", choosing as his own portion Israel. Each "son of El" administers a single territory, but Israel is under direct rule. The model for such a conception is of course the phenomenon of vassalship, or the appointment of governors within an empire - a model familiar in Canaan from the time of the first Egyptian conquests there, through Solomon, and down to the British Mandate.

Mi 4:4-5 affirms the same theology: "for all the nations go each in the name of its god, and we will go in the name of Yhwh [Sebaoth: 4:4] our god forever and aye". Even inside DtrH, traces of a similar attitude survive: in Judg 11:24, Jephthah pleads with the Ammonites: "Should you not take possession of whatever (territory) Chemosh, your god, supplants for you, and what Yhwh, our god, supplants from before us, of that, we should take possession?" The underlying notion is that Yhwh and Chemosh (usually identified with Moab) each administer separate territories - though admittedly, this is a case of international diplomacy in which such a tolerant assumption is most circumspect (which may be why the tradition survives). Nevertheless, reference to Moab as "the people of Chemosh" (Num 21:29), as to Israel as "the people of Yhwh", as much as concedes the legitimacy of Moabite devotion to Chemosh. This, after all, was nothing more than an expression of their national identity, their common kinship.

The traditional Israelite conception, in sum, is that Yhwh Sebaoth is the god, and direct administrator, of Israel: in the natural order, arranged by Yhwh, each nation is assigned a divine master, subordinate to Yhwh - one of his sons, which is to say, an officer of his Host. The cults of the foreign nations, therefore, are dedicated to the subordinates (to whom Israelites also turn - interestingly, Micah and Isaiah both refer positively or neutrally to human sacrifice). In the circumstances, the god of a foreign nation might be regarded as its master - its baal - just as 
Yhwh is Israel's baal (Hos 2:18; cf. Jer 3:14; 31:32). Probably, it is in just such a connection that Isaiah speaks of "the baals of the nations" destroying Moab (Isa 16:8, omitted in Jer 48:31-32): these are the gods to whom Moab will no longer be able to pray when it enters the sanctuaries on its high places (Isa 16:12; cf. Jer 48:35). Indeed, it is tempting to speculate that traditions of a council of seventy elders or sons of a judge or king, headed by Moses and Aaron (in E) or by the judge or king and queen, like the image of seventy sons of Asherah (and El) at Ugarit, reflect ideas of a natural cosmology in which seventy(-two) Great Gods (fifty in Babylonia, and in Zech 4:2-3) administer all the nations ${ }^{97}$.

Yet, on this theory, the Host stood in an ambivalent position. On the one hand, the Host is construed as Yhwh's court (1 Kgs 22:19), as the "sons of gods" (Ps 29:2), as "gods, sons of Elyon" (Ps 82:6). Yet at the same time, the great gods were those of foreign nations. As a consequence, attention to the great gods, the baals, to the Host, can be construed as foreign worship. It is no coincidence that Hosea rails on against both the baals and foreign alliances: symbolically, embracing a foreign patron can be modelled as an equivalent to exalting a subordinate in Yhwh's pantheon. And thus, starting with Hosea in the mid-eighth century, xenophobia, a driving force in the following century in Judah, was enlisted to alienate the pantheon from its controller, Yhwh.

One symptom that this process was the decisive one is the characteristic equation of astral worship in Dtn 17:3 with that of "other gods", the cardinal sin of alien worship. In $2 \mathrm{Kgs} \mathrm{17:16,} \mathrm{the} \mathrm{context} \mathrm{of} \mathrm{worship}$ of the Host is worship of 'the baal' and 'the asherah' and child sacrifice, accusations against the Israelites (not Judah) concretized in accounts of 'baal'-worship and the erection of an 'asherah' under the Omrides. All this material attests to the "otherness" of these classically "other gods", "gods of the foreigner", in this literature. In 2 Kgs 21:3,5, Manasseh is accused of building altars for 'the baal' and 'the 'asherah', an activity resulting in the building of altars for all the Host of Heaven in the temple courts (destroyed in $2 \mathrm{Kgs} \mathrm{23:12):} \mathrm{Manasseh} \mathrm{was} \mathrm{worse} \mathrm{than} \mathrm{the} \mathrm{nations}$ Yhwh supplanted from before the Israelites (21:2), presumably insofar as he introduced such abominations into the temple of Yhwh itself. And

\footnotetext{
97 Such a tradition is present in the Talmud, and is understood in passages there referring to Michael as "the great official", as TB Men 110a and the like. The implication is (and other passages naming Gabriel, for example, likewise imply) that there are other "officials" of the Host. The tradition of seventy(-two) great gods thus presumes that for each planet, there are ten members of the officialdom (as captains of hundreds versus captains of tens), plus two leaders (Yhwh and his asherah?). The tradition of fifty great gods presupposes seven members of the officialdom for each of the planets (plus Marduk, or, in Zech 4:2-3, Yhwh). It is worth noting that the apologetic emendation of Dtn 32:9, "El" to "Israel" reflects an equation of Israel with the stars, and of the stars with the administration of human nations, a sort of combination of the $\mathrm{P}$ notion that Israel was Yhwh's host, with the notion, shared by $\mathrm{P}$, that the Host of Heaven were the stars and the view of Dtn 32:8-9 itself, that the Host administered the nations.
} 


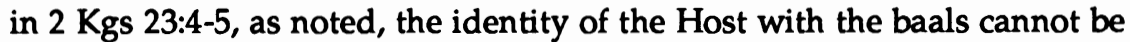
gainsaid. The same equation is clear in Jer 8:2; 19:3; Zeph 1:4-5. The late seventh-century revisionist elite view, again, was that any divine subordinate was an alien (contrast the traditionalists of Jeremiah 44). The identification of the baals with the gods of foreigners, other gods, had alienated the Host of Yhwh of Hosts.

Was this the case with Hosea in the mid-eighth century? The chances are, the answer is yes. Hosea accuses Israel of abandoning her "husband" (baal), Yhwh, for "lovers" whom she thinks sustain her (2:7) - as noted, the concept of Yhwh as a baal (= husband) ${ }^{98}$ has inspired the adultery metaphor. But it is Yhwh himself who has furnished her fertility and rare earths, which she dedicates to 'the baal' (2:10; cf. 2:15). No longer to be called her 'baal' (husband), but her 's, her "man"; here, Hosea puns on the affirmation "DN is!", "there is", as in the names of Jesse and Eshbaal 99 - he represents Yhwh as the living god, 2:1. Yhwh, Hosea avers, will suppress the names of the baals $(2: 19)$ and renew his marriage to Israel as a faithful one, without other gods (2:23-3:5). Aside from breaking the social contract (4:1ff.; 7:1; 10:4), Israel have sacrificed on the hills (4:13-14; 10:2,8; multiplying altars to sin, 8:11), using icons (8:4-6; $10: 2,5 ; 13: 2$, after a tradition that Ephraim died for involvement with 'the baal', 13:1; 14:9), and have sought foreign alliances (7:11-12; 14:4,9), which will lead to exile in those countries (9:3 [cf. Jer 6:20 on 9:4]; 10:6), a motif connected with serving the baals and icons in 11:2,5. The alternation in Hosea between foreign alliance and rural cult and 'baal' suggests that the intellectual process involved is a denial both of subordinate gods and of foreign entanglements, or, to put it differently, of the equa-

98 Significantly, this usage for "husband" occurs only in the following texts: Gen 20:3 (E); Ex 21:3, 22; Dtn 22:22 (phrase of Gen 20:3); 24:4 (note also, however, 21:13; 24:1); 2 Sam 11:26; Hos 2:18; and, in postexilic texts, Joel 1:8; Prov 12:4; 31:11,23,28; Est 1:17,20. Allowing that the concept, "husband", presupposes that a female figure is the subject of discourse, nevertheless, the absence of the term from J, P and Ezekiel, and, two specific laws apart, from nearly all of Deuteronomistic literature and from Jeremiah is striking a virtual adoption of Hosea's advice (Jeremiah does, however, use the verb - 3:14; 31:32). This distribution, with a few exceptions, basically characterizes the use of bacal as a designation for "owner" as well, though texts within DtrH do make use of it - in the following constellations: 1) Dtn 15:2; 2) Jos 24:11;3) Judg 9:2,3,6,7,18,20 [bis],23,24,25,26,46, 47,51;4) Judg 19:22-23; 20:5; 5) 1 Sam 28:7; 6) 2 Sam 1:6; 7) 2 Sam 21:12; 8) 1 Kgs 17:17; 9) 2 Kgs 1:8. Most of these passages either derive from sources or reflect some other hand than that of $H(D t r)$. For 15, "man", as husband, see, e.g., Dtn 22:23; 25:11; Judg 13:6,9,10; 14:15; 19:3; 20:4; 1 Sam 1:8,22,23; 2:19; 3:16; 4:19,21; 25:19; 2 Sam 11:26; 14:5,7; 2 Kgs 4:1,9, $14,22,26$. This term in this semantic capacity is much more widely distributed outside $\mathrm{DtrH}$ in preexilic and exilic literature than is bac al, including occurrences in J (as Gen 3:6; 16:3), E (as Gen 29:32,34; 30:15,18,20), P (Lev 21:7; Num 5:13,19-20,27,29; 30:11-15) and Ezekiel (16:32); further, in the plural, arguably Jer 29:6; Ez 16:45, but more clearly, Jer 44:19. In the postexilic period, however, bac al alone assumes this meaning.

99 CROSS 1973: 64. 
tion of what is foreign (and what is unjust) with worship of subordinate deities.

In Hosea, the background for the intellectual developments of the late 8th and, later, 7th century are present. Indeed, the identification of the "baals" as gods of foreign nations (and Micah 4:4-5 at the end of the 8th century, probably Isa 16:8), as distinct from as gods subordinate to Yhwh, lies at the base of their rejection. The equation of what is foreign with what is evil is a chief point of the method of the historian who produced DtrH. The likelihood is that this was a tendency inherited from earlier members of the Jerusalem elite, starting at least with Hezekiah ${ }^{100}$.

The depersonalization of natural phenomena implied in this transition, the depersonalization of the Host, was part and parcel of the implications of increasingly rigorous monotheism. So, too, was the denial of the power of the dead, of the ancestors, who perhaps figure subliminally as connected to the baal in Jeremiah's metaphor of subterranean "broken cisterns"101. But who was the singular Baal with whom Yhwh allegedly came into conflict in Judg 6:31-32; 1 Kgs 18? The traditional candidates all have their attractions. However, just as Yhwh was the baal at the head of all the baals into the eighth century, it seems most likely that the polemicists of the seventh century understood the baals to be representatives, even reflections, of a single, paradigmatic Baal. And the likelihood is that this figure was identified with the Chemosh, and Milcom, of Solomon's shrine, and with the sun, as the head of all those planets ${ }^{102}$. It is difficult, thus, to imagine any candidate more likely to impress itself on the mind of contemporary Jerusalemites than Baal Shamem, "the Lord of the Heavens", known both through Phoenician and through Aramaic sources, and an appropriate counterpart to the Queen of the Heavens ${ }^{103}$.

But this is not to say that Baal Shamem was the figure with whom Elijah came into conflict, since Jezebel will presumably have come to Samaria, as Solomon's wives came to Jerusalem, with a full panoply of Phoenician gods to placate: "the baal", remembered in the tradition as a single figure, was probably virtually indistinguishable from the Israelite pantheon at the time, but with a Tyrian twist. Hosea's perspective, that the "day of Jezreel", the bloodbath of Jehu, was to be visited on the Nimshides betrays a divorce of that occasion from the confrontation reconstructed in Kings. Hosea's complaints about the baal/baals under the Nimshides underscore the same point. Rather, the reconstruction of a

100 Cf. SPIECKERMANN 1982: 201-211; NOTH 1966: 52-55; HALPERN 1987; 1991.

101 HALPERN 1987; 1991.

102 See TAYLOR 1989.

103 Cf. B. MAZAR 1986: 79-81. One wonders what, if any, relationship obtained with the Sibitti, possibly reflected, as PROPP observes (in conversation), in such names a Bathsheba and Elizabeth; cf. KAI 222A:II. 
Baal other than Yhwh with whom Yhwh came into conflict probably reflects the alienation of the baals, the Host, from Yhwh in the seventh century. Yhwh, on Hosea's admonition, was no longer the Baal, but rather an 15 . He was no longer identified with the sun. Into this vacuum some other emblematic baal had to be sucked. And whoever that figure was - Milcom, Chemosh, Baal Shamem, or all of them or some other his foreign affiliations contributed to the operation of the Josianic polemic, the xenophobic critique of the seventh-century prophets.

The Israelite elite, represented at the end of the Iron Age by Josiah, Jeremiah, Ezekiel, P and H(Dtr), did not arrive at a doctrine of monotheism by rejecting the gods of other peoples. Rather, it arrived at this pass by rejecting the gods that traditional culture, and earlier elite culture, had inherited from the fathers from the remotest bounds of the collective memory. The Deuteronomistic History as much as admits that such gods, and the cultic appurtenances characteristic of their cults, stemmed from the earliest moments of Israel's life in Canaan. And the attribution of Deuteronomy to Moses represents an attempt to manufacture a tradition, of alienation from all gods other than Yhwh, that is older than memory itself - older than the memories of "other gods" who were Israelite gods, who were, in the traditional understanding, a part of Yhwh's heavenly court.

Revolutionaries, like Jeremiah and H(Dtr), lack historical perspective. Whether pretending to be reactionaries, restoring humankind to a primitive Garden of Eden, or whether posing as social engineers, murdering, by the guillotine or by some less violent form of attrition the resistant membership of some former governing class, such world-makers theoretically demonize their opponents' customs, without placing them in a context. This sort of adolescent idealism, unnuanced by an interest in actual observation, invariably breaks down when its adherents achieve power: the result is a terror concentrated on consolidating the power of the Party. Josiah supplied such a terror, an extended attack on the institutions and regalia of traditional culture in Judah and Samaria. Monotheistic purists, in love with the theory of a unified, rather than multifarious, reality, ultimately had to slay the demons of other divinities than Yhwh. Not ironically, to slay those demons, they had to demonize their own history. 


\section{BIBLIOGRAPHY}

-AHARONI, Y.

1968 Arad: Its Inscriptions and Temple. BA 31: 2-32.

1975 Lachish V. The Sanctuary and Residency. Tel Aviv: Institute of Archaeology.

-ANDERSEN, F.I. and FREEDMAN, D.N.

1980 Hosea. AncB 24. Garden City, NY: Doubleday.

1989 Amos. AncB 24A. Garden City, NY: Doubleday.

-AVIGAD, N.

1983 Discovering Jerusalem. Jerusalem: Shikmona.

1986 Hebrew Bullae from the Time of Jeremiah. Jerusalem: Israel Exploration Society.

-BORGER, R.

1956 Die Inschriften Asarhaddons Königs von Assyrien. AfO.B 9. Graz: Weidner.

-BUDDE, $K$.

1890 Die Bücher Richter und Samuel. Giessen: Ricker.

-CROSS, F.M.

1973 Canaanite Myth and Hebrew Epic. Cambridge: Harvard University Press.

-DEVER, W.G.

1984 Asherah, Consort of Yahweh? New Evidence from Kuntillet 'Ajrud. BASOR 255:

21-37.

-DION, P.E.

1991 Deuteronomy 13: The Suppression of Alien Religious Propaganda in Israel during the Late Monarchial Era. Pp. 147-215 in Law and Ideology in Monarchic Israel, ed. B. HALPERN and D.W. HOBSON. JSOTSup Sheffield: Sheffield Academic Press.

-DRIVER, G.R. and MILES, J.C.

1935 The Assyrian Laws. Oxford: Oxford University.

-EISSFELDT, $O$.

1962 Kleine Schriften I. Tübingen: Mohr.

-EITAM, D. and SHOMRONI A.

1987 Research of the Oil-Industry During the Iron Age at Tel Miqne. Pp. 37-56 in Olive Oil in Antiquity. Israel and neighbouring countries, ed. M. HELTZER and D. EITAM. Haifa: University of Haifa, Israel Oil Industry Museum and Dagon Museum.

-FITZMYER, J.A.

1966 The Phoenician Inscription from Pyrgi. JAOS 86: 285-297.

1967 The Aramaic Inscriptions of Sefire. BiOr 19. Rome: Pontifical Biblical Institute.

-FREEDMAN, D.N.

1987 Yahweh of Samaria and His Asherah. BA 50: 241-249.

-GADD, C.J.

1954 Inscribed Prisms of Sargon II from Nimrud. Iraq 16: 173-201.

-GITIN, S.

1989 Incense Altars from Ekron, Israel and Judah: Context and Typology. EI 20: 52*$67^{*}$.

1989b Tell Miqne-Ekron: A Type-Site for the Inner Coastal Plain in the Iron Age II Period: AASOR 49: 23-58.

1992 New Incense Altars from Ekron: Context, Typology and Function, EI 23.

Forthcoming Seventh Century BCE Cultic Elements at Ekron, Proceedings of the Second Congress on Biblical Archeology. Jerusalem: Israel Exploration Society.

-HADLEY, J.M.

1987 The Khirbet el-Qom Inscription. VT 37: 50-62.

-HALPERN, B.

1987 'Brisker Pipes than Poetry': The Development of Israelite Monotheism. Pp. 77115 in Judaic Perspectives on Ancient Israel, ed. J.A. NEUSNER, B.A. LEVINE and E.S. FRERICHS. FS H.L. GINSBERG. Philadelphia: Fortress. 
1988 The First Historians: The Hebrew Bible and History. San Francisco: Harper \&

Row.

1991 Jerusalem and the Lineages in the Seventh Century BCE: Kinship and the Rise of Individual Moral Liability. Pp. 13-108 in Law and Ideology in Monarchic Israel, ed. B. HALPERN and D.W. HOBSON. JSOTSup Sheffield: Sheffield Academic Press.

-HALPERN, B. and VANDERHOOFT, D.S.

1992 The Editions of Kings in the Eighth-Seventh Centuries BCE. HUCA.

-HELD, M.

1982 Studies in Biblical Lexicography in the Light of Akkadian. EI 16: 76-85 (Hebr.).

-HERZOG, Z.

1987 The Stratigraphy of Israelite Arad: A Rejoinder. BASOR 267: 77-79.

-HERZOG, Z., AHARONI, M., RAINEY, A.F. AND MOSHKOVITZ, S.

1984 The Israelite Fortress at Arad. BASOR 254: 1-34.

-HESTRIN, R.

1987 The Lachish Ewer and the 'Asherah. IEJ 37: 212-223.

-HOLLADAY, J.S.

1987 Religion in Israel and Judah Under the Monarchy: An Explicitly Archeological Approach. Pp 249-299 in Ancient Israelite Religion. Essays in Honor of Frank Moore CROSS, ed. P.D. MILLER, P.D. HANSON and S.D. MCBRIDE. Philadelphia: Fortress.

-KAI H. DONNER and W. RÖLLIG, Kanaanäische und Aramäische Inschriften. 3 vols. Wiesbaden: Harrassowitz, 1971.

-KAUFMANN, Y.

1937-56 The History of the Israelite Faith. 4 vols. Tel Aviv: Dvir-Bialik. (Hebr.)

-KEMPINSKI, A.

1987 Some Philistine Names from the Kingdom of Gaza. IEJ 37: 20-24.

-LANGDON, S.L.

1912 Die neubabylonischen Königsinschriften. VAB 4. Leipzig: Hinrichs.

-LEMAIRE, A.

1977 Les inscriptions de Khirbet el-Oom et l'ashérah de YHWH. RB 84: 595-608.

1986 Vers l'histoire de la rédaction des livres des Rois. ZAW 98: 221-236.

-MANDELKERN, S.

1959 Veteris Testamenti Concordantiae Hebraicae atque Chaldaicae. 4th ed. Tel Aviv: Schocken.

-MAZAR, A.

1985 Pottery Plaques Depicting Goddesses Standing in Temple Facades. Michmanim 2:

5-18.

-MAZAR, A. and NETZER, E.

1986 On the Israelite Fortress at Arad. BASOR 263: 87-91.

-MAZAR, B.

1986 The Early Biblical Period. Historical Studies. Jerusalem: Israel Exploration Society.

-MCCARTER, P.K.

1987 Aspects of the Religion of the Israelite Monarchy: Biblical and Epigraphic Data. Pp. 137-155 in: Ancient Israelite Religion. Essays in Honor of Frank Moore CROSS, ed. P.D. MILLER, P.D. HANSON and S.D. MCBRIDE. Philadelphia: Fortress.

-MEIER, G.

1941-44 Die zweite Tafel der Serie bit meseri. AfO 14: 139-152.

-MESHEL, Z.

1978 Kuntillet 'Ajrud. A Religious Centre from the Time of the Judaean Monarchy on the Border of Sinai. Israel Museum Catalogue 175. Jerusalem: Israel Museum.

-METTINGER, T.N.D.

1987 In Search of God. The Meaning and Message of the Everlasting Names. Philadelphia: Fortress Press. 
-MILIK, J.T.

1967 Les papyrus araméens d'Hermoupolis et les cultes syro-phéniciens en Egypte perse. Bib. 48: 546-621.

-MILLARD, A.R.

1976 Assyrian Royal Names in Biblical Hebrew. JSS 21: 1-14.

-NA'AMAN, N.

1987 The Negev in the Last Days of the Kingdom of Judah. Cathedra 42: 4-15.

-NAVEH, J.

1962 The Excavations at Mesad Hashavyahu: Preliminary Report. IEJ 12: 90-113.

1985 Writing and Scripts in Seventh-Century BCE Philistia: The New Evidence from

Tell Jemmeh. IEJ 35: 9-21.

-NOTH, M.

1943 Überlieferungsgeschichtliche Studien. Halle: Niemeyer.

1966 The Laws in the Pentateuch and Other Essays. Philadelphia: Fortress.

-OLYAN, S.M.

1987 The Cultic Confessions of Jer 2,27a. ZAW 99: 254-259.

1988a Asherah and the Cult of Yahweh in Israel. SBLMS 34. Atlanta: Scholars.

1988b Some Observations Concerning the Identity of the Queen of Heaven. UF 19: 161174.

-PECKHAM, J.B.

1987 Phoenicia and the Religion of Israel: The Epigraphic Evidence. Pp. 79-99 in Ancient Israelite Religion. Essays in Honor of Frank Moore CROSS, ed. P.D. MILLER, P.D. HANSON and S.D. MCBRIDE. Philadelphia: Fortress.

-PORTEN, B. and YARDENI, A.

1986 Textbook of Aramaic Documents from Ancient Egypt. 1. Letters. Texts and Studies for Students. Jerusalem: Hebrew University. Department of the History of the Jewish People.

1989 Textbook of Aramaic Documents from Ancient Egypt. 2. Contracts. Texts and Studies for Students. Jerusalem: Hebrew University Department of the History of the Jewish People.

-PRITCHARD, J.B.

1978 Recovering Sarepta, A Phoenician City. Princeton: Princeton University Press.

-REISNER, G. A.

1924 Israelite Ostraca from Samaria. Cambridge: Harvard University.

-RICHTER, W.

1963 Traditionsgeschichtliche Untersuchungen zum Richterbuch. BBB 18. Bonn: P. Hanstein.

1964 Die Bearbeitungen des "Retterbuches" in der deuteronomischen Epoche. BBB 21. Bonn: P. Hanstein.

-ROBERTSON, N.

1982 The Ritual Background of the Dying God in Cyprus and Syro-Palestine. HTR 75: 313-359.

-SMITH, M.

1990 The Early History of God. San Francisco: Harper \& Row.

-SPIECKERMANN, $\mathrm{H}$.

1982 Juda unter Assur in der Sargonidenzeit. FRLANT 129. Göttingen: Vandenhoeck \& Ruprecht.

-STÄHELIN, J.J.

1843 Untersuchungen über den Pentateuch, die Bücher Joshua, Richter, Samuelis und Könige. Berlin: Reimer.

-TAYLOR, J. G.

1989 Solar Worship in the Bible and Its World. Ph. D. Diss., Yale University. 
-TIGAY, J.

1986 You Shall Have No Other Gods. Israelite Religion in the Light of Hebrew Inscriptions. HSS 31. Atlanta: Scholars.

-USSISHKIN, D.

1982 The Conquest of Lachish by Sennacherib, Tel Aviv: Tel Aviv University Institute Archeology.

1988 The Date of the Judaean Shrine at Arad. IEJ 38: 142-157.

-WEINFELD, $M$.

1977 Review of Meshel 1978. Shnaton 4: 280-284.

1978/79 Further to the Inscriptions of 'Ajrud. Shnaton 5-6: 237-239.

-WEIPPERT, M.

1981 Assyrische Prophetien der Zeit Asarhaddons und Assurbanipals. Pp. 71-115 in Assyrian Royal Inscriptions: New Horizons in Literary, Ideological, and Historical Analysis, ed. F.M. FALES. Orientis Antiqui Collectio, 17. Rome: Istituto per l'oriente, Centro per la antichità e la storia dell'arte del vicino oriente.

-WYATT, N.

1990 Where Did Jacob Dream His Dream? SJOT 2: 44-57.

-ZEVIT, Z.

1984 The Khirbet el-Qom Inscription Mentioning a Goddess. BASOR 255: $39-47$. 
DAS UNZUGÄNGLICHE HEILIGTUM

\section{Zur letzten Vision des Amos (Am 9,1-4)}

von

Jörg Jeremias

Evang.-Theol. Fakultät, Ludwig-Maximilians-Universität München

Die fünfte und letzte Vision des Amos ist in der Forschung im Vergleich zu den vorausgehenden vier Visionen stark vernachlässigt worden. Es gibt nur eine kleine Zahl an Spezialuntersuchungen zu ihr' Das mag daran liegen, daß mit der 4. Vision unter der Ankündigung des "Endes meines Volkes Israel" (Am 8,2) ein unüberbietbarer Höhepunkt in den Visionen erreicht zu sein scheint. Zudem enthält die 5. Vision mit Ausnahme des einleitenden Satzes: "Ich habe den Herrn gesehen, wie er auf dem Altar stand", nur Gottesrede. Jedoch hängt an der Deutung der 5. Vision Entscheidendes für das Verständnis des Amosbuches als ganzen. Nirgends sonst im Amosbuch wird derart deutlich, daß Amos ein Judäer war, wie in der 5. Vision. Die Vorstellungen von Am 9,1-4 stammen so deutlich aus Jerusalem, daß einige Ausleger vermutet haben, es müsse deshalb auch der Jerusalemer Tempel gemeint sein ${ }^{2}$; davon ist jedoch mit keiner Andeutung die Rede. Wohl aber kann $\mathrm{m}$. E. die Suche nach einem Ort Thekoa im Nordreich, aus dem der Prophet Amos angeblich stammen soll (Am 1,1), wie sie zuletzt wieder K. KOCH aufgenommen hat ${ }^{3}$, eingestellt werden.

\footnotetext{
1 Außer J. MORGENSTERN, Amos-Studies I, HUCA 11 (1936) 107-129, sind nur zu nennen J. OUELLETTTE, The Shaking of the Thresholds in Amos 9:1, HUCA 43 (1972) 23-27, sowie drei Dissertationen: S. REIMERS, Formgeschichte der prophetischen Visionsberichte, Diss. Hamburg 1976, bes. 100ff; M. KUNTZ, Ein Element der alten Theophanieüberlieferung und seine Rolle in der Prophetie des Amos, Diss. Tübingen 1968, 155-173; G. BARTCZEK, Prophetie und Vermittlung. Zur literarischen Analyse und theologischen Interpretation der Visionsberichte des Amos, EHS XXIII/120, Frankfurt-Bern 1980, bes. 71-90.

2 So schon Tg und ihm folgend ausführlich C.F. KEIL, BC III/4 (31888) z.St. Weitere Vertreter dieser Ansicht nennt W. RUDOLPH, KAT XIII/2 (1971) 244, Anm. 4; vgl. zuletzt M. KUNTZ [A.1] 164ff.

$3 \mathrm{~K} . \mathrm{KOCH}$ und Mitarbeiter, Amos. Untersucht mit den Methoden einer strukturalen Formgeschichte, Teil 2, AOAT 30, Kevelaer-Neukirchen 1976, 2; DERS., Die Profeten I, UB 280, Stuttgart-Berlin-Köln-Mainz 21987, $82 f$.
} 
Auffällig ist in der Tat die Kürze der eigentlichen Vision4: "Ich habe den Herrn gesehen, wie er auf ${ }^{5}$ dem Altar stand". Schon die Tatsache, daß Amos selbst Subjekt des visionären Sehens ist und nicht Objekt einer ihm von Jahwe gewährten Schau wie in allen vorausgehenden Visionen, zeigt, daß die letzte Vision von den ersten vier abgehoben werden soll. Der Grund dieses Wandels liegt am ehesten darin, daß nicht ein Ereignis geschaut wird wie im ersten Visionenpaar (7,1-6: das "Fressen" der Heuschrecken bzw. des kosmischen Feuers), auch nicht ein Gegenstand wie im zweiten (7,7f; 8,1f: Zinn in Gottes Hand bzw. ein Korb mit Sommerobst), sondern Jahwe selber. Damit ändert sich die innere Logik der Visionen entscheidend. Im ersten Visionenpaar liegt der Ton darauf, daß Jahwe ein Unheilsgeschehen in Gang setzt, das er auf die Fürbitte des Propheten hin aber wieder zurückzunehmen bereit ist. Im zweiten Visionenpaar wird eine solche Einwirkungsmöglichkeit des Propheten nirgends auch nur angedeutet. Zwar findet auch hier ein Zwiegespräch zwischen Jahwe und Amos statt, aber Amos muß etwas lernen; er ist der Befragte und muß das Geschaute in Worte fassen, bevor ihm die vollen Implikationen seiner Worte in der harten Deutung Jahwes eröffnet werden. Die wesentliche Steigerung vom ersten zum zweiten Visionenpaar liegt darin, daß Amos es im ersten nur mit einem (geplanten) Handeln Jahwes zu tun bekommt, im zweiten Visionenpaar aber jeweils im Endeffekt mit Jahwe selber. Aus dem Geschauten selbst geht das für Amos selbst zwar noch nicht eindeutig hervor, wohl aber aus der jeweils identischen Quintessenz der Deutung Jahwes in der 3. und in der 4. Vision: "Ich kann nicht länger (schonend) an ihm (d. h. Israel) vorübergehen" $(7,8 ; 8,2)$. Hier wird den Lesern in einem Wortspiel eine grauenhafte Wahrheit vermittelt: Wenn Jahwe nämlich nicht länger an Israel "vorübergehen" kann (עבר mit der Präposition ל), dann ist insofern zwingend "das Ende zu meinem Volk Israel gekommen" $(8,2)$, weil Jahwe dann - und zwar unweigerlich tödlich - "durch deine (d. h. Israels) Mitte hindurchschreitet" (עבר mit der Präposition 5,17$)^{6}$, ein Geschehen, wie es jedem Israeliten aus Passa-

\footnotetext{
4 Die Kürze ist häufig von Kommentaren dadurch verändert worden, daß das folgende Beben der Schwellen noch zur Vision gerechnet wurde; vgl. zuletzt H.W. WOLFF, BK XIV /2 ( $\left.{ }^{3} 1985\right)$ z. St. Aber dieser Texteingriff hat die gesamte Textüberlieferung gegen sich.

5 Die sogleich zu nennende Analogie der 3. Vision in 7,7 schließt die Übersetzung "am Altar" (so die Mehrzahl neuerer Kommentare z. St.; vgl. W. RUDOLPH [A.2]; J.A. SOGGIN [1987]; F.I. ANDERSEN - D.N. FREEDMAN, AncB 24 A [1989]; S.M. PAUL, Hermeneia [1991]) $\mathrm{m}$. E. zwingend aus.

6 Vgl. dazu jüngst K. BALTZER, Bild und Wort. Erwägungen zu der Vision des Amos in Am 7,7-9, in: W. GROSS - H. IRSIGLER - Th. SEIDL (Hg.), Text, Methode und Grammatik, FS W. RICHTER, St. Ottilien 1991, 11-16; 12f. Ihm sei dieser Beitrag als Zeichen des Dankes
} 
texten (Ex 12,12.23) vertraut war. Wo Jahwes עבר ל שבר zu Ende ist und sein עבר ב beginnt, klingt Leichenklage allerorts auf, auf Plätzen und Straßen und selbst an Orten der Freude wie z. B. Weingärten (5,16f.).

Von der 3. und 4. Vision her gelesen, ist die 5. und letzte die unüberbietbare äußerste Steigerung. Wenn Amos hier Jahwe selber schaut, und dazu noch an diesem Ort, dann paßt hier kein Zwiegespräch zwischen Gott und Prophet wie in allen vorangehenden Visionen, kein Einspruch des Propheten und keine göttliche Nachfrage nach dem Geschauten, die erst über die Antwort des Propheten deren Sinn offenlegen würde. Für einen Einspruch des Propheten ist schon seit der 3. Vision kein Raum mehr, und die Schau von 9,1 ist (insbesondere nach 7,7; s. u.) nirgends mißverständlich oder deutebedürftig. Wie sehr die kurze letzte Vision als Steigerung der vorigen verstanden werden will, wird schließlich daran deutlich, daß Gott nicht mehr von "meinem Volk Israel" spricht wie noch in 7,8 und sogar in 8,2, sondern nur noch in denkbar weitem Abstand von "ihnen allen", die sterben müssen. Das "Ende meines Volkes Israel" $(8,2)$ ist schon Ereignis geworden.

II.

Das Ungewöhnliche der 5. Vision wird erst auf dem Hintergrund ihrer Parallelen erkennbar. Wo Jahwe andernorts in Visionen direkt geschaut wird, geht es um eine Beauftragung des Propheten (bzw. "des Geistes") durch den himmlischen Hofstaat, der um den thronenden Himmelskönig Jahwe steht (1 Kön 22,19ff; Jes 6)7. Obwohl Am 9,1 viel mit Jes 6 gemein hat, wie noch zu zeigen ist, fällt eine solche Deutung für Am 9,1 allein schon deshalb aus, weil Amos Jahwe stehend schaut. Ein himmlischer Hofstaat hat bei einem solchen Bild keinen Platz. Diese Aussage verbindet die 5 . Vision vielmehr betont mit der 3. Vision, wo das gleiche Verb für Jahwes Stehen verwendet wird, mit der gleichen Präposition und ebenfalls im Partizip. Hier steht Jahwe auf einer Mauer aus Zinn. Der Sinn der Wortverbindung "Mauer aus Zinn" ist traditionsgeschichtlich vorgeprägt. Zwar ist die Wortververbindung als solche schon darum nicht andernorts zu erwarten, weil Amos für das Metall ein ungebräuchliches Lehnwort aus dem Akkadischen ( $\left.7 \mathrm{k}^{8}\right)$

für nunmehr zwei Jahrzehnte währende warmherzige Kollegialität und Freundschaft gewidmet.

$7 \mathrm{Vgl}$. zu dieser Gattung bes. H.-P. MÜLLER, Die himmlische Ratsversammlung, ZNW 54 (1963) 254-267; O.H. STECK, Bemerkungen zu Jes 6, BZ NF 16 (1972) 188-206; wieder abgedruckt in: DERS., Wahrnehmungen Gottes im AT, TB 70 (1982) 149-170.

${ }^{8} \mathrm{DaB} 7 \mathrm{~m}$ in Am 7,7f wie an/n)aku im Akkadischen "Zinn" bedeutet, haben in jüngerer Zeit eine Fülle von Arbeiten im Anschluß an den grundlegenden Aufsatz von B. LANDSBERGER, Tin and Lead, JNES 24 (1965) 285-296, dem das CAD folgt, mit immer neuen Argumenten nachgewiesen. Ich nenne nur: G. BRUNET, La vision de l'étain; réinterpretation d' 
verwendet, das im AT nicht mehr begegnet und offensichtlich um des Wortspiels mit nur geläufigere Metalle in anderen Texten. So wird bekanntlich der Prophet Jeremia von Jahwe zu einer "ehernen Mauer" gemacht (Jer 1,18; 15,20) und Ezechiel zu einer "eisernen Mauer" (Ez 4,3). Das Bild der ehernen bzw. eisernen Stadtmauer symbolisiert nicht nur in den genannten prophetischen Belegen verläßlichen Schutz und unerschütterliche Sicherheit, sondern auch außerhalb der Bibel, besonders in ägyptischen Texten und in der klassischen Antike. So preist sich z. B. der Pharao des Exodus Israels, Ramses II.: "Wißt ihr nicht, daß ich eure Eisenmauer bin ?", und der Vasallenkönig Abimilki von Tyros bezeichnet den Pharao, seinen Oberherrn, in deutlicher Kenntnis dieses Sprachgebrauchs als eine "eherne Mauer, für 'mich' (?) errichtet"10. S. HERRMANN hat jüngst wahrscheinlich gemacht, daß der traditionsgeschichtliche Ursprung dieser Aussagen in Prädikationen des Sonnengottes lag, genauer: in Beschreibungen seiner idealen Stadt, daß sie also "ein Teilstück der Jenseitsvorstellungen" bildeten, bevor sie auf den ägyptischen König übertragen wurden ${ }^{11}$. Angesichts der jahrhundertelangen Prägung und der weiten Verbreitung dieses Sprachgebrauchs ist sehr gut verständlich, daß Amos auch in sprachlicher Abwandlung mit dem Verständnis seiner Leser rechnet.

Nun aber steht Jahwe in der 3. Vision "auf der Mauer aus Zinn" wie in der 5. Vision "auf dem Altar". In seiner kleinen Monographie

Amos VII 7-9, VT 16 (1966) 387-395; W.L. HolladAY, Once more, "nak = 'tin', Amos VII 78, VT 20 (1970) 492-494; J. OUELLETTE, La mur d' étain dans Amos VII,7-9, RB 80 (1973) 321-331; C. VAN LEEUWEN, Quelques problèmes de traduction dans les visions d' Amos chapitre 7, in: FS A.R. HULST, Nijkerk 1977, 103-112; G. BARTCZEK [A.1] 119ff; H. GESE, Komposition bei Amos, VT.S 32 (1981) 80f; J.H. HAYES, Amos, Nashville 1988, 204f; W. BEYERLIN, Bleilot, Brecheisen oder was sonst? OBO 81 (1988); Chr. UEHLINGER, Der Herr auf der Zinnmauer. Zur dritten Amos-Vision (Am. VII 7-8), BN 48 (1989) 89-104; V. FRITZ, Amosbuch, Amos-Schule und historischer Amos, in: V. FRITZ - K.F. POHLMANN H.-C. SCHMITT (Hg.), Prophet und Prophetenbuch, FS O. KAISER, BZAW 185 (1989) 30f; K. BALTZER [A.6] 11f. Damit findet eine alte Vermutung A. CONDAMINs aus dem Jahr 1900 (RB 9, 586-594) ihre Bestätigung. - Seltsamerweise hat sich diese Erkenntnis zu den neuesten deutschsprachigen Wörterbüchern (HAL und Neuauflage von GESENIUS) nicht herumgesprochen, in denen LANDSBERGER nicht einmal zitiert ist!

9 Vgl. zuletzt überzeugend K. BALTZER [A.6]. Sein Vorschlag findet sich ein erstes Mal bei F. PRAETORIUS, Bemerkungen zu Amos, ZAW 35 (1915) 23; vgl. auch R.B. COOTE, Amos Among the Prophets, Philadelphia 1981, 92f; H.G.M. WILlIAMSON, The Prophet and the Plumb Line, OTS 26 (1990) 117f, Anm. 69.

10 Vgl. J. OUELLETTE [A.8] 324f, Anm. 22-23. Vgl. die weiteren Belege schon bei A. ALT, Hic murus aheneus esto, ZDMG 86 (1933) 33-48, und zu den klassischen Belegen bes. $H$. GESE [A.8] 80f, Anm. 18.

11 S. HERRMANN, Die Herkunft der "ehernen Mauer", in: M. OEMING - A. GRAUPNER (Hg.), AT und christliche Verkündigung, FS A.H.J. GUNNEWEG, Stuttgart 1987, 344-352; 346. 
zur 3. Vision, die deren Deutung erheblich gefördert hat, hatte W. BEYERLIN vermutet, mit dieser Aussage solle die Schutzfunktion der Mauer noch verstärkt werden ${ }^{12}$. Demgegenüber hat Chr. UEHLINGER sowohl mit semantischen als auch mit ikonographischen Vergleichen den Nachweis geführt, daß das "Stehen auf der Mauer" ein vernichtendes, alle Sicherheit zugrunde richtendes Gotteshandeln erwarten lasse ${ }^{13}$. Dafür spricht nicht zuletzt, daß Jahwe ja schon das "Zinn in seiner Hand" hält, das nach der göttlichen Deutung der Vision "mitten in mein Volk Israel hineingelegt werden" soll. Da hier Zinn vermutlich als pars pro toto für Waffen steht, wie häufig und mit besonderer Gründlichkeit von BEYERLIN wahrscheinlich gemacht worden ist, heißt das, daß Jahwe zum Krieger gegen Israel geworden ist; angesichts dessen ist jeglicher Versuch, Schutz zu gewinnen, von vornherein zum Scheitern verurteilt.

Dann aber ist der sprachliche Bezug zwischen der 3. und der 5. Vision deutlich. Ist Gottes Geduld mit seinem Volk am Ende, so daß er "nicht länger (schonend) an ihm vorübergehen kann" $(7,8 ; 8,2)$, so ist damit gleicherweise der bevorstehende Zusammenbruch des Staates wie das Ende des Gottesverhältnisses angezeigt. Die "Mauer aus Zinn" symbolisiert jenen unerschütterlichen Schutz, den der Staat sich nicht selber vermitteln, sondern nur von Gott empfangen kann; Jahwe als Krieger mit "Zinn in seiner Hand" auf dieser Mauer stehend aber heißt nicht nur das Ende dieses Schutzes, sondern die Erfahrung der gleichen Macht, die bisher schützend am Werk war, in der Zerstörung. Analoges gilt für die 5. Vision. Für den gesamten Alten Orient war selbstverständlich, daß das Heiligtum als Zentrum der Gottesbeziehung jeden Volkes nicht von Menschen errichtet, sondern von Gott gegründet war; man vergleiche im AT nur die Zionpsalmen. Jahwe "auf dem Altar stehend" bedeutet dann nicht nur das Ende dieser Gottesbeziehung, sondern das Ende allen menschlichen Lebens, das sich ja nur der Gottesbeziehung verdankt. Dem ist im folgenden näher nachzugehen.

Die Trennung der beiden Aspekte (Staat und Gottesbeziehung) hat später die Tradenten der Amosworte stark beschäftigt. Ich erinnere nur daran, wie die Gliederung des Mittelteils des Amosbuches (Kap. 3-6) in den Überschriften 3,1 und 5,1 nach den Adressaten "die Israeliten" in Kap. 3-4 bzw. "das Haus Israel" in Kap. 5-6 erfolgt ${ }^{14}$, oder wie das in der 3. Vision angesagte Unheil "inmitten meines Volkes Israel" $(7,8)$ in der angeschlossenen Erzählung 7,10-17 damit begründet wird, daß Amos das Reden in Jahwes Namen "inmitten des Hauses Israel" untersagt wird $(7,10.13)^{15}$. Vorgegeben aber war die sprachliche Unterscheidung zwischen Staat und Gottesvolk schon in den Visionen des Amos.

12 W. BEYERLIN [A.8] 46f.

$13 \mathrm{Chr}$. UEHLINGER [A.8] $94 \mathrm{f}$.

14 Vgl. J. JEREMIAS, Amos 3-6, ZAW 100 (1988) Suppl. 123-138; 131.

15 Vgl. den Exkurs "Israel im Amosbuch" bei H.W. WOLFF [A.4] $199 f$. 
Ist das Bild der 5. Vision - Jahwe auf dem Altar stehend - somit in seiner bedrohlichen Bedeutung im Groben verständlich, so bedarf es doch zur präziseren Erfassung der näheren Explikation durch die Gottesrede. Freilich bleibt sie beim ersten Lesen in vieler Hinsicht unverständlich. Es erfolgt ein Schlag auf ein Säulenkapitell, ohne daß deutlich ist, wer schlägt ${ }^{16}$. Als primäre Wirkung des Schlages wird das Beben der Schwellen des Tempeltores genannt, deren Sinn nicht sogleich einsichtig ist. Als Folge des Bebens der Schwellen wiederum erfolgt ein Töten mit dem Schwert, bevor zuletzt in großer Breite die Unmöglichkeit jeglicher Flucht ausgeführt wird.

Offensichtlich liegt der Schlüssel zu dieser ungewöhnlichen Gedankenfolge in den erstgenannten Aussagen: dem Schlag auf das Kapitell und dem dadurch hervorgerufenen Beben der Schwellen. Man hat diese Aussagen gemeinhin allerdings mißverstanden, indem man mit typisch westlicher Logik in Am 9,1 den Sturz des Tempelgebäudes beschrieben fand. "Der allgemeine Sinn ist klar: der Tempel Jahves (in Bethel) begräbt die zusammengeströmte Menge, die sich dort geborgen fühlt ..., unter seinen Trümmern." Schon WELLHAUSEN selbst, der so urteilt, hat jedoch der Phantasie seiner Nachfolger einen Riegel vorgeschoben, indem er darauf verweist, daß "der befohlene Modus der Zertrümmerung" im Dunkeln bleibe, da vom Beben der Türschwellen, nicht aber vom Bersten des Tempeldaches die Rede sei ${ }^{17}$. In der Tat ist vom Zusammenbrechen des Tempels mit keiner Silbe die Rede, während die folgenden Verse mit Schwert, Schlangenbiß etc. andersartige Weisen der Tötung beschreiben. Hinzu kommt, daß sich ohnehin nur die Priester im Tempel befinden würden, die Menge aber in seinen Vorhöfen stünde, wenn man nach den Maßstäben des Jerusalemer Tempels urteilen wollte.

Der entscheidende Fehler dieser geläufigen Deutung liegt in der Deutung der Säule(n), auf die der göttliche Schlag erfolgt, mit der genannten Konsequenz, daß die Schwellen beben. "Der Schlag Jahwes gegen die Säulen ..., auf den der Deckeneinsturz erfolgt, ist die Versinnbildlichung eines von Jahwe herbeigeführten Erdbebens." Wie RUDOLPH in diesem $\mathrm{Zitat}^{18}$, so verlieren auch die meisten anderen Kommentatoren kein Wort darüber, wo sie "die Säulen" vermuten und mit welcher Begründung sie das tun. Sie rechnen offensichtlich mit tragen-

16 Bleibt man beim MT, könnte nur der Auftrag an einen himmlischen Boten gemeint sein. Vielleicht ist der Imp. הך "schlage" aber aus einem Inf. abs. דבה entstanden, wie man seit B. DUHM, Anmerkungen zu den zwölf Propheten, Gießen 1911, 16, oft vermutet hat, da das Folgewort wieder mit $\mathrm{n}$ beginnt. Dann würde Jahwe wie im folgenden sein eigenes Handeln ankündigen.

17 J. WELLHAUSEN, Die kleinen Propheten, Berlin ${ }^{3} 1898,94$.

18 W. RUDOLPH [A.2] 245. 
den Säulen im Hauptraum des Tempels, wie sie weder für Jerusalem noch für Arad belegt sind, d. h. für die einzigen beiden zur Zeit des Amos - literarisch bzw. archäologisch - bekannten Tempel ${ }^{19}$. Für beide Tempel ist vielmehr nur ein Säulenpaar am Tempeleingang belegt. Dabei ist es für unsere Fragestellung ohne Gewicht, ob es sich bei dem Jerusalemer Säulenpaar um freistehende Säulen handelte, wie man aufgrund ihrer Ausführung in Bronze und ihrer Eigennamen (1 Kön $7,15 \mathrm{ff})$ gern angenommen hat, oder aber - wahrscheinlicher - um funktionale Säulen, die das Dach der Vorhalle trugen bzw. wie in Arad (str. $X)$ wohl ein Vordach über dem Eingang ${ }^{20}$. Wesentlich ist allein, daß das Beben der Türschwellen vom Zerbersten der Säulen hervorgerufen wird, die den Eingang flankieren ${ }^{21}$. Die Aussagen der göttlichen Ankündigung sind ganz auf den Eingangsbereich des Tempels konzentriert. Was aber besagt das Beben der Türschwellen?

Die Bedeutung der Türschwellen für den Tempel mußte einem antiken Leser nicht erst erklärt werden. Schon in Privathäusern Mesopotamiens wurden gelegentlich bronzene Figuren von Hunden unter die Türschwelle gelegt ${ }^{22}$, die die gleiche Wächterfunktion innehatten wie die abschreckenden Löwen vor den Tempeltoren, etwa in Alalach oder Hazor, oder die "schrecklichen Wildochsen" aus mit Gold und Edelsteinen überzogenem Kupfer bzw. die furchterregenden Schlangen, die Nebukadnezar II. "an den Schwellen des Tempeltores aufstellen lieB"23. Aus dem AT ist die Polemik Zephanjas gegen den fremdländischen Brauch, über die Schwelle des Königspalastes zu hüpfen, bekannt (Zeph 1,9), wie er ebenso für den philistäischen Tempel in Aschdod belegt ist. Ein hohes Priesteramt in Jerusalem wurde "Schwellenhüter" genannt (2 Kön 12,10; 22,4 u.ö.). In Mesopotamien gab es ein spezielles Ritual für das Einfügen der Tempelschwellen ${ }^{24}$, unter die auch oft die Gründungsinschriften des Tempels gelegt wurden ${ }^{25}$. Von diesen Belegen aus überrascht es nicht mehr, wenn die Torschwellen des Tempels schon im Sumerischen in gewissen Kontexten den Tempel als ganzen vertreten können: Sie "leuchten", wenn das Heiligtum in all seiner Pracht steht, sie "weinen", wenn ihm Schaden zugefügt wird. Allerdings ist auch in solchen Fällen fast durchweg der Eingangsbereich des Tempels im Blick. Die Schwellen sind in Gedeih und Verderb als erste betroffen: Sie "küssen die Füße" dem willkommenen Besucher; wer sich wie Ischtar in der Unterwelt den Zutritt zum Heiligtum gewaltsam erzwingen will, der droht für den Fall, daß der Türhüter nicht öffnet: "I will smash the sippu and I will remove the doors"26.

19 Unter den architektonisch vergleichbaren syrisch-palästinischen Tempeln würde einzig der Migdal-Tempel in Sichem (aus der MB II-Zeit!) eine entfernte Stütze für diese Annahme bilden.

20 So V. FRITZ, Tempel und Zelt, WMANT 47 (1977) 14f.67f. Vgl. die Diskussion der Gründe bei H. WEIPPERT, Palästina in vorhellenistischer Zeit, München 1988, 465f.

21 So mit Recht schon H.W. WOLFF [A.4] z.St.

22 Vgl. z.B. V.E. CRAWFORD, Archaeology XII/2 (1959) 81 mit Taf. XVII.

23 Z.B. V AB IV 158, Kol. VI 28; vgl. CAD "E" 63a. Weitere Belege bei A. SALONEN, Die Türen des alten Mesopotamien, AASF B/124, Helsinki 1961, 65.

24 Vgl. R.S. ELLIS, Foundation Deposits in Ancient Mesopotamia, Yale Near Eastern Researches 2 (1968) 5.33.127.131.

25 Ebd. 94ff.

26 Belege bei A. SALONEN [A.23] 64f. 
Der großen Bedeutung der Schwellen am Tempeltor ist für Am 9,1 $\mathrm{m} . \mathrm{W}$. bislang einzig J. OUELLETTE nachgegangen. Aus Belegen wie dem letztgenannten hat er geschlossen, die Erschütterung der Schwellen deute darauf hin, daß Jahwe sich auf diese Weise seinen Eingang in den Tempel erzwingen wolle, um die dort Schutz suchenden Israeliten eigenhändig zu strafen ${ }^{27}$. Aber diese Interpretation ist schon darum wenig einleuchtend, weil sich die Asylsuchenden nicht im Tempelgebäude aufhielten. Es gäbe zudem für eine solche Vorstellung auch nicht die geringste Spur einer Analogie im AT, für das Jahwe - zumindest in Südreichtexten - auf dem Zion wohnt, im Tempel thront, sich aber nicht den Zugang zu - seinem eigenen! - Wohnhaus erst erzwingen müßte. Aber OUELLETTE hat darin Recht, daß die Zuspitzung des Gedankenganges auf das Beben der Tempelschwellen etwas mit dem Zugang zum Tempel zu tun haben muß. Nur handelt es sich nicht um den Zugang Jahwes, sondern um denjenigen der Israeliten.

IV.

Die einzige alttestamentliche Parallele zum Beben der Schwellen des Tempeltores bietet die berühmte Vision Jesajas in Jes 6 . Sie berührt sich nicht erst in V.4, wo vom Beben der Tempelschwellen die Rede ist, sondern schon am Anfang in V.1 bis in die einzelnen Formulierungen hinein so eng mit Am 9,128, daß ein - wie auch immer gearteter - Zusammenhang zwischen beiden Texten bestehen muß. Offensichtlich hat Amos mit seiner Vision traditionsbildend gewirkt ${ }^{29}$, wie das im Fall seines Einflusses auf die Visionsberichte des Jeremiabuches noch evidenter nachweisbar ist ${ }^{30}$. Was in Am 9,1 nur angedeutet ist, wird in Jes 6 unter Rückgriff auf typisch Jerusalemer Ziontheologie ${ }^{31}$ in aller Deutlichkeit ausgesprochen. Der vom Propheten geschaute "Herr" ("אדנה in Jes 6,1 wie Am 9,1) ist der Weltenkönig, und sein Heiligtum auf dem Zion besitzt kosmische Dimensionen. Der Streit der älteren Ausleger, ob in Jes 6 der irdische oder der himmlische Tempel gemeint sei, ist definitiv entschieden zugunsten der Auffassung, daß diese Alternative

\section{J. OUELLETTE [A.1] 24.26.}

28 Jeweils findet sich a) ein erzählendes ר in 1. Pers. zu Beginn mit b) Gott als Objekt, und zwar unter Vermeidung des Eigennamens in der Bezeichnung ' J7k, c) seine Tätigkeit im Partizip formuliert, d) die Ortsbestimmung mit על angeschlossen.

29 Vgl. schon R. FEY, Amos und Jesaja, WMANT 12 (1963) 109f. Die umgekehrte Möglichkeit, Am 9,1 von Jes 6 her zu deuten, führt G. BARTCZEK [A.1] 89f zu der wenig überzeugenden Annahme, Am 9,1 sei aus drei literarischen Schichten zusammengesetzt. "Damit ist der Visionsbericht als solcher liquidiert": eine merkwürdige Erfolgsmeldung einer Exegese!

30 Vgl. W. BEYERLIN, Reflexe der Amosvisionen im Jeremiabuch, OBO 93 (1989).

31 Vgl. etwa W.H. SCHMIDT, Jerusalemer El-Tradition bei Jesaja, ZRGG 16 (1964) 302313; O.H. STECK, Friedensvorstellungen im alten Jerusalem, ThST 111 (1972) passim. 
künstlich und unsachgemäß ist ${ }^{32}$. Vielmehr werden das Auge des Propheten in der Vision und dasjenige des Lesers im Text ständig zwischen himmlischem (Thron Gottes, Gesang der Seraphen) und irdischem Tempel (Gewandsaum des Himmelskönigs; Beben der Torschwellen; Entsühnung des Propheten) hin und hergeführt, weil es sich nicht um zwei verschiedene heilige Orte handelt, sondern um Dimensionen des einen Wohnortes Gottes, dem die himmlische Gemeinde zusammen mit der irdischen zujubelt. Aus diesem Grund heißen die Tempeltore in Ps 24,7.9 "Tore der Ewigkeit": Sie gehören wie der gesamte Tempel zur Welt Gottes und haben Anteil an deren Heiligkeit und unerschütterlichen Festigkeit. Von ihr abgeleitet, besitzt auch die Erde insgesamt von niemand zu gefährdende Festigkeit ("sie kann nicht wanken"), die allein darauf beruht, daß Gottes Thron für ewig fest steht und nicht nur im Himmel, sondern zugleich inmitten Israels auf dem Zion errichtet ist (vgl. Ps 93,1f mit V.5) ${ }^{33}$. Wo aber die Schwellen der Tempeltore beben und mit ihnen die Türzapfen, die seitlich in Vertiefungen der Schwellen aufsitzen ${ }^{34}$, erschüttert werden, wie Jes 6,4 gegenüber Am 9,1 präzisiert, verlieren die Tempeltore ihre himmlische Qualität und mit ihnen der Tempel insgesamt.

Darüber hinaus hat Jes 6,4 mit Am 9,1 gemein, daß die Außerkraftsetzung der heilvollen Funktionen des Tempels nicht etwa mit der Abwesenheit Gottes begründet wird wie z. B. in der berühmten Klage über die Zerstörung des Heiligtums von Ur ${ }^{35}$, sondern vielmehr gerade mit seiner machtvollen Präsenz. In Jes 6,4 füllt sich unter dem Beben der Torschwellen das Tempel-Innere mit Rauch. Damit wird, wie längst erkannt ist, ein Element vorgeprägter Theophanieschilderungen aufgegriffen, das auch andernorts (etwa Ps 18,8f) parallel zum Beben auftritt; in der Tradition ist es allerdings die Erde oder sind es die Berge, die beben, wenn Jahwe erscheint, um gegen seine Feinde einzugreifen ${ }^{36}$. Diese Feinde aber sind für den Propheten - eine kühne Neuverwendung der Tradition - die Israeliten selber! Jes 6,4 zeigt damit einerseits, daß das gesamte Gottesvolk gerichtsreif ist und Jahwe zum Eingreifen gegen es schreitet, zum anderen, daß der Tempel aufgehört hat, ein Ort der Festigkeit, d. h. des Schutzes und des heilvollen Gotteskontaktes zu

32 Vgl. bes. M. METZGER, Himmlische und irdische Wohnstatt Jahwes, UF 2 (1970) 139 158.

$33 \mathrm{Vgl}$. zum Vorstellungszusammenhang J. JEREMIAS, Das Königtum Gottes in den Psalmen, FRLANT 141 (1987) 14ff.

34 Vgl. etwa K. GALLING - H. RÖSEL, BRL $2348 \mathrm{f}$.

35 Vgl. etwa W. BEYERLIN (Hg.), Religionsgeschichtliches Textbuch zum AT, ATD.E 1 (1975) 140ff, bes. 142 .

36 Zum Traditionszusammenhang vgl. J. JEREMIAS, Theophanie, WMANT 10 (21977) passim (173f zu Jes 6,4) und speziell zu Jes 6 bes. O.H. STECK, Bemerkungen zu Jesaja 6, BZ NF 16 (1972) 195, Anm. 22 (wieder abgedruckt in: TB 70 [1982] 157, Anm. 22) sowie H. WILDBERGER, BK X/1, und O. KAISER, ATD $17^{5}$ z. St. 
sein. In Am 9,1 steht Jahwe, der "nicht länger an ihm (d.h. Israel) vorübergehen kann" $(7,8 ; 8,2)$, "auf dem Altar", der sich im Vorhof des Heiligtums befand. Damit hört dieser Altar nicht nur auf, Ort des Opfers für Jahwe und damit des Gotteskontaktes zu sein, sondern vor allem Ort des schützenden Asyls37, ergreifen doch Asylsuchende im AT "die Hörner des Altars", um vor dem Bluträcher in Sicherheit zu sein. So jedenfalls ist Am 9,1 von den erheblich jüngeren, kommentierenden Versen Am 3,13f verstanden worden ${ }^{38}$, nach denen die Hörner des Altars von Bethel abgeschlagen werden. Hört aber der Tempel auf, Asylstätte zu sein, gelten alle Israeliten als Mörder, die bekanntlich vom Asyl ausgeschlossen waren (vgl. Ex 21,14 u.ö.).

Noch weiter in der Deutung der Vision geht der abschließende Hymnus in 9,5f, der am ehesten mit F. HORST ${ }^{39}$ als "Gerichtsdoxologie" zu deuten und aus dem Gebrauch des Amosbuches in exilischer Zeit herzuleiten ist. Er stellt das "Schwanken der Erde" durch Gottes Berührung (V.5) in einen Kontrast zur "Gründung" des Himmels als seiner Wohnung (V.6). Dazu nutzt V.6 mit To' ein Verb, das üblicherweise die Gründung des Tempels bzw. des Zion und dann die Gründung der Erde bezeichnet ${ }^{40}$. Er bringt damit zum Ausdruck, daß die Unzugänglichkeit des Tempels eine Gefährdung der gesamten Erde heraufführt, die ihre Festigkeit ja nur der Festigkeit des Wohnortes Jahwes verdankt, $\mathrm{daß}$ aber zugleich die Erde nicht dem Weltenkönig entgleiten kann, der seine Himmelswohnung "über der Erde gegründet" hat. Wo er selbst die Erde "schwanken" läßt, ist sie allerdings ohne sein erneutes Eingreifen verloren.

Der Altar, "auf dem Jahwe steht", und der Tempel, "dessen Schwellen beben", sind in Am 9,1 damit weit mehr als Stätte des Opfers, des Asyls, der Anrufung Gottes. Der Tempel ist der Ort, wo der Unterschied zwischen himmlischer und irdischer Welt aufgehoben ist, wo Gott als "Herr (der ganzen Erde)" (Ps 97,5; Sach 4,14; 6,5 u.ö.; vgl. Ps $114,7)$ bzw. als "Herr (aller Herren)" (Ps 136,3) wohnend und thronend anwesend ist, wo damit der Ursprung aller Ordnung der Welt zu finden ist und alle Mächte, die diese Ordnung gefährden wollen, von Gott als seine Feinde besiegt werden. Nur ist eben jetzt das Gottesvolk selber, indem es "Recht und Gerechtigkeit" zu Boden stößt (Am 5,7; 6,12), zu diesem Feind Gottes geworden. Damit aber hört der Tempel auf, Ort der Er-

37 So mit Recht J. OUELLETTE [A.1] 26.

$38 \mathrm{Daß}$ nicht nur - wie häufig angenommen - Am 3,14b $\alpha$, sondern 3,13f insgesamt dem Amosbuch erst spät zugewachsen ist, hoffe ich an anderer Stelle nachweisen zu können. Vgl. einstweilen S. MITTMANN, Amos 3,12-15 und das Bett der Samarier, ZDPV 92 (1976) 149-167; 150-152 sowie R.F. MELUGIN, The Formation of Amos: An Analysis of Exegetical Method, SBL 1978 Seminar Papers Vol. I (1979) 369-391; 382.

39 F. HORST, Die Doxologien im Amosbuch, ZAW 47 (1929) 45-54; wieder abgedruckt in: DERS., Gottes Recht, TB 12 (1961) 155-166.

40 Vgl. W.H. SCHMIDT, THAT I, 736-738; R. MOSIS, ThWAT III, 668-682. 
fahrung der Stabilität der Weltordnung zu sein. Wo die Psalmen mit dem Schwanken der Erde das über die Menschheit hereinbrechende Chaos beschreiben (z. B. Ps 82,5; 75,4; 46,3.6), da stellt ein Amos, dem Jesaja folgt, mit dem Beben der Schwellen des Tempeltores gerade die Gegenwart des richtenden Jahwe als Feind dar, vor dem es keine Zuflucht gibt.

\section{V.}

Wenn Jahwe Israel die Möglichkeit des Asyls nimmt, ist es schutzlos seinem Feind preisgegeben; seit der 3 . Vision ist deutlich, daß Jahwe selber dieser Feind ist. Wenn Jahwe die Schwellen des Tempeltores zum Beben bringt, ist die Sicherheit der Welt aufgehoben; die Weltordnung ist zerrüttet. Beide Aspekte des "Endes Israels" $(8,2)$ führen die folgenden Sätze (Am 9,1b-4) aus, auf die hier nur in äußerster Kürze eingegangen werden kann.

Jahwe als Feind Israels beherrscht den Gedankengang, repräsentiert von seinem Schwert, das in einer Inklusion Anfang und Ende der Aussagen prägt. Wird es anfangs von Jahwe als Instrument gehandhabt (V.1aß), so hat es sich am Ende zu einem selbständigen Werkzeug entwickelt, dem Jahwe wie einem Boten Befehl gibt (V.4). Das "Töten" noch der letzten Überlebenden ist hier wie dort sein Auftrag41; ein menschlicher Feind kommt nirgends in den Blick. Vor dem göttlichen Schwert aber ist jegliche Flucht undenkbar. Dieser Gedanke wird in V.1b thetisch dargelegt:

Kein Fliehender unter ihnen kann fliehen,

kein Entrinnender unter ihnen entrinnen,

bevor V.2-4 ihn in der Stilform einer Priamel42, in der ein festliegender Sachverhalt in einer Reihe von syntaktisch analog formulierten Beispielen erläutert wird, durchführen.

Es ist nun freilich keineswegs zufällig, daß diese Durchführung bis in kosmische Dimensionen ausgreift, weil der künftig unzugängliche Tempel eben kosmische Dimensionen besitzt. Das gilt ganz unabhängig davon, ob man der gelegentlich ausgesprochenen Vermutung zuneigt, daß die Priamel Wachstumsspuren zeige, etwa weil V.2 in kürzerem Rhythmus der Doppelzweier formuliert ist, V.3f. dagegen über dreitakti-

41 Wie das vorgängige Sterben in 9,1 gedacht ist, bleibt aufgrund eines Textfehlers unklar. Liegt dieser im Substantiv, dann kommen "sie alle" wohl unmittelbar "im Beben" um: שת statt okn, so viele Autoren seit P. VOLZ, ThLZ 25 (1900) 291; das Verb ist dann am ehesten mit W. RUDOLPH [A.2] z. St. als ptc. pass. zu vokalisieren; liegt der Fehler im Verb, dann wird nicht wie im MT "(der Lebensfaden) abgeschnitten", sondern ein Schlag (?) trifft "sie alle auf den Kopf". In beiden Fällen ist eine ungesicherte Konjektur erforderlich.

42 W.H. SCHMIDT, ThLZ 96 (1971) 184. 
gen Rhythmus bis zum Doppelvierer voranschreitet, oder weil der spätnachexilische Ps 139 auf Am 9 eingewirkt habe ${ }^{43}$. Eher freilich wird man den Rhythmuswechsel für ein absichtlich steigerndes Stilmittel halten und mit dem umgekehrten Einfluß von Am 9 auf Ps 139 rechnen müssen ${ }^{44}$, so gewiß es prinzipiell denkbar ist, daß die Priamel Psalmensprache aufgreift; die bekannte enge Parallele des El-Amarnabriefes Nr.264 zu Am 9,2 könnte ein Indiz dafür sein ${ }^{45}$. Zudem gilt es, einen auffälligen Sachverhalt wahrzunehmen, den im Gefolge von A. WEISER und H.W. WOLFF insbesondere H. GESE ${ }^{46}$ beobachtet hat: daß die Priamel in 9,2-4 ebenso bewußt fünfgliedrig gestaltet ist wie die analoge Stilfigur in 2,14-1647 und im Großen die Visionsberichte sowie schließlich die Völkersprüche in ihrer ursprünglichen Gestalt. Da auch eine Fülle anderer Beobachtungen darauf hinweist, daß Völkersprüche und Visionsberichte aufeinander zu komponiert sind, um vom Leser miteinander und aufeinander bezogen aufgenommen $\mathrm{zu}$ werden ${ }^{48}$, ist ein literarischer Eingriff in dieses hervorstechende Kompositionsmerkmal ohne zwingende Gründe besonders heikel. M. E. ist in all den genannten Fällen ein literarisches Stadium vor der Fünfer-Struktur nicht zu rekonstruieren.

Wie dem auch sei: Unabhängig von dieser literarkritischen Frage bleibt der universale Horizont der Aussagen in V.2-4 bemerkenswert und bedarf der Erklärung ${ }^{49}$. M.E. kann ein solche Erklärung nur von der universalen Dimension des nunmehr außer Kraft gesetzten Heiligtums her gegeben werden. Die schon genannte exilische Deutung in V.5f bestätigt diese Vermutung. "Das Böse", das Jahwe über Israel bringt

43 In älterer Zeit etwa M. LÖHR, Untersuchungen zum Buch Amos, BZAW 4 (1901) 14; J. MORGENSTERN [A.1] 109ff; in jüngster Zeit H.F. FUHS, Sehen und Schauen. Die Wurzel hzh im Alten Orient und im Alten Testament, fzb 32 (1978), und bes. P. WEIMAR, Der Schluß des Amos-Buches, BN 16 (1981) 60-100; 66.

44 Bes. gilt das für Ps 139,7f; vgl. etwa A. DEISSLER, Die Psalmen, III. Teil, Düsseldorf $1965,192$.

45 "Wenn wir hinaufsteigen zum Himmel, wenn wir hinabsteigen zur Erde, so ist unser Haupt in deinen Händen". J.A. KNUDTZON (Hg.), Die El-Amarna-Tafeln I, Leipzig 1915, 826f. Vgl. W. BEYERLIN [A.8] 44, Anm. 78.

46 H. GESE [A.8] 84.95; vgl. A. WEISER, Die Profetie des Amos, BZAW 53 (1929) 63f. 97f; H.W. WOLFF [A.4] 388.

47 Wo die Satzglieder V.14 und 15aß seit B. DUHM [A.16] 4 und H. GRESSMANN, Die älteste Geschichtsschreibung und Prophetie Israels, SAT II/1 (21921) 335, längst als Nachtrag erkannt sind.

48 Vgl. J. JEREMIAS, Völkersprüche und Visionsberichte im Amosbuch, in: V. FRITZ - K.F. POHLMANN - H.-C. SCHMITT (Hg.), Prophet und Prophetenbuch, FS O. KAISER, BZAW 185 (1989) 82-97.

49 Von daher ist es konsequent, wenn I. WILLI-PLEIN, Vorformen der Schriftexegese innerhalb des AT, BZAW 123 (1971) 52f, V.2-4 insgesamt Amos abspricht, weil "Bilder derart kosmischen Umfanges" zur Zeit des Amos noch nicht denkbar seien. Aber woher weiß sie das so genau, wenn sie doch Jes 6 nicht Jesaja abspricht? 
(V.4b), ist weit mehr als sein staatlicher Untergang (V.4a); es ist eine gott-lose und damit heil-lose Welt.

Sprechen diese Merkmale dann aber nicht doch dafür, daß der Prophet den Tempel zu Jerusalem im Blick hat? Aber wie sollte er dann gerade ins Nordreich gegangen sein und dort verkündet haben? Sowohl die schon genannte Deutung der 5. Vision in Am 3,13f sucht den Ort der 5. Vision in Bethel als auch die Erzählung in Am 7,10-17, die die Tradenten des Amos am ehesten dazu in den Visionenzyklus gestellt haben, um zu begründen, warum Jahwes Bereitschaft zur Unheilsrücknahme auf die prophetische Fürbitte hin nach der 2. Vision enden mußte. Dann aber ist damit zu rechnen, daß am Heiligtum von Bethel prinzipiell vergleichbare Vorstellungen wie in Jerusalem zu Hause waren - die "Himmelsleiter" von Gen 28,10ff ist ebenso Indiz für den kosmischen Anspruch Bethels wie indirekt auch die Polemik Hoseas in Hos 10,5 -, und Amos insofern ihm vertraute Jerusalemer Vorstellungen auf Bethel übertragen konnte. Im Vergleich mit Jes 6 muß ohnehin auffallen, wie Amos vor Nordreich-Lesern typische Begrifflichkeit der Jerusalemer Ziontradition vermeidet. Die jüngeren Tradenten des Buches, die ihm das "Motto" Am 1,2 voranstellten, konnten das vor ihren judäischen Lesern viel unbeschwerter tun.

So wird gerade bei der 5. Vision deutlich, wieviel näher Amos traditionsgeschichtlich dem Jerusalemer Jesaja steht als dem Nordreichspropheten Hosea. 



\section{THE SOVEREIGNTY OF GOD AND THE DESTINY OF THE NATIONS IN THE PROPHECIES OF AMOS, ISAIAH AND JEREMIAH}

von

Kenichi Kida

Saitama, Japan

The rise of the Assyrian empire in the latter half of the eighth century $\mathrm{BCE}$ and the turnover from the Assyrian domination to the NeoBabylonian in the last quarter of the seventh century caused probably more violent changes for the nations of the Ancient Near East than we experience today all over the world. The prophets of Israel who acted during these period, especially Amos, Isaiah and Jeremiah showed great interest for the destiny of Israel and the nations surrounding him.

The Book of Amos begins by the magnificient series of oracles against the nations (Am 1,2-2,5). He delivered them approximately around the year $760 \mathrm{BCE}$, when the expansion of Assyria did not yet begin. Isaiah was called to be a prophet in the year when Uzziah, king of Judah died (739 BCE). ${ }^{1}$ Tiglath-Pileser III (744-727 BCE) ${ }^{2}$ had already started to conquer the nations in the Syro-Palestinian area. Isaiah met with the downfall of Damascus in $732 \mathrm{BCE}$, of Samaria in $722 \mathrm{BCE}$, the destruction of Ashdod in $711 \mathrm{BCE}$. Jeremiah was called to be a prophet to the nations (Jer 1,5) and his prophetic task concerning the nations and the kingdoms was defined as follows:

to pluck up and to break down,

to destroy and to overthrow,

to build and to plant. (Jer 1:10) ${ }^{3}$

In the year 612 BCE he saw the downfall of Nineveh, the capital of the Assyrian empire, which had dominateted Judah for more than half a century. It was a good tidings for the people of Judah (Nah 2:1) but Jeremiah did not accept the event in that way. Later he had to face the Babylonian exile of the Judeans in the years 597 and $586 \mathrm{BCE}$ and the downfall of Judah as a national entity and the destruction of Jerusalem.

In view of this historical outline, it is clear that the problem of the destiny of Israel and Judah as national entities and that of the nations

\footnotetext{
1 According to the chronology of V. PAVLOVSKY and E. VOGT, Die Jahre der Könige von Juda und Israel, Bib. 45 (1964) 328.

2 According to the chronology of The Cambridge Ancient History, ed. by J. BOARDMAN et. al., vol. III, part 2, 1991, by A.K. GRAYSON, 71.

${ }^{3}$ Quotations from the Bible are taken from RSV 1952. If the text is in any way changed, it will be noted.
} 
surrounding them is a crucial concern for these prophets both in its political and theological aspects.

\section{THE WORLD OF NATIONS FOR ISRAEL IN THIS PERIOD}

Amos' oracles against the nations (1:2-2:5) include seven nations: Aram, Philistia, Phoenicia, Edom, Ammon, Moab and Judah. The oracle against Judah (2:4-5) is considered to be secondary ${ }^{4}$, because his transgressions are abstract, neither military nor political as in the case of other nations, but only religious and ethical. It is also to be noted that Amos does not strictly separate Judah as a nation from Israel. In an oracle against the people of Israel (3:1a) a note (3:1b) is added that it includes the whole family which Yahweh had brougth up out of the land of Egypt. When Amos denounces the sanctuaries of Israel, he adds the name of Beer-sheba in Judah as a parallel with Bethel and Gilgal in the north (5:5). In a Woe-oracle Zion is named together with Samaria (6:1).

Besides the oracle against Judah, the authenticity of those of Edom and Tyre is sometimes denied by scholars. ${ }^{5}$ It is pointed out that the crimes committed by Edom reflect the exilic situation (cf. Obd 10-14). However these atrocities of Edom could refer to the events recorded in $2 \mathrm{Kgs}$ 8:20-22 or 16:6. As a reason to suspect the oracle against Tyre it is indicated that the crime in the Tyre oracle (1:9b) is "the same as that in the preceding one on Philistia" (1:6b). 6 We do not know, however, to which historical events the crime mentioned in both passages does refer. The expression both in $v 6 \mathrm{~b}$ and $\mathrm{v} 9 \mathrm{~b}$ : "They delivered up a whole people to Edom", does not make clear which nation is mentioned by "a whole people". In v $9 \mathrm{~b}$ it is added that they "did not remember the covenant of brotherhood". John BARTON insists that behind the crimes denounced by Amos in the series of the oracles against the nations we may assume some kind of "international customary law"7 consciously or unconsciously operating among these nations as peoples related with each other through various ties.

Klaus KOCH pointed out that Amos enumerated in this series of oracles only such nations, which had once belonged to the empire of David and been subjected to the sovereignty of the Israelite God through David. ${ }^{8}$ In the second Book of Samuel it is recorded that David defeated and subdued the Philistines (2 Sam 8,1), the Moabites $(8,2)$, the Syrians from Zobah through Damascus up to Hamath (8,3-10), the Edomites

\footnotetext{
4 See e.g. J. BARTON, Amos's Oracles against the Nations, Cambridge 1980, $23 f$.

5 J. BARTON [A.4] 22-24.

6 J. BARTON [A.4] 22.

7 J. BARTON [A.4] 43-45. BARTON includes in his concept of international customary law, 1) International law proper, 2) Agreed international conventions not legally ratified, 3) Unilaterally accepted norms of international conduct; cf. ibid. 55-61.

${ }^{8}$ K. KOCH, Die Profeten I, UB 280 (1978) 80.
} 
(8,13-14) and the Ammonites (12,26-31). Further David concluded a treaty with Hiram, king of Tyre $(5,11 \mathrm{cf} .1 \mathrm{Kgs} 5,15 \mathrm{ff})^{9}$. These peoples exactly correspond to those nations denounced by Amos.

In the stories of Genesis the Moabities and the Ammonites are the descendants of Lot, nephew of Abraham (Gen 19:30-38). The Edomites are the descendants of Esau, brother of Jacob (Gen 25:30). The Arameans are those of Laban, uncle of Jacob (Gen 24:29). Isaac made a convenant with Abimelech, king of the Philistines (Gen 26:26-33). The people of Israel had build up family kinship with these people since the days of $\mathrm{Da}$ vid, though Israel had once in a while to wage in war them and sometimes experienced bitter defeat.

During the first period of the dynasty of Jehu Israel was invaded by the Arameans but reestablished his hegemony over these nations under Jeroboam II (782-753 BCE). It is recorded in $2 \mathrm{Kgs} \mathrm{14:25}$ as follows: "He restored the border of Israel from the entrance of Hamath as far as the Sea of Arabah." In an oracle against Israel Amos used an almost literally identical description for this area in 6:13b.

This area approximately corresponds to the region, over which Solomon established his dominion: "west of the Euphrates from Tiphsah to Gazah, over all the kings west of the Euphrates" (1 Kgs 5:4). It is a tradition of Israel since the time of Solomon to regard himself as one who should play the role of the political leader in this area. During the reign of Jeroboam II the ruling classes both of Jerusalem and Samaria boasted themselves as "the notable men of the first of the nations" (Am 6:1).

In the post-exilic period this region is called the province of Beyond the River (Abar Nahara) ${ }^{10}$, a term probably derived from the Assyrian administration (ebir-Nâri) established in the days of Esarhaddon 11. According to the satrapy System of Darius II Abar Nahara (the fifth satrapy, Herodotus III.91) consisted of Syria, Phoenicia and Cyprus. When Second Isaiah appeals to "coast-lands" ('/yym) ${ }^{12}$, this term probably refers to that region.

This is the area which includes those nations against which Amos addressed his oracles to. Israel was responsible for the peace of this region, because he is chosen and guided by Yahweh (3:2) but Yahweh leads other peoples as well. So he says:

"Did I not bring up Israel from the land of Egypt,

and the Philistines from Caphtor and the Syrians from Kir?" (9:7)

\footnotetext{
${ }^{9}$ Cf. H. DONNER, Geschichte des Volkes Israel und seiner Nachbarn, ATD.E 4/1 (1984) $200 f$.

10 Ezra 4:10,11,16,17,20; Neh 2:7,9.

11 See W.D. DAVIES et al. (ed.), The Cambridge History of Judaism, vol. I (1984): 4. The Persian empire and the political and social history of Palestine in the Persian Period by E. STERN, 78.

12 Isa $41: 1,5 ; 42: 4,10,12 ; 49: 1 ; 51: 5$.
} 
Israel has greater responsibility than other people in religious and ethical sense, because of his direct relationship with Yahweh (2:9-11). From this point of view there is difference between Israel and the neighbouring nations. These nations are expected to observe such obligations presupposed on the level of "international customary law" as J. BARTON describes ${ }^{13}$, but Israel should establish righteousness and justice among his own community. ${ }^{14}$ Amos' message is summarized in a command of Yahweh:

"Take away from me the noise of your songs; to the melody of your harps I will not listen.

But let justice (nowa) roll down like waters, and righteouness (צP) like an everflowing stream." (5:23f)

As the final punishment for their crimes Amos speaks of the exile not only for Israel $(4: 3,5: 27,6: 7,7: 11,17,9: 4)$ but also for the people of Aram (1:5), and the Ammonites (1:15). Amos does not mention the name of the nation which will invade those countries among which Israel has a destinctive role but he tells how the enemy will devastate the region concerned. Yahweh pronounces as follows:

"For behold, I will raise up against you a nation,

O house of Israel," says the Lord, the God of hosts;

"and they shall oppress you from the entrance of Hamath

to the brook of the Arabah." (6:14)

Isaiah of Jerusalem clearly mentions Assyria by name as a tool of punishment by Yahweh ${ }^{15}$. When the prophets in the preexilic period refer to Assyria or Babylonia on the one hand and to Egypt or Ethiopia on the other, these nations appear for them as enormous powers which threaten the existence of Israel himself. Their strength is beyond the control of both Israel and his surrounding nations. Only Yahweh could use and control them as instruments which might help to realize his purpose in history. One cannot really comprehend the meaning of the activities of these monstrous powers. The only thing which human beings can do against them is to know how one should adjust himself to accept the historical realities of these powers, seeing Yahweh's hand working behind them. For Amos and Isaiah Assyria was a tool of Yahweh to punish Israel and the nations around them. For Jeremiah, however, Nebuchadnezzar was the servant of Yahweh to execute his purpose in history (Jer 25:9; 27,6). For Second Isaiah Cyrus is even the anointed one by Yahweh (Isa 45:1) and the shepherd who should fulfill all his purpose (Isa 44:28).

13 See above note 7.

14 About the meaning of "righteousness and justice", see K. KOCH [A.8] 67-73.

15 See e.g. Isa 7:17,18,20; 8:4,7; 10:5,13,24. 


\section{PROPHECY AND THE DIVINE COUNCIL OF YAHWEH}

Thus far we have examined the structure of the world of the nations presupposed by the prophets of Israel. It consists of three levels: 1) the people of Israel, which is divided into two kingdoms, 2) the nations around Israel belonging to the region west of the Euphrates, and 3) great empires outside this area, in Egypt, Assyria and Babylonia. It is not easy to grasp the political realities of this world, there is especial difficulty to know the destiny of these minor nations which will be determined by the great powers outside the area. But it was exactly the task for the prophets to cope with.

The oracles against the nations by Amos (1:2-2:5) show his extensive knowledge about their political history. This series of the oracles has the same opening sentence at the beginning of each oracle and many other repetitions. As a result one may have the impression that the series had a kind of liturgical character. For instance Aage BENTZEN took it to be a text of an execration ceremony performed in the New Year festival of Egypt. ${ }^{16}$ But it is not a series of curses uttered in a ceremony. Amos points out for each nation concrete crime which was not necessarily directed against Israel but mostly among each other. At the end he comes to denounce the social crimes of the ruling classes of his own country (2:6-8). It is difficult to regard Amos to be a cultic prophet as REVENTLOW did. ${ }^{17}$ In view of his extensive knowledge about the history of these nations it is also difficult to take his occupation as a simple shepherd on the country side (cf. 7:14). It is probably correct to interpret, as S.N. ROSENBAUM recently did, the designation of Amos, "noqed" (1:1), as a title of "district supervisor of royal herds"18 and another one, "boles shiqmim" (7:14), as that of "oversight of sycamore trees held by the crown". ${ }^{19}$ Both of them should mean considerable positions in the northern kingdom. ${ }^{20}$ As "a prominent-citizen-turned-social-critic"21 Amos proclaimed the divine judgment against Samaria, calling other nations to bear witness to her offences.

Proclaim to the strongholds in Ashdod, 22

and to one strongholds in the land of Egypt,

and say, "Assemble yourselves upon the mountains of Samaria, and see the great tumults within her,

and the oppressions in her midst." (3:9)

16 A. BENTZEN, The Ritual Background of Amos i 2-ii 26, OTS 8 (1950) 85-99.

17 H. GRAF REVENTLOW, Das Amt des Propheten bei Amos, FRLANT 80 (1962) 111-116.

18 S.N. ROSENBAUM, Amos of Israel, Merver University Press 1990, 46.

19 S.N. ROSENBAUM [A.18] 50.

${ }^{20} \mathrm{~K}$. KOCH [A.8] 45 also insists on the northern provenance of Amos from Tekoa in Galilee.

21 S.N. ROSENBAUM [A.18] 45.

22 RSV emends it to Assyria but it should be read as it is written in MT. 
He demands the rich peoples in Zion and Samaria to see the other countries in order to compare with themselves.

Pass over the Calneh, and see; and thence go to Hamath the great; then go down to Gath of the Philistines.

Are they better than these kingdoms?

Or is their territory greater then your territory. (6:2)

Amos is thoroughly acquainted with their arrogant and luxurious life. ${ }^{23} \mathrm{He}$ denounces them upon the basis of such knowledge. Such a knowledge can be learned through the experience of daily life, but the predictions of the national destruction are grounded upon the secret knowledge of the decree which is decided in the divine council of Yahweh.

The idea of the divine council of gods, which decides the destiny of the world, is repeatedly recorded in the Babylonian creation epic, Enûma elish. ${ }^{24}$ It is also attested in the Canaanite Pantheon. ${ }^{25}$ In the prophetic literature of Israel we find clear evidence in the opening oracles of Second Isaiah (Isa 40:1-8). ${ }^{26}$ The visual description of the divine council is found in the story of Micaiah the son of Jimlah (1 Kgs 22:1923). For Jeremiah it is crucial to discern the authenticity of a prophet, whether he has received the word from the divine council. It is clearly mentioned in his oracle against false prophets.

For who among them has stood

in the council of the Lord ( $b^{2}$ sod Yahweh)

to perceive and to hear his word,

or who has given heed to his word and listened?

Behold, the storm of the Lord!

Wrath has gone forth,

a whirling tempest;

it will burst upon the head of the wicked.

The anger of the Lord will not turn back

until he has executed and accomplished

the intents of his mind.

In the latter days you will understand it clearly.

"I did not send the prophets,

yet they ran;

I did not speak to them,

yet they prophesied.

But if they had stood in my council ( $\left.b^{\curvearrowright} s \delta d t\right)$,

then they wolud have proclaimed my words to my people, and they would have turned them from their evil way,

${ }^{23}$ See e.g. $3: 12,13 ; 4: 1 ; 6: 4-6 ; 8: 4-6$.

24 ANET 60-72.

25 See E.T. MULLEN Jr., The Divine Council in Canaanite and Early Hebrew Literature, Scholar Press 1980.

${ }^{26}$ See F.M. CROSS, The Council of Jahweh in second Isaiah, JNES 12 (1953) 274-277. 
and from the evil to their doings. (Jer 23:18-22)

The Song of Moses (Dt 32:1-47), the date of which can not be definitely decided, 27 refers to the provenance of the council of Yahweh.

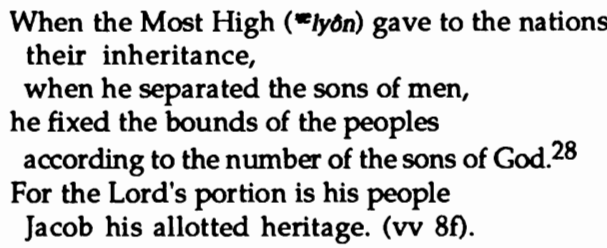

Many scholars have regarded that the form of this song is developed upon the basis of the lawsuit. ${ }^{29}$ At the beginning of the poem heaven and earth are summoned as withnesses (vv 1-3) and the description of the gracious acts of Yahweh for Israel (vv 7-14), the indictment against him infidelity follows (vv 15-18). Then the punishment is renounced (vv 19-25). Those scholars, who argue for the existence of the lawsuit form, assume its origin in the international law. ${ }^{30}$ It is logical to assume an image behind such text as the Song of Moses that the divine council opens the court of lawsuit, in which the international law operates as the standard of a suzerain to punish rebellious vassals. We may also assume the idea of the legal court held by the divine council as the imaginal background of the oracles of Amos against the nations (1:32:3) and the ruling people of Samaria (3:9; 6:1-7).

The hebrew word "sod", which means both the divine council itself and the secret decision by the council, is used in a verse of the book of Amos, which stands among a series of his utterances (3:3-8).

Surely the Lord God does nothing, without revealing his secret (sódo) to his servants the prophets. (3:7)

Thise verse is often deleted as secondary on stylistic and conceptual reasons. H.W. WOLFF regards it deuteronomistic. ${ }^{31}$ However, Y. GITAY has recently defended its authenticity by analyzing its context (3:1-15, especially in vv 3-8) from a rhetorical point of view. ${ }^{32}$

27 See e.g. A.D.H. MAYES, Deuteronomy, NCeB (1979) 380-382.

${ }^{28} \mathrm{MT}$ "sons of Israel". For the reason to emend "Israel" to "God", see the discussions by A.D.H. MAYES [A.27] 384f, D.I. BLOCK, The Gods of the Nations: Studies in Ancient Near Eastern National Theology, Eisenbrauns 1988.

29 G.E. WRIGHT, The Lawsuit of God: a form-critical study of Deuteronomy 32, in: Israel's Prophetic Heritage, ed. by B.W. ANDERSON and W. HARRELSON, 1962, 26-67, and others.

30 A.D.H. MAYES [A.27] 381.

31 H.W. WOLFF, Dodekapropheton 2, Joel und Amos, BK XIV/2 (1969) ad. loc.

32 Y. GITAY, A Study of Amos's Art of Speech: A rhetorical Analysis of Amos 3:1-15, CBQ 42 (1980) 293-309. 
The crucial point, however, lies not in the imaginal channel of revelation but in the message revealed for Amos. It was the destruction of the nation itself by an unknow enemy from far off. That is exactly the kind of destiny which can only be revealed through the divine council. Amos repeatedly declared the judgment of God by an enemy. In the same context in which the word sod is used, it is said:

Therefore thus says the Lord God:

"An adversary shall surround the land and bring down your defences from you,

and your strongholds shall be plundered. (3:11)

At the end of another series of utterances (6:1-14), Amos definitely describes the area which the enemy would invade.

"For behold, I will raise up against you a nation,

o house of Israel," says the Lord, the God of hosts;

"and they shall oppress you from the entrance of Hamath

to the Brook of the Arabah." (v 14)

In both cases, the name of "an adversary" (3:11) and of "a nation" (6:14) is not told. But they will come to the region and devastate all the nations within it, including Israel himself. That is the decree of God which is revealed to Amos. Therefore he must proclaim it for those concerned. Thus he says:

The Lord God has spoken;

who can but prophecy? (3:8b)

E.T. MULLEN, Jr. has made it clear that the prophets of Israel regarded themselves as messengers who were entrusted by Yahweh to announce the decision of the divine council. ${ }^{33}$ We have already referred to the same consciousness in Jeremiah (Jer 23:18-22). The true prophet should receive the word of Yahweh from the divine council. The calling of Isaiah took place in the temple of Jerusalem where the scene of the heavenly council was revealed to him (Isa 6:1-4). He testified in the record of his calling his mission and task given by the divine council.

And I heard the voice of the Lord saying,

"Whom shall I send, and who will go for us?"

Then I said, "Here I am! Send me." (6:8)

The message entrusted to him was a hopeless one (6:9-11). The people would become totally stubborn, if he tells them what he received from the divine council, until the cities of Judah would lie waste and the land be utterly desolate (v 11). It is certainly an irrational decree given by Yahweh. But there are moments in history when people become completely helpless to cope with the impending crisis. It is difficult for any human being to face such a crisis but the classical prophets of Israel

33 E.T. MULLEN, Jr. [A.25] 209-226. 
are exceptional figures who dared to do so. They took seriously the responsibility of the chosen people to carry out the will of Yahweh. They clearly recognized the importance to keep the fraternal relationship with surrounding nations. Beyond these they were aware of the realities which surpassed the human capacity to overcome. The prophets of Israel tried to accept them as the secret decisions of the divine council.

The word of Yahweh spoken in the divine council should have power to turn people from their evil way (Jer 23:2). It has certainly ethical power. If people does not obey to it, Yahweh would punish them (Am 3:1-2). In that sense the word of Yahweh has a rational aspect. However it often makes people stagnant and unable to obey it. This is the irrational aspect of it. The word of Yahweh has both aspects.

Isaiah certainly took over the ethical tradition from Amos. For him too, righteousness and justice were keywords of ethics (Isa 5:7), just as they were for Amos. His denunciations against the arrangeand corruption of the wealthy people of Jerusalem are similar to those of Amos against Samaria. ${ }^{34}$ For Isaiah it is also a nation afar off by which Yahweh punishes the people of Israel.

He (Yahweh) will raise a signal for a nation afar off.

and whistle for it from the ends of the earth;

and lo, swiftly, speedily it comes! (Isa 5:26)

A factor which makes a difference between Amos and Isaiah is that when the latter started prophetic activity the Assyrian power had already begun expansion toward the region west of the Euphrates. The menace of the Assyrian invasion was, however, too greate for the nations of this region to cope with in a realistic way. For Isaiah it was a way toward the self-destruction for any nation to attempt military resistance against the Assyrian assault. Throughout his prophetic activities he kept the political position of nonalignment with any nation in face of the advancing Assyrian power. At the Syro-Ephraimitic war (734-732 BCE) he advised Ahaz king of Judah not to seek the Assyrian intervention to help Judah against these two countries. He insisted on political independence and religious trust in Yahweh's promise to protect Judah. He says as follows:

Take heed, be quiet, do not fear and do not let your heart be faint because of these smouldering stumps of firebrands, at the fierce anger of Rezin and Syria

and the son of Remaliah. (Isa 7:4)

He uttered a woe-oracle against Ephraim (Isa 28:1-4), when he tried to reject the Assyrian control in the year $724 \mathrm{BCE}$. It would only lead to his final downfall (721 BCE). When Ashdod attempted rebellion against

${ }^{34}$ Eg. Isa 1:10-17; 2:6-22; 3:1-4:1; 5:8-24. cf. R. FEY, Amos and Jesaja. WMANT 12 (1963). 
Assyria (714-711 BCE), he warned Hezekiah not to join in the attempt with Ashdod. To symbolize the doom of the exile he walked around the streets of Jerusalem naked and barefooted (Isa 20:1-6). In one of the legends of Isaiah ( $2 \mathrm{Kgs} 20: 12-19=$ Isa 39:1-8) it is recorded that he predicted the Babylonian exile, after Hezekiah showed the envoys sent by Merodach-Baladan, king of Babylon, everything in his treasure house including the whole armoury (703 BCE).

Isaiah's policy of non-coalition was on the one hand based upon his belief in Yahweh's promise to protect Jerusalem. The classical expression is found in the following verse:

Therefore thus says the Lord God,

"Behold, I am laying in Zion for a foundation:

a stone, a tested stone,

a precious cornerstone, of a sure foundation:

'He who believes will not be in haste.' (Isa 28:16)

On the other hand his policy was probably derived from the sober judgment of the international situation. J.M. MILLER and J.H. HAYES pointed out that the Assyrians held it advantageous to allow a semi-independent status for the Phoenicians, Philistine and Arab kingdoms to keep trade relationship in the world of the ancient Near East and for such minor states as Judah, Ammon, Moab and Edom to function as buffer zones between the Assyrian empire and Egypt. The Assyrians were therefore not eager to reduce these countries to their provinces. ${ }^{35}$ Isaiah's admonition to be quiet and to rely upon Yahweh's promise ${ }^{36}$ may be judged to be valid only on the level of religion but it could be on the contrary most realistic to protect the national identity of Judah in the turbulent period in which the Assyrians established themselves as an empire.

For Jeremiah the problem of the national destiny was more imminent than in the cases of Amos and Isaiah. The existence of the nation itself was at stake in his time. We may add a few remarks about his prophecies in comparison with Amos and Isaiah. In the book of Jeremiah a series of oracles against the nations, which is quite similar in its character to that of Amos (Am 1:2-2:3), is preserved (Jer 25:30-38). Its first verses read as follows:

The Lord will roar from on high,

and from his holy habition utter his voice;

he will roar mightily against his fold,

and shout, like those who tread grapes,

against all the inhabitants of the earth.

The clamour will resound to the ends of the earth,

35 J.H. HAYES and J.M. MILLER, A History of Ancient Israel and Judah, Philadelphia $1986,320-322$.

36 E.g. Isa 30:1-5, 15-17; 31:1-5. 
for the Lord has an indictment against the nations;

he is entering into judgment with all flesh,

and the wicked he will put to the sword, says the Lord. (vv 30-31)

In the following verses (vv 32-38) the ultimate destruction which would fall upon the peoples and nations of the earth is depicted. The destroying power is not named but metaphorically called as "a great tempest" from the farthest parts of the earth (v 32). It is not certain whether this series was derived from Jeremiah himself, but it shows the situation of his time. The tradition of Amos was kept alive in the period of Jeremiah.

In a biographical narrative about Jeremiah (Jer 27:1-11), it is reported that he appeared with yoke-bars on his neck before the envoys from Edom, Moab, Ammon, Tyre and Sidon who had come to Jerusalem in the beginning of Zedekiah's reign. The envoys from Aram and Philistia were probably not mentioned, because they could not do so under the Babylonian control. Jeremiah told these envoys the message given by Yahweh to their kings as follows:

Now I have given all these lands into the hand of Nebuchadnezzar, king of Babylon, my servant, ...

If any nation or kingdom will not serve this Nebuchadnezzar, king of Babylon, and put its neck under the yoke of the king Babylon, I will punish that nation with the sword, ...

But any nation which will bring its neck under the yoke of the king of Babylon and serve him, I will leave on its own land to till it and dwell there, says the Lord. $(27: 6,8,11)$

Such an occasion in which the envoys of the neighbouring nations came to greet the Judean king may well also be the one where to oracles against the nations spoken by Amos (1:2-2:3) or by Jeremiah (25:39-38) could be uttered. As to the content of Jeremiah's message for the envoys, it is remarkable in comparison with Isaiah that the king of Babylon is not understood simply to be a tool of Yahweh's punishment (Isa $10: 5,15,24)$ but to be his "servant" appointed to control these nations. Jeremiah abandoned the non-coalition policy of Isaiah and did not hesitate to express a definitely pro-Babylonian position from the beginning of Jehoiakim's reign to the end of Zedekiah's. In the fourth year of Jehoiakim it is reported that Jeremiah took a scroll and wrote on it all the words that Yahweh had spoken to him against Israel, Judah and all the nations, from the days of Josiah until then (Jer 36:1-2). When it was read before Jehoiakim, he burned it and accused Jeremiah saying:

"Why have you written in it that the king of Babylon will certainly come and destroy this land, and will cut off from it man and beast?" (Jer 36:29)

In another context it is also reported that Jeremiah addressed to all the people of Judah and Jerusalem summarizing the message which he had spoken from the time of his calling until the fourth year of Jehoia- 
kim (Jer 25:1-2). He told that Yahweh would punish them by the king of Babylon, his servant (Jer 25:9). To designate the king of the rising empire as Yahweh's servant means to interpret the historical reality in a radically realistic way. We find such an attitude again in the oracles addressed by Second Isaiah. He calls Cyrus "the anointed" (Isa 45:1) and "the shepherd" (44:28) appointed by Yahweh to fulfil his purpose in history.

At the same time, we find in the words, which are probably rooted in the genuine oracles of Jeremiah, an irrational way to represent the power, which was assaulting Israel, as "a hot wind" (Jer 4:11), "a whirlwind" (4:13), "a storm" or "a whirling tempest" (23:19) sent from Yahweh. ${ }^{37}$ Especially in the last case, it is said in the context of the divine council (23:18). The decision of Yahweh, which was proclaimed there, would not turn back until he accomplished the intents of his mind (23:20). The name of the assaulting power is not specified.

There are differences in the way to describe the hostile power between the oracles in prose and those in verse. Generally speaking we detect in the former a retrospective point of view which had already seen the victory of the Babylonian king over the nations of the world. The prose oracle (Jer 25:8-11a) in which the name of Nebuchadrezzar is mentioned is followed by the prediction about the destiny of the exile (11b14). In the biographical narrative mentioned above (Jer 27:1-42) the oracle is developed to the same theme $(27: 4 \mathrm{~b}-11)$. On the other hand we recognize in the latter the struggle of the prophet to cope with the impending downfall by pointing crisis both within and outside the nation. ${ }^{38}$ Nevertheless we could perceive in the biographical narratives the serious endeavour of the prophet to prevent the nation from total destruction. Jeremiah carried out fierce confrontation against Hananiah, the leader of the anti-Babylonian revolt (Jer 28:1-27). The meaning of this fight is clear enough and cannot be dismissed as a later fiction. Jeremiah's advice for Zedekiah to surrender to the Babylonian army (Jer 38:17) ${ }^{39}$ clearly shows his pro-Babylonian standpoint. The record that the king of Babylon took Jeremiah out of the court of the guard and treated him sordially is also an evidence to confirm the same (Jer 39:11-14).

Thus far we have examined that Jeremiah's political attitude in the international problems is apparently quite different from that of Isaiah. We may suppose that Jeremiah's oracles about the destiny of the nation are ultimately derived from the council of Yahweh (Jer 23:18-22). His insight in the actual situation of his time, however, was solidly realistic without having any illusion for the future. Definitely he took the pro-

37 See also Jer 25:32; 30:23.

38 Jer $4: 14-31 ; 23: 20-22$.

39 Cf. also Jer 21:9; $38: 2$. 
Babylonian position. He had no belief in the inviolability of Jerusalem any more. ${ }^{40}$

Seen as a whole, the major prophets of pre-exilic Israel kept the basic principles of social ethics in Israel as the common ground of their activities and refused to take part in the optimistic nationalism of their time. The international situation underwent drastic changes in this period. The emergence of new empires was regarded by them to be caused in the realm of the divine council concealed from the common people. The authority to decide the destiny of the nations belonged for them to the sovereignity of Yahweh. It was a severe task for anyone to be responsible for the international problems in such an age of drastic change. The problems outside a nation are always related with the inner struggles within it. If a nation simply follows the traditional way, it will easily lose its power and disappear from the surface of the world. In such situations the prophets of Israel could keep themselves realistic enough to discern the real problem of the time and try to save the identity of Israel as a people of Yahweh beyond the coming catastrophe. If we try to understand the meaning of their activities, I believe that we should take the historicity of them more seriously than some recent interpreters do. ${ }^{41}$

\footnotetext{
40 Jer 7:1-15; 26:1-19.
}

41 Cf. especially O. KAISER, Jesaja Kap. 1-12, ATD 17 (1981) and R.P. CARROLL, Jeremiah, OTL, London 1986. 



\title{
ZUR WIRKUNGSGESCHICHTE VON PSALM 8
}

\author{
von \\ Hans Klein \\ Hermannstadt, Rumänien
}

Einige wenige Psalmen haben im Urchristentum vermutlich schon früh eine Rolle gespielt und dazu beigetragen, daß sich durch ihre Meditation die Christologie entfaltete ${ }^{1}$. Dazu gehört auch Psalm 8. Er ist von verschiedenen urchristlichen Theologen zur Interpretation des Christusgeschehens herangezogen worden ${ }^{2}$.

Dies ist umso verwunderlicher, als der Psalm, soweit wir es überblicken, weder im Alten Testament noch im Judentum eine messianische Auslegung erfahren hat ${ }^{3}$. Die verschiedenen Texte, die wir aus diesem Umfeld des Neuen Testaments besitzen, lassen aber den Schluß zu, daß der Psalm bekannt und beliebt war. Die Tatsache also, daß er im Urchristentum gedeutet wurde, reiht sich ganz in den Umgang mit dem Psalm innerhalb der frühjüdischen Tradition ein, man las den Psalm im Zusammenhang der eigenen Erfahrung von Gott, Welt und Mensch. Neu war im Urchristentum bloß, daß er konsequent und ausschließlich christologisch gedeutet wurde, offensichtlich bedingt durch die neue Blickrichtung.

Wir möchten im Folgenden diese Auslegung im Urchristentum etwas näher betrachten. Um sie aber recht einordnen zu können, gehen wir zunächst kurz auf die Hauptaussagen des Psalmes selbst ein (I.), besprechen sodann seine Wirkungsgeschichte im AT und dem Frühjudentum (II.), um daraufhin die Erhöhungsvorstellung ins Auge zu fassen, die sich auf Ps 8,7 beruft (III.), werden anschließend das Verständnis von Ps 8,5-7 in Hebr 2 bedenken (IV.) und wenden uns dann Mt 21,14-16 zu, einer Perikope, die aufgrund von Ps 8,3 entstanden ist (V.). Einige Sätze am Ende werden das Ergebnis zusammenfassen (VI.). Die breite Wirkung des Psalms ist damit bereits angezeigt.

I.

Sieht man von dem hymnischen Kehrreim in V.2 und $10 \mathrm{ab}$, der eine eigene Aussage enthält, die aber in der Zeit, die wir betrachten, kei-

\footnotetext{
1 Ps 2; 8; 22; 69; 110.

2 S.u. III-V. Zum frühen Gebrauch von Ps 8,7 vgl. M. HENGEL, Hymnus und Christologie, in: W. HAUBECK und M. BACHMANN (Hrsg.), Wort in der Zeit, FS K.H. RENGSTORF (1980) 1-23; 9-12.

3 G. DELLING, ThWNT VII, 42, Anm. 7; D.A. KOCH, Die Schrift als Zeugnis des Evangeliums, BHTh 69 (1986) 245. Vorsichtig O. MICHEL, Der Brief an die Hebräer, KEK XIII 81949,70 f.
} 
ne eigene Wirkungsgeschichte gehabt hat ${ }^{4}$, dann enthält Psalm 8 zwei Hauptaussagen, die eine in V.3, die andere in V.5-7.

a) Der Satz:

Aus dem Munde von Kindern und Säuglingen

hast du ein Bollwerk gegründet

wegen deinen Bedrängern,

um zum Schweigen zu bringen Feind und Rächer,

ist in seiner Bedeutung umstritten. Die Unsicherheit über die Auslegung könnte schon früh Textergänzungen oder Veränderungen bewirkt haben. Geht man vom Wort "Säugling" aus, dann ist der Schrei des Neugeborenen gemeint, der die Macht des Schöpfergottes vergröBert ${ }^{5}$. Dann ist das Lärmen der Kinder und der Schrei des eben erwachten Lebens im Blick, die unbefangene Lebensäußerung, die jede Frage nach der Macht des Schöpfergottes unnötig und unwirksam macht. Geht man aber vom Worte "Kind" aus und sieht Ps 8,3 im Zusammenhang des Psalmbeginnes, dann ist der Gesang, das Loblied der Kinder im Blick. So hat schon die LXX gedeutet und darum statt "Bollwerk" "Lob" übersetzt, also: "Aus dem Munde der Kinder ... hast du dir Lob bereitet ${ }^{6} . "$ In diesem Falle hat dann das Wort "Säuglinge" nur noch die Funktion eines etwas gedankenlos hinzugefügten Appendixes7.

Nimmt man hinzu, daß die Frage, wie V.2b in seinem jetzigen Konsonantenbestand zu verstehen ist, durchaus Probleme aufwirft und

\footnotetext{
$4 \mathrm{Vgl}$. indes die kaum überbietbare Interpretation des Verses am Anfang der JohannesPassion von J.S. BACH.

${ }^{5}$ W. RUDOLPH, Aus dem Munde von jungen Kindern und Säuglingen, in: H. DONNER, R. HANHART und R. SMEND (Hrsg.), Beiträge zur alttestamentlichen Theologie, FS W. ZIMMERLI (1977) 388-396; 394.

${ }^{6}$ H. SPIECKERMANN, Heilsgegenwart. Eine Theologie der Psalmen, Göttingen 1989, 228, übersetzt darum ib mit "machtvolles Lob". Dagegen mit vielen Belegen V. HAMP, Ps 8,2b.3, BZ NF 16 (1972) 115-120; 118f.

7 So H. SPIECKERMANN [A.6] 230, der "und Säuglinge" als redaktionellen Zusatz ansieht. Da man kaum damit wird rechnen können, daß ein solcher Zusatz gedankenlos erfolgte, auch wenn der Redaktor eine vorgeprägte Wendung "Kinder und Säuglinge" gekannt haben sollte, die unserem "Kind und Kegel" entspricht, was aus den angeführten Belegen kaum geschlossen werden kann, wird man damit rechnen müssen, daß der Redaktor sich etwas dabei gedacht hat. Warum soll man dieses Denken aber nicht gleich dem ersten Sänger zuschreiben? Die LXX hat offensichtlich den Psalm schon gedeutet (s.u. 2d). - Wer "Kinder und Säuglinge" zusammensehen will, deutet den Ausdruck bildlich. So versteht W. BEYERLIN, Psalm 8. Chancen der Überlieferungskritik, ZThK 73 (1976) 122; $15 f$ die Wendung als Metapher für die "Preisgegebenen der zerstörten Zions-Witwe"; P. MŬLLER, In der Mitte der Gemeinde. Kinder im NT, Habil. Schrift, München 1991, 213 sieht darin die "Unmündigen", die zur Weisheit gerufen werden. O.H. STECK, Beobachtungen zu Psalm 8, BN 14 (1981) 54-64; 59 meint, daß der Beter "menschliche Hilflosigkeit assoziieren soll", während A. WEISER, Die Psalmen I, ATD $14\left({ }^{8} 1973\right)$ 95f, meint: "im Kleinen und Unscheinbaren wird Gottes Größe offenbar". Verdeckt hier theologische Sprache unsere eigene Hilflosigkeit, den Text sachgemäß auszulegen?
} 
auch seine Stellung im Psalm umstritten ist ${ }^{8}$, und endlich, daß es für V. 3 keine auch nur entfernte Parallele gibt ${ }^{9}$, die die Deutung erleichtern könnte, dann wird man zum Schluß kommen, daß im Augenblick eine sachgemäße Entscheidung in der Auslegung dieses Psalmes nicht getroffen werden kann. Mt 21,14-16 greift den Text der LXX auf und entscheidet sich damit für den Schwerpunkt "Kinder" unter Vernachlässigung des Wortes "Säuglinge".

b) Die Verse 5-7 sprechen von der paradoxen Niedrigkeit und gleichzeitigen Hoheit des Menschen. Dieses Wesen, das angesichts des Firmamentes ein unscheinbares Ding ist, wird nur "wenig niedriger als Elohim" geschaffen, ihm wird "alles unter die Füße gelegt", d.h. zur Herrschaft übergeben. Das Motiv der "Herrschaftsübertragung", das aus dem Königsritual stammt, wird hier wie Gen 1,28 auf den Menschen allgemein bezogen, die Königsvollmacht gewissermaßen demokratisiert ${ }^{10}$. Aber der Psalm selbst läßt von einem solchen "Demokratisierungsproze $\beta^{\prime \prime}$ nichts ahnen, es geht ihm einzig um die Beschreibung eines kaum verständlichen Phänomens, daß nämlich der Mensch, der angesichts der Schöpfung und somit auch des Schöpfers unendlich klein ist, mit der Herrschaft über die Schöpfung betraut wurde. Das Mittel des Lobliedes ermöglicht dem Denker, diese beiden Gedanken, Kleinheit und Vollmacht des Menschen, zusammenzusehen als Werk des Schöpfers, der weiß, was er getan hat, ein Werk, das aber rational eigentlich nicht faßbar ist, sondern nur als Wunder staunend besungen werden kann ${ }^{11}$.

8 Vgl. die Konjektur bei W.H. SCHMIDT, Gott und Mensch in Ps. 8. Form- und überlieferungsgeschichtliche Erwägungen, ThZ 25 (1969) 1-25; 5, der nach B. DUHM vorschlägt,

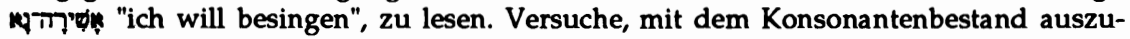
kommen bei V. HAMP [A.6] 119 und bei W. RUDOLPH [A.5] 390f, der sich aber für eine spätere Einfügung entscheidet. - Die Ratlosigkeit der Ausleger wird bei F. CRÜSEMANN, Studien zur Formgeschichte von Hymnus und Danklied in Israel, WMANT 32 (1969) 289, Anm. 2 sehr deutlich.

9 H.J. KRAUS, Die Psalmen I, BK XV (1966) 68.

10 W.H. SCHMIDT [A.8] 10. H. SPIECKERMANN [A.6] 234 Anm. 23 findet den Ausdruck nicht glücklich, "weil er das Mißverständnis begünstigt, mit der Generalisierung sei eine theologische Nivellierung verbunden".

11 Staunend, aber zugleich mit dem Unterton des Schreckens beschreibt auch Sophokles den Menschen und sein Tun in der Antigone Z. 334: "Vieles Gewaltige lebt, nichts ist gewaltiger als der Mensch." Der Chor, der diese Aussage macht, spricht von dem Menschen, der Meere durchfährt, die Erde bearbeitet und sich zum Herrn der Tierwelt macht, auch darin Ps 8 sehr ähnlich. Zweierlei ist anders als im Psalm: 1) Diese Aussage erfolgt nicht vor Gott in einem Hymnus und so wird auch nicht die Kleinheit des Menschen angesichts der ganzen Schöpfung hervorgehoben. 2) Die Aussage hat klaren Bezug zum Willkürhandeln des Kreon, der "Gewaltiges", Furchtbares vollbringen wird. Die Verhaftung des Menschenbildes im Königsbild ist hier noch im Hintergrund, während sie Ps 8 abgestreift ist. Aber gerade dieser Text macht auch deutlich: Wenn die Größe des Menschen unabhängig von der Schöpfung und dem Schöpfer einfach von seiner Möglichkeit her gesehen wird, die Welt zu beherrschen, dann ist Schrecken ganz nahe. Das ist ein Problem, 
II.

Eine Wirkungsgeschichte des Psalms könnte damit beginnen, die Urfassung des Psalms und die Absichten späterer Redaktionen zu eruieren. Wenn wir auf diese Fragestellungen nicht eingehen, dann geschieht es, weil sie kaum jene Aussagen betreffen, die in späteren Werken aufgegriffen wurden, ausgenommen die Übersetzung von V.3 durch die LXX, der dann Mt folgt. Das Problem wurde oben besprochen. Wir gehen Texten nach, die die Aussagen von Ps 8 aufnehmen.

a) Der erste Text, auf den näher einzugehen wäre, ist Ps 144,3. Wiewohl in nur vergleichbarer Terminologie, dürfte Ps 8,5-7 aufgenommen sein:

Was ist der Mensch (r7n), daß du ihn bemerkst (Tפת),

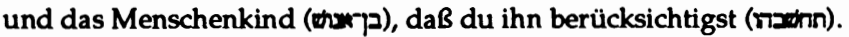

Gleich ist im Verhältnis zu Ps 8 eigentlich nur die Frage nach dem Menschen in der Form eines synonymen Parallelismus. Vergleichbar ist zusätzlich der Gebrauch der Worte "Mensch" und "Menschenkind" insofern, als in Ps 8 der Mensch בן־אדם genannt das Menschenkind wird, während in Ps 144 für den Menschen das Wort aרk, für das Menschenkind בן verwendet wird. vertauscht. Inwieweit dies bewußt geschah, wird man fragen können, ob die Antwort so zu geben ist, daß שנו eher den Menschen in seiner Niedrigkeit sieht, wird offen bleiben müssen. In diesem Falle hätte Ps 8 mit שנו den Menschen in seiner Niedrigkeit vorangestellt, um ihn dann in seiner Hoheit zu beschreiben, während Ps 144, der ein Hilferuf ist, ihn zunächst in seiner Hoheit (אר $ם$ ) anspricht, um dann die Niedrigkeit, die der Beter erlebt, zu formulieren.

Bemerkenswert ist die Änderung der Verben. Statt זכר 'gedenken' in Ps 8 steht in Ps 144 ירע 'bemerken', statt פקר 'heimsuchen', 'annehmen' steht keit des Beters betont herausgestellt ${ }^{12}$. Der Bittsteller wird sich nicht seiner Ausstattung mit Vollmacht, sondern seines ganzen Jammers bewußt, wenn er vor Gott fragt, was der Mensch ist. Gemeint ist: Jahwe, wir sind nichts vor dir. Dem entspricht der Fortgang des Psalmes:

Der Mensch (घ7*) gleicht einem Hauch, seine Tage sind wie ein vergehender Schatten (V.4).

das auch Hiob beschäftigt (s.u. II. b), das wir aber aus den Erfahrungen unserer Zeit den Nachkommen weitergeben müßten.

12 Ein Staunen des Dichters "über das Wunder der Zuwendung Jahwes zum hinfälligen Menschen" kann ich hier im Unterschied zu H. SPIECKERMANN [A.6] 237 nicht finden. 
Da der Psalm nicht ein Loblied ist, wie Ps 8, sondern ein Hilfeschrei, eine Klage, beschreibt der Beter seine Not in der Reflexion über die Nichtigkeit des Menschen. Dies geschieht, obwohl sich das Gebet nicht als Bitte eines beliebigen Menschen versteht, sondern eines Königs (V.10) - darin, und nicht nur darin, dem Prediger Salomo verwandt, der auch Reflexionen über die Vergänglichkeit des Menschen anstellt ${ }^{13}$. Die Paradoxie von Erhabenheit und Niedrigkeit des Menschen wird zugunsten seiner Niedrigkeit aufgelöst. Von der Größe des Menschen ist nichts mehr zu spüren, wohl aber von der Mächtigkeit Gottes (V.5-7), die zur Hilfe gerufen wird. Dieses Thema war in Ps 8 nicht im Gesichtsfeld. Dort war von dem herrlichen Namen Jahwes in der Form eines Lobgesanges die Rede.

b) Eine sehr ähnliche Sicht des Menschen tritt uns Ijob 7,17-18 entgegen. Dort erscheint allerdings der Dialog mit den Aussagen von Ps 8 deutlicher erkennbar:

Was ist der Mensch (đv), daß du ihn groß machst,
daß du deinen Blick (dein Herz) auf ihn legst,
da $\beta$ du ihn heimsuchst jeden Morgen
und jeden Augenblick ihn prüfst?

Die Frage: Was ist der Mensch (שונא), die diese Stelle mit Ps 8,5 gemeinsam hat, reicht nicht $\mathrm{zu}$, eine Aufnahme von Ps $8 \mathrm{zu}$ postulieren. Sie begegnet auch Ijob 15,14 und könnte Redeweise sein. Aber es tauchen zwei Verben aus Ps 8 zusätzlich auf, die aufzeigen, daß dieser Psalm im Hintergrund steht: פק 'heimsuchen' und 'legen'. Der Unterschied der Aussagen von Ps 8,5-7 und Ijob 7,17-18 ist allerdings abgrundtief. Das Wort פ פ 'heimsuchen' hat in Ps 8,5 die Bedeutung einer positiv beobachtenden, gnädigen Zuwendung, hier ist damit ein strafendes Nahe-Sein, das unerträglich wird, ausgesprochen: Jeden Morgen, wenn der Beter Hilfe erwartet (Ps 46,6; 130,6), sucht ihn Jahwe mit neuer Plage heim ${ }^{14}$.

Auch das Verbum no 'legen' hat eine ganz andere Bedeutung in Ps 8,7 als hier. Dort ist ausgesagt, daß Jahwe dem Menschen alles unter die Füße "legt", unterordnet, hier ist ausgesagt, daß Jahwe sein Herz, d.h. seinen Willen auf den Menschen selbst legt, daß er ihn also nicht aus den Augen läßt, ihn mit seiner Allmacht verfolgt. Gottes Wollen liegt also auf dem Kranken, er wird von ihm nicht frei. Auch hier wird also, wie in Ps 144,3f, nicht die Hoheit, sondern die Jämmerlichkeit und Bedauernswürdigkeit des Menschen ausgesprochen. Das illustriert der Fortgang:

Wie lange schaust du nicht weg von mir, gibst mir keine Ruhe, meinen Speichel zu schlucken? (ljob 7,19)

13 Vgl. W. ZIMMERLI, Was ist der Mensch? in: DERS., Studien zur alttestamentlichen Theologie und Prophetie, Ges. Aufs. II, TB 51 (1974) 311-324; 316f.

14 H. SPIECKERMANN [A.6] $237 \mathrm{f}$. 
Hiob wehrt sich gegen die Ansicht, er könnte Gott gefährlich werden. Er bestreitet also nicht nur die Richtigkeit des Menschenbildes von Ps 8,5-7, er bekämpft es, weil er diese Sicht des Menschen als ganz gefährlich erleidet ${ }^{15}$. Gemeint ist: Wenn Gott den Menschen so ansieht, wie er Ps 8 beschrieben ist, dann wird er für ihn bedrohlich, dann greift er zu, denn dann sieht er den Menschen als wirklichen Gegner an. Das ist der Mensch aber nicht, kann es nicht sein. Aus diesem Grunde wird die Armseligkeit herausgearbeitet. Besingt Ps 8 das Wunder der Erhabenheit des Menschen aus der Gnade des Schöpfers angesichts seiner kleinen Dimension im Verhältnis zum Weltall (Ps 8,4-9), so beklagt Ijob 7,17-18 die Tatsache, daß der Mensch von Gott als groß geachtet wird, weil ihm diese verkehrte Sicht zur Quelle des Leidens wird ${ }^{16}$.

Um diese Sicht zu bestätigen, ziehen wir noch Ijob 25,4-6 heran. Hier tritt auch, wenngleich in anderer Formulierung, innerhalb eines Parallelismus das Wortpaar Mensch (שונוא) - Menschenkind (בךרארם) auf, ebenso ist von Mond und Sternen die Rede, wie Ps 8,4f. Wieder steht also Ps 8 im Hintergrund. Und wiederum wird die Erbärmlichkeit der Menschen hervorgehoben, der mit einer Made, einem Wurm verglichen wird (Ijob 25,6). Und die Himmelskörper werden als nicht vollkommen bezeichnet. Gottes Größe und Unvergleichlichkeit wird damit unterstrichen. Schon die Himmelskörper sind unvollkommen, ein Zeichen der totalen Unwürdigkeit des Menschen.

c) Auch Sir 18,8f findet keine Worte mehr, die Erhabenheit des Menschen auszudrücken, wenn er an Formulierungen von Ps 8 anspielt und sagt:

Was ist der Mensch und wozu ist er nütze,

was ist das Gute an ihm und was das Schlechte?

Die Zahl der Tage des Menschen ist - wenn es viele sind - hundert Jahre.

Hier spricht der Weise von der Vergänglichkeit des Menschen und meint damit seine Nichtigkeit (vgl. V.10). Aber im Unterschied zu Hiob hebt Sirach Gottes Größe und sein Erbarmen gegenüber dem vergänglichen Menschengeschlecht hervor. Damit wird das als Geschehen Gottes proklamiert, was Ps 144,3f und Ijob 7,17f ersehnten. Am Menschenbild ändert sich wenig, bloß die Güte Gottes, die auch Ps 8 regierte, wird erneut bedacht. Andere Erfahrungen mit Gott lassen das Gottesbild neu bedenken.

15 G. FOHRER, Hiob, KAT XVI (21988) 180 spricht von "bitterer und parodierender Abwandlung" von Ps 8,5. Ähnlich J. JEREMIAS, Umkehrung von Heilstraditionen im Alten Testament, in: J. HAUSMANN - H.J. ZOBEL (Hg.), Alttestamentlicher Glaube und Biblische Theologie, FS H.-D. PREUSS, Stuttgart 1992, 309-320; 314.

$16 \mathrm{Zu}$ dieser Frage vgl. meinen Beitrag, Die Bewältigung der Not im Alten und Neuen Testament, ThZ 40 (1984) 257-274; 259-263. 
d) Der Targum zu Ps $8^{17}$ und die Übersetzung der LXX haben den Vergleich zwischen Gott und dem Menschen dadurch etwas abgestuft, daß sie אלהים in Ps 8,5 im Sinne von "Engel" deuteten, den Menschen also nur mit "göttlichen Wesen" verglichen sahen und "ein wenig geringer" als diese geachtet. Ob schon Ps 8 אלהים in diesem Sinne verstanden hat, läßt sich schwerlich mit Sicherheit ausmachen ${ }^{18}$. Wenn der Autor von Ijob 7,17f Ps 8 im Ohr hatte, wie wir annahmen, hat er den Menschen Jahwe selber und nicht nur Elohim - Wesen nahe gesehen. Andernfalls ist die betonte Niedrigkeit nicht voll verständlich. Die Übersetzer beabsichtigen ein Abrücken von einer grundsätzlichen Vergleichbarkeit des Menschen mit Gott, und kommen damit zu einem auch Ijob 7 gemäßeren Bild des Menschen. Da auch die Engel sündigen (Ijob 15,15; Sir 17,31f), Mond und Sterne nicht vollkommen sind (Ijob 25,4-6), ist der unendliche Unterschied zwischen Mensch und Gott in diesen Texten festgeschrieben. Daß er in der rabbinischen Zeit wieder aufgelockert wird, ist nun zu zeigen.

e) Die Rabbinen kehren wieder zur Hervorhebung der Erhabenheit des Menschen zurück. Im Midrasch zu Ps 8 § 7 lesen wir:

\begin{abstract}
"Was ist der Mensch, daß du seiner gedenkst? Ps 8,5. Das bezieht sich auf Abraham, wie es heißt: Gott gedachte an Abraham Gn 19,29. "Und des Menschen Kind, daß du es bedenkst?" Ps 8,5. Das bezieht sich auf Isaak, der infolge des "Bedenkens" geboren wurde, wie es heißt: Jahve bedachte die Sara Gen 21,1. "Du ließest ihm nur wenig an der Gottheit fehlen" Ps 8,6; das bezieht sich auf Jakob, der das Kleinvieh bestimmte, gestreifte, gesprenkelte $u$. scheckige Junge zu werfen $(\mathrm{Gn} 30,39$ ). Das lehrt, daß ihm (im Vergleich zu Gott) nur mangelte, in sie Seele zu legen «19.
\end{abstract}

Die Hoheit des Menschen, die ihn ganz nahe an Gott heranführt, besteht darin, daß er das Machbare tut. Es fehlt ihm im Vergleich zu Gott nur die Einstiftung des Lebens. Mit der Natur kann er umgehen, vieles verändern.

Beachtet man also den Menschen im Hinblick auf sein Verhalten zur Welt, die machbare Welt, erscheint der Mensch von der Welt abgesetzt, er kann sie beherrschen, verändern, das Machbare bewirken. Der Unterschied zwischen dem Handeln Gottes in seiner Schöpfung und

17 Str.-Bill. III, 682.

18 Die Stellen, wo die LXX

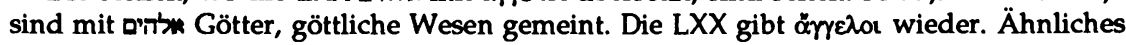
gilt für die מי האלדים in Gen 6,2; Ijob 1,6; 2,1;38,7. So entscheidet sich die Frage betreffend Ps 8,5 auch an der Bewertung der neutestamentlichen Texte, die davon sprechen, daß das Gesetz den Menschen "durch Engel" gegeben wurde (Apg 7,38.53; Gal 3,20; Hebr 2,2). Man muß voraussetzen, daß Traditionen zugrunde liegen, wonach a wiedergegeben wurde. M.W. ist diese Frage im Zusammenhang der neutestamentlichen Texte nicht diskutiert.

19 Str.-Bill. III, 682. Diese Auslegung erscheint mir keineswegs "eigenartig", wie O. MICHEL [A.3] 70 Anm. 5 meint. 
dem des Menschen an derselben reduziert sich darauf, daß Gott Leben bewirken kann, während der Mensch dies nicht vermag.

e) Etwas anders, wenn auch vergleichbar, sehen die Rabbinen Rab und Schemuel um 250 n.Chr. dieselbe Aussage des Psalms. Nach ihnen ist der Satz: "Du hast ihm ein wenig Gott gegenüber fehlen lassen", als fünfzigster Teil der Gesamteinsicht zu verstehen. Gegenüber Gott fehlt also dem Menschen der fünfzigste Teil der Einsicht ${ }^{20}$. Die Nähe zu Gott wird hier in der Möglichkeit des Menschen gesehen, Einsicht zu gewinnen. Gemessen an Gottes Einsicht ist die des Menschen sehr groß. Der Herrschaftsauftrag über die Schöpfung, der im Midrasch zu Ps 8 dort eine Rolle spielte, wo von Jakobs Umgang mit der Herde geredet wird, ist hier ausgeblendet, die Rabbinen betonen die Größe des Menschen kraft seiner Einsicht.

f) Ps 8,3 wird im frühen Judentum so ausgelegt, daß einerseits schon die Kinder im Mutterschoß als das Exoduswunder preisend gedacht sind, wobei it als Ruhm gedeutet wird wie in der LXX (Mekh zu Ex 15,1), andererseits ist die "Macht" - vin in der Tora gesehen, die Kinder gelten als Bürgen, als Garanten für die Tora (Midr Hohesl 1,4) ${ }^{21}$.

g) Sieht man diese Texte zusammen, so fällt auf:

- Zu Ps 8,3 werden sowohl die Worte "Säugling" und "Macht" diskutiert. Die Probleme, die heute mit dem Vers empfunden werden, sind schon damals bekannt gewesen, auch wenn sie anders gelöst wurden.

- Der Unterschied zwischen Gott und Mensch wird dort groß gesehen, wo das Angewiesensein des Menschen auf Gott, seine Anfälligkeit und Vergänglichkeit im Blick ist, während dieser Unterschied gering gesehen wird, wo das Verhältnis des Menschen zur Welt im Vordergrund steht. Ps 8,5-9 ist beides miteinander verbunden. In Ps 8,5 ist die Nichtigkeit des Menschen betont angesichts der Erhabenheit der Schöpfung. In Ps 8,6-9 ist seine Größe angesichts seiner Umwelt ausgesagt. Die Wirkungsgeschichte im Alten Testament und im Judentum ergibt, daß diese beiden Gesichtspunkte nicht mehr zusammengesehen werden.

\section{III.}

Im Neuen Testament ist das Verhältnis Mensch - Schöpfung vor Gott kein Thema. Es konzentriert sich auf die Beziehung Mensch - Gott, genauer Gott - Mensch. So kann auch Ps 8 im Neuen Testament nur insofern zitiert werden, als er dieser Beziehung Rechnung trägt. Im paulinischen und paulinisch beeinflußten Christentum hat Ps 8,7 in Verbindung mit Ps 110,1 eine beachtliche Rolle gespielt. Die Aussagen sind sehr ähnlich:

Ps 110,1: Bis daß ich lege deine Feinde als Fußschemel unter deine Füße.

20 Str.-Bill. III, 682.

21 Str.-Bill. I, 854f. 
Ps 8,7: Alles hast du ihm unter die Füße gelegt.

a) Paulus verbindet 1 Kor 15,25-27 diese beiden Texte miteinander. Das geschieht schon in V.25, wo Ps 110,1 herangezogen wird, dadurch, daß aus Ps 8,7 die Näherbestimmung "alles" eingebracht wird ("alle ... Feinde"). V.27 wird dann Ps 8,7 zitiert: "alles hat er unter seine Füße unterworfen". Das gilt unabhängig davon, ob man V.27b mit "wenn er aber sagt" im Sinne der Wiedergabe des Zitates 22 oder mit "wenn er aber gesagt haben wird" im Hinblick auf ein zukünftiges Reden wiedergibt ${ }^{23}$. Es wird somit deutlich, daß Paulus zwei verwandte Psalmaussagen miteinander verbindet und daraus seine Schlüsse zieht. Sowohl Ps 110,1 als auch Ps 8,7 werden von ihm auf Christus gedeutet, dem Gott alles unterworfen hat bzw. zur Unterwerfung anvertraut hat. Eine Aussage, die einst dem König galt, und die von Ps 8 auf den Menschen als Herrn aller Lebewesen übertragen worden war ${ }^{24}$, geht an den "König" zurück, weil sie nach Meinung des Apostels nur auf ihn gemünzt sein kann: Christus wurde bei seiner Erhöhung die Vollmacht über alles übertragen. Und er herrscht (V.25), bis er alles unterworfen hat. Dann übergibt er seine Macht dem, der ihm sie übertrug (V.28). Ps 8,7 wird somit aus seinem Kontext herausgerissen, sowohl die Herrschaft über die Lebewesen (V.8f) als auch das Gedenken Gottes an den Menschen (Ps $8,5)$ werden ausgeblendet, ganz zu schweigen von der Frage: "Was ist der Mensch?" Darin gliedert sich Paulus durchaus in die Auslegung des Psalmes innerhalb seiner Wirkungsgeschichte ein, die wir außerhalb des NT betrachteten. Man hat zwar gemeint, daß Paulus das Wort "Menschensohn" in 8,5 mitgehört und titular verstanden habe ${ }^{25}$ und daß dieses Verständnis die Heranziehung des Verses veranlaßt habe. Aber diese These läßt sich nicht nachweisen. Wohl aber läßt sie sich mit dem Hinweis entkräften, daß die "Engel", denen der "Mensch" oder der "Menschensohn" nach LXX verglichen wird, nicht andeutungsweise im Kontext begegnen. Das ist dann Hebr 2 anders. Es gibt auch keinerlei Hinweise dafür, daß Ps $8 \mathrm{zu}$ jener Zeit in seiner Gesamtheit christologisch gedeutet wurde 26 . Darum beziehen wir diese paulinische Aussage in die Wirkungsgeschichte ein. Der Halbvers des Psalmes bekommt in einem anderen Zusammenhang eine neue Bedeutung. Er wird christologisch-eschatologisch ausgelegt.

22 A. LINDEMANN, Parusie und Herrschaft Gottes. Zur Exegese von 1 Kor 15,23-28, WuD NF 19 (1987) 87-107; 100. Belege bei H. CONZELMANN, Der erste Brief an die Korinther, KEK V (111969) 326 Anm. 110.

23 CHR. WOLFF, Der erste Brief des Paulus an die Korinther, ThHK 7/II (1982) 183.

24 S.o. bei Anm. 10.

25 So zuletzt M. HENGEL, Psalm 110 und die Erhöhung des Auferstandenen zur Rechten Gottes, in: C. BREYTENBACH - H. PAULSEN (Hrsg.), Anfänge der Christologie, FS F. HAHN (1991) 43-72, 54, vgl. DERS. [A.2] 11 mit Anm. 12.

26 Gegen M. HENGEL [A.2] 11.15 . 
a) Phil 3,21 nimmt Paulus die Aussage von 2 Kor 15,27 wieder auf. Sie bleibt in dem christologisch-eschatologischen Zusammenhang:

... der unsern Leib verwandeln kann ...

gemäß der Kraft, mit der er ihm alle Dinge unterworfen hat ...

Mit dem Gedanken der Verwandlung des Leibes übernimmt Paulus die Aussage von der Überwindung des Todes aus 1 Kor 15,26 und zitiert daraufhin Ps 8,7 wie 1 Kor 15,2727. Die Erkenntnis, die er 1 Kor $15,26 \mathrm{f}$ aus der Schrift erschloß, hat er sich hier zu eigen gemacht. Er sagt jetzt, daß Gott Christus alle Dinge unterworfen hat und damit seine Macht beweist, die auch bei der Verwandlung der Christen am Ende wirksam sein wird. Wir registrieren hier, daß der eschatologische Bezug nur noch dem Christen gilt, Christus ist die Herrschaft ganz übertragen.

c) Eph 1,22 geht hierin einen Schritt weiter. Der Text wird ganz enteschatologisiert:

Er hat ihm alles unter die Füße unterworfen und gab ihn als Haupt über die ganze Gemeinde.

Die Unterwerfung unter die Feinde ist geschehen. Die Endzeit ist nicht mehr im Blick. Hingegen erfolgt eine Einschränkung. So sehr der erste Halbvers davon spricht, daß Christus "alles" unterworfen wurde, wird im zweiten festgehalten, daß er Haupt der Gemeinde, der Christenwelt und nicht der ganzen Menschenwelt oder gar des Alls ist. Ps 8,7 steht hier nicht im Hintergrund ${ }^{28}$, bekannt ist offensichtlich nur noch die Aussage, daß Christus alles unterworfen wurde. Vermutlich wei $ß$ Verf. nicht, daß sie Ps 8,7 entnommen ist. Aber es bleibt beachtlich, daß Eph 1,20 vom "Sitzen zur Rechten" Gottes die Rede ist, also eine andere Aussage von Ps $110,1 \mathrm{mit}$ der aus Ps 8,7 verbunden wird. Man wird diesen Sachverhalt so deuten dürfen: Aufgrund von 1 Kor 15,25-27 wurden die beiden Psalmaussagen einander nahegebracht, aber diese Kombination ist kaum vor Paulus geschehen, denn Paulus kann die Aussage vom Sitzen zur Rechten Gottes noch ganz losgelöst von Ps 8,7 in Röm 8,34 innerhalb einer festgeprägten Wendung bringen.

d) 1 Petr 3,22 ist das Zusammenwachsen der Aussagen vom Sitzen zur Rechten Gottes und von der Unterwerfung des Alls weiter fortgeschritten. Jetzt wird nur noch das einst Ps 8,7 entlehnte Verbum "unterwerfen" übernommen, "alles" wird umschrieben mit "Engel, Mächte, Kräfte", es sind himmlische und irdische Gewalten. Auch hier ist Zitierung von Ps 8,7 nicht anzunehmen ${ }^{29}$. Indes kann man fragen, ob der

\footnotetext{
27 So mit CHR. WOLFF [A.23] 183.

28 Dementsprechend fehlt bei R. SCHNACKENBURG, Der Brief an die Epheser, EKK X (1982) 78 jeglicher Hinweis auf Ps 8,7.

29 Bezeichnend, daß K.H. SCHELKLE, Die Petrusbriefe. Der Judasbrief, HThK XIII,2 (41976) zur Erklärung von 1 Petr 3,22 Ps 8,7 gar nicht erwähnt.
} 
Vers den Abschlußteil eines urchristlichen "Liedes" bildet ${ }^{30}$. Möglich ist aber auch, daß Verf. feierliche Sprache gebrauch ${ }^{31}$. Auf jeden Fall ist die Aussage des Verses sprachlich bereits durchformuliert, die Anklänge an Ps 110,1 und Ps 8,7 miteinander verschmolzen und verchristlicht. Nicht die Psalmen, sondern die Einzelaussagen wirken im neuen Kontext weiter.

e) Dieser Weg findet in Pol Phil 2,1 seinen vorläufigen Abschluß. Innerhalb eines Glaubensbekenntnisses wird festgestellt:

... der unsern Herrn Jesus von den Toten auferweckt hat und ihm Herrlichkeit und Thron(esmacht) zu seiner Rechten gab, dem unterworfen ist das All, das Himmlische und das Irdische, dem jede Seele dient, der kommen wird, zu richten die Lebenden und die Toten.

Gegenüber Eph 1,22 und 1 Petr 1,22 fällt auf, daß das Wort $\tau \grave{\alpha} \pi \dot{\alpha} v \tau \alpha$ 'das All' wieder begegnet, das jene umgingen. Es hat also in den Gemeinden des paulinischen Bereiches ${ }^{32}$ offenbar doch eine stärkere Rolle gespielt, als von Eph 1 und 1 Petr 3 her vermutet. Aber auch hier finden wir bloß einen Anklang an Ps 8,7.

f) Es ergibt sich somit: Paulus hat um die Nähe von Ps 110,1 und 8,7 gewußt und beide Texte aufeinander bezogen. Ob er darin einer vorgegebenen Tradition folgt, läßt sich nicht mehr erkennen. Eph 1; 1 Petr 3 und Pol Phil 2 ist diese Verbindung auch vorhanden, wiewohl an diesen Stellen die Psalmen nicht zitiert werden, so daß offen bleiben muß, ob sie bewußt angespielt werden. Entweder hat eine Kombination der beiden Verse vor Paulus eingesetzt ${ }^{33}$, wobei Paulus aber die beiden Psalmen noch gesondert kannte, oder die Verbindung ist in den paulinischen Gemeinden erfolgt, so daß das Sitzen zur Rechten Gottes aus Ps 110,1 mit der Unterwerfung der Mächte aus Ps 8,7 aneinandergereiht wurde ${ }^{34}$. Da Paulus Röm 8,34 das Sitzen zur Rechten Gottes einerseits und 1 Kor 15,15-27 die Kombination von Ps 110,1 und Ps 8,7, insofern von der Unterwerfung des Alls gesprochen wird, völlig unabhängig voneinander bringt, möchte man den letzteren Fall annehmen. Das würde bedeuten, daß in den paulinischen Gemeinden Ps 110,1b durch den sehr ähnlich klingenden Satz Ps 8,7b aufgrund paulinischer Exegese

30 R. BultmanN, Bekenntnis- und Liedfragmente im ersten Petrusbrief, in: DERS., Exegetica (1967) 285-297; 293.297; R. DEICHGRÄBER, Gotteshymnus und Christushymnus in der frühen Christenheit. Untersuchungen zu Form, Sprache und Stil der frühchristlichen Hymnen, STUNT 5 (1965) 172f.

31 L. GOPPELT, Der erste Petrusbrief, KEK XII,1 $\left({ }^{8} 1978\right) 261$.

32 Dazu zähle ich 1 Petr ebenso wie den Polykarpbrief. Zur Tatsache, daß 1 Petr paulinische Theologie voraussetzt, vgl. bes. W. SCHRAGE, Der erste Petrusbrief, NTD 10 (131985) $59 f$.

33 M. RISSI, Die Theologie des Hebräerbriefes. Ihre Verankerung in der Situation des Verfassers und seiner Leser, WUNT 41 (1987) 50; U. LUZ, Das Geschichtsverständnis des Paulus, BEvTh 49 (1968) 101.344.

34 D.A. KOCH, [A.3] $244 f$. 
ersetzt wurde, so daß hinfort Sitzen zur Rechten Gottes und Unterwerfung der Mächte formelhaft weitergegeben wurden 35 .

IV.

Ein besonderes Interesse an Ps 8,5-7 hat der Verfasser des Hebräerbriefes gefunden. Er hat in Hebr 2,6-8a Ps 8,5-6.7b wörtlich zitiert, dabei freilich Ps 8,7a ausgelassen ${ }^{36}$, möglicherweise um einen strafferen Text zu erhalten ${ }^{37}$. Denn die Aussage von Ps 8,7a: "Du hast ihn über deiner Hände Werk gesetzt" ist in jener Ps 8,7b: "Alles hast du ihm unter die Füße gelegt (unterworfen)" enthalten. Andererseits ist aber in Ps 8,7a die in Hebr 1,4f.13 ausgesprochene Überordnung des Sohnes über die Engel nicht enthalten. Und gerade Hebr 2,8 betont, daß dem Erhöhten nichts ununterworfen blieb, man muß in seinem Sinne schließen, daß auch die Engel ihm unterworfen sind $\mathrm{d}^{38}$.

Für den Hebr ist "der Mensch" bzw. "der Menschensohn", an den Gott nach Ps 8,5 denkt, Jesus, "der kurze Zeit im Vergleich zu den Engeln geringer war" und der ins Leiden ging $(2,9 a)$, um nachher "durch Gottes Gnade" 39 für alle den Tod zu schmecken und mit "Ehre umkränzt" zu werden (2,9b). Jede Aussage von Ps 8,5-6.7b findet an dieser Stelle eine Erläuterung:

- Der "Mensch" Jesus wird von Gott beachtet, durch Gottes Gnade schmeckt er für viele den Tod, er bewirkt, wie 1,3 sagt, die "Reinigung von den Sünden" und wird von Gott "aufgrund seiner Gottesfurcht erhört" wie 5,7 festhält.

- Er wird für kurze Zeit unter die Engel erniedrigt. Hebr versteht das $\beta \rho \alpha \chi v \pi$ der LXX nicht im Sinne der hebr. Vorlage "ein wenig", sondern zeitlich "nur eine kurze Zeit".

- Daraufhin wurde er mit Ehre bekränzt, er durfte sich zur Rechten Gottes setzen, wie 1,3 und 12,2 aussprechen. Er hat damit viel mehr

35 Dieser These widerspricht die Tatsache nicht, daß in Mk 12,36 und Mt 22,42 Ps 110,1c nach Ps 8,7b korrigiert zu sein scheint. Das kann durchaus sprachliche Glättung sein und ist offensichtlich von den Schreibern des MkEv und des MtEv gar nicht empfunden worden, also auch nicht von dem Schriftgelehrten Mt. Bloß Lk hat in 20,41 die Stelle genau nach der LXX wiedergegeben.

36 Ich kann mich also der These von M. HENGEL [A.25] 53 nicht anschließen, wonach Ps 8 und Ps 110 "von der Urgemeinde als 'Messianische Hymnen' gesungen wurden". Es ist möglich, daß solches geschah, doch gibt es für diese Annahme nicht genügend Anhaltspunkte.

37 H. HEGERMANN, Der Brief an die Hebräer, ThHK 16 (1988) 67: "Wahrscheinlich geht es bei der Auslassung um eine rhetorische Straffung des Schriftzeugnisses".

38 G. THEISSEN, Untersuchungen zum Hebräerbrief, StNT 2 (1969) 121: "Will nun der Verfasser betonen, daß Jesus über die bleibende und ewige Welt gesetzt ist, so wäre es

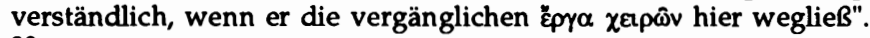

39 F. SCHRÖGER, Der Verfasser des Hebräerbriefes als Schriftausleger, BU 4 (1968) 260. Zur sogenannten "dogmatischen Korrektur" s. die Kommentare. 
"Herrlichkeit und Ehre" als Mose, wird 3,3 in Aufnahme von 2,7 betont ${ }^{40}$.

- Daraufhin wurde ihm alles übergeben. Ihm bleibt nichts ununterworfen $(2,8)$, also auch die Engel müssen ihm gehorchen.

- Aber diese Herrscherstellung Jesu ist noch nicht sichtbar (Hebr 2,6). Sie ist eine Realität bloß für die Engel. Für den Christen bleibt die Aussage von der Unterwerfung des Alls unter Christus eine "noch nicht" sichtbare Realität41.

- Durch seinen irdischen Lebenswandel und seine Erhöhung wird

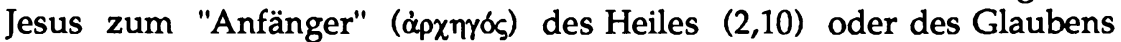
$(12,2)$. Die Christen folgen ihm auf dem nunmehr gebahnten Weg, den er voranging.

Ps 8,5-6.7b wird somit in Hebr 2 nicht nur zitiert, um eine Aussage zu belegen, der Text wird bis in die Einzelheiten hinein ausgelegt. Die Ausrichtung dieser Deutung hat drei Aspekte, einen christologischen, einen anthropologischen und einen eschatologischen:

- Es ist von Jesus die Rede, der auf dem Weg zur Erniedrigung und Erhöhung geführt wurde;

- es wird vom Christen gesprochen, insofern dieser jetzt auch "geringer als die Engel" ist, aber dank Jesu Erhöhung auf dem Weg zur Vollendung hin gehen darf $(2,10 ; 12,2)$. Denn die Christen sind jetzt die Brüder Jesu (2,11f);

- es wird festgestellt, daß erst in der Ewigkeit die volle Unterwerfung unter Christus dem Christen sichtbar wird $(2,8 \mathrm{a})$.

Anstelle des Menschen in Ps 8,5-7 wird in Hebr 2,5-11 von Christus in seiner Niedrigkeit und Hoheit gesprochen ${ }^{42}$. Aber Niedrigkeit und Erhabenheit stehen nicht dicht nebeneinander, sie bilden ein zeitliches Hintereinander, wobei die Niedrigkeit als Zeit der Zuwendung Gottes gesehen wird. Diese Gnade Gottes ermöglicht das Durchhalten, das seinerseits die Erhöhung zur Folge hat. Für den Christen als "Menschen" heißt das, daß er Gottes Hilfe gewiß sein darf, wenn er durchhält, geduldig bleibt. Dann folgt für ihn auch die Erhöhung (12,7-11), dann erlebt er, daß Gott Christus alles unterworfen hat $(2,8 b)$.

Verglichen mit Ps 8 wird hier nicht ein Sein des Menschen beschrieben, das im Verhältnis zum All als Niedrigkeit, im Verhältnis zur

40 Hinweis von W.R.G. LOADER, Sohn und Hoherpriester. Eine traditionsgeschichtliche Untersuchung zur Christologie des Hebräerbriefes, WMANT 53 (1981) 31 Anm. 7.

41 Anders F.J. SCHIERSE, Verheißung und Heilsvollendung. Zur theologischen Grundfrage des Hebräerbriefes, MThSt I, 9 (1955) 101: "Der Zeitpunkt, mit dem die Herrschaft über die zukünftige Welt beginnt, ist die Parusie"; vgl. auch 107. Richtig hingegen E. GRÄSSER, An die Hebräer, EKK XVII,1 (1990) 114: "... daß er als der Erhöhte zwar über alles herrscht, aber eben nicht öffentlich".

42 H.F. WEISS, Der Brief an die Hebräer, KEK XII 151991, 197: "Und genau hier - im Zusammenhang der Rede von der Erniedrigung in V.9 - kommt nun im Rahmen der Auslegung von Ps 8 auch die Rede vom 'Menschen' bzw. vom 'Menschensohn' aus Ps 8,5 zum Zuge: Jesus, der Erniedrigte, das ist der 'Mensch', der 'Menschensohn' von Ps 8,5"! 
Umwelt als Erhabenheit artikuliert wird, sondern ein Weg aus der Erniedrigung heute zur Erhöhung einst.

$$
\text { V. }
$$

Matthäus hat Ps 8 in anderer Weise in sein Evangelium eingebaut. $\mathrm{Ob}$ er das Wort des Auferstandenen: "Mir ist gegeben alle Gewalt im Himmel und auf Erden" (Mt 28,18) etwa im Sinne von Eph 1,20-22 und 1 Petr 3,22 mit Ps 8,7b zusammensah, läßt sich nicht sagen. Sprachlich knüpft es an 11,27 an. Daß Mt aber Ps 8 kannte, zeigt das Zitat von Ps 8,3 in $21,16 \mathrm{~b}$, ein Zitat, das er vorbereitet in 21,14-16a.

Die Perikope 21,14-16 ist eine der wenigen, von denen wir mit hoher Wahrscheinlichkeit sagen können, daß sie vom Evangelisten gestaltet ist $\mathrm{t}^{43}$. Sie läuft auf das Zitat in V.16b hinaus. Das bedeutet, daß Mt eine Perikope für ein Zitat selbst gestaltet hat. Für die Erforschung der Wirkungsgeschichte ist dieser Sachverhalt bedeutsam: Ein Text erzeugt andere Texte, sogar erzählende. Sehen wir genauer $\mathrm{zu}$, wie dies geschieht:

- Mt ändert zunächst den Wortlaut des Lobgesangs der Pilger $(21,9)$. Sie rufen nicht wie bei Mk $(11,9)$ : "Hosianna, gelobt sei, der kommt im Namen des Herrn; gelobt sei die Herrschaft unsers Vaters David; Hosianna in der Höhe!", sondern viel kürzer und in eine bestimmte Richtung hin prägnanter: "Hosianna dem Sohne Davids; gelobt sei der kommt im Namen des Herrn; Hosianna in der Höhe!". Statt der "Herrschaft unsers Vaters David" gilt der Lobpreis dem Davidsohn.

- Dieses Lob wird in verkürzter Form in 21,15 wieder aufgenommen und zwar gerade dort, wo Mt verändert hatte. Die Kinder rufen und sagen44: "Hosianna dem Davidsohn". Seiner Tradition = Mk folgend bringt Mt den Titel gern im Zusammenhang von Blindenheilungen ${ }^{45}$. Das ist wohl der Grund, weswegen Mt auch in 21,14 von dem Zustrom der "Lahmen und Blinden" und ihrer Heilung durch Jesus berichtet. Jetzt preisen die Kinder Jesus als Davidsohn seiner Heilungen wegen ${ }^{46}$. Ob Mt auch noch die Tatsache bedacht wissen wollte, daß Lahme und Blinde nach 2 Sam 5,8 gar nicht in den Tempel einziehen durften, läßt sich nicht sagen. In diesem Falle hätte er angemerkt, daß der Tempel seine ursprüngliche Funktion wieder erhält, wie es auch

43 J. GNILKA, Das Matthäusevangelium, HThK I,2 (1988) 207.

44 Mt 21,9 und 21,15 begegnen die beiden Verben: "rufen" und "sagen".

$45 \mathrm{U}$. LUZ, Eine thetische Skizze der matthäischen Christologie, in: C. BREYTENBACH H. PAULSEN (Hrsg.), Anfänge der Christologie, FS F. HAHN (1991) 221-235; 224f. Ähnlich J. RIEDL, Mt 1 und die Jungfrauengeburt, in: L. OBERLINNER - P. FIEDLER (Hrsg.), Salz der Erde - Licht der Welt, FS A. VÖGTLE (1991) 91-109; 108.

46 Anders P. MÜLLER [A.7] 221: "Der Davidsohntitel zeigt an, daß dieses ganze Geschehen als Ausdruck der eschatologischen Heilszeit zu verstehen ist." Das würde m.E. eher für den Mk-Bericht zutreffen. 
durch die "Säuberung" (21,12f) geschah47. Indes wird man Zweifel an dieser Deutung erheben können, da Jesus die Lahmen und Blinden nicht in den Tempel führt, sie vielmehr selbst einströmen und von ihm geheilt werden. Und die Geheilten sind auf jeden Fall kultfähig. Das spricht dafür, daß die Davidsohnschaft mit der Heilung zusammengesehen werden muß.

- Im Anschluß an die Tempelreinigung ist bei Mk vom Auftreten der "Hohenpriester und Schriftgelehrten" die Rede. Sie beschließen, Jesus umzubringen (Mk 11,18). In den Augen des Mt sind diese Leute die "Feinde" Jesu, deretwillen das Lob der Kinder nach Ps 8,3 erklingt ${ }^{\mathbf{4 8}}$. Damit aber dieses Lob der Kinder mit dem Lob beim Einzug zusammengesehen werden kann, setzt Mt die Tempelreinigung auf denselben Tag im Anschluß an den Einzug an. Bei Mk liegt ein Tag dazwischen.

- Mt hätte, um Ps 8,3 einzubringen, auch so vorgehen können, daß er in 21,9 festgestellt hätte, unter der Menge seien Kinder gewesen ${ }^{49}$. Das hätte ihm ermöglicht, das Zitat mit der ihm vertrauten Wendung 50 anschließen zu lassen: "So erfüllt sich das Wort ...". Daß er nicht so verfuhr, mag man dahingehend deuten, da $\beta$ er der Tempelreinigung eine andere Deutung geben wollte, als sie bei Mk hatte51, wahrscheinlicher ist freilich, daß Mt das angeführte Zitat in seinem unmittelbaren Kontext ernst nahm: "wegen deiner Feinde, um zum Schweigen zu bringen Feind und Widersacher." Dieser Abschnitt wird zwar nicht zitiert, aber es geschieht ihm entsprechend: Das Lob der Kinder und der Hinweis auf die Schrift, macht die Feinde Jesu zunächst mundtot. Jesus geht nach 21,17 weg, und die "Feinde" beschließen nicht, wie bei $\mathrm{Mk}$, ihn umzubringen.

Es wird somit sichtbar, daß Mt von Ps 8,3 her die Geschichte Jesu an einem bestimmten Punkte neu schreibt, nicht nur neu sieht. Die Bibelstelle verändert die Darstellung vergangener Zeit. Dieses Phänomen läßt sich auch 21,5 beobachten. Dem Zitat Sach 9,9 entnimmt Mt, daß Jesus auf zwei Tieren in die Stadt einzog. Daraufhin verändert er die Darstellung, die seine Mk-Vorlage hatte ${ }^{52}$. Wie man auf zwei Tieren reitet, fragt man heute vergeblich, vielleicht dachte $\mathrm{Mt}$, daß es alternativ geschah. Es geht aber Mt nicht um die faßbare Geschichte, sondern um

\footnotetext{
47 A. SAND, Das Evangelium nach Matthäus, RNT 1 (1986) 417; J. GNILKA, [A.43] 208.

48 J. GNILKA [A.43] 209: "Man wird darauf abheben müssen, daß die Kinder die Feinde Jesu widerlegen."

49 Tatsächlich gehörten die Kinder in die Reihe der Hosianna-Rufer; vgl. Str.-Bill. I, 854.

50 Die vertrauteste Einführungsformel des Mt ist: "Damit erfüllt werde das Wort..." (2,15.17; 4,14 u.ö.).

51 E. SCHWEIZER, Das Evangelium nach Matthäus, NTD $2\left({ }^{13} 1973\right) 266$.

52 C.P. MÄRZ, "Siehe, dein König kommt zu dir ...", EThSt 43 (1980) 7 meint, daß die Einführung "eines zweiten Tieres mit dem Parallelismus membrorum bzw. dem Mißverständnis desselben durch Matthäus nicht ausreichend begründet ist".
} 
die wörtliche Erfüllung der alttestamentlichen Verheißung. Die Geschichte Jesu wird im Licht der Schrift neu gelesen und neu geschrieben, und die Schrift hat Priorität vor dem Bericht der Tradition.

VI.

Als Ergebnis können wir festhalten:

a) Die beiden Hauptaussagen von Ps 8 haben im Alten Testament, im Judentum und im Urchristentum eine voreinander sehr verschiedene Wirkungsgeschichte.

b) Wird Ps 8 im Alten Testament und im Judentum anthropologisch ausgelegt, so im Neuen Testament in christologischem Zusammenhang.

c) Das paradoxe Nebeneinander von Erhabenheit und Niedrigkeit des Menschen Ps 8,5-7 wird im Alten Testament zugunsten der Niedrigkeit aufgelöst, während die Rabbinen eher die Größe des Menschen hervorheben. Im Neuen Testament wird die Inthronisation Christi im Himmel aufgrund von Ps 8,7b verkündet.

d) In Hebr 2,5-9 wird aus dem Sein des Menschen von Ps 8 ein Werden, ein Weg. Niedrigkeit und Erhabenheit stehen jetzt nicht mehr nebeneinander, sondern nacheinander: vom Kreuz zur Krone.

e) Während das rabbinische Judentum die Nähe des Menschen zu Gott in der Einsicht bzw. in seiner Fähigkeit zur Veränderung der Schöpfung sieht, erkennt das Christentum, daß die Nähe zu Gott nicht in diesem Leben, wohl aber in der Ewigkeit erlangt werden kann.

f) Während das rabbinische Judentum aufgrund von Ps 8,3 den Sinn des menschlichen Lebens in dem Halten der Tora bzw. im Loben Gottes auch der ungeborenen Kinder sieht, hebt Mt hervor, daß die Kinder die Hoheit Jesu als das Davidsohnes bestätigen.

g) Aus all dem ergibt sich: Die Wirkungsgeschichte zentraler biblischer Aussagen ist immer auch Darstellung wichtiger theologischer Erkenntnisse ${ }^{53}$.

53 Diese Methode, die möglicherweise schon bei der Passionsgeschichte Anwendung fand, geht weit über das Neue Testament hinaus. Das bekannteste Beispiel ist die Anwesenheit von Ochs und Esel im Stall von Bethlehem, die aufgrund von Jes 1,2 in die Weihnachtsdarstellungen einfloß. 


\title{
JESU LEIDEN UND TOD ALS ERZÄHLUNG
}

\author{
von \\ Helmut Koester \\ Harvard Divinity School
}

Die Frage der Entstehung der Passionsgeschichte bleibt nach wie vor umstritten. Auf der einen Seite nimmt man an, daß ein zunächst mündlich umlaufender alter Geschichtsbericht vorlag, der dann nach dem Schema des Kerygmas von Leiden, Tod und Auferstehung mit Hilfe des Weissagungsbeweises und dogmatischer und paränetischer Motive weiter ausgestaltet wurde. ${ }^{1}$ Auf der anderen Seite wird neuerdings die Meinung vertreten, erst der Evangelist Markus habe sowohl den Gesamtzusammenhang als auch die meisten der einzelnen Szenen geschaffen. ${ }^{2}$

Es mag nun in der Tat schwierig sein, auf Grund der Passionsgeschichte des Markus eine ursprünglich mündlich umlaufende Erzählung zu rekonstruieren. Allerdings kann man auf keinen Fall dem Evangelisten Markus die Schaffung des Gesamtzusammenhanges dieser Erzählung zuschreiben; denn die parallelen Passionsgeschichten des Johannes- und des Petrusevangeliums sind nicht von Markus abhängig. ${ }^{3}$ Dem Evangelisten Markus muß also bereits eine ältere mündlich oder schriftlich umlaufende Passionsgeschichte vorgelegen haben, die auch den Verfassern des Petrus- und des Johannesevangeliums zugänglich war.

Aber selbst wenn man so auf eine ältere Version der zusammenhängenden Erzählung schließen kann, deren Varianten die Grundlage der Passionsgeschichten des Markus, Petrus und Johannes waren, bleibt doch eine wesentliche Schwierigkeit bestehen. Während die übrigen Erzählungsabschnitte der Evangelien aus ursprünglich einzeln umlaufenden Geschichten zusammengestellt sind, muß man für die Erzählung von Jesu Leiden und Tod annehmen, daß hier der Gesamtzusammen-

\footnotetext{
${ }^{1}$ R. BULTMANN, Die Geschichte der synoptischen Tradition, 3. Aufl. Göttingen: Vandenhoeck \& Ruprecht 1962, 297-308.

2 So etwa W. H. KELBER, The Oral and the Written Gospel: The Hermeneutics of Speaking and Writing in the Synoptic Tradition, Mark, Paul and Q, Philadelphia: Fortress, 1983, 185-199; B. L. MACK, A Myth of Innocence: Mark and Christian Origins, Phildalephia: Fortress 1988, 288-312.

3 Das habe ich in meinem Buch "Ancient Christian Gospels: Their History and Development" Philadelphia: Trinity Press International 1990, 216-230 dargelegt.
} 
hang das Primäre war. ${ }^{4}$ Ist diese dem Markus-, Johannes- und Petrusevangelium zugrundeliegende Geschichte ein reines Produkt literarischer Schöpfung, oder beruht sie, in welcher Weise auch immer, auf einer älteren Erzählung aus der mündlichen Tradition? Welchen Charakter hatte eine solche mündliche Tradition?

Zur Beantwortung dieser Frage möchte ich nicht bei einer erneuten form- und traditionsgeschichtlichen Analyse der vorhandenen Evangelientexte einsetzen. Das ist oft genug versucht worden. Das Problem hat sich so nicht lösen lassen. ${ }^{5}$ Vielmehr will ich versuchen, mit einigen Überlegungen $\mathrm{zu}$ Stellen aus den paulinischen Briefen einen neuen Ansatz zu gewinnen. Dabei bin ich mir bewußt, daß die folgenden Überlegungen lediglich eine Arbeitshypothese sein können.

An zwei wichtigen Stellen des 1 . Korintherbriefes beruft sich Paulus ausdrücklich auf die Tradition: 1. Kor. 11,23-25 zitiert er die sogenannten Einsetzungsworte des Herrenmahles unter Berufung darauf, daß er sie "vom Herrn empfangen und der

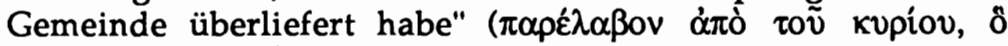

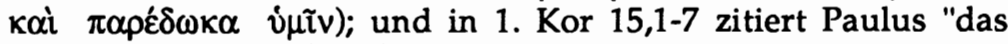

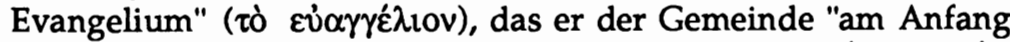

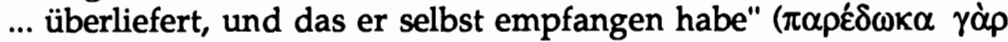

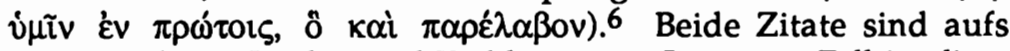
engste auf Jesu Leiden und Tod bezogen. Im ersten Fall ist diese Beziehung ausgedrückt in der Verankerung der Stiftung des Herrenmahles "in der Nacht, in der er (Jesus) überantwortet

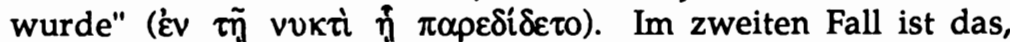
was Paulus zitiert, eine Kurzform der Beschreibung von Tod, Begräbnis, Auferstehung und Erscheinungen Christi.

Nun kann es füglich nicht bestritten werden, daß Paulus in beiden Fällen Überliefertes aus der Tradition der Gemeinde zitiert. Für 1. Kor 15,3-5 ergibt sich aus dem Stil und besonders aus dem unpaulinischen Sprachgebrauch. ${ }^{7}$ In 1 . Kor 11,23-25

\footnotetext{
${ }^{4}$ Diese Formulierung lehnt sich an die oft zitierte Feststellung R. BULTMANNs an, der allerdings diesen Satz qualifiziert: "Anders als für andere Stoffe der Tradition hat sich für die Passionsberichte schon früh ein Zusammenhang herausgebildet; ja man möchte fast sagen, daß der Zusammenhang hier das Primäre war". Geschichte, 297 [A. 1].

5 Eine sehr gute Übersicht über die Schwierigkeiten der verschiedenen Lösungsversuche bietet W.H.KELBER, Gospel, 185-99, [A.2].

6 Zur Frage der Bedeutung der Terminologie der Überlieferung siehe K. WEgENAST, Das Verständnis der Tradition bei Paulus und in den Deuteropaulinen, WMANT 8, Neukirchen: Neukirchener Verlag, 1962, 52-70, 111-113.

7 H. CONZELMANN, Der erste Brief an die Korinther, KEK 5; 11. Aufl. Göttingen: Vandenhoeck \& Ruprecht, 1969, 296.
} 
liegt ebenfalls Gemeindeüberlieferung vor, trotz der Durchbrechung der Traditionskette durch den Anspruch des Paulus, er

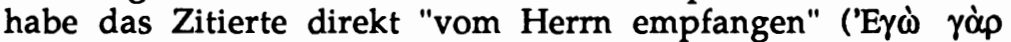

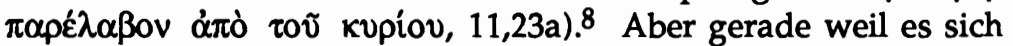
um Formeln handelt, also um aus der Liturgie oder aus dem Bekenntnis stammende Kürzel, stellt sich die Frage nach dem Gesamtzusammenhang, aus dem diese Formeln stammen. Denn es ist ja nicht vorstellbar, daß diese Formeln anfänglich ganz allein standen und sich erst später zusammenhängende Erzählungen oder umfassendere Predigten aus ihnen bildeten. ${ }^{9}$ Wer dieser Christus, der starb, begraben und auferweckt wurde, eigentlich war und warum sein Tod und seine Auferstehung Bedeutung hatten, das muß von vornherein Inhalt einer ausführlichen christlichen Verkündigung und besonders der Predigt des Paulus gewesen sein. Ebenso werden die von Paulus zitierten Einsetzungsworte wohl kaum das einzige gewesen sein, was bei der Feier der Eucharistie gesagt wurde. Die zitierten Formeln setzen also eine entwickelte Ordnung der Eucharistiefeier sowie ein bereits bestehendes Schema der frühchristlichen Predigt bereits voraus.

Der Interpretationszusammenhang, den die 1. Kor 15,3-5 zitierte Formel verkürzt darstellt, ist in der Formel selbst angedeutet: ". . . daß Christus starb für unsere Sünden nach den

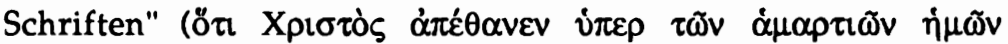

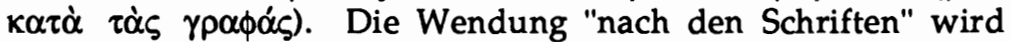
im folgenden Satz über die Auferweckung nochmals wiederholt. Damit ist auf zweierlei hingewiesen: erstens auf die Tatsache, daß der Tod Christi als ein stellvertretendes Sühnopfer verstanden wurde; zweitens darauf, daß sowohl dieser Tod als auch die Auferweckung dem in den Schriften Israels dargestellten Tod für andere entsprach.

Wie muß man sich aber diese Entsprechung vorstellen? $\mathrm{Daß}$ die formelhafte Wendung "nach den Schriften" auf einen apologetischen Weissagungsbeweis deutet, ist unwahrscheinlich; denn solche Beweisgänge sind zum ersten Mal bei Matthäus greifbar und dann bei Justin dem Märtyrer voll ausgebildet. Auch kann man die Wendung "nach den Schriften" nicht als einen begrenzten Hinweis auf nur eine bestimmte

\footnotetext{
8 Ebenda, 230-31.

9 R.BULTMANN, Geschichte, 297-98 [A.1] verweist dabei auf "das Kerygma, wie es in den Leidens- und Auferstehungsweissagungen Mk 8,31;9,31; 10,33f. und in den Reden der Act vorliegt." Aber obwohl bei Markus und in der Apostelgeschichte dem Kerygma analoge Formeln vorliegen, läßt sich nicht beweisen, daß es sich um Formeln handelt, die nichts mit einer bereits vorhandenen Passionsgeschichte zu tun haben.
} 
Schriftstelle, also etwa auf Jes. 53, verstehen. Dem widerspricht schon einfach der Plural, und es entspräche auch keineswegs der sonstigen Verwendung der Schriften Israels bei Paulus. Hinweise auf die Schrift bei Paulus haben in der Regel größere Zusammenhänge im Auge. Das ergibt sich besonders deutlich aus 1. Kor 10,1-11; 2. Kor 3; und Gal 4,21-31.10 "Nach den Schriften" impliziert also wohl zumindest einen längeren Abschnitt der Schrift, wahrscheinlicher aber eine ganze Reihe von Texten. Deshalb möchte ich annehmen, daß der durch "nach den Schriften" angedeutete Interpretationszusammenhang die in verschiedenen Schriftstellen vorliegende Erzählung vom leidenden Gerechten war, der durch Gottes rechtfertigendes Handeln zu neuem Leben erweckt und damit bestätigt wird. Es ist außerdem in den späteren, voll ausgebildeten Passionsgeschichten deutlich, daß eine ganze Reihe von Schriftstellen im Hintergrund von Einzelstücken der Passionserzählung stehen.11

Der spezielle Bezug auf den leidenden Gottesknecht von Jes 53 drängt sich natürlich auf. Es wird weiter unten noch zu diskutieren sein, ob dieser Schrifttext einen besonderen Einfluß auf die Formulierung von 1. Kor 15,3-4 gehabt hat. Aber Vorsicht ist geboten. So sehr das Lied vom für andere leidenden Gottesknecht aus Deutero-Jesaja in der Theologie des frühen Judentums eine entscheidende Rolle spielte, so ist doch auch die Entwicklung dieses Motivs unter hellenistischem Einfluß in Rechnung zu stellen. Diese Entwicklung ist in der Ausbildung des Weisheitsmythus ebenso greifbar wie im 4. Makkabäerbuch. Die Vorstellung des stellvertretenden Leidens ist zwar in Jes 53,4-5 vorgezeichnet, erschien aber auch in anderen Texten Israels und des frühen Judentums und war zudem in der hellenistischen und römischen Welt weithin verbreitet. ${ }^{12}$

Doch genügt diese theoretische Feststellung nicht. Die Beziehung des Leidens und Todes Jesu auf die Schriften hat sicher im Leben der frühchristlichen Gemeinden einen konkreten Ausdruck gefunden. So wie man diese "Schriften" im Gottesdienst der Gemeinde vorgelesen hat, so wird man auch entspre-

10 Es läßt sich meines Erachtens nachweisen, daß auch dort, wo Paulus nur einzelne Verse zitiert, ihm die entsprechenden größeren Zusammenhänge durchaus gegenwärtig sind.

11 Vor allem ist Psalm 22 (21 LXX) hier vorauszusetzen, aber auch wohl andere Klagelieder des Psalmbuches, vgl. z. B. Ps. 68 (69 LXX).

12 S. K. WILliaMS, Jesus' Death as Saving Event: The Background and Origin of a Concept, Harvard Dissertations in Religion, Missoula: Scholars Press 1973; vgl. auch D. GEORGI, Theocracy in Paul's Praxis and Theology (Minneapolis: Fortress 1991, 67-71 (= "Gott auf den Kopf stellen," in J. TAUBES, Theokratie Paderborn: Schöningh 1987. 
chend vom Leiden und Tod Jesu erzählt haben, und zwar in Analogie zu Erzählungen vom leidenden Gerechten, die in Deutero-Jesaja, in den Psalmen und in der Weisheitsliteratur, also in den Schriften Israels, aufbewahrt und zugänglich waren. So erklärt sich die zunächst ganz allgemeine Wendung "nach den Schriften" in 1. Kor 15,3-4.

Es ist aber auch deutlich, daß speziell Jes 53 auf die Erzählung von Christi Leiden und Tod gewirkt haben muß. Nur so läßt sich die Wendung "(gestorben) für unsere Sünden" (vं $\pi \dot{\rho} \rho$

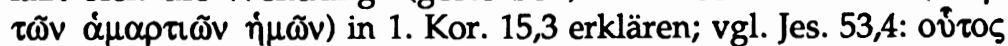

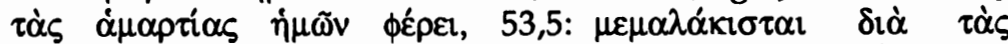

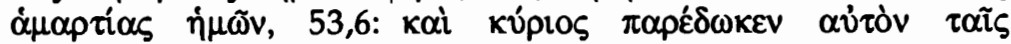

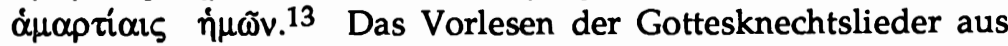
Deutero-Jesaia, besonders von Jes 53, wird neben dem Vorlesen anderer Abschnitte der Schriften, die vom leidenden Gerechten erzählten, also eine hervortretende Rolle im Gottesdienst der paulinischen Gemeinden gespielt haben.

$\mathrm{Da} B$ in der paulinischen Gemeinde eine entsprechende Erzählung nicht nur ihren festen Platz in der Feier des Herrenmahles hatte, sondern auch bereits ein Gesamtzusammenhang der Erzählung da war, beweist die Einleitung zum Zitat der Einsetzungsworte in 1. Kor 11,23: "in der Nacht, in der er

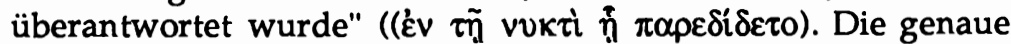
Zeitangabe ist nur sinnvoll, wenn sie an die Einsetzung des Herrenmahles in einem vorausgesetzten größeren Zusammenhang einer Erzählung vom Leiden und Tod Jesu erinnern will. Also hat man schon zur Zeit des Paulus von diesem Geschehen in seinem gesamten Ablauf erzählt. Die später in den Evangelien niedergeschriebenen Passionsgeschichten sind also in der Tat keine Kompositionen von zunächst einzeln umlaufenden Überlieferungsstücken, sondern gehen auf Erzählungen zurück, in denen ein gesamter Zusammenhang von vornherein bestand.

Auch aus der Formulierung der Einleitung zum Zitat der Einsetzungsworte in 1 . Kor 11,23 läßt sich erschließen, daß wiederum die Orientierung der Erzählung an dem Bericht vom leidenden Gottesknecht von Jes 53 eine besondere Rolle spielte. Die Wendung "in der er überantwortet wurde" (ᄁᄁ $\pi \alpha \rho \varepsilon \delta i \delta \varepsilon \tau 0)$ erinnert an den schon oben zitierten Satz aus Jes 53,6: "und der Herr hat ihn um unserer Sünden willen überantwortet" ( $\kappa \alpha \grave{\imath}$

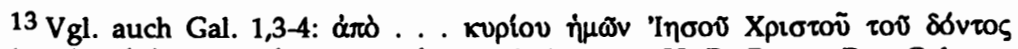

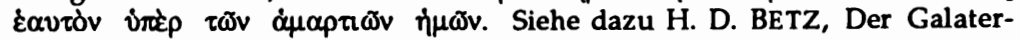
brief, München: Kaiser 1988, 94-95; Literatur ebenda. 


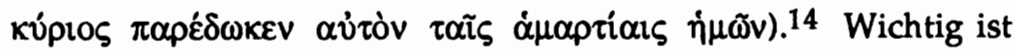
hier außerdem, daß bereits Paulus ein Zeuge für die Zusammengehörigkeit von Passionserzählung und Einsetzung des Herrenmahles ist. Man kann diese Verbindung nicht erst dem Verfasser des Markusevangeliums zuschreiben. Feier des Herrenmahles und Erzählung vom Leiden und Tod Jesu gehören von Anfang an, oder jedenfalls schon sehr früh zusammen. Diese Erzählung läßt sich also ohne weiteres als "Kultlegende" bezeichnen.

Damit ist es möglich, den Sitz im Leben der Passionsgeschichte genauer zu bestimmen. Mit dem "Schriftbeweis" im herkömmlichen Sinne hat dieser Sitz im Leben wenig zu tun; denn um Apologetik geht es hier überhaupt nicht. Weder sollen hier theologische Einsichten zur Schau gestellt noch Glaubenssätze verteidigt werden. Vielmehr geht es um die Feier der Gegenwart des durch sein Leiden und seinen Tod Erhöhten. Dazu gehörten Schriftlesung und Erzählung ebenso wie das Teilhaben am gebrochenen Brot und am Kelch des neuen Bundes.

14 Beim Gebrauch des Verbs $\pi \alpha p \alpha \delta i \delta \omega \mu \mathrm{l}$ ist dabei noch nicht an den "Verrat" des Judas (Mk. 14,10) gedacht. Vielmehr ist diese Episode erst später aus der älteren Zeitangabe herausgesponnen worden. 


\title{
GENESIS 38 - EIN "LEHRSTÜCK" ALTTEST AMENTLICHER ETHIK
}

von

Thomas Krüger

Universität Zürich

Der Königsberger Philosoph Immanuel KANT hat im Jahre 1784 das Anliegen der sogenannten "Aufklärung" in "klassischer" Weise folgendermaßen formuliert:

\begin{abstract}
"Aufklärung ist der Ausgang des Menschen aus seiner selbstverschuldeten Unmündigkeit. Unmündigkeit ist das Unvermögen, sich seines Verstandes ohne Leitung eines anderen zu bedienen. Selbstverschuldet ist diese Unmündigkeit, wenn die Ursache derselben nicht am Mangel des Verstandes, sondern der Entschließung und des Mutes liegt, sich seiner ohne Leitung eines andern zu bedienen. Sapere aude! Habe Mut, dich deines eigenen Verstandes zu bedienen! ist also der Wahlspruch der Aufklärung."1
\end{abstract}

Die Folgen dieser "aufklärerischen" Grundhaltung für die ethische Orientierung liegen auf der Hand: Die Frage "Was soll ich tun?" kann dem "mündigen" Menschen keine politische oder religiöse Autorität und keine ethische Tradition verbindlich beantworten. Jeder muß für sich selbst eine Antwort darauf finden, indem er sich seines eigenen Verstandes, seiner "praktischen Vernunft", ohne Leitung eines andern bedient. $^{2}$

Mit der Aufgabe eines radikalen Traditionsverzichts scheint der Mensch jedoch zugleich radikal überfordert zu sein. So konnte schon KANT selbst das, was er "im einzelnen als universal gültige formal-inhaltliche Pflichten und Rechte formuliert, ... nicht durch transzendentale Reflexion auf die der Vernunft schlechthin immer schon innewohnenden Prinzipien, sondern allein durch einen kritischen Diskurs mit Traditionen und Erfahrungen deutlich machen." "Kants praktische Vernunft ist nicht die Vernunft schlechthin, sondern die vor allem durch platonisch-christliche Traditionen gebildete und durch Erfahrun-

\footnotetext{
1 I. KANT, "Beantwortung der Frage: Was ist Aufklärung?" in: E. BAHR (Hg.), Was ist Aufklärung? Thesen und Definitionen (Reclam TB 9714), Stuttgart 1974 (1981), 9-17: 9.

2 KANT war freilich, "jedenfalls nach den meisten Aussagen seiner praktischen Philosophie, der Überzeugung, daß die praktische Vernunft universal gültig sei, d.h. für alle Menschen ais Vernunftwesen unabhängig von Raum, Zeit und sozialer Schicht, ja sogar für alle intelligiblen Wesen überhaupt unbedingt verbindliche Pflichten und unaufhebbare Rechte enthält" (W. OELMÜLLER, "Versuch einer Orientierungshilfe für sittliche Lebensformen" in: DERS./R. DÖLLE-OELMÜLLER/R. PIEPMEIER, Diskurs: Sittliche Lebensformen [Philosophische Arbeitsbücher 2; UTB 778], Paderborn/München/Wien/Zürich ${ }^{3} 1983$, 9-86: 65).
} 
gen der bürgerlichen Aufklärung 'gereifte Urteilskraft des Zeitalters, welches sich nicht länger durch Scheinwissen hinhalten läßt"'.3

Von daher ist es nur konsequent, wenn Leszek KOLAKOWSKI in einem Aufsatz mit dem provozierenden Titel "Der Anspruch auf die selbstverschuldete Unmündigkeit"4 neben und gegen das "aufklärerische" Postulat einer radikalen Traditionskritik die Forderung nach der Bewahrung der Tradition stellt:

"Es gibt zwei Umstände, deren wir uns immer gleichzeitig erinnern sollen: Erstens, hätten nicht die neuen Generationen unaufhörlich gegen die ererbte Tradition revoltiert, würden wir noch heute in Höhlen leben; zweitens, wenn die Revolte gegen die ererbte Tradition einmal universell würde, werden wir uns wieder in den Höhlen befinden. Der Kult der Tradition und der Widerstand gegen die Tradition sind gleichermaßen unentbehrlich für das gesellschaftliche Leben ... beide sind nötig, können aber immer nur im Konflikt, nie in einer Synthese, koexistieren."

KOLAKOWSKI formuliert damit eine elementare Einsicht, die am Ende der "Neuzeit" wieder stärker ins allgemeine Bewußtsein vordringt: "Menschen können, wenn sie leben und überleben wollen, nicht jedesmal absolut von vorn anfangen, und sie können nicht alles, vor allem nicht alles zur gleichen Zeit, zur Disposition stellen."5 "Zukunft braucht Herkunft"!

Mit dieser Einsicht ist der traditionskritische Impuls der "Aufklärung" freilich keineswegs hinfällig geworden. Die "Spannung zwischen Traditionskritik und Traditionsbewahrung bzw. Traditionstransformation" erfährt damit am "Ende der Neuzeit" nur eine weitere "Verschärfung".7 Welche Probleme sich daraus für die ethische Orientierung in der Gegenwart ergeben, beschreibt Eckart OTTO ${ }^{8}$ folgendermaßen:

"Es ist ethische Signatur unserer Zeit, daß gleichzeitig der Wunsch nach individueller Freiheit im Verhalten und ein Bedürfnis nach ethischer Wei-

3 W. OELMŬLLER [A.2] 65 (Hervorhebung T.K.). 66 (mit Zitat aus: I. KANT, Werke in sechs Bänden, hg. von W. WEISCHEDEL, Darmstadt 1966, Bd.2, 13). Vgl. bereits die eminent ideologie-kritische, auf dem Boden christlicher Traditionen (!) fußende Kritik KANTs durch J.G. HAMANN in seinem "Brief an Christian Jacob Kraus" (in: BAHR [A.1] 18-22) und dazu O. BAYER, Umstrittene Freiheit; Theologisch-philosophische Kontroversen (UTB 1092), Tübingen 1981, $66 \mathrm{ff}$.

4 In: L. REINISCH (Hg.), Vom Sinn der Tradition, München 1970, 1-15; zitiert nach dem Wiederabdruck in OELMÜLLER/DÖLLE-OELMÜLLER/ PIEPMEIER [A.2] 378-389 (Zitat: 378).

5 OELMÜLlER [A.2] 13.

6 O. MARQUARD, "Ende des Schicksals? Einige Bemerkungen über die Unvermeidlichkeit des Unverfügbaren" in: Schicksal? Grenzen der Machbarkeit (dtv 1236), München 1977, 16 (zit. nach OELMÜLLER [A.2] 14).

7 OELMŬ́LLER [A.2] 12.

8 "Die Geburt des moralischen Bewusstseins; Die Ethik der Hebräischen Bibel" in: DERS./S. UHLIG, Bibel und Christentum im Orient (Orientalia Biblica et Christiana 1), Glückstadt 1991, 63-87: 65 (im Anschluß an A. GEHLEN, s. ebd. Anm.3). 
sung und Hilfe in der Lebensgestaltung wachsen. Der in der Zerbröselung traditioneller Handlungsleitungen für den einzelnen wachsende Entscheidungsdruck läßt nach mehr ethischer Anleitung rufen, die aber sofort wieder der Kritik des Wunsches nach individueller Selbstbestimmung unterworfen wird."

Bei der Suche nach "ethischer Weisung" genießen atl. Texte - und hier besonders der Dekalog 9 - nach wie vor hohes Ansehen. Das AT enthält aber nicht nur ethisch relevante Traditionen, die Gegenstand kritischer Rezeption und Transformation in der Gegenwart werden können. Es dokumentiert selbst bereits Prozesse ethischer Reflexion und Diskussion, in denen die Spannung zwischen Traditionskritik und Traditionsbewahrung exemplarisch ausgetragen wird.10

Im Folgenden möchte ich die Erzählung Gen $38^{11}$ als Beispiel für einen derartigen Prozeß analysieren. Meine These ist, daß dieser Text in einem zweifachen Sinn als ein "Lehrstück" atl. Ethik betrachtet werden kann: Zum einen läßt er für eine(n) heutige(n) Leser(in) eine Vielzahl ethischer Probleme erkennen, die bei dem Versuch einer ethischen Orientierung in der Gegenwart im Rückgriff auf atl. Traditionen zu bedenken sind. Zum anderen scheint schon bei der Abfassung des Textes in seiner jetzt vorliegenden Gestalt eben darin seine Funktion bestanden zu haben, solche Probleme aufzuzeigen. Für die gegenwärtige ethische Reflexion bleibt Gen 38 als "Lehrstück" jedoch m.E. auch dann relevant, wenn sich meine These in diesem zweiten, historischen Sinn nicht bewähren sollte.

Mit den im Folgenden an den Text herangetragenen Gesichtspunkten und Fragestellungen der Interpretation versuche ich, der Forderung des Jubilars nach einer "konsequenten Traditionsgeschichte" (und Traditionskritik) in zweifacher Hinsicht nachzukommen: Gen 38 soll erstens nicht nur innerhalb einer (linearen oder verzweigten) Traditions"Entwicklung" verortet, sondern als Produkt kritischer Diskussion mit verschiedenen Traditionen in einer konkreten geschichtlichen Situation verstanden werden. Dabei wird sich zweitens ein von griechisch-abendländischen Traditionen bestimmtes Vorverständnis als fragwürdig erweisen, das "Ethik" als "krit[ische] Untersuchung" der "Ausprägungen, Voraussetzungen und Prinzipien" des "Sittlichen" mit "philosoph[ischer] Wissen-

9 Bei einer Umfrage der Illustrierten "Quick" im Jahre 1989 bejahten 66,4\% der Befragten die Frage "Sind die Zehn Gebote Richtschnur für Ihr Leben?" (27,0\% "Nein", 6,6\% "Weiß nicht"), s. D. PUTTKAMMER/W. WOLF (Red.), Zum Leben befreit; Der Dekalog ... (Texte zur Bibel 5), Neukirchen-Vluyn 1989, 10. (Welcher Prozentsatz die 10 Gebote tatsächlich kannte, wurde offenbar nicht ermittelt.)

$10 \mathrm{Vgl}$. A. SOETE, Ethos der Rettung - Ethos der Gerechtigkeit; Studien zur Struktur von Normbegründung und Urteilsfindung im Alten Testament und ihrer Relevanz für die ethische Diskussion der Gegenwart, Würzburg 1987 (zu Gen 38: 153ff). Zum gegenwärtigen Diskussionsstand im Bereich atl. Ethik s. E. OTTO, "Forschungsgeschichte der Entwürfe einer Ethik im Alten Testament," VF 36/1 (1991) 3-37.

11 S. dazu neben den Kommentaren bes. J.A. EMERTON, "Some Problems in Genesis XXXVIII," VT 25 (1975) 338-361; DERS., "An Examination of a Recent Structuralist Interpretation of Genesis XXXVIII," VT 26 (1976) 79-98 (zu E.R. LEACH, "The Legitimacy of Solomon; Some structural aspects of Old Testament history," Genesis as Myth and Other Essays, London 1969, 25-83. 113-117); DERS., "Judah and Tamar," VT 29 (1979) 403-415. 
schaft" gleichsetzt und die Geschichte der Ethik folgerichtig erst mit Aristoteles beginnen läßt. 12 "Nicht nur die Texte griechischer Philosophie, auch die Texte des Alten Testaments sind Dokumente des Denkens"13 - und als solche ernstzunehmen!

\section{DISTANZIERUNG UND REFLEXION}

Die Erzählung Gen 38 gibt zunächst einmal Einblick in fremdartige "sittliche Lebensformen", in denen nicht weniger fremdartige ethische "Orientierungssysteme"14 wirksam sind: Die Institution der "Schwagerehe", die Todesstrafe (durch Verbrennen) als Sanktion für "Unzucht" - und hier nur für die daran beteiligte Frau! -, die Verfügungsgewalt des Familienoberhauptes über die Sexualität seiner Kinder und seine Jurisdiktions-Gewalt über sie, aber auch die Annahme eines strafenden Wirkens der Gottheit im Hintergrund - all das kann in der gegenwärtigen westlichen Welt kaum noch als anerkennungs- und verteidigungswürdig gelten. Freilich scheinen die "sittlichen Lebensformen" und "ethischen Orientierungssysteme", die die Erzählung voraussetzt, schon in der Zeit der Endgestaltung und Überlieferung dieses Textes wenn auch in anderen Hinsichten als heute - als fremdartig und 2.T. auch anstößig empfunden worden zu sein. Jedenfalls waren im frühen Judentum zur Zeit der Endredaktion des Pentateuch weder das Konnubium von Judäern (!) und Kanaanäern noch die (kultische) Prostitution noch die Bestrafung von "Unzucht" durch Verbrennen noch das Levirat gängige und unumstrittene Praxis - ganz zu schweigen von Tamars Verstoß gegen ein Inzesttabu. ${ }^{15}$

Gerade die Fremdartigkeit und Anstößigkeit des Berichteten kann aber dem Leser (bzw. der Leserin) - damals wie heute - einen gewissen Grad der Distanzierung vom dargestellten Geschehen nahelegen, die den Blick freigibt für die Reflexion der Strukturen und Prozesse ethi-

12 So das dtv-Brockhaus-Lexikon, München 1984, Bd.5, 155. Vgl. etwa R. SMEND, Art. "Ethik III. Altes Testament" in: TRE 10 (1982) 423-435: "Zwar handelt das Alte Testament in allen seinen Teilen von menschlichem Verhalten und gibt Normen dafür oder wendet sie an. Aber eine zusammenhängende Reflexion darüber im abendländischen Sinne fehlt, von einigen Annäherungen abgesehen, durchaus" (423). Der Begriff "Ethik des Alten Testaments" "bezeichnet nicht eine dem Alten Testament bereits in unserem Sinne geläufige Geistesbeschäftigung, sondern vielmehr das Ergebnis von deren heutiger Rückfrage nach den sie beschäftigenden Sachverhalten innerhalb des alten Israel bzw. des Alten Testaments." (423f).

13 E. HERMS, Gesellschaft gestalten; Beiträge zur evangelischen Sozialethik, Tübingen 1991, XVIII, Anm.15.

14 Zur Begrifflichkeit vgl. OELMÜLLER [A.2] 29ff. "Unter einer sittlichen Lebensform verstehe ich ... die Form des Lebens und das Ziel aller Handlungen, die wir durch unser Tun erstreben und für anerkennungs- und verteidigungswürdig halten" (30). "Orientierungssysteme sind letzte Vorgaben bzw. menschliche Errungenschaften aus dem Arsenal der Geschichte, an dem wir uns orientieren können, wenn wir vor uns selbst oder vor anderen alte oder neue Lebensformen kritisieren oder rechtfertigen wollen" (30f).

$15 \mathrm{~S}$. dazu im Einzelnen unten. 
scher Urteilsfindung, die in dieser Geschichte zum Tragen kommen. Neben historisch abständigen Lebensformen und Orientierungssystemen dokumentiert Gen 38 ja auch einen Fall ethischer Konfliktbearbeitung im Rahmen dieser Lebensformen und Orientierungssysteme und deutet mögliche Rückwirkungen auf diese vorgegebenen Rahmenbedingungen ethischer Orientierung an.

$\mathrm{Daß}$ es in der Geschichte von Juda und Tamar um einen ethischen Konflikt (bzw. ein ganzes Bündel ethischer Konflikte) und seine Bewältigung geht, wird deutlich, wenn man ihren wesentlichen Inhalt kurz zusammenfaßt: 16

1. Juda heiratet eine Kanaanäerin und bekommt von ihr drei Söhne: Er, Onan und Schela (V.1-5).

2. Tamar, die Frau des Erstgeborenen Judas, bleibt aufgrund des Fehlverhaltens Ers, Onans und Judas kinderlos (V.6-11).

3. Tamar überlistet ihren Schwiegervater, indem sie sich als Prostituierte verkleidet, und wird von ihm schwanger (V.12-23).

4. Tamar wird der Unzucht angeklagt und verurteilt. Nach Aufdeckung ihres Täuschungsmanövers spricht Juda Tamar jedoch frei und gesteht sein eigenes Fehlverhalten ein (V.24-26).

5. Tamar bekommt Zwillinge (V.27-30).

Nach der "genealogischen" Einleitung in V.1-5 berichten die beiden folgenden Haupt-Abschnitte der Erzählung von ethisch fragwürdigen Handlungen Judas (V.6-11) und Tamars (V.12-23). Mit der GerichtsSzene V.24-26 erreicht die Erzählung ihren Höhepunkt, der zugleich eine ethische Beurteilung des Verhaltens Judas und Tamars bietet (V.26).17 V.27-30 bildet dann wieder einen "genealogischen" Abschluß.

Die kunstvolle Komposition des Textes zeigt sich darin, wie er zunächst verschiedene Handlungslinien entwickelt, um sie dann auf dem Höhepunkt der Erzählung miteinander zu verbinden: Die Anklage gegen Tamar in V.24 bezieht sich (für den Leser) zurück auf ihr Verhalten in V.12-19; mit ihrer Vorlage entlastenden Beweismaterials in V.25 wird die Funktion der Szene V.20-23 deutlich, die zunächst als Abschweifung erscheinen konnte; und in seinem abschließenden Urteil in V.26 nimmt Juda nicht nur auf das Verhalten Tamars (V.12-19), sondern auch auf sein eigenes Verhalten als dessen Auslöser (V.6-11) Bezug.

Einige Auffälligkeiten des Textes deuten darauf hin, daß er nicht nur kunstvoll komponiert, sondern auch etwas künstlich konstruiert ist. So besteht eine gewisse Spannung darin, daB nach V.11 Juda Tamar in ihr "Vaterhaus" entlassen hat, während V.2426 voraussetzt, daB Tamar der Jurisdiktions-Gewalt Judas als ihres "Schwiegervaters" untersteht (und anscheinend auch in seinem Familienverband lebt). Diese Spannung ist erklärbar aus dem Interesse des Erzählers, zugleich den Verstoß Judas gegen die "Schwa-

16 Zur methodischen Bedeutung der Zusammenfassung für die Ermittlung des Themas und der Funktion eines Textes s. T.A. VAN DIJK, Textwissenschaft; Eine interdisziplinäre Einführung, Tübingen 1980, $41 \mathrm{ff}$ und H. UTZSCHNEIDER, Das Heiligtum und das Gesetz; Studien zur Bedeutung der sinaitischen Heiligtumstexte (Ex 25-40; Lev 8-9), OBO 77, Fribourg/Göttingen 1988, 74ff.

17 Daß das Urteil Judas in V.26 "auch die Meinung des Erzählers" zum Ausdruck bringt, ist mit $H$. GUNKEL (Genesis, HK I/1, Göttingen ${ }^{5} 1922,418$ ) anzunehmen. 
gerpflicht" zu unterstreichen (V.11) und diesen selbst als pater familias das Urteil über Tamars und über sein eigenes Verhalten sprechen zu lassen (V.24-26). Konstruiert wirkt auch, daß Tamar als (vermeintliche) Prostituierte mit Juda - und nur mit diesem! - zusammenkommt, und daß Juda sich darauf einläßt, einer wildfremden Hure seine persönlichen Insignien als Pfand auszuhändigen (V.12-19) ${ }^{18}$. Diese Spannungen und Unwahrscheinlichkeiten im Text könnten Indizien dafür sein, daß er - wenigstens in seiner jetzt vorliegenden Gestalt - bereits als "ethisches Lehrstück" konzipiert und konstruiert worden ist.

Jedenfalls kann er aber als solches gelesen werden. Versteht man nämlich unter "Ethik" die Betrachtung menschlicher Handlungen unter normativem Aspekt, 19 enthält die Geschichte von Juda und Tamar neben dem expliziten Diskurs in V.24-26 noch eine ganze Reihe weiteren "ethischen" Diskussionsmaterials.

\section{ETHISCHE NORMEN IM HINTERGRUND DES TEXTES}

Nahezu jede Handlung der verschiedenen Akteure in Gen 38 muß bei den Lesern des Textes die Frage provozieren, ob sie sich "richtig" oder "falsch" verhalten. Für ihre Beantwortung sind mehrere ethische Handlungs-Normen von Bedeutung, die im Text nicht ausdrücklich genannt, wohl aber mehr oder weniger deutlich vorausgesetzt sind.

1. Hier ist zunächst die Sitte des "Levirates", der "Schwagerehe" zu nennen, der nachzukommen Juda in V.8 seinen Sohn Onan auffordert (יבם pi.). Sie ist im AT noch in Dtn 25,5-10 und im Buch Rut belegt, aber auch im Alten Orient und darüber hinaus bezeugt. ${ }^{20}$ In welchem Sinne sie in Gen 38 genau vorausgesetzt ist, ist insofern nicht leicht $\mathrm{zu}$ bestimmen, als hier wie im Buch Rut augenscheinlich nicht die expliziten rechtlichen Regelungen von Dtn 25 im Hintergrund stehen, sondern ein weniger präzise greifbares "Gewohnheitsrecht"21.

Im Kern besagt der familienrechtliche Brauch der Schwagerehe, "daß der überlebende Bruder" eines kinderlos gestorbenen verheirateten Mannes "verpflichtet ist, mit der Schwägerin Kinder zu zeugen, von denen der Erstgeborene dann als Kind des Verstorbenen gilt". 22 Genau dazu fordert Juda in Gen 38,8 Onan auf: "Geh zur Frau deines Bruders, und vollziehe an ihr die Schwagerehe, und verschaffe deinem

18 GUNKEL [A.17] 416 meint dazu: "Daß aber Juda so bedeutsame Gegenstände (Hagg 2,23) weggibt, zeigt seine Gier."

19 Vgl. W. HÄRLE/E. HERMS, Rechtfertigung; Das Wirklichkeitsverständnis des christlichen Glaubens (UTB 1016), Göttingen 1980, $141 \mathrm{ff}$.

$20 \mathrm{Vgl}$. R. DE VAUX, Das Alte Testament und seine Lebensordnungen Bd.I, Freiburg/Basel/Wien 21964, 72ff. 344f (Lit.); E. LÖVESTAM, Art. "Schwagerehe," BHH 3 (1966) Sp. 1746f (Lit.); J. SCHARBERT, Art. "Ehe/Eherecht/Eheschließung II. Altes Testament," TRE 9 (1982) 311-313: 312; C. WESTERMANN, Genesis Bd.3, BK I/3, Neukirchen-Vluyn $1982,46$.

21 SCHARBERT [A.20] 312. Nach Dtn 25,7ff hätte Tamar das Recht gehabt, die Erfüllung des Levirats bei den Ältesten am Tor einzuklagen!

22 GUNKEL [A.17] 412. 


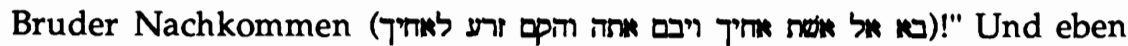
dies verweigert Onan, der zwar immer wieder ${ }^{23}$ zu seiner Schwägerin geht und mit ihr schläft, durch seine empfängnisverhütenden Maßnahmen aber verhindert, "seinem Bruder Nachkommen zu verschaffen" נתן זרע לאחיו) V.9).

Im Anschluß an G.W. COATS 24 meint C. WESTERMANN25: "Gn 38 zeigt noch ..., daß ursprünglich die Witwe nur das Recht auf einen Nachkommen hatte, nicht auf Heirat mit dem Schwager; insofern ist die Bezeichnung 'Schwagerehe' ungenau. Tamar wird nicht Ehefrau Onans, ihr Ziel ist auch nicht, Juda zur Heirat zu zwingen, sondern nur, einen Sohn zu bekommen". Die Annahme, das Levirat beinhalte in Gen 38 nur die Verpflichtung zur Zeugung eines Nachkommens, nicht aber die zur Ehe mit der verwitweten Schwägerin, erklärt nach COATS und WESTERMANN, daß die Erzählung "(m)erkwürdigerweise schließt ..., ohne mitzuteilen, wessen Frau die Tamar denn nun endlich geworden war" (G. VON RAD ${ }^{26}$ ). Sie ist jedoch kaum vereinbar mit zwei expliziten Aussagen des Textes: Nach V.14 ergreift Tamar die Initiative, "weil sie gesehen hatte, da B Schela herangewachsen war, sie ihm aber nicht zur Frau gegeben worden war" (

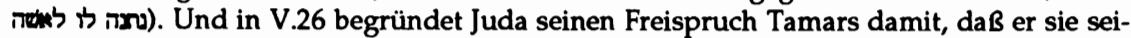

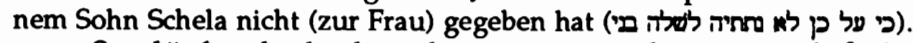

So dürfte doch eher davon auszugehen sein, daß das Levirat auch in Gen 38 neben der Pflicht zur Zeugung eines Nachkommens für den verstorbenen Bruder die Verpflichtung einschließt, die verwitwete Schwägerin als Ehefrau aufzunehmen. Die Funktion der Schwagerehe, wie sie in Gen 38 vorausgesetzt ist, besteht dann neben dem Erhalt der Familie des Verstorbenen ${ }^{27}$ wohl auch in der sozialen Absicherung seiner Witwe, die so vor dem doppelten Übel der Witwenschaft und Kinderlosigkeit bewahrt bleibt. ${ }^{28}$ Daß sie auch der Sicherung des Erbbesitzes für die Witwe des Verstorbenen diente, ist zu vermuten. ${ }^{29}$

Mit ihrer "Verkleidungsaktion" verschafft sich Tamar dann aber nicht das ihr von Onan und Juda vorenthaltene Rech ${ }^{30}$ des Levirats; sie

23 in V.9 hat offenbar iterativen Sinn!

24 "Widow's Rights: A Crux in the Structure of Genesis 38," CBQ 34 (1972) 461-466.

25 [A.20] 46.

26 Das erste Buch Mose; Genesis, ATD 2-4, Göttingen 101976, 295.

27 Durch den ihm zugeschriebenen Nachkommen (זרע Gen 38,8; vgl. Dtn 25,6: בטר [vl.: [ב]) bleibt sein "Name" erhalten ( 0 ot Dtn 25,6; Ru 4,5) und wird ihm ein "Haus" bzw. eine "Familie" gebaut (בית Dtn 25,9).

28 Vgl. GUNKEL [A.17] 414: "Das israelitische Weib betrachtet als den Zweck ihres Lebene [sic!] das Kinderzeugen. Am Besitz von Kindern hängt ihre Ehre im Hause und unter den Leuten. Kinderlosigkeit ist Schande; das schlimmste Los der Frau ist, als kinderlose Witwe ins Vaterhaus zurückgeschickt zu werden, wo sie sich vor dem Spott in einer Jammerecke verkriechen mag."

29 Vgl. COATS [A.24] 462: "Implicit in the custom is protection for the widow's inheritance rights within the father-in-law's family. The concern is not simply for 'Er's future line ... The concern is for Tamar's future" (mit Hinweis auf T. u. D. THOMPSON, "Some Legal Problems in the Book of Ruth," VT 18 [1968] 79-99).

30 So WESTERMANN [A.20]: "Die Geschichte erzählt, wie sie (scil. Tamar) selbst das Recht auf ein Kind, das ihr von der Familie des Mannes vorenthalten wird, in einem kühnen Wagnis sichert" (43); "sie verschafft sich selbst ihr Recht" (47). Vgl. z.B. H. 
verschafft sich (und zugleich der Familie ihres verstorbenen Mannes) so auf anderem Wege als dem "Rechtsweg" des Levirats, aber durchaus in dessen Sinne Nachkommen - die dementsprechend auch nicht dem Brauch der Schwagerehe entsprechend als Kinder Ers gelten, sondern als Nachkommen ihres "biologischen" Vaters Juda. ${ }^{31}$ Daß Tamar am Ende weder Judas noch Schelas Frau wird, ist wahrscheinlich eine Folge ihrer Verletzung gängiger Inzesttabus (s.u.): Mit ihrer "SelbsthilfeAktion" hat sie sich ihr "Recht" auf die Schwagerehe selbst verbaut!

Die Sitte des Levirats ist im AT keineswegs unumstritten. "Dt 25,510 zeigt, daß der Brauch Widerstand fand und weitgehend abgelehnt wurde":32 Die Pflicht zur Schwagerehe wird eingeschränkt auf Brüder, die "beieinander wohnen" (V.5); 33 und für den Fall ihrer Verweigerung erhält die verwitwete Schwägerin zwar ein Klagerecht, nicht aber die Möglichkeit, ihren Anspruch wirksam durchzusetzen: Weigert sich ihr Schwager standhaft, die Ehe mit ihr einzugehen, muß er sich "nur" eine öffentlich entehrende Behandlung durch sie gefallen lassen. Wenn schließlich Lev 20,21 die Ehe zwischen Schwager und Schwägerin generell mit Kinderlosigkeit bestraft, wird die Schwagerehe damit "wahrscheinlich ... überhaupt verboten".34

2. Vergleichsweise klarer ist die ethische Norm, die der Anklage gegen Tamar in V.24 zugrunde liegt: das Verbot von "Unzucht" bzw. "Hurerei" (נוננים) - Als solche gilt im AT "das ungeregelte, unrechtmäßige geschlechtliche Verhalten zwischen Mann und Frau ... Wer Hurerei treibt, begeht eine Schandtat in Israel (Lev 19,29 zimma; Dtn 22,21 $n^{e}$ bala). Entsprechend wird Hurerei bestraft: wer hurt, wird verbrannt (srp ni. Gen 38,24; Lev 21,9), ausgerottet (krt hi. Lev 20,6; br pi. Dtn 22,21; smt hi. Ps 73,27)."35 Dabei spiegelt die in Gen 38,24 über Tamar zunächst verhängte Strafe des Verbrennens, die in Lev 21,9 (nur) für den Fall der "Hurerei" einer Priester-Tochter vorgesehen ist, vielleicht ein frühes Stadium der Rechts-Entwicklung wider. ${ }^{36}$

SCHÜNGEL-STRAUMANN, "Tamar - eine Frau verschafft sich Recht," Bibel und Kirche (Schweiz) 39 (1984) 148-157.

31 So jedenfalls Gen 46,12; Num 26,19ff.

32 WESTERMANN [A.20] 46.

33 Dagegen interpretiert C.M. CARMICHAEL (Women, Law and the Genesis Traditions, Edinburgh 1979, 66 [mit Verweis auf D. DAUBE, "Consortium in Roman and Hebrew Law," Juridical Review 62 (1950) 72-74]) den Anfang von Dtn 25,5 als Einschränkung der folgenden Bestimmungen "for the particular circumstances in which the head of the family, the father, is dead." Dies erscheint mir jedoch ebenso unwahrscheinlich wie seine These, daß " $(t)$ he entire law is inspired by the Deuteronomist's reflection upon the Tamar tradition" (ebd.).

34 WESTERMANN [A.20] 46.

35 J. KÜHLEWEIN, Art. "זֶ znh huren," THAT I (31978) 518-520: 519.

36 WESTERMANN [A.20] 49. 
Hinsichtlich des Verbots von "Unzucht" ist allerdings zwischen dem Anspruch des Deuteronomiums und des Heiligkeitsgesetzes einerseits und dem allgemeinen Rechts- bzw. Unrechtsbewußtsein andererseits zu unterscheiden: "Die später von den Propheten so leidenschaftlich bekämpfte Kultprostitution (Hosea, Ezechiel) ist zu der Zeit, in der die Erzählung spielt, in einer gemischten Bevölkerung noch anerkannt. Die religiöse Prostitution hat seit alters bei den Völkern Vorderasiens eine Rolle gespielt." In diesem Zusammenhang ist es "(b)ezeichnend ..., daß die (angebliche) Dirne (Iיונה" (V.15) in V.21f "von Hira, dem Gefährten Judas, p 'die Geweihte' oder Hierodule genannt wird". 37

3. Eine weitere Norm, die im Text zwar nicht ausdrücklich genannt wird, bei der Beurteilung des Verhaltens seiner Akteure durch die Leser aber ebenfalls eine Rolle spielen dürfte, ist das Inzesttabu, gegen das Juda und Tamar verstoßen, wenn sie miteinander schlafen (Lev 18,15). Lev 20,12 belegt den Beischlaf zwischen Schwiegervater und Schwiegertochter als "schändliche Tat" (תבל) mit der Todesstrafe (für beide Beteiligten!). Nach den Inzest-Verboten in Lev 18 und 20 wären aber auch sexuelle Beziehungen zwischen Schwager und Schwägerin (und damit das Levirat?) tabuisiert $(18,16 ; 20,21)$. Schließlich wäre - auch abgesehen davon - aufgrund der Tabuisierung sexueller Kontakte eines Mannes mit der Frau seines Vaters (Dtn 23,1; 27,20; Lev 18,8; 20,11) eine Ehe zwischen Tamar und Schela nach ihrer "Affäre" mit Juda keineswegs ethisch unproblematisch.

Auch im Falle der Inzesttabus ist allerdings zu fragen, inwieweit ihre Fixierung im Heiligkeitsgesetz dem allgemeinen Rechtsbewußtsein (zur Erzähl-Zeit und zur erzählten Zeit des Textes) entspricht. Hier ist freilich durchaus mit einer weiter zurückreichenden Traditions-Geschichte zu rechnen. Der Text selbst deutet jedenfalls in V.16 und 26 an, daß die sexuelle Beziehung zwischen Juda und Tamar ein Tabu verletzt: "Juda wäre aus freien Stücken diesen Verkehr nimmermehr eingegangen 16, wie er denn auch später seiner Schwiegertochter nicht zu nahe gekommen ist 26 ."38

4. Als eine weitere ethische Handlungs-Norm im Hintergrund der Erzählung wäre schließlich die kommunikative "Aufrichtigkeit", "Zuverlässigkeit" und "Wahrhaftigkeit" zu nennen: Onan täuscht die Erfüllung seiner Schwagerpflicht nur nach außen hin vor (V.9). Juda täuscht Tamar (und vielleicht auch sich selbst) über seine wahren $\mathrm{Ab}$ sichten mit Schela (V.11.14; vgl. V.26). Tamar verkleidet sich als Prostituierte (V.14) und erschleicht sich Judas Insignien als Pfand (V.17f). Damit verletzen sie elementare Normen zwischenmenschlicher Kommu-

37 WESTERMANN [A.20] 48.

38 GUNKEL [A.17] 415. 
nikation, die im Hebräischen etwa mit nak oder auf den Begriff gebracht werden könnten: ${ }^{39}$

"'Zuverlässigkeit' ist im Alten Testament kein Wert an sich im idealistischen Sinn. Aber sie ist unendlich wertvoll für das Gedeihen einer Gesellschaft, insofern sie erst eine wirkliche Gemeinschaft unter Menschen ermöglicht. Es ist in einem Gemeinschaftsleben unentbehrlich, daß man sich aufeinander verlassen kann, daß das Verhalten eines Menschen gegen seinen Mitmenschen - in positivem Sinne - kalkulierbar ist." $\mathbf{4 0}$

In welche Gefahren eine Gemeinschaft (die Familie Judas) und ein Einzelner (Tamar) durch Unaufrichtigkeit und Unzuverlässigkeit geraten können, führt Gen 38 anschaulich vor Augen.

\section{PROBLEME DER ANWENDUNG ETHISCHER NORMEN}

Der Text regt seine Leser aber nicht nur zur Betrachtung und Beurteilung des Verhaltens seiner Akteure vor dem Hintergrund ethischer Handlungs-Normen an. Er macht sie zugleich auf eine Reihe von Problemen aufmerksam, die sich bei der Anwendung solcher Normen - in "evaluativer" oder "präskriptiver" Funktion - auf konkrete Entscheidungs-Situationen ergeben können. 41

1. Am deutlichsten wird das Problem der Anwendung ethischer Normen (in "evaluativer" Funktion) im "Ehebruchproze 3 "42 gegen Tamar in V.24-26: Die Schwangerschaft der verwitweten und unverheirateten Tamar kann zunächst nur auf "Unzucht" (זנונים - zurückgeführt werden. Angesichts dieser vermeintlich klaren Sachlage bestimmt Juda als Familienoberhaupt: "Sie soll verbrannt werden" (V.24). Tamars Enthüllung der Vaterschaft Judas (V.25) nötigt diesen dann aber zu einer Revision seines Urteils: "Sie ist im Recht - im Gegensatz zu mir" (מקי צ.26). ${ }^{43}$

39 Vgl. H. WILDBERGER, Art. "ןn 'mn fest, sicher," THAT I (31978) 177-209: 196ff. 201ff; E. WÜRTHWEIN/O. MERK, Verantwortung, Biblische Konfrontationen 9, Stuttgart/Berlin/Köln/Mainz 1982, 39f.

40 WÜRTHWEIN/MERK [A.39] 40.

41 Zur Notwendigkeit der Anwendbarkeit von Handlungsnormen s. HÄRLE/HERMS [A.19] 150; zu ihrer evaluativen und präskriptiven Funktion a.a.O. 153ff. "Man kann generell sagen: die evaluative Funktion von Normen ist die des Prüfens von Handlungsmöglichkeiten bzw. -vollzügen, die präskriptive Funktion ist die des Entscheidens von Handlungsalternativen. Dabei liegt der Zweck des Prüfens letztlich im Entscheiden und die Begründung der Entscheidung im Prüfen. Beide Funktionen sind also eng aufeinander bezogen, aber in dieser Bezogenheit auch wiederum deutlich voneinander unterschieden" (155f).

42 Vgl. H.J. BOECKER, Redeformen des Rechtslebens im Alten Testament, WMANT 14, Neukirchen-Vluyn 1964, 127.

${ }^{43} \mathrm{Zu}$ diesem Sinn der komparativischen Formulierung s. BOECKER, ebd. (im Anschluß an

K. KOCH, Sdq im Alten Testament, Diss. Heidelberg 1953, 71). 
Damit führt der Text zunächst einmal an einem Beispiel vor, daß ein und dasselbe Verhalten durch ein und dieselbe Person unter verschiedenen Umständen in unterschiedlicher Weise ethisch beurteilt werden kann. Zur ethischen Urteils-Kompetenz, wie sie Juda hier in vorbildlicher Weise demonstriert, gehört demnach mehr als die Kenntnis der relevanten Handlungs-Normen; dazu gehört auch die Fähigkeit, diese Normen in konkreten Entscheidungs-Situationen in richtiger Weise anzuwenden - und sein Urteil gegebenenfalls zu revidieren!

Was Juda zur Revision seines Urteils über Tamar nötigt, ist eine verbesserte Kenntnis der Situation. Der Tatbestand, daß Tamar eine unrechtmäßige sexuelle Beziehung hatte und damit "Unzucht" getrieben hat, bleibt bestehen. Es kommt sogar noch hinzu, daß sie sich Juda gegenüber unaufrichtig verhalten und wahrscheinlich auch ein Inzesttabu gebrochen hat. Ihr Verhalten erscheint nun aber in einem neuen Licht: Juda weiß jetzt, von wem sie schwanger ist, und warum sie sich mit ihm sexuell eingelassen hat. Und in diesem Kontext erscheint ihm ihre Handlungsweise trot $z$ der damit verbundenen Norm-Verletzung(en) als gerechtfertigt. ${ }^{44}$

Hier zeigt sich als ein Problem der Anwendbarkeit von Handlungs-Normen die Komplexität ethischer Entscheidungs-Situationen. In Anbetracht dieser Komplexität ist eine sachgemäße Urteilsfindung nur bei möglichst genauer Kenntnis der Situation möglich. Hinzu kommt aber noch ein Weiteres: Mit der Revision seines Urteils über Tamar verändert Juda nicht nur seine Beurteilung ihres Verhaltens; er setzt dieses zugleich in Beziehung zu seinem eigenen Handeln: "Sie ist im Recht - im Gegensatz zu mir!" Damit tritt als ein weiterer Aspekt der Komplexität ethischer Entscheidungs-Situationen deren soziale Dimension zu Tage: Das Verhalten eines Menschen kann nur in seiner komplexen Verflechtung mit dem Verhalten anderer Menschen sachgemäß beurteilt werden.

Dabei ist im vorliegenden Fall das Verhalten Judas nicht weniger normwidrig als das Tamars: Kann er seinen inzestuösen sexuellen Kontakt mit seiner Schwiegertochter noch damit entschuldigen, daß "er ja nicht wußte, daß es seine Schwiegertochter war" (V.16), ist dies für sein eigenes "unzüchtiges" Verhalten ${ }^{45}$ und vollends für seine Unterbindung (oder mindestens Hinauszögerung) der Schwagerehe zwischen

$44 \mathrm{Daß}$ Tamars Verhalten "ganz und gar gegen die Sitte verstößt" (GUNKEL [A.17] 415), wird durch das - relative! - Urteil in V.26 nicht bestritten!

$45 \mathrm{DaB}$ Judas Kontakt mit einer Prostituierten ethisch jedenfalls nicht völlig unbedenklich ist, zeigen sowohl die Notiz über den Tod seiner Frau in V.12, als auch die Einschaltung Hiras in V.20-23: Ersteres "beweist, daß man es schon in alter Zeit zum mindesten nicht für schön gehalten hat, wenn der Ehemann zur Hure geht" (GUNKEL [A.17] 414), letzteres läßt erkennen: "Dergl. wie der Verkehr mit der Hure, das sind Dinge, die ein vornehmer Mann wohl tut, aber oon denen er nicht offentlich redet" (a.a.O. 417), die also mindestens mit einem gewissen Tabu-Charakter behaftet sind. 
Tamar und Schela nicht möglich. Insofern ist sein abschließendes Urteil über Tamar ein relatives. Ethische Handlungs-Normen ermöglichen also nicht in jedem Fall eindeutige Entscheidungen. (Daß es auch solche Fälle gibt, zeigen die Urteile über Er und Onan in V.7 und 10.)

Am Verhalten Judas wird schließlich noch ein weiterer Aspekt der Komplexität ethischer Entscheidungs-Situationen erkennbar, den man als ihre personale Dimension bezeichnen könnte: Der Text enthält ja durchaus auch Elemente, die die Tendenz zeigen, "Juda als einen ehrenhaften Mann zu schildern"46. Der Erzählung über seinen Kontakt mit einer (vermeintlichen) Prostituierten geht in V.12 eine Notiz über den Tod seiner Frau voraus, "um eine Komplikation des nun Folgenden durch eine noch bestehende Ehe Judas zu vermeiden"47. Und die Episode V.20-23 macht deutlich, daß er sich nicht in "ehrenrührig(er)" Weise "um den Lohn gedrückt" hat. 48 An dieser Ambivalenz des Verhaltens Judas zeigt sich, daß ethische Urteile über Handlungen nicht notwendig auch schon Urteile über den Handelnden sein müssen. (Daß auch solche Urteile möglich sind, zeigt wieder V.7 in Bezug auf Er.) Als "ehrenwerte(r) Mann" erweist sich Juda am Ende gerade darin, daß er "sich der schwierigen und in gewisser Weise demütigenden Situation" seiner Überführung durch Tamar "gewachsen" zeigt und sich selbst schuldig spricht (V.26).49

2. Welche Probleme sich aus der Komplexität ethischer Entscheidungs-Situationen und ihrer begrenzten Erkennbarkeit für den Handelnden im Blick auf die Anwendung ethischer Normen (in "präskriptiver") Funktion ergeben können, zeigt auch das Verhalten Judas in V.6-11. Ziel seiner Handlungen ist die Erhaltung seiner Familie durch die Erzeugung von Nachkommen. Deshalb nimmt er für seinen Erstgeborenen Er eine Frau (V.6). Aus demselben Interesse heraus fordert er, nachdem Er kinderlos gestorben ist, Onan dazu auf, seine "Schwagerpflicht" zu erfüllen und seinem Bruder Nachkommen zu verschaffen (V.8). Dabei stimmen die Interessen Judas mit der Funktion der "Schwagerehe" als ethischer Norm überein.

Zum Entscheidungs-Konflikt kommt es für Juda, als auch Onan stirbt: Er zögert, Tamar seinem dritten und letzten Sohn Schela zur Frau zu geben, weil er befürchtet, es könnte auch dieser sterben wie seine Brüder (V.11). Vorausgesetzt ist dabei, daß Juda die Gründe für den Tod

46 WESTERMANN [A.20] 48.
47 WESTERMANN [A.20] 47.

48 WESTERMANN [A.20] 48. Ob es "der Erzähler" (und Juda) "nicht als ehrenrührig" ansieht, "(d)aß Juda zu einer Dirne ging", wie WESTERMANN (ebd.) meint, erscheint mir jedoch fraglich. Judas Befürchtung, "zum Gespött zu werden" (V.23), scheint doch weniger darauf zu zielen, daß die (vermeintliche) Prostituierte ihn bezichtigen könnte, ihr den Lohn vorenthalten zu haben, als darauf, daß sie mit Hilfe seiner Insignien seinen Kontakt zu ihr öffentlich machen könnte.

49 WESTERMANN [A.20] 49. 
Ers und Onans (V.7.9f) nicht bekannt sind. So "hatte er wirklich Grund, für das Leben seines letzten ihm noch verbliebenen Sohnes zu fürchten, denn in solchen Fällen legte sich den Alten die Vermutung nahe, daß an der Frau selbst irgendetwas Todbringendes hafte (vgl. Tob 3,7ff; 8,9f)." 50 Hier zeigt sich wieder die Bedeutung der Situations-Erkenntnis für die richtige Anwendung ethischer Normen. Aufgrund seiner begrenzten Situations-Kenntnis ergibt sich für Juda nun aber noch ein weiteres Problem: der Konflikt zwischen der Funktion einer ethischen Handlungs-Norm und den (vermeintlichen) Auswirkungen ihrer Anwendung in einer konkreten Situation: Wenn Tamar in den Augen Judas "irgendwie am Tod ihrer Männer schuld"51 ist, dient die Anwendung der Norm des Levirates in ihrem Fall allem Anschein nach nicht dem Erhalt der Familie, sondern führt zur Bedrohung ihres Bestandes.

Wenn Juda die Erfüllung dieser Norm deshalb zunächst hinauszögert (V.11) und schließlich de facto verweigert (V.14), steht also seine Handlungsweise zwar im Widerspruch zur Norm der Schwagerehe als ethischer Handlungsanweisung; seine Handlungsabsichten, die Interessen, die er mit seinem Verhalten verfolgt, stimmen jedoch mit (einer) der Funktion(en) der Schwagerehe als ethischer Handlungs-Norm überein. Darin unterscheidet sich das Verhalten Judas in V.11 von dem Onans in V.9. Dieser erfüllt die Norm des Levirates nicht, weil ihre Funktion seinen eigenen Interessen widerspricht: Er wollte seinem Bruder keine Nachkommen verschaffen, weil er wußte, daß ihm die Kinder nicht gehören (V.9) und wahrscheinlich auch seinen eigenen Anteil am Erbe seines Vaters schmälern ${ }^{52}$ würden.

3. Die Bedeutung der Situations-Kenntnis für die Anwendung ethischer Handlungs-Normen (in "evaluativer" und "präskriptiver" Funktion) wird schließlich auch erkennbar am Beispiel des (de facto inzestuösen) sexuellen Kontakts zwischen Juda und Tamar: Juda "wußte nicht, daß es seine Schwiegertochter war" (V.16); sobald er es erfährt, stellt er den sexuellen Kontakt zu ihr ein (V.26). Tamar dagegen weiß sehr wohl, was sie tut - entscheidet sich aber aus übergeordneten Gründen für einen bewußten Normverstoß. Hier zeigt sich das Problem der Beurteilung wissentlicher und unwissentlicher Normverletzungen -

50 VON RAD [A.26] 293; vgl. GUNKEL [A.17] 413f. WESTERMANNs ([A.20] 46) Einwand, es werde "doch vorher ausdrücklich gesagt, daß der Tod Ers und Onans durch sie selbst verschuldet ist", verfängt nicht, da er die Perspektiven der Akteure im Text und der Leser des Textes nicht unterscheidet.

51 GUNKEL [A.17] 413.

52 Vgl. COATS [A.24] 462 (mit Verweis auf THOMPSON [A.29] 93); CARMICHAEL [A.33] 58. 102 Anm.5. - Wenn SOETE ([A.10] 159) die "Selbstsucht Onans, der keine Kinder zeugen will, die ihm nicht selbst gehören" und die "Selbstsucht Judas, der seinen jüngsten Sohn nicht einer Frau geben will, 'die schon zwei Männer unter die Erde gebracht hat" auf eine Ebene stellt, verwischt sie die Unterschiede zwischen den Handlungsmotiven Onans und Judas. 
das seinerseits noch weiter kompliziert wird durch die Überschneidung mehrerer Normen und Handlungs-Interessen.

Die Erzählung macht so an den verschiedenen Handlungen ihrer Akteure vor dem Hintergrund als bekannt vorausgesetzter Normen die Komplexität ethischer Entscheidungs-Situationen deutlich: Sie haben immer auch eine soziale und eine personale Dimension; und es kann zu Konflikten kommen zwischen den in einer ethischen Norm enthaltenen Handlungsanweisungen, ihren Funktionen und ihren in der konkreten Situation zu erwartenden Wirkungen sowie den Interessen der Handelnden. Hinzu kommt, daß ethische Entscheidungs-Situationen in ihrer Komplexität für den Menschen oft nur begrenzt erkennbar und durchschaubar sind. Damit kann aber die Anwendung ethischer Handlungs-Normen - in "präskriptiver" oder "evaluativer" Funktion im konkreten Fall problematisch werden.

So beruht auch die "Lösung", der Juda den Prozeß gegen Tamar in V.26 zuführt, nicht einfach auf der Anwendung ethischer HandlungsNormen oder der Abwägung konkurrierender Normen. Bevor diese "Lösung" näher betrachtet wird, soll aber noch auf ein weiteres ethisches Problem aufmerksam gemacht werden, das der Text andeutet: das Verhältnis von

\section{"ETHIK" UND "THEOLOGIE"}

C. WESTERMANN bezeichnet Gen 38 als "eine durch und durch profane Erzählung"53. Und G. VON RAD meint:

"Wie stark hier der Mensch und das Menschliche dominieren, wird daran deutlich, daß die eigentliche Erzählung in V.12-30 von einem Handeln oder Reden Jahwes überhaupt nicht spricht. Tatsächlich entbehrt das in sich verschlungene Geschehen jedes spezifischen religiösen Aspektes." 54

Nun spricht der Text allerdings in seinem Eingangsteil immerhin zweimal sehr prononciert von Gott:

"Er, der Erstgeborene Judas, war schlecht (bzw. böse) in den Augen Jahwes.

Da tötete ihn Jahwe (bzw. ließ ihn sterben)" (V.T).

"In den Augen Jahwes war es schlecht (bzw. böse), was er (Onan) getan hat-

te. Da tötete er auch ihn (bzw. ließ auch ihn sterben)" (V.10).

Diese beiden Aussagen sind insofern für den gesamten Text von Bedeutung, als sie den Lesern die Möglichkeit einer ethischen Beurteilung von Menschen durch Jahwe sowie von Eingriffen der Gottheit zur Sicherung einer "sittlichen Weltordnung" gleich zu Anfang vor Augen

\footnotetext{
53 WESTERMANN [A.20] 51.
}

54 VON RAD [A.26] 296. VON RAD fährt allerdings fort: "Und trotzdem ist es eine Welt, in der Jahwe nach der Meinung des Erzählers selbstverständlich gegenwärtig ist (V.7 und 10). Man muß ja nicht immer davon reden." In dieser Interpretation von V.7 und 10 ist deren Tragweite für die Aussage des Textes jedoch m.E. stark unterschätzt. 
führen. Daß dieser Gesichtspunkt im Fortgang der Erzählung nicht mehr zur Sprache kommt, ist dann aber durchaus signifikant und könnte ein Indiz für eine hintergründige Aussageabsicht des Textes sein.

1. V.7 und 10 sind ja auch für den Fortschritt der Handlung durchaus nicht nebensächlich: Daß Er und Onan sterben, ist Voraussetzung für den im Folgenden sich entwickelnden Konflikt. Daß beide aber - in der Perspektive des Erzählers und der Leser - keineswegs zufällig sterben, sondern infolge von Eingriffen der Gottheit zur Sicherung einer "sittlichen Weltordnung", verleiht diesem Konflikt eine "theologische" Dimension: Gerade durch diese Eingriffe zur Verwirklichung einer "sittlichen Weltordnung" bringt Jahwe deren Verwirklichung auf der zwischenmenschlichen Ebene in Gefahr! Das Konzept der Gottheit als Garant einer "sittlichen Weltordnung", in der Tun und Ergehen, Haltung und Geschick eines Menschen einander entsprechen, 55 erweist sich damit unter ethischen Gesichtspunkten als durchaus nicht unproblematisch.

2. Dies gilt zumal dann, wenn Eingriffe Gottes zur Sicherung der "sittlichen Weltordnung" nicht ohne weiteres als solche erkennbar sind. Eben dies ist in der Perspektive Judas der Fall, der die Todesfälle seiner beiden Söhne offenbar auf den Einfluß Tamars zurückführt und damit mißdeutet (s.o.).

3. Auffällig ist schließlich, daß im Text ethische Urteile mit Todesfolge für den Betroffenen nur von Jahwe gefällt und durchgesetzt werden. Die Pointe der rein zwischenmenschlich-"profanen" Konfliktbewältigung in V.24-26 besteht demgegenüber gerade darin, daß das ursprünglich von Juda über Tamar verhängte Todesurteil (V.24) revidiert wird (V.26). Deutet der Text damit an, daß Todesurteile von Menschen über Menschen angesichts der Komplexität ethischer Entscheidungs-Situationen und ihrer begrenzten Durchschaubarkeit für den Menschen generell ethisch fragwürdig sind?

Jedenfalls ist es angesichts der Verse 7 und 10 bemerkenswert, daß er in V.24-26 ein Beispiel "profaner" zwischenmenschlicher Konfliktbewältigung präsentiert, in der - trotz gravierender Normverletzungen auf beiden Seiten - beide Parteien nicht nur am Leben bleiben, sondern ihr Leben in ungeminderter Weise weiterführen können. Welches ethische Orientierungssystem ermöglicht diese "Lösung"?

55 S. dazu etwa K. KOCH/J. ROLOFF, Art. "Tat-Ergehen-Zusammenhang," DIES./E. OTTO/H. SCHMOLDT (Hg.), Reclams Bibellexikon, Stuttgart 1978, 485-488 sowie K. $\mathrm{KOCH}$ (Hg.), Um das Prinzip der Vergeltung in Religion und Recht des Alten Testaments, WdF 125, Darmstadt 1972. 
Mit dem Satz צדקה סמני, der die "Gerichtsverhandlung" in V.24-26 abschließt, fällt Juda das Urteil über Tamar und sich selbst. Insofern kann das Verb צ hier im Sinne von "im Recht sein" bzw. "unschuldig sein" verstanden werden: "Sie ist im Recht (bzw. unschuldig) - im Gegensatz zu mir!" Diese Übersetzung ist jedoch insofern irreführend, als צ צier nicht einfach ein "normgemäßes Verhalten" bezeichnet ${ }^{56}$ Tamar hat mit ihrem Handeln ja gleich mehrere ethische Normen verletzt (s.o.).

Wie u.a. K.H. FAHLGREN 57 und $\mathrm{K}$. KOCH ${ }^{58}$ gezeigt haben, bezeichnet das Verb צדק (צרקה צדe (ebenso wie die Nomina und dere auch ein "gemeinschaftstreues", "loyales" Verhalten. Dementsprechend übersetzt KOCH den Satz צדקה משר in Gen 38,26: "Sie hat loyal gehandelt und ist unschuldig, ich nicht". .59 In dieser Übersetzung wird der ethische Orientierungs-Horizont erkennbar, in dem Juda sein Urteil fällt und implizit auch begründet: die Sozialgemeinschaft der (Groß)-Familie, in der Juda und Tamar als Schwiegervater und Schwiegertochter zusammenleben.

Anders als in V.24 beurteilt Juda in V.26 nicht eine einzelne (aus dem Tatbestand ihrer Schwangerschaft erschlossene) Handlung Tamars unter dem Gesichtspunkt ihrer Übereinstimmung oder Nicht-Übereinstimmung mit einer vorgegebenen Handlungs-Norm, sondern ihr gesamtes Verhalten unter dem Gesichtspunkt der "Loyalität" zur Sozialgemeinschaft. Indem Tamar "Ehre und Leben aufs Spiel setzt"60, um ein Kind zu bekommen, das abstammungsmäßig zur Familie ihres verstorbenen Mannes gehört, verfolgt sie jedenfalls nicht nur ihre eigenen Interessen, 61 sondern auch die Interessen der Familie Ers an ihrer Reproduktion - und dies in einem Ausmaß, das "weit über bloße Pflichterfüllung hinaus"62 geht. Demgegenüber hat Juda mit seinem Verhalten (ebenso wie Onan) der Sozialgemeinschaft de facto geschadet, indem er

56 Zur Kritik des Verständnisses von pדצ als "normgemäßes Verhalten" s. K. KOCH, Art. "צ sdq gemeinschaftstreu/heilvoll sein," THAT II (21979) 507-530: 514f.

57 Sedaqa, nahestehende und entgegengesetzte Begriffe im Alten Testament, Diss. Uppsala 1932; z.T. abgedruckt in KOCH (Hg.) [A.55] 87-129.

58 Sdq [A.43]; vgl. DERS., Art. p צ [A.56].

59 [A.56] 513.

60 SOETE [A.10] 160.

61 SOETE [A.10] 159 meint: "Daß es Tamar um eigene Besitzverhältnisse ging, scheint nicht der Fall zu sein; bei der Familie Judas hatte sie offenbar völlig ihr Auskommen und ein geregeltes Leben." Vielleicht spiegelt sich jedoch in der Spannung zwischen V.11 (Tamar kehrt in die Familie ihres Vaters zurück) und V.24ff (Tamar gehört als Schwiegertochter Judas zu dessen Familie) auch die Unsicherheit ihrer sozialen und rechtlichen Position, die erst durch die Geburt ihrer gemeinsamen Kinder mit Juda beseitigt wird.

${ }^{62} \mathrm{KOCH}$ [A.56] 513. 
ihre Reproduktion durch eine Schwagerehe zwischen Tamar und Schela verhindert hat.

Das abschließende Urteil Judas über Tamar in V.26 deutet also ein ethisches Orientierungssystem an, in dem die Komplexität der ethischen Entscheidungs-Situation reduziert wird: die Sozialgemeinschaft der (Groß)Familie. Insofern fungiert צ förderlichen Verhaltens hier als eine Art "Grundnorm"63, von der aus die Einzel-Normen im Hintergrund des Textes kritisch relativiert werden. ${ }^{64}$ Sie unterscheidet sich von solchen Einzel-Normen jedoch dadurch, daß sie nicht bestimmte Handlungen oder Verhaltensweisen vorschreibt bzw. verbietet, sondern Handlungen oder Verhaltensweisen unter dem Gesichtspunkt ihrer Wirkung auf die Sozialgemeinschaft beurteilt.

Darin liegt freilich in Gen 38 zugleich ihre Aporie: Auch Juda ging es ja bei seiner Hinauszögerung der Schwagerehe zwischen Tamar und Schela um die Sicherung des Bestandes seiner Familie, der ihm durch Tamar bedroht erschien (V.11). Als "nicht-gemeinschafts-förderlich" hat sich sein Handeln erst nachträglich erwiesen (V.26). So ermöglicht das Kriterium eines gemeinschafts-förderlichen Verhaltens hier zwar im Rückblick ("evaluativ") eine eindeutige ethische Beurteilung des Handelns Judas und Tamars; demgegenüber erweist sich jedoch seine ("präskriptive") Orientierungs-Leistung im Blick auf die Entscheidung zwischen alternativen Handlungs-Möglichkeiten als begrenzt. Insofern hat auch die "Gemeinschaftstreue" (צדקה - צדק) Anteil an der Komplexität ethischer Entscheidungs-Situationen, die für den Menschen nicht völlig reduzierbar ist, wie der Text im Vorhergehenden zeigte.

\section{KRITIK UND TOLERANZ}

Mit seiner kunstvollen Kombination mehrerer Handlungen verschiedener Akteure, die aus unterschiedlichen Motiven handeln und dabei mit verschiedenen Normen in Komflikt geraten, regt Gen 38 seine Leser zu einer kritischen Reflexion ethischer Grundprobleme an. Der Text zeigt die Schwierigkeiten, die sich bei der Anwendung ethischer Normen in konkreten - für den Menschen meist schwer durchschaubaren - Entscheidungssituationen ergeben. Er macht auf die Probleme des "theologischen" (bzw. "religiösen") Postulats einer "sittlichen Weltordnung" aufmerksam. Und auch der "Wert"-Begriff der "Gemeinschaftstreue", den die Erzählung am Ende als "Lösung" anbietet, ermöglicht in der Sicht des Textes nur eine begrenzte ethische Orientierung. Das alles zeigt einen erstaunlichen Grad an kritischer Reflexion, die hier in

63 Vgl. WÜRTHWEIN/MERK [A.39] 37ff.

64 Vgl. SOETE [A.10] 160. Ob "șdq hier ... unter Berücksichtigung einer Werte- und Güterordnung gebraucht ist" (ebd.), erscheint mir allerdings fraglich. 
scheinbar "harmloser", narrativer Form vorgeführt wird.65 Es besteht Anlaß zu der Vermutung, daß diese Kritik hier nicht "um ihrer selbst willen" entwickelt wird, sondern auf konkrete sittliche Lebensformen und die ihnen zugrundeliegenden ethischen Orientierungssysteme zielt.

Im Vergleich mit anderen Texten des AT fällt es nämlich auf, wie unbefangen Gen 38 von den engen Beziehungen zwischen Juda und der kanaanäischen Bevölkerung seines Siedlungsgebietes - bis hin zur Verschwägerung - spricht: Juda heiratet eine Kanaanäerin (V.2) und gibt mit Tamar seinem Sohn Er wohl ebenfalls eine Kanaanäerin zur Frau (V.6).66 Ein derartiges Verhalten wird an anderen Stellen des AT ausdrücklich verboten (Ex 34,11-16; Dtn 7,1-7) bzw. scharf kritisiert (Jos 23,12f; Ri 3,5f; vgl. 1 Kön 11,1-8; Ps 106,34-39) und von den übrigen "Erzvätern" Israels (mit Ausnahme von Joseph: Gen 41,45 !) peinlich vermieden (Gen 24,3f; 26,34f; 28,1f.6-9). Die Bücher Esra (9-10) und Nehemia $(10,31 ; 13,1-3.23-29)$ dokumentieren - unabhängig vom Urteil über die "Historizität" des dort berichteten - Tendenzen zu einer rigorosen $\mathrm{Ab}$ lehnung der Exogamie.

65 Trifft diese Interpretation zu, steht die Funktion dieses Textes als "Lehrstück" in Opposition zur Funktion der sog. ("weisheitlichen") "Lehrerzählung", die H.-P. MŨLLER ("Die weisheitliche Lehrerzählung im Alten Testament und seiner Umwelt," WO 9 [1977/78] 77-98) folgendermaßen beschrieben hat: "(1) Mittels des sie verkörpernden Helden bringt sie eine Tugend oder einen Komplex von Tugenden zu paradigmatischer Darstellung. (2) Sie interpretiert die Wirklichkeit nach Maßgabe eines Ordnungspostulats, auf Grund dessen die dargestellte Tugend als sinnvoll erscheint" (94f). "Ihre Unverwechselbarkeit beruht auf der Orientierung an einem sittlichen Weltordnungspostulat, das der Gottheit wie dem Menschen ihre Rollen vorschreibt: beide müssen im Sinne einer weisheitlichen Retributionstheorie einander Gerechtigkeit widerfahren lassen, der Mensch durch die Bewährung seiner Tugend, die Gottheit durch deren Bestätigung mittels der Wirklichkeit" (97). - Anders als in den ("weisheitlichen") "Lehrerzählungen" stehen sich Juda und Tamar in Gen 38 nicht als "Held(in)" und "Antiheld(in)" gegenüber; der Konflikt wird hier nicht durch "Tugendbewährung" bewältigt; die verschiedenen "(Un)Tugenden" der Akteure - bis hin zur "Gemeinschaftstreue" (צד) - erweisen sich als ambivalent; und die Konfliktlösung kommt ohne Bestrafung eines "Antihelden" und ohne Eingreifen der Gottheit zustande. Wie in den ("weisheitlichen") "Lehrerzählungen" wird auch in Gen 38 individuelles Handeln vor dem Hintergrund "sittlicher Ordnun$\mathrm{g}(\mathrm{en})$ " betrachtet; dabei werden aber Spannungen und Ambivalenzen nicht aufgelöst, sondern aufgezeigt und festgehalten. - Als vergleichbare "Lehrstücke" im AT wären m.E. etwa Texte wie Koh 4,14-16; 9,15f anzusprechen; das vorliegende Hiob-Buch könnte vielleicht als Produkt der Umgestaltung einer "Lehrerzählung" zu einem "Lehrstück" verstanden werden.

66 S. E. BLUM, Die Komposition der Vätergeschichte, WMANT 57, Neukirchen-Vluyn 1984, 225 (mit Verweis auf EMERTON [A.11: VT 26] 90ff). "Geradezu notwendig ist diese Annahme, sofern die Geschichte im Kontext unserer Vätergeschichte gelesen wird, da es nach deren Erzählfiktion im Lande keine verwandte Frau für Juda geben konnte. Diese Voraussetzung gilt freilich nicht unbedingt für die selbständige Einzelerzählung" (BLUM, ebd. Anm.7). 
Sie zeigen darüber hinaus, daß diese sittliche Lebensform einer rigorosen Abgrenzung nach außen begründet werden konnte mit der Berufung auf die Bestimmungen des mosaischen "Gesetzes" als Kodex ethischer Normen (vgl. Esr 9,4; 10,3; Neh 10,30f; 13,1-3). Die einschlägigen Gesetzes-Bestimmungen in Ex 34,11-16 und Dtn 7,1-7 begründen sie ihrerseits mit dem Verweis auf die exklusive "religiöse" Bindung der Sozialgemeinschaft Israel an ihren Gott Jahwe. Ex 34,16 begründet das Verbot, seine Söhne mit Töchtern der nicht-israelitischen Landesbewohner $\mathrm{zu}$ verheiraten, folgendermaßen:

"Wenn dann ihre Töchter mit ihren Göttern Unzucht treiben (7rt), könnten sie auch deine Söhne dazu verleiten, mit ihren Göttern Unzucht zu treiben (הנה hi.)" (vgl. Dtn 7,4).

Gen 38 kann nun als gezielte Kritik dieser sittlichen Lebensform und des ihr zugrundeliegenden ethischen Orientierungssystems gelesen werden:

1. Die Berufung auf ethische Normen, die im "Gesetz" vorgegeben sind, wird kritisch in Frage gestellt durch den Aufweis der vielfältigen Schwierigkeiten, die sich bei der Anwendung ethischer Normen in konkreten Entscheidungs-Situationen ergeben können.

2. Die "religiöse" bzw. "theologische" Legitimation einer rigorosen Abgrenzung nach außen wird problematisiert: Konnte ein Leser im Falle Ers zunächst noch denken, er mißfalle Jahwe, weil er ein "Halb-Kanaanäer" ist (V.7), macht der Text doch sogleich bei Onan deutlich, daß Jahwe bei seiner Beurteilung eines Menschen nicht nach dessen ethnischer Zugehörigkeit fragt, sondern nach der ethischen Qualität seines Verhaltens (V.10). Darüber hinaus wird durch den Aufweis der Probleme, die sich durch göttliche Eingriffe zur Stützung einer "sittlichen Weltordnung" für die ethische Orientierung des Menschen ergeben, vielleicht eine noch grundsätzlichere Kritik an einer zu engen Verbindung von "Ethik" und "Theologie" bzw. "Religion" angedeutet.

3. Die Bedeutung der Sozialgemeinschaft als Orientierungsrahmen wird in ethnischer wie in ethischer Hinsicht kritisch relativiert: Die Kanaanäerin (?) Tamar zeigt ein höheres Maß an "Gemeinschaftstreue" als Juda; und was für die Gemeinschaft letztlich förderlich oder abträglich ist, ist nicht immer auf den ersten Blick zu erkennen!

4. Die Erzählung von der Verführung Judas durch die vermeintliche (Kult)Prostituierte Tamar kann geradezu als Parodie auf die Befürchtung gelesen werden, fremde Frauen könnten die Israeliten zum "Götzendienst" verführen - zumal wenn der von Juda der Tamar versprochene Ziegenbock als "Hetärenopfer im Dienst der Liebesgöttin"67 verstanden wurde: Tamar hat Juda in der Tat "verführt" - aber nur zum Wohle seiner Sippe!

67 WESTERMANN [A.20] 48. 
Diese Beobachtungen legen es m.E. nahe, wenigstens mit der Möglichkeit zu rechnen, daß Gen 38 seine vorliegende Gestalt ${ }^{68}$ im Zusammenhang der nachexilischen Diskussion über die Möglichkeit eines Konnubiums mit Nicht-Judäern bzw. Nicht-Juden erhalten hat. In dieser Diskussion würde der Text dann nicht nur gegen ein rigoroses Exogamieverbot Position beziehen, sondern diese Position auch durch eine kritische Reflexion ethischer Grundprobleme argumentativ begründen.

In der Forschung wird das Fehlen von Abgrenzungstendenzen im Text häufig mit der Annahme seiner Entstehung unter den Bedingungen "eines gutnachbarlichen Zusammenlebens (und Konnubiums) zwischen Judäern und Kanaanäern in der nördlichen Schephela zu erklären" versucht. ${ }^{69}$ So meint etwa C. WESTERMANN ${ }^{70}$ : "Das beweist den frühen Ursprung der Erzählung; sie entstand in einer Zeit, in der noch niemand daran Anstoß nahm. Anders ist es in 24,3; Gn 24 muß daher später entstanden sein als Gn 38 ..." Mit dieser Erklärung durch die Situation der Produktion des Textes entsteht jedoch sogleich ein neues Problem im Blick auf seine Rezeption, das WESTERMANN (ebd.) selbst andeutet: "Erstaunlich ist, daß die frühe Verbindung mit Kanaanäern und das Konnubium mit ihnen in dieser Erzählung in einer langen Traditionsgeschichte erhalten blieb." Wenn nun aber in der Endphase der produktiven Gestaltung des Pentateuchs in nachexilischer Zeit das Problem der ethnischen Abgrenzung "Israels" und der "Mischehen" mit "fremden Frauen" in besonderer Weise virulent wurde (vgl. Esr 9f; Neh 10,31; 13,1-3. 23-29) und die Option gegen ein Konnubium in Gen 24,3f; 26,34f und 28,1f. 6-9 ihren literarischen Niederschlag gefunden hat ${ }^{71}$, dürfte mindestens damit zu rechnen sein, daß Gen 38 unabhängig von seiner Entstehungszeit - als Stellungnahme gegen eine rigorose ethnische Abgrenzung rezipiert wurde.

Dafür spricht auch ein Vergleich mit dem Buch Rut: Hier wird nicht nur explizit auf Gen 38 verwiesen (Rut 4,12).

"Darüber hinaus entsprechen sich wesentliche Züge der Handlung: In Juda (bei Ruth im ro $\mathrm{m}_{\text {) }}$ ist durch den Tod der Männer die Fortführung der Sippe in Frage gestellt. Beide Male wird diese 'Gefährdung' durch die

${ }^{68} \mathrm{DaB}$ es sich bei Gen 38 um "eine überlieferungsgeschichtlich einheitliche Erzählung" handelt, wie BLUM ([A.66] 224) "(m)it den meisten Auslegern" annimmt, erscheint mir eher unwahrscheinlich. Daß der Text kaum der (mittlerweile ohnehin fragwürdigen) "Quellenschrift J" zugeordnet werden kann, hat WESTERMANN ([A.20] 42f) m.E. überzeugend gezeigt. Indizien für ein literarisches Wachstum des Textes könnten neben der "relative(n) Eigenständigkeit von 1-11 und 27-30" gegenüber V.12-26 (WESTERMANN [A.20] 43) u.a. im Nachtrags-Charakter von V.14b, im terminologischen Wechsel von הis (V.15) zu חซาp (V.21f) und im Fehlen des Namens "Hira" in V.20ff vorliegen. Im Blick auf die weitere (vor-literarische) Überlieferungsgeschichte des Textes bleiben m.E. die Hinweise GUNKELs ([A.17] 419f) auf die verschiedenen hier verarbeiteten "Motive" sowie auf Hos 12,1b als mögliches Zeugnis für eine ältere Überlieferungsstufe von Gen 38 (a.a.O. 411) weiterhin erwägenswert (vgl. auch Hos 4,14?).

${ }^{69}$ BLUM [A.66] 225 (mit Hinweis auf M. NOTH, Überlieferungsgeschichte des Pentateuch, Stuttgart 1948, 163 mit Anm.424 und EMERTON [A.11: VT 29] 411).

70 [A.20] 45; ähnlich z.B. GUNKEL [A.17] 412.

71 So jedenfalls BLUM [A.66] 386f. 427. 453, der in Gen 24; 26,34f und 27,46-28,9 einen Reflex der "nachexilischen Mischehenproblematik" erkennt. Vgl. auch B. DIEBNER/H. SCHULT, "Die Ehen der Erzväter," DBAT 8 (1975) 2-10, die allerdings mit ihrer Interpretation von Gen 38 als Votum gegen "ein Konnubium mit 'Kanaanäern'" (9 Anm.23) die Pointe dieses Textes m.E. verfehlen. 
außergewöhnliche Initiative einer nicht-israelitischen Frau (beide 'verführen' den betreffenden Mann) überwunden. Zudem geht es auch bei Ruth um ein der Leviratsehe vergleichbares Problem. Vor allem aber zielt die Ruth-Novelle am Ende auf die Genealogie Davids $(4,17)$ und rezipiert demnach Gen 38 auch unter dieser Perspektive."72

Nun ist allerdings die "(w)eit verbreitet(e)" und "z.B. von BERTHOLET, ROST und WEISER vertretene Ansicht", im Buch Rut komme "eine antirigoristische, gegen die von Esra und Nehemia geübte Auflösung der Mischehen gerichtete Tendenz" zum Ausdruck ${ }^{73}$, keineswegs unumstritten. Dagegen meint etwa O. KAISER (im Anschluß an E. WÜRTHWEIN), "daß der hesed, die Treue, im Mittelpunkt der Erzählung steht, vgl. 1,8$\beta$; 2,20 und 3,10"; daß Rut Ausländerin ist, ist s.E. für den Erzähler nur insofern von Bedeutung, als es ihm "die Möglichkeit" gibt, "die Bedeutung des hesed an dem Grenzfall besonders eindrücklich zu zeigen, vgl. 1,16 und 3,10."74 Doch lassen Rut 2,10 und 4,675 das Problem des Ressentiments gegenüber Ausländern mindestens anklingen. Und die in Rut 4,18ff wohl sekundär angehängte und durch 4,17b mit der Erzählung verklammerte $\mathrm{Ge}$ nealogie Davids (vgl. $1 \mathrm{Chr} 2,9-15)^{76}$ ist als zusätzliche Legitimation der Möglichkeit des Konnubiums mindestens ebensogut erklärbar wie als Versuch, "die fehlende Geburtslegende Davids beizubringen"77. So bleibt es m.E. doch wahrscheinlich, daß das Buch Rut sich - mindestens unter anderem auch - kritisch mit zeitgenössischen Tendenzen im nachexilischen Judentum auseinandersetzt, die eine Exogamie rigoros ablehnen. Dann zeigen aber die Anklänge an Gen $38 \mathrm{im}$ Buch Rut, daß die Erzählung von Juda und Tamar als Votum gegen eine rigorose Abgrenzung nach außen verstanden werden konnte.

Ein weiteres Indiz dafür könnte schließlich die redaktionelle Einordnung von Gen 38 in die Josephs-Geschichte sein. ${ }^{78}$ Sie ist zwar bereits erzähltechnisch hinreichend erklärbar: "in der Josephssage liegt nach Kap. 37 eine Zeit, wo wir nichts von den Brüdern hören: in dieser Zeit wird - so dachte der Einsetzer - die Geschichte Kap. 38 geschehen sein."79 Sie könnte aber darüber hinaus auch dadurch motiviert sein, daß Gen 38

72 BLUM [A.66] 227. Möglicherweise enthält Gen 38 neben einer (impliziten) "Ätiologie ... der Vorrangstellung von Davids Geschlecht innerhalb Judas" (in V.27ff, a.a.O. 226) noch weitere "versteckte Hinweise auf David" (s. a.a.O. 227).

73 O. KAISER, Einleitung in das Alte Testament, Gütersloh 51984 , 196; vgl. z.B. M. SMITH, Palestinian Parties and Politics That Shaped the Old Testament, New York/ London 1971, 161f; C. MESTERS, Der Fall Rut, Erlangen 1988.

74 KAISER [A.73] 197; vgl. E. WÜRTHWEIN, "Ruth," DERS./K. GALLING/O. PLÖGER, Die fünf Megilloth, HAT I/18, Tübingen 21969, 1-24: 5f. Gegen WÜRTHWEIN hält KAISER ([A.73] 198) freilich an einer "Spätdatierung" des Buches fest.

75 Hier ist es wenigstens denkbar, daß der "Löser" die Heirat mit Rut u.a. deswegegen ablehnt, weil "er die Ausländerin scheut" (WÜRTHWEIN [A.74] 22).

76 Vgl. KAISER [A.73] 196.

77 So KAISER, ebd.

78 S. dazu etwa G.W. COATS, "Redactional Unity in Genesis 37-50," JBL 93 (1974) 15-21: 16f; W. DIETRICH, Die Josephserzählung als Novelle und Geschichtsschreibung; Zugleich ein Beitrag zur Pentateuchfrage, BThSt 14, Neukirchen-Vluyn 1989, 51 mit Anm. 144. Die Spekulationen von CARMICHAEL [A.33] 59ff und G.R.H. WRIGHT, "The Positioning of Genesis 38," ZAW 94 (1982) 523-529 erscheinen mir doch eher unwahrscheinlich.

79 GUNKEL [A.17] 411. 
ebenso wie die Josephs-Geschichte ${ }^{80}$ und im Gegensatz zu den Väter-Erzählungen in Gen 12-36 als Votum gegen ein rigoroses Exogamieverbot verstanden wurde.

Angesichts dieser Hinweise auf eine Rezeption von Gen 38 als kritische Stellungnahme gegen Tendenzen einer rigorosen Abgrenzung nach außen erscheint mir die Annahme, daß dieser Gesichtspunkt schon bei der Produktion des Textes in seiner jetzt vorliegenden Gestalt eine Rolle gespielt haben könnte, mindestens erwägenswert.

Trifft die hier vorgeschlagene sozialgeschichtliche Einordnung der Endgestalt von Gen 38 als Stellungnahme gegen eine rigorose Abgrenzung der israelitischen (bzw. früh-jüdischen) Sozialgemeinschaft nach außen zu, zeigt dieser Text beispielhaft, wie eine (selbst)kritische Reflexion ethischer Traditionen zu einer "toleranten" Praxis führen kann - ohne dabei auf jegliche ethische Orientierung $\mathrm{zu}$ verzichten. Insofern kann er m.E. als ein "Lehrstück" ethischer Reflexion im AT gelten: Die Vielzahl und Komplexität der Probleme ethischer Orientierung, die in diesem Text erkennbar werden, setzt Maßstäbe auch für die gegenwärtige Reflexion ethischer Fragen in kritischer Auseinandersetzung mit den Traditionen des AT.

80 Vgl. DIEBNER/SCHULT [A.71] 9 Anm.18: "Aus dem Rahmen fällt Josephs Verhaiten. Er heiratet eine Ägypterin (Gn 41,45). Seine Kinder aus dieser Ehe $(41,50-52)$ werden nachträglich den Söhnen Jakobs gleichgestellt $(48,6)$." 


\title{
DIE DREI WICHTIGSTEN QUMRANPARALLELEN ZUM GALATERBRIEF \\ Unbekannte Wege der Tradition
}

\author{
von \\ Heinz-Wolfgang Kuhn \\ Evang.-Theol. Fakultät, Ludwig-Maximilians-Universität München
}

Die folgenden drei Parallelen gehören zu den zehn wichtigsten in den sieben authentischen Paulusbriefen. Das ist das Ergebnis einer Sichtung der in der bisherigen Forschung herangezogenen Vergleichsstellen, die Mitarbeiter von mir und ich vor Jahren begonnen haben. Eine knappe Charakterisierung dieser zehn Stellen habe ich auf dem Qumran-Symposium in Haifa/Tel Aviv im März 1988 vorgetragen $^{1}$ und lege hier zum ersten Mal eine ausführliche Fassung für die drei Galaterstellen vor, und zwar schon in der Form, wie sie später in Buchform veröffentlicht werden soll. Aus dem in Heidelberg begonnenen und in München fortgeführten Projekt "Qumran und das Neue Testament" ist auch der vermutlich älteste Paulusbrief, der 1 . Thessalonicherbrief, bereits vorgestellt worden (auf dem internationalen Qumran-Kongre $B$ bei Madrid im März 1991)2. Der Galaterbrief im Ganzen und insbesondere die hier nicht behandelten Parallelen sollen im Juli 1992 in Paris bei der Gründung der internationalen Organisation für die QumranForschung (IOQS) vorgetragen werden.

Das folgende ist so angelegt - und das ist mir methodisch besonders wichtig -, daß immer bestimmte neutestamentliche Stellen, in diesem Falle aus dem Galaterbrief, mit bestimmten Qumranstellen verglichen werden. Öfter werden in der bisherigen Forschung die jeweiligen Einzelstellen in den Qumrantexten und im Neuen Testament vernachlässigt und lieber Thesen und Themen im Zusammenhang eines Vergleichs relativ abstrakt (unter bloßer Nennung einiger Stellen) abgehandelt. Die Fragestellung des Projekts "Qumran und das Neue Testament" ist also immer: Für welche ganz bestimmten Aussagen im Neuen Testament stellen ein oder mehrere Qumrantexte eine gewisse Parallele und damit auch eine Hilfestellung in der Interpretation dar? An konkreten einzelnen Stellen (und gegebenenfalls bestimmten archäologischen Er-

1 Die Veröffentlichung ist vorgesehen in: Devorah DIMANT und Ulrich RAPPAPORT (Hg.), The Dead Sea Scrolls: Forty Years of Research. Jerusalem, unter dem Titel: "The Impact of the Qumran Scrolls on the Understanding of Paul".

2 Die Veröffentlichung ist unter dem Titel "Die Bedeutung der Qumrantexte für das Verständnis des Ersten Thessalonicherbriefes: Vorstellung des Münchener Projekts "Qumran und das Neue Testament" " (mit englischer Einleitung und Zusammenfassung) in einem Band mit Beiträgen des Kongresses vorgesehen. 
kenntnissen) müssen sich alle Hypothesen, die solche Vergleiche ziehen, bewähren.

Es ist auch zu beachten, daß der Begriff "Qumran" kein einheitliches Schriftkorpus meint. Nicht nur ist für die in der Qumrangemeinde (nur in Chirbet Qumran am Toten Meer?) entstandenen Schriften (unbestritten insbesondere 1QS, 1QH und alle Pescharim) eine Entwicklung zwischen der Mitte des 2. Jh.v.Chr. und den ersten Jahren des ersten Jüdischen Krieges (ab $66 \mathrm{n}$.Chr.) anzunehmen, sondern es ist bekanntlich auch damit zu rechnen, daß ein großer Teil der ca. 800 Schriften aus den Höhlen I-XI in die Qumranbibliothek mehr oder weniger von außen eingebracht wurde. Selbst innerhalb der eigentlichen Qumrantexte können Stücke aufgenommen worden sein, die vorqumranisch sind (das ist z.B. für den unten unter $\mathrm{Gal}$ 5,16-23 behandelten Text aus $1 \mathrm{QS}$ immerhin vermutet worden).

Methodisch ist ferner bei einem Vergleich zu bedenken, daß wir nur einen Bruchteil der jüdischen Texte jener Zeit kennen und selbst Anschauungen, die wir frühjüdisch nur für Qumran belegen können, durchaus damals auch allgemeiner jüdisch verbreitet waren (das gilt z.B. sicherlich für das unten zum zweiten Galatertext, d.h. 3,13, Gesagte). Auch mit Parallelbildungen im frühen Judentum und im Urchristentum aufgrund des gleichen biblischen (d.h. alttestamentlichen) und jüdisch-zeitgenössischen Hintergrunds ist natürlich zu rechnen.

Für das Projekt "Qumran und das Neue Testament" ist deshalb nicht maßgebend, ob eine auch nur indirekte Beeinflussung eines urchristlichen Autors durch die Qumrangemeinde vorliegt, sondern allein, ob ein - abgesehen von der sog. Damaskusschrift (CD) - nun zum ersten $\mathrm{Mal}$ in der Originalsprache vorliegender jüdischer Text aus der Qumranbibliothek, der auch außerhalb der Qumrangemeinde entstanden sein mag, die Interpretation neutestamentlicher Texte fördern kann. Die Beschränkung auf die Texte aus dem Korpus der Qumranbibliothek hat zum großen Teil einfach den praktischen Grund der Überschaubarkeit und wenigstens relativen inhaltlichen und zeitlichen $\mathrm{Zu}$ sammengehörigkeit. Nur mit solchen Einschränkungen und einer methodischen Vorsicht in der eben genannten Weise kann z.Zt. an "Parallelen" zwischen Qumrantexten und dem urchristlichen Schrifttum gearbeitet werden. Freilich schließen die genannten Unsicherheiten nicht aus, daß da und dort festgestellt oder wenigstens vermutet werden kann, eine Anschauung sei spezifisch qumranisch oder allgemeiner jüdisch. Man möge auch bedenken - und das gilt sowohl für den, der spezieller an den Qumrantexten als auch für den, der spezieller am Neuen Testament interessiert ist -, daß ein Vergleich verwandter oder auch nur scheinbar verwandter Aussagen in jedem Fall die Sicht für die Besonderheiten des jeweiligen Textes schärft. Und schon das ist nicht wenig! Bescheidenheit bei religionsgeschichtlich-kausalen Urteilen, die nicht aus Bequemlichkeit resultiert, ist also durchaus angebracht. Nach den 
nächsten religionsgeschichtlichen Parallelen eines Textes muß man aber durchaus fragen (s. den unten an dritter Stelle besprochenen Galatertext 5,16-23).

\section{3,11 AUSLEGUNG VON HAB 2,4b}

Es geht hier nicht, wie in der Regel bei den in diesem Forschungsertrag herangezogenen Qumranstellen, primär um die Nähe einer ntl. Aussage zu diesen Schriften, sondern darum, daß für eine Bibelstelle (Hab 2,4), die für Paulus im Zusammenhang seiner Rechtfertigungsaussagen ein entscheidendes Argument ist, eine zeitgenössische jüdische Auslegung zur Verfügung steht.

\section{QpHab VII 17 (oder 18) 3 -VIII 3}

[..."Aber der Gerechte wird aufgrund seines Vertrauens 4 leben (ronks p p in') (Hab 2,4b)".] VIII 1Seine Deutung (sc. des Bibeltextes) bezieht sich auf alle Täter der Tora (סל פוש דרוּה) im Haus Juda, die ${ }^{2}$ Gott erretten wird (יצי) aus der Stätte (wörtlich: aus dem Haus) des Gerichts ${ }^{5}$ wegen ihrer

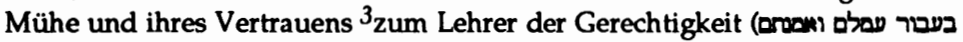
(בטרד דצר).

Der angeführte Text fährt mit der Zitierung von Hab 2,5f fort; vorher wird in Kol. VII in $\mathrm{Zl}$. 14 bis zur letzten Zeile dieser Kolumne Hab 2,4a angeführt und kommentiert. Während der Qumrankommentar auch die הusk zum "Tun" der Tora zählt (vgl. syrBar 54,16), trennt Paulus hier und in Röm 1,17, wo Hab 2,4b noch einmal zitiert wird,

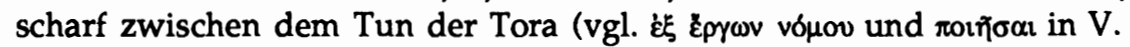

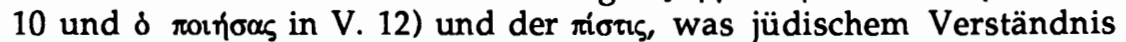
nicht entspricht (vgl. dazu auch unter Lit.). Im Qumrantext wird das Tun der Tora ausdrücklich als Heilsweg verstanden (die "Täter der Tora" werden im Gericht "errettet"). Die Fixierung der i.S. von "Ver-

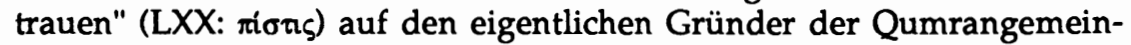
de, den Lehrer der Gerechtigkeit, als einer Art menschlicher Heilsgestalt ist im jüdischen Denken der Spätantike bisher analogielos (vgl. G. JERE-

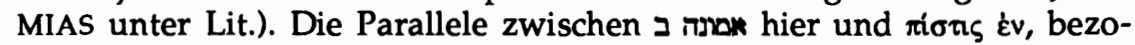
gen auf Jesus Christus, in den Deuteropaulinen - riotis \&v findet sich

${ }^{3}$ ELLIGER, Studien, passim, nahm an, daß 1 QpHab jeweils 18 Zeilen je Kolumne (statt nur 17) umfaßte (maximal 16 Zeilen sind erhalten). Mit nur 17 Zeilen für Kol. VII rechnet LOHSE, Texte (trotz seiner Einleitung 227: "durchschnittlich je 18 Zeilen"; für keine Kolumne druckt LOHSE eine vermutete Zl. 18). BROWNLEE, Midrasch 54 läßt die Frage für $1 \mathrm{QpHab}$ offen, druckt aber immer nur 17 Zeilen. HORGAN, Pesharim, zieht immer 17 Zeilen vor (vgl. bei ihm auch 23). KNIBB, Community 221 spricht von "apparently seventeen lines" für $1 \mathrm{QpHab}$.

4 So ist das Wort im folgenden Kommentar gedeutet; ursprünglich ist die "Treue" des Gerechten gemeint.

5 Offenbar ist die Stätte des eschatologischen Gerichts gemeint; vgl. unmittelbar vorher VII 16. Die Wendung "Haus des Gerichts" findet sich auch in X 3. 
nicht bei Paulus selbst (auch nicht in Gal 3,26) - und im 1. Clemensbrief $(22,1)$ wäre bei Kol 1,4 zu besprechen ("Glaube an Jesus Christus" o.ä. begegnet bei Paulus mit Gen. obj., z.B. Gal 3,22, oder in Phlm 5 mit $\pi p \delta \varsigma)$.

Hab 2,4b hat für die paulinischen Rechtfertigungsaussagen eine herausragende Bedeutung, so daß Paulus die Bibelstelle noch einmal, und zwar sogar in der Nennung des Themas für den Römerbrief in Röm 1,17 anführt (dort im Gegensatz zu Gal 3,11 mit Zitationsformel). In beiden Fällen lehnt sich Paulus im Wortlaut an die LXX an (LXX: $\delta \delta \varepsilon$

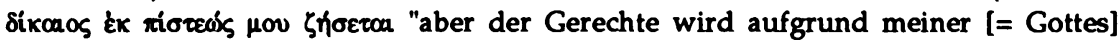
Treue [oder: der Treue gegen mich] leben"). Jedoch läßt Paulus im Galaterbrief nicht nur das $\delta \varepsilon$ aus, sondern in beiden Briefen vor allem auch das $\mu 00$. Das bedeutet, daß Paulus das Verständnis der Stelle gegen das nicht eindeutige $\mu$ ơ der LXX ihrem ursprünglichen Sinn wieder annähert. Sollte Paulus hier eine andere Lesart in seiner Bibel vorgefunden haben (einige unbedeutende Hss. lassen $\mu 00$ aus)? Ähnlich liegt der Fall vom Sinn her in Hebr 10,38, wo $\mu 00$ an síxouos angehängt ist: "Aber mein Gerechter wird aus Glauben leben". Während in Gal 3,11b das Habakukzitat wohl entsprechend der atl. Syntax des Satzes zu übersetzen ist ("der Gerechte wird aufgrund des Glaubens leben", in chiasti-

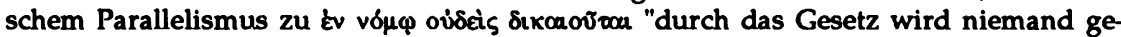
rechtgesprochen" in V. 11a), könnte der Sinn in Röm 1,17b bereits verchristlicht sein: "Der aus Glauben Gerechte wird vielmehr leben" (vgl. Röm 5,1 u.a.). Aber diese Deutung ist eher unwahrscheinlich, weil von der Parallelität zwischen V. 17b und V. 17a her am ehesten jeweils zwei Nomina, nämlich "Gerechtigkeit" bzw. "der Gerechte" und "Glaube", als selbständige Größen erscheinen: (1) Die eschatologische Gerechtigkeit Gottes wird jetzt schon, jedoch nur im Bereich des Glaubens offenbar. (2) Auch individuell formuliert lebt "der Gerechte" nur "aufgrund des Glaubens".

Lit.: Bei den Exegeten des Galater- und Römerbriefes ist der Verweis auf unsere Qumranstelle zur Pflicht geworden (z.B. MUSSNER, Gal. 227; KÄSEMANN, Röm. 28f; CRANFIELD, Röm. 101; BRUCE, Gal. 162; H.D. BETZ, Gal. 267 Anm. 81 [engl.: 147 Anm. 85]). - G. JEREMIAS, Lehrer 145f weist in einer ausführlichen Darstellung auch auf den theologischen Unterschied zwischen der Stelle im Pescher Habakuk und dem Neuen Testament hin; S. 144 spricht er von der "Kluft von Gesetz und Evangelium" (richtig müßte es heißen: " ... Gesetz und Glaube"); auf S. 145 ist noch zu polemisch gegenüber dem Judentum formuliert. Ebd. stellt JEREMIAS m.R. fest, daß pHab VIII $2 f$ "die einzige bisher bekannte Stelle" ist, "in der im Judentum die von pHab 2,4 [1. Hab 2,4] auf eine Person bezogen wird" (von KÄSEMANN, Röm. 29 aufgegriffen). DANIÉLOU, Manuscrits 94 hebt ebenfalls den theologischen Unterschied zwischen Paulus und Qumran hervor: "Dans un cas la foi est opposée à la Loi, dans l'autre elle est liée à la Loi". Überflüssig ist die vorsichtige Vermutung DANIÉLOUs, daß Paulus hier gegen qumranisches Denken polemisiere, weil es hier sicherlich um ein allgemeinjüdisches Verständnis geht. - MUSSNER, Gal. 227 sagt, auch im Blick auf 1QpHab: "Der Jude wird ihm [sc. Paulus] deshalb [sc. wegen seines Verständnisses von $\pi i \sigma \pi \zeta]$ seine Auslegung nicht abnehmen". - FITZMYER, Advance 236-246 hat wegen des Qumrantextes dem Verhältnis von Hab 2,3f zum NT einen eigenen Aufsatz gewidmet (sorgfältige exegetische Diskussion vieler Einzelfragen); für Paulus stellt er S. 242 fest: "he fills that word [sc. rionc] with his own Christian meaning of 'faith"'. 


\section{3,13 DTN 21,22f AUF DIE KREUZESSTRAFE BEZOGEN}

\section{QT LXIV 6-13}

Volksverrätern (Zl. 6-9) und Überläufern (Zl. 9-13) wird hier die Kreuzesstrafe angedroht. Der Abschnitt lehnt sich vor allem an Dtn 21, $22 \mathrm{f}$ an (der masoretische Text dieser Stelle steht in der folgenden Übersetzung in Kursive); dabei wird der biblische Text zweimal in der Weise in der Tempelrolle verändert, daß die Reihenfolge von Tod und Aufhängen am Pfahl umgekehrt wird, damit die Stelle auf eine Todesstrafe durch "Aufhängen" paßt (in Dtn 21,22f geht es darum, daß ein bereits Getöteter zur zusätzlichen Bestrafung auch noch am Pfahl aufgehängt wird).

"(V. 22) Wenn 7ein Mensch" als "Verräter (eigentl. Verleumder) in" seinem "Volk (Lev 19,16)" auftritt, dabei sein Volk einem fremden Volk preisgibt und unter seinem Volk Böses tut, 8"dann sollt" ihr "ihn ans Holz hängen", so daß er "stirbt". "Aufgrund von zwei Zeugen oder aufgrund von drei Zeugen

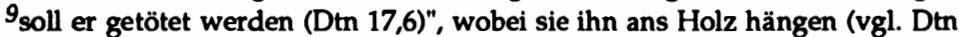
17,7).

"Wenn durch einen Menschen ein todeswürdiges Verbrechen geschieht", er dann in ${ }^{10}$ die Völkerwelt flieht und sein Volk, die Kinder Israels, verflucht, "dann sollt" ihr auch "ihn ans Holz hängen", ${ }^{11}$ so daß er "stirbt". Ihr "(V. 23) Leichnam soll nicht am Holz hängenbleiben, sondern du mußt" sie "am selben Tag begraben, denn" 12 wer am Holz "hängt", (gehört zu den) "von Gott" und von Menschen "Verfluchten, und du darfst das Land nicht verunreinigen, das" ich 13"dir zum Erbteil gebe".

\section{Q169 pNah 3-4 I 4-9}

Die schwer zu rekonstruierenden Zeilen $4 \mathrm{~b}-6 \mathrm{a}$ (selbst wenn man nur eine inhaltliche Rekonstruktion versucht) zitieren Nah 2,13a und geben dann eine Auslegung; die Zeilen $6 b-8 b \alpha$ enthalten den Bibeltext von Nah 2,13b und seine Deutung (in $\mathrm{Zl}$. $8 \mathrm{bB}$ bis vermutlich $\mathrm{Zl}$. 10a wird dann im folgenden Nah 2,14 zitiert, worauf sich im weiteren ebenfalls eine Auslegung anschließt). Mit dem "Zorneslöwen" (Zl. 5 und 6) ist offenbar der Hohepriester und König Alexander Jannaios (103-76 v.Chr.) gemeint. Sein Kriegsgegner, der Seleukide Demetrios III, wird in Zl. 2 ausdrücklich mit Namen genannt. Ihn hatten die Pharisäer (im Text erscheinen sie in Zl. 2 und 7 als "Schmeicheleisucher") zu Hilfe gerufen (s. ebenfalls bereits $\mathrm{Zl}$. 2), wofür sich Alexander Jannaios später an diesen durch die hier erwähnte Kreuzigung von 800 Aufständischen um 90 v.Chr. rächte (Josephus, Antiquitates 13,380-383; Bellum 1,96-98; S. dazu SCHÜRER, History I 223-225). 
[...] "(V. 13a) Der Löwe raubte nach Bedarf für seine Jungen und würgte (pana) für seine Lowinnen Beute ${ }^{6} . " 5$ [Seine Deutung (sc. des Bibeltextes) bezieht sich auf ...] auf (?) den Löwen des Zorns, der durch seine Mächtigen schlug und (durch) die Männer seines Rates ${ }^{6}[. . . "(V .13 b)$ Und so füllte er mit Raub] eine Felsklippe (BH: seine Höhlen) und sein Lager mit Zerrissenem." Seine Deutung (sc. des Bibeltextes) bezieht sich auf den Löwen des Zorns ${ }^{7}[\ldots]$ gründliche R[ache](?) an ${ }^{7}$ den Schmeicheleisuchern, indem er lebendige Menschen aufhängt ${ }^{8}[\mathrm{am} \mathrm{Holz}(?)$... es war Gesetz(?)] in Israel zuvor, denn von einem, der lebendig "a[m] Holz" "aufgehängt (Dtn 21,22f)" wird, lie[st man (in der Schrift)] ( ( [dich] oor, ${ }^{9}$ spr[icht Jahwe Zebaoth ...] ...".

Nimmt man jeweils die für den Vergleich mit Paulus ungünstigste Deutung der beiden Qumrantexte, so würde 11QT gar nicht von der Kreuzesstrafe handeln, sondern vom Galgen, und in $4 \mathrm{QpNah}$ wäre nicht von einem Gekreuzigten, sondern von einem, der kreuzigt, die Rede. Beides vertritt BAUMGARTEN in ErIs 1982, 7*-16*. Aber beide Deutungen überzeugen nicht. In der Zurückweisung der Ergebnisse BAUMGARTENs stimme ich HENGEL (Legende 27-36), einem hervorragenden Kenner der antiken Kreuzesstrafe, zu.

Zunächst zum oben zitierten Text der Tempelrolle: Wie es in Texten, die römische Bestrafungen anführen, bis zur Abschaffung der Kreuzesstrafe durch Konstantin d.Gr. offenbar keinen eindeutigen Beleg für eine römische Hinrichtung durch den Galgen gibt (s. H.-W. KUHN, ANRW II 25/1, 681f; zum "Aufhängen" am "arbor infelix" ebd. 686), so gilt das ebenfalls für das jüdische Recht in der rabbinischen Literatur und vorher; auch etwa Targum zu Ruth 1,17 (xיסיכת "Aufhängen am Holz") ist kein Beleg für den Galgen; der Tod durch "Erwürgen" (pr), der traditionsgeschichtlich hinter der Todesart hier steht, geschah nach jüdischem Recht jedenfalls nicht durch Aufhängen (s. z.B. mSan 7,3). Die in der rabbinischen Literatur öfter bezeugte Kreuzesstrafe (s. H. W. KUHN, a.a.O. 681f) konnte freilich von jüdischen Lehrern als "römisch" ausdrücklich abgelehnt werden (so SifDev § $221 \mathrm{zu}$ 21,22). Entscheidend für die Tempelrolle ist aber folgendes: Für das Palästina vom 4. Jh. bis zum Anfang des 1. Jh. v. Chr., also das Palästina der Perser und der Diadochen, für die ebenfalls die Kreuzesstrafe belegt ist (s. HENGEL, Crucifixion 22.73-76; Legende, bes. 30 Anm. 57; H.-W. KUHN, a.a.O. 682f) - dieser Raum und diese Zeit sind für das Verständnis der Tempelrolle heranzuziehen - ist der Galgen ebenfalls nicht mit einiger Wahrscheinlichkeit nachzuweisen (das gilt z.B. auch für das Esterbuch). Die weite Spanne der möglichen Entstehungszeit der Tempelrolle stellt die Deutung auf die Kreuzesstrafe natürlich nicht in Frage (so meinte mich HENGEL, Legende 34, Anm. 64 verstehen zu müssen). Ein eindeutiger Beleg für den Vollzug der Kreuzesstrafe im vorrömischen Palästina ist

6 "Beute" steht zusätzlich zum MT.

7 Vgl. ב ת ת "sich rächen an" z.B. 1Sam 18,25. 
z.B. die Hinrichtung von 800 Aufständischen durch Alexander Jannaios um 90 v.Chr. in Jerusalem (auf dieses Geschehen nimmt der oben zitierte Text aus 4QpNah Bezug); für weitere Stellen sei verwiesen auf $H$.W. KUHN, a.a.O. 707f (vgl. jetzt auch noch HENGEL, Legende). Die Deutung des Textes in der Tempelrolle auf die Kreuzesstrafe (s. außer HENGEL z.B. auch FITZMYER, Advance 129ff; HALPERIN, JJS 1981, bes. 43.46) ist also zweifellos die einzig richtige. Wie sich im urchristlichen Schrift-

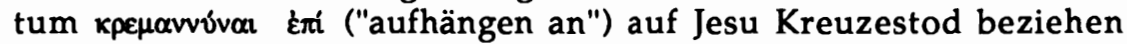
kann (Gal 3,13; Apg 5,30; 10,39), so kann sich auch ("גלה על ("aufhängen an"), wenn es sich um die Todesstrafe selbst handelt, auf die Kreuzigung beziehen. Und das ist hier wegen der fehlenden Belege für die Todesstrafe am Galgen ohne Zweifel der Fall. Damit ist aber noch nichts darüber gesagt, ob die Tempelrolle eine tatsächliche Rechtspraxis in $\mathrm{Pa}$ lästina widerspiegelt.

Für den oben zitierten Text im Pescher Nahum ist zwar die Deutung auf die Kreuzesstrafe nicht umstritten ${ }^{8}$, zumal Josephus in seiner Darstellung des offensichtlich gleichen Vorgangs eindeutig die Kreuzesstrafe für dieses Geschehen um 90 v. Chr. nennt (àvaoravpoov Bellum

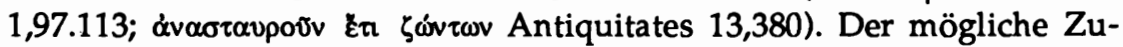
sammenhang zwischen dem "Erwürgen" im zitierten Bibeltext (Z1. 4: חנ) und dem "Aufhängen" (Zl. 8: תלה) der Aufständischen durch Alexander Jannaios kann daran nichts ändern. Auch BAUMGARTEN bestreitet den Bezug auf die Kreuzesstrafe nicht, meint aber (a.a.O. 14*), daß die im Pescher Nahum in Zl. 8 gebrauchte Form n (als Part. Passiv "einer, der aufgehängt wird" = ein Gekreuzigter) aktivischen Sinn habe ("einer der aufhängt" = kreuzigt); er verweist dafür, abgesehen vom Aramäischen und der Mischna (s. SEGAL, Grammar § 336), auf Cant 3,8 (vgl. GESENIUS/KAUTZSCH, Grammatik § 50f) und fälschlich unter den Qumrantexten auf $1 \mathrm{QJes}^{\mathrm{a}}$ unter Berufung auf KUTSCHER, Language $349 \mathrm{f}$ (in keinem Fall hat hier 1QJesa eine solche als Aktiv zu verstehende Form). Damit will BAUMGARTEN die Schwierigkeit lösen, die dadurch entsteht, daß manche Exegeten und er selbst gegen das übliche Schema eines Pescher die Auslegung des Bibeltextes in $\mathrm{Zl} .8$ direkt in das folgende Bibelzitat übergehen lassen, was nur bei einem aktivischen Verständnis von תinn mache (S. 13*; die von HORGAN, Pesharim 179 genannte Parallele für einen solchen Übergang, nämlich 4QpJesb II 7, ist offenbar nur ein Einzelfall gewesen). Sowohl diese Art der Fortsetzung eines Pescher als auch der aktivische Sinn der in Frage stehenden Form sind aber in den Qumrantexten im ersten Fall die Ausnahme und, was den zweiten Fall betrifft, gar nicht zu belegen. Der Preis für ein solches Textverständnis - gleich zwei eher unwahrscheinliche Deutungen - ist sicherlich zu hoch.

8 Früher einmal meinte Rowley, der Bezug auf die Kreuzesstrafe sei wegen des mehrdeutigen nל nicht sicher, nur wahrscheinlich (JBL 1956, 190f). 
Für das Verständnis der Kreuzesstrafe im Detail ist die Zeile 8 im zitierten Pescher Nahum entscheidend. Die beiden Hauptprobleme in dieser Zeile sind die Ergänzung der großen Lücke Zl. 8a und die Anspielung auf das "Aufhängen" von Dtn 21,22f in Zl. 8b. Das Folgende kann besonders gut verdeutlichen, welchen Schwierigkeiten - gerade aufgrund des fragmentarischen Charakters der Handschriften und aus philologischen Gründen - die Interpretation der Qumrantexte immer wieder begegnet.

Je nach Ergänzung der Lücke in $\mathrm{Zl.8a}$ wird die Kreuzesstrafe als in Israel üblich (gemäß der Tempelrolle) oder als jüdisch verwerflich bezeichnet; dementsprechend wird das Vorgehen Alexander Jannaios' gegen die Pharisäer positiv (die Pharisäer als "Schmeicheleisucher") oder negativ beurteilt. In $\mathrm{Zl}$. $8 \mathrm{~b}$ ging es bisher vor allem darum, ob der Vf. zeigen will, daß ein Gekreuzigter von Gott verflucht ist (der nicht ausdrücklich genannte Fluch des atl. Textes mußte dementsprechend mitgehört werden), oder ob er den Hinweis auf die Kreuzesstrafe mit dem in Zl. 8bB folgenden Bibeltext ("Siehe, ich gehe gegen dich vor ...") verbindet. Eine befriedigende Lösung gab es bisher nicht. Deutlich ist jedenfalls, daß der Kommentar die Gegner von Alexander Jannaios als "Schmeicheleisucher" durchaus negativ beurteilt (s. Zl. 2 und 7 .

Als erstes muß die urspringliche Länge der Lücke in $\mathrm{Zl}$. 8a bestimmt werden; sie läßt sich durch zwei Zeilen dieser Kolumne (Z1. 2 und 9) festlegen, die praktisch sicher zu ergänzen sind. Danach beträgt die Größe der Lücke am Anfang von Zl. 8 etwa 30 Einheiten (= Buchstaben + Leerstellen zwischen den Buchstaben): Was zunächst die Heranziehung von Zl. 9 betrifft, so ist in der Lücke nur der Bibeltext aus Nah 2,14 zu ergänzen; die Gesamtlänge der hier jedoch am linken Rand verkürzten Zeile (s. die Fotografie der Hs.) macht 68 Einheiten aus (die Verkürzung beträgt etwa 7 Einheiten, was folglich als normale Zeilenlänge, z.B. entsprechend Z1. 7, etwa 75 Einheiten ergibt). Auch die Ergänzung des Anfangs von Zl. 2 ist, weil es weithin um Bibeltext geht, sehr sicher vorzunehmen (beide Ergänzungen so auch z.B. bei LOHSE); hier ist die Zeile am linken Rand etwa um eine Einheit länger; ferner muß berücksichtigt werden, daß die Hs. vor einem einleitenden פon "Seine Deutung bezieht sich auf" zusätzlich in der Regel etwa 3 Einheiten als Zwischenraum freiläßt (vgl. 3-4 II 4.11; III 6; IV 7; anders IV 3.5), so daß wir hier ebenfalls eine Normallänge von 75 Einheiten konstatieren können. Legen wir die Ergänzungen von Zl. 2 und 9 in einer vertikalen Linie bei Beginn des erhaltenen Textes von Zl. 8 zugrunde, so müßten am Anfang von Zl. 8 etwa 29 Einheiten (gemäß Zl. 2 bis zum letzten Buchstaben von Oro'a) bis etwa 33 Einheiten (gemäB ZI. 9 bis zum letzten Buchstaben von רוכנה) ergänzt werden (eine ähnliche Berechnung findet sich bei HORGAN, Pesharim 171).

Vor allem zwei Ergänzungsvorschläge für die Lücke am Anfang von Zl. 8 stehen sich gegenüber (die genaue Stellung der eckigen Klammern im folgenden geht auf den Vf. zurück). Schon ALLEGRO hatte in der Erstedition in JBL 1956 mit Fragezeichen eine Ergänzung vorgeschlagen, die die Kreuzesstrafe als etwas Unjüdisches betrachtet: רen .... 年 "... which was never done (?)] before in Israel" (in der Edition in DJD ergänzte ALLEGRO die Lücke nicht). Diesem ursprünglichen Vorschlag von ALLEGRO hatte sich u.a. G. JEREMIAS, Lehrer $135 \mathrm{f}$ angeschlossen und das theologische Gewicht der Wendung "So etwas geschieht nicht in Israel" betont. Nach Öffnung der Tempelrolle, die die Kreuzesstrafe für bestimmte Vergehen in Israel vorsieht, gerade auch für Verräter, als welche man die Gegner von Alexander Jannaios beurteilen konnte, hielt der spätere Herausgeber der Tempelrolle, YADIN, bereits in IEJ 1971 eine andere

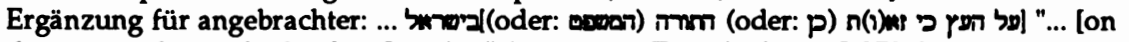
the tree as this is the law] in Israel ..." (in: DERS., Temple Scroll I 378 fehlerhafter und ungenauer Bezug auf IEJ 1971). Ähnlich schlug FITZMYER, Advance 130 als Ergänzung 


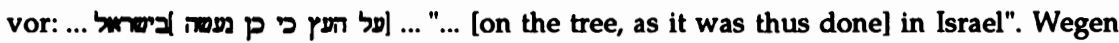
der Tempelrolle ist in der Tat eine Ergänzung, wie sie YADIN vorgeschlagen hat, vorzuziehen (man beachte die Verbindung von Kreuzesstrafe und Volksverrat im 0 . zitierten Text von 11QT LXIV 6-9!), wenngleich auch damit die vorauszusetzende Lücke von ca. 30 Einheiten noch nicht ausgefüllt wird. YADINs und FITZMYERs Ergänzungsvorschläge im Detail sind mindestens ein Drittel zu kurz (YADIN, a.a.O. 10 hat auch die Größe der Lücke mit 22 Einheiten zu kurz berechnet). Nun ist sicherlich die Lücke überhaupt zu groß, um eine einigermaßen zweifelsfreie Ergänzung vertreten zu können. Entsprechend der sachlich richtigen Ergänzung von YADIN sollte der Text aber so verstanden werden, daß die von Alexander Jannaios Gekreuzigten als Verräter hingerichtet wurden.

Ferner zur philologischen Deutung oon $\mathrm{Zl}$. 8b: Die für $\mathrm{Zl}$. 8b vorgeschlagene elliptische Deutung des Textes mit der im Bibeltext genannten, aber nicht mitzitierten Verfluchung versteht den Text so: "denn von einem", der lebendig "a[m] Holz" "aufgehängt wird" (Dtn 21,22f), hei[Bt es] (in der Schrift) <: "er ist ein Gegenstand des göttlichen Fluchs" (Dtn 21,23)>. Diese Ergänzung findet sich ebenfalls bereits bei ALLEGRO in der Erstveröffentlichung (JBL 1956, 91), dem sie, wie er mitteilt, von F.M. CROSS und D.N. FREEDMANN vorgeschlagen wurde. G. JEREMIAS, Lehrer 128 und andere übernahmen diese philologisch und nach dem Auffinden der Tempelrolle auch inhaltlich problematische Lösung. Die heute dagegen bevorzugte Interpretation, die sich bei ALLEGRO in seiner DJD-Edition von 1968 findet, begegnet schon bei BARDTKE, Handschriftenfunde (Sekte von Qumran) 298 und verbindet das m(p) i.S. von "man liest (in der Schrift)" mit dem folgenden Zitat aus Nah 2,14 (so auch LOHSE z. St.; MAIER I z.St.; SCHÜRER, History I 225 Anm. 22; HORGAN, Pesharim 163.179; BAUMGARTEN, ErIs 1982, 14; KNIBB, Community 210.213). Dabei wird in der Regel verkannt, daß sich Nah 2,14 gemäß der Deutung ab Zl. 10 gerade nicht auf die gekreuzigten Pharisäer, sondern offenbar weiterhin auf Alexander Jannaios, sein Heer und überhaupt die hasmonäischen Hohenpriester bezieht; BAUMGARTEN, der diese Schwierigkeit sieht, versteht ja deshalb, aber zweifellos zu Unrecht (s.o.), die betreffende Form (nלn) in $\mathrm{Zl} .8$ (trotz des auch von ihm zugestandenen Anklangs an Dtn 21,23) als Aktiv (bezogen auf den seine Gegner kreuzigenden Alexander Jannaios), damit der folgende Bibeltext ("Siehe, ich gehe gegen dich vor ...") paßt. KNIBB, a.a.O. 213 sieht die Lösung darin, Nah 2,14aa aus der folgenden Kommentierung ab $\mathrm{Zl} .10$ auszuklammern (und, wie gesagt, als direkte Fortsetzung des vorhergehenden Kommentars zu deuten); aber das entspricht ebenfalls nicht der Auslegungsweise in den Pescharim, auch wenn die Auslegung zu Nah 2,14 ausdrücklich erst mit der "Menge" in Nah 2,14aß einsetzt.

Folgender, soweit ich sehe, neuer Vorschlag für Zl. 8 erscheint dem Text syntaktisch und inhaltlich besser gerecht zu werden (s.o. die Übersetzung): daß die Kreuzesstrafe bereits von alters her in Israel Recht ist (vgl. zur Ergänzung des Textes in Z1. 8 Ruth 4,7, worauf YADIN, a.a.O. 10 Anm. 34 aufmerksam macht), wird damit begründet, daß man die Strafe in der Bibel findet: "... liest man (in der Schrift)". Wie auch immer Zl. 8 $\mathrm{zu}$ verstehen ist, zweifellos ist hier jedenfalls, wie wir sahen, die Kreuzesstrafe gemeint.

Paulus bezieht also die in Gal 3,13 in Anlehnung an die LXX zitierte Stelle Dtn 21,23 (vgl. zusätzlich 27,26), wie die Qumrantexte, auf die

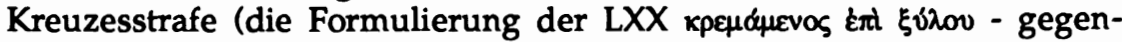

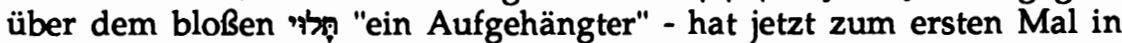
den beiden zitierten Qumrantexten eine wörtliche hebräische Parallele: "ein am Holz Aufgehängter"; vgl. auch Apg 5,30; 10,39). Der atl. Text selbst bezieht sich dagegen, wie oben schon gesagt, auf bereits 
Hingerichtete, die anschließend noch an einem Pfahl aufgehängt wurden. Bisher war die Deutung von Dtn 21,22f auf die Kreuzesstrafe für die zeitgenössische jüdische Auslegung nicht mit einiger Wahrscheinlichkeit zu belegen.

Zwar findet sich in Justins 'Dialog mit dem Juden Tryphon', der in der Mitte des 2. Jh. entstanden ist, in Kap. $98 \mathrm{f}$ ein solches Verständnis der atl. Stelle im Munde des Juden, aber bisher mußte man eher annehmen, daß es sich bei dem entsprechenden Argument des Juden Tryphon nur um eine christlich erfundene, d.h. aus Paulus erschlossene Úberlegung handelt, und das vor allem deshalb, weil Justin in 96,1 Dtn 21,23 - gegen den Wortlaut der LXX und der hebräischen Bibel - entsprechend Gal 3,13 zitiert. Justin läßt den Juden Tryphon unter Verweis auf "das Gesetz" (Dtn 21,22f) sagen: "Daran zweifeln wir, daß der Messias aber auch so ehrlos gekreuzigt wurde, denn aufgrund des Gesetzes ist der Gekreuzigte verflucht ... Deutlich ist, daß die Schrift einen leidenden Messias verkündet. Wissen möchten wir aber, ob du auch beweisen kannst, daß das auch für das im Gesetz verfluchte Leiden gilt" $(89,2)$. "Beweise uns, daß er aber auch gekreuzigt wurde und so schmählich und ehrlos durch einen im Gesetz verfluchten Tod starb. Denn wir können uns das nicht einmal vorstellen [!]" $(90,1)$. Entsprechend heißt es in 32,1: "Euer sog. Christus" sei "dem schlimmsten Fluch im Gesetz Gottes verfallen, denn er wurde gekreuzigt" (vgl. noch 96,1).

Ebenfalls im Pentateuch der syrischen Standardbibel, der Peschitta, der sehr alt sein kann (1./2. Jh.) und vielleicht jüdischer oder judenchristlicher Herkunft ist, wird Dtn 21,22 auf die Kreuzesstrafe bezogen (s. dazu WILCOX, JBL 1977, 90).

Dagegen deutet die Mischna in San 6,4 den Bibeltext von Dtn 21,22f dahin, daß umgekehrt der Hingerichtete den Namen Gottes verflucht habe; das gilt z.B. auch für die Übersetzung des AT von Symmachus, einem Juden oder Judenchristen der 2. Hälfte des

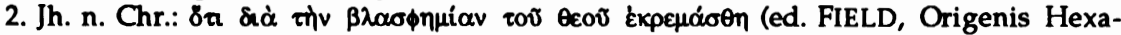
plorum I 304b).

Paulus geht in Gal 3,13 von der Verfluchung eines Gekreuzigten entsprechend einem frühjüdischen Verständnis von Dtn $21,22 \mathrm{f}$ aus. Judaisierenden Christen, die am "Gesetz" ("Tora" bzw. vónos) als 'Heilsweg' festhalten, wird von Paulus entgegengehalten, daß Christus gerade als Gekreuzigter die Glaubenden vom vónos befreit hat. Er hat nämlich durch seinen Kreuzestod "für uns" ( sprochenen Fluch, der jeden trifft, der sein Leben vom Tun des vollständigen ( $\pi \delta \sigma v !)$ Gehorsam fordernden und niemals (vgl. oúdeís in Verbindung mit $\pi \tilde{\alpha} \sigma v$ !) zu erfüllenden "Gesetzes" herleitet $(3,10 f)$, auf sich genommen (als Sündloser ist offenbar gemeint: s. 2Kor 5,21). Damit - so ist Paulus weiterhin zu interpretieren - hat Christus das Tun der To-

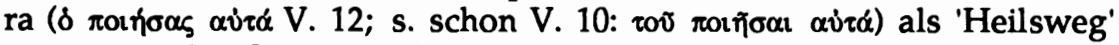
zugunsten des Glaubens als 'Heilsweg' beseitigt ("Der gekreuzigte Christus wird zum Ausdruck der Unvereinbarkeit von Gesetzesweg und Glaubensweg" [KERTELGE, Grundthemen 75 mit Berufung auf Gal 3,12 und den Kontext dieses Verses]). Der jüdische vónos ließ den Gekreuzigten als Verfluchten erscheinen. Vom ürìp $\eta_{\mu} \tilde{\omega} v$ her, d.h. vom Gedanken des "uns zugute" bzw. vom Stellvertretungsgedanken, erscheint nun umgekehrt das Kreuz als Entmächtigung der Tora. Der vielleicht schon jüdische Vorbehalt gerade gegenüber dem gekreuzigten Christus aufgrund von Dtn 21,23 wird von Paulus aufgenommen und gegen an der 
Tora als 'Heilsweg' festhaltende Christen gewandt. Die christlichen Gegner des Paulus mußte dieses Argument um so härter treffen, weil es ihre Position, nämlich Christus plus Tora, in der Wurzel angriff, da Jesus eben von der Tora als Verfluchter gekennzeichnet war (vgl. zum Ganzen auch H.-W. KUHN, ZThK 1975, 33-36).

Während der Text der Tempelrolle den biblischen Text so erweitert, daß von einer Verfluchung durch Gott und Menschen gesprochen wird, hat Paulus gegen den Wortlaut der Hebräischen und Griechischen Bibel das "durch Gott" ausgelassen. Man meinte darin eine Parallele zur vermeintlichen Ellipse in $4 \mathrm{QpNah}$ (s.o.) sehen zu können. In beiden Fällen liege eine Scheu gegenüber dem Fluch des Bibeltextes vor. Für Paulus könnte vielleicht eine Scheu gegenüber der Aussage gelten, daß Christus von Gott verflucht sei. Aber genauer wird die Auslassung damit zusammenhängen, daß Paulus unmittelbar vorher vom "Fluch des

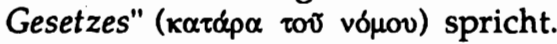

Lit.: Aus der Literatur vor der Veröffentlichung des relevanten Abschnitts der Tempelrolle (1971) sei nur die ausführliche Besprechung von G. JEREMIAS, Lehrer 133-135 genannt. Er kommt zum Ergebnis: "Paulus fußt in Gal 3,13 auf der zeitgenössischen Exegese von Dt 21,23"

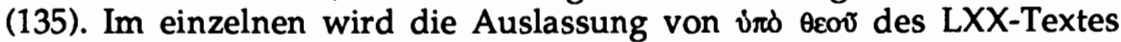
durch Paulus (auch das AT hat "von Gott") mit der vermeintlichen Ellipse im Pescher-Nahum-Text in Verbindung gebracht und als Grund "die Scheu" genannt, "expressis verbis von dem Fluch Gottes zu sprechen" (133; wir hatten o. die Auslassung anders begründet). Unter Verweis auf Justins Dialog mit dem Juden Tryphon vermutet JEREMIAS hinter dem Paulustext eine jüdische "Christuspolemik", "die sich auf $\mathrm{Dt}$ 21,23 berief" (134). JEREMIAS verweist in diesem Zusammenhang auf weitere $n$ tl. Stellen, die Paulus in seiner vorchristlichen Vergangenheit als "Lästerer" (1Tim 1,13) bezeichnen oder von Juden sprechen, die Jesus "lästern" (z.B. Apg 18,6). - H.-W. KUHN, ZThK 1975, 33-36 zieht beide Qumranstellen zur Deutung der paulinischen Aussagen heran und schreibt 11QT wegen des hier eindeutig vorkommenden und sogar durch einen Zusatz hervorgehobenen Fluches die größere Bedeutung zu (34); die paulinische Auslassung des "von Gott" bei dem Wort "verflucht" wird wie oben mit der im Kontext begegnenden Rede vom "Fluch des Gesetzes" begründet (36 Anm. 155). Daß es sich bei der paulinischen Aussage um ein Argument des Apostels aus der Zeit vor seiner Bekehrung/Berufung handele, wird (gegen J. JEREMIAS, Opfertod 14) als bloße "biographische Vermutung" bezeichnet, aber auch die Überlegung, daß ein jüdisches Argument gegen die Christen vorliege, wird nur als Vermutung hingestellt (ebd.) (von H. D. BETZ, Gal. 275 Anm. 132 [engl.: 152 Anm. 136] dagegen ohne Einschränkung als Meinung KUHNs ausgegeben). Die beiden Qumrantexte bzw. vor allem 11QT wurden auch später von KUHN mit der paulinischen Stelle in Verbindung gebracht (z.B. ANRW II 25/1, 674 bei Zurückhaltung gegenüber der These 
eines von Paulus schon vorgefundenen "jüdischen Schriftarguments gegen die Christen"; s. ferner TRE 19, 1990, 720, 13ff). - WILCOX, JBL 1977, 88-90 stellt unter Verweis auf die Peschitta zu Dtn 21,22 (s.o.) fest: entweder habe es eine frühe Textvariante zu Dtn 21,22 i.S. der Qumrantexte, des Paulus und der Peschitta gegeben (u.a. "aufhängen" als kreuzigen), die sich wohl auch in Apg 5,30; 10,39 widerspiegele ("variant textual tradition"), oder eine entsprechende, in der rabbinischen Literatur nicht belegte Auslegungstradition ("interpretative tradition") (90). Die letztere Auffassung von WILCOX verdient den Vorzug, obgleich sich beides nicht ausschließen muß. - FITZMYER, Advance 138-140 sieht die Bedeutung der beiden Qumrantexte für Gal 3,13 in drei- bzw. vierfacher Weise: (1) Die Kreuzesstrafe konnte schon vorchristlich als "hanging on a tree" verstanden werden. (2) Wenigstens einige Juden um die Zeitenwende hätten Dtn 21,22f - im Gegensatz zum ursprünglichen Sinn - auf die Kreuzesstrafe bezogen. (3) Die Auslassung bei Paulus ("von Gott") und die (oben abgelehnte) Ellipse im Pescher Nahum seien verwandt. (4) Die rechtlichen Probleme des Todes Jesu, d.h. die Frage der jüdischen Beteiligung an der Kreuzigung, würden sicher keine Erhellung durch diese Qumrantexte erfahren (das stellt WILCOX mit Recht fest). - KIM, Origin 46: Hinweis auf beide Qumrantexte als Beleg für die Deutung von Dtn 21,23 auf die Kreuzesstrafe und die Verfluchung eines Gekreuzigten. - SCHELKLE, Paulus 168 formuliert unter Hinweis auf die Tempelrolle zurückhaltend: "Vielleicht antwortet Paulus jüdischen Gegnern". - SCHWEIZER, TRE 16, 1987, 689 beruft sich für "das Kreuz als Fluchtod" in Gal 3,13 auf die Deutung von Dtn 21,23 in 11QT.

\section{5,16-23 LASTER- UND TUGENDKATALOG}

\section{QS III 25-IV $14^{9}$}

Die beiden Abschnitte 1QS III 25ff und Gal 5,16ff haben folgenden Aufbau (Gal 5,16-23 steht im paränetischen Teil des Briefes, der von 5,13 bis 6,10 reicht; 1QS III 25-IV 14 gehört in den großen Zusammenhang III 13-IV 26 über den qumranischen Dualismus ${ }^{10}$ ):

\footnotetext{
9 Die Zeilen IV 4-6 sind z.T. auch in Fragment 16 von 4Q502 ("Rituel de Mariage") enthalten, die Zeilen IV 4-10.13-15 z.T. in 4QSc 2 I (vgl. MILIK, RB 1960).

10 Selbst wenn der Abschnitt 1QS III 13-IV 26 vorqumranisch sein sollte, wofür ich keine ausreichenden Anhaltspunkte erkennen kann, hätten ihn die Qumranfrommen in ihre "Gemeinderegel" aufgenommen (zu STEGEMANN, RdQ Nr. 49-52, bes. 125ff). - III 13$15 \mathrm{a} \alpha$ gibt inhaltlich die drei Themen des gesamten Abschnitts bis IV 26 an, wobei allerdings der Abschnitt ab IV 15 die Themen 1 und 3 wieder aufgreift; s. dazu BALTZER, Bundesformular 105-115 (wie die Zeilen 13-15a $\alpha$ genau die dreifache Gliederung beschreiben, ist freilich umstritten), der auch 1QS III 15-IV 1 vom sog. atl. Bundesformular her deutet: III 15-IV 1 als "dogmatischer Teil" an der Stelle der "Vorgeschichte"; IV $2 \mathrm{f}$ an der Stelle der "Grundsatzerklärung" zusammen mit dem Tugend- und Lasterkatalog an der Stelle der "Einzelbestimmungen" als "ethischer Teil" IV 2-6.9-11; schließlich die
} 
III 25aß-IV 1 dualistische Einleitung im engeren Sinn zum Tugend- und Lasterkatalog (der größere Zusammenhang ist III 15aß-IV 1)

IV 2aa dualistische Überschrift über die beiden Wege

IV 2aß-3aa Einleitung zum Tugendkatalog

\section{3aß-6a Tugendkatalog}

IV 6b-8 Zusammenfassung des Tugendkatalogs und eschatologische Vergeltung für die Tugenden (Segen)

IV 9aa Einleitung zum Lasterkatalog

IV 9aß-11ba Lasterkatalog

IV 11bß-14 eschatologische Vergeltung für V. 23b indirekte Segensverheißung die Laster (Fluch)
V. 16-18 dualistische Einleitung zum Laster- und Tugendkatalog
V. 19a Einleitung zum Lasterkatalog

\section{19b-21a Lasterkatalog}

V. 21b eschatologische Vergeltung für die Laster (Fluch)

V. 22a Einleitung zum Tugendkatalog

\section{22b-23a Tugendkatalog}

V. 24-26: V. 24 spezifisch paulinische Weiterführung; V. $25 \mathrm{f}$ Folgerungen für das christliche Leben

Und er selbst (sc. Gott) hat die Geister von Licht und Finsternis erschaffen und (dabei) jegliches Tun auf sie gegründet,

26 au[f ...] allen Dienst und auf ihre Wege al[le(n/s?) .... $]^{11}$

Den einen liebt Gott für alle $I V 1_{\text {ewige }}$ Zukunft, und an allen seinen Handlungen wird er (also) für immer Wohlgefallen haben.

Den anderen (aber) verabscheut er zutiefst ${ }^{12}$ und (dabei) haßt er alle seine Wege für immer.

2Und dies sind ihre Wege auf der Welt:

$<$ Der Geist der Wahrheit (sucht) $>13$ das Herz eines Menschen zu erleuch-

ten

eschatologischen Vergeltungen an der Stelle von Segen und Fluch. Rein formal liegt eine etwas andere dreifache Gliederung in III 13-IV 26 vor: auf eine Einleitung folgen die Teile III 15-IV 1; IV 2-14 und IV 15-26.

11 Die versuchte stichische Gliederung spricht gegen die von vielen für $\mathrm{Zl}$. 26 angenommene Dittographie.

12 Lies mit STEGEMANN, RdQ Nr. 49-52, 104 mo (s. 1QS X 16).

13 Es ist vielfach beobachtet worden, daß hier Text ausgefallen sein muß. Ich ergänze gemäß III 18.24; IV 9.23: רחז הח 
und ihm (einerseits) alle Wege wahrhaftigen Rechtseins zu ebnen und (andererseits) sein Herz durch ${ }^{3}$ Gottes Rechtsentscheide zu erschrecken:

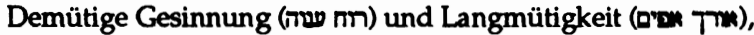
viel Barmherzigkeit und unendliche Güte (טרום (כסים);

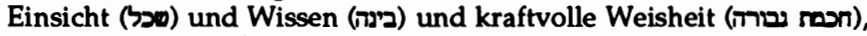
die auf alle ${ }^{4}$ Taten Gottes vertraut (nene) und sich auf die Fülle seiner Gnade stützt;

Geist der Erkenntnis (ת und Eifer (imp) für gerechte Rechtsentscheidungen;

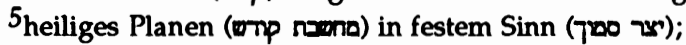

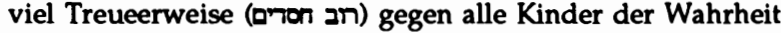

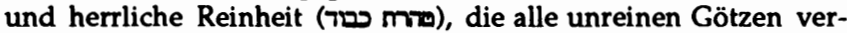

demütiges Wandeln (הכצע לכת) ${ }^{6}$ in Klugheit (טרטה) gegen jeden abscheut; und treues Verbergen (rask) der Geheimnisse der Erkenntnis.

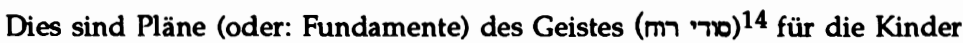
der Wahrheit (in) der Welt, und die Heimsuchung aller, die in ihm wandeln (כל הזלכי בה), (führt)

zu Heilung ... 7 ... mit allen dauernden Segnungen ...

${ }^{9}$ Aber zum Geist des Frevels (gehören) Habgier (Din $2 \mathrm{~m}$ ) und lässige Hände (arr $a$ ( $ם$ ) beim Dienst an der Gerechtigkeit;

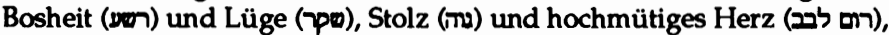

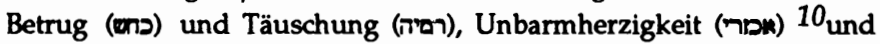
viel Ruchlosigkeit (חת חב);

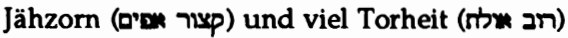
und vermessener Eifer (pris nmp);

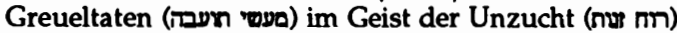
und Wege des Schmutzes (דרכי נרד) im Dienst der Unreinheit (שבודת)

הMan);

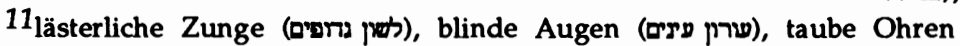

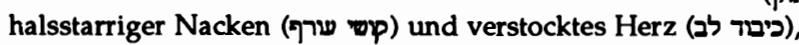

(כבוד (כוק), so daß man auf allen Wegen der Finsternis wandelt und (in) böser List (עn nav).

Und die Heimsuchung ${ }^{12}$ aller, die darin (sc. im Geist der Finsternis) wandeln, (führt)

14 ס 14 (eigentlich "Plan, Geheimnis" oder "Kreis von Vertrauten") ist hier vielleicht i.S.

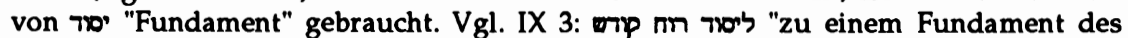
heiligen Geistes". In 1QH VI 26 und VII 9 steht 7 zweifellos für 700 "Fundament". Andererseits findet sich in einem mit unserem Abschnitt verwandten Kontext nach der hier nur teilweise wiedergegebenen Rekonstruktion von Puech (RdQ 13 Nr. 49-52, s. bes. 65) in $1 \mathrm{QH}$ XIII oben $(=1 \mathrm{QH}$ f 31,1$)$ eine erstaunliche Parallele: Bei hypothetischer Übernah-

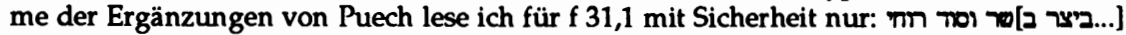
[... שולה], gemäß Puech: ("Einsicht zu geben" [= f 15 rechts (!), Z1.3]) "[in] flei[schliches Trachten] und den Plan [böser] Geister". 
zu vielen Plagen ... 14 ohne daß ein Rest bleibt und es für sie Rettung gibt.

Stellen wir im folgenden die freilich in sich nicht einheitliche "Gemeinderegel" 1QS und die sieben authentischen Paulusbriefe gegenüber: Nur in Gal 5 gibt es in den authentischen Paulusbriefen wie im oben zitierten Qumrantext das Nebeneinander von sog. Tugend- und Lasterkatalogen (bzw. bei Paulus in umgekehrter Reihenfolge); die Kataloge in Gal 5 nennen fünfzehn Laster und neun Tugenden, die in 1QS IV etwa siebzehn Tugenden und dreiundzwanzig Laster. In den authentischen Paulusbriefen finden sich noch weitere Lasterkataloge (1Kor 5,10f; 6,9f; 2Kor 12,20f; Röm 1,29-31; 13,13), aber nur zwei Tugendkataloge (2Kor 6,9f; Phil 4,8). In der "Gemeinderegel" gibt es ebenfalls noch weitere, im Vergleich mit 1QS IV kürzere Tugendkataloge (II 24; V 3f; VIII 2-4; X 25-XI 1), jedoch nur einen - formal aufgelockerten - Lasterkatalog (X 21f.24). Also auch hierin liegen die Dinge in den authentischen Paulusbriefen und $1 Q S$ gerade umgekehrt, d.h. in 1QS dominieren die Tugendkataloge, bei Paulus die Lasterkataloge! Dementsprechend beginnt Paulus auch mit einem Lasterkatalog in Gal 5 (übrigens werden in der Überschrift zu 1QS III 13-IV 26 in III 13-15 die Vergeltungen, die den Lastern entsprechen, zuerst genannt, und umgekehrt setzt Paulus in der Einleitung zum Laster- und Tugendkatalog in 5,16-18 mit dem "Geist" ein). Wie sehr die Lasterkataloge bei Paulus und im gesamten NT überwiegen, zeigt ungefähr ein Vergleich der entsprechenden Stellenangaben bei Nestle/Aland zu Röm 1,29ff bzw. zu Gal 5,22f. Der in der Forschung eingeführte Terminus "Tugend- und Lasterkataloge" wird hier beibehalten, obgleich er zu sehr griechischem Denken verhaftet ist und jedenfalls auch den paulinischen Katalogen nicht wirklich entspricht.

Die Parallele zu Qumran, genauer 1QS, besteht nicht primär in den inhaltlichen Übereinstimmungen der einzelnen Tugenden und Laster, obgleich es deutliche Entsprechungen gibt. Ich nenne in der folgenden Übersicht nur die Übereinstimmungen zwischen unseren beiden Texten 1QS IV und Gal 5. Im Tugendkatalog sind (unter Berücksichtigung der hebräisch-griechischen Entsprechungen in der LXX) folgende Zuordnungen möglich:

\begin{tabular}{|c|c|c|c|}
\hline רוח עגוה & $\begin{array}{l}\text { "demütige } \\
\text { Gesinnung" }\end{array}$ & $\pi \rho \alpha$ ț & "Sanftmut" \\
\hline אורך אפים & "Langmütigkeit" & $\mu \alpha к \rho \circ \theta u \mu i \alpha$ & "Langmut" \\
\hline סוב עולטים & "unendliche Güte" & $\dot{\alpha} \gamma \alpha \theta \omega \sigma v \dot{v} \eta$ & "Güte" \\
\hline מאטין & "vertrauend" & $\pi i \sigma \pi \zeta$ & "Vertrauen, Glaube" \\
\hline
\end{tabular}

Eine weitere ungefähre Entsprechung:

"viel Treueerweise" d a


Keine Entsprechung zwischen den Tugendkatalogen in Gal 5 und

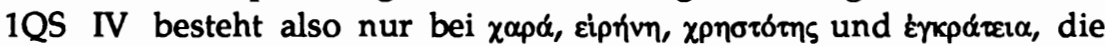
auch in den anderen Tugendkatalogen von 1QS keine Parallele haben. Allerdings finden sich xapd und eipriv als של שים ("ewige Freude") und ("viel Friede") in der anschließenden Beschreibung des künftigen eschatologischen Heils in IV 7 (von Paulus also schon für die Gegenwart reklamiert); ferner steht hinter $\chi \rho \eta \sigma \tau \delta$ ms in der LXX immer die Wurzel (für FLUSSER, Judaism 70 Anm. 157 entspricht sogar der

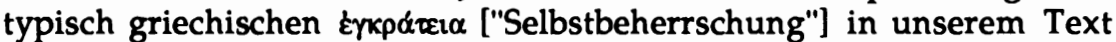
die "herrliche Reinheit, die alle unreinen Götzen verabscheut" [IV 5]). Die hauptsächliche Tugend in 1QS ist "treue Liebe" (Ton Ka), die sich in allen weiteren Tugendkatalogen von $1 Q S$ findet (II 24; V 4; VIII 2; $X$ 26), freilich nie an erster Stelle, und die in unserem Katalog als רח ("viel Treueerweise"; חהתה "Liebe" Jer 2,2), und zwar "gegen alle Kinder der Wahrheit", erscheint. Bei Paulus ist die dyór in innerhalb eines Tugendkatalogs sowohl in Gal 5,22 (hier also an erster Stelle; vgl. 1Kor 13) als auch in 2Kor 6,6 (hier jedoch gegen Ende als $\alpha \gamma \alpha-$ $\pi n$ d́vvrókpı $\tau o s$ "ungeheuchelte Liebe") genannt. Paulus beginnt übrigens auch den paränetischen Teil des Galaterbriefes in 5,13-15 unter Hervorhebung der dydirn (V. 13f). Die durchaus auch inhaltliche Verwandtschaft zwischen 1QS und den Paulusbriefen in diesem Punkt beleuchtet die Feststellung von H.D. BETZ für den Paulustext: "Außer der 'Liebe'

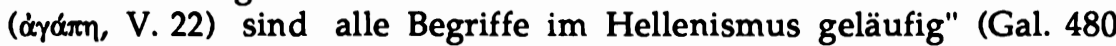
[engl.: 281b]).

Hinsichtlich der inhaltlichen Füllung des Lasterkatalogs in Gal 5 (wieder unter Berücksichtigung der LXX) sind die Entsprechungen zwischen den beiden Texten - gemessen an der Vielzahl der Laster in Gal 5 und in IQS IV - geringer:

\begin{tabular}{|c|c|c|c|}
\hline קצור :מים & "Jähzorn" & $\theta v \mu o i ́$ & "Jähzorn" \\
\hline קיאז ורון & "vermessener Eifer" & $\zeta \hat{\eta} \lambda \circ \zeta$ & "Eifersucht" \\
\hline (רוד) זנטת & $\begin{array}{l}\text { "(Geist der) } \\
\text { Unzucht" }\end{array}$ & 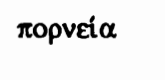 & "Unzucht" \\
\hline (בטבודת) טמדי) (דריה & $\begin{array}{l}\text { "(Wege des) } \\
\text { Schmutzes (im } \\
\text { Dienst der) } \\
\text { Unreinheit" }\end{array}$ & $\dot{\alpha} \kappa \alpha \theta \alpha \rho \sigma i \alpha$ & "Unreinhe \\
\hline
\end{tabular}

Aus dem Tugendkatalog IV 5:

"alle unreinen
Götzen"

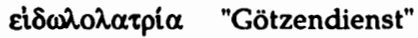


Wie in 1QS V 10 stehen übrigens auch in Gal 5,19 "Unzucht" und "Unreinheit" nebeneinander. Die eigentliche Übereinstimmung zwischen dem Paulustext und dem Qumranabschnitt besteht in der dualistischen und im strengen Sinn eschatologischen Einbettung ("streng eschatologisch" ist hier verstanden i.S. einer unumkehrbaren Wende für die Welt). In der Tat kommt kein anderer Text der Umwelt im ganzen gesehen Gal 5 so nahe. Während die verbreitete Rede von den beiden "Wegen" in 1QS im größeren Kontext erscheint (III 20f), aber im Corpus Paulinum, nicht jedoch in der sonstigen urchristlichen Literatur (s. vor allem Did 1-6 und Barn 18-20) fehlt, sprechen der Qumranabschnitt und der Paulustext in diesem Zusammenhang nicht nur ausdrücklich vom "Wandeln" (תepinareiv Gal 5,16; הלך 1QS IV 6.11.12), sondern noch ge-

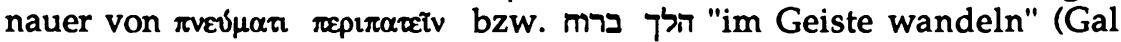
5,16 bzw. 1QS IV 6; s. auch III 18); für diese Wendung ist mir vom AT bis zur rabbinischen Literatur und in paganen Texten keine Parallele bekannt. Im Kontext des Qumranabschnitts steht freilich sonst "Geist" nur dualistisch als Geist des "Lichts" und der "Wahrheit" dem Geist der "Finsternis" und des "Frevels" gegenüber (1QS III 18f.25; IV 23), ist also mit רוח nicht der heilige Geist Gottes gemeint (außer in IV 21, jedoch im futurisch-eschatologischen Sinn). Die Ambivalenz der Formulierung in IV 6 läßt vermuten, daß hier die gut jüdische Anschauung von Gottes heiligem Geist mit der andersartigen Vorstellung zweier Geister konkurriert. Diese Unklarheit sollte man nicht vorschnell aufzulösen versuchen (so meint z.B. LICHTENBERGER, Studien 133 Anm. 43 nach רוח sei ein nan ausgefallen, der Text habe also vom "Geist der Wahrheit" gesprochen; dagegen nimmt SEKKI in seiner hervorragenden Studie über "Geist" in Qumran an, IV 6 beziehe sich eher undualistisch auf Gottes Geist [Ruah 89f. 218f]).

Das Alte Testament bietet zwar einige Parallelen für die Katalogform (am ehesten sind Stellen wie Hos 4,1f; Prov 6,16-19; Hi 1,1.8; 2,3 zu nennen; vgl. WIBBING, Tugend- und Lasterkataloge 24-26), aber vor allem ist die "ganze dualistische Denkweise" von 1QS IIIf "dem alttestamentlichen Denken fremd" (K.G. KUHN, ZThK 1952, 303). Die pagane Ethik der Antike und das zeitgenössische Judentum kennen Tugend- und Lasterkataloge, aber für die dualistische (i.S. antithetischer 'Mächte') und insbesondere die im strengen Sinn eschatologische Struktur und Rahmung dieser Kataloge gibt es weithin keine Parallelen. Im folgenden können nur die wichtigsten Bereiche angesprochen werden. Im Ganzen negativ ist das Ergebnis für die Stoa und stoisch-kynische Popular-

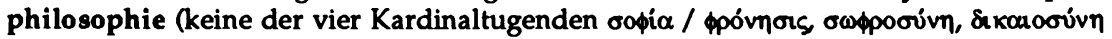

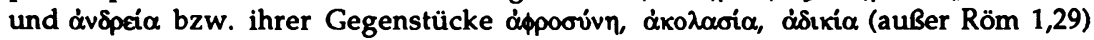

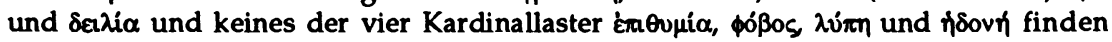
sich in den Katalogen der authentischen Paulusbriefe (vgl. WIBBING, a.a.O. 14-23; KAMLAH, Paränese 139-148; 144 weist KAMLAH aber auf eine Antithese zwischen Tugend und Laster mit noch erkennbarem Segen und Fluch für den Gründer der stoischen Schule um $300 \mathrm{v}$. Chr., Zenon, hin, die eine erstaunliche Nähe zum iranischen Dualismus zeigt). Das negative Ergebnis gilt ferner für das hellenistische Judentum, wenn man von den gleich noch zu nennenden Testamenten der Zwölf Patriarchen in gewisser Weise absieht (vgl. WIBBING, a.a.O. 23-30; obgleich Philo vor allem in seinen "Quaestiones in Exodum" I 23 seine Abhängigkeit vom iranischen Dualismus zeigt: s. KAMLAH, a.a.O. 
50-53.104-115). Nur bedingt parallel sind Texte des Gnostizismus (MUSSNER, Gal. 379 Anm. 32 und ROHDE, Gal. 237 mit Anm. 87 verweisen auf Lasterkataloge in den Schriften von Nag Hammadi VI 3 p. 31 und VI 4 p. 39). Das gilt auch für Texte aus dem wohl im wesentlichen im 2. Jh.n.Chr. entstandenen Corpus Hermeticum (KAMLAH, a.a.O. 115 spricht zu Unrecht für die Vorstellung, "daß die Seele bei der Auffahrt durch die Sphären in jeder Schicht ein Laster ablegt", von einem "eschatologischen Mythos"; in den Doppelkatalogen der Guten und der Bösen im Poimandres $\$ \S 21-23$ ist noch am ehesten eine Parallele zu erkennen, weil hier, wie in Qumran [s. auch H.-W. KUHN, Enderwartung, insbes. 127-130], iranische Vorstellungen zugrunde liegen und das Ziel der Ekstase zum Teil mit eschatologischer Begrifflichkeit beschrieben wird; beide Kataloge der Guten und der Bösen schließen mit Aussagen über eine entsprechende Vergeltung ab). Eine nur bedingte Parallele ist auch in der älteren rabbinischen Literatur zu entdecken. Weniger dualistisch im strengen Sinn, aber mit eschatologischem Ausblick, begegnen hier - freilich sehr selten - solche Kataloge (vgl. KAMLAH, a.a.O. 150ff); ein besonders schönes Beispiel findet sich in der Mischna in Av 5,19, wo je drei Tugenden und drei Laster und für beide die entsprechende Vergeltung genannt werden.

Eine relativ nahe Parallele zu 1 QS IV und Gal 5 findet sich im 1.Henoch (vgl. dazu WIBBING, a.a.O. 31.39f), von dem Teile - mit Ausnahmen der Bilderreden Kap. 37-71 - in Qumran in Aramäisch gefunden wurden. Gemeint ist 91,6f.18f im sog. Paränetischen Buch (vgl. auch 94,1.3). Unter den Qumrantexten sind zwar nicht der Lasterkatalog in 91,6f., aber die Gegenüberstellung der beiden "Wege" und die eschatologische Bestrafung für die Gottlosen in V 18f fragmentarisch in 4QEng 1 II 17-21 noch erhalten. Verwiesen sei auch auf das ebenfalls mit Qumran verwandte und dort auch hebräisch gefundene Jubiläenbuch (vgl. WIBBING, a.a.O. 31.41), und zwar vor allem auf den Lasterkatalog mit eschatologischer Vergeltung, aber ohne direkt dualistischen Charakter in 21,21f. Die in Entstehung und Datierung und hinsichtlich ihrer christlichen Zusätze und ihrer Verwandtschaft mit den Qumrantexten umstrittenen Testamente der Zwölf Patriarchen zeigen ebenfalls vielfach ein mit $1 Q S$ IIIf verwandtes Denken, das aber traditionsgeschichtlich schon eine spätere Stufe darstellt. Wie im 1.Henoch und in Jubiläen fehlen auch hier ausgeführte Tugendkataloge (vgl. aber Testlss 7,5f neben einer Art Lasterkata$\log$ in 7,2-4 und ferner 4,2-6 und TestJos 10,1f; unter den Lasterkatalogen s. bes. TestRub 3,3-7), die dualistische Einrahmung tritt sehr zurück (s. aber z.B. TestIss 7,2-7), und der eschatologische Bezug der Kataloge fehlt. Im Ganzen gesehen stellt TestIss 7,2-7 die engste Parallele in den TestXII dar. Abseits der Kataloge findet sich öfter ein den Qumrantexten verwandter dualistischer Zusammenhang, in dem sich Gott und Teufel (Beliar) (z.B. TestLev 19,1), Licht und Finsternis (z.B. ebd. und TestNaph 2,10), gut und böse (z.B. TestAss 1,5) gegenüber stehen ( $\varepsilon v$ katevava toṽ kvós "eines dem anderen gegenüber" TestAss 1,4) oder auch zwei "Geister" wie in 1QS IIIf (mit eschatologischer Ausrichtung

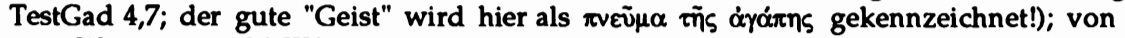
zwei Wegen wie 1QS IIIf sprechen TestAss 1,3.5.

Die größte Verwandtschaft zwischen den Tugend- und Lasterkatalogen der paganen, frühjüdischen und frühchristlichen Texte besteht zweifellos zwischen 1QS IIIf und Gal 5. Das schließt natürlich nicht aus, daß Paulus die typisch griechische Tugend der غ̇yxpázeı $\alpha$ "Selbstbeherrschung" anführt oder zweifellos auch konkrete Schwierigkeiten in den

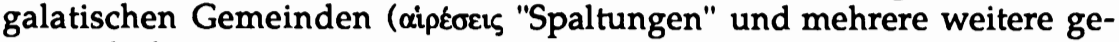
meinschaftssprengende Laster; s. V. 15!) benennt (so sehr freilich solche Kataloge traditionsverwurzelt sind). Gegenüber der strukturellen und zum Teil inhaltlichen Übereinstimmung zwischen 1QS IIIf und Gal 5 sind die Unterschiede zwischen beiden Texten religionsgeschichtlich nicht so hoch zu bewerten. Insbesondere theologisch ist jedoch die Dif- 
ferenz zwischen dem paulinischen Dualismus von "Geist" und "Fleisch" und den beiden "Geistern", denen רוח als prädestiniertes Sein oder Selbst des Menschen entspricht (s. H.-W. KUHN, Enderwartung 120-126; SEKKI, Ruah, passim, bes. 95-143. 193-219), durchaus nicht unerheblich, gerade auch, wenn man die Gabe des heiligen Geistes für die paulinische Paränese würdigt und sieht, daß "Fleisch", anders als in 1QS, bei Paulus - wenn auch zurückhaltend - auch als eine Art "Macht" neben dem $\pi v \varepsilon \tilde{\mu} \mu \alpha$ verstanden werden kann (so immer noch mit Recht BULTMANN, Theologie 244f; s. auch SCHWEIZER, ThWNT 7, 131-133). Paulus, bei dem hier gegenüber Qumran auch die Kosmologie fehlt, geht gut urchristlich von dem einen heiligen Geist aus (ein Begriff, den Qumran sogar in diesem Kontext kennt: 1QS IV 21) und stellt ihm das "Fleisch" ( $\left.\sigma^{\prime} \mathbf{q}^{\xi}\right)$ gegenüber (ein Terminus, den ja auch Qumran in anderem Zusammenhang äußerst negativ verwendet, in 1QS vor allem in XI 9: בשר עול "sündiges Fleisch"; anstelle von "Werken des Greuels" oder "Werken der Täuschung", wie es in dem großen Dualismusabschnitt in IV 10 bzw. 23 heißt [vgl. auch "Werke des Unrechts" in 1QS II 5], spricht Paulus entsprechend seiner Terminologie von "Werken des Fleisches"; aber gemäß 1QH XVII 25 hat selbst der Fromme in diesem dualistischen Text auch einen "Geist des Fleisches"). Der Abschnitt über den qumranischen Dualismus kennt auch ein gewisses Nebeneinander von "Fleisch" (בשר) und "heiligem Geist" an der schon genannten Stelle IV 21 (hier auf das Eschaton bezogen), doch steht dies nur am Rande; vielmehr geht es in 1QS IIIf - offensichtlich aufgrund von iranischen Traditionen - um den Gegensatz der beiden Geister des Lichts und der Finsternis (vgl. H.-W. KUHN, Enderwartung 121f. 127-130). Sie stehen sich als Feinde gegenüber: 1QS IV 17f (איכח עולם "ewiger Streit" und תkנp "streitender Eifer" heißt es im Blick auf die beiden Geister) und 23 (יריבו רוחי אמת וצול) "es kämpfen die Geister der Wahrheit und des Frevels" im Menschen); entsprechendes sagt auch Gal 5,17: $\tau \alpha \tilde{\tau} \tau \alpha$... $\dot{\alpha} \lambda \lambda \eta^{\prime}-$

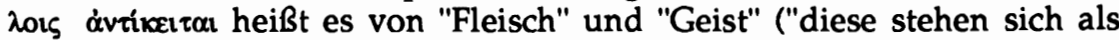
Feinde gegenüber"). Dieses Gegenüber findet sich auch ausdrücklich in einem Kontext, der weniger dualistisch formuliert (i.S. zweier 'Mächte') in der o. genannten Stelle TestAss 1,4.

$\mathrm{Da}$ Paulus in unmittelbarem Kontext, abgesehen vom ethischen Dualismus und den erstaunlichen Parallelen bis in einzelne Formulierungen, keine spezifische Qumranterminologie benutzt, ist der Traditionszusammenhang zwischen dem paulinischen und dem qumranischen Denken für diese Stelle nicht direkt nachweisbar, obgleich Paulus in 1Thess 5,4-9 diesen doch wohl spezifischen Qumrandualismus auch noch in anderer Weise und für Qumran charakteristisch verwendet und in Röm 13,12 das Gegenüber von Licht und Finsternis immerhin im Zusammenhang eines Lasterkatalogs (V.13) nennt.

Lit.: Von den drei bedeutendsten Monographien zu den Tugendund Lasterkatalogen im NT (VöGTLE, 1936; WIBBING, 1959 und KAM- 
LAH, 1964) setzen die beiden letzten schon die Veröffentlichung von 1QS (vollständig erschienen 1951) voraus. Während VöGTLE noch eine wesentlich hellenistische Herkunft aus der popularphilosophischen Diatribe angenommen hatte, betont nun WIBBING den frühjüdischen Hintergrund aufgrund von Schriften, die - abgesehen von der vorliegenden Fassung der Testamente der Zwölf Patriarchen - weithin palästinischen Ursprungs sind und weniger hellenistische Prägung zeigen; speziell zu den "stoischen Katalogen" fehle im NT - mit Ausnahme von 2Petr 1,5-7 - "in Form und Aufbau jede spezifische Beziehung"; so sei das Schema der "4 Kardinaltugenden" und der "4 Hauptaffekte" für den Aufbau nicht grundlegend (86); die Verbindung von "Gesinnung und Tat" in den ntl. und frühjüdischen Katalogen wird als "ein wesentliches Kennzeichen für ihren traditionsgeschichtlichen Zusammenhang" beurteilt (108). Auffallend ist für WIBBING "die dualistische Gegenüberstellung der Tugend- und Lasterkataloge" gerade bei Paulus und in bestimmter frühjüdischer Literatur (ebd.), und hier wieder vor allem in 1QS (die Wurzeln dafür lägen in der iranischen Religion [64]), auch wenn sich in den kanonischen Schriften des NT "die spezielle", aber nicht unbedingt dualistische "Ausdrucksweise der 'beiden Wege"" "nicht durchgesetzt hat" (109). WIBBING betont ferner die eschatologische Ausrichtung der Kataloge bei Paulus und zum Teil im Frühjudentum (114-117). Es hätte von WIBBING noch schärfer herausgestellt werden können, daß 1QS IIIf bei weitem die nächste Parallele zu Gal 5 ist und $\mathrm{da} ß$ andere jüdische Schriften nur Ansätze zu entsprechenden $\mathrm{Ka}$ talogen und ihrer dualistisch-eschatologischen Einbettung enthalten. KAMLAH sieht die unmittelbare Voraussetzung der ntl. katalogischen Paränese in jüdischen Texten (150ff); letztlich stehe der "Dualismus in der konkreten Gestalt der iranischen Kosmologie" dahinter (V). Als Vermittler komme der Synkretismus in Frage, "den das achämenidische Großreich angebahnt und der Hellenismus weitergeführt" habe (56). Einerseits wird die Herleitung der paränetischen Doppelkataloge aus der iranischen Kosmologie sicherlich zu einseitig durchgeführt, andererseits tritt bei der Fülle des von KAMLAH ausgebreiteten Materials die besonders enge Beziehung zwischen 1QS IIIf und Gal 5 nicht genügend deutlich hervor. Im Zusammenhang eines Verweises auf den "unversöhnlichen Haß" zwischen den beiden Geistern und darauf, daß "im Wortlaut gerade IV,16-18 an Gal 5,17" offenbar anklingt, wird sogar eine Differenz behauptet, die gar nicht besteht; nur in Gal 5,17 sei "das Kampffeld das Innere des Menschen" (48); KAMLAH übersieht, daß die o. genannte Stelle 1QS IV 23 genau das besagt (leider beruft sich später MUSSNER auf diese falsche Behauptung [s. gleich u.]). - BRAUN I 212-214 gesteht für Paulus und Qumran zu, daß "die Paränese in eine dualistische Grundstruktur eingebettet ist", hebt aber die unterschiedliche Strukturierung in "Geist/Fleisch" bzw. zwei "Geister" hervor (213), ferner die verschiedenen Inhalte der Kataloge (214) und das entgegenge- 
setzte Verhältnis bei Paulus und in Qumran zur Tora (213; neben 5,18 ist aber auch $5,23 \mathrm{~b}$ zu beachten). Was die "Liebe" betrifft, so überzieht er den Gegensatz zwischen Qumran und Paulus, weil ihm die gewisse $\mathrm{Pa}$ rallelität, wenn man die übrigen Tugendkataloge in $1 \mathrm{QS}$ mit heranzieht, entgangen ist (214). Das religionsgeschichtlich-traditionsgeschichtliche Problem bleibt bei BRAUN unberücksichtigt.

In den Kommentaren zum Galaterbrief findet sich der Bezug auf 1QS IV öfter (er fehit aber z.B. bei BECKER, Gal. 70-74, der nur sehr vage feststellt, daß "solche katalogische Ermahnung" "Paulus aus dem Judentum und der kynisch-stoischen Popularphilosophie bekannt" sei [72]; auch bei LÜHRMANN, Gal. 90 fehlt der Hinweis auf 1QS IV; er meint zu Unrecht, daß den paulinischen Listen "stärker Texte aus dem Judentum" entsprechen, "die mehr oder weniger Beziehungen zur griechischen ethischen Unterweisung zeigen" (an welche Texte denkt LÜHRMANN?); gar nichts zum religionsgeschichtlich-traditionsgeschichtlichen Problem der Tugend- und Lasterkataloge finde ich bei FUNG, Gal.): MUSSNER, Gal. geht sowohl innerhalb des laufenden Kommentars (374388) als auch in einem eigenen Exkurs über "Gal 5,16-25 und 1 QS IV" (392-395) ausführlich auf die Qumrantexte ein. Leider diskutiert er die übrigen Vorkommen und die religions- und traditionsgeschichtlichen Herleitungen von Tugend- und Lasterkatalogen nicht. Das hat zur Folge, daß er nur von einem "gewissen gemeinsamen Rahmen dualistischer Natur" zwischen Gal 5 und 1QS IV spricht (381), ja feststellt, der "'Dualismus' der Qumrankataloge" sei "ganz anders strukturiert" (394). Dabei wird unter Verweis auf KAMLAH eine Differenz behauptet, die gar nicht besteht ( 377 Anm. 23 trotz 394; s.o. bei KAMLAH). Natürlich ist nicht $\mathrm{zu}$ bestreiten, daß der große sachliche Unterschied zwischen dem paulinischen Gegensatz von "Fleisch" und "Geist" und den zwei antithetischen "Geistern" in 1QS IIIf theologisch herauszuarbeiten ist (aber möglichst ohne apologetische Töne, wie sie sich vor allem WIBBING, a.a.O. 121 zuschulden kommen läßt). Die Bedeutung der "Liebe" in den Tugendkatalogen von $1 Q S$ erkennt MUSSNER nicht (385. 393f). - Auch H.D. BETZ, Gal. widmet dem Tugend- und Lasterkatalog einen eigenen Exkurs (480-482 [engl.: 281b-283a]), aber 1QS IV spielt kaum eine Rolle bei ihm. Die Begrifflichkeit des paulinischen Katalogs komme aus der "hellenistischen Philosophie" (480 [engl.: 281b]), was eine einseitige Behauptung ist (nicht einmal das gleiche Nebeneinander von "Unzucht" und "Unreinheit" in Gal 5,19 und 1QS IV 10 notiert BETZ, geschweige denn die relative inhaltliche Nähe der beiden Tugendkataloge); für die nicht-hellenistische "Liebe" fällt BETZ in 1QS nichts auf. Zu 1QS IV 3-11 stellt er als Problem fest, daß der doppelte Qumrankatalog "keinen Einfluß griechischer Philosophie aufweist" (481 [engl. 282a]); für den Dualismus des paulinischen Textes spricht er von einer Nähe nur zum Gnostizismus (482 [engl.: 282b])! Für die eschatologische Warnung in Gal 5,21b sieht er allerdings in 1QS IV 11-14 eine "eindrucksvolle 
Parallele" (486 Anm. 128 [engl. 285 Anm. 130]). Immerhin erwähnt BETZ, daß Forscher "auf die große Ähnlichkeit zwischen Gal 5,16ff und dem anthropologischen Abschnitt 1 QS 3.13-4.26 hingewiesen" hätten; "die Unterschiede sind jedoch noch auffallender und" - das ist in der Tat eine immer wieder zu machende Erfahrung bei religionsgeschichtlichen Vergleichen - "beleuchten die Theologie des Paulus mittels des Kontrastes" (475 Anm. 62 [engl.: 278 Anm. 64]). - BRUCE, Gal. nennt zwar als einzigen außerchristlichen Text für Tugend- und Lasterkataloge 1QS IV 2-14 (247), aber sonst erfährt man zum Problem fast nichts.

Sehen wir uns noch einige weitere Stellungnahmen zum Verhältnis von Gal 5 und 1QS IIIf an: unmittelbar nach der Veröffentlichung unseres 1QS-Textes verweist K.G. KUHN für Gal 5,16-23 (und Eph 5,1-7) auf eine Analogie zwischen den ntl. Texten und dem Qumrantext (ZThK 1952, 207 Anm. 6; 212.214 [= in der revidierten engl. Fassung 266 Anm. 15; 104f]). - W.D. DAVIES, Scrolls 170 war 1957 im Zusammenhang der Heranziehung der beiden Lasterkataloge in Gal 5 und 1QS IV zu dem Ergebnis gekommen: "Paul was drawing upon a didactic tradition within Judaism which is represented for us in one of its forms in the Scrolls", aber "any direct relation between the Pauline and the Qumran material cannot be assumed" (170). Der Gebrauch von "Fleisch" sei in den Qumrantexten anders: "Nowhere is the 'flesh' in the Scrolls equated with the spirit of error, rather it is the sphere where this works. The parallelism between Paul and the Scrolls at this point, therefore, is loose" (171). Das wird richtig, wenn man feststellt, daß die oóp als in Qumran (soweit ich sehe) - bei Paulus auch als eine Art 'Macht' verstanden werden kann. - FLUSSER, Judaism 70 weist auf die Parallelität zwischen Gal 5,19-23 und 1QS IV 2-14 hin und stellt eine so große Entsprechung zwischen den beiden Tugendkatalogen fest, daß er sogar von "even literary affinity" spricht. Für die Qumrantexte schließt er ferner auf eine Tendenz zur Gegenüberstellung von "Geist" und "Fleisch". - Gemäß PRYKE, RdQ Nr. 19, 357 sind die Kataloge in Gal 5 und 1QS IV "not dissimilar". - HILL, Words 270 Anm. 5 stellt zum Vergleich von 1QS IV 2ff und Gal 5,18ff m.R. fest: "The contexts also are similar, in that Paul (like the Manual) is discussing the principle or power by which life may be founded and controlled." - Unter ausdrücklicher Nennung von 1 QS IV 23-25 heißt es bei LOHSE, Umwelt 81: "die Grundstruktur dieses [menschlichen] Ringens, wie es in den Texten aus Qumran und von Paulus dargestellt wird, weist recht ähnliche Züge auf." - VIELHAUER, Literatur 54 erkennt klar die "Strukturverwandtschaft" zwischen 1QS IIIf und Gal 5 und stellt fest, daß der paulinische Text "traditionsgeschichtlich von einem in 1QS $3 f$ faßbaren dualistischen Schema abhängig ist" (s. 121); FS Käsemann 545 setzt VIELHAUER für die Forschung am Galaterbrief voraus, daß "1QS 3,25-4,14 als formale und inhaltliche Parallele zu dem Laster- und Tugendkatalog Gal 5,19(16)-23 bekannt ist". SCHWEIZER, FS Käsemann 467 mit Anm. 20 nennt als religionsge- 
schichtliche Parallele für Gal 5,19ff nur 1QS IV 2ff und betont für die "Art Tugendliste" in 5,22f, daß hier "die vier griechischen Kardinaltugenden fehlen". - SCHRAGE, Ethik 134 beobachtet hinsichtlich der Tugend- und Lasterkataloge, daß sich "vor allem Gal 5" insbesondere von den Qumrantexten "gut begreifen" lasse. - Ähnlich wie H.D. BETZ liegt meines Erachtens auch bei SYNOFZIK, Gerichts- und Vergeltungsaussagen, der die Ergebnisse der Arbeiten von WIBBING und KAMLAH ausdrücklich ablehnt (134 Anm. 19), ein exegetisches Fehlurteil vor: er sieht für das NT in den Katalogen, speziell in den Lasterkatalogen (vom Thema seiner Untersuchung her) des jüdischen Hellenismus (z.B. in SapSal 14,25f.30f) die nächsten religionsgeschichtlichen Parallelen; die ntl. Kataloge enthielten "als neues und eigenes Element" die eschatologisch begründete Paränese, obgleich SYNOFZIK eine gewisse Parallele zu 1QS IV im Eschatologischen annimmt (67f). - Abseits von der sonstigen Forschung zu diesem Problem vertritt BERGER in einem Kapitel über "Tugend- und Lasterkataloge" (ANRW II 25/2, 1088-1092) die eigenartige These, daß die dualistische Form dieser Kataloge (Hinweis von BERGER speziell auf Gal 5,19.22) "aus der paganen Tradition über Herakles am Scheidewege" abzuleiten sei; anstelle von zwei Frauen und ihrem Gefolge werde in der jüdischen (mit Ausnahme von Philo) und christlichen Tradition aber immer nur von "zwei Arten von Geistern" (Hinweis auf 1QS IIIf), "zwei Engeln" oder "zwei Wegen" gesprochen (1090; zurückhaltender in der gleichzeitig erschienenen Formgeschichte des NT 150f).

Die Ergebnisse für den Vergleich der drei Paulustexte mit den Qumranschriften seien hier unter traditionsgeschichtlichen Gesichtspunkten zusammengefaßt:

(1) Das Spannende an dem Vergleich ist, daß deutlich wird, wie der (ehemalige) Pharisäer Paulus (Phil 3,5 ) jüdische Traditionen einerseits aufnimmt und andererseits radikal verändert. Das theologische Profil des Apostels kann überhaupt nur herausgearbeitet werden, wenn auch die jüdischen Traditionen, von denen her er denkt, freigelegt werden.

Im Zusammenhang der Auslegung von $\mathrm{Hab}$ 2,4b in Gal 3,11 wird deutlich, daß der schwerwiegendste theologische Schritt, den Paulus gegenüber seiner jüdischen Tradition - und hier geht es nicht um spezifisch Qumranisches - getan hat, darin liegt, daß er den "Glauben" von dem "Tun" der Tora trennt, weil für ihn die Offenbarung des Heils gemäß Röm 3,21 "abseits von der Tora" ( $\chi$ wpis vónov) erfolgt ist. Nach 1QpHab VIII 1-3 erlangen nur die "Täter der Tora" das eschatologische Heil, und insofern ist die Tora für den Qumranfrommen, aber auch für jeden anderen Juden 'Heilsweg'. Der Pharisäer Paulus hat mit seiner Deutung der für seine Theologie so wichtigen Prophetenstelle Hab 2,4 theologisch zweifellos einen Schritt jenseits des Judentums getan - und das also unter Rückgriff auf die gemeinsame Bibel. Speziell für den Qumranfrommen gehört zum Tun der Tora auch das "Vertrauen" auf 
den Lehrer der Gerechtigkeit. Daß Paulus ähnlich vom "Glauben an Jesus Christus" spricht, zeigt demgegenüber eine erstaunliche und bisher sonst frühjüdisch nicht belegte Gemeinsamkeit. Daß wir nun eine zeitgenössische jüdische Auslegung einer für Paulus zentralen Bibelstelle im Original besitzen, kann nicht hoch genug eingeschätzt werden.

Die Tora ist auch in Gal 3,13 betroffen. Unter Heranziehung einer Auslegung von Dtn 21,22f, von der wir erst durch die Qumrantexte sicher wissen, daß sie nicht von Paulus selbst stammt, sondern schon vor Paulus im Judentum vorhanden war (Deutung dieser Bibelstelle auf die Kreuzesstrafe), proklamiert Paulus vom Kreuzestod Jesu her für die Glaubenden das Ende der Flüche, die die Tora gegenüber denen ausspricht, die sie nicht halten (Paulus zitiert in 3,10 Dtn 27,26 und spielt in 3,13 auf diese Stelle an).

Bei dem Tugend- und Lasterkatalog in Gal 5,16-23, der bis zum Auffinden der Qumrantexte generell als spezifisch hellenistisch beurteilt wurde, greift Gal 5 wie ein Text der Gemeinderegel auf eine dualistische Tradition zurück, die weder biblisch noch generell hellenistisch oder hellenistisch-jüdisch ist, sondern offenbar von Haus aus mit iranischer Tradition zu tun hat. Paulus geht aber noch einen Schritt weiter in der Auflösung des iranischen Dualismus, als es der Qumrantext tut. Er stellt nicht wie die Qumrantexte (auch außerhalb von 1QS IIIf) zwei antithetische "Geister" gegenüber, die auch als prädestiniertes Sein das Individuum bestimmen, sondern führt einerseits gut jüdisch die "Tugenden" auf Gottes heiligen Geist zurück (was dem Qumrantext theologisch nicht "gelungen" ist) und stellt andererseits, ganz unalttestamentlich (vgl. aber Num 16,22 und 27,16 LXX gegen den hebräischen Wortlaut), das "Fleisch" dem "Geist" als eigene Mächtigkeit (s. gerade in Gal 5 V.17 und vgl. auch V.13 und V.19 mit V.22) gegenüber (was der Qumrantext, trotz aller negativen Wertung des "Fleisches", nicht getan hat). Hervorzuheben ist noch einmal, wie Paulus und 1QS im Zusammenhang der Tugendkataloge - anders als die hellenistische Tradition in den Katalogen - die "Liebe" betonen.

(2) Wie steht es aber mit einer direkten oder indirekten Abhängigkeit des Paulus von der Qumrangemeinde? Nur aufgrund der hier behandelten drei Stellen ist eine genauere Antwort nicht möglich. Deshalb sei nur so viel gesagt: Abgesehen von dem wohl unpaulinischen Einschub in 2Kor 6,14-7,1 zeigt der vermutlich älteste Paulusbrief in 1Thess 5,4-9 die deutlichste Nähe zur Qumrangemeinde. Im Galaterbrief steht vor allem noch die den Gegnern des Paulus in 4,10 vorgeworfene Beobachtung von Kalenderdaten, wo eine mit 1QS X 5f sehr verwandte Aufzählung vorliegt (in 1QS "Monate", "festgesetzte Zeiten" [öfter wiederholt], "Tage" und "Jahre"), in Verdacht, traditionsgeschichtlich mit der Qumrangemeinde zusammenzuhängen.

Leider gibt es im Augenblick noch keine sichere Erkenntnis darüber, ob wir nicht auch zum ersten Mal für die im Galater- und Römerbrief begegnende Wendung épya vópov mit dem Sinn "Werke des Gesetzes" eine außerchristliche Parallele in den Qumrantexten 
haben. Das Leder ist in 4Q174 Flor 1-2 I 7 gerade bei dem bisher weithin gelesenen 7 (vb तin) offenbar leicht beschädigt, und kompetente Forscher, die die Originalhandschrift im Sommer 1991 eingesehen haben, sprechen sich, wie ich von ihnen erfuhr, entgegen der Edition des Textes für die eher seltsame Formulierung "Werke des Lobpreises" (Trm चפס) aus. Meine Überprüfung am Original im Rockefeller-Museum in Jerusalem im Juli $1992 \mathrm{er}$ gab, daß sehr wahrscheinlich ein Dalet zu lesen ist (s. Einzelheiten in meinem Beitrag im Band des Pariser Qumran-Kongresses vom Juli 1992).

Obgleich fast alle oben ausführlich zitierten Qumrantexte zu Schriften gehören, die in der Qumrangemeinde entstanden sind (1QS, 1QpHab und 4QpNah; nur die Tempelrolle dürfte schon vorqumranisch sein), läßt sich für die oben genannten Parallelen zwischen Qumran und den drei Galaterstellen höchstens für die dualistische Einbettung der Tugend- und Lasterkataloge ein vielleicht indirekter traditionsgeschichtlicher Zusammenhang herstellen. Wir sind über das gesamte Judentum der neutestamentlichen Zeit zu wenig informiert, um hier mehr sagen zu können. Wo und ob überhaupt Wege der Tradition zwischen der Qumrangemeinde und Paulus verlaufen - wie indirekt auch immer -, wird erst die abschließende Untersuchung des gesamten Materials für die authentischen Paulusbriefe vielleicht ein wenig präziser formulieren können.

\section{ZITIERTE LITERATUR}

Für die Abkürzungen der Zeitschriften usw. - auch z.T. der in diesem Beitrag genannten jüd. Schriften - s. S. SCHWERTNER, Theologische Realenzyklopädie: Abkürzungsverzeichnis. Berlin/New York 1976. - Die Editionen der Qumrantexte und ein Verzeichnis ihrer Abkürzungen s. bei J.A. FITZMYER, The Dead Sea Scrolls: Major Publications and Tools for Study. SBL 20. [3.,] korr. Aufl. Atlanta 1990; für alle weiteren Editionen antiker Schriften - sofern sie nicht im Text genannt sind - sei vor allem auf die einschlägigen neueren Nachschlagewerke verwiesen.

-ALLEGRO, J[ohn] M. "Further Light on the History of the Qumran Sect". JBL 75 (1956): 89-95. Tafeln I-IV.

-BALTZER, Klaus. Das Bundesformular. WMANT 4. 2., durchges. Aufl. Neukirchen 1964. -BARDTKE, Hans. Die Handschriftenfunde am Toten Meer: Die Sekte oon Qumran. 2. Aufl. Berlin 1961 [11958].

-BAUMGARTEN, Joseph M. "Hanging and Treason in Qumran and Roman Law". ErIs 16 (1982): $7^{*}-16^{*} .202$.

-BECKER, Jürgen. "Der Brief an die Galater". Die Briefe an die Galater, Epheser, Philipper, Kolosser, Thessalonicher und Philemon. Übers. und erkl. von DERS. [u.a.]. NTD 8. 17. (= 4.) Aufl. Göttingen 1990 [14(=1)1976]. 1-85.

-BERGER, Klaus. Formgeschichte des Neuen Testaments. Heidelberg 1984.

-. $\quad$ "Hellenistische Gattungen im Neuen Testament". ANRW II 25.2 (1984): 1031-1432.

-BETZ, Hans Dieter. Galatians: A Commentary on Paul's Letter to the Churches in Galatia. Hermeneia. Philadelphia. 1979 [21984 (korrigierter Nachdruck) war mir nicht zugänglich]. Deutsche Ausgabe: Der Galaterbrief. Ein Kommentar zum Brief des Apostels Paulus an die Gemeinden in Galatien. Übers. und bearb. von S. ANN. München 1988.

-BRAUN, Herbert. Qumran und das Neue Testament. Bd. 1. Tübingen 1966 [zuerst als Aufsätze 1962-1964].

-BROWNLEE, William H. The Midrash Pesher of Habakkuk. SBLMS 24. Ann Arbor 1979. 
-BRUCE, F.F. The Epistle of Paul to the Galatians: A Commentary on the Greek Text. New Intern. Greek Test. Comm. Exeter 1982.

-BULTMANN, Rudolf. Theologie des Neuen Testaments. UTB 630. 9., von Otto MERK durchges. u. erg. Aufl. Tübingen 1984 [11953].

-CRANFIELD, C.E.B. A Critical and Exegetical Commentary on the Epistle to the Romans. ICC. Bd. 1. 3., korr. Aufl. Edinburgh 1980 [1 1975]; Bd. 2. Edinburgh 1979.

-DANIÉlOU, Jean. Les manuscrits de la mer Morte et les origines du christianisme. 2. durchges. u. erw. Aufl. o.O. 1974 [11957].

-DAVIES, W.D. "Paul and the Dead Sea Scrolls: Flesh and Spirit". The Scrolls and the New Testament. Hg. K. STENDAHL. New York 1957. 157-182. 276-282.

-ELLIGER, Karl. Studien zum Habakuk-Kommentar oom Toten Meer. BHTh 15. Tübingen 1953.

-FIELD, Fridericus. Origenis Hexaplorum quae supersunt sive veterum interpretum Graecorum in totum Vetus Testamentum fragmenta. Bd. 1. Oxford 1875; Nachdruck Hildesheim 1964.

-FITZMYER, Joseph A. "Crucifixion in Ancient Palestine, Qumran Literature, and the New Testament". DERS. To Adoance the Gospel: New Testament Studies. New York 1981. 125-146.

-. "Habakkuk 2:3-4 and the New Testament". DERS. To Adrance the Gospel: New Testament Studies. New York 1981. 236-246.

-FLUSSER, David. "The Dead Sea Sect and Pre-Pauline Christianity" (1958). DERS. Judaism and the Origins of Christianity. Jerusalem 1988. 23-74.

-FUNG, Ronald Y.K. The Epistle to the Galatians. NIC. Grand Rapids 1988.

-GESENIUS, Wilhelm, und E[mil] KAUTZSCH. Hebräische Grammatik. 28., vielf. verb. u. verm. Aufl. Leipzig 1909; Nachdrucke.

-HALPERIN, David J. "Crucifixion, the Nahum Pesher, and the Rabbinic Penalty of Strangulation". JJS 32 (1981): 32-46.

-HENGEL, Martin. Crucifixion in the Ancient World and the Folly of the Message of the Cross. Übers. von J. BOWDEN. London/Philadelphia 1977.

-. Rabbinische Legende und frühpharisaische Geschichte: Schimeon b. Schetach und die achtzig Hexen oon Askalon. AHAW.PH 2. Heidelberg 1984.

-HILL, David. Greek Words and Hebrew Meanings: Studies in the Semantics of Soteriological Terms. MSSNTS 5. Cambridge 1967.

-HORGAN, Maurya P. Pesharim: Qumran Interpretations of Biblical Books. CBQ. MS 8. Washington 1979.

-JEREMIAS, Gert. Der Lehrer der Gerechtigkeit. StUNT 2. Göttingen 1963.

-JEREMIAS, Joachim. Der Opfertod Jesu Christi. CwH 62. 2. Aufl. Stuttgart 1966 [11963].

-KÄSEMANN, Ernst. An die Römer. HNT 8a. 4., durchges. Aufl. Tübingen 1980 [11973].

-KAMLAH, Ehrhard. Die Form der katalogischen Paränese im Neuen Testament. WUNT 7. Tübingen 1964.

-KERTELGE, Karl. "Das Verständnis des Todes Jesu bei Paulus" (1976). DERS. Grundthemen paulinischer Theologie. Freiburg/Basel/Wien 1991. 62-80.

-KIM, Seyoon. The Origin of Paul's Gospel. WUNT 2.4. 2. rev. u. erw. Aufl. Tübingen 1984.

-KNIBB, Michael A. The Qumran Community. Cambr. Comm. on Writ. of the Jew. and Christ. World $200 \mathrm{BC}$ to AD 200 2. Cambridge [u.a.] 1987.

-KUHN, Heinz-Wolfgang. Enderwartung und gegenwärtiges Heil. Untersuchungen zu den Gemeindeliedern oon Qumran mit einem Anhang uber Eschatologie und Gegenwart in der Verkindigung Jesu. StUNT 4. Göttingen 1966.

-. $\quad$ "Jesus als Gekreuzigter in der frühchristlichen Verkündigung bis zur Mitte des 2. Jahrhunderts". ZThK 72 (1975): 1-46. 
-. "Die Kreuzesstrafe während der frühen Kaiserzeit: Ihre Wirklichkeit und Wertung in der Umwelt des Urchristentums". ANRW II 25.1 (1982): 648-793.

-. "Kreuz. II. Neues Testament und frühe Kirche bis vor Justin". TRE 19 (1990): 713725.

-KUHN, Karl Georg. "Die Sektenschrift und die iranische Religion". ZThK 49 (1952): 296-316.

-. "Пвц den Vorstellungen". ZThK 49 (1952): 200-222. Rev. engl. Fassung: "New Light on Temptation, Sin, and Flesh in the New Testament". The Scrolls and the New Testament. Hg. K. STENDAHL. New York 1957. 94-113. 265-270.

-KUTSCHER, E. Y. The Language and Linguistic Background of the Isaiah Scroll (1 $Q$ Isa $a^{a}$. Leiden 1974.

-LICHTENBERGER, Hermann. Studien zum Menschenbild in Texten der Qumrangemeinde. StUNT 15. Göttingen 1980.

-LOHSE, Eduard. Die Texte aus Qumran. 4. Aufl. Darmstadt 1986 [= 21971].

-. Umwelt des Neuen Testaments. GNT 1. 8., durchges. u. erg. Aufl. Göttingen 1989 [1971].

-LÜHRMANN, Dieter. Der Brief an die Galater. ZBK NT 7. 2. Aufl. Zürich 1988 [11978].

-MAIER, Johann. Die Texte vom Toten Meer. 2 Bde. München/Basel 1960.

-MILIK, J[osef] T., Rez. "P. WERNBERG-MøLLER. The Manual of Discipline translated and annotated" (Leiden 1957), RB 67 (1960): 410-416.

-MUSSNER, Franz. Der Galaterbrief. HThK 9. 5., erw. Aufl. Freiburg/ Basel/Wien 1988 [11974].

-PRYKE, John. "'Spirit' and 'Flesh' in the Qumran Documents and some New Testament Texts", RdQ 5 Nr. 19 (1965): 345-360.

-PUECH, Émile. "Un Hymne essénien en partie retrouvé et les Béatitudes. 1QH V 12-VI 18 (= col. XIII-XIV 7) et 4QBéat". RdQ 13 Nr. 49-52 (1988): 59-88.

-ROHDE, Joachim. Der Brief an die Galater. ThHK 9. 1. Aufl. der Neubearbeitung. Berlin 1989.

-ROWLEY, H. H. "4QpNahum and the Teacher of Righteousness". JBL 75 (1956): 188-193. -SCHELKLE, Karl Hermann. Paulus: Leben - Briefe - Theologie. EdF 152. 2. Aufl. Darmstadt 1988 [11981].

-SCHRAGE, Wolfgang. Ethik des Neuen Testaments. GNT 4. 5., neubearb. und erw. $(=2$.) Aufl. Göttingen 1989 [ $\left.{ }^{4(=1)} 1982\right]$.

-SCHÜRER, Emil. The History of the Jewish People in the Age of Jesus Christ (175 B.C.A.D. 135). Bd 1. Überarb. u. hg. von G. VERMES und F. MILLAR. Edinburgh 1973.

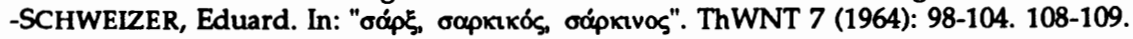
118-151.

-. "Gottesgerechtigkeit und Lasterkataloge bei Paulus (inkl. Kol und Eph)". Rechtfertigung. Festschrift für Ernst Käsemann zum 70. Geburtstag. Hg. J. FRIEDRICH [u.a.]. Tübingen/Göttingen 1976. 461-477.

-. $\quad$ "Jesus Christus. I. Neues Testament". TRE 16 (1987): 671-726.

-SEGAL, M. H. A Grammar of Mishnaic Hebrew. Oxford 1927.

-SEKKI, Arthur E. The Meaning of Ruah at Qumran. SBLDS 110. Atlanta 1989.

-STEGEMANN, Hartmut. "Zu Textbestand und Grundgedanken von 1QS III,13-IV, 24". RdQ 13 Nr. 49-52 (1988): 95-131.

-SYNOFZIK, Ernst. Die Gerichts- und Vergeltungsaussagen bei Paulus: Eine traditionsgeschichtliche Untersuchung. GTA 8. Göttingen 1977.

-VIELHAUER, Philipp. Geschichte der urchristlichen Literatur: Einleitung in das Neue Testament, die Apokryphen und die Apostolischen Väter. Berlin/New York 1975. 
-. "Gesetzesdienst und Stoicheiadienst im Galaterbrief". Rechtfertigung. Festschrift für Ernst Käsemann zum 70. Geburtstag. Hg. J. FRIEDRICH [u.a.]. Tübingen/Göttingen 1976. 543-555.

-VÖGTLE, Anton. Die Tugend- und Lasterkataloge im Neuen Testament: Exegetisch, religions- und formgeschichtlich untersucht. NTA 16,4/5. Münster 1936.

-WIBBING, Siegfried. Die Tugend- und Lasterkataloge im Neuen Testament und ihre Traditionsgeschichte unter besonderer Berücksichtigung der Qumran-Texte. BZNW 25. Berlin 1959.

-WILCOX, Max. "'Upon the Tree' - Deut 21:22-23 in the New Testament". JBL 96 (1977): 85-99.

-YADIN, Yigal. "Pesher Nahum (4Q pNahum) Reconsidered". IEJ 21 (1971): 1-12. Tafel 1.

-. The Temple Scroll. Bd. 1-2. Jerusalem 1983 (zuerst 1977 modern-hebr.), Bd. 3 (mit Supplementary Plates). Jerusalem 1977. 


\section{ZUR FABEL IN DTN 31-32}

von

Norbert Lohfink

Frankfurt a.M.

\section{ZUR FRAGESTELLUNG}

Darf man im Deuteronomium nach der Fabel ${ }^{1}$ fragen? Dagegen spricht: Das Deuteronomium hatte eine lange und komplizierte Entstehungsgeschichte. Es ist aus Stücken verschiedener Herkunft zusammengefügt und immer wieder "fortgeschrieben" worden. Dazu ist es in der Hauptsache ein Gesetzbuch. Kommt da dem Handlungsablauf noch Relevanz zu? Haben sich letzte Redaktoren noch solchen Sorgen hingegeben - daß ihr Text so sein müsse, daß er eine Fabel besitze? Andererseits: Darf man die Frage nach der Fabel eines erzählenden Textes nur stellen, wenn sicher ist, daß Verfasser oder Redaktoren in ihrer Textbildungsstrategie eine Fabel ausdrücklich angezielt haben? Und nochmals andersherum: Sind wir denn selbst bei späten biblischen Redaktoren sicher, daß sie keine Fabel im Sinn hatten?

Natürlich darf man die Frage nach der Fabel, stellt man sie an den Endtext, auch nicht mit falschen Erwartungen beladen. Selbst aus einem einzigen Wurf stammende Erzählungen können Lücken, Leerstellen, Unbestimmtheiten ${ }^{2}$ in der Fabel aufweisen. Vorläufige Lücken der Fabel können strategische Leserführung, Unbestimmtheiten können die interpretative Freiheit des Lesers herausfordern wollen. Nichts spricht dagegen, daß die Redaktoren des Deuteronomiums vorgegebene Inkongruenzen ihres Materials zur Erzeugung von Leerstellen in der Fabel bewußt beließen. Genau solche Möglichkeiten bedürfen aber, treibt man schon Exegese, reflexer Diskussion.

Für ein analoges und benachbartes Problemfeld, den Pentateuch, hat E. BLUM nun allerdings die Frage gestellt, ob dieser überhaupt als einheitlicher Text gelesen werden, ob er nicht inkonsistent sein will ${ }^{3}$. In der Tat könnte der Pentateuch aus einem "Kompromiß" stammen, der innerjüdisch geschlossen wurde, um die persische "Reichsautorisation" erlangen zu können. Er könnte nicht mehr als eine Art Anthologie sein, die, obwohl oberflächlich in einer gewissen narrativen Kontinuität

\footnotetext{
1 Zur verwendeten Terminologie: "Fabel" = engl. "plot". In der neueren Kommentarliteratur habe ich eine wirkliche Diskussion der Fabelproblematik für Dtn 31-32 nur bei HUMMELAUER, Deuteronomium, ab S. 490, gefunden.

2 Die drei Wörter geben im folgenden je nach Kontext das wieder, was das englische Wort "gap" meint.

3 BLUM, Endgestalt.
} 
geordnet, verschiedene juristische Sichten, aber wohl auch verschiedene Konzeptionen der Anfänge Israels unaufgelöst nebeneinanderstellt. Das Deuteronomium bietet dann eine der konkurrierenden Perspektiven. Doch selbst wenn man das annimmt, muß man das gleiche Gattungsmuster nicht ohne weiteres noch ein zweites Mal postulieren, nun innerhalb des Deuteronomiums. Schon ein der "Reichsautorisation" vergleichbarer historischer Anlaß wäre kaum aufzufinden. Der außerordentlich starke Gestaltungswille, den die sprachliche Oberfläche des Deuteronomiums trotz aller diachronen Textschichtung bezeugt, spricht eher dagegen.

Ich schränke die Frage auf Dtn 31-32 ein. Denn hier fallen im Deuteronomium die wichtigsten Entscheidungen. Den Rest des Deuteronomiums hoffe ich bei anderer Gelegenheit behandeln zu können. Ich frage erst recht nicht nach jenem ersten Teil der deuteronomischen Fabel, der dem Bucheinsatz kurz vor dem Tod Moses vorausliegt und in verschiedenen Reden Moses nachholend eingebracht wird. Behandelt sei nur, was an dem einen Tag, den der Bucherzähler selbst abrollen läßt, als Geschehensfolge dem Text unterliegt, und das eingegrenzt auf Dtn 31-32. Dabei möchte ich, da die Frage so ungewohnt ist, in den Abschnitten 2 und 3 ihr Recht zunächst noch einmal aus verschiedenen Beobachtungen $\mathrm{zu}$ legitimieren versuchen.

\section{DTN 31-32 LXX UND DAS PROBLEM DER FABEL}

In Dtn 31-32 zeigt der Unterschied der LXX- und der MT-Fassung, daß die Frage nach der Fabel zumindest in den ersten Phasen der Texttradition aktuell war. Ich beginne mit einer Beschreibung des masoretischen Textes.

So sehr in den beiden Kapiteln zitierte Reden das Bild bestimmen es spricht auch eine Erzählerstimme, die die Reden zitiert. Diese Stimme spricht überdies nicht selten. In 31,1 erzählt sie, daß Mose das Wort an "ganz Israel" richtete, und leitet so eine Rede ein. In 31,7 erzählt sie, daß Mose Josua "rief" und vor "ganz Israel" zu ihm sprach. In 31,9 erzählt sie, daß Mose die Tora ${ }^{4}$ schriftlich aufzeichnete und sie "den Priestern, den Leviten, die die Lade des Jahwebundes trugen, sowie allen Ältesten Israels" übergab. Dann $(31,10)$ führt sie die Rede ein, mit der Mose die Verlesung der Tora in jedem siebten Jahr anordnete. In 31,14 führt sie ein Jahwewort ein, das selbst wieder eine Theophanie ankündet. In

\footnotetext{
4 N.M. SARNA, EJ IV, 821 (unter "Bible"), schreibt zu 31,9-12.24: "The reference here seems more likely to be to the succeeding song (Deut. 32), as is indicated by verses 19 and 22." FISHBANE, Varia, 350f, nimmt das auf und versucht, durch Hinweis auf den häufigen keilschriftlichen Kolophonvermerk qati, wozu 31,24.30 פר zu vergleichen sei, eine entstehungsgeschichtliche Erklärung nachzuliefern. Mir scheint die Referenz von ח המרז dann, wenn im Deuteronomium einmal das Kapitel 31 erreicht ist, absolut festzuliegen.
} 
31,15 schildert sie diese Theophanie. Sie führt dann in 31,16 noch innerhalb der Theophanie ein Gotteswort an Mose ein, erzählt - vermutlich im Vorgriff ${ }^{5}$ - in 31,22, Mose habe die ihm gegebene Weisung ausgeführt, das ihm geoffenbarte Lied aufgeschrieben und es noch am gleichen Tag die Israeliten gelehrt. In 31,23 führt die Erzählerstimme ein zweites Gotteswort aus der Theophanie ein. Es ist an Josua gerichtet ${ }^{6}$. In 31,24f greift sie nochmals auf die Niederschrift der Tora durch Mose zurück (... וויה ככלות משדה לכתב) und leitet eine Rede ein, die Mose im Anschluß an die Niederschrift "den Leviten, die die Lade des Jahwebundes trugen," hielt. Mose übergab ihnen die Tora und forderte sie auf, "alle Ältesten der Stämme und die Schriftführer" zusammenzurufen, damit er sie ermahnen könne. Die Wörter, die er dabei in 31,28-30 gebraucht, lassen ahnen, daß er ihnen das Moselied übermitteln will - zumindest wird sich dieser Zusammenhang zeigen, wenn das Lied nun sofort zitiert wird7. Die Erzählerstimme führt denn auch in 31,30 das Moselied $(32,1-43)$ ein. Mose sprach es "in die Ohren der ganzen Versammlung Israels (כלדקהל ימוראו)". Nach dem Ende des Liedzitats teilt die gleiche Stimme in 32,44 mit, Mose sei "gekommen" - in eine Versammlung hinein "aufgetreten"? - und habe, zusammen mit Josua, den gesamten Text des Liedes "in die Ohren des Volkes" gesprochen. Die Frage, ob hier nochmals dasselbe gesagt wird wie in 31,30, oder ob es sich um die Kurznotiz über einen zweiten Vortrag des Moselieds vor einem anderen Publikum handelt, wird uns später beschäftigen müssen. Dann stellt die Erzählerstimme in 32,45 das Ende des Redens Moses zu "ganz Israel" fest und führt in 32,46 sein letztes Wort ein. In 32,48 führt sie ein Jahwewort an Mose ein, das an "ebendiesem Tage" ergangen sei. Jahwe befahl Mose, den Berg zu besteigen, wo er sterben sollte.

Kein Zweifel also: So voluminös das Zitierte sein mag, ein Erzähler erzählt. Der Text ist seiner Gattung nach "Erzählung". Bei einer Erzählung aber ist, da Erzählfolge und erzählte Ereignisabläufe nun einmal differieren können ${ }^{8}$, die Frage nach der Fabel am Platz. Daß sie sich

\footnotetext{
5 Es wird nicht nötig sein, mit EISSFELDT, Umrahmung, 327, mit "um es die Israeliten zu lehren" zu übersetzen und das wayylqtol als Ausdruck der "verfolgten Absicht" zu interpretieren.

6 Vgl. Anhang I, unter I.2.

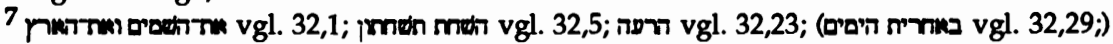
לדבעיט vgl. 32,16.19.21.(21.27). EISSFELDT, Umrahmung, 331, muß sich damit auseinandersetzen, daß nach seiner Theorie diese Verse dennoch vom Gesetz handeln. Seine Theorie ist allerdings darauf fundiert, daß er als ursprünglichen Ort von 32,44 den Platz vor 32,1 annimmt und zudem für 31,30 postuliert, התור ersetze ein ursprüngliches Beides ist unbeweisbar.

8 Ich setze in der ganzen nun folgenden Diskussion voraus, daß mit wayyiqtol eingeleitete erzählende Hauptsätze zwar normalerweise, aber keineswegs grundsätzlich eine Handlung benennen, die auf der Ebene der Fabel an die Handlung des vorausgehenden Hauptsatzes anschließt. Der Anschluß wird formal nur auf der Ebene des Erzählens hergestellt.
} 
sofort und fast automatisch gestellt haben muß, zeigt ein Blick auf die Textform, die in der Septuaginta vorliegt ${ }^{9}$, und für die es vermutlich schon eine hebräische Vorlage gab ${ }^{10}$. Diese Textgestalt scheint gegenüber einer Vorform, welcher der masoretische Text im allgemeinen noch näher steht, neu redigiert zu sein ${ }^{11}$. Zumindest die meisten wirklich wichtigen Unterschiede erklären sich am leichtesten, wenn man sie als ein Ringen um die offenbar nicht sofort auf der Hand liegende Fabel des älteren Textes ansieht ${ }^{12}$.

In 31,1 MT beginnt Mose in Abhebung von der in 29-30 zitierten

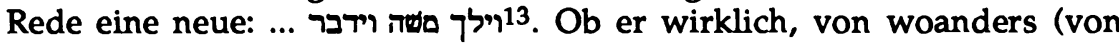
Gott?) kommend im realistischen Sinn des Wortes zum versammelten Israel hingeht und derart eine ganz neue Szene eröffnet ${ }^{14}$ ? Ob ויל vor einem zweiten finiten Verb nur einfach "den Vorgang anschaulich" macht ${ }^{15}$, vielleicht als "mere introductory word" 16 mit der Nuance des Neuansatzes im Weitergang einer zusammenhängenden Ereigniskette? ${ }^{17}$ Die erste Möglichkeit liegt beim Blick auf den Gebrauch von

\footnotetext{
9 Ich halte mich an den kritischen Text in WEVERS, Deuteronomium.

10 Vgl. 1QDeut ${ }^{b}$, das in 31,1 liest: ויכל משה לדבר אח כל הד] (DJD I, 59). Das Manuskript geht aber nicht überall mit LXX zusammen.

11 Einzeldiskussion relevanter Varianten: Anhang I.

12 Ich sehe von den Unterschieden innerhalb des Moselieds ab. Sie sind separat zu diskutieren, da nicht ohne weiteres ausgeschlossen werden kann, daß dieses Lied noch einmal eine besondere Textgeschichte hatte. Zum Text des Lieds vgl. zuletzt BOGAERT, Rédactions.
}

13 Ein "Gehen" (הלך) Moses zu den Israeliten gibt es im Deuteronomium nur noch in 5,30 und 10,11, zwei Gottesbefehlen. Gleiche Konstruktion wie 31,1 hat 31,14. Mose "geht", in Ausführung eines Gottesbefehls, zusammen mit Josua zum Zelt. Der Zusammenhang legt eine Ortsveränderung nahe. Es gibt keine deuteronomischen Parallelen zum "Gehen" Moses zu einer Versammlung. In 32,44 steht in analogem Zusammenhang ma (dazu vgl. unten). Ein Gottesbefehl an Mose, zum versammelten Israel zu gehen und zu ihnen zu reden, steht nur in 5,30 ohne Ausführungsbericht). Doch mit ihm hat 31,1 nichts zu tun. Der Sinn von 31,1 muß mom außerdeuteronomischen Gebrauch von מרץ her geklärt werden.

14 So etwa LUTHER, BUBER, Einheitsübersetzung. Hier wird wohl insgeheim ein nicht berichteter Gottesbefehl vorausgesetzt. In der Tat leitet oft ein mit dem Imperativ von זיר eingeleiteter Befehl eine Ausführungserzählung ein, die dann mit וילך o.ä. beginnt. Vgl. Ex 4,12.18; 4,27; 1 Kön 17,3.5; 2 Kön 5,5; 22,13.14; Hos 1,2.3. In den meisten Belegen der narrativen Abfolge "gehen - reden" wird nicht abgeblaßt gebraucht, das Gehen ist eine reale Ortsveränderung. Vgl. Gen 50,18; Ex 4,18; Num 22,7; Jos 5,13; 9,6.11; Ri 9,1; 1 Sam 3,6.8.

15 Formulierung in HAL 236b, unter 3. Dort Belege.

16 So formuliert BDB 234a, unter I.5.f, vgl. GB 16 181b, unter 5.a: "als Einleitung". Standardbeispiele für diesen Gebrauch von 24,2 hatte LXX eine knappere Vorlage oder hat - wegen Schwierigkeiten mit dem Idiom? - zusammenziehend übersetzt. Jedenfalls fehlt eine Entsprechung zu מביז וחרכה

17 Vgl. etwa Gen 22,13; Ex 2,1; Ri 9,7.8; 2 Sam 6,12; 1 Kön 16,31; 1 Kön 17,5 (गך); 2 Kön 3,7; 2 Kön 5,11. In fast allen Fällen kann man aber auch die Meinung vertreten, es sei echte örtliche Bewegung gemeint. In Dtn 31,1 geht eine ausgedehnte Rede voraus, so daß man, will man die Handlungskette sehen, fast schon das ganze Buch ins Auge fassen muß. In 
statistisch näher, die zweite ist aber nicht ausschließbar. Auf jeden Fall wird die schon mindestens seit 29,1 vor "ganz Israel" spielende Handlung zu Neuem vorangetrieben. Es ist zumindest nicht ganz klar, ob 31,1-6 in MT noch in die gleiche Szene gehören wie 29,30 oder nicht. Nach 31,1f LXX dagegen steht der Gedanke des Endes der in 29,1 beginnenden Rede im Vordergrund. Mose beendet sie, indem er jetzt nur

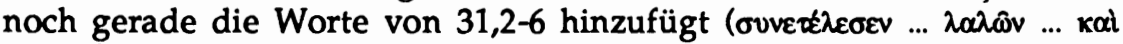
हimev)18. Der Zusammenhang mit den beiden vorangehenden Kapiteln ist auch dadurch verstärkt, daß bei LXX die Erweiterung der Adressaten-

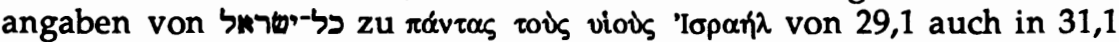
durchgeführt ist ${ }^{19}$. Durch ihre andere Formulierung, die sich in der hebräischen Vorlage nur minimal von der in MT unterscheidet, ähnelt die Aussage von 31,1f LXX der von 32,45f. Doch handelt es sich in 31,1f LXX um das Schlußstück einer bestimmten Rede Moses, in 32,45f LXX um das Schlußstück jeglichen Redens Moses zu ganz Israel ${ }^{20}$. Auf jeden Fall: In LXX läuft nach 31,1 die Szene von 29-30 weiter.

In 31,1 könnte - zumindest am Anfang des Verses - LXX die ältere Gestalt bieten, von der sich eher MT entfernt ${ }^{21}$. Anders ist das in 31,23 .

Dort spricht in LXX das Zitat über Jahwe in dritter Person. Es kann daher nur als Moserede, nicht als Jahwerede verstanden werden. In MT ist es Jahwerede. LXX interpretiert das in der Redeeinleitung am Anfang von 31,23 nicht genannte Subjekt der Rede also anders als MT. Wir sind schon außerhalb der Theophanie. Der Anlaß für diesen Umbau dürfte 31,22 gewesen sein. Die proleptische Ausführungsnotiz in diesem Vers (Niederschrift des Lieds und Weitergabe an die "Kinder Israels") wurde als Signal für das Ende der Theophanie genommen. Das war eine Entscheidung über die Fabel.

In 31,28 LXX läßt Mose die Leviten nicht nur die Stammesältesten und Listenführer einberufen, sondern alle jene Amtsträger, die 29,9 LXX aufzählt. Dort werden in 29,10 zwar noch andere Gruppen hinzugefügt (Kinder, Greise, Frauen, Fremde, vom Holzarbeiter bis zum Wasserträger), doch selbst ohne diese Zusatzliste weckt die erweiterte Amtsträger-

Dtn 31,1 wäre bei dieser Deutung als einer Art makrosyntaktischen Signals für Ablaufgliederung die sachgemäße Übersetzung vielleicht schlicht: "Mose sagte dann noch zu ganz Israel."

18 Also: Er führte zu Ende, indem er noch dieses Wort sagte. Kaum wird man die zugrundeliegende hebräische Vorlage deuten können als: "Er beendete, und dann sagte er außerdem noch das folgende Wort." So verstehen es offenbar ZB, NAB, NEB und NRSV.

${ }^{19} \mathrm{Zu}$ Problemen, die LXX mit dem Ausdruck כל-משר gehabt zu haben scheint, vgl. auch 18,$6 ; 21,21$.

${ }^{20}$ Noch größere Identität des Wortlauts wäre gegeben, wenn LXX in 32,45f dem Text von

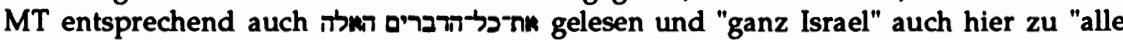
Söhne Israels" erweitert hätte.

21 Vgl. Anhang I, unter II.1. 
liste in 31,28 beim Leser schon die Vermutung, daß wie in 29,1 auch hier jetzt die Vollversammlung aller Israeliten einberufen werden soll.

32,44a LXX wiederholt, zusätzlich zu MT, den Text von 31,22. Wahrscheinlich wurde hier die richtige Zeitstelle für die in 31,22 proleptisch ausgesagte Handlung vermutet. Aus der Analepse eines vorgreifenden Satzes an der Stelle, die bei linearem Erzählen seinem Ort in der Fabel entspricht, ersieht man, daß LXX Korrespondenz zwischen Erzählfolge und Fabel sucht und höchstens noch zusätzlich einen vorgreifenden Erfüllungsvermerk zuläßt. Oder hat LXX 31,22 gar nicht als Prolepse verstanden?

32,44a LXX erzählt nach einem ersten Vortrag des Lieds dessen Niederschrift und lehrende Vermittlung. Ob letzteres nun nur noch einmal alles zusammenfaßt oder noch einmal eine ausgesprochene Lernaktion besagen will - auf jeden Fall handelt es sich bei den Vorgängen von 31,30-32,44a in LXX um einen einzigen Handlungszusammenhang, nicht um zwei getrennte Vorgänge vor verschiedenem Publikum. Die "ganze Versammlung Israels" von 31,30 LXX ist wohl auch als Vollversammlung gemeint. Hier ist zweifellos an der Fabel gearbeitet worden.

Anschließend bringt LXX in 32,44 noch den gleichen Text wie 32,44 MT, doch mit einer gewichtigen Änderung: Mose und Josua lehren nicht das Lied, sondern die Tora. Ob das deshalb geändert wurde, weil nach 31,22 allein Mose das Lied lehrte, also ohne Josua? Aber in 31,19, wo Mose und Josua in MT zusammen den Auftrag bekommen, das Lied aufzuzeichnen, nur Mose jedoch den Auftrag, es zu lehren, hat LXX alle Befehle in den Plural gesetzt, auch den zur Lehre des Lieds. Oder sollte die Urseptuaginta (gegen WEVERS) in 31,19 überall den Singular gelesen haben, wie die afrikanische Textfamilie der Vetus Latina bezeugen könnte 22 , und das habe in der hebräischen Vorlage gestanden? Dann hätte Josua in LXX bisher nichts mit dem Lied zu tun gehabt. Ein nochmaliger Vortrag des Lieds "in die Ohren" der Zuhörer wäre nicht plausibel gewesen. Da 32,46f von der Tora handeln, hätte es näher gelegen, $\mathrm{da} ß$ sie eine Tora-Verkündigung abschließen. So empfahl sich eine Tora-Verkündigung, diesmal nicht durch Mose allein, sondern durch Mose und Josua. Das Gesetz wird nach Jos 1,823 und 8,32-3524 in Josuas Leben ja eine große Bedeutung haben. Auch bei dieser Textdifferenz geht es um die Fabel.

Während 32,45 MT die Schlußworte der Liedmitteilung einzuführen scheint (auch wenn diese selbst dann zum Thema "Tora" zurück-

$22 \mathrm{Vgl}$. die von WEVERS registrierten Lesarten des lateinischen Pentateuchpalimpsests der Münchener Staatsbibliothek (Lat. Monac. 6225, bei WEVERS Nr. 104).

23 LXX erwähnt allerdings die Tora noch nicht in Jos 1,7, wo MT sie offenbar nachträglich eingebracht hat. Zudem ist es nicht sicher, ob man das Josuabuch bei einer Analyse der Pentateuch-LXX mit heranziehen darf.

24 LXX hat diesen Text erst nach 9,2. 
leiten), ist 32,45 LXX als Einführung eines Schlußwortes Moses für sein gesamtes Sprechen vor "ganz Israel" umstilisiert. Wieder ist die Fabel geändert.

Mit ersten vorbereitenden Worten schon in 31,29 hat die LXX-Fassung in 32,44ff die Fabel umgearbeitet. Aus der doppelten Verkündigung des Moselieds hat sie eine einzige gemacht, und dann hat sie noch eine weitere Toraverkündigung hinzugefügt - diesmal durch Mose und Josua zusammen. Erst beim Abschlußwort Moses in 32,46f laufen die Fabeln von MT und LXX wieder zusammen.

Die Umgestaltungen zeigen zumindest, daß es der von der LXX bezeugten Textredaktion darum ging, unter Voraussetzung weitgehender Korrespondenz zwischen Erzählfolge und Fabel die Fabel durchsichtiger herauszubringen.

Es ist also keine ungeschichtlich in einen antiken Text hineingelesene Fragestellung moderner Literaten, wenn man nach der Fabel von Dtn 31-32 fragt. Über den vorausgesetzten Ablauf der Ereignisse hat man sich auch damals schon seine Gedanken gemacht. Wenn man bedenkt, wie elegant in Dtn 1-3, Dtn 5 und Dtn 9f durch ein mehrfach gestaffeltes System von Rückblenden Fabel und Erzählstruktur gerade im Auseinanderklaffen beziehungsreichen neuen Sinn produzieren, ist es fast zu vermuten, daß ähnliche Sachverhalte die Schwierigkeiten bildeten, welche die von LXX bezeugte Redaktion in Gang brachten.

\section{DTN 31 MT: DIE PROBLEMATIK DER ERZÄHLSTRUKTUR}

Daß in Dtn 31-32 MT der Ablauf der Fabel einfach der Erzählfolge entspricht - ein Postulat, das nach den obigen Ausführungen den Umbauten in der LXX-Fassung zugrundezuliegen scheint -, ist unwahrscheinlich, weil vor allem Dtn 31 in seiner Endgestalt eher von systematischen und ästhetischen Prinzipien als von einer Sorge um die genaue Reproduktion der Ereignisabfolge her gestaltet ist. Das mag mit der möglicherweise vielstufigen und langwierigen Entstehungsgeschichte des Kapitels zusammenhängen. Anders ließ sich das weithin vorgeprägte Material vielleicht gar nicht zusammenfügen, wollte man es nicht allzusehr verändern. Aber das soll uns jetzt nicht kümmern. Wichtig ist nur: Die Gestalt des Kapitels ist in einem solchen Ausmaß von anderen Rücksichten bestimmt, daß wir kaum erwarten dürfen, daß man die einzelnen Handlungen auch noch genau nach ihrer Abfolge in der vorausgesetzten Fabel anordnen konnte, falls man es überhaupt wollte.

Die systematisch-ästhetisch bestimmte Erzählstruktur von Dtn 31 ist in diesem Aufsatz natürlich nicht zu erarbeiten. Ich will nur gerade andeutend auf sie hinweisen ${ }^{25}$. Die hier vorgelegte Sicht der Erzählstruktur ist auch nicht die logische Voraussetzung bei der Erarbeitung

25 Die entscheidenden Analysen habe ich in LOHFINK, Bundesschluß, 48-55, vorgelegt. 
der Fabel. Die Erzählstruktur macht nur verständlich, warum in diesem Textbereich Fabel und Erzählfolge sich fast notwendig nicht decken können.

Leitend für die erzählerische Gestaltung sind - mit einziger Ausnahme des knappen Berichts über die Theophanie in 31,14b.15 - die zitierten Reden. Man kann das Kapitel als "Redenmontage" charakterisieren. Die 7 Reden des Kapitels sind nach Länge, Themen und Rednern komponiert.

Eine erste Übersicht zeigt den Wechsel zwischen langen und kurzen Reden, dem ein Wechsel in der Thematik entspricht. Die Thematik "Texte" und die Thematik "Josuaeinsetzung" sind systematisch miteinander verflochten, und zwar so, daß die Theophanie, die sich mit der 4 . Rede verbindet, im Zentrum steht:

\begin{tabular}{|c|c|c|}
\hline $\begin{array}{ll}\text { 1. } & 2-6 \\
\text { 2. } & 7-8 \\
\text { 3. } & 10-13 \\
\text { 4. } & 14 \\
\text { 5. } & 16-21 \\
\text { 6. } & 23 \\
\text { 7. } & 26-29\end{array}$ & $\begin{array}{c}\text { lang (78 Wörter) } \\
\text { kurz ( } 34 \text { Wörter) } \\
\text { lang (75 Wörter) } \\
\text { kurz (11 Wörter) } \\
\text { lang (140 Wörter) } \\
\text { kurz (16 Wörter) } \\
\text { lang (82 Wörter) }\end{array}$ & $\begin{array}{l}\text { an-Gebot } \\
\text { Josua } \\
\text { Tora } \\
\text { Theophanie, Josua } \\
\text { Moselied } \\
\text { Josua } \\
\text { Tora, Moselied }\end{array}$ \\
\hline
\end{tabular}

Die Länge der Reden und ihre Themen lassen sich leicht am Text verifizieren. Nur daß 31,2-6 auf das חרי-Gebot zugespitzt ist, wird gewöhnlich nicht gesehen - doch es ist $\mathrm{so}^{26}$.

Eine weitere Übersicht zeigt die Abfolge der redenden Subjekte. Hier ist das Schema 3+3+1 durchgehalten, das auch sonst häufig Siebenerfolgen aufgliedert:

$\begin{array}{lll}\text { 1. } & 2-6 & \text { Mose } \\ \text { 2. } & 7-8 & \text { Mose } \\ \text { 3. } & 10-13 & \text { Mose } \\ \text { 4. } & 14 & \text { Jahwe } \\ \text { 5. } & 16-21 & \text { Jahwe } \\ 6 . & 23 & \text { Jahwe } \\ \text { 7. } & 26-29 & \text { Mose }\end{array}$

26 Die meisten Kommentare stellen völlig andere Inhalte aus 31,2-6 heraus und erwähnen diesen Zielpunkt der "Predigt" (G. VON RAD z.St.) nicht einmal. Die in 31,5 ent-

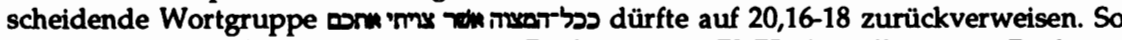
schon IBN EZRA. Näheres bei SKWERES, Rückverweise, 73-75, der selber einen Rückverweis auf Dtn 7 annimmt. Doch das kommt letztlich auf dasselbe hinaus. LXX setzt einen

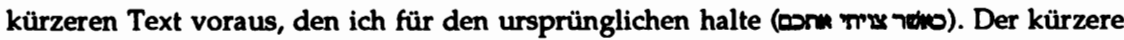
Text impliziert aber den gleichen Rückverweis. 
Bei den langen Reden, die also "Texte" betreffen, ist es noch so, daß die beiden ersten Reden positive Möglichkeiten der Zukunft ins Auge fassen, die beiden letzten negative Möglichkeiten:

\begin{tabular}{|c|c|c|}
\hline $\begin{array}{l}2-6 \\
10-13\end{array}$ & $\begin{array}{l}\text { lang } \\
\text { lang }\end{array}$ & $\begin{array}{l}\text { arn-Gebot: Gelingende Landeseroberung } \\
\text { Tora: Leben im Lande in Kenntnis der } \\
\text { Tora durch alle Generationen }\end{array}$ \\
\hline $16-21$ & lang & $\begin{array}{l}\text { Moselied: Nach Bundesbruch zu erwar- } \\
\text { tendes Unheil }\end{array}$ \\
\hline $26-29$ & lan & Tora und Moselied: Dasselbe. \\
\hline
\end{tabular}

Durch seine Struktur wird das Kapitel vor allem aussagen wollen, daß Nachfolgeregelung und im Bund gegebene Tora engstens zusammengehören. Zugleich ist es wahrscheinlich, daß die Abfolge der Reden in dieser ästhetischen Komposition kaum dem in der Fabel vorausgesetzten Ablauf der Ereignisse entspricht. Es ist daher notwendig, den Text in seinen Einzelheiten auf jene Hinweise abzuhören, durch die er dem Leser die Fabel insinuiert.

\section{DER FRÜHE ORT DER THEOPHANIE IN DER FABEL}

Als Ausgangspunkt können bei der Suche nach der Fabel zwei ähnlich beginnende Aussagenreihen dienen, bei denen schon G. VON RAD gemeint hat, es müsse sich wohl um den gleichen Vorgang handeln ${ }^{27}$. Nach 31,9 schreibt Mose die Tora nieder und übergibt sie dann zur offiziellen Deposition an die priesterlich-levitischen Ladeträger und die Ältesten Israels. Anschließend erläßt er an diese Gruppe die Vorschrift, alle 7 Jahre eine Gesetzesverlesung vorzunehmen. 31,24 greift (mit וידי beginnend) nochmals auf das gleiche Ereignis zurück. Mose hat die Tora aufgeschrieben und wendet sich an die Leviten. Hier allerdings: an diese allein ${ }^{28}$. Ihnen übergibt er die geschriebene Tora. Dann läßt er die Leviten eine Versammlung der Stammesältesten und der Listenführer einberufen, damit er diese das Moselied lehren kann. Der einen Aktion in Richtung auf Leviten und Älteste in 31,9 entspricht hier also eine gestufte Aktion über die Leviten zu den Ältesten. Aber in beiden Fällen beginnt alles mit der Niederschrift der Tora.

27 G. VON RAD, Deuteronomium, 136: "Das Verhältnis der Rede an die Leviten in V. 24ff. zu der Rede an die Leviten in V. 9-13 wird sich kaum im Sinne von zwei einander chronologisch folgenden Aufträgen verstehen lassen, sondern eher im Sinne von Dubletten. Das ganze Kapitel bietet ja mehr Traditionsgeröll als ein wirkliches Fortschreiten in der erzählenden Darstellung."

28 Einige feine Unterschiede in der Charakterisierung der beiden Gruppen, die zweifellos mit der verschiedenen Schichtzugehörigkeit der Texte zusammenhängen, können so wichtig sie bei diachroner Rückfrage sind - bei der Frage nach der Fabel des Endtexts vernachlässigt werden. 
Da 31,24 ער תמם וידי כ einfach an die Niederschrift von 31,9 anknüpft und man kaum auf die Idee kommen wird, die gleiche Tora sei den gleichen Leuten zweimal zur Aufbewahrung übergeben worden, muß man bei dem, was folgt, wohl mit dem selben Geschehen rechnen. Nur, daß es unter verschiedener Rücksicht und in unterschiedlicher Konkretisierung erzählt sein will. Mose muß - so wird die Fabel laufen -, zunächst den Leviten die Tora übergeben, dann die Ältesten das Lied gelehrt $(31,28$ und 30$)$ und schließlich den Leviten und Ältesten zusammen die Vorschrift zur Gesetzesverlesung gegeben haben (31,10-13). Letzteres muß in der Fabel den Schluß bilden, weil die Ältesten am Anfang noch nicht dabei waren. Die Tatsache, daß Mose zunächst den Leviten allein den Toratext zur Aufbewahrung bei der Bundeslade übergab $(31,25 f)$ und dann die Ältesten nach ihrer zusätzlichen Einberufung durch die Leviten das Moselied lehrte, muß, zusammengenommen, die Übergabe der Tora an Leviten + Älteste sein.

Das impliziert aber, daß Jahwe Mose das Lied schon vor der Einberufung der Leviten $(31,9=25)$, ja vielleicht schon vor der Niederschrift der Tora $(31,9=24)$ mitgeteilt haben muß. Die Mitteilung geschah im Rahmen der Theophanie von 31,14f. Also liegt die Theophanie mit den in ihr ergehenden Gottesworten (31,14-23, mit Ausnahme des proleptischen Verses 22) der Einberufung der Leviten, vielleicht sogar der Toraniederschrift, voraus. Josua ist von Gott schon zum Feldherrn eingesetzt, wenn Mose den Leviten das Gesetz übergibt und die Ältesten das Moselied lehrt.

Auf die Moserede an die Leviten bei der Übergabe des Gesetzes in 31,26-29 folgt im Text eine Redeeinleitung zum Moselied (31,30). Nach ihr trug Mose den Text des Liedes dem ganzen the oben angedeutet, steht zu dieser Angabe in Konkurrenz der Erzählertext, der sich an das Moselied unmittelbar anschließt. Nach 32,44 trugen Mose und Josua zusammen das Moselied "dem Volke" vor. Ist das eine Zusammenfassung des vorher schon mitsamt Zitat des Lieds Ausgeführten? Oder handelt es sich um einen zweiten Vortrag vor einem anderen, weiteren Zuhörerkreis, der jetzt in dieser Notiz erstmalig zur Sprache kommt?

Bei der Doppelung 31,9ff || 31,24ff konnte davon ausgegangen werden, daß trotz einiger Differenzen bezüglich der Adressaten die Tora nicht zweimal bei zwei verschiedenen Gelegenheiten den Ladeleviten zur ständigen Aufbewahrung übergeben wurde. In unserm Fall liegen wieder Differenzen, wieder auch bezüglich der Adressaten, vor. Aber es ist sehr viel leichter denkbar, daß ein Lied vor zumindest teilweise nicht identischem Publikum zweimal vorgetragen wird. So sind hier die beiden Möglichkeiten vom Text her gegeneinander abzuwägen.

Zunächst sei gefragt, ob der in 31,30 beschriebene Vortrag des Liedes jener ist, den Mose in seiner Rede an die Leviten in 31,28f plant. Dessen Publikum sollen ja die Stammesältesten und Listenführer sein. 
Gegen die Annahme spricht, daß die Stammesältesten und Listenführer versammelt werden sollen, daß der Vortrag sich aber an

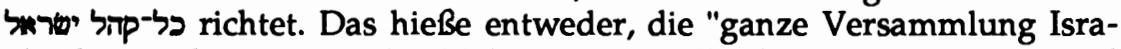
els" bestünde nur aus der Nobilität oder allenfalls aus Priestern und Nobilität, oder es hieße, aus der Einberufung der Nobilität habe sich eine Versammlung des ganzen Volkes entwickelt, ohne daß der Erzähler das eigens vermerkt. Beides ist zumindest auf den ersten Blick überraschend.

Für die Annahme spricht, daß man direkt im Anschluß an 31,28f die Ausführung des dort von Mose durch einen Befehl Angezielten erwarten darf, selbst unter Auslassung selbstverständlicher Zwischenhandlungen, wie etwa der Versammlungseinberufung durch die Leviten. Außerdem gibt es eine klare Stichwortaufnahme: Der Terminus

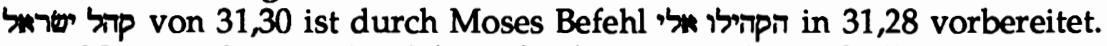

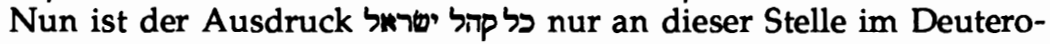
nomium belegt. Er ist überhaupt sehr selten. Von Lev 16,17 abgesehen findet er sich nur in deuteronomistischer und chronistischer Literatur. Dort zeigt ein Durchgang durch die Belege, daß er überall eine Notabelnversammlung meinen kann, nicht eine Versammlung aller Israeliten und Israelitinnen, und daß er es an einer Stelle klar meint ${ }^{29}$. Das gleiche wäre hier in 31,30 von 31,28 her anzunehmen. Sicher sind wir

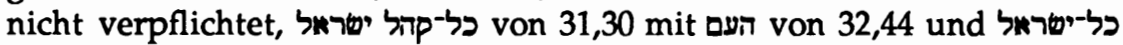
von 32,45 einfach gleichzusetzen. Eher ist es auffallend, daß anstelle der im Deuteronomium bei der Kennzeichnung der in ihm beschriebenen Versammlungen des ganzen Volkes häufig vorkommenden Termini

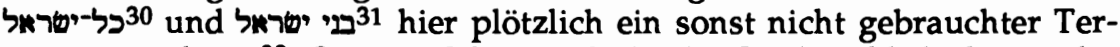
minus erscheint ${ }^{32}$. So trägt Mose in 31,30 das Lied wohl doch nur der von den Leviten zusammengerufenen Nobilität vor.

Nun die zweite Frage: Handeln 31,30 und 32,44 vom selben Vorgang? Dafür könnte die in beiden Aussagen gleiche Verbalphrase sprechen: דבר באונים. Dann wäre 32,44 als eine Art Wiederaufnahme des durch das lange Lied in Vergessenheit geratenen narrativen Zusammenhangs zu betrachten. Dagegen: Neben die zu vermutende Differenz des Publikums treten auch noch andere Differenzen.

Einmal, daß jetzt nicht nur Mose, sondern mit ihm auch Josua das Lied mitteilt. Das verweist auf die Theophaniepassage, wo das Lied Mose in Josuas Gegenwart geoffenbart wurde und als Adressaten nicht die Notabeln Israels, sondern בניי-ישראל $(31,19.22)$ ins Auge gefaßt waren. Der Auftrag, das Lied zu lehren, wurde zwar nur Mose gegeben, und die proleptische Notiz in 31,22 sprach auch nur von ihm. Doch kann man

\footnotetext{
29 Näheres in Anhang II.

${ }^{30}$ Dtn 1,$1 ; 5,1 ; 27,9 ; 29,1 ; 31,1.7 ; 32,45 ;$ vgl. $31,11.11$.

31 Dtn 1,$3 ; 4,44.45 ; 28,69,33,1 ;$ vgl. $31,19.22$.

32 Selbst הפם steht außer in 32,44 in solchen Zusammenhängen noch in 27,1.9.11; vgl.

27,12-26 und 31,12.
} 
31,19 so verstehen, daß Josua zumindest den Befehl zur Aufzeichnung des Lieds mitempfing. So ist Josua dort doch irgendwie mit im Blick. Sein Auftreten mit Mose zusammen in 32,44 ist nicht ganz überraschend.

Sodann wird mit dem von einem weiteren finiten Verb gefolgten der Satz auf eine Weise eingeleitet, als handle es sich wirklich um eine neue Szene, bei der der Hauptakteur den Schauplatz erst betritt 33 .

Alles zusammengefaßt: Ich neige dazu, in der Fabel mit einer doppelten Verkündigung des Moselieds zu rechnen, an die Notabelnversammlung und an die Vollversammlung Israels, durch Mose allein und durch Mose mit Josua zusammen. Die strittige Frage ist dabei nur, ob das Moselied zweimal vorgetragen wurde, nicht, ob es die beiden verschiedenen Versammlungen gab. Es gab sie in der Fabel auf jeden Fall. 31,28 ist in MT auf keinen Fall ein Befehl zur Einberufung "aller Kinder Israels". Zu ihnen gehört schon ein größerer Kreis von Respektspersonen, dazu die Frauen, Kinder und Fremden (vgl. 29,9f). Nur: Wenn das Moselied nur einmal vorgetragen wurde, ging die begrenztere Versammlung gewissermaßen fließend in die Vollversammlung Israels über, und dann erst wurde das Lied vorgetragen.

Damit wären für die Fabel hinter 31,9-32,47 vier aufeinander folgende Situationen erschlossen: 1. die Theophanie vor Mose und Josua, 2. Mose vor den Leviten, 3. Mose, die Leviten und die Nobilität in der לxר

\section{EINE ODER ZWEI VERSAMMLUNGEN VON "GANZ ISRAEL"?}

Auch 31,1-8 spielen vor "ganz Israel": vgl. 31,1.7. Wo sind die hier geschilderten Vorgänge zu situieren? Da die erst nach der Theophanie anzusetzenden Ereignisse von 31,9-13 schon vor der Theophanie erzählt werden, kann nicht automatisch angenommen werden, die davor stehenden Verse 31,1-8 gehörten in der Fabel an den Anfang der Ereigniskette. In Erweiterung des zwischen 31,9-13 und 31,14-23 beobachteten zeitlichen Rücklaufs der Erzählstruktur läge es nahe, die Versammlung von 31,1-8 mit der von 32,44-47 zu identifizieren.

Das ergäbe für Dtn 31-32 folgenden Fabelablauf:

Theophanie vor Mose und Josua, in ihr Offenbarung des Moselieds und Einsetzung Josuas durch Gott zum Feldherrn bei der Landeseroberung $(31,14-23)$

$33 \mathrm{Vgl.} \mathrm{k}$ in 1 Kön 8,3, und für Mose in Ex 19,7 und 24,3. Die interessante Diskussion des Problems bei KLOSTERMANN, Pentateuch, 249-251, ist literarkritisch orientiert, zeigt aber den Zusammenhang mit der Theophaniepassage abermals auf. Auf der Ebene des definitiven Textes: Selbst wenn Mose nach der Theophanie schon bei den Leviten und Ältesten war - vor dem ganzen Volk gab es einen neuen Auftritt. 
Niederschrift von Lied und Tora durch Mose $(31,9.22 .24)$

Einberufung der Leviten durch Mose und Übergabe der schriftlichen

Tora an sie $(31,24-27$, vgl. 31,9$)$

Einberufung der Ältesten durch die Leviten, mündliche Übergabe des

Liedes an sie (vgl. 31,28-30)

Anweisung an beide Gruppen zusammen zur Durchführung der

Gesetzesverkündigung jedes siebte Jahr $(31,10-13)$

Allgemeine Volksversammlung, in der Mose ganz Israel auf die kom-

mende Eroberung des Westjordanlandes ausrichtet $(31,1-6)$, Josua

zum Feldherrn und zum Landverteiler einsetzt $(31,7 \mathrm{f})$ und dann

zusammen mit Josua das ganze Volk das Lied lehrt $(32,44)$

Letzte Worte Moses vor ganz Israel $(32,45-47)$

Die jetzige Erzählstruktur hätte die Fabel keineswegs wahllos zerstückelt und dann ohne Regeln neu verbaut. Vielmehr setzte sie bei der in der Fabel alles beschließenden großen Versammlung ein. Dann liefe sie chronologisch rückwärts zur Leviten- und Notabelnversammlung, und von dort nochmals rückwärts zur Theophanie vor Mose und Josua. Von ihr als erzählerischem Wendepunkt aus schritte sie, nun im Sinne der Fabelabfolge, wieder vorwärts, weitere Elemente der verschiedenen schon bekannten Phasen nachliefernd. Alles endete schließlich mit der Großversammlung ganz Israels, mit welcher der Text begonnen hatte. Schematisch:

$\begin{array}{lc}29,1-31,8 & \text { Ganzes Volk (III) } \\ 31,9-13 & \text { Repräsentantenversammlung (II) } \\ 31,14-23 & \text { Theophanie vor Mose-Josua (I) } \\ 31,24-32,43 & \text { Repräsentantenversammlung (II) } \\ 32,44-47 & \text { Ganzes Volk (III) }\end{array}$

Für diese Sicht von Fabel und Erzählstruktur spräche noch eine weitere Überlegung. Die Versammlung von 31,1-8 könnte bei MT nicht minder als bei LXX mit der von 29-30 identisch sein ${ }^{34}$. LXX spricht das nur viel klarer aus. Nun finden sich in den Reden von 29-30 mehrfach Hinweise auf die schon schriftlich vorliegende Tora: 29,19.20.26; 30,10. Also kann diese Versammlung erst nach der Niederschrift der Tora stattgefunden haben.

Nun wird aber in 31,9 und 24 die Übergabe der Tora an die Leviten und Ältesten direkt nach der Notiz von der Niederschrift der Tora berichtet. Folgert man daraus, Mose habe die Tora erst an seinem letzten Lebenstag, und zwar unmittelbar vor ihrer Übergabe, niedergeschrieben, dann können die Reden von 29,1-31,8 erst nach der Notabelnversamm-

34 Vgl. oben bei Anm. 13-21, wo Gründe dafür angegeben wurden, daß auch לך in 31,1 nicht notwendig den Anfang einer neuen Versammlung anzeigen muß. 
lung gehalten worden sein, also in der Versammlung, von der 32,44-47 handeln.

Doch fordert der wayylqtol-Anschluß der jeweils folgenden Aussage in 31,9 und 24 diese Annahme nicht notwendig. Da wayylqtol Zeitabstände zuläßt, können 31,9 und 24f auch so verstanden werden, als habe Mose den Leviten (und Ältesten) eine schon zu einem früheren Zeitpunkt angefertigte Niederschrift der Tora übergeben. Dann könnte die schriftlich vorhandene Tora auch bei einer Vollversammlung von "ganz Israel", die schon vor der Theophanie stattfand, vorhanden gewesen sein.

Diese Annahme wäre weniger sparsam, da mit zwei Vollversammlungen am gleichen Tag gerechnet werden müßte. Doch lassen sich für sie zwei Gründe ins Feld führen.

1. Die Reden von 29-30 spiegeln eine Bundesschlußzeremonie ${ }^{35}$. Dieses Ritual käme, gehörte es in die Versammlung von 32,44-47, in der Fabel hinter der Deposition des Dokuments zu stehen, auf das man einen Eid leistete. Das wäre genau das Gegenteil dessen, was für ein analoges Geschehen (ebenfalls ein Fall von כרח ברית in Dtn 5,22 (vgl. 9,9f) zu lesen ist: Zuerst wurde der Dekalog vor der Versammlung proklamiert, dann übergab Gott Mose die von ihm beschriebenen Tafeln mit dem Text ${ }^{36}$. So wird man zweifeln können, ob Übergabe und Deposition des Dokuments vor der feierlichen Verlesung und Beschwörung den Ablauferwartungen der deuteronomischen Leserschaft für derartige Rechtsakte entspricht. Notizen über Ausfertigung und Deposition von Dokumenten finden sich meist am Ende von Schriftstücken, und der entsprechende Vorgang wird normalerweise auch am Ende der Rechtshandlungen gestanden haben. Niederschrift des einschlägigen Dokuments vorgängig zu einer Abschlußzeremonie ist dagegen gerade bei Verträgen normal. Man verhandelte über einen Text. Wenn dieser stabilisiert war, konnte man den Vertrag unter Verlesung des Texts beschließen. Dann konnte man Dokumente austauschen oder deponieren. Im Pentateuchzusammenhang vergleiche man Ex 24,3-8, wo die Niederschrift eindeutig vor der Verlesung in der eigentlichen Bundesschlußzeremonie steht. Vorhandene Ablauferwartungen, mit denen wir rechnen müssen, könnten also dafür sprechen, die Ereignisse von 31,1-9 in der Fabel noch vor der Theophanie anzusetzen.

2. Eine weitere Beobachtung kommt hinzu. In der Erzählstruktur gibt es ein sauberes System, nach dem die Amtsübergabe an Josua abläuft: In 31,7f setzt Mose Josua in seine beiden Funktionen ein, die des Landeroberers und die des Landverteilers; in 31,23 stellt Jahwe sich da-

35 Vgl. BALTZER, Bundesformular, 43-45; dann LOHFINK, Bundesschluß, 36-45, und gegen Bestreitung - DERS., Bundestheologie, 335f. Es sei betont, daß es jetzt nicht um historische Rückschlüsse auf faktische Bundschließungsakte oder praktizierte Rituale geht, sondern nur um die implizierte Fabel eines vorhandenen Textes.

36 Zur engen Beziehung der beiden Aussagenkomplexe im Deuteronomium vgl. BEGG, Tables. 
hinter und setzt Josua selbst in die erste Funktion ein, die des Landeroberers; in die zweite Funktion setzt er ihn dann in Jos 1,6.9b ein; außerdem gibt Jahwe Josua in Jos 1,1-5 den Befehl, seine erste Aufgabe auszuführen, in Jos 13,1b.7 den entsprechenden Befehl für die zweite Aufgabe ${ }^{37}$. Ist die Versammlung von 31,1-8 mit der von 32,44-47 identisch, dann ist die Fabel nicht so logisch wie die Erzählfolge. Am Anfang stünde die Einsetzung Josuas durch Jahwe in eine einzige Funktion, dann käme die Einsetzung durch Mose in beide Funktionen, schließlich die Einsetzung durch Jahwe in die zweite Funktion. Ferner ist es etwas schwer verständlich, warum Jahwe in 3,28 darauf drängt, daß Mose Josua einsetzt, wenn er dann doch selbst schon vor Mose eine Einsetzung vornimmt. Man müßte mit einer erst redaktionell in der Erzählstruktur zum Ausdruck gebrachten Systematik rechnen, die aufgrund zu vieler festliegender anderer Textsachverhalte aber in der dabei notwendig entstehenden Fabel nicht mehr verankert werden konnte. Die Redaktion wäre an nicht mehr überschreitbare Grenzen gestoßen. Diese bei Annahme einer einzigen, am Ende stehenden Vollversammlung ganz Israels notwendige Folgerung spricht nicht für die Annahme.

Nimmt man zwei verschiedene Vollversammlungen an, die Versammlung, in der der Bund geschlossen wird, vor der Theophanie, und eine zweite, in der das Moselied allen gelehrt wird, nach der Theophanie, und zwei kleineren Versammlungen, dann entschwindet dieses Problem. Allerdings muß in Kauf genommen werden, daß die Niederschrift der Tora und ihre Übergabe an die Ladeleviten nicht unmittelbar aufeinander folgen.

Ich neige trotzdem zu der zuletzt erörterten Fabelrekonstruktion. Es wäre also zwischen einer ersten und einer zweiten Volksversammlung zu unterscheiden. Von einer historisch gemeinten Frage, ob sich denn überhaupt zwei so große Versammlungen mitsamt mehreren anderen zeitraubenden Ereignissen an einem einzigen Tag durchführen lassen, darf man absehen. In der ersten Großversammlung, die am Anfang der Ereignisse von Dtn 31-32 steht, würde aufgrund der schon schriftlich vorliegenden Tora der "Moabbund" geschlossen (Dtn 29-30). An ihrem Ende würde Josua durch Mose in seine beiden Ämter eingesetzt (31,7f). Gott erschiene erst nach diesem Bundesschluß am Zelt ähnlich wie sich in 1 Sam 12 die Gewittertheophanie erst an die Samuelrede 12,6-7 anschließt, in der Saul zum letzten Mal und in definitiver Form als König eingesetzt wird. Von der Theophanie ab liefe dann alles wie bei der anderen Rekonstruktion der Fabel - nur daß die letzte Vollversammlung einen etwas anderen Charakter annähme.

37 Näheres bei LOHFINK, Darstellung. Vgl. auch MCCARTHY, Installation Genre; BLUM, Studien, 87 Anm. 187, und als Antwort LOHFINK, Väter Israels, 45 Anm. 43. 
Die Fabel wäre folgendermaßen zu formulieren:

(Zu unbestimmter Zeit:) Niederschrift der Tora durch Mose $(31,9.24)$

Allgemeine Volksversammlung (I), in der Mose den Moabbund

schließt (29-30), ganz Israel auf die kommende Eroberung des

Westjordanlandes ausrichtet $(31,1-6)$ und Josua zum Feldherrn

und Landverteiler einsetzt $(31,7 \mathrm{f})$

Theophanie vor Mose und Josua, in ihr Offenbarung des Moselieds und

Einsetzung Josuas durch Gott zum Feldherrn $(31,14-23)$

Einberufung der Leviten durch Mose und Übergabe der schriftlichen

Tora an sie $(31,24-27, \mathrm{vgl} .31,9)$

Einberufung der Ältesten durch die Leviten, mündliche Übergabe des

Liedes an sie (vgl. 31,28-30)

Anweisung an beide Gruppen zusammen zur Durchführung der

Gesetzesverkündigung jedes siebte Jahr (31,10-13)

Allgemeine Volksversammlung, in der Mose zusammen mit Josua das

ganze Volk das Lied lehrt $(32,44)$

Letzte Worte Moses vor ganz Israel $(32,45-47)$

Erzählfolge und Fabelfolge würden sich im allgemeinen decken, nur daß nach der ersten großen Versammlung die Übergabe der Tora proleptisch schon ein erstes Mal erzählt würde, wobei es vor allem um die Anordnung der Gesetzesverlesung im siebten Jahr ginge. Es wäre ein Vorgriff, ähnlich wie wir im Blick auf das Moselied in 31,22 einen Vorgriff auf in der Fabel später anzusetzende Vorgänge annehmen müssen.

\section{DIE NIEDERSCHRIFT DES MOSELIEDES}

Eine Detailfrage habe ich bisher übergangen: Wann hat Mose das Lied aufgeschrieben? 31,22 muß, wie gesagt, ein Vorgriff sein. Nach diesem Vers hat Mose das Lied aufgeschrieben, bevor er (und Josua) das Lied in der Versammlung von ganz Israel allen Israeliten vortrug. Das Lied muß daher mindestens direkt vor dieser Versammlung, eher sogar schon zwischen Theophanie und Übergabe der Tora an die Leviten aufgeschrieben worden sein.

Auch wenn die Tora schon viel früher niedergeschrieben worden sein sollte, ist natürlich nicht ausschließbar, daß sie nach der großen Bundeszeremonie noch einmal ergänzt wurde. Im Klartext: daß das Moselied noch in die Rolle eingetragen wurde. Man könnte die Formulierung עa in 31,24 als Hinweis auf eine solche letzte Ergänzung betrachten. Ich glaube, der Leser hat die Freiheit, die Fabel in diesem Sinne zu präzisieren.

Doch bleibt der Text so unbestimmt, daß der Leser dazu nicht gezwungen ist. Die Doppelsetzung von ער תם 31,24 (Tora) und 31,30 (Lied), die in ihrer Parallelität zweifellos beabsichtigt ist, legt eher eine 
andere Aussageintention nah: Beide Texte, Tora wie Lied, sind Israel vollständig bekannt. Nichts ist Israel vorenthalten worden.

Wurde das Lied nicht noch in letzter Minute in die Torarolle selbst, sondern unabhängig von dieser Rolle in ein zweites Dokument eingetragen, dann hören wir über dieses Dokument nichts mehr. Es bleibt insofern ein totes Motiv, während die schriftliche Weiterexistenz der Tora wesentlich ist. Nach 31,21 werden die späteren Generationen das Lied auswendig wissen. Es ist der mündlich bekannte ער neben dem schriftlichen ער, der Tora ${ }^{38}$. Die Tora erfährt Mose am Horeb, das Moselied in Moab. Die Tora wird erst verkündet, dann aufgeschrieben (und

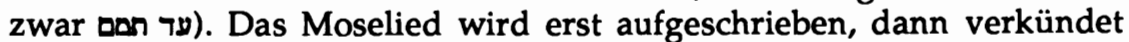
(und zwar ער תח (ע). Dauer hat die Tora in Schriftlichkeit, das Moselied in Mündlichkeit. Eine schon sehr eigentümliche Systematisierung, und das auf der Ebene der Fabel.

\section{AUSBLICK}

Da mehrere Leerstellen, Unbestimmtheiten und Lücken innerhalb der Fabel konstatiert werden mußten, waren unterwegs Wahrscheinlichkeitsentscheidungen zu fällen. Ich habe versucht, immer den plausibelsten Weg einzuschlagen. Doch ist es leicht möglich, daß weitere Sachverhalte am Text von Dtn 31-32, die mir entgangen sind, eine andere Rekonstruktion der Fabel nahelegen könnten - in Einzelheiten oder sogar im ganzen. Das wäre kein Unglück. Wichtig ist mir vor allem, daß die Frage nach der Fabel für das trotz aller gehaltenen Reden durchaus auch narrative Deuteronomium überhaupt einmal in Gang kommt.

Außerdem könnte es sein, daß die Ausdehnung der Frage auf das ganze Deuteronomium noch einmal Sachverhalte zu Tage fördert, die auch für die Fabel in 31-32 die Gewichte verschieben. Doch ist das auch wieder unwahrscheinlich, da die Handlung des Buches offenbar gerade in diesen beiden Kapiteln verknotet ist. Genau hier werden die bisher teilweise getrennt geführten thematischen Fäden miteinander verschnürt.

Dabei scheint das Deuteronomium auf der Ebene der Fabel in 3132 eine ebenso dichte Zuordnung der Land-, Nachfolge-, Bundes- und Gesetzesthematik aufzuweisen wie in der hochästhetischen Erzählstruktur. Klaus BALTZER hat in seinem Buch "Das Bundesformular" unter dem Stichwort "Bestätigung des Bundes" gezeigt, daß die Bundesthematik sich speziell mit der Nachfolgeproblematik für die Führung Israels verbinden kann. Einer seiner Ausgangspunkte war dabei der Textkomplex von Dtn 1-Jos 139. Vielleicht haben die vorgetragenen Analy-

$38 \mathrm{Zu}$ ער = "rechtskräftiges Beweismittel" vgl. SCHENKER, Zeuge.

39 BALTZER, Bundesformular, 76-79. 
sen einiges neu beleuchten können, was er vor nunmehr schon über 30 Jahren gesehen hat.

\section{ANHANG I: ZUM VERHÄLTNIS VON MT UND LXX IN DTN 31-32}

In einer ersten Untersuchungsreihe möchte ich zeigen, daß die Vorlage von LXX (im folgenden meist vereinfachend ebenfalls LXX genannt) gegenüber der Textgestalt von MT sekundär ist (I), in einer zweiten, daß in anderen Fällen die Lesart von LXX ursprünglich sein könnte (II). Ich untersuche nicht alle Probleme in den beiden Kapiteln, doch so viele, daß dieser Doppelbefund gesichert erschein $t^{40}$. Aus ihm folgt dann, daß keine der beiden Textgestalten auf die andere zurückgeführt werden kann, beide vielmehr einen gemeinsamen Prototyp voraussetzen. Die Sonderlesarten von LXX greifen teilweise so in den vorauszusetzenden älteren Textbestand ein, daß man mit einer durchlaufenden Absicht rechnen muß. Im Haupttext des Beitrags wird dann deren Intention erschlossen: die Klärung der Fabel. LXX bietet also einen redigierten Text. MT steht dem gemeinsamen Prototyp trotz mancher Erweiterungen näher ${ }^{41}$. Die Untersuchung beschränkt sich auf den Prosatext und klammert das Moselied aus. Die Folgerung gilt nicht automatisch für andere Bereiche des Deuteronomiums.

I.1 In 31,9a hat LXX gegenüber MT und Sam einen längeren Text, der dem von 31,24 entspricht, also sekundär angeglichen sein wird (und zwar in der Vorlage, vgl. den Übersetzungsunterschied $9 \dot{p} \eta \mu \alpha \tau \alpha-24 \lambda \sigma-$ yous):

I.2 MT und Sam nennen in 31,23 nicht den Sprecher des dann folgenden Zitats. Auch O-LXX nicht: Die Nennung von Mose ist innergriechischer Zuwachs. Das Zitat selbst ist in MT und Sam als Jahwewort, in LXX als Mosewort stilisiert. Man kann es auch in MT und Sam als Mosewort verstehen, wenn man annimmt, Mose habe nach Art der Schriftpropheten hier im Ich Jahwes gesprochen ${ }^{42}$. Doch ist das im Deuteronomium nicht üblich3. Da das letzte genannte Subjekt Mose war (31,22), paßt LXX an den engeren Kontext an. Subjektwechsel ohne

\footnotetext{
40 Interessant wäre vor allem noch eine Diskussion von 31,14f, wo beide Texttraditionen ihre gemeinsame Vorgabe auf verschiedene Weise weiterzuentwickeln scheinen.

41 In diesem Ergebnis unterscheide ich mich von der mehr Varianten bearbeitenden und auf jeden Fall stets heranzuziehenden gründlichen Untersuchung von LABERGE, Texte. LABERGE teilt fast durchgehend den Lesarten von LXX die Priorität vor MT zu.

42 So LABERGE, Texte, $156 f$.

43 Dtn 11,14f; 29,4f und Jer 25,4f sind keine Gegeninstanzen (wie LABERGE vertritt). Die Mose-Ich-Aussagen in 11,14f (wohl auch schon in 11,13) und in 29,4f sind, im Gegensatz zu dem in 31,23 MT und Sam ganz als Gottesrede auftretenden Zitat, in Moserede eingebettet. Vermutlich spielen sie auf bekannte Texte an, in denen Jahwe in 1. Person redete. Den Jeremiatext, der die Jahwe-Ich-Stilisierung nach Art von Prophetenworten im übrigen nicht in MT, sondern in LXX aufweist, sollte man zur Klärung deuteronomischen Stils vielleicht doch lieber nicht heranziehen.
} 
ausdrückliche Nennung des neuen Subjekts ist im Hebräischen aber durchaus möglich, sobald der Sachverhalt vom Inhalt her klar ist. Die Frage ist also nur, ob in 31,23 sprachliche und inhaltliche Hinweise auf einen Subjektwechsel gegenüber 31,22 vorliegen. Sie sind vorhanden.

a) In der zweiten Hälfte des ersten Satzes des Zitats und im zweiten Satz spricht in MT und Sam eindeutig Jahwe. Die erste Hälfte des ersten Satzes enthält keine Elemente, die auf einen anderen Redner hinweisen. Die Rede gibt sich im Wortlaut also als Jahwerede.

b) Die Ankündigung eines Rechtsaktes Jahwes bezüglich Josuas in 31,14 (rrum) bliebe ein totes Motiv, wenn 31,23 nicht die Einlösung dieser Ankündigung wäre. Die durch 31,14 in geweckte Lesererwartung, durch das überraschende Jahwewort an Mose in $31,16 \mathrm{ff}$ retardiert und damit in ihrem Spannungscharakter eher noch gesteigert, wird durch das den Vers 31,23 einleitende Verbum um eingelöst. Es ist so deutlich auf seine Ankündigung in 31,14 bezogen, daB eine Subjektnennung überflüssig ist. Die Tätigkeit des kann an dieser Stelle also nur von Jahwe ausgeübt werden. Das seit 31,14 erwartete Stichwort erweist den vorausgehenden Vers 31,22 als vorgreifende Erfüllungsnotiz für 31,19 .

c) Die weiterwirkende Kraft des עuxk von 31,14 muB dem Sprachgefühl so selbstverständlich gewesen sein, daß in 31,25 MT und Sam, wo die gleiche Hauptsatzeinleitung w» wiederkehrt, nunmehr zur Klärung der Frage, wer Subjekt der Handlung sei, der Name eingesetzt werden muß, obwohl Mose auch im vorangehenden Vers 31,24 mit ausdrücklicher Namensnennung als Subjekt der Handlung fungierte ${ }^{44}$.

d) Innerhalb des gleichen Formularablaufs wie in 31,7 und 31,23 wird in Jos 1,6-9 Josua von Jahwe in seine zweite (!) Funktion eingesetzt, die der Landverteilung. Mose hatte ihn, entsprechend der Anweisung von Dtn 3,28, in Dtn 31,7 in zwei Funktionen eingesetzt, die der Landeroberung und die der Landverteilung. In Dtn 31,23 wird Josua in die erste Funktion, die der Landeroberung, eingesetzt. Von Jos 1,6-9 her gesehen handelt es sich, wenn Jahwe hier spricht, um ein "missing link" des Aussagensystems. Wenn Mose hier der Sprecher wäre, wiederholte er, was er in 31,7 auch schon getan hatte, aber nur halb. Wenn LXX im engeren Kontext glatter eingepaßt ist, so produziert es doch für den weiteren Kontext Ungereimtheiten.

I.3 In 31,28 haben MT und Sam eine zweigliedrige Liste von Amts-

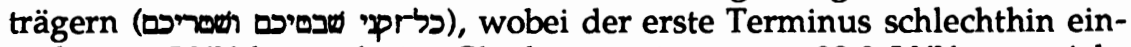
malig ist. LXX hat auf vier Glieder erweitert, was 29,9 LXX entspricht

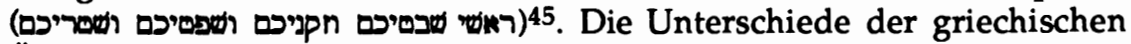
Übersetzung in 29,9 und 31,28 zeigen, daß die Parallelisierung von 29,9 und 31,28 schon im hebräischen Bereich vorhanden war. Der Versuch von LABERGE, die Priorität der viergliedrigen Liste von LXX nachzuweisen, überzeugt mich nich ${ }^{46}$.

44 LXX hat in 31,25 die Subjektangabe Mwovons nur in späten, schon nach MT rezensierten Handschriften, ursprünglich also nicht. Es ist hier nicht nötig, zu entscheiden, was den älteren Text spiegelt. Falls MT ursprünglich ist, hat LXX die nochmalige Nennung von Mose für das Griechische als Redundanz und damit als sprachwidrig empfunden. Falls LXX eine Vorlage ohne hatte und diese den älteren Text darstellt, war innerhalb der protomasoretischen Textüberlieferung die oben beschriebene Unklarheit empfunden worden, und man hatte durch Einfügung von inús Klärung geschaffen.

45 Zu 29,9 MT vgl. BEGG, Reading - eine Untersuchung, die LABERGE leider nicht kannte.

46 Texte, 158f. Er rechnet mit stufenweisem Zerfall der Liste und sieht $\mathrm{TgN}$ als Zeuge eines Zwischenstadiums an. Wenn überhaupt, dann könnte ich mir höchstens ein Ho- 
I.4 Der erste Satz in 32,44 LXX, der mit 31,22 identisch ist und in MT und Sam nicht belegt ist, muß als sekundär gelten.

I.5 32,44 LXX התור ist sekundär gegenüber dem in MT und Sam belegten השירה. Mechanischer Schreiberfehler ist nicht ausschließbar, doch scheinen mir die breiter wahrnehmbaren Tendenzen zur Neugestaltung der Fabel für bewußte Änderung zu sprechen. Eine bewußte Änderung eines השירה zunnerhalb der masoretischen Textüberlieferung ist unwahrscheinlich, da die Tendenz dort auf stärkere Herausarbeitung der Rolle des Gesetzes geht - vgl. unter II.2 zu 31,5.

II.1 31,1 MT und Sam וילך משה וידבר und LXX ויכל משה לדבר ל כ) = 1QDeut $\left.{ }^{b}\right)$ könnten auf mechanische Vertauschung von $\supset$ und zurückgehen, mit späterer Anpassung des folgenden Verbs. Die Richtung der Veränderung ist schwer zu erschließen. MT impliziert nicht notwendig, daß eine neue Versammlung begann ${ }^{47}$. Nach dem Prinzip der lectio difficilior könnte man vielleicht trotzdem MT und Sam als ursprünglich betrachten ${ }^{48}$. Das Prinzip der Kontextgemäßheit spräche aber eher für LXX49. Dem neige ich zögernd zu. Vgl. noch II.5 zu 32,45.

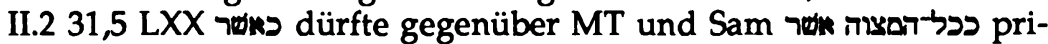
mär sein. Ein Verweis auf die Gesetze als ganze ist hier an sich nicht zu erwarten. Doch ist es verständlich, daß ein solcher im Blick auf die textliche Umgebung sekundär geschaffen wurde. Diese Annahme erklärt auch, warum im Relativsatz steht, und nicht, wie üblich, אנכי מצוך (היום) (vgl. zuletzt 30,11) - außer man setzt ein sehr starkes Bewußtsein dafür voraus, daß die Gesetzesproklamation genau mit 30,20 beendet war und vom nächsten Vers an auf sie zurückgeblickt werden mußte. Für LXX spricht ferner, daß V mit LXX geht. Da V einem protomasoretischen Text folgt, könnte die protomasoretische Texttradition noch gespalten gewesen sein ${ }^{50}$.

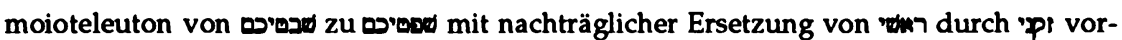
stellen, um die Ältesten wieder hineinzubringen. Aber das ist eine sehr komplizierte Theorie, und sekundäre Harmonisierung mit 29,9 ist wahrscheinlicher.

47 Vgl. o. bei Anm.13-21.

48 BARTHÉLEMY, Report, 299. Bei LXX wird hier außerdem Angleichung an 32,45 angenommen, während sich für MT keine deuteronomische Parallele findet. Bei dieser Auffassung müßte man wohl mit einer stehengebliebenen Formulierung eines hier eingebauten Textstückes rechnen, in dem zum Beispiel ein nicht mehr erhaltener Gottesbefehl mit ל vorausging. Doch deutet nichts auf so etwas hin.

49 Vgl. TOV, Use, 290. Von der in diesem Aufsatz erarbeiteten Fabel her könnte man in 31,1 als Signal für das nahende Ende der ersten Versammlung von ganz Israel betrachten, parallel zum לכי in 32,45 als Signal für das nahende Ende der zweiten Versammlung. Das wäre ein weiteres Argument.

50 Vgl. LABERGE, Deutéronome 31, $147 \mathrm{f}$. 


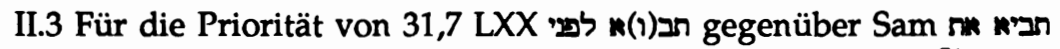
und MT n n n verweise ich auf die Argumentation bei LABERGE51.

II.4 In 31,17f liest LXX דהיר פנים "das Gesicht abwenden", MT und Sam lesen הסתיר פים für die Priorität der LXX-Lesart plädieren 52 .

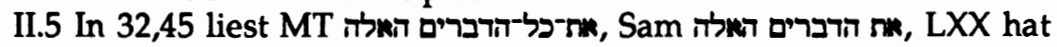
diese Wortgruppe nicht. Wir haben hier wohl Zeugen eines sukzessiven Textwachstums. Der Befund reizt zur Annahme, daß die erste, in Sam bezeugte und auch in MT vorauszusetzende Erweiterungsstufe eine Angleichung an 31,1 war, wo damals am Anfang des Satzes noch לग gestanden hätte.

\section{ANHANG II: ZUM TERMINUS}

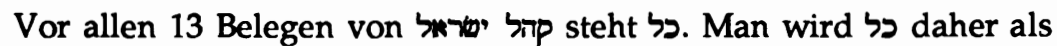
festen Bestandteil des Ausdrucks betrachten müssen. Durch ChronikDoppelungen zu den Königsbüchern schrumpft die Zahl der selbständigen Belege in MT auf 954 . Abgesehen von Lev 16,17 finden sich nur Belege im deuteronomistischen Geschichtswerk und in der Chronik. Über Lev 16,17 läßt sich wegen der Einmaligkeit des Ausdrucks in den priesterlichen Gesetzen und fehlender Anhaltspunkte im Kontext schwer etwas sagen. Ich scheide die Stelle deshalb aus den weiteren Überlegungen aus. Über die Hälfte der 7 Belege im deuteronomistischen Geschichtswerk steht in 1 Kön 8. Es könnte terminologischer Gebrauch vorliegen. Daher sollte man bei der Klärung der Referenz des Ausdrucks כל כל-קהל ישראל nicht von unterminologischem Gebrauch oder von anderen terminologischen Wortverbindungen mit - wie etwa mis inp $^{55}$ - ausgehen.

51 Texte, 148f. Die Einfügung des vermutlich ebenfalls sekundären $m$ in 31,8 MT und Sam, die ich nicht erörtern will, könnte mit dem hier diskutierten Problem zusammenhängen. 52 Texte, $154 f$.

53 Da dieser Anhang nur die Möglichkeit einer bestimmten Auslegung von Dtn 31,30 aufweisen will, verzichte ich auf jede Auseinandersetzung mit Kommentaren und neuerer Literatur. Für LXX halte ich mich an die Handausgabe von RAHLFS. Eine genauere Untersuchung des Komplexes wäre wünschenswert.

54 Lev 16,17; Dtn 31,30; Jos 8,35; 1 Kön 8,14.14.22.55; 12,3; 1 Chr 13,2; dazu als

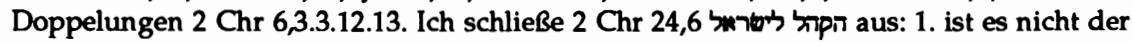
feste Ausdruck; 2. ist nicht klar, ob לישר überhaupt dem Wort hip zuzuordnen ist und

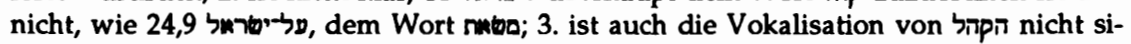
cher, vgl. LXX.

55 Hier trotzdem die Belege: Num 16,3; 20,4; Dtn 23,2.3.3.4.4.9; Mi 2,5; 1 Chr 28,8; vgl. קול המלהים dort gemeinten Teilnehmer sind nach 28,1: Alle Sarim Israels, die Sarim der Stämme, die Sarim der Abteilungen im Dienst des Königs, die Sarim der Tausendschaften, die Sarim der Hundertschaften, die Sarim des ganzen Besitzes und Viehbestands des Königs und seiner Nachkommen, dazu die Hofbeamten, die Helden und der ganze Herrbann in Jerusalem. Alle diese Beamten und Offiziere scheinen für die israelitische Gesamtbe- 
1. Nach Jos 8,35 MT verlas Josua das Gesetz vor כל-קהל ישראל und so wird hinzugefügt - vor den Frauen, Kindern und mitziehenden Fremden. Sie waren also zusätzlich zu כל-קהל ישראל anwesend. In LXX

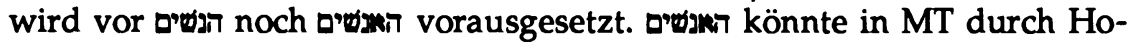
moioteleuton ausgefallen sein. Dann ist die ganze Aufzählung eine

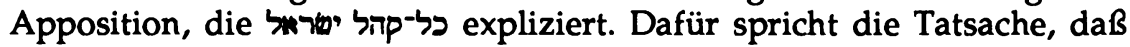
Dtn 31,12 schon bei der Abfassung des Textes die Vorlage gewesen zu sein scheint. Doch ist nicht ausschließbar, daß umgekehrt die Vorlage von LXX im Blick auf Dtn 31,12 das Wort האנשים hinzugefügt haben könnte, wobei כל-קהל ישראלישראל כל כל כל כim Sinne vorstanden wurde, ähnlich wie von LXX in Dtn 31,30.

In 8,33 werden die Anwesenden schon einmal aufgezählt. Zuerst

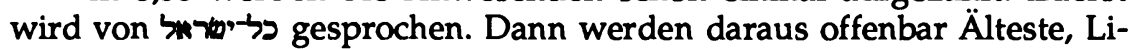
stenführer und Richter noch einmal herausgehoben (denn sie gehören ja sicher auch zu כל-שראל), ferner die levitischen Priester, die die Lade trugen. Anschließend wird כל-ישראל noch einmal als Gesamtgröße in Fremde und Bürger aufgeschlüsselt, wobei der Ton darauf liegen dürfte, daß auch die Fremden dabei waren ${ }^{56}$.

Liest man 8,35 nach MT, dann umfaßt כל-ישראל alle Anwesenden, während כל-קהל ישראי nannte Teilmenge der Ältesten, Listenführer und Richter, eventuell noch der Ladepriester, bietet sich bei der Nähe der beiden Verse für die konkrete Füllung des Begriffs von כל-קהל ימר מאל an. In der deuteronomischen Bezugsstelle, Dtn 27, wird im Blick auf diese Zeremonie bei Sichem nur von כל־העם gesprochen. Es ist fast zu vermuten, daß כל־קהל יפראל auf Dtn 31,30 und seinen Kontext zurückgreift. Dann ist

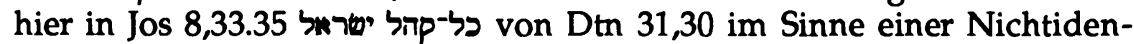
tität mit כל-ישראל intepretiert. Es bleibt das Problem der verlockenden Lesart von LXX.

2. In 1 Kön 8,1 werden diejenigen aufgezählt, die Salomo zur Übertragung der Lade in den neugebauten Tempel einberief (ה hi.). Es sind wieder Notabeln, wenn auch in etwas anderer Umgrenzung ${ }^{57}$. In 8,2 versammeln sie sich (itp ni.)58. In 8,3 beginnt die liturgische Handlung. Hier werden in MT die Notabeln verkürzt noch einmal genann $t^{59}$, und die Priester kommen als Ladenträger hinzu. Doch gibt es viel mehr

völkerung des Davidreichs zu stehen, die als völlig durchbürokratisiert und durchmilitarisiert gedacht ist. Der Terminus kann natürlich im Laufe der Zeit seine Referenz geändert haben. Die Chronik könnte auch frei phantasieren, vgl. RÜTERSWÖRDEN,

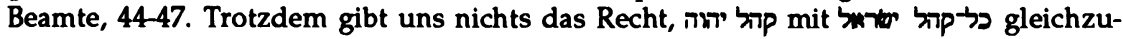
setzen, auch nichts im Deuteronomium.

56 Das "dazu" der EÜ ist Unsinn.

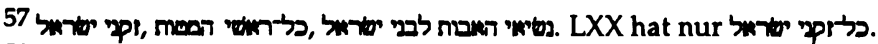

58 Sie werden hier in MT als כל כל- bezeichnet, doch fehlt dies in LXX.

59 כלדי Der Satz hat keine Entsprechung in LXX. 
Beteiligte. Opferspender ist nicht nur Salomo, sondern nach MT

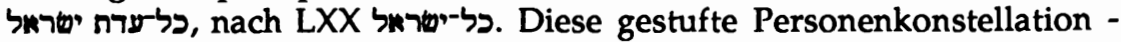
einfacher in LXX, weiterentwickelt in MT - ist schon entworfen, wenn nun in den drei Redeeinleitungen zu den drei deuteronomistischen Haupttexten dreimal der Ausdruck כל-קהל ישראל gebraucht wird. Jedesmal wird eine Art liturgischer Regie beschrieben.

8,14: Salomo hat den Weihespruch offenbar mit Blick zum Tempelhaus gespro-

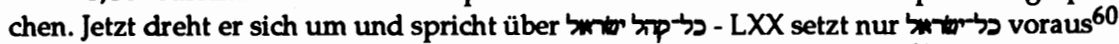
- den Segen, wobei למר לדי - so nun auch bei LXX - aufrecht steht ${ }^{61}$. Nach LXX ist

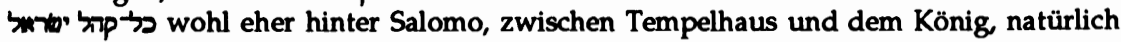
zu beiden Seiten des Altars, vorzustellen. Ob das Zitat 8,15-21 der Segen ist oder eine an den Segen sich anschließende Rede Salomos, kann offen bleiben.

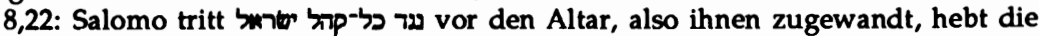
Hände 62 und spricht das Tempelweihgebet. Bedeutet 72 "gegenüber" und ist die Ge-

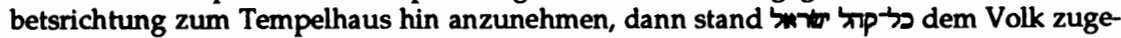
wandt zwischen dem König und dem Tempelhaus - natürlich zu beiden Seiten des Altars. Das paßt zur Vorstellung bei LXX in 8,14.

8,55: Salomo steht nach dem Gebet wieder auf und segnet stehend mit lauter Stim-

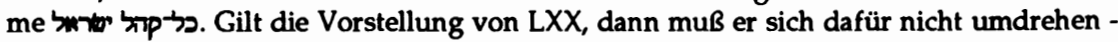
was im Text auch nicht behauptet wird.

Nach diesen drei großen Zitaten wendet der Text sich von 8,62 an wieder den Opfern zu. Sofort ändert sich auch wieder die Terminologie für die Beteiligten. כל- כל-62,62 MT; 8,65 - hier noch mit der Apposition (קהל גדול מלבוא חםח ער־נול מצרים und (8,62 LXX63; 8,63) opfern mit Salomo zusammen und feiern mit ihm das Fest.

Aus diesem Text allein, speziell noch angesichts seiner textkritischen Probleme, läßt sich nicht mit Sicherheit klären, ob כל-ישראל מל מ

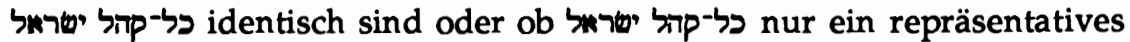
Gremium ist, in diesem Fall am ehesten die am Anfang des Kapitels eigens einberufene Gruppe von Personen. War jedoch für den Leser die Terminologie im zweiten Sinne klar, dann liest sich das Kapitel entschieden konkreter. Dann gab es in jenem inneren Tempelhof, in dem der Altar stand (und der ja auch sicher nicht die גדול ständig fassen konnte), zunächst einmal einen Platz für das Notabelngremium, und normale Volksmitglieder waren nur noch im freibleibenden Raum und außerhalb dieses Hofs zu denken. 1 Kön 8 ist also

60 Anders die Parallele $2 \mathrm{Chr} 6,3 \mathrm{LXX}$, die mit 1 Kön 8,14 MT geht.

${ }^{61}$ Man wird die Darstellung von LXX schon deshalb für ursprünglich halten müssen, weil sie differenzierter ist. Zu MT ergeben sich außerdem zwei Fragen: 1. Warum wird

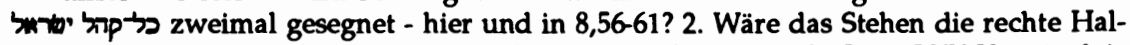
tung, wenn man einen Segen empfängt? In 8,55 steht der Segnende. Beim LXX-Verständnis von 8,14 stünde möglicherweise

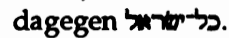

62 8,54 wird nachtragen, daß er dabei kniete. In der Chronik, wo der Segen von 1 Kön 8,56-61 unterdrückt wird, werden Informationen aus 8,54f in $2 \mathrm{Chr} 6,13$ eingebaut, mitsamt dem Ausdruck wer stp, sowohl in MT als auch in LXX.

63 Wohl in Anpassung an den folgenden Vers. 
zumindest offen für ein Verständnis von כל-קהל ישראל = Notabelnversammlung, und wenn man es so versteht, wird es plausibler.

3. In 1 Kön 12,1 kommt כל-לישר in Sichem zusammen. Nach 1 Kön 12,3 MT tritt dort der aus Ägypten zurückgekehrte Jerobeam zusammen mit כל־קהל ישראל vor Rehabeam hin, um ihm Bedingungen zu stellen64. Die Referenz von לאר sie sind hier die Nordstämme. Wird die Szene

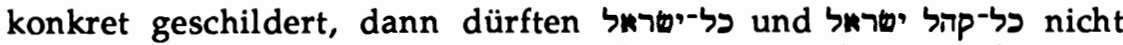

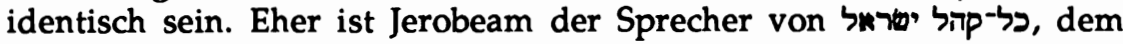
repräsentativen Gremium der Nordstämme.

4. Ob $1 \mathrm{Chr} 13,2$ (aus dem Sondergut der Chronik) 13,1 expliziert oder von einer zweiten Handlung Davids spricht, kann offenbleiben. Je-

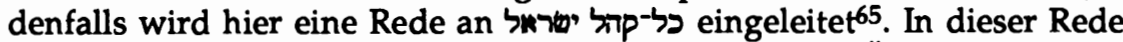
holt David das Einverständnis ein, daß er כל-ישראל zur Überführung der Lade in Jerusalem zusammenrufen dürfe (הק hi.) - mit dieser Terminologie jedenfalls wird der Antrag von David aus 13,2f in der Ausführungsnotiz 13,5 zusammengefaßt. Diese Stelle zeigt wohl am ein-

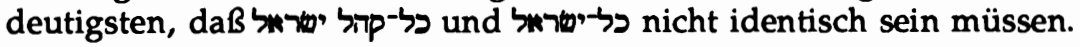

\section{LITERATURVERZEICHNIS}

-BALTZER, K., Das Bundesformular (WMANT 4) Neukirchen 1960

-BARTHÉlemY, D., u.a., Preliminary and Interim Report on the Hebrew Old Testament Project. Preliminary Report on the Pentateuch, London o.J. (1974)

-BEGG, C., The Reading sbty(km) in Deut. 29,9 and 2 Sam 7,7, EThL 58 (1982) 87-105

-DERS., The Tables (Deut. $x$ ) and the Lawbook (Deut. xxxi), VT 33 (1983) $96 f$

-BLUM, E., Studien zur Komposition des Pentateuch (BZAW 189) Berlin 1990

-DERS., Gibt es die Endgestalt des Pentateuch?, in: EMERTON, Leuven 1989, 46-57

-BOGAERT, P.-M., Les trois rédactions conservées et la forme originale de l'envoi du cantique de Moïse (Dt 32,43), in: LOHFINK, Deuteronomium, 329-340

-BRAULIK, G., Die Ausdrücke für "Gesetz" im Buch Deuteronomium, Bib. 52 (1970) 39-66 (= DERS., Studien, 11-38)

-DERS., Studien zur Theologie des Deuteronomiums (SBAB 2) Stuttgart1988

-DERS., Deuteronomium 16,18-34,12 (NEB) Würzburg 1992

-BREkelmaNS, C., \& LUST, J. (Hg.), Pentateuchal and Deuteronomistic Studies. Papers

Read at the XIIIth IOSOT Congress Leuven 1989 (BEThL 94) Leuven 1990

-EMERTON, J. A., Congress Volume Leuven 1989 (VT.S 43) Leiden 1991

-EISSFELDT, O., Die Umrahmung des Mose-Liedes Dtn 32,1-43 und des Mose-Gesetzes Dtn 1-30 in Dtn 31,9-32,47, WZ(H).GS 4 (1944/45) 411-417 (= DERS., K1.Schr. III, 322-334 hiernach zitiert)

-DERS., Kleine Schriften III, Tübingen 1966

-FISHBANE, M., Varia Deuteronomica, ZAW 84 (1972) 349-352

-HUMMELAUER, F. de, Commentarius in Deuteronomium (CSS VT I.III.2) Paris 1901

64 In O-LXX werden (sowohl in 12,3 als auch in 12,24p RAHLFS) die Bedingungen einfach

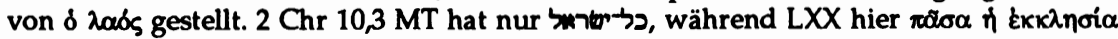
Topari liest (= 1 Kön 11,3 MT).

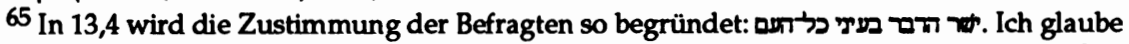
nicht, daß כלדתם den befragten in meint. Eher hat dieser zugestimmt, weil er wußte, daß die ganze Bevölkerung dachte wie David. 
-KLOSTERMaNN, A., Der Pentateuch. Beiträge zu seinem Verständnis und seiner Entstehungsgeschichte, Leipzig 1893

-LABERGE, L., Le texte de Deutéronome 31 (Dt 31,1-29; 32,44-47), in: BREKELMANS \& LUST, Studies, 143-160

-LOHFINK, N., Der Bundesschluß im Land Moab. Redaktionsgeschichtliches zu Dt 28, 69-32,47, BZ 6 (1962) 32-56 (= DERS., Studien I, 53-82)

-DERS., Die deuteronomistische Darstellung des Übergangs der Führung Israels von Moses auf Josue. Ein Beitrag zur alttestamentlichen Theologie des Amtes, Schol. 37 (1962) 32-44 (= DERS., Studien I, 83-97)

-DERS. (Hg.), Das Deuteronomium. Entstehung, Gestalt und Botschaft (BEThL 68) Leuven 1985

-DERS., Studien zum Deuteronomium und zur deuteronomistischen Literatur I (SBAB 8) Stuttgart 1990

-DERS., Die Väter Israels im Deuteronomium (OBO 111) Freiburg/Schweiz u. Göttingen 1991

-MCCARTHY, D. J., An Installation Genre?, JBL 90 (1971) 182 (= DERS., Institution, $182-$ 192)

-DERS., Institution and Narrative. Collected Essays (AnB 108) Rom 1985

-RAD, G. VON, Das fünfte Buch Mose. Deuteronomium (ATD 8) Göttingen 1964

-RÜTERSWŌRDEN, U., Die Beamten der israelitischen Königszeit. Eine Studie zu s̀r und vergleichbaren Begriffen (BWANT 117) Stuttgart 1985

-SCHENKER, A., Zeuge, Bürge, Garant des Rechts. Die drei Funktionen des "Zeugen" im Alten Testament, BZ 34 (1990) 87-90

-SKWERES, D. E., Die Rückverweise im Buch Deuteronomium (AnB 79) Rom 1979

-TOV, E., The Text-Critical Use of the Septuagint in Biblical Research (Jerusalem Biblical Studies 3) Jerusalem 1981

-WEVERS, J. W., adiuvante U. QUAST, Deuteronomium (Septuaginta.Vetus Testamentum Graecum Auctoritate Academiae Scientiarum Gottingensis editum, III,2) Göttingen 1977 



\title{
WAS WISSEN WIR ÜBER DEN ZWEITEN TEMPEL AUS SACH 1-8?
}

\author{
von \\ Peter Marinkovic \\ Augustana-Hochschule, Neuendettelsau
}

\section{SACHARJA ALS FÖRDERER DES TEMPELBAUS - EINE THESE UND IHRE PROBLEME}

Der Prophet Sacharja wird weithin als Förderer des Baus des zweiten Tempels betrachtet und mit dem Wirken des Propheten Haggai und dessen Botschaft in (mehr oder weniger enge) Verbindung gebracht. Bezeichnend hierfür ist - als ein Beispiel unter vielen - die folgende $\mathrm{Zu}$ sammenfassung H. DONNERs, der in seiner "Geschichte des Volkes Israel und seiner Nachbarn" im Blick auf Wirksamkeit und Verkündigung der beiden Propheten festhält: "Kurze Zeit danach (520) traten in Jerusalem zwei Propheten auf und riefen zum Tempelbau: Haggai und Sacharja." 1 Interessanterweise kann DONNER hierbei auf die bereits innerbiblisch erfolgte Rezeption der beiden Propheten zurückgreifen. Denn schon im Buch Esra finden sich Notizen, die ein gemeinsames Auftreten von Haggai und Sacharja erwähnen. Hier zunächst Esr 5,1f:2

$[(4,24)$ Da wurde verhindert das Werk am Hause Gottes in Jerusalem, und es blieb verhindert bis zum zweiten Jahr der Regierung des Darius, des Königs oon Persien.]

(1) Es prophezeiten Haggai, der Prophet, und Sacharja, der Sohn Iddos ${ }^{3}$, die Propheten, für die Juden in Juda und Jerusalem im Namen des Gottes Israels, [der] über ihnen [wachte].

(2) Da machten sich auf Serubbabel, der Sohn Schealtiëls, und Jeschua, der Sohn des Jozadak, und begannen das Haus (aram. (a) Gottes in Jerusalem zu bauen (aram. $n$ ), und mit ihnen Propheten Gottes, welche sie unterstützten.

Ebenso deutlich spricht es Esr 6,144 aus:

\footnotetext{
${ }^{1} \mathrm{H}$. DONNER, Geschichte des Volkes Israel und seiner Nachbarn in Grundzügen, Bd 2, ATD.E 4/2, Göttingen 1986, 412. Vgl. B. DUHM, Israels Propheten, Lebensfragen 26, Tübingen 21922, 321: "Er [Sacharja] stellt sich dieselbe Aufgabe wie Haggai, er will den Tempelbau fördern".

2 Übersetzungen in enger Anlehnung an A.H.J. GUNNEWEG, Esra. Mit einer Zeittafel von Alfred JEPSEN, KAT XIX/1, Gütersloh 1985.

3 Zur Abstammung Sacharjas aus der Familie des Iddo: vgl. auch Neh 12,16, sofern dort von der gleichen Person die Rede ist.

4 A.H.J. GUNNEWEG [A.2] $95 f$ u. 112, erörtert ausführlich die chr Überarbeitung dieses Verses, die vermutlich zur Einfügung der Propheten Haggai und Sacharja in die sog. aramäische Grunderzählung, Esr 4,6-6,14*, geführt hat. Esr 5,1f hält GUNNEWEG für eine rein chr Bildung (95f). Damit ergibt sich eine Nähe zu der von W.A.M. BEUKEN u.a. herausgestellten gemeinsamen chr Überarbeitung der Bücher Hag und Sach 1-8, die sich u.a.
} 
Und die Ältesten der Juden bauten (aram. Prophetien des Propheten Haggai und des Sacharja, des Sohnes Iddos, und sie vollendeten den Bau (aram. N2$^{5}$ gemäß dem Befehl des Gottes Israels und dem Befehl des Kyros und Darius [und des Artaxerxes, des Königs von Persien] ${ }^{6}$.

Bei näherer Betrachtung der beiden an Summarien erinnernden Zitate fällt auf, daß von einem Aufruf zum Tempelbau durch Haggai oder Sacharja, explizit jedenfalls, nicht die Rede ist. Ebenso wird nicht ausgesagt, daß beide die gleichen Verkündigungsinhalte oder wenigstens die gleichen Schwerpunkte in ihrer Verkündigung hätten. Lediglich die (implizit enthaltene und von daher vermutbare) Gleichzeitigkeit ihres Auftretens $(5,1)^{7}$ und die Unterstützung des Tempelbaus $(5,2)$ bzw. das gute Vorankommen dank ihrer Verkündigung $(6,14)$ werden betont. Gleichwohl dürften diese beiden Stellen, Esr 5,1f u. 6,14, wesentlich dazu beigetragen haben, daß in der forschungsgeschichtlichen Sacharjarezeption nicht nur das zeitliche Auftreten beider Propheten parallelisiert worden ist (was ja historisch wahrscheinlich zutrifft), sondern darüberhinaus sind auch der Kern der Botschaft Sacharjas und derjenige der Botschaft Haggais parallelisiert (und letzlich ineinsgesetzt) worden. D.h. konkret: die Rezeption geht davon aus, daß die Verkündigungen beider Propheten gemeinsam geprägt sind vom (expliziten?) Aufruf zum Tempelbau ${ }^{8}$, wörtlicher (und etwas vorsichtiger) formuliert, vom Aufruf zum Bau des Hauses Gottes in Jerusalem. ${ }^{9}$

Den Ausgangspunkt meiner Untersuchung bildet die Beobachtung folgender Diskrepanz: Untersucht man Sach 1-8 unter der Fragestellung "Was sagen die Texte konkret über den zweiten Tempel (bzw. seinen Bau) aus?", so ergibt sich eine auffällige Diskrepanz zu den Aussagen in Esr 5,1f; 6,14 und der sich daran anschließenden forschungsgeschichtlichen Rezeption. Denn erstens gibt es in Sach 1-8 kaum Textpassagen über den Tempel, es sind nur wenige einzelne Verse, die zudem meist

in deren auffälligem Datierungsformular zeigt (die Datierungen entsprechen den Angaben in Esr 5,1f; 6,14), s. hierzu Anm. 37.

5 Wörtlich: "bauten und vollendeten".

6 Das in eckigen Klammern hinzugesetzte Stück wird von den meisten Auslegern als Zusatz betrachtet, s. A.H.J. GUNNEWEG [A.2] 112.

7 Auch die Orte ihres Auftretens werden nicht genannt. Lediglich aus den Adressatenangaben läßt sich eine, wenn auch nur grobe Einordnung vornehmen: Juda und Jerusalem (Esr 5,1; indirekt auch Esr 6,14); ob demnach die Gola als weiterer Verkündigungsort ausscheidet, läßt sich zumindest allein aufgrund von Esr 5,1, nicht entscheiden.

8 Siehe das Zitat von H. DONNER [A.1], das als Wiedergabe einer forschungsgeschichtlichen opinio communis gelten kann.

9 Und d.h. damit eben auch, daß die Botschaft Sacharjas im Grunde aus der Perspektive der Verkündigung Haggais interpretiert worden ist, wie eine inhaltliche Durchsicht des Buches Hag zeigt, s.u. 
am Rand der Texte gelegen oder eingebunden sind in eine Reihe anderer Grundaussagen. Und zweitens beschäftigt sich der Großteil der Texte in Sach 1-8 mit ganz anderen thematischen Schwerpunkten. So hat z.B. keine einzige der acht Visionen den Tempel als solchen oder seinen Wiederaufbau zum Thema ${ }^{10}$.

Ganz im Gegensatz zu den Aussagen von Esr 5,1f und 6,14 finden sich also in Sach 1-8 im Verhältnis zu Hag ${ }^{11}$ relativ wenig Äußerungen über den Tempel(bau). Um ein genaueres Bild über die Hauptthemen von Sach 1-8 (und damit über die Verkündigungsschwerpunkte Sacharjas) zu gewinnen, möchte ich als nächstes einen inhaltlichen Überblick über die Kernaussagen von Sach 1-8 bieten. Danach werde ich in einem zweiten Schritt auf alle diejenigen Verse in Protosacharja eingehen, die die signifikanten Begriffe für Haus bzw. Tempel enthalten,

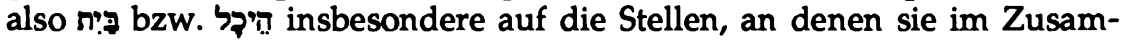
בנה menhang mit den Termini für Bauen bzw. Gründen/ Vollenden bzw. 70 / בצi genannt werden. Und zum Schluß werde ich versuchen, anhand der Ergebnisse dieser Untersuchung eine Antwort auf die Frage zu geben, wie es dazu gekommen sein kann, daß in Esr 5,1f; 6,14 Sacharja gemeinsam mit Haggai als Förderer des Baus des Hauses Gottes in Jerusalem bezeichnet worden ist.

\section{THEMATISCHE SCHWERPUNKTE IN SACH 1-8}

\subsection{JHWHS RÜCKKEHR NACH UND SEIN WOHNEN IN JERUSALEM ALS WENDEPUNKT FÜR DIE HEIMKEHR SEINES VOLKES NACH JERUSALEM}

Aussagen über die Rückkehr JHWHs nach Jerusalem und seine erneute Wohnungnahme dort finden sich in der ersten und dritten Vision (Sach $1,8-17 ; 2,5-9)$, in der unmittelbar darauffolgenden Gottesspruchsammlung $(2,10-17)$ und im Verheißungsteil der sog. Fastenrede (8,1-8). Sie bilden damit gewissermaßen einen Rahmen, genauer gesagt: ein Fundament für die übrigen Inhalte von Sach 1-8. Zu den Stellen im einzelnen:

In der ersten Vision $(1,8-17)$ geht es eindrücklich um die Frage nach dem Ende der Gerichtszeit des Exils: "wie lange noch willst du dich nicht erbarmen über Jerusalem und die Städte Judas, denen du zürnst, jetzt schon siebzig Jahre lang?" $(1,12)$. Und die Antwort JHWHs darauf

10 Vgl. hierzu Ez 40-48, wo mehrere Kapitel direkt und einige Passagen indirekt vom neuen Tempel und seinem Ausbau bzw. seiner Organisation (Priester, Leviten, Opferregeln) handeln. Zur Josua- und zur Leuchtervision (Sach 3f) als mögliche Bestandteile einer judäischen Entsprechung zum (akkad.) babylonischen kak-Ritual der Tempelrestaurierung, s. 2.2.

11 Ausführlicheres zu Hag später. Hier sei vorerst nur darauf verwiesen, daß in Hag die termini ר? 


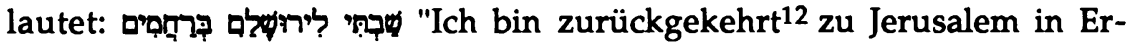
barmen" $(1,16)$. Die Rückkehr JHWHs nach Jerusalem ist demnach bereits vollzogen, zumindest als Entschluß. Mit dieser Perspektive beginnt der Visionszyklus, und dies ist prägend für alle folgenden Aussagen Protosacharjas.

In der dritten Vision (2,5-9) wird das Vorhaben, Jerusalem auszumessen (vermutlich als Vorbereitung zukünftiger Bautätigkeit ${ }^{13}$ ), gestoppt. Zur Erklärung heißt es: "Jerusalem wird als offene Stadt wohnen im Blick auf die Menge an Menschen und Tieren in seiner Mitte" $(2,8 b)$. Und Gott kündigt an: "Und ich werde für es sein - Spruch JHWHs - eine Feuermauer ringsum und zum ksbod in seiner Mitte" $(2,9)$. Diese komplementäre Schilderung drückt die Totalität der heilvollen Gegenwart JHWHs in Jerusalem in eindrucksvollen Bildern aus: einerseits umgibt Gott die Stadt als schützende Feuermauer ringsum, andererseits ist er (gleichzeitig!) in ihrer Mitte als kabod (und wird so zu ihrem Glanz, ihrer Herrlichkeit, ihrem Ruhm, ihrer Ehre). Diese Zusage JHWHs steht vom Kontext her betrachtet - in unmittelbarem Zusammenhang mit der Ankündigung der zukünftigen Fülle an Menschen und Tieren in Jerusalem, die als impliziter Hinweis auf die Heimkehr der Exulanten nach Jerusalem gewertet werden kann.

Bestätigt wird diese Vermutung durch die nachfolgende Gottesspruchsammlung (2,10-17), in der - schon gleich zu Beginn - zur Flucht aus dem Land des Nordens und zur Rettung aus Babel aufgefordert wird (2,10f). Im zweiten Teil der Spruchsammlung ruft JHWH die Tochter Zion auf, zu jubeln und sich zu freuen: "Denn siehe ich bin gerade dabei/im Begriff, zu kommen und in deiner Mitte zu wohnen/Wohnung zu nehmen - Spruch JHWHs" $(2,14) .14$ Die erneute Wohnungnahme Gottes inmitten der Tochter Zion als Gemeinschaft JHWHs steht also unmittelbar bevor. 2,15 erwähnt das zukünftige Hinzutreten vieler Völker zum Gottesvolk und wiederholt das Wohnen JHWHs in dessen Mitte. Und 2,17 meldet schließlich den Vollzug des Aufbruchs Gottes hin zu seiner neuen Wohnstätte.

\footnotetext{
12 Zur Übersetzung des qãtal unter Berücksichtigung des Aspekts der Abgeschlossenheit des Vorgangs (und von daher hier deutsch im Tempus der Vorzeitigkeit wiedergegeben) s. R. BARTELMUS, HYH. Bedeutung und Funktion eines hebräischen "Allerweltswortes" - zugleich ein Beitrag zur Frage des hebräischen Tempussystems, ATS 17, St. Ottilien 1982, 51-54, sowie R. HANHART, Sacharja, BK XIV/7.1, Neukirchen-Vluyn 1990, 57: "Die Rückkehr ist als Entschluß Vergangenheit, geschehen ...".

13 Aus dem Text geht nicht explizit hervor, ob und, wenn ja, was gebaut werden soll. Das JHWH-Wort (2,8bf: Offenheit Jerusalems, JHWH als schützende Feuermauer), das im Kontext der Vision als Reaktion JHWHs auf das menschliche Vorhaben aufzufassen ist, legt es allerdings nahe, den Bau einer Stadtmauer zu vermuten.

14 Das futurum instans (' $\not ?+q 0$ tel) wird durch ein w'qatal fortgeführt, so daß die Zeitstufe des unmittelbar bevorstehenden, ja schon beinahe eingetretenen Vorgangs auch auf das zweite Prädikat zu beziehen ist, s. R. BARTELMUS [A.12] 73-79.
} 
Im Gottesspruch 8,3a heißt es dann: "Ich bin zurückgekehrt zu Zion und habe Wohnung genommen inmitten von Jerusalem."15 Die Rückkehr JHWHs nach Jerusalem ist vollzogen. 8,4f stellt das Bild der zukünftigen Fülle an Bewohnern vor Augen. Und 8,7f kündigt an, daß die Rückführung des Volkes nach Jerusalem durch JHWH unmittelbar bevorsteht. ${ }^{16}$

Zusammenfassend ist festzuhalten, daß zum einen an all diesen Stellen, mit Ausnahme von Sach 1,16,17 im Zusammenhang mit der erneuten Wohnungnahme JHWHS in Jerusalem mit keinem Wort der Tempel erwähnt wird. Immer ist es ganz Jerusalem, das als Ort der unmittelbar bevorstehenden wie der bereits eingetretenen Gegenwart Gottes benannt wird, oder aber die Tochter Zion (und die vielen Völker) als Menschengruppe, als Gemeinschaft JHWHs, in deren Mitte Gott gegenwärtig sein wird. Nirgendwo aber wird der Tempel selber als (besonderer) Ort der Gegenwart Gottes genannt.

Zum andern ist es auffällig (im Vergleich zu Haggai), daß an den behandelten Stellen keinerlei Bedingungen angeführt werden, die vor der Rückkehr JHWHs (und seines Volkes) nach Jerusalem von Menschen (seinem Volk) zu erfüllen wären. Es ist also eine bedingungslose Rückkehr Gottes, die an keinerlei zu erbringende Voraussetzung gebunden ist, also auch nicht an die Voraussetzung eines zuvor erfolgten Tempelbaus. Bei Haggai hingegen sieht es ganz anders aus. Die Mißerfolge des Volkes bei den Ernten, das Ausbleiben der Segnungen des Landes also, führt Haggai gerade auf die Abwesenheit oder vielmehr Nochnicht-Anwesenheit der heilvollen Gegenwart JHWHs zurück, und diese wiederum steht deshalb noch aus, weil der Tempel, als Ort und sichtbares Zeichen der Gegenwart JHWHs, noch nicht wieder aufgebaut ist. Stattdessen kümmere sich das Volk, so klagt Haggai, nur um den Bau seiner eigenen Häuser (Hag 1,2.3-11).

Zum dritten: Das Wohnen JHWHs in Jerusalem wird meist mit dem (zukünftigen) Wohnen seines Volkes dort (nach dessen Rückkehr also) in Verbindung gebracht (vgl. die Erwähnung der Bundesformel, 2,15; 8,8, und der Menschenfülle in Jerusalem, 2,8; 8,4f). Es geht in Sach 1-8 also ganz wesentlich um die Rückkehr JHWHs und seines Volkes nach Jerusalem und um deren gemeinsames Wohnen in Jerusalem. Die Rückkehr JHWHs stellt den Wendepunkt und damit den Beginn dieses Prozesses dar.

Auch die anderen beiden Kernaussagen von Sach 1-8 stehen im Dienst dieser Hauptbotschaft, nämlich der "Neuordnung des Gottesvol-

15 qutal-Aussagen mit Betonung des Aspekts der Abgeschlossenheit des Vorgangs, vgl. Anm. 12.

16 Futurum instans mit nachfolgender w?qatal-Reihe, s. Anm. 14.

17 Näheres zu 1,16 in 3.3. 
kes", wie es H.-G. SCHÖTTLER im Untertitel seiner Arbeit über Sach 1-6, "Gott inmitten seines Volkes", formuliert hat. ${ }^{18}$

\subsection{DIE LEITUNG DER JHWH-GEMEINSCHAFT IN JERUSALEM}

In den Visonen 4 und 5 (Sach 3,1-4,14) geht es um die neue Leitungsstruktur der JHWH-Gemeinschaft in Jerusalem/Juda. Es wird also eine Zeit anvisiert, in der das in den ersten drei Visionen angekündigte Geschehen bereits eingetreten ist, d.h. also die Rückkehr der Exulanten schon vollzogen ist oder zumindest deutlich spürbar eingesetzt hat. Mit der Leitung der neuen JHWH-Gemeinschaft werden zwei Ölsöhne beauftragt, zu deuten vermutlich als ein priesterlicher und ein königlicher Gesalbter (Sach 4).19 Darüberhinaus wird der Priester vor seiner Amtseinsetzung einem Reinigungsakt unterzogen (3,1-5).

Die Josua- und die Leuchtervision sind weniger als Teile einer hypothetisch postulierten israelitischen Fassung des (akkad.) babylonischen kalu-Rituals zu werten. Sie bieten vielmehr Aussagen über die zukünftigen Träger der Leitungsfunktionen innerhalb der Gemeinde JHWHs in Jerusalem. Somit sind diesen beiden Visionen kaum Aussagen über den Tempel zu entnehmen (wenn überhaupt, dann höchstens präsuppositionell - abgesehen von 3,7 und 4,9), es geht vielmehr um Aussagen über Personen und deren zukünftige Funktion in einem Gemeinwesen ${ }^{20}$.

18 H.-G. SCHÖTTLER, Gott inmitten seines Volkes. Die Neuordnung des Gottesvolkes nach Sacharja 1-6, TThSt 43, Trier 1987. Die Frage nach der Gestalt des Gottesvolkes spielt überhaupt in der spätexilisch-frühnachexilischen Zeit eine große Rolle, s. hierzu die Arbeiten von J. HAUSMANN, Israels Rest. Studien zum Selbstverständnis der nachexilischen Gemeinde, BWANT 124, Stuttgart 1987, oder H. UTZSCHNEIDER, Das Heiligtum und das Gesetz. Studien zur Bedeutung der sinaitischen Heiligtumstexte (Ex 25-40; Lev 8-9), OBO 77, Göttingen-Fribourg 1988.

19 So interpretiert jedenfalls die große Mehrheit der Kommentatoren (oft mit Hinweis auf Josua und Serubbabel), z.B. W. NOWACK, Die kleinen Propheten, HK III/4, Göttingen 31922, 358; E. SELLIN, Das Zwölfprophetenbuch, KAT XII, Leipzig 2.31930, 506; Th. ROBINSON-F. HORST, Die zwölf kleinen Propheten, HAT I/14, Tübingen 31964, 231; J.G. BALDWIN, Haggai, Zechariah, Malachi, TOTC, Downers Grove/Ill. 1972, 124; W. RUDOLPH, Haggai - Sacharja 1-8 - Sacharja 9-14 - Maleachi, KAT XIII/4, Gütersloh 1976, 108; R.A. MASON, The Books of Haggai, Zechariah and Malachi, CBC, Cambridge 1977, 48; K. ELLIGER, Das Buch der zwölf kleinen Propheten II, ATD 25, Göttingen 81982, 110f; A. DEISSLER, Zwölf Propheten III, NEB, Würzburg 1988, 281. Demgegenüber befürworten D.L. PETERSEN, Haggai and Zechariah 1-8: A Commentary, OTL, Philadelphia 1984, 234, und C.L. MEYERS/E.M. MEYERS, Haggai, Zechariah 1-8: A New Translation with Introduction and Commentary, AncB 25B, Garden City/N.Y. 1987, 258f, lediglich die Legitimierung einer dyarchischen Grundstruktur für das nachexilische Juda.

${ }^{20}$ Sach 3 hat die Reinigung des Hohenpriesters Josua zum Thema und nicht die kultische Reinigung des alten Tempelgeländes vor dem Beginn des Wiederaufbaus des Tempels, wie es dem (akkad.) babylonischen kala-Ritual der Tempelrestaurierung entsprechen würde; anders A. PETITJEAN, La mission de Zorobabel et la reconstruction du temple, 
Die anschließenden Visionen 6 und 7 (Sach 5,1-11) beschäftigen sich v.a. mit der inneren Beschaffenheit der restituierten JHWH-Gemeinschaft in Jerusalem. Die sechste Vision betont die Entfernung der Meineidigen und Diebe aus der Gemeinschaft $(5,1-4)$. Denn gerade diese beiden Vergehen, Meineid und Diebstahl, sind von solcher Art, daß sie das Vertrauensverhältnis einer Gemeinschaft belasten und die Atmosphäre des Miteinanders gefährden können. Die siebte Vision geht sogar noch einen Schritt weiter und beschreibt die Entfernung der Sünde generell aus dem Land und ihren Abtransport ins Land Schinear ${ }^{21}$ (5,5-11).

In der sog. Fastenrede (Sach 7f) finden sich noch konkretere Anweisungen für das ethische Verhalten und den Umgang miteinander in der JHWH-Gemeinschaft von Jerusalem. In den Gottessprüchen 7,9f und 8,16f wird aufgerufen zu gerechtem Gericht, zu gegenseitiger Liebe und Barmherzigkeit und zur Wahrheit untereinander. Untersagt wird die Unterdrückung von Witwen, Waisen, Fremdlingen und Armen, das Planen von Bösem gegeneinander und der Meineid. Diese ethischen Anweisungen stehen der prophetischen (Rechts-) Tradition sehr nahe (z.B. Am 5,24; Hos 12,7; Jes 1,17.23; Jer 7,5f; 21,12; 22,3 - vgl. aber auch Ex 22,21.24).

\subsection{FAZIT}

Sacharja hat in seiner Verkündigung im Grunde stärker ein "Jerusalem-Gemeinwesenkonzept" befürwortet, d.h. ein Konzept für eine erneuerte JHWH-Gemeinschaft in Jerusalem. JHWHs Rückkehr nach Jerusalem und die Rückkehr seines Volkes unter Einbeziehung all derer, die sich JHWH (und seinem Volk) anschließen wollen, gehören nach Sach 1-8 untrennbar zusammen zum Aufbau der JHWH-Gemeinschaft in Jerusalem, die nach den ethischen Grundsätzen JHWHs leben wird.

Zach 3,8-10, EThL 42 (1966), 40-71, und - mit Bezug auf Sach 4 - B. HALPERN, The Ritual Background of Zechariah's Temple Sons, CBQ 40 (1978), 167-180. Zur umstrittenen Echtheit von Sach 3 vgl. die Kommentare von F. HORST [A.19] 210; K. ELLIGER [A.19] 120; A. DEISSLER [A.19] 267, die für eine spätere Hinzufügung zum Visionszyklus plädieren, während z.B. W. RUDOLPH [A.19] 94; D.L. PETERSEN [A.19] 112; C.L. MEYERS/E.M. MEYERS [A.19] LVI-LVIII.215, an der ursprünglichen Zugehörigkeit zum Sacharja-Grundbestand festhalten, wobei gerade MEYERS/MEYERS die Sonderstellung von Sach 3 im Rahmen der übrigen Visionen besonders betonen (" $7+1$ ", a.a.O. LVII).

21 Bezeichnenderweise soll dem Epha, in dem die Sünde festgehalten wird, dort ein n? gebaut werden, in dem es aufgestellt werden kann. 
Kurz gesagt: Es geht in Sach 1-8 um die erneute Begründung des Gemeinschaftsverhältnisses zwischen JHWH und seinem Volk in Jerusalem. ${ }^{22}$ Das Ziel der sog. Restauration hat Sacharja m.E. nicht primär im Wiederaufbau des Tempels gesehen, sondern in der Restitution bzw. Neukonstitution und Organisation einer JHWH-Gemeinschaft in Jerusalem.

Wir haben es also in der Verkündigung Protosacharjas mit einer anders akzentuierten Botschaft $\mathrm{zu}$ tun als derjenigen des vermutlichen Zeitgenossen Haggai, der den Wiederaufbau des Tempels ganz besonders betont hat (Hag 1,2-11.14; 2,1-9.15-19). ${ }^{23}$ Sacharja zielt demgegenüber stärker auf eine "Gemeindekonzeption"24 ab. Bei ihm steht - wie schon dargelegt - nicht so sehr der Tempelbau im Mittelpunkt ("Haus" als Gebäude, vgl. Hag), sondern der "Gemeindebau" ("Haus" als Gemeinschaft). Auch seine wenigen Äußerungen zum Tempelkonzept (Josua-Vision Sach 3,1-10 u.ä.) beschäftigen sich stärker mit Fragen der Leitung einer Gruppe als mit dem Vorankommen des Tempelbauprogramms. ${ }^{25}$

\section{DER AUFBAU EINER JHWH-GEMEINSCHAFT IN JERUSALEM:

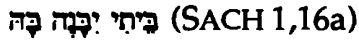

Es hat sich bislang gezeigt, daß im Unterschied zu den Aussagen von Esr 5,1f und 6,14 und im Unterschied zu Haggai der Tempel nicht im Mittelpunkt der Botschaft von Sach 1-8 steht. Alles dreht sich mehr oder weniger um die Stadt Jerusalem als solche und um das Wohnen von JHWH und seiner Gemeinschaft dort (Formen des Miteinanders, Leitung der Gemeinschaft u.a.m.).

22 Das Stichwort Bund fällt in Sach 1-8 gerade nicht, aber die beiden (Halb-) Zitate der Bundesformel, gerade an denjenigen aufschlußreichen Stellen in Sach 1-8, wo vom Wohnen JHWHs in Jerusalem die Rede ist $(2,15 ; 8,8)$, machen deutlich, daß der Sache nach durchaus davon die Rede ist. S. K. BALTZER, Das Bundesformular, WMANT 4, Neukirchen 1960, 69f.

23 "... Haggai mentions neither Jerusalem nor Zion but rather concentrates on the temple building itself", C.L. MEYERS/E.M. MEYERS, Jerusalem and Zion after the Exile: The Evidence of First Zechariah, in: M. FISHBANE u.a. (Hg.), "Sha'arei Talmon". Studies in the Bible, Qumran, and the Ancient Near East. Presented to Shemaryahu Talmon, Winona Lake/Ind. 1992, 121-135 (Zitat: 132).

24 Der Begriff "Gemeinde" ist im Blick auf das zu Beginn der persischen Periode in Jerusalem entstandene, recht uneinheitliche soziale Gebilde nicht unproblematisch und erfordert eine eigene Auseinandersetzung und Bearbeitung; deshalb wird er in diesem Aufsatz meist durch das Kompositum "JHWH-Gemeinschaft" ersetzt. Auf diese Weise soll dem Umstand Rechnung getragen werden, daß als einzige für alle Gruppen gleichermaBen konstitutive Größe der Bezug auf JHWH gelten kann.

25 Die bisher nicht näher behandelten Visionen 2 und $8(2,1-4 ; 6,1-8)$ beschäftigen sich mit den Auswirkungen der Exilswende, der Rückkehr JHWHs und seines Volkes nach Jerusalem, auf das Weltgeschehen. Sie gehen auf den Tempel oder seinen Bau mit keinem Wort ein. 
Dennoch finden sich in Sach 1-8 (im Verhältnis zu Hag ${ }^{26}$ nur) einige wenige Stellen, die die signifikanten Begriffe für Haus bzw.

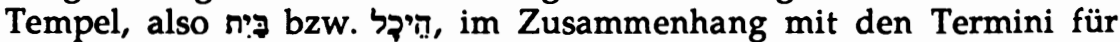
Bauen bzw. Gründen/Vollenden בנה bzw. בצע/ pi. enthalten.

Bevor ich auf diese Stellen näher eingehe, möchte ich noch einen kurzen Einblick in das Bedeutungsspektrum der beiden wichtigsten Begriffe, בנה ביב בית , bieten; denn diese beiden kommen auch in Esr 5,1f; 6,14 (aram.) vor.

\section{1. $\pi$}

תezeichnet oft ein Gebäude und ist in solch einem Fall mit Haus zu übersetzen. In Verbindung mit einem Gottesnamen ist dann in der Regel sachgemäßer von einem Tempel(gebäude) zu sprechen. בִיח kann aber auch eine Gemeinschaft/Gruppe, eine Familie bzw. Sippe oder eine Dynastie bezeichnen. Beispiele hierfür sind Haus Josef, Haus Juda, Haus Israel oder Haus Ahabs und Haus Davids. ${ }^{27}$ Diese constructus-Verbindungen mit einem Namen, bei denen die zweite Bedeutung von zur Geltung kommt, sind auch noch in anderer Hinsicht interessant; denn rein formal gesehen liegt bei der Verbindung von mit einem Gottesnamen zunächst genau das gleiche sprachliche Phänomen vor, obgleich wir beim Haus Davids kaum je an den Palast Davids denken. Ganz zu schweigen davon, daß wir uns bislang kaum Gedanken darüber gemacht haben werden, welches Gebäude mit dem Haus Juda oder dem Haus Israel gemeint sein könnte. Ich möchte also vorschlagen, einmal den Versuch zu unternehmen, bei der Übersetzung und Interpretation von הית הית nicht automatisch nur an das Tempelgebäude zu denken, sondern auch an die dahinter stehende (Tempel-) Gemeinschaft. ${ }^{28}$ Konkret gesagt: ich möchte vorschlagen, jeder Fundstelle sofort und ausschließlich als Tempel zu deuten, sondern erst einmal zu prüfen, ob nicht die zweite Bedeutung, als Familie, Volk bzw. Gemeinschaft JHWHs ${ }^{29}$, u.U. besser paßt. Mir scheint dies

26 Hier sei nochmals darauf verwiesen, daß in Hag die termini עִ עִ völlig fehlen, während na und

27 Siehe hierzu H.A. HOFFNER, ת.7 , ThWAT I, Stuttgart 1973, 629-638, der eine Fülle von Belegstellen bietet.

$28 \mathrm{Vgl}$. in unserem modernen Sprachgebrauch die Unschärfe und Mehrdeutigkeit des Begriffes "Kirche": Gebäude, Gemeinschaft, Gottesdienst.

29 Diese Verwendung von הo als Soziomorphem findet sich z.B. auch in Hos 8,1 (anders wieder Hos 9,4). Vgl. die Versuche von H.W. WOLFF, Dodekapropheton 1. Hosea, BK XIV/1, Neukirchen 4 1990, 176, und H. UTZSCHNEIDER, Hosea, Prophet vor dem Ende: zum Verhältnis von Geschichte und Institution in der alttestamentlichen Prophetie, OBO 31, Fribourg-Göttingen 1980, 182, die darauf hinweisen, da B in Hos 8,1 (und 9,8.15) mit בית weder ein Tempel noch sonst ein Gebäude gemeint sein kann, es aber im Sinne von Land als Eigentum JHWHs bzw. Gebiet JHWHs (und insofern als Siedlungs- 
gerade im Hinblick auf den bisherigen inhaltlichen Befund bei Sach 1-8 ein vielversprechender Versuch zu sein, wenngleich vor Überinterpretation gewarnt werden muß. Auch T.C. ESKENAZI hat in ihrer Arbeit über Esr/Neh "In an Age of Prose" gezeigt, daß das Konzept des "Hauses Gottes" über den Tempel hinaus ausgeweitet und auf die Stadt Jerusalem als ganze übertragen werden kann. ${ }^{30}$

\section{בפה .3.2}

בנה meint in ursprünglicher Bedeutung bauen, aufbauen, wiederaufbauen (von Mauern, Gebäuden u.ä). בנה wird aber auch häufig in übertragener Bedeutung gebraucht und bezeichnet dann u.a. den Aufbau einer Gemeinschaft, Familie, Sippe oder Dynastie, insbesondere wenn es zusammen mit n gebraucht wird. Beispiele hierfür sind Rut 4,11 (Rahel und Lea haben das Haus Israel aufgebaut) und Dtn 25,9 (Leviratsehe). 31

Besonders eklatant ist aber die Verwendung beider Begriffe in der Nathanverheißung, 2 Sam 7 par. 1 Chr 17. Dort wird mit der Doppeldeutigkeit beider Begriffe geradezu gespielt und dies nicht nur einmal. Will David Gott ein Haus zum Wohnen bauen, so lehnt JHWH dies ab mit dem Verweis darauf, daß er selber David ein Haus, gemeint ist eine Familie, eine Dynastie bauen wird (2 Sam 7,11.27 par. $1 \mathrm{Chr} 17,10.25$, wobei interessanterweise in 2 Sam 7,11 עמש verwendet wird, während in 1 Chr 17,10 dies in בנה verändert wird in Angleichung an die zweite Stelle). 32 Die Textaussage der ursprünglichen Erzählung läuft gerade darauf hinaus, daß eben nicht der Bau eines Tempelgebäudes, sondern vielmehr der Aufbau einer Gemeinschaft bzw. Familie(ndynastie) von JHWH bevorzugt wird.

\subsection{ZUR BEDEUTUNG DER BEGRIFFE IN SACH 1-8}

Ich möchte nun versuchen, auf dem Hintergrund der Kernaussagen von Sach 1-8 bezüglich des Aufbaus einer JHWH-Gemeinschaft in

gebiet Israel-Efraims) erklären. Demgegenüber bleibt festzuhalten, daß zumindest in Hos 8,1 der Kontext es nahelegt, eher an eine Gruppe als an ein Gebiet zu denken.

30 T.C. ESKENAZI, In an Age of Prose. A Literary Approach to Ezra-Nehemiah, SBL Mon Ser 36, Atlanta 1988, 53ff. In meiner Deutung von Esr 5,1f; 6,14 unterscheide ich mich aber von ESKENAZIs Lösung, den Aufbau der ganzen Stadt als sachgemäße Interpretation vom "Bauen des Hauses Gottes" zu betrachten, s.u. 4. Vgl. hierzu D.L. PETERSEN, The Temple in Persian Period Prophetic Texts, Biblical Theology Bulletin 21 (1991), 88-96, bes. 90 f. 31 Siehe hierzu S. WAGNER, n, ThWAT I, 689-706, mit einer Fülle von Stellenangaben.

32 Dies könnte ein Hinweis für eine nachexilische Veränderung hinsichtlich des Sprachgebrauchs sein, muß aber sicherlich noch an einer Reihe von anderen signifikanten Stellen überprüft werden. 
Jerusalem und unter dem eben gewonnenen Blickwinkel bezüglich der Doppeldeutigkeit von בגה בידית diejenigen Textstellen in Sach 1-8 einer genaueren Betrachtung $\mathrm{zu}$ unterziehen, die diese oder eine entsprechende Begriffskombination enthalten, und prüfen, ob nicht die zweite übertragene Bedeutung eine sachgemäßere Interpretation liefern kann.

$\mathrm{Zu}$ den Stellen im einzelnen:

Sach 1,16a: Darum - so spricht JHWH: Voll Erbarmen habe ich mich Jerusalem wieder zugewandt. Man wird mein Haus dort aufbauen - Spruch JHWH Zebaoths.

Haus läßt sich hier vom Kontext her sowohl in der Bedeutung Tempel als auch in der Bedeutung Gemeinschaft interpretieren. Keiner der beiden Lösungen kann zunächst eindeutig der Vorzug gegeben werden.

Auch bei der nächsten Stelle ist von רִּ die Rede:

Sach 3,7: "Wenn du auf meinen Wegen gehst und wenn du meine Ordnung einhältst, dann wirst du es sein, der mein Haus richtet und meine Höfe verwaltet, und ich gebe dir Zutritt zu meinen Dienern hier."

Auch hier kann zunächst bei בָּ בית mit beiden Bedeutungen gearbeitet werden: allerdings fällt es schwer, das Verb דị (richten) mit dem Tempel als Gebäude zu verbinden. Die meisten Ausleger setzen deshalb

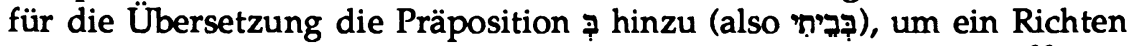
im Tempel als ursprünglichen Sinn dieser Stelle zu erheben. ${ }^{33}$ Die Übersetzung mit "du wirst meine Gemeinschaft richten" fügt sich allerdings grammatikalisch besser ein als "du wirst den Tempel bzw. im Tempel richten" und paßt auch inhaltlich gut zum Kontext. Denn die sog. Josua-Vision $(3,1 \mathrm{ff})$ handelt ja überhaupt nicht vom Tempelbau als solchem, sondern von der Einsetzung einer Person in eine Leitungs-

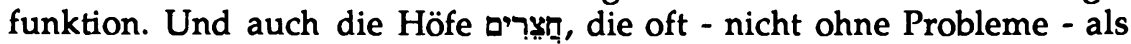
Vorhöfe des Tempels gedeutet werden, können (wie z.B. in Neh 12,29) die Jerusalem umgebenden, unbefestigten Siedlungen bezeichnen, die zum Einflußgebiet der Stadt und damit auch zu ihrer Verwaltung gehören. Als Übersetzung schlage ich daher für die Sacharjastelle vor: "du wirst meine Gemeinschaft richten und meine Gehöfte verwalten". Im übrigen erscheint auch in Num 12,7 בָיחי innerhalb einer JHWH-Rede. Es ist dort keinesfalls als Terminus für den Tempel zu verstehen, sondern vielmehr als Synonym zu Bezeichnungen von sozialen Größen, wie

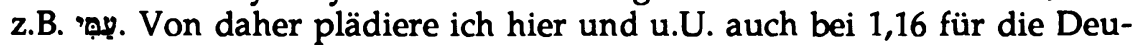
tung von בָּירי als "meine Gemeinschaft".

Sach 4,9a: Serubbabels Hände haben den Grund zu diesem Haus gelegt, und seine Hände werden es vollenden.

Sach 8,9: So spricht JHWH Zebaoth: Ihr werdet eure Hände stark machen, wenn ihr in diesen Tagen diese Worte aus dem Mund der Propheten hören

33 Siehe hierzu die Diskussion bei C.L. MEYERS/E.M. MEYERS [A.19] 195. 
werdet, am Tag, an dem das Haus JHWH Zebaoths gegründet worden ist, der Tempel, damit er gebaut werde.

Hier geht es beidesmal um die Gründung (יס) des Hauses, wobei die Deutung als Grundsteinlegung gerade im Kontext von 4,6b-10a durchaus wahrscheinlicher ist als die Deutung in Richtung auf eine feierliche Neugründung der JHWH-Gemeinschaft in Jerusalem (entsprechend etwa den Vorgängen in Neh 8 oder 9f).34 Die zweite Stelle wäre durchaus offener für die letztere Deutung, zumal unmittelbar vorher in 8,7f von der Rückführung des Volkes nach Jerusalem die Rede ist und zum einzigen Mal in Sach 1-8 die Bundesformel voll zitiert wird. Doch das in Apposition hinzugesetzte 7 , das sonst an keiner Stelle in Sach 1-8 gemeinsam mit genannt wird, scheint den Ausschlag zugunsten der Deutung als Grundsteinlegung geben zu können, wenn es an dieser Stelle ursprünglich ist. Der Nebensatz fügt sich nämlich syntaktisch nur schwer in den Kontext ein, weshalb die Herausgeber der BHS hier eine spätere Glosse vermuten. ${ }^{35}$

\begin{abstract}
Sach 6,12.13a.14.15a.: (im jetzigen Kontext als Wort über den Hohenpriester Jeschua ausgewiesen!) ... So spricht JHWH Zebaoth. Da ist ein Mann, Sproß ist sein Name; denn wo er steht, wird es sprossen, und er wird den Tempel wieder aufbauen. Er ist es, der den Tempel baut... Die Krone wird zur Erinnerung an ... im Tempel JHWHs liegen. Aus der Ferne werden sie kommen und am Tempel JHWHs bauen.
\end{abstract}

An diesen Stellen ist von היקל die Rede, das m.E. nirgendwo in der Bibel als Soziomorphem verwendet wird. Hier, bei der den Visionszyklus abschließenden Zeichenhandlung ist mit an Sicherheit grenzender Wahrscheinlichkeit vom Tempelbau die Rede. Allerdings ist es vom Textbefund her sehr wahrscheinlich, daß 6,9-15 redaktionelle Eingriffe erfahren hat, doch scheint der ursprüngliche Sinn die Krönung Serubbabels gewesen zu sein. Anläßlich dieser Zeichenhandlung ergeht dann an ihn die Verheißung, daß er in der Zukunft die Herrschaft ausüben und den Tempel bauen wird (gemäß der im Alten Orient üblichen königlichen Pflichten).

\footnotetext{
${ }^{34}$ Unterstützt wird diese Interpretation auch durch die parallele Satzfortführung mit בצi. ("vollenden").

35 Sach 8,9-13 wird von vielen Auslegern, u.a. auch von W. RUDOLPH [A.19] 148f, wegen der sonst nirgendwo in Sach 1-8 so großen Nähe zu Hag (bes. 1,6.9-11; 2,15-19) als spätere redaktionelle Zufügung aufgefaßt.
} 
Serubbabel hat den Grundstein gelegt, und ihm ist auch verheißen, den Tempelbau in Zukunft zu vollenden $(4,9 ; 6,12 f)$. Ferne (Rückkehrer?) werden sich daran beteiligen. Darüberhinaus wird über den Tempelbau in Sach 1-8 nichts Konkretes gesagt. Und es ergeht auch nirgendwo eine explizite Aufforderung, sich am Tempelbau (in unmittelbar bevorstehender Zukunft) aktiv zu beteiligen. ${ }^{36}$ Der Tempel spielt also in Sach 1-8 nur eine untergeordnete Rolle gegenüber dem Hauptthema, dem Aufbau der Gemeinschaft zwischen JHWH und seinem Volk in Jerusalem.

\section{DIE REZEPTION VON HAGGAI UND SACHARJA IN ESRA 5,1f; 6,14}

Meine These hierzu lautet: Der Bau des äußeren und der Bau des "inneren" "Hauses" JHWHs sind im Esrabuch als komplementäre Konzepte rezipiert. Der (Wieder-)Aufbau des Tempelgebäudes und der Tempelgemeinde in Jerusalem sind zentrale Aufgaben der Frühzeit der nachexilischen Epoche. Die beiden Konzepte können in ihrem Verhältnis zueinander gesehen werden wie die zwei Seiten einer Medaille. Haggai betont den Aufbau des Tempelgebäudes, während in Sach 1-8 der Aufbau der JHWH-Gemeinschaft Jerusalems (oder um der Parallelität willen besser gesagt: der Tempelgemeinde) im Mittelpunkt steht. Aber die Botschaften der beiden Propheten müssen nicht notwendigerweise als solch komplementäre Konzepte konzipiert worden sein. Deutlich scheint mir nur, daß die Rezeption in Esra sie nach diesem Interpretationsmuster einander zugeordnet hat und von daher vermutlich zu ihrer Beurteilung gekommen ist, die beiden Propheten als Förderer des Baus des Hauses Gottes in Jerusalem zu betrachten.

Eine Probe aufs Exempel für die o.g. Lösung bietet m.E. der Aufbau des Buches Esra. Nach dem einleitenden Bericht über die Rückkehr der Exulanten (Esr 1f) werden in Esr 3,1-6,22 zunächst der Aufbau des Tempelgebäudes und die näheren Begleitumstände geschildert. Danach erfolgt in Esr 7,1-10,44 (bzw. Neh 8.9f) ein Bericht über wichtige Stationen beim Aufbau der Tempelgemeinde (einschließlich der Verkündigung von Regelungen u.a. für das Zusammenleben der Gemeinde, dem sog. Gesetz Esras). Diesem Ablauf entspricht die sehr wahrscheinlich erst re-

36 Zwei Auffälligkeiten können an diesen Texten beobachtet werden: Zum einen die gegensätzlichen Aussagen von Sach 4,9 und 6,12f hinsichtlich der Person des Haus- bzw. Tempelgründers (Serubbabel bzw. Josua), zum andern der unterschiedliche Sprachgebrauch, wenn vom Haus bzw. Tempel die Rede ist. Sach 1,16; 3,7; 4,9 sprechen von n:? (Haus, Tempel), Sach 6,12f.15 hingegen von סקי (Palast, Tempel). Nur die letzte Stelle, Sach 8,9 , gebraucht beide Begriffe nebeneinander. 
daktionell gebildete ${ }^{37}$ Abfolge der Bücher Haggai (mit seiner Betonung des Vorranges des Tempelbaus) und Sach 1-8 (mit dem Schwerpunkt auf dem Aufbau der JHWH-Gemeinschaft, der "späteren" Tempelgemeinde). Diese beiden Momente des Baus des Hauses JHWHs gehören demzufolge nach Esra (bzw. der Redaktion des Buches Esra) ${ }^{38}$ untrennbar zusammen.

Der Tempelbau ist ja nicht Selbstzweck und als solches Ziel der Bemühungen der frühnachexilischen Epoche (in Jerusalem). Er ist vielmehr Symbol und äußeres Zeichen für die Verbundenheit von Gott und seinem Volk und deren gemeinsames Wohnen in Jerusalem. Der Tempel wird somit zum sichtbaren Zeichen der Erneuerung des Bundes zwischen JHWH und seinem Volk, aber das eigentliche Ziel, das vor und über allem anderen erreicht werden soll, ist ja gerade eben die erneuerte Gemeinschaft zwischen Gott und seinem Volk, und nicht bloß der Bau eines Tempels. So betont Sacharja eben dieses Hauptziel (den inneren Grund für den Tempelbau), während Haggai die Erstellung des äußeren, sichtbaren Zeichens zur Verdeutlichung dieses Hauptzieles fordert.

Stellen wie 2 Sam 7 par. $1 \mathrm{Chr} 17$ können uns daran erinnern, gerade bei exilisch-nachexilischen Texten öfter an die Doppeldeutigkeit von בנד בדית zu denken: ein Gebäude bzw. eine Gemeinschaft aufbauen.

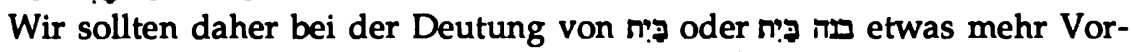
sicht walten lassen, gerade auch in den Fällen, in denen der kontextuelle Zusammenhang Stichwörter aus dem kultisch-priesterlichen Bereich liefert, wie z.B. die Begriffe Hoherpriester, Opfer u.a.m. Es wird manchmal hilfreich sein zu prüfen, ob die Bedeutung Tempel(gebäude) oder die übertragene Bedeutung Gemeinschaft, also (Tempel-) Gemeinschaft oder Volk bzw. Gemeinde JHWHs vorliegt. Gerade in exilischnachexilischen Texten könnten wir da noch manch überraschende Erkenntnis gewinnen, wenn wir nicht immer gleich an den zweiten Tempel denken. Trotzdem sollte dies auch nicht übertrieben und zum Auto

37 Darauf hat immer wieder P.R. ACKROYD hingewiesen, gerade angesichts der (bes. formal) auffälligen Parallelität der Datierungsangaben in Hag und Sach 1-8, so z.B. in: The Books of Haggai and Zechariah I-VIII, JJS 3 (1952), 151-156; Exile and Restoration. A Study of Hebrew Thought of the Sixth Century B.C., OTL, London 1968, 154f; Historical Problems of the Early Achaemenian Period, Orient 20 (1984), 12-14 [reprinted in: P.R. ACKROYD, The Chronicler in His Age, JSOTS 101, Sheffield 1991, 152-154]. Vgl. auch W.A.M. BEUKENs ausführliche Analyse der dtr und chr Überarbeitungsschichten in Hag und Sach 1-8: Haggai-Sacharja 1-8. Studien zur Überlieferungsgeschichte der frühnachexilischen Prophetie, SSN 10, Assen 1967, 10-20.331-336.

38 Vgl. hierzu die gemeinsame, von W.A.M. BEUKEN als chr gedeutete Überarbeitungsschicht der Bücher Hag und Sach 1-8 [A.4 u. 37]. 
matismus werden, indem wir überall nurmehr Gemeinschaft statt Tempel lesen. ${ }^{39}$

39 Diese Überlegungen habe ich auf dem SBL International Meeting 1991 in Rom vorgetragen und für den Druck um Anmerkungen und Ergänzungen erweitert. Ich widme sie meinem Doktorvater Klaus BALTZER, der uns gelehrt hat, kritisch, konstruktiv und kreativ biblische Traditionen in reale Lebenswelten - historische wie gegenwärtige - umzusetzen. 

von

Eckhard von Nordheim

Münster/Odenwald

Das Gottesurteil ist kein Thema für die heutige Zeit. Spricht trotzdem einmal jemand davon, dann steht schnell das Mittelalter vor Augen - abschreckend, fremd und ganz fern von unserem Welt- und Menschenbild. Vielleicht ist das der Grund, warum der Abschnitt Num 5,11-31 heute so wenig Beachtung findet. Das hier festgehaltene Ritual für den Vollzug eines Gottesurteiles wird allzu schnell mit den grausamen Gottesurteilen des Mittelalters in einen Topf geworfen - ganz zu Unrecht, wie sich noch herausstellen wird.

1) Was ist eigentlich ein Gottesurteil? Grundsätzlich ist es ein Rechtsentscheid. Gottesurteile gehören in das Gerichtswesen; sie sind Teil eines Rechtsverfahrens, das nur gegenüber anderen, "normalen" Prozessen die Besonderheit besitzt, daß es für die vermutete Verfehlung keinerlei Zeugen gibt und natürlich auch kein Geständnis. Da jedoch der Verdacht besteht, daß wichtiges Recht gebrochen wurde, aber die menschlichen Möglichkeiten nicht ausreichen, Schuld oder Unschuld nachzuweisen, muß die Gottheit selbst für das Recht eintreten. Der Ritus des Gottesurteils hat also zum Ziel, Gott als Richter anzurufen, um seinen Willen zu erfragen und sein Urteil zu erfahren. Dabei kann die an Gott gerichtete Frage entweder lauten: Ist N.N. schuldig oder unschuldig? (Ex 22,8) oder: Wer von beiden (oder mehreren) ist der Schuldige? (so z.B. bei Achans Diebstahl in Jos 7, bei der Verfehlung Jonathans in 1.Sam 14 oder dem Sturm auf dem Meer in Jona 1; auch Ex 22,9.11; 1.Kön 8,31f).

In Israel waren auch andere Möglichkeiten bekannt, den Willen Gottes zu erfragen: mit Hilfe des Ephod, durch Urim und Tummim und andere Lose, durch die Teraphim oder die Lade, durch Träume (wahrscheinlich an einem Heiligtum) oder durch außergewöhnliche Zeichen und Wunder, wie Gideon sie nach Ri 6 erbeten hat. Darüberhinaus wissen wir, daß man auch in Israel wie in den umliegenden Völkern des Alten Vorderen Orients die Toten befragte, Zeichen deutete, Wahrsagerei und Zauberei praktizierte. Diesen verbotenen Methoden aus dem Bereich der Magie wie auch den zuerst aufgeführten, die wohl lange Zeit als legitim angesehen wurden, stellt das Deuteronomi-

${ }^{1}$ Habilitationsvortrag, gehalten am 16.5 .1990 vor dem Fachbereich Evangelische Theologie der Universität Frankfurt. 
um die Prophetie als einzig rechtmäßiges Mittel gegenüber, den Willen Gottes zu erfragen.

Alle diese Praktiken (einschließlich der Prophetie in dieser Funktion) sind Orakel, mit deren Hilfe die Menschen in einer schwierigen Notlage den Willen Gottes für die unmittelbare Zukunft erfahren möchten. Ein Gottesurteil ist aber etwas anderes: Es ist eher vergangenheitsorientiert, indem es ein geschehenes Vergehen aufdeckt bzw. einen Schuldigen überführt oder einen Unschuldigen freispricht. Die Fremdheit unserer Zeit diesen Riten gegenüber sollte uns nicht dazu verleiten, alles in einen Topf zu werfen, weil uns dann wichtige Merkmale für ein differenziertes Verständnis entgehen.

2) Gottesurteile hat es wohl bei allen Völkern und Kulturen gegeben. Uns sind solche Rituale im Bereich des Orients aus Babylon, Assyrien, Mari, Persien, Indien und Arabien überliefert. Demgegenüber scheint Israel von der Möglichkeit des Gottesurteils eher zurückhaltend Gebrauch gemacht zu haben - jedenfalls, so weit wir uns auf die Textbasis des AT stützen.

Der Codex Hammurapi enthält eine Verfahrensanweisung für ein Gottesurteil im Fall von unbewiesenem Ehebruch, ganz wie in Num 5. Sie lautet:

\begin{abstract}
"Gesetzt, auf die Gattin eines Mannes ist wegen eines anderen Mannes der Finger ausgestreckt worden, sie ist (aber) nicht ertappt worden, wie sie bei einem anderen Manne schlief, so wird sie für ihren Gatten im Flusse untertauchen." 2
\end{abstract}

Wie dies "Untertauchen" vonstatten ging und bewertet wurde, erfahren wir aus einem anderen Teil des Codex Hammurapi, in dem es um den Vorwurf der Zauberei geht:

\footnotetext{
"Gesetzt, ein Mann hat einem anderen Zauberei vorgeworfen, hat ihn aber nicht überführt, so wird derjenige, dem Zauberei vorgeworfen worden ist, zum Fluß gehen, in den Fluß untertauchen.

Gesetzt, der Fluß hat ihn überwältigt, so darf derjenige, der ihn bezichtigt hat, sein Haus wegnehmen;

gesetzt, diesen Mann hat der Fluß als rein bezeichnet, und er ist unversehrt geblieben, so wird derjenige, der ihm Zauberei vorgeworfen hat, getötet. Derjenige, der in den Fluß untergetaucht ist, darf das Haus dessen, der ihn bezichtigt hat, nehmen."3
}

Der Fluß ist hier natürlich nicht als allgemeine Gefahrenquelle gemeint und das Untertauchen etwa als Mutprobe, vielmehr geht es um einen direkten Kontakt mit dem Flußgott! R. PRESS urteilt ganz zu-

2 H. GRESSMANN, Altorientalische Texte zum Alten Testament, Berlin/Leipzig ${ }^{2} 1926$ (AOT) 394 (§ 132).

3 AOT 383 (\$ 2), sprachlich geglättet anhand von J.B. PRITCHARD, Ancient Near Eastern Texts relating to the Old Testament, Princeton/New Jersey 1950, 166. 
treffend, wenn er feststellt: "Eine so innige Berührung mit der Gottheit, wie sie das Eintauchen in den Stromgott (...) mit sich bringt, muß einen Frevler töten."4 Der eigentlich Handelnde bei diesem Flußordal ist also die Gottheit. Das wird noch deutlicher in einem akkadischen Beschwörungstext, der bei einem solchen Ordal rezitiert wurde. Hier scheinen beide Gegner in den Fluß geworfen worden zu sein. Während der eine anscheinend schon untergeht, spricht der andere:

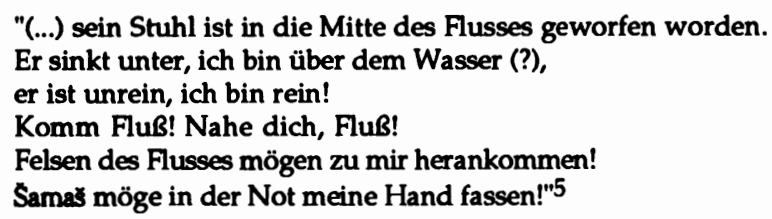

Der Sprecher redet nicht nur den Fluß persönlich, also als einen Gott an, sondern wendet sich zusätzlich noch an Samaš, den Sonnengott, mit der Bitte um Hilfe. Die Gottheit entscheidet den Streitfall, doch scheint das dazu gewählte Verfahren, das "Untertauchen in den Fluß", auch für den Unschuldigen nicht ungefährlich gewesen zu sein, wenn er flehentlich die Götter beschwört. Das war in Israel anders, wie der Text von Num 5,11-31 zeigt.

3) Dieser Text ist die ausführlichste Verfahrensanweisung für ein Gottesurteil im Alten Testament. Von anderen Gottesurteilen gibt es allenfalls Andeutungen. J. MORGENSTERN nennt diesen Ritus "one of the most interesting ceremonies of ancient Israel".6 Sicherlich ist dieser Text alt und war schon vor seiner Aufnahme in den jetzigen Kontext, die Priesterschrift, selbständig literarisch überliefert worden. ${ }^{7}$ Das spricht dafür, daß er keine Nebensache berichtet, kein Verfahren am Rand der allgemeinen Aufmerksamkeit. Ähnlichkeiten im Aufbau, in der Wortwahl, im ganzen "Ritualstil" mit den Opferbestimmungen in den ersten Kapiteln des Buches Leviticus fallen auf. ${ }^{8}$

Der Bruch nach V.20 und einige Wiederholungen im Ablauf des Verfahrens hatten vor allem ältere Ausleger zu der Vermutung geführt, der Text sei nicht einheitlich, sondern aus zwei bis drei Quellen zusammengesetzt und durch einige Glossen erweitert. Bei J. MORGENSTERN findet sich eine Auflistung der verschiedenen Versuche. ${ }^{9}$ Für

4 R. PRESS, Das Ordal im alten Israel, ZAW 51 (1933) 121-140.227-255, hier 133.

5 E. EBELING, Tod und Leben nach den Vorstellungen der Babylonier. I. Teil: Texte, Berlin/Leipzig 1931, 99.

$6 \mathrm{~J}$. MORGENSTERN, Trial by ordeal among the Semites and in Ancient Israel, HUCA Jubilee Vol. (1875-1925) 1925, 113-143, hier 113.

7 M. NOTH, Das vierte Buch Mose. Numeri, Göttingen 1966 (ATD 7) 46, stellt nur kleinere Ergänzungen der priesterschriftlichen Redaktion fest.

8 Siehe M. NOTH [A. 7 ] 46.

9 J. MORGENSTERN [A. 6] 127f. 
diese Annahme finden sich heute kaum noch Vertreter. ${ }^{10} \mathrm{M}$. NOTH hält allerdings eine vorliterarische Geschichte des Textes für möglich, in der drei ursprünglich selbständige Formen von Gottesurteilen zusammengewachsen seien: heiliges Wasser und heilige Erde vom Boden des Tempels, die Selbstverfluchung und das Aufschreiben einer Fluchformel auf ein Blatt mit anschließender Aufnahme durch die verdächtigte Person. Allerdings seien diese drei Elemente jetzt so miteinander verzahnt, daß sie literarisch nicht mehr abgetrennt werden könnten. ${ }^{11} \mathrm{Ob}$ sie tatsächlich einmal selbständig waren, sei dahingestellt.

J. MORGENSTERN und R. PRESS behaupten eine Entwicklung in religionsgeschichtlicher Hinsicht: Ursprünglich sei das Verfahren eine rein magische Handlung gewesen ohne irgendeinen religiösen Bezug ("nonYahwistic in origin and essential character"). ${ }^{12}$ Es sei von einem Magier - keinem Priester - an einem beliebigen Ort durchgeführt worden. Erst später seien religiöse Elemente dazugetreten wie der feierliche Eid im Heiligtum vor Jahwe, verbunden mit einem Opfer, ausgeführt durch einen Priester. Das Ziel der religionsgeschichtlichen Entwicklung aber sei der reine Eid im Heiligtum in Verbindung mit einem Opfer - ohne alle zusätzliche Symbolik.

Die Annahme dieser drei Entwicklungsstufen ist nichts weiter als ein religionsgeschichtliches Axiom so, als müsse die Entwicklung immer vom Einfachen, Animistischen, Magischen zum Hochentwickelten, auf äußere Elemente und Symbole Verzichtenden gehen. In unserem Fall kann ein Gottesurteil ja nie ohne religiöse Bezugnahme existiert haben. (Auch Magie ist ja nicht unreligiös.) Es muß immer eine Gottheit als Autorität des Verfahrens, als oberste Appellationsinstanz, gegeben haben. Mit Magie kann man Menschen und Götter beeinflussen, aber nicht die Wahrheit über Schuld oder Unschuld in einem schwierigen Gerichtsverfahren finden. Andererseits zeigt die akkadische Beschwörung eine sicher urtümliche Verbindung von Flußordal und Eid und ein Gottesurteil aus den mittelassyrischen Gesetzen stellt Orakel und Eid auf die gleiche Stufe. Das eine kann also nicht höher entwickelt sein als das andere; eine Entwicklung vom rein Magischen zum "rein Religiösen" (was auch immer das sein mag) ist jedenfalls für unseren Text nicht nachweisbar.

4) Betrachten wir den Text einmal im einzelnen: Die Einleitung in V.11 und V.12a charakterisiert alles Folgende als eine Gottesrede, gerichtet an einen Boten, der die Worte Gottes dem Volk Israel übermitteln soll. Wir haben es also mit einem Botenauftrag zu tun, der typischen prophetischen Rede - von der Form her gesehen. Inhaltlich haben wir

10 Lediglich E.F. DE WARD, Superstition and judgement: archaic methods of finding a verdict, ZAW 89 (1977) 1-19, argumentiert auf dieser Basis.

11 M. NOTH [A. 7] 46.

12 J. MORGENSTERN [A. 6] 137. 
aber eine ausführliche Anweisung vor uns, wie in einem bestimmten Rechtsfall verfahren werden soll. Eingangs in V.12b-14 wird die Problemlage geschildert (begründete oder unbegründete Eifersucht des Ehemannes gegenüber seiner Frau); die Schlußverse V.29-31 fassen alles noch einmal zusammen und enthalten zusätzlich ein abschließendes Urteil über Strafe und Straffreiheit, auf das wir noch einmal zurückkommen werden. Den ganzen Mittelteil V.15-28 nimmt die Verfahrensanweisung ein, in dem jeder einzelne Schritt der Durchführung des Gottesurteils dezidiert beschrieben wird. Jede Willkür wird ausgeschlossen: Der Priester soll sich exakt an die Vorschriften halten; die Frau soll genau wissen, worauf sie sich einläßt.

Zur Eröffnung der Untersuchung bringt der Ehemann seine Frau ins Heiligtum; $a b$ da handelt nie mehr er, sondern nur noch der Priester. Es ist ab jetzt ein reines Kultritual, ganz herausgenommen aus dem Bereich der Rechtsprechung der Sippe, in das es ursprünglich gehört. Nun folgen eine Reihe von Handlungen, die alle das Ziel haben, die Frau in eine besondere Nähe zu Gott zu bringen, eine Nähe, die natürlich höchst gefährlich ist, sollte die Frau schuldig sein.

a) Zuerst bringt der Priester die Frau "vor den Herrn", d.h. er läßt sie an den Altar herantreten. Sie steht nun vor dem Angesicht Gottes.

b) Nun füllt der Priester "heiliges Wasser", in das er Staub vom Boden des Heiligtums mengt, also "heilige Erde", in ein Tongefäß. "Heiliges Wasser" und "heilige Erde" verweisen vielleicht auf Gott als Herren über die Natur, also über das Leben. Das Tongefäß soll sicherlich nach Gebrauch zerbrochen werden: ein Hinweis darauf, daß die Handlung besonders wichtig ist, weil das Gefäß nicht mehr anderweitig verwendet und damit profanisiert werden darf.

c) Dann soll der Priester der Frau das Haupthaar lösen. Überall sonst im AT ist das aufgelöste Haar ein Trauerritus, ein Element der Totenklage. Es ist nicht einzusehen, warum die Bedeutung nur hier in diesem Zusammenhang eine andere sein sollte. ${ }^{13}$ Der folgende Ritus der Selbstverfluchung, den die Frau auf sich nehmen muß, ist eine so ernste, lebensbedrohende Angelegenheit, daß in seiner Begleitung ein symbolischer Trauerritus durchaus angebracht erscheint.

d) Danach legt der Priester der Frau das Opfer auf ihre Hände. Es wird hier "Eifersuchtsopfer" und "Erinnerungsopfer, das Schuld in Erinnerung ruft", genannt. Dieses Opfer ist also kein Dankopfer. Es soll auch nicht Gemeinschaft mit Gott und den Familienangehörigen herstellen. Es dient auch nicht zur Sühne und Vergebung von Schuld, eher im Gegenteil: Es soll Schuld "in Erinnerung rufen", ans Licht bringen, aufdecken. Man fühlt sich an die Erzählung von Elia und der Witwe in Sarepta in 1.Kön 17 erinnert. Als Elia im Haus der Witwe zu Gast ist, und deren Sohn lebensgefährlich erkrankt, wirft die Witwe Elia vor:

${ }^{13}$ Gegen M. NOTH [A. 7$] 47$. 
"Was habe ich mit dir zu schaffen, du Mann Gottes? Du bist ja nur gekommen, daß meiner Schuld gedacht werde und mein Sohn sterbe!" (V.18). Die Frau fürchtet, daß durch die Begegnung mit dem Göttlichen, auch wenn es nur ein Bote Gottes ist, verborgene Schuld ans Licht käme und sogleich bestraft würde. Dieselbe Bedeutung wird auch der Opferritus in unserem Text haben.

e) Nun holt der Priester das "bittere, fluchbringende Wasser". Es ist viel gegrübelt worden, was man sich darunter vorzustellen habe: Salzwasser wurde vorgeschlagen, doch woher sollte man im Landesinneren Salzwasser haben, und was sollte man damit erreichen wollen? Es könnte vergiftetes Wasser gewesen sein, das den Fluch in sich trägt. Das allerdings würde dem ganzen Verfahren einen außergewöhnlichen Charakter verleihen: Die Frau wäre - physisch gesehen - schon dem Tod preisgegeben. Die Menschen hätten sie bereits verurteilt; die Gottheit müßte sie durch ein Wunder retten. Doch dies würde der ganzen Grundintention des Verfahrens zuwiderlaufen: Die Menschen sehen sich ja gerade nicht in der Lage zu urteilen; denn es gibt ja nur einen Verdacht aber dafür keine Zeugen und kein Geständnis. Deswegen sind die menschlichen Möglichkeiten, Recht zu sprechen, am Ende. Daher wird die Gottheit angerufen, mit ihren Möglichkeiten der Wahrheit zum Recht zu verhelfen, ein Urteil zu fällen. Gift liegt im Handlungsfeld der Menschen. Gott, der ins Herz der Menschen sieht, hat andere Mittel zur Verfügung, seinen Willen durchzusetzen.

Die altorientalischen Parallelen unterstützen dies: Zwar ist ein groBer Fluß immer eine Gefahr für den Menschen, aber doch keine so absolute wie Gift. Der/die Verdächtigte ist nicht schon zum Tod verurteilt dadurch, daß er/sie "in den Fluß untertaucht". Gott kann ihn/sie retten. Gott kann ihn/sie strafen - beides ist offen zu Beginn des Ordals.

Darüberhinaus gibt es weitere Hinweise, daß von Gift keine Rede sein kann:

- Das "bittere" Wasser soll der Frau, wenn sie schuldig ist, zur "Bitternis" werden (v.24.27). "Bitternis" kann hier nur im übertragenen Sinn gemeint sein, etwa als Unheil, Unglück, Strafe, aber nicht im biologischen Sinn als Gift.

- In Ex 32 wird berichtet, daß Mose das goldene Kalb zu Staub zerreiben ließ, es in Wasser schüttete und das den Israeliten zu trinken gab. Gold an sich ist nicht giftig, aber wenn es zu einem Götzenbild gehörte, dann ist es Träger des Zornes Gottes und wird demjenigen schaden, der es zuvor als Gegengott verehrt und damit das erste Gebot übertreten hat. So legt auch der Talmud diese Erzählung aus (Aboda Zara 44a).

- Hätte das Wasser schon Gift enthalten, dann wäre es nicht notwendig, noch eigens Fluchworte aufzuschreiben und in das Wasser hinein abzuwaschen. Der Sinn kann doch nur der sein, daß erst dadurch das Wasser zum Fluchwasser wird und der Frau Unglück bringt, wenn sie vom Fluch mit Recht getroffen wird, d.h. wenn sie schuldig ist. Nicht das 
Wasser an sich ist giftig; der Fluch wird zum Gift für die Schuldige. ${ }^{14}$ Die "in dem Wasser enthaltene potentielle Todeswirkung"15 geht ausschließlich vom Fluch aus und nicht von einem dem Wasser beigegebenen toxischen Element.

f) Im Zentrum des ganzen Gottesurteils steht aber der Ritus der Selbstverfluchung. Zwar wird der Fluch der Frau vom Priester vorgesprochen, doch muß sie den Fluch auf sich selbst übertragen durch ein zweimal ausgesprochenes Amen. Dadurch wird der Fluch zur Selbstverfluchung. Was ist eigentlich ein Fluch? Segen oder Fluch sind nach altorientalischem Verständnis mehr als nur ein paar freundliche oder unfreundliche Worte, auch etwas anderes als gute Wünsche oder Drohungen. Segen und Fluch sind eigene Sphären, die das Leben des Menschen umgeben und seine Zukunft bestimmen. Beide gehen von einer Gottheit aus, werden aber fast wie selbsttätige Mächte verstanden, die den einzelnen schützen oder ihn verfolgen, ihm Wohlergehen oder Unheil bringen. Der Fluch liegt immer begründet in einer bösen Tat des Menschen. Ein Verbrechen stellt den Täter in eine Sphäre des Unheils, die so unabdingbar Strafe über ihn bringt, wie auf die Saat die Ernte folgt und eine Pflanze Früchte trägt. Das Schicksal des Menschen wird durch seine Tat entschieden, und Jahwe setzt diesen Zusammenhang von Sünde und Unheil eigentlich nur in Kraft.16 Diese Vorstellung steht ja auch schon hinter dem "Erinnerungsopfer", wie wir gesehen haben.

Im AT finden wir verschiedene Formen von Selbstverfluchungen, die allerdings in der Regel konditionalen Charakter haben: der Sprecher wünscht auf sich eine schlimme Strafe herab für den Fall, daß er von einem bestimmten Vorsatz, den er sich fest vorgenommen hat, abweichen werde.

- Beispiel:

"Die Götter mögen mir dies und das tun,

wenn ich nicht morgen um diese Zeit dir tue,

wie du ihnen getan hast!"

(Isebel zu Elia in 1.Kön 19,2)

- Oder.

"Der Herr tue dem Jonathan dies und das:

Wenn mein Vater das Unheil über dich beschließt,

so will ich es dir offenbaren ..."

(Jonathan zu David in 1.Sam 20,13)

14 So W. MCKANE, Poison, trial by ordeal and the cup of wrath, VT 30 (1980) 474-492; E.F. DE WARD (A. 10]; PH. REYMOND, L'eau, sa vie, et sa signification dans l'Ancien Testament, VT.S 6 (1958) 217-220 u.a.

15 M. NOTH [A. 747.

16 Siehe K. KOCH, Gibt es ein Vergeltungsdogma im Alten Testament?, ZThK 52 (1955) 1-42; wiederabgedruckt in: DERS., Um das Prinzip der Vergeltung in Religion und Recht des Alten Testaments, WdF 125, Darmstadt 1972, 130-180. 
In beiden Fällen ist die Strafankündigung nicht spezifiziert, sondern nur ganz allgemein gehalten, allerdings wird der Gottesname erwähnt oder jedenfalls der Bezug zu den Göttern hergestellt.

In anderen Fällen wird die Strafankündigung verdeutlicht.

- Beispiel:

"O Herr, mein Gott, habe ich das getan,

ist Unrecht an meinen Händen,

habe ich dem Böses getan, der mit mir friedsam gelebt,

und den bedrückt, der mich ohne Ursache bedrängt hat,

so verfolge der Feind mich und hole mich ein,

trete zu Boden mein Leben und lege in den Staub meine Ehre!" (Ps 7,4-6)

- Oder:

"Vergesse ich dein, Jerusalem,

so müsse meine rechte Hand verdorren!

Die Zunge müsse mir am Gaumen kleben,

wenn ich dein nicht gedenke,

wenn ich nicht Jerusalem setze über meine höchste Freude!" (Ps 137,5f).

Hier werden die Straffolgen im einzelnen beschrieben - sicherlich in der Absicht, den Vorsatz noch unbedingter erscheinen zu lassen als in der ersten, viel allgemeineren Form, und das, obwohl die Selbstverfluchung an sich schon eine nicht mehr überbietbare Art einer Selbstverpflichtung darstellt.

Und doch gibt es noch eine Steigerung, bei der zur Spezifizierung der Strafankündigung noch eine Ritualisierung hinzutritt: In Jer 34,1820 wird den Fürsten Judas und Jerusalems und dem ganzen Landvolk Unheil angekündigt, weil sie

"meinen Bund übertreten und die Worte des Bundes nicht gehalten haben, den sie vor mir geschlossen hatten, indem sie das Kalb entzweischnitten und zwischen seinen Stücken hindurchgingen..." (Jer 34,18)

Die Fürsten und die Vertreter des Landvolkes hatten einen Bund vor Gott geschlossen und sich feierlich verpflichtet, seine Bedingungen einzuhalten. Zur symbolischen Bekräftigung hatten sie auf einen im Alten Orient auch sonst bekannten Ritus zurückgegriffen: Man nahm ein Tier, zerschnitt es in zwei Hälften und legte die Teile getrennt einander gegenüber. Dann schritten die Vertragschließenden zwischen den Hälften hindurch und wünschten dadurch das Schicksal des Tieres auf sich herab für den Fall, daß sie den Bund brechen würden. Die Strafankündigung wird durch den Bezug auf das Tier spezifiziert, der Gottesname wird genannt ("vor mir") und eine Fluchsymbolik tritt hinzu.

Vergleicht man diesen Bundesschluß bei Jeremia mit dem Gottesurteil in Num 5, dann sieht man sofort die Verwandtschaft: In beiden Fällen haben wir einen Selbstverfluchungsritus vor uns mit spezifizier- 
ter Strafankündigung, unter Nennung des Gottesnamens, verbunden mit einer Fluchsymbolik.

Doch die Selbstverfluchung im Gottesurteil übertrifft sogar noch den "Bundesschluß zwischen den Stücken": Zu den genannten Elementen tritt noch ein Opfer hinzu, dargebracht im Heiligtum. Im Vergleich mit den anderen im AT bekannten Formen von Selbstverfluchung wird uns erst die Schärfe bewußt, die das Verfahren des Gottesurteils kennzeichnet. Man kann sich wirklich nicht mehr vorstellen, wie dieser Ritus an Unerbittlichkeit überboten werden könnte. Diese Strenge bezieht sich natürlich nur auf den Fall der Schuld. Ihr korrespondiert die absolute Unversehrtheit der Person, wenn sie unschuldig ist.

g) Doch verfolgen wir nun den Ablauf des Gottesurteils weiter: Der Priester läßt die Frau das fluchbringende Wasser trinken und nimmt die Opferhandlung vor. Noch einmal wird dann auf das Trinken des Fluchwassers Bezug genommen, um im Anschluß daran wiederum die Konsequenzen bei Schuld wie bei Unschuld auszumalen. In der Zusammenfassung am Schluß überrascht der letzte Vers etwas:

"Der Mann soll frei sein von Schuld,

aber jene Frau soll ihre Schuld tragen" (V.31).

Dieser Satz, das abschließende Urteil, bezieht sich nur auf den Fall der Schuld. Gab es für den Ehemann, der seine Frau ohne Grund beschuldigt hat, keine Konsequenzen? Der Codex Hammurapi und die altassyrischen Gesetze kennen Strafbestimmungen für beide Seiten, für den Angeklagten, wenn er schuldig war, und für den Ankläger, wenn sich die Unschuld des Angeklagten herausgestellt hat. Entsprechend müßten wir in Num 5 erwarten, daß der Ehemann bestraft wird, wenn das Gottesurteil die Unschuld seiner Frau erwiesen hat. Diese Bestimmung aber fehlt. Vielleicht ist sie irgendwann weggefallen; denn von der Form eines Prozesses her, der von einer doppelten Problemstellung ausgeht, müßte ursprünglich auch eine Strafe für beide Fälle vorgesehen gewesen sein.

Interessanterweise ist trotz aller Härte und Schärfe der Selbstverfluchung nirgendwo im Text von der Todesstrafe die Rede, die doch eigentlich nach Lev 20,10 und Dtn 22,22 verhängt werden müßte, und zwar für die Ehebrecherin und den Ehebrecher. Die Strafen für die Frau, sollte sie schuldig sein, sind schlimm und schmerzlich, doch sie bedeuten nicht den Tod; und der Partner ihres Vergehens wird überhaupt nicht erwähnt. Die Erklärung liegt wohl darin, daß die Todesstrafe eine Sakralrechtsbestimmung war und damit der Ehebruch aus dem Familienrecht gelöst und dem Gottesrecht zugeordnet wurde. Ob die Todesstrafe im Sakralrecht, vor allem in späterer Zeit, tatsächlich vollstreckt wurde, bleibt offen und ist gerade im Blick auf Ehebruch mehr als zwei- 
felhaft. ${ }^{17}$ Einen biblischen Bericht darüber gibt es nicht. Auch der Verweis auf die Perikope der Ehebrecherin in Joh 8 überzeugt nicht; denn einmal fehlte der Partner ihres Ehebruchs, der gemäß dem Sakralrecht hätte ebenfalls bestraft werden müssen, zum anderen traf niemand Anstalten, die Frau tatsächlich zu steinigen. Die Schriftgelehrten brachten die Frau zu Jesus, um zu sehen, wie er die alten Sakralrechtsbestimmungen auslegen würde. Die Erzählung ist also eigentlich eine Gesetzesdisputation, nur anhand eines Exempels. Wie wir noch sehen werden, hätten mit größter Wahrscheinlichkeit auch die Pharisäer die Steinigung abgelehnt, nur wollten sie eben wissen, wie Jesus mit dem Fall umgeht und wie er die alten Bestimmungen für die Gegenwart auslegt. ${ }^{18}$

Was soll nun der Fluch bei der Frau, sofern sie schuldig ist, bewirken? Dazu müssen wir noch einmal zur Ausgangslage des ganzen Verfahrens zurückkehren:

Ein Mann ist eifersüchtig und vermutet, daß seine Frau mit einem anderen Mann geschlechtlich verkehrte. Er hat sie aber weder dabei ertappt noch gibt es andere Zeugen dafür, und seine Frau bestreitet den Vorwurf. Unter diesen Umständen gibt es nur einen einzigen Grund für einen solchen Verdacht: den, daß die Frau schwanger ist und der Mann aus irgendeinem Grund seine Vaterschaft anzweifelt. Die Schwangerschaft ist also im Text vorausgesetzt; denn sie ist der erkennbare Grund für die Eifersucht des Ehemannes. ${ }^{19}$

Diese scheinbare Selbstverständlichkeit eröffnet doch erst den Sinn von zwei ansonsten schwer verständlichen Stellen im Text:

a) Das "Einfallen der Hüfte" kann dann nichts anderes bedeuten, als daß die Frau eine Fehlgeburt erleidet und ihr Kind verliert. Eine körperliche Entstellung in irgendeiner Form ist damit nicht gemeint.

b) Das Verb sbh ist ein hapax legomenon im AT. Es kommt nur in unserem Kapitel in den Versen 21, 22 und 27 vor. Üblicherweise wird es mit "anschwellen" übersetzt. Doch welchen Sinn soll es haben, wenn als Strafe der Bauch einer Schwangeren anschwillt? Er ist es doch bereits. Nun hat G.R. DRIVER ${ }^{20}$ eine Ubersetzung vorgeschlagen, die weit besser in den Duktus und in die Intention des Textes paßt. Er leitet sbh von dem syrischen sba "trocken sein" ab, so daß man nun übersetzen kann: "Ihr Schoß wird trocken", d.h. die Frau erleidet Sterilität. Nimmt man nun dazu, daß die Frau nach V.28 bei erwiesener Unschuld weiter-

17 So H. MCKEATING, Sanctions against adultery in ancient Israelite society, with some reflections on methodology in the study of Old Testament ethics, JSOT 11 (1979) 57-72, hier $58 f$.

18 Siehe H. MCKEATING [A. 17] 58 A. 3.

19 So auch in vergleichbaren frühchristlichen Texten (Protevangelium des Jakobus Kap. 15-16, Pseudo-Matthäus Kap.12).

20 G.R. DRIVER, Two Problems in the Old Testament examined in the Light of Assyriology, Syria 33 (1956) 73-77. 
hin schwanger werden kann, dann zeigt sich, daß sich sowohl bei Schuld wie bei Unschuld alles um Schwangerschaft, Fehlgeburt, Sterilität oder unversehrte Empfängnisfähigkeit dreht. Irgendwelche bleibenden körperlichen Entstellungen haben in diesem Gedankenkreis gar keinen Sinn.

Außerdem kommt nun der alte Grundsatz von der Verhältnismäßigkeit der Mittel von Strafe und Vergehen zur Geltung: Die Frau, wenn sie schuldig ist, erwartet ein Kind aus einer verbotenen Verbindung. Also wird sie als Strafe dieses Kind verlieren und darüberhinaus auch in der Zukunft nie mehr in der Lage sein, ein Kind zu empfangen. Die unschuldige Frau dagegen wird in ihrer Schwangerschaft nicht angetastet und kann auch weiterhin schwanger werden. Genaugenommen erleidet die schuldige Frau drei Folgen ihrer Selbstverfluchung: Sie muß eine Fehlgeburt hinnehmen, ist auf Dauer steril und ihr Schicksal wird zum Fluchwort in ihrem Volk. So wie man sich bei Ephraim und Manasse in Israel Segen wünscht (Gen 48,20), und sich in Abrahams Namen alle Geschlechter der Erde segnen sollen (Gen 12,3), flucht man bei dem Namen dieser Frau.

Ganz anders stellt sich die Situation dar, wenn die Frau sich unschuldig weiß. Ihr Mann beschuldigt sie zu Unrecht, aber wie soll sie sich gegen seine Verdächtigung wehren? Sein ausgesprochener wie sein unausgesprochener Vorwurf, sein bleibendes Mißtrauen gefährden die Ehe. Aussage steht gegen Aussage, Beweise gibt es nicht. Bevor nun ihre Lebensgemeinschaft ganz unerträglich wird, kann sich die Frau auf das Gottesurteil berufen. Schlägt der Ehemann es aus, so hat sein Verdacht keinen Tiefgang. Willigt er aber ein, so kann die Frau getrost dem Priester gegenübertreten, sich dem Altar nähern, das Opfer auf ihre Hände nehmen und das fluchbringende Wasser trinken. Sie ist sich ja sicher, daß ihr nichts davon schaden kann, auch nicht die Selbstverfluchung in ihrer Härte. Sie kann vertrauensvoll das ganze Ritual über sich ergehen lassen und etwa mit dem 5. Psalm denken:

"Denn du bist nicht ein Gott, dem gottloses Wesen gefällt;

wer böse ist, darf nicht bei dir weilen." (V.5)

"Mörder und Falsche sind dem Herrn ein Greuel." (V.7)

Der Herr beweist ihre Unschuld im Angesicht ihrer Feinde. Das ist der kultische Aspekt des Verfahrens.

Unter rechtlichen Gesichtspunkten stellt sich die Sache noch etwas anders dar: Die Frau muß sich keiner Prozedur unterziehen, die ihr irgendwie körperlich, physisch schadet. Wenn sich nichts an ihrem äußerlichen Zustand ändert, gilt das als Zeichen ihrer Unschuld. Die Schuld muß sich also beweisen, nicht die Unschuld! Das Verfahren des Gottesurteils gibt der Frau eine Möglichkeit, ihre Unschuld zu unterstreichen, die sowohl ihr Mann wie alle Außenstehenden anerkennen müssen! So fremdartig uns heute ein solches Gottesurteil anmutet, so 
muß man doch zugeben, daß es in alten Zeiten für eine bedrängte und in ihrem Ruf geschädigte Frau ein erfolgreiches Medium gewesen ist, ihre angetastete Würde in aller Öffentlichkeit wiederherzustellen.

Wie ist man nun in späteren Zeiten mit diesem Gottesurteil umgegangen? In der Mischna Sota 9,9 heißt es, daß das fluchbringende Wasser abgeschafft worden sei. Rabbi JOCHANAN BEN ZAKKAI hätte das veranlaßt, und zwar mit der interessanten Begründung, daß die Ehebrecher - in der männlichen Form wohlgemerkt - sich gemehrt hätten. Schon vorher wurde der letzte Vers unseres Kapitels (31) so ausgelegt, daß das fluchbringende Wasser dann unwirksam sei, wenn auch der Ehemann sich von geschlechtlichen Verfehlungen nicht freigehalten habe. Rabbi JOCHANAN hat nun anscheinend bei den Männern seiner Zeit so viel Ehebruch erlebt, daß es von vornherein fast aussichtslos erschien, noch ein Verfahren in alter Wirksamkeit durchzuführen. Daher wurde die Sota-Untersuchung, (die Prüfung, ob eine Frau Ehebruch begangen habe), ganz eingestellt. Ähnliches steht in Sifre Numeri § 21 zu Num 5,31. Das Judentum hat also auf die Durchführung von Gottesurteilen als Rechtsentscheiden ganz verzichtet.

Anders stand es im Christentum: Im Mittelalter gelangten Gottesurteile zu neuer Blüte. Nicht nur, aber in erster Linie wurden sie bei Hexenverfolgungen eingesetzt. $\mathrm{Ob}$ nun die beklagenswerten Frauen mit nackten Füßen über glühende Kohlen laufen mußten oder gefangen in einem Käfig in einen Fluß gesenkt wurden oder anderes erduldeten, was an religiösem Wahn erkrankte Gehirne sich ausdachten, immer war es so, daß ihre körperliche Unversehrtheit mit Gewalt angetastet, ihr Leben und ihre Gesundheit massiv bedroht wurden. Im Vergleich zum Gottesurteil in Numeri 5 zeigen sich grundlegende Unterschiede:

a) Im alten Israel enthielt kein Element des Verfahrens eine physische Gefährdung für die Frau. Die Gottheit sollte eingreifen, um die Schuld ans Licht zu bringen. Auf jeden Fall mußte die Schuld bewiesen werden.

b) Im christlichen Mittelalter bestand für die als Hexe verdächtigte Frau in dem Verfahren von Anfang an physische Gefahr, in den meisten Fällen Lebensgefahr. Gott sollte eingreifen, um durch ein Wunder die Unschuld an den Tag zu bringen. Immer mußte die Unschuld bewiesen werden.

Man muß also feststellen, daß die Gottesurteile des Mittelalters das altisraelitische Verfahren direkt auf den Kopf gestellt haben. In Israel konnte niemals der Tod einer Unschuldigen eintreten, wie wir gesehen haben; im Mittelalter war die Verschonung die seltene Ausnahme, das Wunder.

An zwei Stellen beobachten wir beim Verfahren des Gottesurteils religiösen Radikalismus mit seinen menschenfeindlichen Konsequenzen: bei der Todesstrafe für Ehebruch im israelitischen Sakralrecht - diese Strafe wurde aber wohl selten oder nie tatsächlich vollstreckt - und 
bei den Hexenverfolgungen im Mittelalter, dem Tausende von Frauen und auch mitunter Männer zum Opfer fielen.

Die christliche Kirche hat in ihrer 2000jährigen Geschichte in zwei Bereichen unendliche Schuld auf sich geladen: indem sie den Hexenwahn im Volk nicht nur nicht gebremst, sondern sogar noch gefördert hat, und weil sie durch theologischen Antijudaismus dem Antisemitismus den geistigen Weg bereitet hat, der seinen grausigen Höhepunkt im Holocaust fand. Möge Gott die Kirche vor einer ähnlichen Schuld in der Zukunft bewahren! 



\title{
THE COHERENCE OF THE JERICHO NARRATIVE:
}

\section{A Literary Reading of Joshua 6}

\author{
von \\ Robert B. Robinson \\ Lutheran Theological Seminary at Philadelphia
}

In a wonderfully illuminating article on 1 Kings 21 Professor BALTZER explored the legal and ideological background behind the humble Naboth's refusal to sell his hereditary vineyard to Ahab, the powerful king of Israel.1 Ahab offered just compensation or advantageous exchange for the vineyard, but, even had he desired to accommodate the king, Naboth was constrained from accepting the offer by time honored legal traditions that prohibited an Israelite from alienating his land. Behind these legal traditions stood an ideology of land tenure. God, the original title holder, freely apportioned each Israelite family its inheritance in the land. No Israelite might undo that apportionment by conveying his land outside the family. ${ }^{2}$ Freedom to alienate the hereditary land would imply personal ownership of the land, forgetting God's prior title and denying that the land was received as a gift.

Professor BALTZER's article foregrounds a single incident, but characteristically illumines a rich background of associations with other passages and motives. Behind Naboth's refusal to sell his land lies at no great distance the stories of the conquest and apportionment of the land in Joshua and, behind those stories, the theme of the promise of land to Israel's ancestors in the Pentateuch. The present study, which focuses on the story of the conquest of Jericho (Joshua 6), takes its inception from the stimulus of Professor BALTZER's work and is offered in deep respect and gratitude for his teaching on the occasion of his sixty-fifth birthday.

\footnotetext{
${ }^{1}$ K. BALTZER, "Naboths Weinberg (1. Kön. 21). Der Konflikt zwischen israelitischem und kanaanäischem Bodenrecht," WuD 8 (1965) 73-88.

2 Essentially the same ideological principle is at play in the case of the daughters of Zelophehad, Num 36:1-12. Absent male heirs, the family inheritance of land passed to daughters. This caused no conflict with the ideology of land tenure in the generation of the daughters, but because inheritance was patrilineal, the daughters' land would pass into the tribe of their husbands in the following generation and be alienated from the tribe to which it was originally apportioned by God. The case is resolved by requiring daughters receiving inheritance under these circumstances to marry within their tribe, thus preserving the integrity of God's apportionment of the land.
} 
"From the outset [Joshua] is the intended continuation of the Pentateuch."3 Carl STEUERNAGEL's judgment, rendered at the turn of the century, articulated a consensus among scholars of his time on the relationship between Joshua and the Pentateuch. It seemed virtually selfevident on the basis of content alone that Joshua must have arisen in connection with the Pentateuch. Without the book of Joshua the Pentateuch was a "torso" lacking a fitting conclusion. ${ }^{4}$ In particular - this seems to be the heart of the matter - the theme of the promise to Israel's ancestors, so richly developed in the Pentateuch, simply demanded fulfillment in Joshua's stories of the conquest of Canaan, the "Promised Land."

For STEUERNAGEL and his generation of scholars continuity in content and theme entailed literary sources running continuously from the Pentateuch into the book of Joshua. Broad continuities in characters, chronology, setting, theme, and theological tendency were characteristic features of unified literary works. Inconsistencies and infelicities of style in the final form of the narration might be explained by the coarse amalgamation of variant literary sources. However, a narrative document without a fitting conclusion - the Pentateuchal sources without the conquest - would represent a degree of literary incoherence that could not be reconciled with the hypothesis of unified literary sources. The source critical hypothesis itself, which conceived the sources of the Pentateuch as extended and coherent literary works, predisposed scholars to find continuity between the Pentateuchal documents and Joshua. Further, since the source critical hypothesis assumed that written literary documents were the most fundamental building blocks of a composition such as Joshua, and that nothing significant lay before them, the assumption that Joshua was composed of the same written documents as the Pentateuch was a simpler, more elegant explanation than the alternative, which required positing a completely distinct set of written documents for the book. It was necessary to speak of a Hexateuch. Detailed scholarship turned to the task of distinguishing the continuations of the Pentateuchal sources J,E, D, and P in the book of Joshua.

New methods of investigation, particularly form-criticism and tradition history, destroyed the aura of coherence of the sources. By focusing on the smaller, pre-literary units of tradition, these methods of study abandoned the presupposition of broad coherence that accompanied the concept of fixed literary sources. ${ }^{5}$ Each small, independent unit

3 C. STEUERNAGEL, Deuteronomium und Josua, HKAT 1/3; Göttingen: Vandenhoeck und Ruprecht, 1900, 131.

4 C. STEUERNAGEL [A.2] 131.

5 The preoccupation with the smallest pre-literary units and the reticence concerning the combination of these individual units into connected sources can be seen from the earliest 
must, of course, be coherent. But coherence no longer meant thematic continuity and non-contradiction between units - continuities of character, chronology, or narrative action. Coherence now meant that each individual unit was 1 ) internally non-contradictory, 2) conformed structurally to a recognized literary Gattung, and 3) served a defined function within a specific Sitz im Leben. Coherence at a higher level, the relationship between independent formal or traditional units, required a developmental account of how and why the independent units came together that was decisively more difficult to provide than the account of coherence provided by source criticism, and, given the emphasis on the earliest stages in composition, of considerably less interest. ${ }^{6}$

In the specific case of the book of Joshua the coherence of the stories of the conquest of Canaan with the Pentateuchal sources was decisively denied by the work of Martin NOTH. Applying the criteria of consistent vocabulary and unified content that served to distinguish the Pentateuchal sources, NOTH detected no evidence that the Pentateuchal documents continued into Joshua. ${ }^{7}$ Instances of possible continuation could not withstand close examination. For example, Jos 2:10 and 4:23 allude to the crossing of the Reed Sea, but the formulation employed in Joshua differed from the Pentateuchal formulations in Ex 14. ${ }^{8}$ Some manner of relationship was undeniable - the allusion was obvious - but the distinctively different formulations precluded attributing both passages to the same source. The same pattern obtained elsewhere - although there were undeniable thematic relationships, they could not be correlated with continuous source documents. Despite the impression of broad continuity between the Pentateuchal story and Joshua, the continuity could not be demonstrated on rigorous source critical lines. At a stroke NOTH eliminated a documentary base for the sense of continuity that STEUERNAGEL and his generation found so obvious between the Pentateuch and Joshua.

statements of the new form-critical movement. Hermann GUNKEL insisted, "Every individual saga must first be interpreted in its own right. The more independent a narrative, the more certainly it has retained its older form. The relationship which exists between the individual sagas in many cases is of later origin, if not simply an imposition of the interpreter." (H. GUNKEL,Genesis, HKAT I/1, 3rd ed.; Göttingen: Vandenhoeck und Ruprecht, 1910, xxxiii. My translation).

6 The difficulties in explaining continuity between pre-literary units were not initially recognized. Compatibility between source critical and form critical methods, which has now come to be seen as highly problematic, was simply assumed. See R. RENDTORFF, The Problem of the Process of Transmission in the Pentateuch, JSOTSup 89; Sheffield: Sheffield Academic Press, 1990.

7 M. NOTH, Das Buch Josua, HAT 7; Tübingen: J.C.B. Mohr, 1938, XIII. M. NOTH, Überlieferungsgeschichtliche Studien, 3rd ed.; Tübingen: Max Niemeyer, 1967, 180.

8 M. NOTH [A.7, Josua, XIII]. 
NOTH could free himself from the compulsion of the source critical hypothesis because he had an alternative model for the composition of Joshua. Written documents were no longer the fundamental building blocks of a work, but the much earlier units of tradition discerned by form criticism and tradition history. He had an earlier starting point than the source critics. In the conquest narratives of Joshua 1-12 the original units were independent etiological sagas explaining cultic observances, natural or constructed phenomena, or social relationships between groups, all recounted in the Benjaminite shrine city of Gilgal or its near environs, together with several tales of heroes of different provenance. Coherence at the level of these smallest units was exceptionally strong. Internal contradictions were eliminated by designating contradictory elements in the literary form of the sagas as later additions or unrelated traditions, the etiological saga was a recognized Gattung, and the etiologies filled an easily comprehended role in their social setting, explaining the origins of institutions and phenomena found in and around Gilgal. The depiction of the earliest units, the etiological sagas, was elegant.

The etiological sagas were originally completely independent of one another. Their centrifugal movement of association and combination with other material constituted the compositional history of the book. NOTH conceived the process in several broad stages. Relatively early the sagas came together to form a rudimentary conquest account restricted in its perspective to the territory of the tribe of Benjamin around Gilgal. ${ }^{9}$ During the reign of Saul, when Gilgal served as an important cultic center for all the tribes, this Benjaminite conquest account attracted local traditions from other tribes, expanding to explain how all the tribes had attained their inheritance in Canaan.10 Around 900 B.C.E. this all-Israel conquest account received distinctive written form from an author NOTH called the Sammler.11 Early in the exile the Deuteronomist further expanded this document to near its present form and incorporated it into the Deuteronomistic History.12 Still later the deuteronomistic form of the book was expanded with additions at least related to the Priestly source of the Pentateuch to complete the book. ${ }^{13}$

\footnotetext{
9 M. NOTH [A.7, Josua, XI]. In the Uberlieferungsgeschichtliche Studien [A.7, 41, n. 1] NOTH accepted the argument of K. MÖHLENBRINK, "Die Landnahmesagen des Buches Josua," ZAW 56 (1938) 240, that the sagas in their original independent form provided etiological accounts of the Benjaminite conquest of particular areas. The common theme of conquest in the original etiologies themselves helped fill a weakness in NOTH's argument by explaining how orignally unrelated etiologies could be drawn together to form a connected conquest account.

${ }^{10}$ M. NOTH [A.7, Josua, XI].

11 M. NOTH [A.7, Josua, XI].

12 M. NOTH [A.7, Josua, XIII-XIV].

${ }^{13} \mathrm{M}$. NOTH [A.7, Josua XIV]. In the Joshua commentary NOTH is very cautious about attributing any part of Joshua to the Pentateuchal source P. By the Überlieferungsge-
} 
In a final phase the complete Deuteronomistic History was joined with the final form of the Pentateuch to form the biblical text in nearly its present shape. 14

The great strength of NOTH's reconstruction lay in the coherence of the earliest oral stories, the etiological sagas. It is easy to conceive these simple stories functioning quite naturally to explain local phenomena. Later stages were more troubling. Sigmund MOWINCKEL, for instance, found it difficult to accept NOTH's complete separation of Joshua from the Pentateuch until very late in the redactional process. This late dating now caused severe problems. In Das formgeschichtliche Problem des Hexateuch Gerhard VON RAD had demonstrated to MOWINCKEL's satisfaction a process of development in which two originally independent traditions, one concerning the settlement of the land and the other concerning events at Sinai, were brought together by incorporating the Sinai tradition into the settlement tradition. 15 The addition of ancestral traditions and the primeval history resulted in a unified account stretching from creation to the settlement of the land of Canaan. VON RAD held, and MOWINCKEL concurred, that the achievement of this unified account was the work of the Yahwist. ${ }^{16}$ In VON RAD's tradition historical work MOWINCKEL found new support for the source critics' assumption that the Pentateuchal sources extended into Joshua. Yet NOTH's categorical denial that Joshua contained any material from the Tetrateuchal sources required one to accept that the ending of this comprehensive Yahwist narrative had been lost, indeed lost without so much as a trace, even though the material in Joshua largely corresponded to the expected conclusion. NOTH's conclusion seemed most improbable, and its improbability provided a warrant for a renewed attempt to find the lost ending in Joshua.

MOWINCKEL's arguments need not be reviewed here in detail. Sifting through Joshua once again, MOWINCKEL felt justified in identifying the Rahab story, a few other short passages in Joshua(Jos 15:13-19; 15:63; $16: 10 ; 17: 12-13 ; 17: 14-18$; and 19:47), and the opening chapter of the book of Judges as remnants of the J account. The common element connecting these passages with one another was their conception of the con-

schichtliche Studien (182-190, particularly 190) NOTH strenuously denied the attribution of any material in Joshua to $P$.

14 M. NOTH [A.7, Überlieferungsgeschichtliche Studien, 211-216].

15 G. VON RAD, Das formgeschichtliche Problem des Hexateuch, BWANT 78; Stuttgart: Kohlhammer, 1938.

16 S. MOWINCKEL, Tetrateuch--Pentateuch--Hexateuch: Die Berichte über die Landnahme in den drei Altisraelitischen Geschichtswerken, BZAW 90; Berlin: Töpelmann, 1964, 9. 
quest of Canaan as incomplete. ${ }^{17}$ The $\mathrm{J}$ account did indeed extend into Joshua.

MOWINCKEL's work represents an attempt to return to the hypothesis of continuous documentary sources in order to explain the thematic continuity perceived between the Pentateuch and Joshua. It cannot, however, be said that MOWINCKEL succeeded in providing a satisfactory account of the thematic continuity one feels running between the books. Even if one accepts all of MOWINCKEL's arguments against NOTH for the continuation of $\mathrm{J}$ in Joshua, the most MOWINCKEL is able to rescue for J is two legs and an ear. If, as VON RAD and MOWINCKEL accept, it was J who brought the Sinai and settlement traditions together with a climax in the settlement of the land, and if MOWINCKEL's reconstruction represents the total extent of J's settlement account, then we must posit a profound failure of creative energy at the crucial moment. J's account of the settlement is exceedingly modest. MOWINCKEL does posit further oral development of $J$ (what others identified as $E$ and NOTH identified as the work of his Sammler) which is far closer to what we would expect as the conclusion to the $\mathrm{J}$ source. Yet this material does not directly align with the J source in the Pentateuch. In MOWINCKEL's reconstruction we are left with the puzzling oddity that J would introduce the theme of promise of the land, build toward a dramatic fulfillment, and then leave it to further development of tradition or a later author to supply the full conclusion. MOWINCKEL fares little better than NOTH in providing an account of the sense of thematic continuity that exists between the Pentateuch and Joshua.

It is difficult to escape the skeptical conclusion that no developmental schema can provide an adequate account of the continuity between Joshua and the Pentateuch. Crucial elements of continuity somehow slip through source critical or tradition historical nets. The paradox is that great precision in describing constituent strands of the final form of the text does not insure a satisfying account of the rich relationship existing between them. The very power of these methods to distinguish layers of the text from one another works, it seems, against successful reintegration.

If source critical and tradition historical methods experience difficulty in providing adequate accounts of the relationship between texts, they also have trouble explaining the relationships between elements within a single text. Difficulties arise for two primary reasons. First, the historical critical method of analysis of a text emphasizes inconsistencies in a text. Inconsistencies or disruptions are paramount criteria in discer-

17 S. MOWINCKEL [A.16] 12-33. 
ning different layers of the text. Discerning different layers is the goal of the analysis because it allows one either to arrive at the earliest stage of the history of a text - long the primary goal of historical analysis - or to trace the complete compositional history of a text or, more recently, tradition. Accordingly, great accumen is employed to recognize contradictions in the text, with the not very surprising result that the final text appears incoherent, riddled with inconsistencies.

Secondly, historical critical methods tend to relate elements in a text vertically through time rather than horizontally to other elements in the text that exist at the same point in time. To use other current terminology, historical methods stress the diachronic relationships of elements in the text over the synchronic. What is too often forgotten in this procedure is that at every point in time the text must make sense synchronically. Historical critical analysis may be able to explain how and when a particular feature came into a text, but not what sense it makes within the text once it has been incorporated.

Several examples focusing on Jos 6 will both illustrate the problems and begin to turn us toward the passage that is the primary concern of this study. It is generally conceded that the description of the procession around Jericho in Jos 6 is complex. Jay A. WILCOXEN focuses on a particular aspect of that complexity, the three different presentations of the way the auditory component of the procession is to be carried out. 18 In one presentation seven priests carry seven horns which they are to blow only at the end of the final circumambulation on the seventh day (Jos 6:4-5, 16a, 20b). In a second version Joshua instructs the people to raise a war whoop, also at the end of the seventh day (Jos 6:10, 16b). In a third presentation, the rear guard as well as the priests carry horns, which they blow continuously (Jos 6:8-9, 13). WILCOXEN is concerned to explain how these seemingly contradictory presentations might have served simultaneously within Israel's cult and therefore why they appear simultaneously in the text of Jos 6 . His explanation is wonderfully simple, if rather implausible. The three variants are alternate rubrics, the first, second, and third settings of the cultic procession. ${ }^{19}$ All three variants are preserved because each represents a legitimate alternative form of the cultic procession, any one of which the priest might choose on the day of the celebration.

The great virtue of WILCOXEN's suggestion is that it takes seriously the fact that even contradictions must have made some sense or served some purpose if they were preserved in a text or by oral tradition. If the tradition preserved three variant instructions, there must be a reason. However, the implausibility of his specific suggestion indicates how dif-

18 J.A. WILCOXEN, "Narrative Structure and Cult Legend: A Study of Joshua 1-6" in J.C. RYLAARSDAM (ed.), Transitions in Biblical Scholarship, Chicago: University of Chicago Press, 1968, 49.

19 J.A. WILCOXEN [A.18] 53. 
ficult it is correlate contradictions in texts with comprehensible features of the life or cultic practice of the Israelite people. The threads of tradition in Jos 6 are so thoroughly intertwined that it is difficult to picture them providing clear legitimation for three distinct practices. After intense study modern scholars have not come to agreement on the precise contours of the procession. Would not such a complex cult legend have created more arguments among the cultic personnel than it would have resolved? WILCOXEN's problem is that, having shown the incoherency of the text, he is hard put to provide a consistent account of what functional sense it could have had.

Hans SEIDEL concentrates on a different type of inconsistency in the account of the procession around the walls in Jos 6, the differing designations of the wind instruments and who employed them. ${ }^{20}$ Three designations appear: the ram's horn (היקר, Jos 6:5); the trumpets of

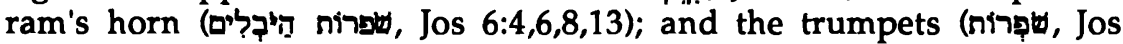
$6: 4,5,8,9,13,16,20$ ). These three designations provide SEIDEL a criterion to disentangle three strands in the procession account. The ram's horn (P) is associated with an early layer of tradition that served as the cult legend of a ceremonial procession around a city, presumably Jeri-

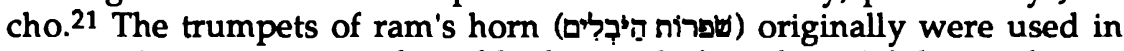
ceremonies announcing the sabbath year before those jubilee traditions were assimilated (for whatever reason) with the Jericho cult legend.22 The trumpets (t) represented redactional additions. These late redactional additions are of particular interest. SEIDEL discerns two reasons for these additions. First, the redactor was concerned with the fine points of terminology. In instances such as Jos 6:5 in which the received text contained some variant designation for the horns used in the procession, the redactor found ways to provide "the correct, for the writer only official name for the wind instrument = shofar." 23 Secondly, the redactor wished to restrict the use of these trumpets in ceremonial contexts to the priests. The redactor therefore emphasized in passages such as Jos 6:4 that the priests (scil. not lay Israelites) blow the trumpets. ${ }^{24}$

SEIDEL's effort here once again is to provide a motivation for the suggested redactional additions by explaining their social function, in this case to ensure proper terminology and to advance claims to priestly prerogatives. Once again the proposed motivations are implausible, here precisely because they do not pay attention to the way the whole text would be heard synchronically but only to the additions. The ob-

\footnotetext{
${ }^{20}$ H. SEIDEL, "Der Untergang Jerichos (Jos 6) - Exegese ohne Kerygma?", Theologische Versuche 8; Berlin: Evangelische Verlagsanstalt, 1977.

21 H. SEIDEL [A.20] 13.

22 H. SEIDEL [A.20] 12-13.

23 H. SEIDEL [A.20] 14.

24 H. SEIDEL [A.20] 14.
} 
vious fact is that Israelites who read Jos 6 or heard Jos 6 read to them would hear three different designations for the instruments employed, not two terms and an addition. Only the scholar's tradition historical observation that the term $\$ \delta p^{2}$ rôt is an addition to the text draws exceptional attention to that term. ${ }^{25}$ Likewise, the full form of the text, as it would have been heard by the Israelites after the additions had been made, does not contain an exclusive claim to priestly use of the musical instruments in the procession. Jos 6:9,13 explicitly allow the rearguard (הָ) use of the trumpets and Jos 6:20, despite some difficulties, seems to indicate that the people (דֶ) blew the trumpets. SEIDEL's explanation would make sense of the sôp $p^{2} \hat{t} t$ if they appeared in isolation, as discrete additions, as the historical development schema tends to present them. But it fails to present a convincing account of how these "additions" function in conjunction with other features of the text, with which they now form a common structure.

\section{III}

Two areas have been of concern in the previous sections. First, the historical and developmental categories fundamental to tradition history and source criticism make it difficult to affirm the rich, allusive and thematic associations that are often felt to exist between texts. Early critics felt the rich associations between Joshua and the Pentateuch, associations that could only be explained by continuity of sources. Closer examination has made the continuation of Pentateuchal sources problematic as a matter of historical fact. No other compositional history has proved more successful. Yet the sense of continuity and rich association persists, despite the inability of historical categories to account for it.

Secondly, historical categories of interpretation make it difficult to relate features of a specific text to one another. In part this is a result of the centripetal impulse that has dominated historical criticism. Texts must be pulled apart in order to reach the earliest historical units. Preoccupation with the earliest stages is no intrinsic part of historical study and recent research has paid more attention to later, assimilative stages in the composition of a text, but the legacy of earlier study continues to have influence. More fundamental, perhaps, is the tendency of historical study to relate features of the text to earlier stages in a historical reconstruction rather than to other features of the contemporaneous text. This sort of analysis makes it very difficult to see how a text could have been understood at any one moment.

The difficulties encountered in relating texts to one another and in relating features of individual texts to one another warrant a different

25 If revisions in terminology were required, they could be explicitly marked in the text. See 1 Sam 9:9. 
approach. The interpretation of Jos 6 that follows adopts a different mode of interpretation than that presupposed by historical critical study. Historical critical methods assume that the significance of particular features of a text are best explained as effects of creative processes at work in the historical situation that is the context for the composition of the work. The mode of explanation is causal, and it has its own integrity. A particular motive or impulse active in the historical situation outside the text - to preserve variant rubrics for the performance of a procession - leads to particular features of a text - the twisted and inconsistent instructions in Jos 6 . The approach adopted here presumes a different type of explanation. Literary features of the text gain their significance from the constellation of relationships in which they stand with other features of the immediate text and with other texts. The mode of explanation is relational or, though this term may mislead, structural. Particular literary features derive their value and significance from their position in a pattern, and from the specific relationships they establish with other features that make up the pattern.

The heart of the interpretation offered is an effort to make sense of what the text of Jos 6 presently offers. Although the text is difficult, it is not fully incomprehensible unless we insist that it make sense in terms of coherent descriptions of historical reality lying outside the text. The obvious must be granted. Jos 6 in its present form fails to describe a sensible plan of attack on a city or consistent rubrics for a cultic procession. Even to correlate the present text with a comprehensible process of composition is daunting. Granted. But only if we insist that the text must provide a description or correlation with some such historical reality to be intelligible does the failure so readily granted sponsor a disarticulation of the text into more nearly consistent constituent parts. The present interpretation does not insist on a self-consistent historical correlate for the text. Rather, it seeks intelligibility in patterns of intertextual and intratextual relationships, first between literary features of Jos 6 and its immediate literary environs and then more broadly with features of other biblical passages, particularly in the Pentateuch.

\section{IV}

Operations at Jericho make no military sense. Yet they have a military consequence. Walls fall, smoke rises from a deserted city. The tension between narrated action and narrated result is the most striking feature of the Jericho story, a tension that exceeds any natural interpretation and so promises rich thematic implications. ${ }^{26} \mathrm{Had}$ Israel surroun-

26 J. GRAY, Joshua, Judges and Ruth, Rev. Ed., NCeB; London: Oliphants, 1977, 67, perceives the tension between the military nature of the capture of a city and the patently unmilitary activities of the Israelites. Typically, he attempts to remove the tension by positing two different traditions, a secular one in which the military men silently sur- 
ded the city and brought up the instruments of siege, we would have had few questions to ask. But it did not. For seven days the Israelites ceremonially marched around the city, then, without firing a shot, went up into the defeated city. Certainly any interpretation of the story must begin here.

Even before Jos 6 opens there is a significant interaction between military and sacral images. In the prolog in Jos 5:13-15 Joshua the leader of Israel encounters what he takes to be an armed man in Jericho. Acting as a sentry Joshua confronts him. "Are you on our side or for our enemy." The challenge to stand and be identified is standard military procedure. The supposed man identifies himself as the captain of the host of the Lord. The commander's position is somewhat ambiguous. The position of sar hasssab normally means the commander of an army, as, for instance, in the case of Sisera, who commands the army for Jabin, the king of Canaan, in Jud 4:2. But God's host, although it may be invol-

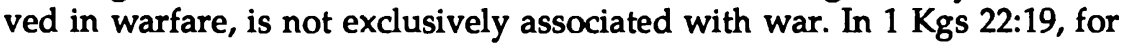
instance, Micaiah perceives the host surrounding the divine throne in heaven while God holds audience. The host represents the divine court, accompanying the divine presence. The captain therefore appears in uncertain capacity, as captain of the divine armies and leader of the divine entourage. The conversation is exceptionally brief, seemingly incomplete. The full import of the commander's message is to instruct Joshua to remove his sandals, for the place on which he stands (Jericho) is holy. This unmistakable allusion to Moses's meeting with God at the burning bush on Mount Horeb (Ex 3:5b = Jos 5:15a $\beta$ ) serves to continue a longstanding identification of Joshua with Moses's authority, but it also introduces a tremendous expectation. A holy place like Horeb, the captain of the host of the Lord in attendance, all this leads to expectations of a theophany similar to God's appearance at Horeb, but this time at Jericho, before which Israel stands drawn up for battle. Military and sacral images are held in a very rich, unresolved tension which sets the stage for the account of the conquest of the city itself.

Jos 6 opens, it must be said, with much of that tension dissipated. The account bristles with preparation for war. Jericho is a city under attack, prepared to withstand siege. The Lord gives Joshua assurance of victory, "See. I have given Jericho into your hands." As Gerhard vON RAD has shown, this or similar phrases regularly precede the outbreak of holy warfare in Israel.27 With the outcome not in doubt, decisive battle ensues, God fighting at the side of Israel. Preparations for battle

round the city, and a sacred one, the etiology of a cultic procession. Dissolution of the tension denies any thematic significance to what is arguably the most obvious feature of the text.

27 G. VON RAD, Der Heilige Krieg im alten Israel, 4th ed.; Göttingen: Vandenhoeck und Ruprecht, 1965, 7-9. 
follow immediately. God gives instructions for the disposition of the Israelite troops. The characters receiving the instructions are the men of

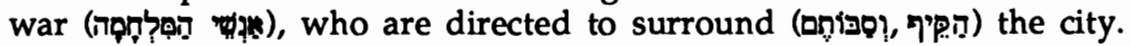
Attack is imminent.

Just at this point a small detail signals that our understanding of the nature of this event must be revised. The men of war are to surround the city one time (פקט ). How odd! Attackers intent on capturing a city do not surround it one time. They surround it, dig in, and prosecute the attack until the city is taken or the siege lifted. The instruction to encircle the city one time requires that we shift our understanding from a single, non-repeatable action, surrounding the city, to an action that can be done one time, then repeated, as the instructions go on to direct, on each of six successive days. The men of war are not instructed to surround the city in preparation for attack, as we were led to assume, but to make a procession around it.

The revision of assumptions about the nature of the event at Jericho is a highly artful device. It trades on ambiguities in the key verbs

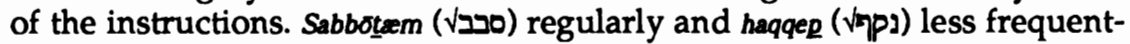

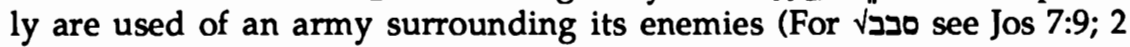
Sam 18:15; 2 Kgs 3:25; 6:15; 8:21; Ps 88:18; 118:10,11. For ل^pJ see 2 Kgs 6:14; Ps $17: 9 ; 88: 18$.) The overwhelmingly martial atmosphere at the beginning of the book of Joshua encourages initially taking the verbs in this familiar sense. Both verbs, however, also occur, although less frequently, in cultic settings to describe processions (For $V_{2}$ see Ps 26:6; 48:13; perhaps 7:8. For $\sqrt{ } \eta$ p see Ps $48: 13$.). The inadmissibility of pasam sot in a military context abruptly shifts the understanding of the verbs from one semantic field to the other, a shift one would naturally assume is thematically significant.

The semantic shift is reinforced by additions to the personnel. Priests appear at the side of the men of war and take their positions at the center of the procession as it forms. Priests are not, to be sure, unknown presences in the camps of war. Hophni and Phinehas, the two priestly sons of Eli, for instance, die in battle when they accompany the ark into combat against the Philistines (1 Sam 4:11). Priests are not therefore out of place in a war-like setting, but their primary associations are with cultic activities. The presence of priests bearing the ark as Dtn 10:8 prescribes and blowing the trumpets moves us toward conceiving the event at Jericho as a cultic procession. The martial context still surrounds the procession forming, but now there is some tension between that context and the preparations being made before Jericho. The cultic procession forming has no obvious military purpose.

It may be objected that too much is made of both the tension and artful intertwining of military and cultic preparations. A series of masterful studies has instructed us that our modern understanding of warfare as the secular activity bears no relationship to the Bible's portrayal 
of war. ${ }^{28}$ The Lord is a man of war (פרד Ex 15:3) and warfare therefore intrinsically a sacral activity, conducted according to a panoply of ritual instructions and practices. A clear distinction between military and sacral activities runs precisely counter to the biblical conception of warfare. Battle is sacred ritual.

The caution is pertinent. It is inappropriate to dissociate sacral aspects from martial. Preparations for battle in Jos 6, as we have seen, conform in part to what VON RAD called "the theory of holy war", at least in respect to the assurance that God had delivered the city into Joshua's hand. ${ }^{29}$ We may entertain no suggestion of a thorough dissociation of military operations and sacral practices in Jos 6 . The tension in the passage is not of this simple order. The precise nature of the tension becomes clearer if we compare other passages of holy war, Saul's battle with the Ammonites at Jabesh-Gilead (1 Sam 11), for instance. Saul is returning from the fields when he receives word of the horrifying ultimatum presented Jabesh-Gilead by the Ammonites. The spirit of God seizes him and he prepares to lead the people in holy war. To summon the people to battle Saul ritually sacrifices the oxen he has been using in the fields and dispatches pieces of the flesh to all the territory of Israel. The people report. The city is relieved and the Ammonites routed. The logic that structures this account is the logic of warfare. Activities described are pertinent to the prosecution of battle, such as summoning the troops, but they are performed in a prescribed and ritualized fashion, in this case by dividing the oxen and dispatching them through the tribes. Throughout the episode it is the requirements of warfare that structure the narrative, from description of the situation that requires battle to the successful conclusion of hostilities.

In Jos 6 the relationship between military elements and cultic elements of the event is far more complex. The narrative begins as if the siege of Jericho were a straightforward military operation unfolding from laying the siege by surrounding the city to successful attack and capture of the city. But with the first specific instructions, that significant "one time," development toward the expected climax of capture of the city is retarded by what appears purely a cultic activity without military significance. No one in the procession pays the slightest attention to Jericho. All attention is centered on the ark. In other circumstances we might understand the retarding element as a device to build suspense. But there is no suspense at Jericho. God has already given assurance of victory - "I have given Jericho and its king into your hand"- and we accept that assurance on the strength of its author. The interruption of the unfolding plot must therefore have more profound significance, an in-

28 F. SCHWALLY, Der Heilige Krieg im alten Israel, Leipzig: Dieterichsche Verlagshandlung, 1901; J. PEDERSEN, Israel: Its Life and Culture, III-IV, London: Oxford University Press, 1947; G. VON RAD [A.27].

29 G. VON RAD [A.27] 6. 
tent to qualify and interpret the nature of the event that is taking place at Jericho. The cultic procession is introduced into the narrative lest we misunderstand events at Jericho, lest we think it simply the capture of a fortified city.

The ark is the heart of the procession that breaks into the siege of Jericho. The armed men, the priests, and the rear guard find their places in relation to its gravity. Israel enters the field to accompany the ark in fitting ceremony and not to do battle. Four different terms are used for

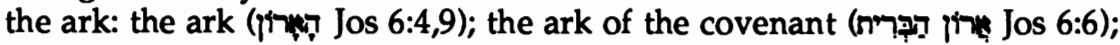
the ark of YHWH (Tris Jos 6:6,7,11,12,13,13); the ark of the covenant

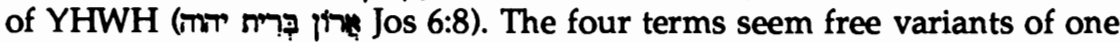
another. ${ }^{30}$ They do not point to different realities or different aspects of the same reality, but indicate a single, seemingly unified reality, the ark. The significance of the ark in the procession results from its near identity with the presence of YHWH. The identification of the ark with God's presence is implicit in the great care with which the procession is formed around it, the centrality of the priests in the procession, and in the continuous accolades of the trumpets as the ark is borne around the city. The solemn, sacramental procession itself elevates the sanctity of the ark. Priests and trumpets and jubilant people honor its holiness. One verse, Jos 6:8, more explicitly indicates the equation of the ark with the Lord. The verse recounts the priests' fulfillment of Joshua's instructions to circle the city, "As Joshua had commanded the people, the seven priests carrying the seven trumpets of ram's horn before the Lord went forward, blowing the trumpets, with the ark of the covenant of the Lord following them." Attention falls on the phrase "before the Lord," which might easily be misheard. In God's instructions to Joshua (Jos 6:4) and Joshua's repetition of those instructions (Jos 6:6), the phrase is "before the ark" or "before the ark of the Lord," respectively. Now it simply says "before the Lord" without significant variation in meaning. The priests bear their trumpets before the Lord or before the ark of the Lord; it is nearly the same thing. The equation of the ark with God is not developed in a speculative manner in the narrative. ${ }^{31}$ As the subtlety of the alternation of "before the Lord" and "before the ark" suggests, the equation is simply assumed. The ark symbolizes or represents or embodies the presence of the Lord. Every abstract term struggles to capture what the narrative naturally renders. ${ }^{32}$ The procession around the city is not

30 In Jos 6:4, for instance, God's insructions to Joshua concerning the procession, the ark is called the roon habbirît. When Joshua conveys those same instruction to the priests in Jos $6: 6 \mathrm{~b}$, the ark is called * rôn $Y H W H$, without apparent distinction.

31 For a thorough account of scholarly attempts to establish the origin, function, and inherent nature of the ark, see R. SCHMITT, Zelt und Lade als Thema alttestamentlicher Wissenschaft: Eine kritisch forschungsgeschichtliche Darstellung, Güterslohe: Gütersloher Verlagshaus Gerd Mohn, 1972, 49-174. 
focused on Jericho, but on the presence of God in the midst of the people. It is, quite strictly, the proper cultic celebration of God's presence.

The procession, although focused on the presence of God in its center, is not totally devoid of martial associations. The ark itself is often associated with warfare. When David seeks to entice Uriah to go down to Bathsheba so that David's adultery may be concealed, Uriah protests. "The ark, and Israel and Judah remain in booths" on the field of battle at Rabbah (2 Sam 11:11). The ark accompanies Israel to battle. Closer to our story, when the elders of Israel are hard pressed by the Philistines in 1 Sam 4, they say: "Let us bring the ark of the covenant of the Lord here from Shiloh, so that he may come among us and save us from the power of our enemies." (1 Sam 4:3). The ark is thoroughly identified with God's military power. The procession itself has a martial character by its

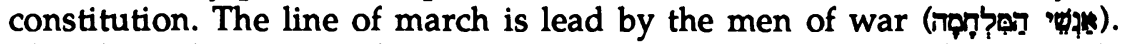
Elsewhere these men of war are called "the armed men" († Jos 6:9, 13). The detachment that follows the ark, called the rear guard (7) כos Jos $6: 9,13)$, is not so clearly military in character, but military associations are not remote. ${ }^{33}$ The martial associations of the ark and of the procession serve to keep the cultic procession from constituting a completely heterogeneous element in the conquest story. The cultic procession retards movement toward the military climax of the story but does not deny the martial character of the event at Jericho. The movement toward conquest established at the beginning of the narrative by the description of the fortified city is not completely halted by the procession. The procession itself has martial associations and so, we presume, is somehow related to the goal of conquering Jericho, although that relationship is not immediately clear.

The ark and the procession that accompany it enter into a rich and still somewhat puzzling relationship with the military plot line building toward a climax in the fall of the city. They also establish a pattern of associations with other narratives, associations that take us outside the immediate context and deepen our understanding of what occurs at Jericho. The closest association is with the crossing of the Jordan, a miraculous event that immediately precedes Israel's arrival at Jericho. In both episodes the ark, borne by priests, is the center of a procession made up of all Israel. At the Jordan when the soles of the feet of the priests bearing the ark touch the water, the river stops its flow and the people are able to pass through on dry land. There are differences in detail be-

32 R. SCHMITT [A.31] 131-138, presents an excellent discussion of scholarly efforts to conceptualize the identification of the ark with the Lord, from the ark as fetish to Paul Tillich's understanding of symbol. However helpful the exercise, the imperfect fit between abstract conceptualization and narrative rendering illustrates the differences and distance between the two modes of understanding reality.

33 See Num 10:25; Is 52:12 
tween the two processions. The horns and other auditory phenomena so prominent at Jericho are missing at the Jordan. Yet the procession around Jericho seems a continuation of the procession through the Jordan. ${ }^{34}$ The relationship is very close and specific. Before Israel crosses the river Joshua explains the significance of what is about to happen. Stopping the flow of the river is a sign and promise that all the land of Canaan will be given to the people Israel (Jos 3:7-13). The procession of the ark around Jericho is now part of the fulfillment of that sign and promise. Crossing Jordan and marching around Jericho, although separate events, are to be seen as sequential parts in a single larger event, the conquest of the whole land.

The associations begun with the crossing of the Jordan extend further. The crossing of the Jordan is itself related typologically to the crossing of the Reed Sea (Ex 14). God cuts off the waters of both sea and river, so that Israel may pass out of Egypt and into Canaan on dry land. Exodus from Egypt and crossing the Jordan into Canaan, although discrete, form acts in a larger drama which, it is now apparent, includes the conquest of Jericho as its next decisive moment. Jericho's significance is the place it assumes in this continuing story of deliverance and promise.

The instruction for the ceremonial procession and the description of its execution are undeniably confusing. The auditory phenomena, blowing horns and mighty shout, contribute much to this confusion. Should the horns be blown continually as the people circle the city (Jos $6: 4,8,9,13$ ) or does the procession move in somber silence (Jos 6:10)? Who blows the horns? The priests? The armed men? The rear guard? The complexity is of such a magnitude that it resists resolution into consistent strands, as WILCOXEN and SEIDEL attempted. Yet the complexity is not so entangled that it defies literary interpretation. Just the opposite. Precisely those elements of the text that cannot be read as mutually consistent descriptions of a real event force the reader to seek literary explanations. In Jos 6 the literary significance of the auditory phenomena is nearly transparent. The complexity is largely a matter of the horns doing double duty. On the one hand the horns serve a cultic, ceremonial function, accompanying the ark as it circles the city. Other biblical passages make this cultic function familiar. The sôpar sounds on each new moon and festal day (Ps 81:4). The sôpar is heard continuously as David conducts the ark to its new home in Jerusalem (2 Sam 6:15). Most revealingly, at Mt Sinai the sound of the sopar indicates God's presence on the moun-

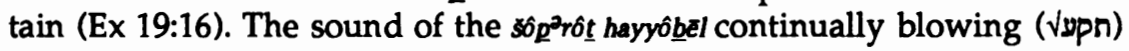

34 The connection of Jos 6 to Jos 3 rests squarely on the centrality of the ark in both processions. It is striking that all four variant terms for the ark found in Jos 6 also occur in Jos 3 and nowhere else in conjunction with one another in the Bible. In Jos 3:13 the apposition * dón kdl hr'aress is added to the *rôn YHWH of Jos 6:6,7,11, etc, but the other terms are perfectly parallel. 
is the proper cultic accompaniment to the ark as it is carried around Jericho. On the other hand the horn serves in Jos 6 as a signal, a quite distinct function. At the climactic moment the horn sounds, signalling the people to raise a great shout, and the walls collapse (Jos 6:5,16). This signalling function is also well attested elsewhere in the Bible. Horns often served as signals, particularly in warfare, to muster troops to battle (Jud 3:27; 1 Sam 13:3) or to recall them (2 Sam 2:28). The ceremonial and signal functions of the horns are clearly distinct from one another and are used in distinctively different ways in Jos 6 . Little regard is paid to the fact that the two functions stand in some tension with one another. The continuous playing of the horns appropriate to the cultic function would, in an actual event, interfere with their usefulness as a signal at the climactic moment. That is obvious. And obviously of little account. The horns in Jos 6, it must be seen, are not employed in the narrative as accurate descriptions of an event but as literary figures to characterize the cultic and climactic nature of different moments in the event.

The horns in Jos 6 go beyond their use as figures to still more central matters. The climactic moment at Jericho is the instant the walls fall. Every detail leads to this moment, yet in the narrative there is a remarkable reticence to describe what takes place. No weapon is hurled against the walls, nor is there movement from the line of march, save after the walls have fallen. The narrative shrouds the crucial moment from direct examination. The nature of the climactic moment must be inferred from the details that are given and, in guiding this inference, the horns play an important part.

The climactic destruction of the walls is anticipated in Jos 6:5, as the people are instructed to blow a long blast on the horn and raise a great shout at the appropriate instant. It is striking that the phrase used for

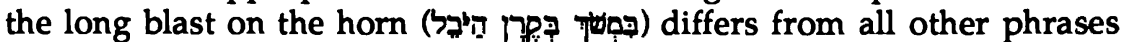
for the playing of the horn in Jos 6, so that the phrase attracts attention. Although the complete phrase does not appear in exactly this form else-

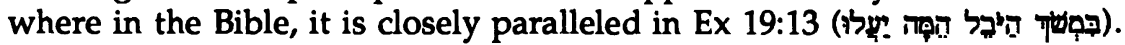
Only the term qeren is missing. The allusion to Mt Sinai is unmistakeable - and instantly illuminating. As at Mt Sinai the people are assembled before the holy place (Jos 5:13-15). As at Mt Sinai the long blast is the signal for their ascent (Vivin, Ex 19:13; Jos 6:5,20) into the sacred precincts. ${ }^{35}$ The nature of the climactic moment, the allusion suggests, is also the same: a theophany in which all the people participate by going up to the city in good order (1) Whe summoned by the horn. The destruction of the city, we are to understand, occurs at the moment of God's theophanic appearance at Jericho.

35 On פלה a a technical term for the ascent to a shrine, see H.W. HERTZBERG, Die Bücher Josua, Richter, Ruth, ATD 9; Göttingen: Vandenhoeck and Ruprecht, 1953, 44. 
The blast on the horn which constitutes the call for the people to go up to the theophany serves simultaneously as a signal for another

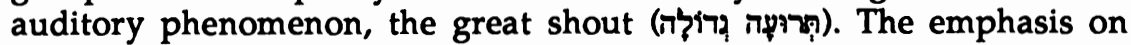
the shout is particularly strong in Jos 6:20, the moment when the walls actually fall. It would be wrong to think of this shout as a spontaneous uproar, a response to the spectacle of the walls collapsing. ${ }^{36}$ The shout comes before the walls fall and is carried out pursuant to specific instructions given in advance. It is a ritual act. The nature of that ritual act is not explicitly given, but the erúsh has rich military associations. ${ }^{37}$ The truses is a war cry as the warriors draw up the battle line (1 Sam 17:20) and the victory shout as the tide decisively turns (1 Sam 17:52). The Prûcah raised at Jericho certainly has this martial character, marking both the moment of attack and the moment of decision as the same moment. Yet it is possible to see the trûch in a still more illuminating light by again referring to 1 Sam 4 . When the ark is brought from Shiloh into the

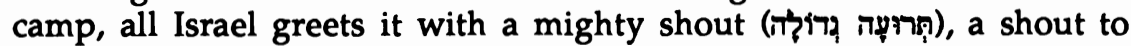
shake the earth. The erusth has a double character. It is a war cry, as the champion enters the camp to do battle with the enemy, and, simultaneously, a cultic or ceremonial shout, a joyous acclamation of God's presence in the camp. The double character of the Prust is unified by the figure $\mathrm{YHWH}$, who is at once God of Israel, center of the cult, and warrior God summoned to fight for Israel.

At Jericho the cultic and martial associations of the reructh again come together in a manner that both helps define the climactic moment when the walls collapse and finally draws together the military and cultic strands in the narrative. The Prúcah is at once the acclamation of God's theophany and a war cry as the divine warrior enters battle. The climactic moment toward which the narrative has moved from the beginning is, surprisingly, not a set battle but a theophany of God at Jericho, a theophany that has direct military consequences. There are not two separate events at Jericho, a theophany and a battle. There is but one event, a theophany which captures the city. The indirectness of the narrative has carefully built to this conclusive instant, mixing cultic preparations and military associations in the only way that could adequately depict the full nature of the capture of the city. Seeming inconsistencies and contradictions in the narrative are not marks of fundamental incoherence, but the literary means to present a deeper coherence.

A final significant note needs to be recorded before considering the continuations of the story. Although Israel undertakes nearly all the observable activity at Jericho, it plays precisely no military role in the conquest of the city. Israel forms a guard of honor while God deals with the

36 P. HUMBERT, Le terou'a: Analyse d'un Rite Biblique, Neuchatel: Universite de Neuchatel, 1946, 11, argues that trútsh is never used in the Bible for a spontaneous shout, but always represents a ritual action.

37 P. HUMBERT [A.37] 29-30. 
city in that magnificently nondescriptive moment in which the walls fall. The procession around the city has been fitting preparation for the theophany but without direct military consequences. Even when Israel enters the city it is not as conquering army rushing through breached walls but as cultically prepared people going up to the place of theophany. The city falls to God alone.

Jericho falls to God alone but it is destined for Israel. As Israel stands encamped before the closed and fortified city, God says, "I have given Jericho into your hands." Joshua recalls those words as he gives the command for the great shout that accompanies the fall of the city walls, "Shout, for the Lord has given you the city." God alone captures the city, but Israel takes possession of Jericho; it is given into Israel's hands. Jericho becomes the first enclave to come into Israel's possession in the land of Canaan, which God promised to give in its entirety to Israel. That promise was first given to Abram, who leaves his land on the strength of a promise (Gen 12:1-9). Each generation received a renewal of the promise of land, a promise that is prolonged and delayed by slavery in Egypt and wandering in the wilderness, but is renewed once again on the banks of the Jordan (Jos 3:10). There is no explicit connection between the fall of the city of Jericho and the promise to Abram. The narrative does not bind Jos 6 to Gen 12 through express reference to the promise nor by the sort of typological allusion which exists to the theophany at Mt Sinai. The capture of Jericho recalls God's promise to Abram: "To your descendants I will give this land" (Gen 12:7), by the subtlety of Israel's exclusion from the conquest of the city. God will take this land and God will give it to the descendants of Abram.

The Jericho narrative reaches its climax at the moment the walls collapse. That is already a crowded moment, so many previous actions rushing to a common point. But just at the crisis, after Joshua has given the command to shout, the climax is interrupted by a new set of detailed instructions. Everything in the city is to be destroyed except Rahab, the harlot who shielded the spies, and her family. Israel further receives a stern warning against taking any of the articles slated for destruction and provision is made to place metals that cannot be burnt in the treasury of the Lord. Only after these protracted instructions do the horns blow, the people shout, and the city walls fall. The moment only becomes more crowded.

Striking, even shocking, about Joshua's new instructions is their utter extremity. Every living creature is to be killed, every product burned, all are to become heræm, the technical term for such proscribed material. The totality of the ban is extreme even by biblical standards in which the total destruction of captured cities, their inhabitants, and pro- 
perty is often required practice. Other passages soften the requirement. In Dtn 7 and 20, two legal sections that require the destruction of captured cities, the extremity is softened by rationalizing the herem: The inhabitants of Canaan would lead Israel into the worship of alien gods. The herem is a preventative measure. Or in Dtn 2:34f and 3:6f the kingdoms of Sihon and $\mathrm{Og}$, east of the Jordan, are herem, but Israel takes the cattle and other spoils for its own use. Jos 6 does not soften the heræm or entertain exceptions, save in the case of Rahab, for due cause.

It is perhaps troubling to report that the extremity seems somehow appropriate in Jos 6 . In all respects the conquest of Jericho is a radical intervention by God. The radical nature of the herem, the total annihilation of everything in the city, is, in a sense, qualitatively coherent with the event itself. That sense of coherence needs to be explored.

Joshua prefaces his specific instruction to destroy everything in Jericho by a general statement that the city and everything in it is devoted to the Lord (m) ליד, Jos 6:17). "Devoted to the Lord" here seems to indicate a special status, a special relation to the Lord which serves as the grounds for the specific instructions to destroy everything. ${ }^{38}$ The special status is understood very concretely. Israel is warned to take particular caution against contact with the herem, lest Israel become herem by the contact and itself subject to destruction.

Aid in understanding the nature of perem best begins with another story, 1 Sam 15, the turning point in Saul's kingship. Saul receives a commission from the Lord to destroy totally (2) the Amalekites in retribution for their obstruction as Israel passed through their territory on the way to Canaan. The Amalekites had hindered the fulfillment of God's promise. Saul mobilizes his forces, crushes the Amalekites, puts all survivors to the sword (except their king), but fails to destroy the best of the sheep and cattle. When the prophet Samuel confronts him for failing to carry out the ban, Saul protests that he intended to sacrifice (r) the animals to the Lord. Samuel finds that answer provoking rather than satisfactory and Saul's intent to sacrifice the animals rather than submit them to the heræm becomes the grounds for stripping the kingship from him.

Everything rests on the distinction between sacrifice and heræm. Sacrifice lies within Saul's control. It is the offering of one's property to God and that is a pious act. But material devoted to heræm lies outside Saul's control, neither belongs to him nor is in any way at his disposal. It is God's by virtue of the herem, not Saul's by virtue of ownership. Saul loses his royal title for failing to understand the distinction.

Jericho and everything in it is herem PYHWH, devoted to the Lord. By virtue of God's purposes to give Israel the land, by virtue of the theophany at the city, by virtue of the place being holy ground, Jericho is so-

38 N. LOHFINK, "תרם" ThWAT 3 (1982) 196-197. 
lely and radically related to the Lord. Israel has no claim on the city, no ownership, and its relationship to Jericho is defined by negation; Israel cannot possess what stands so directly related to God. The extremity of negation which herem represents emphasizes the exclusiveness of God's activity at Jericho. The placement of the new instructions at the precise instant before the city falls serves once again to interpret the event as the sole activity of God.

The command to destroy the city admits one exception, Rahab and her family. Rahab is exempted from the general destruction because of her conspicuous service to Israel in concealing the spies sent to search out the city. The spies promised Rahab that she and her family would be spared if she concealed them. Joshua now gives explicit instructions that their promise be honored.

Many commentators on the book of Joshua have noticed that spying out Jericho plays no part in the conquest of the city as it is reported in Jos 6.39 Spies report on weaknesses in defenses and therefore anticipate a military siege and attack not reported in Jos 6 . It is therefore sometimes held that little connects the account of Rahab and the spies with the narrative of the fall of the city. It may be readily agreed that a connection between the spy story and the fall does not exist at the level of military tactics. The story of Rahab and the spies does not prepare the attack on the city. It prepares the survival of one of the families of the city. Amid the total destruction of Jericho, one family survives and, we are told, dwells in the midst of Israel "to this day" (Jos 6:25).

The survival of Rahab and her family, the true import of the spy story, provides an important counterpoint to the promise of land which the fall of Jericho fulfills. When God promised Abram a land, God also promised that "By you all the families of the earth shall bless themselves" (Gen 12:3). God's promise to Abram was not exclusive but embraces, in a manner left obscure, all the families of the earth by virtue of their relationship to Abram and his descendants. The promise to associate other families with the promise to Abram is not an isolated gesture, an afterthought. Its repetition in succeeding generations, four times in Genesis $(18: 18 ; 22: 18 ; 26: 4 ; 28: 14)$, indicates that the inclusion of other peoples in God's blessing is an integral part of the promise. The survival of Rahab and her family fulfills this promise to all the families of the earth.

The other families of the earth become associated with God's promise in odd ways. The people of Gibeon, a city in Israel's path, for instance, hear of Israel's victory at Jericho and devise an elaborate ruse to trick Israel into entering into a treaty (Jos 9). It works. Although by all rights Gideon should have shared the fate of "the Canaanites, the Hitti-

39 G. HÖLSCHER, "Zum Ursprung der Rahabsage," ZAW 38 (1919-20) 54 ff.; M. NOTH [A.7, Josua, 18]; K. MÖHLENBRINK [A.9] 258f; S. MOWINCKEL [A.16] $13 f$. 
tes, the Hivites, the Perizzites, the Girgashites, the Amorites, and the Jebusites," Gideon is preserved by a trick. Its destiny becomes linked to Israel. Rahab is drawn into the promise because she is able to see which way the wind blows. Everyone in Jericho sees the same things as Rahab, God's delivering Israel from Egypt, defeating the two kings of the Amorites (Jos 2:9-11).40 Everyone trembles and adds a stouter bar to the gate. Except Rahab. Rahab, that prescient woman, alone recognizes the work of God and where it tends. When the spies appear at her door, she throws in her lot with the bearers of the promise. In fact, she bargains hard, trading cooperation with the fulfillment of the promise in return for a share. The promise is not a theological abstraction that might be captured by set phrases, but is just such a bargain as Rahab strikes to bring her and her family into the midst of Israel "to this day."

The intrusion of new instructions concerning the herem into the crucial moment before the city's fall provides an opportunity for the positive conclusion of Rahab's story. It also opens onto more ominous events. The people are to be especially careful with the devoted things, appropriating nothing from the herrem for their own use, lest they themselves become herem, a chilling prospect. This stringent prohibition generates a story. Achan, one of the Israelites, took a few paltry items from among the devoted things and hid them in his tent. An air of fatality accompanies the report of his theft. The recent prohibition magnifies a trifle. Massive consequences follow. When Israel undertakes to continue the conquest of Canaan by attacking $\mathrm{Ai}$, they fail utterly, and are thrown back in headlong flight. By a wholly characteristic train of thought, military disaster reveals the transgression against God. God then directly reveals the nature of the transgression and a judicial inquiry conducted by sacred lot identifies Achan as the culprit. In a moving exchange with Joshua, Achan confesses his action and he and his family are lead away to execution.

Disproportion is the heart of this story. Achan's flight from the prohibition against taking the hæræm lands him in a great web. Achan, God says in accusation, has transgressed the covenant and done a shameful thing (Tit) in Israel. The terms of the accusation are ominous. In Jud 19-21, an equally horrifying story, the rape of a Levite's concubine is repeatedly characterized as a $n^{2} \underline{b} \mathbf{I}$ tah (Jud 19:23,24; 20:6,10). Again, an isolated crime against a single individual threatens the whole people. Benjamin is nearly eliminated as a tribe when all the other tribes rally to the Levite's cause. Consequences grow out of all proportion. All

40 For detailed analysis of this section see L. STONE, "Ethical and Apologetic Tendencies in the Redaction of the Book of Joshua," CBQ 53 (1991) 28-29. STONE sees clearly an apologetic intention to make the fate of the Canaanites dependent on their recognition of YHWH's power, a theme that might also be brought into the interpretation of the fall of Jericho, but does not connect the preservation of some of the Canaanites with the theme of promise. 
Israel rising to the defense of the Levite is not an act of spontaneous outrage, although the crime is despicable beyond endurance. The tribes are obligated to respond. Dispersed throughout Israel because of their priestly functions, without a territorily unified tribe to protect them, Levites require and receive the protection of all the tribes. To injure a Levite is a $n^{2} \underline{b}$ alah, an offense that directly involves all the tribes, an offense of the most grave proportions. Achan's $n^{2} \underline{b} a l s h$ achieves similar proportions. A few items from the heræm, chosen by fancy, buried in the heart of the camp.

The crime is also characterized as transgression of the covenant. We naturally think of the Ten Commandments and the prohibition of theft. But if Achan's crime is simple theft, the disproportion remains unexplained. The punishment exacted on Achan and his family goes well beyond any biblical sanction for theft. We come further with a suggestion by Norbert LOHFINK that Achan's offense is transgression against the first commandment, the command to honor God alone.41 Jos 22 certainly understands Achan's offense this way. Achan's example is there invoked against the Reubenites, Gadites, and half tribe of Manasseh, who collectively have fallen into false forms of worship. Achan's fate would prove a caution to the most obdurate. Remember, the Israelites whisper to their straying kin, "He did not perish alone for his iniquity." (Jos 22:20). Achan's crime is equated with the apostasy of the trans-Jordan tribes.

Achan's theft is failure to honor God not just because theft from God constitutes lese majeste. The seriousness of the theft is not compounded because the material stolen belonged to God. The immense seriousness of the theft lies in its implications. If Achan (and Israel, by extension) took the spoils, then Achan and Israel conquered the city. To the victor belongs the spoil. Hail Achan, conqueror of Jericho. Achan's beautiful mantle, two hundred shekels of silver, and bar of gold deny God the victory. By a chain of inexorable implication, the theft denies God's presence at Jericho, denies that Jericho fell to God's power, denies, finally, that God is a faithful God who gives Israel the land in fulfillment of promise. Achan fails to honor God in the most absolute manner, by denying God a place in Israel's story. This is breach of covenant indeed and it places all Israel in jeopardy until the threat is completely rooted out. The heart of Achan's story is the disproportion. It is not, however, the disproportion between crime and punishment, which only reveals the truly profound disproportion between Achan's trifling theft and the near absolute negation of God's action at Jericho.

Achan's story begins at the moment of triumph at Jericho and is a commentary on that triumph, a commentary in the form of a negative sequel. Achan's story is not a continuation of the conquest of Jericho as

41 N. LOHFINK [A.38] 198. 
it is so carefully narrated in Jos 6 . The expected continuation of the Jericho story would have been the uneventful capture of $\mathrm{Ai}$, perhaps the account presently found in Jos 8:1-29, followed by the capture of the remainder of the promised land of Canaan. Achan's theft interrupts that expected continuation; its force is precisely its failure to continue the story of the triumph at Jericho. Ai cannot be taken because Achan has displaced God as the central character of the narrative. Achan's story therefore leads to the only conclusion possible, to its own negation. Achan's version of the capture of Jericho comes to a definitive close, stoned and buried in the Valley of Achor. It has no sequel, no continuation. With the denial of Achan's counter-narrative, the story of Jericho can return to its proper continuation, to the conquest of $\mathrm{Ai}$ and the remainder of Canaan, and to God's distribution of the land to the tribes as an inheritance, according to the promise to Abraham.

\section{VI}

Jos 6 is a complicated text. There can be no disagreement on this. But it is far from an unintelligible text. All significant literary texts, including Jos 6 , require the reader to integrate a panoply of literary features into a comprehensible synthesis. In Jos 6 simply the major literary features requiring integration include:

1) a variation in semantic field between military and cultic language. Some images in the passage seem strictly military in character, some strictly cultic. Other images - the ark, or the horns and the shout, for instance - have dual associations, while still others, the first instructions for the procession, move from one semantic field to the other;

2) a retarding element that interrupts the directness of plot development from laying siege to final capture of the city. Because final victory is assured, the delay represented by the procession does not heighten tension, a common result of retarding the plot. Rather, it raise the question of the nature of the event taking place at Jericho;

3) remarkable compression of the climactic moment. Nearly all the literary features of the narrative are focused on this one point. The retarding element represented by the procession ends here. The tension between military and cultic imagery is resolved by the theophany of the warrior God. The plot reaches its climax in the city's fall. The two interpretive stories of Rahab and Achan explicitly begin within this crucial moment. Nearly all the action and imagery in the passage either begins or ends in this single instant. And yet, most remarkably, the crucial moment is undefined. The narrative refrains from explicit description of its climactic moment;

4) allusive and loose thematic relations to other biblical texts. Even the strongest allusion, to the theophany at Sinai, is a matter more of similar context and action than explicit citation of the earlier text. The re- 
lationship between Jericho and the theme of promise is largely a matter of seeing how God's exclusive activity in capturing the city or Rahab's preservation and association with Israel fits the expectations raised by the earlier promise passages. Intertextual relations are notably understated; and

5) avoidance of explicit commentary interpreting events. Rather than stepping outside of the narrative mode to interpret the meaning of the event at Jericho, the text adds narratives: the encounter with the captain of the host, Rahab's story, and the account of Achan's theft even the procession around Jericho might be seen as commentary on the capture of the city. Narrative interprets narrative with a richness unattainable in explicit commentary.

Each of these features disrupts an uncomplicated reading of the story of the fall of Jericho, a simple following of a simple plot. That is precisely their function. By forcing us to abandon a straighforward reading of the fall of Jericho as a simple conquest tale, they lead us to a higher level synthesis of the significance of events at Jericho than the simple plot line offers. ${ }^{42}$ The narrative is the story of the fall of a city. Indeed. That fact is never lost from sight. But how thin and pale that synopsis appears next to the fullness of the event revealed by the literary intricacy of the narrative. Even the complexity of the literary structure of this passage is scarcely adequate to what it has to convey: the faithfulness of a God who brings Israel to a land in fulfillment of promise.

42 The literary theorist M. RIFFATERRE, Semiotics of Poetry, Bloomington: Indiana University Press, 1984, 2-22, calls such disruptions of a text "ungrammaticalities," using a linguistic metaphor. By preventing reading from continuing at the same level, "ungrammaticalities" force the reader to a higher level synthesis. RIFFATTERRE's remarks point to the decisive difference between historical critical interpretation and literary interpretation. For historical critical analysis such "ungrammaticalities" are evidence of a composite text and lead to division. For literary analysis they are the signs and warrants of a higher order of integration of the text. 



\title{
DIE LANDVERHEISSUNG AN DIE VÄTER ALS EINFACHE ZUSAGE, ALS EID UND ALS "BUND"*
}

\author{
von \\ Josef Scharbert \\ München
}

\begin{abstract}
Der Kollege, dem diese Festschrift gewidmet ist, hat durch seine Arbeit über das Bundesformular die Diskussion um den "Bund" im Alten Testament in neue Bahnen gelenkt, indem er ein "Bundesformular" erschloß, welches das AT mit dem Vertragsformular altorientalischer Völker gemeinsam hat ${ }^{1}$. Seine Ausführungen zu Segen und Fluch innerhalb jenes Formulars waren der Anlaß dazu, daß der Verfasser dieses Beitrags mit ihm brieflichen Kontakt und bald auch freundschaftliche Verbindung aufnahm, die bis heute andauert. In der weiteren wissenschaftlichen Diskussion um den Bundesgedanken trat das Interesse am Bundesformular stark zurück und konzentrierte sich auf die Frage, ob der deutsche Terminus "Bund" überhaupt die angemessene Wiedergabe des hebräischen Ausdrucks borit ist, wie man bisher annahm ${ }^{2}$. Trotz mancher Differenzierungen blieben die meisten Exegeten
\end{abstract}

\footnotetext{
* In IATG nicht vorkommende Abkürzungen: EÜ: Einheitsübersetzung der Heiligen Schrift, NEB: Neue Echter-Bibel, Würzburg, SBAB: Stuttgarter Biblische Aufsatzbände.

1 K. BALTZER, Das Bundesformular, WMANT 4, Neukirchen-Vluyn 1960, 21964, engl.: The Covenant Formulary in Old Testament, Jewish and Early Christian Writings, ed. D.E. GREEN, Oxford 1971. Fast gleichzeitig mit dieser Arbeit erschien die deutsche Ausgabe von G.E. MENDENHALL, Law and Convenant in Israel and the Ancient Near East, Pittsburg 1955: Recht und Bund in Israel und dem alten vorderen Orient, ThSt(B)14, Zürich 1961. Aus der Wirkungsgeschichte dieser beiden Untersuchungen sei erinnert an: D.J. MCCARTHY, Treaty and Covenant, AnBib 21, Rom 1963, 21978; F. NÖTSCHER, Bundesformular und Amtsschimmel, BZ NF 9 (1965) 181-214; J. L'HOUR, La morale de l'Alliance, CRB 5, Paris 1966; deutsch: Die Ethik der Bundestradition im Alten Testament, SBS 14, Stuttgart 1967; P. KALlUVEeTTIL, Declaration and Covenant, AnBib 88, Rom 1982; Th.E. MCCOMINSKEY, The Covenant of Promise, Grand Rapids 1985 - Nottingham 1987; J. VERMEYLEN, Le Dieu de la promesse et le Dieu de l'Alliance, LeDiv 126, Paris 1986; A.S. KAPELRUD, The Covenant as Agreement, ScandJOT 2/1 (1988) 30-38; R. DAVIDSON, Covenant and Ideology in Ancient Israel, in: R.E. CLEMENTS (ed.), The World of Ancient Israel, Cambridge (UK) 1989, 323-347; D.J. MCCARTHY, Covenant Relationships, in: C. BREKELMANS (éd.), Questions disputées d'Ancien Testament, BEThL 33, Leuven 21989 , 91-103 und 214-216.

2 Nachdem bereits J. BEGRICH, Berit, ZAW 60 (1944) 1-11, jetzt in: DERS., Gesammelte Studien zum Alten Testament, TB 21, München 1964, 55-66, und A. JEPSEN, Berith, in: FS W. RUDOLPH, Tübingen 1961, 161-179, jetzt in: DERS., Der Herr ist Gott, Berlin 1978, 196-210, entsprechende Zweifel angemeldet hatten, nahm E. KUTSCH in einer Reihe von Aufsätzen seit 1967 einen leidenschaftlichen Kampf gegen die Wiedergabe von $b^{a}$ rît mit
} 
des AT beim Begriff "Bund"3. In letzter Zeit verlagert sich der Schwerpunkt der Diskussion wiederum, und zwar auf die Frage nach dem $\mathrm{Al}$ ter der Bundesvorstellung im AT und im Zusammenhang damit auf die Frage nach dem "Väterbund" bzw. auf die Frage nach dem Wesen der "Väterverheißung"4. Diesem Thema soll dieser Beitrag gewidmet sein. Bei der Auswertung der betreffenden Texte scheint sich eine überlieferungsgeschichtliche Entwicklung von einer einfachen Zusage Gottes an die Erzväter über die Vorstellung von einem Eid Gottes bis zum

"Bund" auf, die zusammengefaßt sind in: DERS., Verheißung und Gesetz, BZAW 131, Berlin 1973, ferner DERS., Gottes Zuspruch und Anspruch, in: C. BREKELMANS (éd.), Questions disputées d'Ancien Testament, BEThL 33, Leuven 21989, 71-89 und 213f; Neues Testament - Neuer Bund? Neukirchen-Vluyn 1978; "Ich will euer Gott sein", ZThK 71 (1974) 361-388, u.a. - Zur Diskussion mit E. KUTSCH: J. SCHARBERT, "Berît" im Pentateuch, in: FS H. CAZELlES I, Paris 1981, 163-170; S. HERRMANN, "Bund" eine Fehlübersetzung von b rît?, in: DERS., Gesammelte Studien, TB 75, München 1986, 210-220; R. WONNEBERGER - H.P. HECHT, Verheißung und Versprechen. Eine theologische und sprachanalytische Klärung, Göttingen 1986; R. RENDTORFF, "Covenant" as a Structural Concept in Genesis and Exodus, JBL 108 (1989) 385-393; N. LOHFINK, Der Begriff "Bund" in der biblischen Theologie, ThPh 66 (1991) 161-176.

3 Außerhalb der deutschsprachigen Literatur bleibt man allgemein bei "covenant", "alliance", "aleanza", "przymierze" u. dgl. Die Jahrestagung der deutschsprachigen katholischen Alttestamentler 1991 in Augsburg stand unter dem Generalthema "Bund", wenn auch dabei durchaus die Problematik des Begriffs gesehen wurde; die Referate werden demnächst in QD veröffentlicht.

4 Seitdem L. PERLITT, Bundestheologie im Alten Testament, WMANT 36, NeukirchenVluyn 1969, nachzuweisen versucht hat, daß die atl. Bundesvorstellung erst im Dtn oder gar erst in der deuteronomistischen Bewegung entstanden ist, wird neuestens auch die Vorstellung von der Väterverheißung bzw. vom "Väterbund" erst der deuteronomistischen Bewegung zugeschrieben, vgl. insbesondere M. KÖCKERT, Vätergott und Väterverheißung, FRLANT 142, Göttingen 1988, und Th. RÖMER, Israels Väter, OBO 99, FribourgGöttingen 1990.- Daß die Vorstellung von einem "Bund" mit den Vätern sehr viel differenzierter zu betrachten ist als es KÖCKERT und RÖMER getan haben, hat jüngst N. LOHFINK, Bundestheologie im Alten Testament. Zum gleichnamigen Buch von Lothar Perlitt, SBAB 8 (1990) 325-362, und: Der Begriff "Bund" in der biblischen Theologie, ThPh 66 (1991) 161-176, gezeigt; in einem Brief an mich 1991 kündigt er dazu eine eingehende Untersuchung in OBO an. Die dort angekündigte Stellungnahme zu Th. RÖMER ist mit einem Nachtrag von Th. RÖMER erschienen: N. LOHFINK, Die Väter Israels im Deuteronomium. Mit einer Stellungnahme von Thomas Römer (OBO 111) Freiburg/ Schweiz Göttingen 1991, in der LOHFINK die Dtn-Texte mit einem Eid Jahwes an die Väter so versteht, daß der Eid Abraham, Isaak und Jakob geleistet wurde, und die Erwähnung der namentlich genannten Erzväter im Dtn nicht als spätere Einträge, sondern als ursprünglich zum Dtn-Text gehörend ansieht; RÖMER dagegen bleibt bei seiner in OBO 99, 1990 vertretenen Auffassung. Unterdessen ist die Arbeit von Suzanne BOORER, The Promise of the Land as Oath (BZAW 205), Berlin 1992 erschienen; sie hält die Verheißungstexte in Ex und Num für vordeuteronomisch (Ausnahme nur Num 32,11, nachdtr.) und betrachtet die "Väter" in den Verheißungstexten, auch in $\mathrm{Dtn}$, als die Patriarchen. - Ob die jüngst angekündigte Arbeit von zu diesem Thema von M. WEINFELD, The Promise of the Land (Taubman Lectures in Jewish Studies 3, Berkeley) bereits erschienen ist, entzieht sich meiner Kenntnis. 
Theologumenon eines "Bundes" Gottes mit den Erzvätern Israels abzuzeichnen. Dabei soll hier vorwiegend der Aspekt der Landverheißung in das engere Blickfeld genommen werden, während die Nachkommenverheißung nur soweit berücksichtigt wird, als diese mit der Landverheißung eng verbunden ist. Auch wird nur der Tetrateuch und die deuteronomisch-deuteronomistische Literatur in Betracht gezogen.

\section{DIE LANDVERHEISSUNG ALS EINFACHE ZUSAGE AN DIE ERZVÄTER}

Als die wichtigsten Landverheißungstexte gelten die Gen-Stellen 12,6f; 13,14-17; 15,17-20 mit Abraham, 26,2-4 mit Isaak und 28,13 und 35,11f mit Jakob als Adressaten. Diese Stellen wurden in der klassischen Pentateuchforschung bis in die letzten Jahrzehnte hinein den vorpriesterlichen Pentateuchquellen J, E oder JE zugewiesen. Dabei nahm man immer auch an, daß die sog. Quellenautoren selbst wieder ältere Traditionen verarbeitet haben. Da jeder der drei Erzväter seinen "Haftpunkt" in einem eng umgrenzten Gebiet zu haben scheint, Abraham um Hebron-Mamre, Isaak im Negeb zwischen Gerar und Beerscheba, Jakob im samaritanischen Bergland zwischen Sichem und Bet-El, und offensichtlich erst sekundär in das genealogische Schema Vater-Sohn-Enkel eingeordnet wurde, ist anzunehmen, daß jeder der drei Erzväter einst Eponym oder "Stammvater" eines Clanverbands war, der seine Ansprüche auf sein Siedlungs- bzw. Weidegebiet auf eine Zusage seines VaterGottes an den Stammvater gründete. Diese Annahme legt sich auch deshalb nahe, weil jeder der entsprechenden Verheißungstexte seine charakteristische, sonst nicht mehr vorkommende Formulierung hat, in der offensichtlich das zugesagte Land nicht ganz Kanaan, sondern ein wesentlich engeres Gebiet umfaßt. Diese "Urverheißungen" wurden durch spätere Tradenten, durch die "Quellenautoren", so erweitert und harmonisiert, daß die Zusagen an den "jüngeren" Stammvater als Wiederholung und Bestätigung der Zusage an den "älteren" erscheint und das verheißene Land jetzt ganz Kanaan umfaßt. Hier ist also einzusetzen, wenn wir die besondere sprachliche Form der ursprünglichen $\mathrm{Zu}$ sagen und ihre charakteristische Terminologie erschließen wollen.

Die kürzeste Landzusage steht in Gen 12,6f: Jahwe soll Abraham bei Sichem erschienen sein und gesagt haben: "Deinem Samen gebe ich dieses Land". Dieser Satz steht aber in einem traditionsgeschichtlichen Zusammenhang, nach dem Abraham bereits der Vater Isaaks und Großvater Jakobs gewesen sein und schon alle Orte besucht haben soll, die erst in der Jakoberzählung von Bedeutung sein werden. Das Land ist hier zweifellos schon ganz Kanaan. Der Text ist demnach aus der Reihe der "Urverheißungen" auszuscheiden.

Auszuscheiden ist auch Gen 15,17-20. Der Text ist quellenkritisch ungemein kompliziert, weist Merkmale später Formulierung auf und 
bezieht sich ebenfalls auf das ganze Land Kanaan, so daß auch für ihn eine lange Traditionsgeschichte anzunehmen ist.

Am ehesten kann Gen 13,14-17 zur Erschließung einer traditionsgeschichtlich alten Landzusage in Anspruch genommen werden. Nach der Trennung von Lot soll hier Jahwe zu Abraham "gesagt" haben ('ômer): "Heb deine Augen auf und blicke von dem Ort, wo du bist, nach Norden und Süden, nach Osten und Westen! Das ganze Land, das du überblickst, gebe ich dir und deinem Samen für immer". Die Wendung "und deinem Samen" klappt im hebräischen Text nach, so daß sie vielleicht erst sekundär eingefügt wurde. Die folgende Verheißung zahlreichen Samens ist bereits Angleichung an andere Verheißungen, die der Jahwist vorgenommen hat. Auch hat dieser die Landgabe bereits auf das ganze Land Kanaan bezogen. Die oben herausgearbeitete Landzusage ist aber offenbar in der Nähe von Mamre-Hebron erfolgt und betrifft ein Gebiet, das ein einzelner überblicken und in seiner ganzen Länge und Breite mit seinen Herden durchziehen kann; ganz Palästina, das freilich der Jahwist gemeint hat, ist dafür wohl zu ausgedehnt.

Eine ähnliche Verheißung soll nach Gen 26,2-4 Isaak erhalten haben. Er wird aufgefordert, in der Gegend zwischen Gerar und Beerscheba zu bleiben, und sein Gott weist ihm für diesen Fall Land an: "Bleib in diesem Land wohnen! Denn Dir und deinem Samen gebe ich alle diese

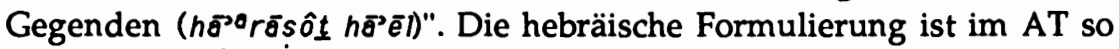
einmalig, daß sie die späteren Tradenten, als sie die Erzväterverheißungen einander anglichen, nicht $z u$ verwischen wagten; sie muß zum Grundbestand der Tradition gehört haben. "Alle diese Gegenden" sind wohl nur die ökologisch sehr verschiedenen Landschaften zwischen Gerar und Beerscheba, wo nach Gen 26,17-23 Isaak Brunnen vorfand bzw. grub, jedenfalls nicht ganz Palästina ${ }^{5}$. Alles andere sind wieder Angleichungen an andere Väterverheißungen, vorgenommen durch spätere Tradenten, vor allem durch den Jahwisten.

Komplizierter ist die Grundgestalt der Jakobverheißung in Gen 28,13-15. Jakob sieht, als er auf dem blanken Boden in der Nähe von BetEl schläft, Gott über sich stehen und hört ihn sagen: "Das Land, auf dem du liegst, dir gebe ich es". Der Flecken Land, auf dem Jakob schläft, ist doch wohl eine sehr kleine Fläche. Da ihm ein größerer Siedlungsraum zugewiesen werden soll, fährt Gott fort: "Du wirst aber durchbrechen

\footnotetext{
5 Für die Behauptung von E. BLUM, Die Komposition der Vätergeschichte (WMANT 57), Neukirchen-Vluyn 984, 299, "impliziert ist offenbar eine 'imperiale' Vorstellung von der

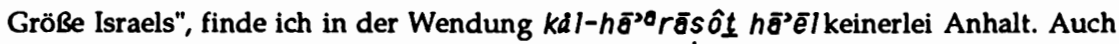
die Argumentation von K. BERGE, Jahvistens tid, Bergen 1985, 115-117, deutsch: Die Zeit des Jahwisten, BZAW 186, Berlin-New York 1990, 85f, die Wendung sei sehr spät, finde ich nicht überzeugend, weil die dafür angeführten Texte auf völlig anderen Voraussetzungen beruhen, vgl. N. LOHFINK, Die Landverheißung als Eid (SBS 28), Stuttgart 1967, 97, und A. DE PURY, Promesse divine et légend cultuelle dans le cycle de Jacob, I, Paris $1975,198 f$.
} 
nach Westen und Osten, nach Norden und Süden, und in dir werden alle Clanverbände des Ackerlands Segen erfahren"6. Damit wird Jakob als Stammvater eines um Bet-El siedelnden Verbands "Israel" ein Lebensraum zugesichert und ihm zugleich angedeutet, daß die Erweiterung seines Lebensraums über Bet-El hinaus für die dort lebenden anderen Verbände oder Ansässigen nicht von Nachteil sein wird, sondern daß es mit ihnen zu einer fruchtbaren Symbiose kommen wird7. Auch diese Zusage ist einmalig; eine gegenseitige Beeinflussung zwischen Gen 28,14b und 13,14 - wie gelegentlich vermutet wurde - ist nicht zu erkennen, da Wortlaut und Zusammenhang völlig verschieden sind. Auch hier hat erst ein späterer Tradent eine Angleichung an andere Verheißungen vollzogen ${ }^{8}$.

Alle diese drei "Urverheißungen" werden schlicht eingeleitet mit "Jahwe/Gott sagte"('ōmer). Auch die Landübergabe wird mit dem alltäglichen Verbum "geben" ( $n \overline{\bar{a}} \mathrm{t} a n)$ und der Präpositionalverbindung PKK $=$ "dir" bezeichnet; das $\hat{u}^{p} z a r^{\circ} \mathrm{K} \mathrm{Ka}=$ "und deinem Samen" gehört wohl nur in Gen 26,3 dazu; an beiden anderen Stellen klappt es syntaktisch nach und dürfte erst später ergänzt sein.

Der Jahwist hat, wie schon oben vermutet, Gen $12,6 \mathrm{f}$ in seine Geschichtsdarstellung eingefügt, hat die überlieferungsgeschichtlich primären Verheißungen, oder besser: Landübergaben, einander angeglichen, sie nach seinem genealogischen Schema zuerst Abraham, dann seinem Sohn Isaak und schließlich seinem Enkel Jakob gegeben sein lassen, hat das "Land" als das ganze Land Kanaan verstanden und dieses

${ }^{6}$ Man vergleicht diese Aufzählung der vier Himmelsrichtungen in der Regel mit der in 13,14 , als ob die beiden Texte dasselbe meinten und also der eine vom anderen abhängig sei; das ist aber m.E. ein Irrtum: 1) Die Aufzählung ist verschieden; 2) Abraham soll in die vier Himmelsrichtungen blicken, Jakob aber soll nach allen Seiten "durchbrechen"; 3) Abraham soll sich in einem relativ menschenleeren Land niederlassen, Jakob aber in einem dichter besiedelten, ohne deswegen mit der dort lebenden Bevölkerung in Konflikt zu geraten.

7 Vgl. dazu Gen 34,8-11.16-24.

8 Vgl. H. SEEBASS, Gehörten Verheißungen zum ältesten Bestand der Väter-Erzählungen? Bib. 64 (1983) 189-209; J. SCHARBERT, Verheißung als "Urgestein" der Patriarchentradition, in: FS M. DELCOR, AOAT 215, Kevelaer-Neukirchen-Vluyn 1985, 359-368, und DERS., Genesis 12 - 50, NEB, Würzburg 1986, 185f. - Im Anschluß an R. RENDTORFF, Das überlieferungsgeschichtliche Problem des Pentateuch, BZAW 147, Berlin 1976, 42-44, gesteht E. BLUM [A.5] 291 dem Grundbestand dieser Erzählungen, vor allem 13,14-17 und 28,13-15, wegen der "nichtformelhaften Formulierung" und ihrer "nicht abgegriffenen Formulierung der Landverheißung ... eine relativ frühe Gestaltung" zu; er sieht in 28,14a "den noch erkennbaren ältesten Kernbestand von Verheißungselementen", während er in den Richtungsangaben von 13,17 und 28,14 schon sekundäre Angleichungen der Verheißungstexte vermutet. Die Unterschiede sind m.E. aber doch so beträchtlich, daß man sie nicht einfach verwischen kann. Auch M. KÖCKERT [A.4] 318-321 weist zwar auf Unterschiede in den drei Verheißungstexten hin, beachtet aber dabei zu wenig gerade den Wortlaut der Landverheißung und nimmt darum an, daß "es sich in 12,1-37; 13,14-17 und 28,13 um e i n e Schicht handeln dürfte" (Sperrung von mir). 
noch nicht als ihnen übergeben, sondern als ihnen und ihren Nachkommen erst versprochen angenommen. Aber auch er ist bei der einfachen Aussage geblieben, Jahwe habe zu den Erzvätern "gesprochen". Das "Geben" des Landes, das in den Grundtexten in der erzählten Gegenwart erfolgt, soll nun erst dem "Samen", also den Nachkommen Abrahams, Isaaks und Jakobs, zuteil werden.

In Gen 26,2-4 ist allerdings umstritten, wieweit daran J beteiligt ist. Der Jahwist muß aber an dieser Stelle eine ähnliche Verheißung gehabt haben, weil auch für ihn Isaak der Sohn Abrahams und der Vater Jakobs ist. Diese Verheißung hat der Elohist, falls er der Autor einer selbständigen Pentateuchquelle ist, oder der Jehowist, falls er nur J "fortschreibt", überarbeitet. Dafür sprechen das nur in E-Texten vorkommende Hitpa"el der Wurzel brk = "sich segnen" bzw. "Segen erfahren" und die hier vorkommende Wendung hēqîm 'œt-høšš $\not \hat{u}$ ' Schwur in Kraft setzen" o.ä. in V.3, die J fremd ist. Sie hat ein deuteronomistischer Bearbeiter übernommen und mit der unten zu besprechenden Formel ${ }^{\circ}{ }^{\circ}$ šr nišbo $P$ N.N. lätēt $P$ N.N. = "den er geschworen hatte dem N.N., um ihm (das Land) zu geben" kombiniert ${ }^{9}$.

Gen 24,7 wird heute mit der ganzen Erzählung von der Brautwerbung für Isaak einem exilischen oder gar erst nachexilischen Tradenten zugeschrieben, ob zu Recht oder zu Unrecht, mag offen bleiben. Hier bezieht sich Abraham in seinem Auftrag an den Knecht zurück auf die an ihn ergangene Verheißung: "Jahwe hat mich aus dem Haus meines Vaters und aus meinem Heimatland herausgeholt und $\mathrm{zu}$ mir gesagt (dibbær): "Deinen Samen gebe ich dieses Land ". Das dazwischen stehende wosešær nišba $\hat{\imath}=$ "und der mir eidlich versichert hat" ist wahrscheinlich auszuscheiden. Die Verben dibbør und nišbo 'kommen in dieser Reihenfolge sonst nicht mehr vor. Hier muß ein Tradent mit dem einfachen "er hat gesagt" nicht zufrieden gewesen sein; er wollte die Zusage Gottes durch einen Eid Gottes stärker abgesichert wissen.

In Gen 26,2-4 und 28,13-15 haben J und E bzw. JE die Landverheißung mit der Verheißung zahlreicher Nachkommen und mit der Segensverheißung verbunden, so daß jetzt die Erzväter nicht nur das Land Kanaan, sondern - um es besiedeln zu können - auch zahlreiche Nachkommen erhalten sollen; sie erhalten ferner mit Rücksicht auf die in das Davidisch-Salomonische Reich und später in die getrennten Reiche eingegliederten Völker die Zusage, durch sie werden auch andere "Clanverbände" (bei J) bzw. "Völker" (bei E oder JE) Anteil am göttlichen Segen bekommen.

Eine einfache Zusage oder Absicherung durch einen Eid oder einen "Bund" ( $\left.b^{\partial} r \hat{i} t\right)$ innerhalb des Buchs Genesis findet sich noch in

\footnotetext{
9 Jer 11,5 und Gen 26,3 sind nicht so ähnlich, daß man ohne weiteres in Gen 26,3 auf dtn oder dtr Formulierung schließen kann, wie es oft geschieht.
} 
35,11f. Hier soll Gott bei einem zweiten Besuch Jakobs in Bet-El die Verheißung von Land an Abraham und Isaak erneuert haben, das er jenen bereits "gegeben hat" (n̄̄ton) und nun Jakob und seinem Samen "geben will" ('œt $t^{2} n \circledast n n \bar{h} h$ ). Voraus geht die Nachkommenverheißung, hier aber mit einem sonst nicht mehr vorkommenden Inhalt: "Eine Schar von Völkern" und "Könige" werden von ihm abstammen. In dieser Gestalt stammt der Text wohl erst vom Pentateuchredaktor, der die älteren Verheißungstexte mit der Mehrungszusage "Vermehre dich und sei fruchtbar" entsprechend seinem Geschichtsbild (vgl. Gen 36) kombiniert.

Der Gedanke, daß Jahwe "dir" - gemeint ist Israel - bzw. "den Vätern" das Land in einem schlichten Wort (dibbær, "āmer) "gegeben" hat, ohne es durch einen Eid oder den "Bund" (b $\left.b^{2} r \hat{t}\right)$ abzusichern, ist innerhalb des Pentateuchs und des Deuteronomistischen Geschichtswerks nur noch in Dtn 12,1; 27,3; Jos 18,3; 1 Kön 8,34.40 belegt, wobei aber die Dtn-Stellen an die Zusage Jahwes in Ägypten nach Ex 3,7-10, die anderen Stellen an die Josua-Generation denken. Die einfache Zusage läßt sich in die Formel zusammenfassen: "Jahwe/Gott sprach: "Ich gebe dir dieses Land/den Ackerboden ". Dtn hat diese Formel in der für es charakteristischen Weise abgewandelt, in 12,1 durch die Ergänzung Prištāh = "um es in Besitz zu nehmen", in 27,3 dadurch, daß Jahwe im Begriff ist, jetzt Israel in das Land zu führen, "wie er dir gesagt hat" ( $k 0^{20}$ šer dibbær läk). Dabei ist von "unseren Vätern", denen Jahwe das Land "gegeben" hat, nur noch in 1 Kön 8,34.40 die Rede, die aber nicht mehr die Erzväter sind, sondern die Josua-Generation. An den drei anderen Stellen sind die Väter als die Erzväter nur genannt in der Wendung "Jahwe, der Gott unserer Väter", der das Land aber der JosuaGeneration übergeben hat.

\section{DIE LANDVERHEISSUNG ABGESICHERT DURCH EINEN EID}

Wir haben schon bisher festgestellt, daß bei der Überarbeitung älterer Verheißungstexte bisweilen von einem Eid die Rede war, den Jahwe geschworen haben soll. Als älteste Erwähnungen eines einem Patriarchen geleisteten Eids Gottes dürften Gen 22,16f und 50,24 in Frage kommen.

Gen 22,1-15 hat E bzw. JE im wesentlichen schon in der Tradition vorgefunden. Dann muß er zwangsläufig die Verse 16-18 angefügt haben; denn der Gehorsam Abrahams forderte geradezu ein anerkennendes Gotteswort. Die Formel $n^{2 \supset} u m$ jhwh spricht für die Herkunft des Texts aus einem durch die Prophetie beeinflußten Kreis, was für E wohl zutreffen würde. Der Text lautet: "Bei mir (bî) habe ich geschworen Spruch Jahwes - weil du das getan hast und deinen einzigen Sohn (mir) nicht vorenthalten hast: Ich segne dich und mache deinen Samen zahl- 
reich wie die Sterne am Himmel und den Sand am Strand des Meeres, damit er das Tor seiner Feinde in Besitz nimmt. Dann werden sich durch deinen Samen alle Völker der Erde Segen zusprechen deshalb, weil du auf meine Stimme gehört hast". Hier ist zwar nicht direkt von der Landgabe die Rede, aber "das Tor der Feinde in Besitz nehmen" steht für das sonst übliche "das Land in Besitz nehmen"10. Das Bild von der Besitznahme des Tores der Feinde ist bedingt durch die kriegerische Situation in der Königszeit ${ }^{11}$. Diese Verheißung ist wieder mit der Mehrungs- und Segensverheißung verbunden, weil ja E bzw. JE längst die verschiedenen Angleichungen der Erzväterverheißungen von J kennt ${ }^{12}$. Daß Gott "bei sich schwört", wird sonst bei keiner Verheißung gesagt; so wurde also wohl von $\mathrm{E}$ bzw. JE formuliert ${ }^{13}$.

In Gen 50,24 sagt Josef vor seinem Tod zu seinen Brüdern, Gott werde sie "hinaufführen in das Land, das er Abraham, Isaak und Jakob mit einem Eid zugesichert hat" (nišbo' $\beta$ ). Hier ist die Quellenzugehörigkeit umstritten; es spricht aber m.E. nichts gegen $\mathrm{E}$ oder JE ${ }^{14}$.

Einem späteren, deuteronomistischen Tradenten ist Num 11,12 zuzuschreiben ${ }^{15}$. In einer Klage beschwert sich Mose bei Jahwe, daß er ihm den zu schweren Auftrag gegeben habe, das Volk - wie ein Wärter den Säugling - "auf den Ackerboden ("odēmāh) zu tragen, den du ihren

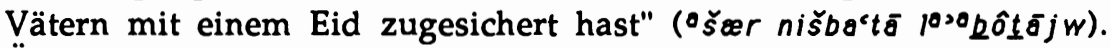
Ähnliche Formulierungen begegnen uns in Ex 13,5; Num 14,16.23 und $32,10 \mathrm{f}$ in dtr Einschüben, im Deuteronomium $(6,18.23 ; 8,1 ; 26,15)$ und im Dtr Geschichtswerk (Dtn 31,20f.23; 34,4 und Ri 2,1. Sie lassen sich in die

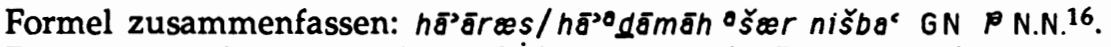
Diese Formel wird gelegentlich - je nach Zusammenhang und Satzfügung - etwas abgewandelt: "Gott gibt das Land/den Ackerboden

\footnotetext{
10 Zuletzt dazu E. BLUM [A.5] 384-389 und M. KÖCKERT [A.4] 183-189.

11 E. BLUM [A.5] 364 äußert sich nicht zum kriegerischen Aspekt der Verheißung.

12 E. BLUM [A.5] 363-365 weist Gen 22,16-18 einer D-Schicht zu und betont die enge Bindung an 22,1-15; er denkt dabei aber nicht an eine der E- bzw. JE-Schicht bereits vorliegenden älteren Tradition. - A. DE PURY [A.5] 331-333 betrachtet die Verse 16-18 als "postélohiste"; sie könnten also von JE stammen. Anders Th. RÖMER [A.4], der sie für nachdeuteronomistisch hält.
}

13 Vgl. G. GIESEN, Die Wurzel עב "schwören", BBB 56, Königstein-Bonn 1981, 308.

14 Gegen R. RENDTORFF [A.8] 75-77, 163-166 und E. BLUM [A.5] 255f.- H. DONNER, Die literarische Gestalt der alttestamentlichen Josefgeschichte, SHAW. Ph 1976/2), Heidelberg 1976, 35, denkt an E oder einen protodeuteronomischen Tradenten; vgl. auch J. SCHARBERT, "Ich bin Josef, euer Bruder", St. Ottilien 1988, 78, wo der Satz vom Schwur Jahwes JE zugewiesen wird.

15 Vgl. J. SCHARBERT, Numeri, NEB, Würzburg 1992, z.St.

16 Die verschiedenen mit שבע gebildeten Formeln für die beeidete Landverheißung haben zusammengestellt J.G. PLÖGER, Literarische, formgeschichtliche und stilkritische Untersuchungen zum Deuteronomium, BBB 26, Bonn 1967, 65, M. KÖCKERT [A.4] 168f und Th. RÖMER [A.4] 13.15 . 
entsprechend dem Wort, das Gott unter Eid dem N.N. gegeben hat" (Dtn 9,5); Gott möge den Ackerboden segnen, "wie er dem N.N. mit einem Eid zugesichert hat" (Dtn 26,15). Mose bzw. Josua erhoffen für Israel von Gott "die Barmherzigkeit und Gnade" (Dtn 13,18), die Annahme als Volk Jahwes $(28,9)$ und die Gewährung der "Ruhe" (Jos 21,44), "wie er dem N.N. durch einen Eid zugesichert hat". Ähnlich sagt Mose in einem dtr Zusatz in Ex 13,11 zum Volk: "Jahwe wird dich in das Land (der Kanaaniter) bringen, wie er in einem Eid dir und deinen

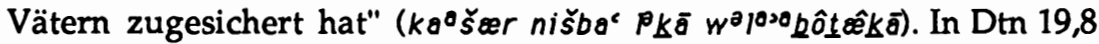

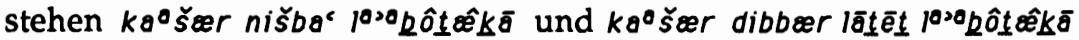
nebeneinander. In Dtn 29,12 unterscheidet aber der Deuteronomist zwischen der einfachen Zusage (dibbær) an das gegenwärtige Volk vor dem Jordanübergang und der beeideten Zusage an die Väter (nišbac

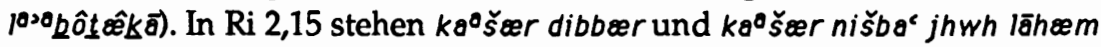
nebeneinander nicht in einer Zusage, sondern in einer Unheilsansage, wohl in Anspielung an Dtn 28,15-68.

Im Deuteronomium, beim Deuteronomisten und in einer dtr Überarbeitung des Tetrateuchs hat sich eine erweiterte Formel der be-

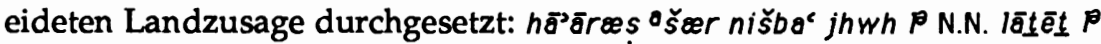
N.N. = "Das Land, das Jahwe dem N.N. unter Eid zugesagt hat, es dem N.N. zu geben". So in Dtn $1.8 .35 ; 6,10 ; 7,13 ; 10,11 ; 11,9.21 ; 28,11 ; 30,20$; 31,717 ; Jos 1,$6 ; 5,6 ; 21,43$; Ex 13,5. In Ex 33,1 hat ein dtr Tradent den Infinitiv lōtēt lāhem aufgelöst in ein Zitat aus dem angeblichen Schwur Jahwes. Jahwe trägt Mose auf: "Geh in das Land, das ich in einem Eid Abraham, Isaak und Jakob zugesichert habe mit den Worten (lēemōr): "Deinem Samen gebe ich es". Eine leichte Abwandlung hat die Formel auch in Dtn 6,23 erfahren.

In Ex 6,8 hat $\mathrm{P}$ die Formel übernommen, hat aber statt nišba ${ }^{\star} t \hat{\imath}=$

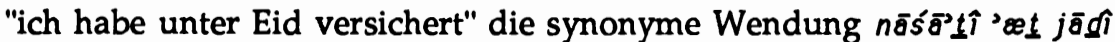
= "ich habe meine Hand (zum Schwur) erhoben" angewandt; er hat außerdem den Gedanken von einem Eid Jahwes mit dem Bundesgedanken verbunden. Ganz aufgelöst hat die Formel ein dtr Bearbeiter von Ex 32,13. Er läßt hier Mose in einer Fürbitte für das sündige Volk zu Gott sagen: "Denk an Abraham, Isaak und Israel, deine

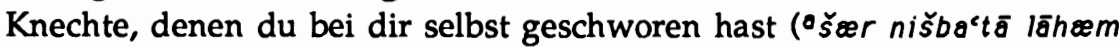
$b \bar{a} k$ ) und zu denen du gesagt hast (wat to dabbēr 'olēhæm): "Ich vermehre euren Samen wie die Sterne am Himmel, und ich gebe dieses ganze Land, das ich erwähnt habe ( $0^{\circ}$ šr 'ämartî), eurem Samen, und so werden sie es für immer erben «".

17 Hier kann nicht näher die Zugehörigkeit zu den verschiedenen Schichten des Deuteronomiums untersucht werden; dazu vgl. die Dtn-Kommentare und zuletzt vor allem $M$. KÖCKERT [A.4] und TH. RÖMER [A.4]. 
Die Vorstellung von einem durch Jahwe den Erzvätern geleisteten Eid, durch die die Landverheißung abgesichert wurde, dürfte erstmals bei E oder JE aufgekommen sein und wurde insbesondere im Deuteronomium formelhaft ausgestaltet und hat auf die deuteronomistische $\mathrm{Li}$ teratur und auf die Priesterschrift einen Einfluß ausgeübt; der Deuteronomist und die Priesterschrift haben sich aber nicht mehr streng an die Formel gehalten, sondern sind recht frei damit umgegangen.

\section{DIE LANDVERHEISSUNG ABGESICHERT DURCH EINEN "BUND"}

Am meisten umstritten ist heute unter den Exegeten die Vorstellung von einem "Bund" ( $\left.b^{2} r \hat{i} t\right)$ Gottes mit den Erzvätern. Bis um 1970 galt es als eine sichere Erkenntnis, daß der Glaube Israels an einen Bund Jahwes mit seinem Volk bis in die Zeit des DavidischSalomonischen Reiches zurückreicht, wobei man sich vor allem auf Gen 15,8-12.17f berief, das man dem Jahwisten zuschrieb. Nachdem aber Ernst KUTSCH sich aus semantischen Gründen gegen die Bundesvorstellung ausgesprochen und $b^{2} r i \hat{t}$ als Verpflichtung verstanden hatte ${ }^{18}$, hat Lothar PERLITT auch das hohe Alter der Bundesvorstellung bestritten und sie erst dem Deuteronomium oder gar erst dem Deuteronomisten zugeschrieben ${ }^{19}$. Man wird aber kaum bestreiten können, daß $b^{2} r i t$ in Zusammenhang mit zweiseitigen Verträgen bereits in der vordeuteronomischen Erzählungstradition des AT belegt ist, nämlich in den Patriarchenerzählungen des Jahwisten (Gen 26,28-31 und 31,44) und des Elohisten (21,27-32), wobei für "einen Vertrag schließen" die

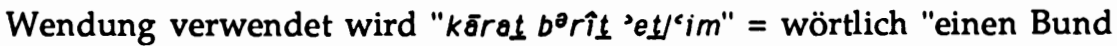
schneiden mit"20. Zwar nicht diese Wendung, wohl aber der Glaube, daß Jahwe und Israel einen auf gegenseitiger Verpflichtung beruhenden Bund geschlossen haben, ist eindrucksvoll in Ex 19 und 24 belegt. Hier sind alle Elemente eines Vertragsabschlusses ausführlich geschildert: Das Vertragsangebot Jahwes an Israel, übermittelt durch Mose; die Annahme des Angebots, gleichfalls übermittelt durch Mose; die Vorbereitungen zum formellen Vertragsabschluß; der Vertragsabschluß selbst mit gegenseitiger Vereidigung durch den Bundesmittler Mose; die notarielle Beglaubigung durch die schriftliche Beurkundung und die Verlesung der Urkunde durch den "Notar" Mose; das Bundesmahl21.

\footnotetext{
18 S. o. Anm. 2.

19 L. PERLITT [A.4]. Weitere Literatur zur Semantik und Geschichte des Bundesbegriffs s. o. Anm. 1 und 2 und die theologischen Worterbücher zum AT s. v. $t^{\circledR}$ rît.

20 Vgl. J. SCHARBERT, Genesis 12-50, NEB, Würzburg 1985, zu den erwähnten Stellen.

21 Diese m.E. völlig einsichtige Struktur ist bisher nie erkannt worden, sondern durch zahlreiche Spezialuntersuchungen einzelner Verse und Abschnitte der beiden Kapitel völlig zerredet und verwischt worden. Auch die Pentateuchredaktoren haben diese
} 


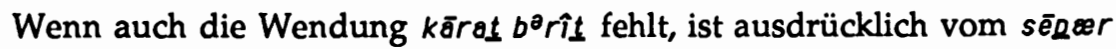
$b^{\ominus} r \hat{i} t$, also der "Bundesurkunde", und vom dam habbarît, dem "Blut des Bundes" die Rede, die den Vertrag erst gültig machen. Diesen Bericht vom "Bundesschluß" hat m.E. der Jehowist aus Elementen von J und $E$ zusammengestellt ${ }^{22}$. Ob Ex 34,10 schon dem "Privilegrecht Jahwes" angehört, wie Jörn HALBE annahm ${ }^{23}$, oder einem späteren Tradenten zuzuschreiben ist ${ }^{24}$, kann hier auf sich beruhen; jedenfalls ist die Vorstellung von einem "Bund" Jahwes mit Israel im Sinn einer zweiseitigen Abmachung dem Jehowisten bekannt. Sie liegt m.E. auch in Ex 34,10 vor, weil die Zusage Jahwes nur gilt, wenn Israel die Bestimmungen des "Privilegrechts" beobachtet. Daß aber Jahwe eine $b^{\partial}$ rît im Sinne einer einseitigen Zusage schon an die Erzväter eingegangen ist, ist wohl erstmals in Gen 15,8-10.17-21 belegt.

Gen 15 gehört allerdings heute zu den literar-, redaktions- und überlieferungskritisch umstrittensten Texten des $\mathrm{AT}^{25}$. Der uns hier vor allem interessierende Teil des Kapitels umfaßt die Verse 7-10 und 17f und lautet: "Da sprach er (Jahwe) zu ihm (Abraham): "Ich bin Jahwe, der dich aus Ur in Chaldäa herausgeführt hat, um dir dieses Land zu geben, es in Besitz zu nehmen " (Prištōh). Da sagte er (Abraham): "Mein Herr Jahwe, woran kann ich erkennen, daß ich es in Besitz nehme? « Da sagte er zu ihm: „Nimm mir ein dreijähriges Kalb, eine dreijährige Ziege und einen dreijährigen Widder, eine Turteltaube und eine Haustaube!« Da nahm er für ihn alle diese (Tiere), teilte sie in der Mitte und legte ein Stück dem anderen gegenüber, die Vögel aber zerteilte er nicht. Dann geschah es: Als die Sonne untergegangen und Finsternis eingetreten war, siehe, da war da ein rauchender Ofen und eine feurige Fackel, die zwischen den Stücken hindurchfuhren. An jenem Tag schloß Jahwe mit Abraham ein Abkommen (kārot borît 'eț 'abrāhām), das besagte: „Deinem Samen gebe ich hiermit dieses Land vom Strom Ägyptens bis zum grossen Strom, dem Eufrat‘". Es folgt die Aufzählung von zehn Völkern, die der Tradition nach die Bevölkerung Kanaans vor der

Struktur durch die Zwischenschaltung des Dekalogs und des "Bundesbuchs" unkenntlich gemacht; vgl. J. SCHARBERT, Exodus, NEB, Würzburg 1989.

22 Vgl. J. SCHARBERT [A.21] 79.

23 J. HALBE, Das Privilegrecht Jahwes Ex 34,10-26, FRLANT 114, Göttingen 1975.

24 Vgl. J. SCHA RBERT, Jahwe im frühisraelitischen Recht, in: E. HAAG (Hrsg.), Gott, der Einzige (QD), Freiburg 1985, 160-183, bes. 163f.

25 Die ältere Literatur dazu ist bei N. LOHFINK [A.5] zusammengestellt; weitere Lit.: G.D. BUTTRICK, Gen 15,1-18, Interp. 42 (1988) 393-397; E. HAAG, Die Abrahamtradition in Gen 15, in: FS J. SCHARBERT, Stuttgart 1989, 83-106; N. LOHFINK, Dtn 12,1 und Gen 15,18, ebd. 183-210; K. BERGE [A.5] 51-53 bzw. 38-43. Neue eingehende Analysen von Gen 15 legen vor: M. KÖCKERT [A.4] 165f. 198-232 (mit einer forschungsgeschichtlichen Synopse 325-327), und P. WEIMAR, Genesis 15, in: FS J. SCHARBERT, Stuttgart 1989, 361-411. 
Landnahme Israels gebildet haben soll; diese Aufzählung dürfte ein späterer Zusatz sein.

Bis zur Untersuchung von Lothar PERLITT ${ }^{26}$ galt die Wendung "ein Abkommen treffen" ( $k \bar{r}$ rot $b^{2}$ rît 'et) und die Schilderung des Ritus des Hindurchschreitens zwischen Fleischstücken als ein uralter Ritus, weshalb man den Text J oder zumindest einen vordeuteronomischen Tradenten zuschrieb 27 . Der Text ist einerseits eine in sich geschlossene Einheit, aus dem man kaum etwas herausnehmen kann, ohne den Sinn empfindlich zu stören, und weist andererseits eindeutige Hinweise auf eine spätere Formulierung auf, so daß er nicht wesentlich älter als das Deuteronomium sein kann. Die Bezeichnung der Heimat Abrahams als "Ur in Chaldäa" ist außerbiblisch erst um 700 v.Chr. nachweisbar. Der Infinitiv Prištāh und das Verbum jöroš in der Bedeutung "(das Land) in Besitz nehmen" sind für das Deuteronomium, für die dtr Literatur und für $\mathrm{P}$ charakteristisch ${ }^{28}$. Der Ritus des Hindurchschreitens durch Fleischstücke ist innerhalb der Bibel nur noch in Jer 34,18f belegt, und ähnliche Riten bei Eid und Vertragsabschlüssen sind zwischen 800 und 200 v.Chr. bezeugt ${ }^{29}$, müssen also nicht unbedingt uralt sein. Gen 15,7-10.17f dürfte kurz vor Dtn entstanden sein und kann als "protodeuteronomisch" bezeichnet werden. Die Wendung $k \bar{a} r a t b^{\partial} r i \hat{t}$ 'et hat dieser Tradent wohl den Erzählungen von sonstigen Bundesschlüssen zwischen menschlichen Partnern in Gen entnommen. Die Präpositionen 'et bzw. (an anderen Stellen) 'im, die beide "mit" bedeuten, scheinen mir doch immer auf ein zweiseitiges Verhältnis hinzudeuten, selbst wenn nur der eine, der wichtigere, Partner erwähnt wird.

26 S.o. Anm. 4.

27 Vgl. H. GUNKEL, Genesis, Göttingen 71966, 181; N. LOHFINK [A.4] 89-100; H. SEEBASS [A.8] 205-209.

28 Vgl. M. WEINFELD, Deuteronomy and the Deuteronomic School, Oxford 1972, 313-316; N. LOHFINK, Kerygmata des Deuteronomistischen Geschichtswerks, in: FS H.W. WOLFF, Neukirchen 1981, 87-100; DERS., Die Bedeutung von Hebr. jrš qal und hif, BZ NF 27 (1983) 14-33; A. SCHART, Mose und Israel im Konflikt, OBO 98, FribourgGöttingen 1990, 152.

29 Die Belege stellen zusammen D.J. MCCARTHY [A.1]; E. KUTSCH [A.2, 1973] 45f; M. WEINFELD s.v. קּ iฺ in ThWAT I, 809f. Einschlägige griechische und lateinische Texte haben schon R. KRAETZSCHMAR, Die Bundesvorstellung im Alten Testament, Marburg 1896, und P. KARGE, Die Geschichte des Bundesgedankens im Alten Testament, 1910, verzeichnet. Neueste Literatur dazu: Z. ZEVIT, A Phoenician Inscription and Biblical Cove-

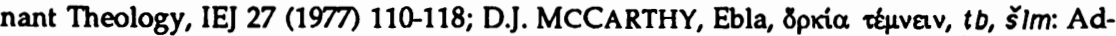
denda to Treaty and Covenant, Bib. 60 (1979) 247-253; jetzt in: DERS., Institution and Narrative, AnBib 108, Rom 1985, 67-73; G.J. WENHAM, The Symbolisms of the Ancient Rite in Gen 15, JSOT 22 (1982) 134-137; A.S. KAPELRUD, The Interpretation of Jeremiah 34,18ff, ebd. 138-140; J.C. GREENFIELD, An Ancient Treaty Ritual and Its Targumic Echo, in: In Memoriam Alejandro Diez MACHO, Madrid 1986, 391-397; Ch. T. BEGG, Rereadings of the "Animal Rite" in Gen 15 in Early Jewish Narratives, CBQ 50 (1988) 36-46. 
Das Reden von einer $b^{\partial} r \hat{\imath} \underline{\underline{t}}$ Jahwes ist eine Fortentwicklung der Vorstellung von einem Eid Jahwes. Der Satz A $k \bar{a} r a t b^{\partial}{ }^{2} \hat{i} \underline{t}{ }^{2} e \underline{t} /{ }^{\prime} \mathrm{im} B$ ist $m . E$. eine Brachylogie für "A schließt ein Abkommen mit $B$ unter dem Zeichen des Zerschneidens/Zerhauens von Tieren", wobei beide oder einer der Partner zu verstehen gibt, daß er wie die Tiere zerstückelt werden will, wenn er die Abmachung bricht. Es liegt also auch eine Art Eid, verbunden mit einer bedingten Selbstverfluchung vor. War schon die Vorstellung, Jahwe habe einen Eid geschworen, in E bzw. JE ein für einen Israeliten kühner Gedanke, mußte erst recht die Behauptung, Jahwe habe eine Zusage an Menschen durch eine zeichenhafte Selbstverfluchung bekräftigt, ein gewiß äußerst krasser Anthropomorphismus, für das Deuteronomium fast unerträglich sein. Der Tradent von Gen 15 hat diesen groben Anthropomorphismus nur notdürftig kaschiert durch die Behauptung, nicht Jahwe persönlich, sondern eine in Theophanieschilderungen vorkommende Feuererscheinung habe sich diesem Ritus unterzogen. Andererseits war diese Schilderung so beeindruckend, daß fortan Israel von einer durch eine $b^{2} r i ̂ t$ bekräftigten $\mathrm{Zu}$ sage Jahwes gesprochen hat, ohne dabei freilich jemals wieder die Schilderung des Ritus $z u$ wiederholen ${ }^{30}$.

Es fällt auf, daß das Deuteronomium zwar den Gedanken, Jahwe sei mit Israel bzw. mit den "Vätern" einen Bund, eine borît, eingegangen, übernommen hat, dabei aber die Wendung $k \bar{\theta} r a \pm b^{2}$ rît ganz selten gebraucht, und zwar nur für den Horeb- bzw. den Moabbund. So erinnert Mose das Volk in Dtn 5,2: (jhwh) kērot 'immēnū borît $b^{2} h o ̄ r e ̄ b=$ "Jahwe hat mit uns am Horeb einen Bund geschlossen" und fährt in V.3 ausdrücklich fort: "Nicht mit ('et) unseren Vätern hat Jahwe diesen Bund geschlossen, sondern mit uns hier, die wir heute alle am Leben sind". Dabei wechselt der Tradent bei der Präposition zwischen "im und 'et. Hier ist aber nicht mehr von der Landzusage, sondern vom Gehorsam gegenüber dem Dekalog die Rede (V.6-11).

In Dtn 28,69 bezieht sich die Wendung kārot barît 'et sowohl auf den Bund Jahwes mit Israel im Gebiet von Moab, als auch auf den Bund am Horeb und hat keine Beziehung zur Landverheißung. Das mit der Segens- und Fluchsanktion abgeschlossene deuteronomische Gesetzescorpus wird hier zusammengefaßt mit dem Satz: "Das sind die Worte des Bundes, den mit den Söhnen Israels zu schließen Jahwe dem Mose befahl, abgesehen von dem Bund, den er mit ihnen am Horeb

30 An den Ritus - wobei jetzt aber wie in Jer 34 die Vertreter Israels "hindurchschreiten" erinnert nur noch beiläufig Dtn 29,11: "Du schreitest hinein in den Bund Jahwes, deines Gottes, den (von ihm auferlegten) Fluchschwur ( $2010 \overline{0} 0$ ), den er mit dir heute schließt (kōrēt 'immª $k$ )." Die EÜ verdeutlicht das Gemeinte umschreibend: "Du schreitest jetzt zwischen den Zeichen des Bundes mit dem Herrn hindurch, den Zeichen der Selbstverfluchung. Der Herr, dein Gott, schließt heute mit dir diesen Bund". Der Vorschlag zu dieser umschreibenden Wiedergabe kam von N. LOHFINK. 
geschlossen hat". - In Dtn 7,9 wird allgemein festgestellt, daß Jahwe "der zuverlässige Gott ist, der den Bund und die Treue bewahrt denen, die ihn lieben und seine Gebote halten für tausend Generationen", ohne daß sich ein Hinweis darauf findet, welcher "Bund" gemeint ist und worauf er sich bezieht.

Nur zweimal sind im Deuteronomium die "Väter" im Zusammenhang mit dem "Bund" erwähnt, in 7,12 und 8,18. In 7,12 heißt es: Wenn Israel die deuteronomischen Vorschriften beachtet, dann wird auch Jahwe "zu deinen Gunsten den Bund und die Treue halten, die er deinen Vätern mit einem Eid beschworen hat". 8,18 behauptet, Jahwe habe Israel bisher, d.h. bis zum Aufenthalt in Moab, Kraft und Reichtum verliehen, "weil er den Bund, den er deinen Vätern beschworen hat, in Kraft setzt (hēqîm borît), wie er es heute tut". Ein Bezug zur Landgabe besteht zumindest indirekt, weil es ja jetzt gerade um den Einzug in das verheißene Land geht. Wer die "Väter" sind, denen Jahwe "den Bund beschworen hat", wird nicht ausdrücklich gesagt; die Patriarchen dürften aber zumindest mitgemeint sein ${ }^{31}$. Dasselbe wird von der dtr Stelle 4,31 gelten, die allerdings eine auffallende Terminologie aufweist, indem sie vom "Bund deiner Väter" spricht: "(Jahwe) vergißt nicht den Bund deiner Väter, den er ihnen beschworen hat". Zwar wird hier Israel an das Sprechen Jahwes "aus Feuer und Donner, das du gehört hast", d.h. an die Sinaitheophanie, und an die Großtaten Jahwes seit dem Auszug aus Ägypten erinnert (V.32-36) ${ }^{32}$; aber dieses Handeln Jahwes zu Gunsten Israels wird damit begründet, daß er "deine Väter liebte und nach ihnen ihre Nachkommen erwählte" (V.37); dann können die "Väter" nur die Erzväter sein ${ }^{33}$. Auch hier besteht nur ein indirekter Zusammenhang zur Landzusage.

Komplizierter ist das Problem, wer die Väter sind, mit denen Jahwe einen Bund geschlossen hat, in dem gleichfalls dtr Text Dtn 29,11-14. Hier heißt es zunächst: "Du trittst in den Bund Jahwes, deines Gottes,

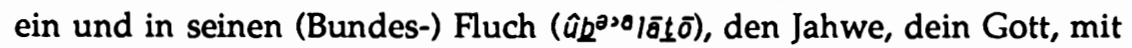
dir heute zu schließen im Begriff ist" (kōrēt ' $\left.i m m^{\partial} k \bar{\theta}\right)$. Die 'ōlōh ist die bedingte Selbstverfluchung des den "Bund" Eingehenden im Fall des

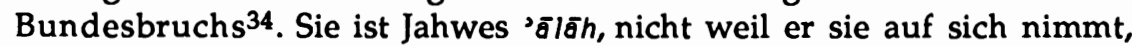
sondern weil er mit ihr Israel auf den Bund verpflichtet. Der Bund besteht darin, daß er "dich heute für sich zum Volk einsetzt und für dich Gott sein will, wie er dir zugesagt und wie er es deinen Vätern

\footnotetext{
31 G. BRAULIK, Deuteronomium 1-16,17, NEB, Würzburg 1986, 72 f.

$32 \mathrm{Vgl}$. G. BRAULIK [A.31] 45.

33 Vgl. G. BRAULIK [A.31] 45.

$34 \mathrm{Zu}$ 'ölōh = "Eidfluch, Bundesfluch" s. J. SCHARBERT, ThWAT I und C.A. KELLER, THAT I s.v.; M.S. GEHMAN, The Oath in the Old Testament, in: FS L.J. KUYPER, Grand Rapids 1975, 51-63; Z. ZEVIT [A.29]; H. TADMOR, Treaty and Oath in the Ancient Near East, Shnaton 5/6 (1978/79) 149-174 (hebr.).
} 
Abraham, Isaak und Jakob unter einem Eid zugesichert hat". Dieser Bund soll aber nicht nur für die jetzt in Moab anwesenden Israeliten gelten, sondern auch für die Nachkommen: "Nicht mit euch allein

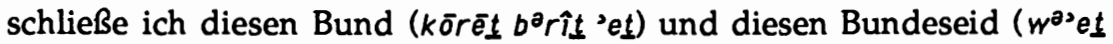
$h \overline{\theta^{\top}} \overline{\bar{\theta}}(\overline{\bar{a}} \boldsymbol{h}$ hazzōt), sondern (auch) mit denen, die nicht mit uns hier heute vor dem Angesicht Jahwes, unseres Gottes, stehen". Es wird also hier unterschieden zwischen dem "heute" mit den Anwesenden zu schließenden Bund, zwischen dem auch für die folgenden Generationen geltenden Bund und dem Bund und Schwur an die Väter, die namentlich als Abraham, Isaak und Jakob identifiziert werden. Auch hier besteht nur ein indirekter Bezug zur Landverheißung, insofern es eben jetzt um den Einzug in das verheißene Land geht ${ }^{35}$.

Einen direkten Bezug zu Gen 15,18 hat Norbert LOHFINK in Dtn 12,1 herzustellen versucht in dem Satzteil "im Land, das Jahwe, der Gott deiner Väter, dir gegeben hat, um es in Besitz zu nehmen alle Tage, die ihr auf dem Ackerboden leben werdet"36. Da hier aber weder vom Schwur Jahwes noch von seiner $b^{2}$ rît mit den Vätern gesprochen wird, mag dieser Text auf sich beruhen.

Im DtrG ist nur noch einmal vom Bund Jahwes mit den Erzvätern die Rede, in 2 Kön 13,23: Jahwe wendet sich seinem Volk wieder zu "wegen meines Bundes mit ('et) Abraham, Isaak und Jakob". Hier sind, wohl unter dem Einfluß von Gen 15,17f, die Verheißungen an alle drei Erzväter als "Bund mit" ihnen zusammengefaßt. Alle anderen Stellen in Ri und Kön, wo ein Bund mit den Vätern erwähnt wird, meinen nicht einen Bund mit den Erzvätern, sondern immer den Bund mit der Auszugs- bzw. der Sinaigeneration ${ }^{37}$. Ähnliches gilt von den deuteronomistischen Stellen im Jeremiabuch ${ }^{38}$.

Eine besondere Ausgestaltung hat der Gedanke des "Bundes" mit den Erzvätern in der Priesterschrift erfahren, ja sie kennt überhaupt nur den Bund mit ihnen und spricht weder vom Sinaibund, noch von einem anderen Bund. Der Grundtext ist Gen 1739. Hier finden wir eine

35 EÜ hat in 29,11 eine enge Beziehung zu Gen 15,17f herzustellen versucht, indem sie das

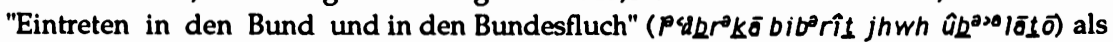

"Hindurchschreiten" zwischen den Zeichen des Bundes Jahwes, den Zeichen der Selbstverwünschung umschrieb; s. oben Anm. 30.

36 N. LOHFINK 1989 [A.25].

37 Ri 2,1.20; 1 Kön 8,21; 2 Kön 17,15.35.38.

38 Jer 14,$21 ; 31,32 ; 34,13$.

39 Literatur zu Gen 17: S.E. MCEVENUE, The Narrative Style of the Priestly Writer, AnBib 50, Rom 1971, 145-150; C. WESTERMANN, Gen 17 und die Bedeutung von berit, ThLZ 101 (1976) 161-170, jetzt in: DERS., Gesammelte Studien III, TB 73, München 1984, 66-78; W. GROSS, Bundeszeichen und Bundesschluß in der Priesterschrift, TrThZ 87 (1978) 98-115; T.D. ALEXANDER, Genesis 22 and the Covenant of Circumcision, JSOT 25 (1983) 17-22; E. BLUM [A.5] 420-432; S.R. KÜLLING, Zur Datierung der "Genesis-PStücke", namentlich des Kapitels XVII, Richen 21985; P. WEIMAR, Gen 17 und die prie- 
sehr differenzierte Terminologie für den Gedanken, daß Jahwe mit Abraham einen Bund eingegangen ist. Nach V.2 sagt Jahwe in der IchForm und Du-Anrede: "Ich gebe $(n t n)$ meinen Bund zwischen (bên) mich und dich". Nach V.4 wird "mein Bund mit dir ( $b^{\circ} r \hat{\imath} \hat{\imath} \hat{\imath}{ }^{~} i t t \bar{z} k$ ) darin bestehen, daß Abraham "Vater einer Menge von Völkern" wird. Nach V.7 sagt Jahwe: "Ich errichte ( $h^{\circ}$ qîmōtîi) meinen Bund zwischen (bên) mir und dir und deinem Samen nach dir für ihre Generation als einen ewigen Bund" (libarît côlēm). Abraham und seine Nachkommen sollen "meinen Bund beobachten" (šmr). Nach V.10-14 ist "der Bund zwischen mir und euch und euren Nachkommen, den ihr beobachten sollt", die Beschneidung, die "zum Zeichen des Bundes zwischen mir und euch" werden und die "mein Bund an eurem Fleisch als ein ewiger Bund" sein soll. Wer sich nicht beschneiden läßt, "hat meinen Bund gebrochen" (nēpor). Auch mit dem Sohn Abrahams, Isaak, "errichte ich meinen Bund mit ('et) ihm als einen ewigen Bund" (V.19.21). Inhalt des Bundes ist, daß "Gott für Abraham und seinen Samen zu Gott wird" (V.7), daß Gott Abraham sehr fruchtbar macht (V.2.4-6) und ihm und seinem Samen "das Land, in dem du als Fremdling lebst, das ganze Land Kanaan, zum ewigen Besitz" gibt.

Der Verfasser der Priesterschrift vermeidet also den krassen Anthropomorphismus von Gen $15,17 \mathrm{f}$ und hat auch sonst versucht, Mißverständnisse hinsichtlich der Vorstellung von einem Bund Gottes mit einem Menschen abzuweisen, indem er in dem für $\mathrm{P}$ charakteristischen umständlichen Stil das Bundesverhältnis und sein Zustandekommen mit wechselnder Terminologie und immer wieder neuer Umschreibung deutlich zu machen versucht. Sogar die Wendung $k \bar{r} r a \pm b^{2} r \hat{i} t$ vermied er, weil auch sie zu sehr an Gen $15,17 \mathrm{f}$ erinnerte. P macht aber immerhin auch deutlich, daß beim Beschneidungsbund, der "zwischen" (bên) den beiden Partner besteht, beide Seiten eine Bindung eingehen ${ }^{40}$ : Gott verheißt Abraham Nachkommen, für die er in besonderer Weise "Gott sein" will und denen er das Land Kanaan verspricht; dafür verlangt er von Abraham und seinen Nachkommen die Beschneidung als Zeichen des bestehenden Bundesverhältnisses, das sie "an ihrem Fleisch" zu tragen haben. Gott bindet sich auch selbst und verpflichtet sich zu einem Treueverhältnis gegenüber Abraham und durch ihn auch gegenüber Israel ${ }^{41}$. Der in Gen 17 zustande gekommene Bund wird bei $P$ in Ex 2,24 und 6,4 sowie in Lev 26,42 auf alle drei Patriarchen ausgedehnt, wobei es an den beiden zuletzt angeführten Stellen um das

sterliche Abrahamsgeschichte, ZAW 100 (1988) 22-60; W. BRUEGCEMANN, Gen 17:122, Interp. 45 (1991) 55-59.

40 Zur Zweiseitigkeit der barît in Gen 17 und der Übersetzung "Bund" s. C. WESTERMANN [A.39].

41 Vgl. M. KÖCKERT [A.4] 314. 
Land, in Ex 2,24 aber um die Rettung aus der Knechtschaft in Ägypten geht.

Auf diesen Bund verweisen außerhalb des Pentateuchs Ps 105,9-11; $1 \mathrm{Chr}$ 16,15-17 und Neh 9,7f. In Neh 9,7f dürfte die Aufzählung der Völker Kanaans auch Gen 15,17-21 im Blick haben.

\section{ZUSAMMENFASSUNG}

Bei der Durchsicht des Pentateuchs und der deuteronomistischen Literatur zeichnet sich also folgende Überlieferungsgeschichte für das Verständnis und den Inhalt der Landverheißung ab:

1. Die erschließbaren "Urverheißungen" kennen nur die einfache Zusage Jahwes an einen der Erzväter: "Dir (und deinem Samen) gebe ich dieses Land". Sie sind also eigentlich nicht Verheißungen, sondern Landübergaben. Das "Land" ist ein relativ eng begrenztes Gebiet, in dem der betreffende Stammvater mit seinem Verband siedeln bzw. Weideland in Anspruch nehmen kann. Die Übergabe erfolgt nicht in der $\mathrm{Zu}-$ kunft, sondern in der erzählten Gegenwart.

2. Die Quellenautoren J und E bzw. JE haben die Erzvätertradition so in ihre Geschichtsdarstellung eingearbeitet, daß die drei Erzväter als Vater, Sohn und Enkel erscheinen. Sie haben aus der Landübergabe eine Landverheißung gemacht, haben das ursprünglich eng begrenzte Gebiet zum ganzen Land Kanaan erweitert, das erst der "Same" in Besitz nehmen wird, und haben die einem späteren Stammvater gegebene Verheißung als Wiederholung und Bestätigung der dem früheren oder den früheren Stammvätern gegebenen Verheißung verstanden, wobei sie den Wortlaut der Verheißung um eine Mehrungs- und Segenszusage erweiterten und die entsprechenden Texte einander anglichen. Aber auch sie bleiben bei der einfachen Zusage, "Gott/Jahwe sagte/sprach zu N.N".

3. Seit E oder JE wird aus der einfachen Zusage eine durch Gott beeidete Verheißung. Im Deuteronomium und in der deuteronomistischen Literatur wird der Glaube, Jahwe habe den Vätern einen Eid geleistet, ihnen das Land zu geben, in formelhaften Sätzen ausgesprochen, vor allem in der Formel: "Jahwe hat Abraham, Isaak und Jakob" bzw. "unseren Vätern geschworen, ihnen das Land (Kanaan) zu geben". Die Formel kann je nach Zusammenhang oder Satzfügung leicht abgewandelt werden. Oben wurde, wenn nur "die Väter", ohne namentliche Nennung der Erzväter, erwähnt wurden, mit Absicht nicht im einzelnen untersucht, wer jene "Väter" sind und bei welcher Gelegenheit Jahwe ihnen den Eid geleistet haben soll, weil dazu der zur Verfügung stehende Raum in dieser Festschrift nicht ausgereicht hätte; aber schon eine oberflächliche Lektüre der oben angeführten Stellen zeigt, daß unter den "Vätern" bisweilen auch spätere Generationen, die Generation in Ägypten unmittelbar vor dem Auszug oder die Sinai-Horeb-Genera- 
tion oder gar erst die Josua-Generation gemeint ist ${ }^{42}$. $\mathrm{P}$ hat in der Formel den Terminus für "schwören" durch die Wendung "die Hand erheben" ersetzt oder die Formel aufgelöst und anders umschrieben.

4. Kurz vor der Entstehung des Deuteronomiums, in der "protodeuteronomischen" Epoche, regt das bereits seit alter Zeit vorhandene Wissen um Bundes- bzw. Vertragsschlüsse zwischen menschlichen Partnern, der in JE bezeugte Glaube an den am Sinai geschlossene Bund zwischen Jahwe und Israel und der Glaube an einen Eid Jahwes, den Vätern das Land zu geben, dazu an, die Landverheißung an die Erzväter, vor allem an Abraham, als Bestandteil eines "Bundes" zu verstehen, den Jahwe eingegangen ist. Da zu jener Zeit Vertragsabschlüsse unter Riten erfolgten, die dem Vertragsbrüchigen das Schicksal von zu diesem Zweck in Stücke gehauener Tieren symbolisch androhen, hat man sogar Jahwe ähnliche Riten zugetraut und hat die von solchen Riten abgeleitete Formel kārot barît auch auf Jahwe übertragen. Daß dabei Jahwe selbst durch die Stücke zerhauener Tiere hindurchgeschritten ist, wird freilich nur in Gen 15 bezeugt, wobei aber wegen des allzu krassen Anthropomorphismus die Gestalt Jahwes durch eine aus Theophanieschilderungen bekannte Feuererscheinung ersetzt wurde. Weil die Wendung kārot $b^{\partial} r_{i ̂ t}{ }^{\prime} e t /{ }^{\prime} i m$ immer noch zu deutlich an den Ritus erinnert, vermeidet sie noch das Deuteronomium; sie wird aber in der deuteronomistischen Literatur ohne Bedenken verwendet. Dabei verstärkt sich aber auch die Tendenz, die Vorstellung von der durch einen Bund abgesicherten Landverheißung von den Erzvätern auf eine spätere Vätergeneration, auf den Sinai-Horeb oder nach Moab, zu verlagern. Die "Schule", aus der die Priesterschrift kommt, vermeidet dann die anthropomorphe Ausdrucksweise noch stärker; sie gibt die Wendung kērot $b^{2}$ rît ganz auf und spricht nur noch von einem "zwischen" (bên) Gott und den Erzvätern bestehenden "Bund", dessen Inhalt die Beschneidung auf Seiten des menschlichen Partners und die Mehrungszusage und die Landgabe auf Seiten Gottes sind. Die Beschneidung wird dabei auch als Bundeszeichen deklariert. Dieser Bund zwischen Gott und den Erzvätern, insbesondere mit Abraham, ist dabei in P sogar der einzige Bund; das Sinai-Geschehen ist nur die Folge oder Ausgestaltung jenes Bundes.

42 Das Ergebnis, zu dem Th. RŌMER [A.4] 586-575 kommt, bedarf m.E. einer eingehenden Nachprüfung: Die "Väter" seien in Dtn und im DtrG nie die Erzväter, sondern immer spätere Generationen; Abraham, Isaak und Jakob würden nie "Väter" genannt, sondern nur namentlich aufgeführt; wo die drei Namen zusammen mit den "Vätern" genannt werden, handle es sich immer um nachdtr Zusätze. Wie N. LOHFINK darüber denkt, wurde oben in Anm. 4 angedeutet. 


\title{
"ZIEHET AUS IHRER MITTE UND SONDERT EUCH AB!" Abgrenzung als Ursprungssituation paulinischer Gemeindebildung Beobachtungen zu 2Kor 6,14 - 7,1
}

\author{
von \\ Eberhard Schwarz \\ Kirchhain bei Marburg
}

\section{VORBEMERKUNG}

2Kor 6,14 - 7,1 scheint wie kaum ein anderer neutestamentlicher Text die rigorose Abgrenzung zum Prinzip zu erheben. Er spiegelt ein schroffes Gegenüber von Gläubigen und Ungläubigen und es ist deutlich, daß der Abgrenzung der einen von den anderen identitätsstiftende Funktion zukommt. Im Rückgriff auf die Tradition werden bestimmte Stichworte und Verheißungen aufgenommen und auf die eigene Gruppe bezogen. Indem sie für sie in Anspruch genommen werden, wird das Selbstverständnis der Gemeinschaft definiert - im Gegenüber zu den "Gegnern", denen die Rechtgläubigkeit abgesprochen wird: "Wir aber sind der Tempel des lebendigen Gottes" (16b). Zur Wahrung der eigenen Identität bedarf es daher der Abgrenzung von den anderen (14.17)2.

Entspricht dieses Konzept paulinischem Gemeindeverständnis? Ist es legitim, mit Rekurs auf diesen Abschnitt heutige Abgrenzungsforderungen theologisch zu begründen? Hilft die Exegese dieses Passus bei der Diskussion um heutiges Gemeindeverständnis, bei der Klärung unseres Kirchenbildes?

Bevor diese Fragen aufgegriffen werden können, scheint es mir sinnvoll, den Abschnitt einer genaueren Analyse zu unterziehen ${ }^{3}$. Dabei ist von der seit Beginn der kritischen Arbeit am NT immer wieder gemachten Beobachtung auszugehen, daß 2Kor 6,14 - 7,1 ein in sich abgeschlossenes, klar strukturiertes Textstück darstellt, das den offenkun-

1 Der vorliegende Aufsatz weist die traditionsgeschichtliche Relevanz des in meiner Promotion aufgezeigten Konzepts "Identität durch Abgrenzung" am Beispiel von 2Kor 6,14 - 7,1 für die Zeit urchristlicher Gemeindebildung nach.

2 Zur Traditionsgeschichte dieses Konzepts in alt- und zwischentestamentlicher Zeit s. E. SCHWARZ, Identität durch Abgrenzung. Abgrenzungsprozesse in Israel im 2. vorchristlichen Jahrhundert und ihre traditionsgeschichtlichen Voraussetzungen. Zugleich ein Beitrag zur Erforschung des Jubiläenbuches, EHS XXIII/162, Frankfurt/Main-Bern 1982.

${ }^{3}$ Neben der Bearbeitung in Kommentaren und Monographien zum 2Kor sind eine ganze Reihe von Aufsätzen speziell zu unserem Abschnitt erschienen. Zur literarischen Problematik des 2 Kor und zu umfassenden Literaturangaben s. zuletzt W. SCHENK, Art. Korintherbriefe, TRE XIX (1990) 620ff. 
digen Zusammenhang $6,11-13 ; 7,2 \mathrm{ff}$ zerreißt $\mathrm{t}^{4}$. So soll also zunächst der Versuch gemacht werden, 2Kor 6,14 - 7,1 aus sich selbst heraus zu erklären. Läßt sich etwas über seinen ursprünglichen "Sitz im Leben" ausmachen?

\section{THESE ZUM "SITZ IM LEBEN" VON 2KOR 6,14 - 7,15}

2Kor 6,14 - 7,1 spiegelt eine Ursprungssituation urchristlicher, vermutlich paulinischer Gemeindebildung, wie sie Lukas in der Apg wohl idealtypisch schildert. So berichtet er zB im Zusammenhang der paulinischen Missionsarbeit in Ephesus ${ }^{6}$, daß Paulus drei Monate in der Synagoge gelehrt bzw gepredigt habe und seine Zuhörer vom Reiche Gottes zu überzeugen suchte. Dann fährt er fort:

Als aber einige sich verstockten und den Gehorsam verweigerten, indem sie den "Weg" vor der Menge schmähten, trennte er sich von ihnen und sonderte die Jünger ab und predigte täglich im Lehrsaal des Tyrannus.

Ganz entsprechend schildert Lukas den Prozeß der Verselbständigung der Gemeinde in Korinth?

Mir scheint sicher, daß sich in diesen lukanischen Schilderungen reale Vorgänge aus der paulinischen Missionspraxis spiegeln ${ }^{8}$. So dürf-

\footnotetext{
4 Dabei gehen die Aussagen über die Herkunft des Textabschnittes erheblich auseinander: Geht er nun auf Paulus selbst zurück? Ist es eine nichtpaulinische Interpolation essenischer bzw judenchristlicher Herkunft? Ist es gar "an Anti-Pauline fragment", wie H.D. BETZ vermutet? BETZ gibt eine sehr sorgfältige literarische Analyse und Gliederung unseres Abschnittes (JBL 92 [1973].88ff; s.a. DERS., Der Galaterbrief, München 1988, 554 557) mit dem Ergebnis, es handle sich um eine "judenchristliche Kultparänese", die von den galatischen Gegnern des Paulus stamme und vom Redaktor der paulinischen Briefe aus einem uns unbekannten Grunde an diese Stelle eingefügt worden sei. Als ursprünglichen "Sitz im Leben" vermutet er den antiochenischen Zwischenfall. Eine explizite Auseinandersetzung mit den Thesen von Betz führt J. LAMBRECHT, The fragment 2 Cor VI 14VII 1. A Plea for its Authenticity, in: Miscellanea neotestamentica Bd.2 = NT.S 47,1 (1978) $143 f f$.

5 Neben der eben genannten These von H.D. BETZ verdient G. KLINZING mit seiner Vermutung Beachtung, daß unser Abschnitt eine "in weitem Umfang der Qumrangemeinde" entstammende Paränese darstelle, die im christlichen Bereich dann als Taufparänese im Gottesdienst Verwendung gefunden habe. "Die Annahme eines zentralen und verbreiteten gottesdienstlichen Stückes" erkläre auch eher die spätere Aufnahme in den Brief, sei es durch Paulus selbst, sei es durch einen anderen. G. KLINZING, Die Umdeutung des Kultus in der Qumrangemeinde und im NT, StUNT 7, Göttingen 1971, 172ff.

6 Apg 19,8f. Zu "Paulus in Ephesus" s. J. BECKER, Paulus. Der Apostel der Völker, Tübingen $1989,160 f f$.

${ }^{7}$ Apg 18, bes. V.4-8. Zum "Gründungsaufenthalt in Korinth" s. J. BECKER [A.6] 154ff.

8 Zur "selbstverständlichen Anknüpfung in der Synagoge" (E. HAENCHEN, Die Apostelgeschichte, KEK, Göttingen 1968, 356) s. Apg 9,20ff; 13,5; 13,14ff; 14,1ff; 17,1ff; 17,10ff; 17,17; 18,1ff; 18,26; 19,8ff. Zur Sache s. K.G. KUHN, ThWNT VI, 744f; sein Fazit: die Darstellung der paulinischen Missionstätigkeit in der Apg entspricht "genau den damaligen Verhältnissen. Sie ist also sachgemäß, und es besteht kein Anlaß, ihre historische
} 
ten die "Anknüpfung in der Synagoge", die Erfahrung des Widerstandes gegen die neue Lehre und als Konsequenz davon die Verselbständigung der Gemeinde in einem für sie günstigereren Versammlungsraum drei Elemente in jenem Proze $B$ der Herausbildung christlicher Gemeinden gewesen sein, die Anspruch auf Historizität haben und sich so mehrfach wiederholt haben mögen: Immer wieder kam es zur Aufhebung der synagogalen Gemeinschaft, zur Absonderung und zur Verselbständigung der christlichen (Haus-) Gemeinden.

2Kor 6,14-7,1 wurzelt in diesem Konflikt, hat hier seinen konkreten Anlaß und gewinnt auf solchem Hintergrund faszinierende Eindeutigkeit seiner Aussagen. Eine erzählende Paraphrase mag dies verdeutlichen:

Ich stelle mir vor, daß Paulus mit seiner Botschaft zunehmend auf Widerstand gestoßen ist. Der letzte Auftritt in der Synagoge endete mit tumultartigen Szenen. Seitdem schwirren Gerüchte durch die Stadt. Angeblich will man ihn nicht mehr in der Synagoge reden lassen. Auch soll er aus der Stadt gewiesen werden. Die, die schon längere Zeit mit der neuen Lehre symphathisierten, bekommen die Ablehnung ihrer Mitbürger und bisherigen Glaubensgenossen deutlich zu spüren. Der Druck von Seiten der Gemeindevorsteher wächst.

Wie soll es weitergehen? Was ist $\mathrm{zu}$ tun? Um dies zu überlegen, trifft man sich einige Tage nach dem letzten Auftritt des Paulus, diesmal aber nicht in der Synagoge, sondern in einem größeren Raum eines

Richtigkeit zu bezweifeln". S.a. C. BURCHARD, Der dreizehnte Zeuge. Traditions- und kompositionsgeschichtliche Untersuchungen zu Lukas' Darstellung der Frühzeit des Paulus, FRLANT 103, Göttingen 1970, 165ff, bes. A.16. Ganz anders dagegen G. LÜDEMANN, Paulus, der Heidenapostel Bd 1 Studien zur Chronologie, FRLANT 123, Göttingen 1980, der meint, Paulus habe keine Judenmission betrieben. "Die kritische Forschung ist sich darüber einig, daß die stereotype Anknüpfung Pauli bei den Juden in den Berichten der Apg lukanisches Schema ist und in dieser Ausschließlichkeit jedenfalls nichts mit der paulinischen Missionsmethode gemein hat" aaO 96 Anm. 85. S. DERS., Das frühe Christentum nach den Traditionen der Apostelgeschichte. Ein Kommentar, Göttingen 1987. S. jetzt aber W. STEGEMANN, Zwischen Synagoge und Obrigkeit; zur historischen Situation der lukanischen Christen, FRLANT 152, Göttingen 1991. STEGEMANN geht bei dem Versuch einer "historischen Einordnung der Rolle der Synagogen im Kontext der Gefährdungen der lukanischen Christen" auch auf "entsprechende Reflexe solcher Erfahrungen" u.a. im paulinischen Schrifttum ein und kommt - ohne Berücksichtigung von 2Kor 6,14-7,1 - zu folgendem Ergebnis: "Generell wird man sagen dürfen, daß die Verfolgeraktivitäten des Paulus bzw. seine eigenen entsprechenden Erfahrungen einen innerjüdischen religiösen Konflikt voraussetzen, in dem Urheber und Betroffene Juden sind. Es geht hier nicht um einen interreligiösen Konflikt zweier unterschiedlicher Glaubensgemeinschaften oder religiöser Systeme. Von jüdischer Seite aus geht es um die Disziplinierung von (vermeintlichen) Apostaten bzw. deren Protagonisten. Ganz offenkundig handelt es sich hier also um Erfahrungen aus den Anfängen der Entstehung christlicher Gemeinschaften, in denen das messianische Glaubensbekenntnis, zumal dessen Propagierung im Einflußbereich der Synagogen als religiöse Devianz ... gemaßregelt wird" (aaO 134ff; die Zitate 134.135). 
Privathauses. Die Besitzer gehören seit längerem zu den Anhängern der neuen Lehre und haben in Absprache mit Paulus zu der Versammlung eingeladen. Die Stimmung ist gespannt als Paulus das Wort ergreift und nach einigen einführenden Sätzen die Anwesenden wie folgt anredet ${ }^{9}$ :

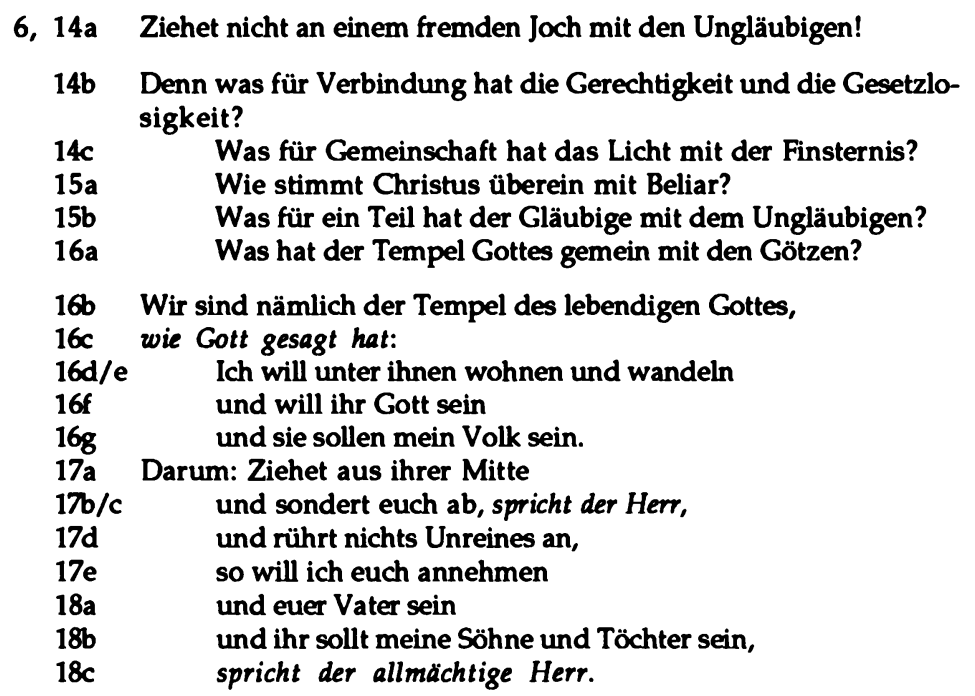

7, 1a Da wir nun diese Verheißungen haben, Geliebte,

1b wollen wir uns reinigen von aller Befleckung des Fleisches und des Geistes

1c und die Heiligung vollenden in der Furcht Gottes.

\section{ANALYSE DER EINZELNEN AUSSAGEN}

Im Zentrum der Paränese steht - unter Aufnahme von den Zuhörern vertrauten Zitaten ihrer Tradition- die klare und eindeutige Aufforderung:

6,17a-d Ziehet aus ihrer Mitte und sondert euch ab, spricht der Herr, und rührt nichts Unreines an!

In der bisherigen Auslegung des Abschnittes ist dieser Satz oft als schwierig empfunden worden.

Zum einen hat man gemeint, der Gedanke einer strikten Abgrenzungsforderung widerspreche paulinischer Theologie ${ }^{10}$ und sieht deshalb hierin ein weiteres Indiz für die Nichtechtheit des Abschnittes.

Andere, die den Passus für Paulus zu retten versuchen, tun sich aber ebenfalls schwer mit der Deutung dieser klaren Mahnung. So

9 Die Gliederung folgt der detaillierten Analyse von H.D. BETZ [A.4; 1988] 554ff.

${ }^{10}$ Meist unter Hinweis auf 1Kor 5,1ff (V.9f!); 7,12-14 und 10,27. 
meint zB M.E. THRALL11, daß Paulus, der hier ein vorgegebenes Textstück mit mehreren Schriftzitaten übernommen habe, diesen Satz wohl oder übel stehengelassen habe, weil sein eigentliches Interesse bei der Aufnahme dieser Katene auf die folgenden Verheißungen gerichtet gewesen sei. Und J. LAMBRECHT meint, diese Formulierungen (wie auch andere) seien "in a figurative sense" gebraucht. "The antithetical way of speaking is decidedly paradoxical and should not be taken as literal speech demanding a strict and 'bodily' separation"12. Damit wird aber der hinter dem Text stehende Konflikt heruntergespielt und die scharfen Konturen, die der Text spiegelt, verwischt!

Nein, Paulus nimmt diese "Zitate" absichtlich und überlegt auf bzw "zitiert" diese Schriftstellen bewußt, weil er damit aussagen kann, was aus seiner Sicht Gebot der Stunde ist:

Ziehet aus ihrer Mitte und sondert euch $\mathbf{a b}^{\mathbf{1 3}}$ und rührt nichts Unreines an!

Dies ist ganz konkret gemeint und auf die Aufhebung der bisher praktizierten Gemeinschaft mit der Synagoge bezogen! Indem Paulus Jes 52,11 LXX aufnimmt, setzt er die Situation der werdenden christlichen Gemeinde am Ort in Beziehung zu der der Exulanten in Babylon. Auszug ist angesagt, in Erinnerung an den Exodus der Exilierten aus der babylonischen Gefangenschaft nunmehr aus dem als feindlich erlebten Verband der Synagoge ${ }^{14}$. Wohl aber auch aus anderen religiösen und kultischen Lebenszusammenhängen, in denen seine Zuhörer bisher existierten.

Eine derartige Deutung kann durch Verweis auf - wenn unsere $\mathrm{Zu}$ ordnung des Abschnittes stimmt - etwa zeitgleiche wie auch spätere paulinische Aussagen gestützt werden. So lesen wir zB in 1Thess 4,1-8 in V.7 die die vorangehenden Paränesen begründende und zusammenfassende identitätsstiftende Aussage:

\footnotetext{
11 M.E. THRALL, The problem of II Cor.VI.14-VII.1 in some recent discussion, in: NTS 24 (1977/78) $132 \mathrm{ff}$.

12 J. LAMBRECHT [A.4] 159.

13 Ist es nur Zufall, daß Lukas in Apg 19,9 berichtet, daß Paulus sich von innen (den Widerstand leistenden Mitgliedern des Synagogenverbandes) "trennte" und auch die Jünger "absonderte"(!)? H.D. BETZ [A.4; 1973] 96 Anm. 54: "In the NT, the term dipopi $\zeta a v$ in this sense (scil. as cultic-ritual separation from the 'unclean') occurs only in 2Cor 6:14 and Gal 2:12." Das stimmt so nicht. Neben Apg 19,9 sind zumindest auch Mt 13,49 und 25,32 heranzuziehen für das damit angedeutete Konzept (das hebräische Schlüsselwort ist ברד, s. dazu E. SCHWARZ [A.2] passim und für die neutestamentlichen Belege 151f). Wie weit es dann bei den einzelnen Belegstellen um eine "cultic-ritual separation from the 'unclean'" geht, ist eine zweite Frage.

14 Vielleicht darf man als konkreten Hintergrund für den dritten Teil des Zitats "und rührt nichts Unreines an!" auf Vorgänge verweisen, wie sie Lk in Apg 19,18f; 19,23ff berichtet. Dabei gilt es zu beachten, daß unter seinen Zuhörern neben Juden auch "Gottesfürchtige" und Griechen sind.
} 
Denn Gott hat uns nicht berufen zur Unreinheit, sondern zur Heiligung 15 .

Der abgrenzende Unterton ist deutlich hörbar, ausdrücklich in V.5, wo "die Heiden" genannt sind.

In Röm 6,19 samt Kontext markiert die christliche Taufe einen grundlegenden Wechsel von einem Herrschaftsbereich in den anderen, vom "Dienst der Unreinheit und Ungerechtigkeit" zum "Dienst der Gerechtigkeit", "zur Heiligung"16.

Diese beiden Belege mögen genügen, um die Vermutung, Paulus selber habe bewußt die genannten alttestamentlichen Texte "zitiert", um die Anwesenden in jener konkreten Situation zu den Schritten zu bewegen, die er für notwendig hielt, durch ähnliche unbestritten paulinische Argumentationsgänge zu stützen.

Wie begründet nun Paulus diese im Zentrum seiner Paränese stehende Aufforderung zur Aufhebung der synagogalen Gemeinschaft und zur Abgrenzung von der bisherigen religiös-kultischen Heimat? Er erhebt seine Forderung ja offenkundig ( $\delta$ ió am Anfang von 17!) als Folgerung, als Konsequenz seiner bis dahin gemachten Ausführungen.

Diese beginnt er ebenfalls mit einer Mahnung:

6,14a Ziehet nicht an einem fremden Joch mit den Ungläubigen!

Paulus ruft also die Versammelten zunächst auf, nicht weiterhin am für sie fremden Joch mit den Ungläubigen zu ziehen. Über die Deu-

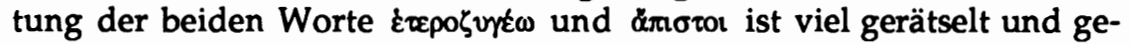
schrieben worden. Was ist gemeint?

Es liegt nahe, unter dem "fremden Joch" die Lehre der Widersacher zu verstehen, vorab also die der Synagoge. Dies legt der vermutete "Sitz im Leben" nahe, dies wird aber auch durch sprachliche Beobachtungen gestützt'17.

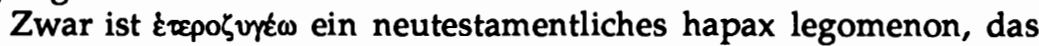
auch weder in der LXX noch in den Apokryphen und auch nicht in son-

$15 \mathrm{~S}$. in 1Thess 4,1 den Gedanken der "Vervollkommnung" (vgl 2Kor 7,1), dann 1Thess 4,3: "Dies ist nämlich der Wille Gottes, eure Heiligung (vgl 2Kor 7,1), daß ihr meidet die Unzucht". Im Anschluß an die dann folgenden Konkretionen dann in V.7 die das vorangegangene begründende Aussage, bei der Paulus sehr grundsätzlich argumentiert und zwei Bereiche einander entgegenstellt (vgl 2Kor 7,1 und schon 6,14b-16a). In V.8 schließlich noch das Motiv des von Gott "in euch" gegebenen heiligen Geistes; vgl 2Kor 16d.f und dazu H.D. BETZ [A.4; 1973] 93-95.

áxatapoia bis auf Mt 23,27 nur in Paulusbriefen (6x) sowie im Eph (2x) und im Kol (1x).

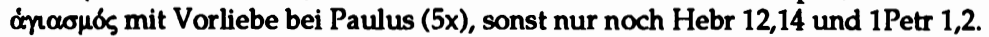
ónoúvn nur bei Paulus (neben 2Kor 7,1 noch Röm 1,4; 1Thess 3,13).

16 S. Röm 6,17f.20.22: "Knechte der Sünde" - "Knechte der Gerechtigkeit" bzw "Knechte

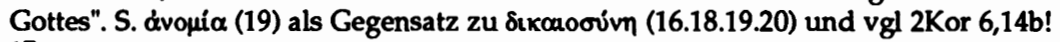

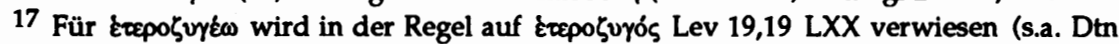
$22,10)$ und von da aus der Sinn zu erfassen gesucht. Doch liegt hier offenkundig bildhafte Rede vor, und dafür gibt es näherliegende, das Verständnis der Stelle erhellende Belegstellen. 
stigen griechischen Schriften der vorchristlichen Zeit vorkommt, aber es gibt, so scheint mir, bei Paulus selbst eine Stelle, die uns die Richtung für die Auslegung weisen kann: Gal 5,1.

Wieder, wie schon in 1Thess 4,1ff und Röm 6, geht es um die Gegensätzlichkeit zweier Bereiche: in der Zeit vor Christus waren wir unmündig, führt Paulus in Gal 4,1ff aus, unter der Knechtschaft der Mächte der Welt ${ }^{18}$. Durch Christus aber sind wir aus Knechten zu Kindern Gottes geworden ${ }^{19}$ und als solche auch Erben. Es folgt dann eine Mahnung, nicht aus dem neuen Stand in den alten, vergangenen zurückzufallen 20. Diesen Gedanken nimmt Paulus in Gal 5,1 wieder auf und formuliert sehr grundsätzlich und zusammenfassend:

Zur Freiheit hat uns Christus befreit!

So steht nun fest

und laßt euch nicht wieder das Joch der Knechtschaft auflegen.

Es ist nicht nötig, hier auf die Frage der Identifikation der galatischen Gegner des Paulus einzugehen21. Wichtig ist mir nur die sachliche Parallele zwischen Gal 5,1 und 2 Kor 6,14: was Paulus dort "Joch der Knechtschaft" nennt, bezeichnet er hier als "fremdes Joch" und meint damit jeweils die Lehre seiner Widersacher ${ }^{22}$. In dem "fremden Joch" von 2 Kor 6,14, das die Versammelten nicht weiter mittragen sollen, ist dann aber wohl konkret das jüdische Verständnis vom Gesetz zu sehen. Denn dies dürfte wohl der "Knackpunkt" gewesen sein, an dem sich die Auseinandersetzung und der Widerstand gegen die paulinische Lehre von der Freiheit vom Gesetz entzündet hat ${ }^{23}$.

$\mathrm{Da}$ wir es bei dem "fremden Joch" von 2Kor 6,14 mit der gegnerischen jüdischen Gesetzeslehre zu tun haben, dafür spricht schließlich

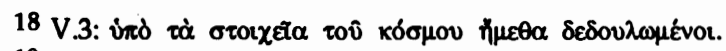

19 V.5.6.7! V.7 bezieht sich zurück auf 3,$29 ; 4,1$.

20 V.8ff.

21 S. etwa P.-G. KLUMBIES, Zwischen Pneuma und Nomos. Neuorientierung in den galatischen Gemeinden, WuD NF 19 (1987) 109ff (Lit!) sowie H.D. BETZ [A.4; 1988].

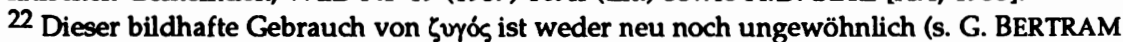
/ K.H. RENGSTORF, ThWNT II, 898ff, bes. 901ff). Von Interesse ist für uns vor allem der rabbinische Sprachgebrauch (aaO 902f und H.D. BETZ [A.4; 1973] 89f). J.A. FITZMYER, Qumran and the interpolated paragraph in 2 Cor 6,14-7,1, CBQ 23 (1961) 271ff hat zusätzlich auf alttestamentliche und qumranische Belege für solches Verständnis aufmerksam gemacht (aaO 276f Anm. 17): Ps 106,28; Num 25,3 sowie $1 \mathrm{QH} 5,24 ; 6,19$. Hier meint die hebr. Verbform jeweils "believing a teaching, following a doctrine".

In der Sache ist vielleicht 1 Makk 1,11ff zu vergleichen, wo die Ausgangslage des Konflikts zwischen den Makkabäern und den zur Assimilation an den Hellenismus bereiten Juden thematisiert wird. In V.15 wird die Position der assimilationsbereiten Glaubensgenossen aus der Sicht der Makkabäer beschrieben als: "sie verbanden sich mit den Hei-

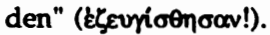

23 Es mag sein, daß das Jesuswort Mt 11,29f Paulus im Sinn war: Es geht um den Konflikt zwischen dem von Jesus auferlegten "Joch", das Paulus meint zu verkündigen, und dem, unter das seine Hörer bisher gespannt waren. 
eine Notiz des Lukas über die Auseinandersetzung auf dem sog. Apostelkonvent in Jerusalem, bei dem es ja um die Frage der Legitimität der paulinischen Heidenmission unter Absehung der weiteren Gültigkeit des jüdischen Gesetzes ging. Dort argumentiert Paulus gegen die judenchristlichen Brüder so:

Warum versucht ihr denn nun Gott dadurch, daß ihr ein Joch auf den Nacken der Jünger legt,

das weder unsere Väter noch wir haben tragen können ${ }^{24}$ ?

Nach dem bisher Ausgeführten ist klar, daß mit den äroror in 2Kor 6,14 die Teile der Synagogengemeinde gemeint sein müßten, die Paulus widersprachen, die "ungläubig blieben" 25 und sich verbal und nonverbal gegen seine Lehre auflehnten. Ist eine derartige Titulierung, bezogen auf die Synagoge, im Munde des Paulus denkbar?

Zunächst: Paulus gebraucht mehrfach in seinen Briefen ḋaoros, zT im Singular ${ }^{26}$, aber auch im Plural ${ }^{27}$, ohne daß eine bestimmte Identifizierung erkennbar wäre. Es sieht eher nach nicht festgelegtem, auf die jeweilige Situation bezogenem Sprachgebrauch aus. Es gibt aber eine ganze Reihe von Belegstellen, die eine derartige Titulierung im Munde des Paulus und auf die Synagoge bezogen als durchaus möglich bzw als wahrscheinlich erscheinen lassen.

Ein besonders interessanter Abschnitt ist für uns der Kontext von

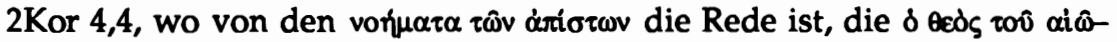
vos roviov verblendet habe ${ }^{28}$. Ein Blick auf 2Kor 3,4 - 4,6 zeigt, daß Paulus sich als "Diener eines neuen Bundes" versteht. Zwei (zeitlich) getrennte Bereiche stehen einander gegenüber, der "Dienst des Todes" bzw der "Dienst der Verurteilung" dem "Dienst des Geistes" bzw dem "Dienst der Gerechtigkeit". Das eine bezieht sich auf die Synagoge und ihre Gottesdienste, das andere meint die paulinische Christusverkündigung.

Die Sinne, die Gedanken der "Kinder Israels"(!) waren verstockt, die jüdische Verkündigung ist "bis auf den heutigen Tag" verhüllt, bei jeder Verlesung des Alten Bundes/Mose liegt eine Hülle "auf ihrem Herzen". Erst, wenn sich jemand zum Herrn bekehrt, wird die Hülle fortgenommen. Demgegenüber ergeht die paulinische Verkündigung unverhüllt. Sie ist nur denen verborgen, die verloren gehen, eben "den Ungläubigen, denen der Gott dieser Welt den Sinn verblendet hat". Es

\footnotetext{
24 Apg 15,10. S.a. V.23-29.

25 Vgl Apg 19,8f.

26 1Kor 7,12.13.14.15 und 1Tim 5,8.

27 Kor 6,6; 10,27; 14,22-24; Tit 1,15 (hier im gleichen Atemzug mit dem Gegensatzpaar

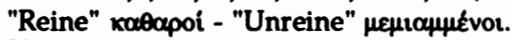

28 S. 3,14! Eindeutig die Juden meinend! Zu 2Kor 3 s. O. HofIUS, Gesetz und Evangelium nach 2.Korinther 3, JBTh 4 (1989) 105ff.
} 
ist deutlich, daß hier mit den àravor die Juden gemeint sind, die sich der paulinischen Botschaft widersetzen.

Verwiesen sei auch auf zwei Stellen im Röm, wo Paulus, sich mit der Frage des Verhältnisses der Juden zu seiner Christusbotschaft auseinandersetzend, vom "Unglauben" ámotía der Juden spricht.

In Röm 11,17-24 entfaltet er am Bild vom Ölbaum das Problem des Verhältnisses von Christen und Juden, von Kirche und Synagoge. Zwar wurden die Juden "wegen ihres Unglaubens" aus dem Olbaum ausgebrochen (V.20), aber sie können wieder eingepfropft werden, wenn sie "nicht im Unglauben bleiben".

Ebenso deutlich ist Röm 3,1ff, wo Paulus ja schon einmal, wenn auch nicht so ausführlich wie in Röm 9-11, die Frage nach dem Verhält-

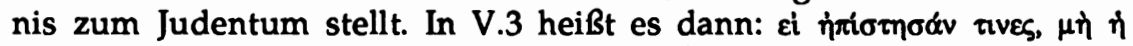

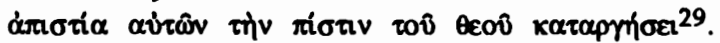

Eine Deutung von 2Kor 6,14 in dem Sinne, daß Paulus hier zur Absonderung von sich der paulinischen Verkündigung widersetzenden Teilen der Synagoge auffordert, scheint mir nach dem bisher Gesagten durchaus möglich und im Einklang mit anderen paulinischen Aussagen zu stehen.

Wie begründet nun Paulus seine Aufforderung an die Versammelten, fortan nicht mehr der Lehre derer zu folgen, die seiner eigenen Verkündigung widersprechen? Es folgen in 14b-16a fünf rhetorische Fragen, denen gemeinsam ist, daß sie die Unvereinbarkeit zwischen den Teilen der Synagoge, die an ihrer Tradition festhalten wollen, und denen, die der neuen Lehre folgen wollen, aufzuweisen suchen.

$\mathrm{Daß}$ wir bei den bisher herangezogenen paulinischen Texten mehrfach auf das Gegenüber zweier Bereiche bzw Gruppen gestoßen sind, zeigt, daß hier kein für Paulus ungewöhnliches Denken vorliegt. Die hier vorliegende Häufung und Schroffheit der Gegensatzpaare hängt mit der konkreten Situation der Auseinandersetzung zusammen. Wenige Bemerkungen zu den einzelnen Gegensatzpaaren sollen die bisherige These erhärten und die Aussagen auf dem Hintergrund des vermuteten Konflikts verdeutlichen.

6,14b Was für Verbindung hat die Gerechtigkeit und die Gesetzlosigkeit ${ }^{30}$ ?

29 Auffällig ist das durchgängige paulinische Bemühen um Differenzierung! Er spricht jeweils nur von einem Teil der Juden, die widerstehen (s. Röm 3,3; 11,5-10.17-24.25 u.ö.). Dies spiegelt $\mathrm{mE}$ die historische Erfahrung, wie ich sie oben skizziert habe.

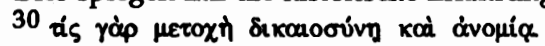


$\mu \varepsilon \tau o x$ is ist neutestamentliches hapax legomenon ${ }^{31}$, aber Paulus kennt die Verbalform $\mu \varepsilon \varepsilon \chi^{2} \omega^{32}$. In 1Kor 10,14-22 geht es ihm ebenfalls um die Unvereinbarkeit zweier einander sich ausschließender Größen. Ich kann nicht an der Gemeinschaft des Leibes/Blutes Christi teilhaben und an der Gemeinschaft der bösen Geister ${ }^{33}$, weshalb Paulus diesen Abschnitt mit der Mahnung eröffnet:

Darum, meine Geliebten ${ }^{34}$, flieht den Götzendienst!

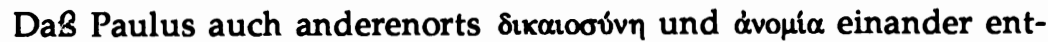
gegensetzt, haben wir bereits in Röm 6,19 gesehen. Dabei ist der Gesamtzusammenhang in Röm 6 aufschlußreich. Insbesondere der Abschnitt 6,16-23 läßt die Alternative deutlich werden, "Knechte der Sünde" oder "Knechte der Gerechtigkeit" zu sein (17f). Weil das durch die Taufe entschieden ist, kann Paulus dann in V.19 mahnen:

Wie ihr eure Glieder hingegeben hattet an den Dienst der Unreinheit und Ungerechtigkeit

zu immer neuer Ungerechtigkeit, so gebt nun eure Glieder hin

an den Dienst der Gerechtigkeit, zur Heiligung ${ }^{35}$.

6,14c Was für Gemeinschaft hat das Licht mit der Finsternis ${ }^{36}$ ?

Daß Paulus mehrfach mit dem Gegensatzpaar "Licht" - "Finsternis" arbeitet, zeigt ein Blick in die Konkordanz ${ }^{37}$. Noch signifikanter

\begin{abstract}
31 Eines der immer wiederkehrenden Argumente gegen paulinische Herkunft des Abschnittes ist das der vielen hapax legomena in $2 \mathrm{Kor} 6,14 \mathrm{ff}$. Hier sind $\mathrm{mE}$ methodische Bedenken angebracht. S. dazu die guten Bemerkungen bei G.D. FEE, II Corinthians VI,14VII,1 and food offered to idols, NTS 23 (1976/77) 144ff.

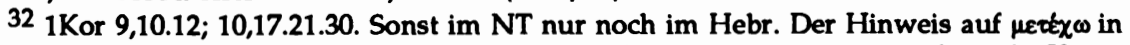
1 Kor 10 bei A. SCHLATTER, Paulus der Bote Jesu. Eine Deutung seiner Briefe an die Korinther, Stuttgart 1956, 580f und G.D. FEE [A.31] 144f. FEE versucht, 2Kor 6,14-7,1 insgesamt

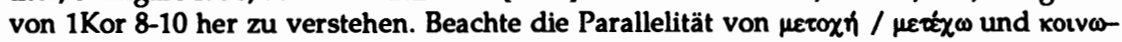
via sowohl in 1 Kor $10,14 \mathrm{ff}$ wie in 2 Kor 6,14f. Es gibt $\mathrm{mE}$ keinen grundsätzlichen Unterschied der beiden die jeweiligen Abschnitte einleitenden Imperative. Beide sind situationsbezogene Aussagen, die auf Abgrenzung in einer bestimmten Situation zielen. Beide dürfen nicht als allgemeine Aussagen des Paulus bzw christlicher Ethik mißverstanden werden!

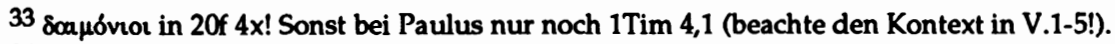

34 dyountol hier wie in 2 Kor 7,1 !
\end{abstract}

35 S. bereits oben A.15. Wie bringt H.D. BETZ den Befund von Röm 6 in Einklang mit

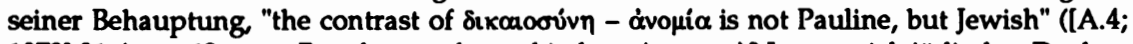
1973] 91 Anm. 12 unter Berufung auf verschiedene Autoren)? Lassen sich jüdisches Denken und die sich entwickelnde(!) Theologie des Juden (!) Paulus so eindeutig voneinander abgrenzen? - Der Hinweis auf Röm 6,19 auch bei G.D. FEE [A.31] 147. Im übrigen: Vgl zu Röm 6,192Kor 7,1! In der Intention der Aussage besteht für mich kein Unterschied.

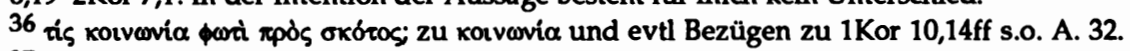

37 An folgenden Stellen finden sich beide Begriffe beieinander: Röm 2,19; 13,12; 1 Kor 4,5 (hier wrí(w); 2Kor 4,6 (V.3-6!); 6,14; 1Thess 5,4f (vgl noch Eph 5,8, beachte hier den 
aber als dieser Befund sind die inhaltlichen Bezüge, die wir beobachten können. So, wenn er in Röm 13,12 mahnt:

Laßt uns ablegen die Werke der Finsternis und anlegen die Waffen des Lichts ${ }^{38}$.

In Röm 2,19 ergeht der Vorwurf an die Juden, sie maßten sich an, und zwar aufgrund ihrer Gesetzeslehre, Leiter der Blinden, Licht derer zu sein, die in Finsternis sind, obwohl sie in Wahrheit doch selber blind sind bzw in Finsternis leben ${ }^{39}$.

In 1Thess 5,4f werden "die Kinder des Lichts" denen gegenübergestellt, die in der Finsternis sind 40 .

Auch 2Kor 4,3-6, den wir oben schon einmal herangezogen haben, muß hier genannt werden: Das paulinische Evangelium bleibt den "Ungläubigen" verdeckt, weil "der Gott dieser Welt" ihren Sinn verblendet hat, daß sie nicht sehen das helle Licht des Evangeliums von der Herrlichkeit Christi ... Gott ... hat aber in die Herzen des Paulus (und seiner Mitarbeiter) einen hellen Schein hineingegeben, daß durch sie die Erleuchtung entstünde ...

Schließlich sei auf 2Kor 11,14 und Kontext aufmerksam gemacht, wo Paulus in harter Auseinandersetzung mit den gegnerischen "Überaposteln" bzw "falschen Aposteln", die sich als "Apostel Christi" darstellen, dies darauf zurückführt, daß sich der "Satan" selbst als "Engel des Lichts" verstelle, was erkläre, daß sich "seine Diener" als "Diener der Gerechtigkeit" ausgeben.

6,15a Wie stimmt Christus überein mit Beliar ${ }^{41}$ ?

Diese dritte Frage, mit der Paulus die Angeredeten von der Richtigkeit und Notwendigkeit seiner Eingangsparänese zu überzeugen sucht, ist nun von besonderer Bedeutung für die Verortung des Gesamtabschnittes.

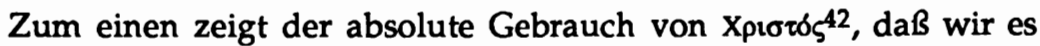
mit einem Text zu tun haben, der aus einer christlichen Gemeinde bzw von einem christlichen Verfasser stamm ${ }^{43}$.

Kontext ab V.1ff!, Kol 1,12f). Diesen Stellen stehen nur wenige gegenüber, wo Paulus nur einen Begriff bringt: 2Kor 11,14 und 1Tim 6,16 (s.a. Eph 6,12).

$38 \mathrm{Vgl}$ TestLev 19,1: "Und jetzt, meine Kinder, habt ihr alles gehört. Wählt euch das Licht oder die Finsternis, das Gesetz des Herrn oder die Werke Beliars".

39 V.17-29. Es folgt dann der oben schon herangezogene Abschnitt Röm 3,1ff.

40 "Kinder des Lichts" im NT nur noch in Eph 5,8. Der Abschnitt Eph 5,1ff ist in vielerlei Hinsicht ein mit 2Kor 6,14ff vergleichbarer Abschnitt.

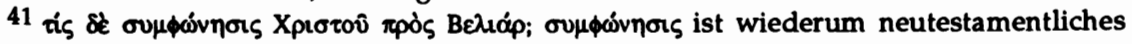
hapax legomenon, doch s. oípwovos 1 Kor 7,5 .

42 Für Paulus überhaupt nichts ungewöhnliches, s. Konkordanz.

43 Verfechter einer Herkunft aus essenischen Kreisen müssen hier von "christlicher Überarbeitung" ausgehen (so zB J.A. FITZMYER [A.22] 275). 
Zum anderen fällt der Gebrauch des Namens Beliar auf, der weder bei Paulus noch sonst im NT begegnet, wohl aber aus zahlreichen zwischentestamentlichen Schriften und vor allem auch aus Qumrantexten bekannt ist ${ }^{44}$. Es war - offenbar in unterschiedlicher Namensform - eine zZ des Paulus für Juden "geläufige Satansbezeichnung"45. Deshalb scheint es mir keineswegs zwingend, aus dem auf das NT bezogen alleinigen Vorkommen in 2Kor 6,15 auf essenischen Ursprung des Abschnitts zu schließen und im Vorkommen der Bezeichnung ein Indiz für nicht-paulinische Herkunft zu sehen. Warum sollte Paulus hier nicht sehr bewußt eine Bezeichnung für den göttlichen Widersacher gebrauchen, mit dessen Nennung seinen Hörern sogleich das damit signalisierte Konzept vor Augen steht, freilich nun auf die neue, eigene, gegenwärtige Situation bezogen? Paulus tut damit nichts anderes als was in den innerjüdischen Streitigkeiten um das wahre Israel gang und gäbe war!

$\mathrm{Da} B$ Paulus die Vorstellung eines göttlichen Gegenspielers teilt, geht aus seinen Briefen eindeutig hervor. In der Regel verwendet er dabei den Begriff $\sigma \alpha \tau \alpha v \hat{s}$, gebraucht aber auch eine ganze Reihe weiterer unterschiedlicher Bezeichnungen. Zwei Abschnitte mögen als Beleg dafür genügen:

Noch einmal sei auf 2 Kor 4,3f verwiesen, wo er davon spricht, daß sein Evangelium den Ungläubigen verdeckt bleibt, weil ihnen "der Gott dieser Welt" den Sinn verblendet hat.

Und auch 2Kor 10-12 sei noch einmal angeführt, wo sich Paulus mit Angriffen anderer "Apostel" auf sich und sein Apostelamt auseinandersetzt und folgende Argumentation aufbaut:

Die Gegner sind "falsche Apostel", "betrügerische Arbeiter", die sich als "Apostel Christi"(!) verstellen, als "Diener der Gerechtigkeit", als "Diener Christi"(!), während sie in Wirklichkeit - jedenfalls aus der Sicht des Paulus - "Diener des Satans" sind, der sich seinerseits als "En-

\footnotetext{
44 S. für Qumran K.G. KUHN, Konkordanz zu den Qumrantexten, Göttingen 1960, 33 (allerdings immer Belial; doch sind insgesamt verschiedene Namensformen belegt, s. etwa K. BERGER, Das Buch der Jubiläen, JSHRZ II/3, Gütersloh 1981, 318.409). Dabei signalisiert die Bezeichnung Beliar / Belial oftmals eine erstaunliche konzeptionelle Nähe der Texte. Ich nenne vor allem 1QS II,1ff (s.a. 1QM XIII,1-6); 1QM I,1ff; XIII,9ff; 4QFlor I,79. - Außerhalb Qumrans sei verwiesen auf TLev 19,1 (s.o. A.37); TIss 6,1; TNaph 2,6f; TDan 5,1; TJos 20,2; Jub 1,19-21; 15,30-34. An diesem Abschnitt ist für uns besonders aufschlußreich, daß hier die Bezeichnung "Söhne Beliars" (V.33) innerjüdisch auf die Gruppe der Gegner angewandt wird. Weitere Belege bei K. BERGER 318. - S.a. J. GNILKA, 2Kor 6,14-7,1 im Lichte der Qumranschriften und der Zwölf-Patriarchen-Testamente, in: Neutestamentliche Aufsätze. Festschrift für Prof. J. Schmid zum 70. Geb., Regensburg 1963, 90f; G.D. FEE [A.31] 146; W. FOERSTER, Art. Beliar, ThWNT I, 606. Zur Sache s. P. VON DER OSTEN-SACKEN, Gott und Belial. Traditionsgeschichtliche Untersuchungen zum Dualismus in den Texten aus Qumran, StUNT 6, Göttingen 1969.

45 K. BERGER [A.44] 409. Ähnlich G.D. FEE [A.31] 146: "It is a thoroughgoing trademark of the Jewish apocalyptic period".
} 
gel des Lichts" verstellt. Die Gegenüberstellung, die Paulus hier vornimmt, die Art der Argumentation und der konzeptionelle Hintergrund, auf dem dies geschieht, entspricht bis zu einem gewissen Grade der aus Qumran und zwischentestamentlichen Texten bekannten Sichtweise, was bis in die Begrifflichkeit hineinreich ${ }^{46}$, ohne daß jemand deshalb dem Paulus diese Kapitel absprechen wollte ${ }^{47}$.

Die Gegenüberstellung von Christus und Beliar in 2Kor 6,15 geht nun aber in nichts über die in 2Kor 10-12 zu erschließende von Christus und Satan hinaus, und ich sehe keinen Grund, diese Gegenüberstellung Paulus abzusprechen, sie etwa als nachträgliche christliche Bearbeitung eines essenischen Textes zu verstehen. Nein, Paulus bringt hier sein Anliegen auf den kürzestmöglichen Punkt: Weil es zwischen Christus und Beliar keine Gemeinschaft geben kann, kann es auch keine geben zwischen denen, die Christus angehören wollen und denen, die sich so die paulinische Deutung! - in Ablehnung seiner Christusbotschaft als Anhänger Beliars entpuppen ${ }^{48}$.

\section{6,15b Was für ein Teil hat der Gläubige mit dem Ungläubigen ${ }^{49}$ ?}

Ist es Zufall, daß Paulus in den ersten beiden Fragen abstrakte Gegensatzpaare wählt und in den nächsten beiden "Personen" einander gegenüberstellt? So wie es keine Gemeinschaft zwischen Christus und Beliar als den beiden Exponenten der Bereiche Licht und Finsternis geben kann, so auch kein gemeinsames (Erb-) Teil ${ }^{50}$ zwischen ihren je-

$46 \mathrm{Vgl}$ etwa 1QM XIII,9ff, wo einander gegenübergestellt werden: Fürst des Lichts / alle Söhne der Gerechtigkeit / Söhne des Lichts - Belial=Engel der Feindschaft / Engel des Verderbens / Söhne der Finsternis.

47 Das, was seine Konzeption von der seiner jüdischen Glaubensbrüder unterscheidet, ist seine Christologie!

48 Es sei noch einmal darauf aufmerksam gemacht, daß es eine enge sachliche Verbindung zwischen dem Gegensatzpaar "Licht - Finsternis" und dem von "Christus - Beliar" gibt. TLev XIX,1; TNaph II,6f; TJos XX,2; 1QS II,1ff; 1QM I,1ff; XIII,1ff.9ff; 4QFlor I,7-9 u.ö. zeigen, daß im Umfeld der Rede von Beliar o.ä. die Gegensatzpaare "Licht - Finsternis" bzw "Söhne des Lichts - Söhne der Finsternis" fast schon stereotyp zum Wortfeld hinzugehören. Daher scheint es mir problematisch zu sein, wenn H.D. BETZ [A.4; 1973] 91 Anm. 14 behauptet: "The coordination of with Xporos, and of oxóros with Belial is found only here in the NT". Einerseits stimmt der Satz natürlich deshalb, weil Beliar eben nur in 2Kor 6,15 innerhalb des NT vorkommt. Andererseits zeigen die eben benannten Belege, wie wenig neu - abgesehen vom Christusnamen natürlich - die Zuordnung des Gegensatzpaares von $14 \mathrm{c}$ "Licht - Finsternis" mit dem von 15a ist. Und 2Kor 4,3f sowie 2Kor 11,14f zeigen, daß Paulus diese konzeptionell bedingte Zuordnung wohl vertraut ist, wenn auch seine Begrifflichkeit in der Bezeichnung des göttlichen Gegenspielers flexibel ist (Gott dieser Welt - Satan - Beliar).

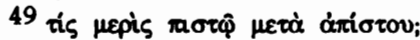

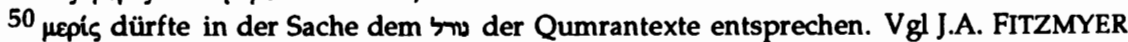
[A.22] 274f; H.D. BETZ [A.4; 1973] $91 \mathrm{mit}$ Anm. 13. Oft wird auf Kol 1,12 verwiesen. Röm 8,17 etwa wäre dann auch zu nennen (hier: $k_{\lambda}$ npovó $\mu$ ol) ebenso wie 1 Kor 6,9-11! Zum Konzept s. dann auch Lk 12,46; Offbg 21,8 (jeweils $\mu$ epos). 
weiligen Anhängern, dem Glaubenden einerseits, dem Ungläubigen andererseits.

Paulus nimmt damit das Stichwort ¿noror aus der Eingangsparänese auf, spricht nun aber jeden Einzelnen seiner Hörer an. Es geht um persönliche Entscheidung für oder gegen Christus.

6,16a Was hat der Tempel Gottes gemein mit den Götzen ${ }^{51}$ ?

Das fünfte Gegensatzpaar "Tempel Gottes - Götzen" ist, wie wir sehen werden, für den Fortgang der paulinischen Gedankenführung wichtig. Zuvor aber sei noch eine Beobachtung zu oupkardécors festgehalten, dessen Wiedergabe schwierig ist, wie ein Vergleich gebräuchlicher Übersetzungen zeigt ${ }^{52}$. Ist es denkbar, daß Paulus formuliert hat auf

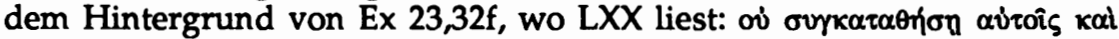

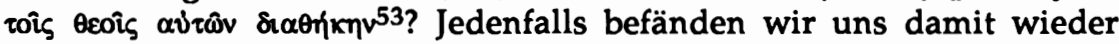
im gleichen konzeptionellen Kontext der Identitätsgewinnung durch Abgrenzung54. Da paßt die in 2Kor 6,16 vorhandene Polemik und Abwehr der "Götzen" exakt in das aus der Geschichte jener Tradition bekannte Bild. Es ist dort ein über mehr als ein Jahrtausend konstanter Topos der Entfaltung des jeweiligen Grundgebotes mit unterschiedlichen Konkretionen, die vom Gebot zur Zerstörung fremder Kultstätten über das Fremdgötterverbot bzw das Gebot zur alleinigen Verehrung Jahwes bis hin zur Untersagung der Teilnahme an fremden Opfermahlzeiten reichen ${ }^{55}$.

Was könnte nun in der von mir vorausgesetzten Redesituation

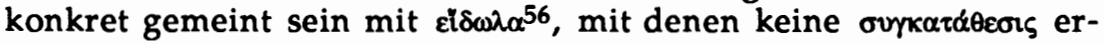
laubt ist? Erinnert sei daran, daß die Versammlung nicht nur aus Juden, sondern zu einem erheblichen Teil auch aus Nichtjuden bestanden

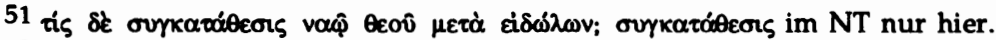

52 Luther: Was hat der Tempel Gottes gemein mit den Götzen?

EÜ: $\quad$ Wie paßt der Tempel Gottes zu den Götzen?

Zürcher: Was für eine Vereinbarung besteht zwischen dem Tempel Gottes und den Götzen?

So auch H.D. BETZ [A.4; 1988] 555. Letztere Übersetzung ist am dichtesten am Text, aber was besagt sie?

53 Hinweis auf Ex 23,32f auch bei J. GNILKA [A.44] 88 mit Anm. 9, irrtümlich auf die vierte statt auf die fünfte Frage bezogen.

$54 \mathrm{Zu}$ Ex 23,20-33 und verwandten Texten s. E. SCHWARZ [A.2] 41ff. Nachdem das in vorexilischer Zeit gültige grundsätzliche Vertragsverbot aufgrund gewandelter politischer Verhältnisse nicht mehr zu realisieren war, trat an seine Stelle in nachexilischer Zeit die ebenso grundsätzliche Absonderungsforderung (aaO 63ff). ME steht 2Kor 6,14-7,1 in eben dieser Traditionsgeschichte, deren Wirkungsgeschichte ich für das Jubiläenbuch ebenso wie für Qumran in der genannten Arbeit aufgezeigt habe.

55 E. SCHWARZ [A.2] 23ff.48ff.106ff.

56 Auffällig ist die Konzentration dieses und verwandter Worte auf das paulinische Schrifttum (s. Konkordanz und F. BÜCHSEL, Art. Ě $\delta \omega \lambda$ Jv, ThWNT II, 373ff). G.D. FEE [A.31] $158 \mathrm{f}$ und passim versteht unseren Abschnitt von 1Kor 8-10 her. 
haben wird. Ihnen zumindest war die Verehrung diverser Gottheiten und ihrer Kultbilder in den zahlreichen Tempeln der Stadt selbstverständlich ${ }^{57}$. Dies, so macht Paulus klar, muß sich ändern, wenn sie in Zukunft zum "Tempel Gottes" gehören wollen. Eine weitere Verehrung der bisher von ihnen angebeteten Götter und ihrer Kultbilder ${ }^{58}$ ist dann ausgeschlossen 59 .

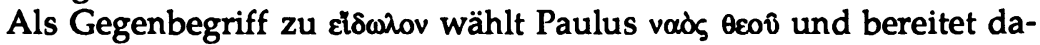
mit die seine fünf Fragen abschließende identitätsstiftende Aussage von $16 \mathrm{~b}$ vor. Dieser Sprachgebrauch von vads $\theta \varepsilon 00$ als Selbstbezeichnung ist ebenfalls von Qumran her bekannt ${ }^{60}$, begegnet aber dann auch in 1 Kor $3,16 \mathrm{f}$ und in etwas anderer Weise in 1Kor 6,19.

Nun ist die Basis für die konstruktive Schlußfolgerung gelegt. 16b als "bekenntnishafte Selbstdefinition der Gemeinde"61 formuliert in Aufnahme von 16a die Identität der neu zu bildenden Gemeinde:

6,16b Wir sind nämlich der Tempel des lebendigen Gottes.

Ich vermag keinen Unterschied in der Intention dieser Aussage zu der von 1Kor 3,16f zu sehen, wo Paulus die Korinther anspricht:

Wißt ihr nicht, daß ihr der Tempel Gottes seid,

und daß der Geist Gottes in euch wohnt?

Wenn jemand den Tempel Gottes verdirbt, den wird Gott verderben;

denn der Tempel Gottes ist heilig; der seid $i^{62}$.

$57 \mathrm{Ob}$ es sich nun um Korinth oder eine der anderen Städte paulinischen Wirkens handelt. Für Korinth s. zB H. CONZELMANN, Die Apostelgeschichte, HNT, Tübingen 1963, 105: "Sie (die Stadt) besaß ein fluktuierendes religiöses Leben, war eine Einfallspforte für asiatische Kulte". S.a. die diversen Tempel auf dem Lageplan Korinths, auf der aus BHH stammenden Kartenbeilage zu CONZELMANNs Kommentar.

58 F. BÜCHSEL [A.56] 375: ǩ Kultbilder".

59 Verwiesen sei auf Apg 19,23ff, den Bericht vom Tumult des Demetrius. Danach steht Paulus mit seiner neuen Lehre in offenem Konflikt mit dem Tempel der Artemis. Dies betrifft offenbar nicht nur den dort praktizierten Kult, sondern auch das mit der Herstellung von Kultfiguren befaßte Handwerk, das nun um seine Existenz bangt als Konsequenz paulinischen Wirkens. Derartiges könnte durchaus den konkreten Hintergrund dieses letzten Gegensatzpaares abgegeben haben. Paulus nimmt diesen Gedanken ja in der grundlegenden, die Konsequenzen aus seinen fünf Fragen ziehenden Abgrenzungsforderung noch einmal auf, wenn er die Versammelten mahnt: "... und rührt nichts Unreines an" (17d).

60 S. etwa H.D. BETZ [A.4; 1973] 92 mit Anm. 20 (Lit.) sowie G. KLINZING [A.5].

61 H.D. BETZ [A.4; 1988] 557.

62 S. E. SCHÜSSLER-FIORENZA, Zu ihrem Gedächtnis ... Eine feministisch-theologische Rekonstruktion der christlichen Ursprünge, 1988, 246f und F. LANG, Die Briefe an die Korinther, NTD 7, Göttingen 1986 zSt. 
Daß dies ein totaler Affront gegen eine bestimmte Ausprägung jüdischer Tempeltheologie darstellt, liegt auf der Hand, ist aber im Grunde nichts Neues 63 .

Dieses Selbstverständnis der neu zu bildenden Gemeinde wird dann von Paulus durch drei Schriftverweise legitimiert; er nimmt Bezug auf Lev 26,11-13, Jes 52,11 und 2Sam 7,14.

Indem Paulus Lev 26 aufnimmt, argumentiert er aus dem konzeptionellen Zusammenhang der (Sinai-) Bundestheologie, die aber als Begründungszusammenhang hinter dem Konzept "Identität durch $\mathrm{Ab}$ grenzung" steht ${ }^{64}$. Die christliche Gemeinde erscheint bei ihm nun in Anknüpfung an prophetische Verheißungen wie etwa Jer 31,31ff als der "neue Bund"65! Liest man Lev 26,13 noch mit (bzw hat es im Ohr), dann ergibt sich erstens mit dem "ich habe euer Joch zerbrochen"66 eine in-

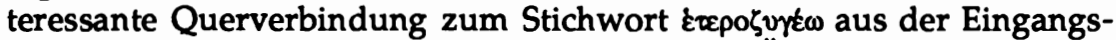
paränese $14 \mathrm{~b}$ und zweitens mit "der euch aus Ägypten herausgeführt hat" das Stichwort für das anschließende "Zitat" aus Jes 52,11. Dort nämlich wird in Erinnerung an den ersten Exodus zum Auszug aus dem babylonischen Exil aufgerufen ${ }^{67}$. Paulus deutet also hier den Auszug aus der Synagoge als Auszug aus der Knechtschaft in die Freiheit.

Das hebräische דקר "reinigt euch" kann auch als "sondert euch ab" verstanden werden ${ }^{68}$ und wird in LXX mit á weise nochmals auf die exakte Analogie des Vorganges in Apg 19,9, wo (Zufall?) auch das zweite Verb aus Jes 52,11 ápiorouar begegnet. Der Aspekt des Sich-Reinigens wird dann übrigens in 7,1 aufgenommen!

Wie erklärt sich nun die Aufnahme des dritten "Zitats" 2Sam 7,14? Der Text ist ja charakteristisch verändert, aus dem Singular in den Plural gesetzt. Seine Verheißung gilt nun nicht mehr nur dem Sohn des Davididen, sondern all den Männern und Frauen, die dem paulinischen Ruf zum Auszug aus der Synagoge folgen 69.

63 S. schon 1.Kön 8,27 (vgl Apg 7,48). In der Sache gehört hierher auch Mk 14,58: Die christliche Gemeinde tritt an die Stelle des Tempels.

64 E. SCHWARZ [A.2] passim.

65 Neben 1 Kor 11,25 s. vor allem 2 Kor 3,6 in seinem Kontext! Dazu oben A.28 sowie O. HOFIUS [A.28] (Lit.).

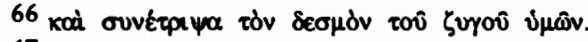

67 S. das zweimalige w¥. Zur dtjes Deutung des Exilsendes als 2. Exodus s. C. WESTERMANN, ATD 19, Göttingen 1986 zSt und 21.

68 V. HAMP in ThWAT I (1972) 842.

69 Nach E. SCHÜSSLER-FIORENZA [A.62] 250 zeigt die Anwendung des geänderten Textes von 2Sam 7,14 auf die christliche Situation, "daß die David, dem König Israels, von Gott zugesagte Sohnschaft für die Männer und Frauen in der Kirche gilt." SCHÜSSLERFIORENZA verortet 2Kor 6,14-7,1 in der "judenchristlichen Missionsbewegung" und hält ihn für ein "vorpaulinisches (aber nicht notwendig antipaulinisches) Fragment" (aaO 248). Der Deutung von H.D. BETZ zu 6,14 ([A.4; 1988] 554 Anm. 2) vermag auch sie nicht zu folgen. Sie deutet statt dessen die Eingangsmahnung "als Warnung vor der Mischehe 
Nachdem Paulus seine identitätsgründende Aussage über die neue sich bildende Gemeinschaft samt den dazu nun notwendig werdenden konkreten Konsequenzen mit Hilfe der Schriftverweise begründet hat, kommt er in 7,1 zum Schluß. 'A yórntor ist geläufige paulinische Adressatenbezeichnung. Paulus bittet die Anwesenden in dieser Schlußmahnung, die nun notwendigen Schritte zu tun. Er deutet diese auf Grund des zuvor gebrauchten Bildes vom Tempel Gottes in einer dieses Bild aufnehmenden Sprache als Reinigungsproze $B$ mit dem Ziel der Vollendung der Heiligung ${ }^{70}$.

\section{ZUSAMMENFASSUNG UND SCHLUSSBEMERKUNG}

2Kor 6,14-7,1 spiegelt die Ursprungssituation einer christlichen (Haus-) Gemeinde wieder, die ihre Selbständigkeit durch Herauslösung aus dem Synagogenverband durch Paulus gewinnt ${ }^{71}$. Der Abschnitt

zwischen Gläubigen und Ungläubigen" (aaO 249f). Ich hoffe, eine einleuchtendere Deutung gegeben zu haben.

70 S. dazu etwa 1Thess 4,3; 4,7 (oben bei A.14) und Röm 6,19 (oben bei A.35). H.D. BETZ [A.4; 1973] 98 mit Anm. 73f sowie DERS. [A.4; 1988] 556 mit Anm. 15.17 sieht in dieser Sprache deutliche Hinweise auf den nichtpaulinischen Charakter des Abschnittes. Dagegen zB G.D. FEE [A.31] 160. Ähnliches gilt für den Gebrauch von "Fleisch und Geist": H.D. BETZ [A.4; 1973] 556 Anm. 16 und dagegen FEE unter Berufung auf C.K. BARRETT. S.a. J. LAMBRECHT [A.4] 153 Anm. 22.

71 Die hier vorgetragene These zum Sitz im Leben von 2Kor 6,14-7,1 könnte auch die schwierige Frage nach dem jetzigen Ort des Abschnittes im 2Kor klären helfen.

Immerhin ist es erheblich einfacher, anzunehmen, ein altes paulinisches Stück, vielleicht eine Art Auftrittsskizze, habe später innerhalb der Zusammenstellung des Briefmaterials im Kontext der Apologie 2Kor 2,14-7,4 seinen Platz gefunden und damit gleichsam eine zweite Auslegungsebene, als mit dem Hereinkommen eines anti-paulinischen Textstückes in einen Paulusbrief zu rechnen. Man muß doch davon ausgehen, daß diejenigen, die die Sammlung der Paulusbriefe vorgenommen haben, bemerkt haben dürften, daß hier ein nicht- bzw gar anti-paulinisches Stück vorliegt. Warum hätten sie es einbauen sollen? Dies spricht mE stark gegen die These von H.D. BETZ insbesondere auch gegen seinen Versuch, die anti-paulinische Herkunft sprachlich aufzuweisen. Wenn die Unterschiede, ja Gegensätze zum übrigen paulinischen Schrifttum so groß wären, hätte dieses Textstück niemals seinen Ort innerhalb des corpus paulinum erhalten.

Vielleicht darf die Aufnahme in die Sammlung der Korintherbriefe auch als Indiz dafür gewertet werden, daß sich in diesem Abschnitt eben die Ursprungssituation der korinthischen Gemeinde spiegelt. Wie sehr der Apostel gerade im Blick auf diese Gemeinde seine "Gründungsvaterfunktion" betont, ist ja bekannt: S. nur 1Kor 4,14f; 3,6ff, wo Paulus die Korinther an seine "Grundlegung" der Gemeinde erinnert. Interessanterweise läuft die paulinische Argumentation ausgerechnet auf den Topos von der von ihm gegründeten Gemeinde als dem Tempel Gottes hinaus (1Kor 3,16f). Und bei keiner anderen paulinischen Gemeindegründung hatte wohl die "Synagoge so schwer verwindbare Abgänge zu verzeichnen" (J. BECKER [A.6] 156) wie in Korinth (vgl Apg 18)!

Schließlich sei in diesem Zusammenhang noch eine weitere Vermutung erlaubt: Wir wissen aus Röm 1,1 und Gal 1,15, daß Paulus sich als "Knecht Jesu Christi", "berufen zum Apostel", "ausgesondert, zu predigen das Evangelium Gottes" (ò 
steht also am Anfang einer Entwicklung, auch einer (Weiter-) Entwicklung paulinischer Sprache und Theologie. Seine Aussagen sind auf eine ganz konkrete Konfliktsituation bezogen und wollen von hierher verstanden werden.

Ist der Abgrenzungsproze $B$ erst einmal vollzogen, die aktuelle Konfliktlage dadurch beruhigt, kann Paulus ganz anders reden ${ }^{72}$. Insbesondere im Blick auf den scheinbar antijüdischen Duktus dieses und anderer paulinischer Abschnitte muß dies festgehalten werden. Es geht nicht um antijüdische Polemik, sondern in gewisser Weise um innerjüdische Auseinandersetzungen um das wahre Israel. Und was Paulus dazu zu sagen hat, zeigen insbesondere Röm 9-11.

Dies bedeutet nun aber auch, daß ein solcher Abschnitt nicht einfach als Legitimation für heute angeblich erforderliche Abgrenzungsprozesse "benutzt" werden darf. Eine Ursprungssituation wie die hier skizzierte läßt sich nicht mit volkskirchlicher Wirklichkeit unter bundesrepublikanischen Verhältnissen von 1992 vergleichen. Um über christliches Gemeindeverständnis unter heutigen Rahmenbedingungen nachzudenken, gilt es, die Traditionsgeschichte in Frage kommender biblischer Texte wahrzunehmen, ihre Fortschreibung etwa schon bei Paulus selbst im Blick $\mathrm{zu}$ behalten und so $\mathrm{zu}$ heute theologisch verantwortbaren Antworten zu kommen. Ich danke dem Jubilar, daß er mir als jungem Studenten und später dann als Doktorand die Freude an der biblischen Exegese und ihre Relevanz nahe gebracht hat. Für mich ist Gemeindepfarramt, Pfarrerfortbildung und nun wieder Gemeindearbeit ohne dieses ständige Gespräch mit biblischer (und dann natürlich auch darüberhinausgehender) Traditionsgeschichte undenkbar.

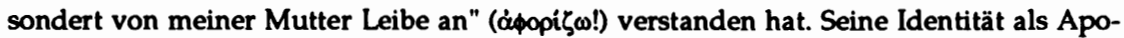
stel gründete in seinem Ausgesondertsein durch Gott. Liegt es bei solchem Selbstverständnis (zu "Selbstbezeichnungen und Selbstverständnis des Paulus" s. J. BECKER [A.6] 81ff.) nicht nahe, daß er den identitätsgründenden Schritt der Gemeindebildung durch Herausgehen aus dem synagogalen Verband ebenfalls mit diesem Begriff beschreibt, zumal er damit auf eine lange und für Israel fundamentale Tradition des Selbstverständnisses zurückgreifen konnte?

72 Vgl etwa 1Kor 7,12ff, wonach "ungläubige" Ehepartner "geheiligt" sind durch den christlichen Partner und aus solchen Ehen hervorgehende Kinder von Paulus als "heilig" statt "unrein" apostrophiert werden, sowie 1Kor 10,27. 


\title{
THE PATIENCE OF JOB IN THE EPISTLE Of JAMES
}

\author{
von \\ Christopher R. Seitz \\ Yale University
}

Within critical and general readership circles it has become popular to contrast the patient Job of the book's prologue (chaps. 1-2) with the impatient, seemingly blasphemous Job of the bulk of the book (chaps. 3$31)^{1}$. The text itself seems to commend such a reading. A noticeable change in Job's character can be detected when one crosses the border which divides chapters two and three. The transition across this gulffirmly-fixed is jarring. Where Job once patiently and proverbially maintained "the LORD gave, and the LORD has taken away; blessed be the name of the LORD" (1:21), in chap. 3 he curses the day of his birth (3:1) and sets in motion a vitriolic attack on his comforters, their God, and his own, the likes of which cannot be found in the strongest laments of the Psalter. This impatient attack is not relaxed until God himself speaks in 38:1. In the movement of the book in its present form, the patient Job exchanges the proverbial platitudes of the Prologue (1:21 and 2:10) for new and powerful forms of speech, whose characterization as "impatient" is in fact too weak.

The contrast so described exists at the flat (synchronic) level of the text. The prevailing critical model has, however, attempted to explain the origin of this contrast in terms of the Book of Job's overall development. Patience, it is argued, belongs to the earliest level of Job tradition. The diachronic argument has both a logical and a literary component. In the Book of Ezekiel, Job is included with the famous intercessors Noah and Dan'el (14:14), thus establishing his ancient origin in tradition-historical terms ${ }^{2}$. The intercessory component in Job's character is mentioned in passing in Job 1:4-5, where the reader learns that Job offered burnt offerings on behalf of his sons continually (1:5). This description is consistent with the information given about Job in Ezekiel.

\footnotetext{
${ }^{1}$ For a fuller discussion of introductory critical matters, consult the commentary of $M$. POPE, Job, AB 15: Garden City, NY: Doubleday, 1973, xv-lxxxiv. A more holistic reading has been advocated recently by N. HABEL, The Book of Job: A Commentary, Philadelphia: Westminster 1985, using the language of literary theorists ("plot development"; "plot anticipation"). See also my "Job: Full Structure, Movement, and Interpretation", Interpretation 43 (1989) 5-15.

2 For a critical discussion see M. NOTH, "Noah, Daniel und Hiob in Ezechiel XIV", VT 1 (1951) 251-60.
} 
On logical grounds, then, scholars have inferred that the Prologue (chaps. 1-2) enshrines the story of this legendary intercessor Job, with important new touches relevant to the Job story but not mentioned in the admittedly brief Ezekiel reference. Central among them is Job's patience under affliction (1:21-22; 2:10).

The literary argument is more sophisticated and involves a full description of the literary forms and growth of the wider Book of Job ${ }^{3}$. Stated simply, the Prologue and Epilogue (42:7-17) are written in a distinctive prose style, in contrast to the poetic forms of the dialogues (chaps. 3-31), Elihu (32-37) and divine speeches (38-42:6). Literary observations argue for a theory urging separate temporal, theological and authorial provenance for the various units of the book and their respective Joban presentations. The Prologue and Epilogue (together with now-missing episodes) ${ }^{4}$ are termed an "Old Folktale", whose chief subject was the patience of Job. The Dialogues are assumed to have arisen later, from a different hand. Their purpose was to demolish the older portrait of Job and free post-exilic Israel from orthodoxies encouraging (1) patience before suffering or (2) loyality to pious theories linking reward and punishment, sin and suffering. The latter are judged to be cut out of the same cloth as the proverbial niceties of the Prologue: "Shall we receive good at the hand of God, and shall we not receive evil" $(2: 10)^{5}$ ? In the present shape of the text, the patient Job becomes impatient in order that stilted doctrines of retribution might be pushed off their narrow Folktale base. Patience gives way to impatience in the character of Job, mirroring the impatience of the dialogue's composer with doctrinal explanations for suffering. This theory of the book's development has gained widespread acceptance.

That the Folktale and Dialogues should be distinguished on literary grounds is compelling, in both the synchronic and diachronic models. It should, however, be noted that the sort of distinctiveness exploited in the diachronic model, with all its wider consequences for understanding the growth of the book, depends primarily on the contrasting pictures of Job's character seen on the axis of patience/impatience. If this contrast were taken away, one could easily imagine arguments defending the coordinating and coherent nature of the juxtapositioning of prologue and dialogues in the present form of the text. Such arguments could be made and still fall short of urging common authorship and provenance for both. Instead, continuity would be established at an editorial level, involving discrete levels of tradition capable of integra-

\footnotetext{
${ }^{3}$ For a sample discussion, from a form-critical perspective, see C. WESTERMANN, The Structure of the Book of Job, Philadelphia: Fortress, 1981.

4 For a reconstruction, see H. FINE, "The Tradition of a Patient Job", JBL 74 (1955) 28-32.

5 In essence, this is the view of many general introductions to Israelite wisdom. See, for example, J.L. CRENSHAW, Old Testament Wisdom: An Introduction, Atlanta: John Knox, $1981,100-125$.
} 
tion, literary and theological. The diachronic model, however, has always viewed the tension between prologue and dialogues as irreduceable. The conclusion derived from this is that the Folktale was already in fixed and unalterable literary form, in the same way that Job's patient character was fixed and unalterable within it. Only the lengthy depiction of the "impatient Job" in the dialogues could remedy the situation and produce a tale about Job worth reading.

Curiously enough, Job exegetes whose instincts would not otherwise take them beyond the Book of Job (or Ezekiel) for critical interpretation have sought confirmation of their diachronic reconstructions in the New Testament, specifically in the Epistle of James, with its reference to "the patience of Job" at 5:11.

You have heard of the patience of Job, and you have seen the purpose of the Lord, how the Lord is merciful and compassionate ${ }^{6}$.

Admittedly, this citation does not form the cornerstone of diachronic arguments. Rather, it is used as an illustration of how, within the biblical period itself, one might have read the Book of Job and emerged with a summary picture emphasizing Job's patience. Almost inadvertently, James seems to bear out the truth of the diachronic observation regarding patience/impatience as a key index in the growth of Job traditions. This inadvertence is, however, translated into direct proposal when two more recent commentators use the James' reference right at the outset of their labors to provide simple illustration of complex literary theories to follow. Instructive are the comments of H.L. GINSBERG:

The particular virtue of the hero of the framework of Job is unflinching loyalty to God under unimaginably severe trials or, in the phrase which the King James Version of the Epistle of James v 11 has made a household word wherever English is spoken, "the patience of Job". Building on this phrase we may say that there are two main strata in the Book of Job: the Book of Job the Patient, or JP; and the Book of Job the Impatient, or JIP7.

The opening remarks of M. POPE's widely used commentary are strikingly similar:

This traditional view of the patient Job, as it is stated in the New Testament Epistle of James ( $v$ 11), is familiar to nearly everyone. It is, however, scarely a balanced view, since it ignores the thrust of more than nine tenths of the book and appears to take account only of the beginning and end of the story ${ }^{8}$.

\footnotetext{
6 This translation is taken from M. POPE's commentary [A.1] xv, where the verse serves as an introduction to the critical notes which follow.

7 H.L. GINSBERG, "Job the Patient and Job the Impatient", VT.S XVII (1960) 88.

8 see note 5 above.
} 
Thus, the Epistle of James serves as an example of an early reading which gave prominence to the Folktale's "patient Job" over against the Job of the dialogues, thereby confirming the modern critical reading9.

Given the indirect relevance this NT reference has had for critical reconstructions of the Book of Job, it seems wise to look more closely at the Epistle of James which has - via the King James Version - bequeathed to the modern commentary tradition and the broader age in which it stands the popular expression, "the patience of Job". Does this characterization of Job derive from an idiosyncratic, selective, or even inadvertantly diachronic reading of Job by James? This is the question to be explored in our brief essay. In conclusion we will return to the question of literary development in the Book of Job and the theory of patience/ impatience as an important key in that development.

Scripture (Old Testament) plays an important role in the Epistle of James. It is cited to commend faithful action (2:8). Its characters are held up as exemples of faith during trial (Abraham, 2:21) or of the power of prayer from the righteous (Elijah, 5:16). The author sees these figures as "of like nature with ourselves" (5:17); for this reason they are compelling paragons for the wider Christian community, under trial while awaiting the Parousia.

In order to encourage strong faith until the second coming (5:7), the author likens the believer to a farmer who waits for seed already sown to bear fruit, after the rains come in their due season. Action has been taken (planting), but co-operation of natural forces must ensue.

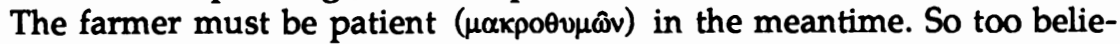

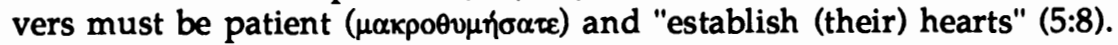
The seed has been planted (first coming) and the community must await God's co-operative action (5:8). Held up next to the faithful are "the prophets who spoke in the name of the Lord". The motivation for this is spelled out in verse 11: "Behold, we call those happy who were steadfast (rois irrourivavias)" 10 . Introduction of this key term clarifies the

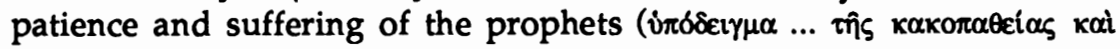

\footnotetext{
${ }^{9}$ G. V. RAD also assumes without further ado a strict differentiation between the Job cited in James and the figure of the dialogues. For example, he speaks of the place of Job in Christian theology, but means by this "not the Job of the narrative framework, for 'the story of Job's patience' (James 5.11) has, of course, always had its place in Christian preaching. But what of [the Job of] the poetic dialogue?" (Wisdom in Israel, Nashville: Abingdon, 1981, 238). James is about the patient Job of the folktale - not the Job of the dialogues.

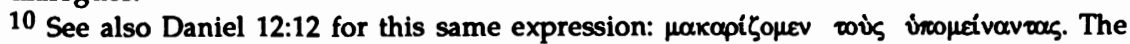
same context of steadfast waiting exists for Daniel's readers, during different historical circumstances.
} 
$\tau \hat{\eta} \varsigma \mu \alpha x p o \theta 0 \mu i \alpha \varsigma)$ spoken of in verse 10. It is seen as the result - if not the reward itself - for patient suffering.

Only at this moment is the figure of Job introduced. Note that the prior terms (patience, suffering) are not used here. What is of interest to James is the steadfastness of Job, for which a different term is used (ino$\left.\mu \circ \eta^{\prime}\right)$. Job's steadfastness is presented as an example of the kind of reward spoken of in verse 11, for which one is to be accounted blessed. Within the scope of this statement, "you have heard of the inouovin of Job", the author therefore includes the final complementary clause: "and you have seen the purpose of the Lord, how the Lord is compassionate and merciful". This latter phrase clearly refers to God's final appearance and restitution of Job, spoken of in the final chapters of the book (chaps. 38-42). The significance of this fact will be taken up shortly.

What is the range of a term like inouovin, translated by RSV at James 5:11 "steadfastness" (see also 1:3,4) and as has been noted, by KJV and

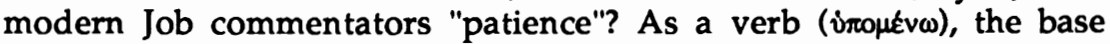
meaning is "to remain", with the nuance "behind, while others go away" (Lk 2:43; Acts 17:14) or "instead of fleeing" (Mt 10:22; 24:13; Mk 13:13; 2 Tim 2:12). In the former instance, the verb is used in neutral contexts: "... and when the feast was ended, the boy Jesus stayed behind

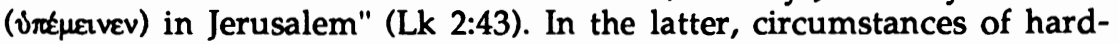
ship are presupposed; "stand one's ground", "hold out", or "endure" would all be acceptable translations. Frequently it is used in contexts where the possibility of faith wearing down is indicated:

You will be hated by all for my sake. But he who endures to the end ( $\delta \delta \dot{\varepsilon}$

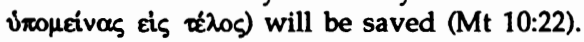

Predictably, the nominal form is similar in meaning; irouovin is best translated "endurance", "fortitude", or "steadfastness" and is to be distinguished from other Greek terms, such as "patience" ( $\mu \alpha$ kpoov $\mu_{i} \alpha$ )

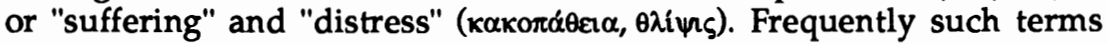
appear in the same context, as in James 5:7-11, but they are kept distinct one from another. One has the sense that "patience" may lead to "endurance", and this is the sense implied in the movement of James 5:7-11 described above. Endurance can be produced as well by trials ( and "testing of faith", such as is indicated in the introduction to James (1:2-3), or by suffering (exiqis), as in the catalogue of Romans 5:3: "we rejoice in our sufferings, knowing that suffering produces endurance (ino$\mu \circ v \eta)$, and endurance produces character, and character produces hope".

In these various instances, a distinction is to be maintained between "patience" and "endurance", similar to what one finds in a modern English-language dictionary. Endurance is defined as "to continue in the same state; tu undergo without giving in"; patience as "bearing 
pains or trials calmly or without complaint"11. The word "patience" involves attitude or emotional disposition. "Endurance" involves commitment through time without specific reference to emotional state, apart from the necessity of fortitude. Complaining or the lack thereof is not relevant unless it should slacken the ability to endure and hold fast to the end. The temporal dimension within the term "endurance" is clearly paramount. Consistent with this, in biblical texts reference is frequently made to a time-frame within which endurance is to be made manifest. The "end" (titos) has a temporal and a moral dimension, where reward for endurance is to be expected. By contrast, temporal specificity plays no necessary role in contexts of "patience". In fact, the patient person may be asked to forego knowledge of the temporal link between affliction and resolution. In this may consist true patience. In sum, one can talk about "patient endurance" and thereby qualify further what form of endurance is intended. But the two terms involve different aspects of forbearance or steadfastness ${ }^{12}$.

Seen strictly from the standpoint of etymology, several modern words have had the potential for capturing the essential quality of ino-

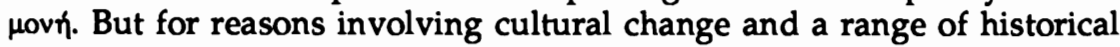
factors, several important candidates have become less helpful equivalents of the Greek inoukvw13. One thinks here of "suffer" (from the French, "to bear under")14. "Patience" was itself once quite close to this meaning of "suffer"15. It lies beyond the scope of this study to examine the semantic shift many of these words have undergone, much less provide an explanation for why shifts have occurred. Instead we would

11 Webster's Seventh New Collegiate Dictionary, Springfield, Mass.: G. \& C. Merriam, 1971.

12 The Revised Standard Vision translation of "steadfastness" for viropovin is to be commended. New Revised Standard Version also avoids "patience", adopting instead "endurance". As a nominal form, "steadfastness" is as acceptable as "endurance", its only drawback being the lack of a clear verbal form similar to "endure". This is most unfortu-

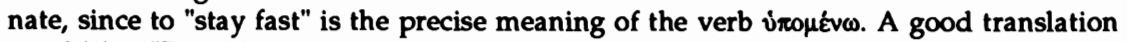
would be: "Behold we call those happy who have stayed fast. You have heard of the steadfastness of Job, and you have seen the purpose of the Lord ...". The verbal quality of "steadfastness" would thus be clearly highlighted by the (to modern English ears) etymologized form "stayed fast", for the Greek participle inourivavtac.

13 Thus confirming the objections of J. BARR regarding biblical word studies which fail to take seriously the context in which words are used. See "Etymologies and Related Arguments" in "The Semantics of Biblical Language", Oxford: University, 1961, 107-160. "Correct" translations cannot be argued for on the grounds of etymological purity, since the meanings of words change with time and under cultural influences heedless of the "true meanings" of words.

14 Anglo-French "suffrir"; Old French "sofrir", Modern French "souffrir" (Oxford English Dictionary, Oxford: Clarendon, 1933, ad. loc.).

15 In manuscripts of John WYCLIFFE's 14th century New Testament, the tension between Anglo-Saxon and Middle English renderings has occasioned a gloss for "suffring" of "pacience" at the translation of 5:11. 
urge that "endurance" or "steadfastness" are the best modern candidates for inouovi, recognizing that, historically, other terms might have served the purpose well. A verbal form like "perdure" would also capture well the sense of the verb inoukvw, though "endure" or "persevere" cover the same basic territory for modern English-speaking readers. We have already mentioned how the Anglo-Saxon verb "stead", combined with the adverbial "fast", would produce a good English rendering ("to stay fast") of $v^{\prime \prime} 0 \mu \varepsilon^{\prime} v \omega^{16}$.

One related issue can be mentioned in conclusion. It is probably the case that what we encounter in the King James' translation of "the patience of Job" at James 5:11 does not so much involve matters of translation accurancy, but rather the way in which a translator's own language undergoes change or slippage in the course of time. It is difficult to chart the differing ways culture has heard and used the word "patience"17. In any event the word irouovin must be translated with the best possible English equivalent for modern readers. In this case, the translation "patience" misses an important nuance of the Greek ijropovin, regardless of whether it covered this ground originally for KJV readers. Moreover, adoption of the term "endurance" allows us to make the correct distinction between the various Greek words employed in the James pericope (5:7-11). The following translation is able to make such a distinction:

As an example of suffering and patience, brethren, take the prophets who spoke in the name of the Lord. Behold, we call those happy who have endured. You have heard of the endurance of Job, and you have seen, the purpose of the Lord, how the Lord is compassionate and merciful ${ }^{18}$.

With this sense of the word iropovn in place, we return to the critical problem in Job.

That the English word "patience" has lost the specific sense of the Greek inouovin sketched above is made particularly clear in the quote of H.L. GINSBERG. Patience for this commentator is "unflinching loyalty ... under unimaginable severe trials"19. This is consistent with the dictionary definition cited above which spoke of "bearing trials without com-

16 See The Oxford English Dictionary [A.14] entry for "steadfast".

17 Changes in understanding of the word "patience" probably involve changing attitudes regarding authority and eschatology. External and transcendent authority have lost much of their meaningfulness since FREUD and FEUERBACH. Patience involves a commitment to final temporal purpose and works best with a coherent eschatology, about which there is considerable debate or complete disinterest, for the religious as well as the secular world. "Patience" makes little sense in such a world. It has come to mean a kind of passive attitude, a cowering before lost and longed-for authority.

18 The NRSV has now adopted a translation very close to this.

19 Cf. footnote 7. 
plaint". The repression of (negative) emotion, and the will to alter the circumstances, is also implied in modern understandings of "patience". If this was in fact the range covered by the Greek word inouovn, one could find compelling the argument that James was only reading the Prologue. For there Job's stance is one of "unflinching loyalty". In fact, his reaction of pious reserve approaches the stylized or unbelievable. Terming it "patience" is a testimony to the way the term has come to be understood in modern parlance. One might even suspect that the dictionary entry, "bearing pains or trials calmly or without complaint", was based on this powerful depiction of Job in the Prologue. The back-influence of a translation on the culture that produced it is a another interesting topic lying beyond the scope of our study 20 .

If James' word inomovry is better translated by the English "endurance", however, a different picture emerges of Job and the commendation of him to James' community. "Endurance" would be a wholly inappropriate characterization of Job in the Prologue. It would serve far better as a description of Job in the dialogues (chaps. 3-31) - that section of the book termed by GINSBERG JIP (Job the Impatient) and thought by nearly all moderns to blatantly contradict any portrait of patience. In short, the precise opposite proposal presents itself: James was speaking of the Job of the whole book, especially its central section, and certainly not just the Prologue Job. Here is an instance where use of the term "patience" to discuss the growth of the Book of Job has simply confused the issue.

Adoption of the translation "endurance" produces a different effect altogether. The contrast between Prologue and Dialogue sections does involve emotional suppression and emotional release, such as might well be termed patience and impatience. But another contrast is far more compelling. In the Prologue, Job refuses to engage God directly and instead only utters conventional proverbs. This may be patience, in the modern sense, but it has nothing to do with endurance ${ }^{21}$. It is only as Job moves toward God and demands to know him, rather than the conventions of his own moving construction (The Lord giveth, the Lord taketh away; Blessed be the name of the Lord"), or those of others (the views of the friends in the Dialogues), that the potential for endurance is made real in the book. One thinks here of statements that occur throughout the dialogues, which stand in considerable contrast to the two pious confessions of the Prologue $(1: 21 ; 2: 10)$.

\footnotetext{
I will say to God, Do not condemn me; let me know why thou dost contend against me. (10:2) Behold, he will slay me; I have no hope; yet I will defend my ways to his face. (13:15) Oh, that I knew where I might find him, that I might come even to his seat! (23:3) Here is my signature! Let the Almighty answer me! (31:35)
}

20 Obviously, one of the best examples of this would be the influence of LUTHER's translation of the Bible on the German language.

21 Again, herein lies their essential difference. 
There is a wider implication of the perspective on Job provided by James. Patience giving way to impatience has been used as a major plank in the diachronic argument urging an early Folktale and subsequent Dialogue correction. More to the point, patience giving way to impatience has provided proponents of this understanding of the book with a key theological index for interpreting the Book of Job. In this model, "impatience" implies a criticism of conventional wisdom in favor of a kind of snorting and liberated agnosticism 22 .

What is the effect if one considers James' reading of Job on an endurance axis? The Prologue could still be viewed as earlier tradition, but its adoption by the author of the Dialogues would have to be differently conceived. It was utilized because it provided key background material the story required to unfold properly. Critical in this regard was its single poignant question, which in the present form of the book now hovers over the entire proceedings, confronting Job and his friends, Job and God, Job and readers: Can a mortal fear God for nought? Is there such a thing as gratuitous love and service of God, for nothing but God's own sake? This question is not answered by rejecting patience and giving in to impassioned tirades - a typically modern reading. Rather, it can be answered only through endurance and the free decision to "stay fast" in the quest to know God and "see with the eye" (42:5) his relationship to the cosmos and the individual. The author of the dialogues does not set out to cynically expose the weaknesses of a "patient piety". Rather, he sets out to show that the answers to Job's dilemma could never be found in even the most powerful statements of resigned loyalty: "Shall we receive good from God and shall we not receive evil?" At best, such statements compel either enormous pathos or bitter resentment for the man Job. But they do nothing to drag us or him to the throne of God for an answer that will reveal God's essential nature and our own. Only endurance keeps one moving down this road.

It may be ironic coincidence that one of the nuances of the verb inoukv ${ }^{2}$ involves remaining behind after others have left. For this is precisely what happens in the flow of the dialogues, the main section of the present book of Job. All remain in silence with Job in the Prologue (2:13). But in the Dialogues the friends are silenced and eventually come forward no more. After Elihu's attempt at resolution fails (chaps. 32-37), only Job remains behind to hear God's response to his challenge: "Here is my signature; let the Almighty answer me". As a reward for this "staying fast" (inouoví), Job sees with the eye what he had heard before

22 Which the blustering Job must then unfortunately "repent of" in the Divine Speeches. In order to retain a heroic and unrepentant protagonist, this model for understanding Job either takes Job's response as tongue-in-cheek (see J.B. CURTIS, "On Job's Response to Yahweh", JBL 98 [1979] 497-511), or sets out to write Job Ch. 43 (so C. JUNG; R. FROST; A. MACLEISH), where Job gets more and better to stay. 
only through hearsay (42:5). After he resumes his Prologue-role as intercessor, this time for the friends, God "restores his fortunes". Or, in the language of James, Job endured and was blessed thereby (5:11). What he saw was "the purpose of the Lord, how the Lord is compassionate and merciful" (5:11). That at 5:11 James had in mind the episode of the Epilogue, where Job received double what he had lost, is clear. This is the reward that comes from endurance, and it is this endurance James commends to his readers:

Count it all joy, my brethren, when you meet various trials, for you know

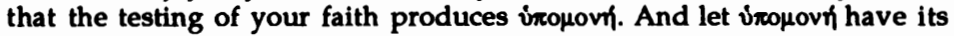
full effect, that you may be perfect and complete, lacking in nothing James 1:2-4).

The author of the Prologue introduced Job using similar language (perfect and complete, 1:1), before the trials and testing of faith had begun. After these trials, Job is doubly recompensed (42:10). James clearly has the full story before him when he holds up Job, along with Abraham and Elijah, to the "twelve tribes in the Dispersion" (1:1). In the restoring of Job's fortunes, God reveals his compassionate purpose (James 5:11). At the same time, Job's endurance has, in the language of James, been brought to its "full effect". It is for this reason that James can say with confidence to the community awaiting the Parousia, during times of affliction, "You have heard of the endurance of Job, and you have seen the purpose of the Lord, how the Lord is compassionate and merciful". Modern critical reading which separates the Prologue and Epilogue from the Dialogues on the axis of patience and impatience will inevitably miss the central message grasped by James and his audience: that the whole book of Job, with all its parts together cooperating - Prologue, Dialogues, Elihu and Divine Speeches, Epilogue - tells a compelling story about endurance and its ultimate reward, a story capable of sustaining faith through even the most difficult times of trial23.

23 I am honored to be included among Professor BALTZER's colleagues and students offering tribute on this occasion. Klaus BALTZER has always displayed a keen appreciation for the meaning of words, for the tradition process that moves beyond the Old Testament and extends into the New, and for the art and mystery of good modern translation work. This essay is offered with special thanks for his teaching and friendship over the years, and with fond memories of hours spent reflecting on and working at the task of translation. 


\title{
ZUR VIERFACHEN LEKTÜRE DES ALTEN TESTAMENTS \\ BIBELREZEPTION ALS ERFAHRUNG VON DISKREPANZ UND PERSPEKTIVE*
}

\author{
von \\ Helmut Utzschneider \\ Augustana-Hochschule, Neuendettelsau
}

\section{LECTOR IN BIBLIA}

Für den modernen Leser, und damit meine ich in gleicher Weise auch die moderne Leserin, ist die Lektüre des Alten Testaments ein vielfältiges und nicht selten widerständiges, provozierendes Erlebnis.

Ein Beispiel für viele: Mitten in der Zeit des Golfkrieges schickt sich ein Chor an, Felix Mendelsohn-Bartoldys Vertonung des 2. Psalms, die Mottete "Warum toben die Heiden ...", einzustudieren. "Warum toben die Heiden, und warum murren die Völker so vergeblich", heißt es da im Psalm und im Text der Mottete, und weiter: "Der im Himmel wohnt, lachet ihrer ... einst wird er mit ihnen reden in seinem Zorn, und mit seinem Grimm wird er sie schrecken." Im Chor erhebt sich Widerspruch; eine Frau meint: "So etwas kann und will ich heute nicht singen ...". Die Mottete wird nicht gesungen. Der Hiatus, die Diskrepanz zwischen dem brennenden Wunsch nach Frieden und einem Gotteslob, das sich auf den Krieg mit den Völkern gründet, war für die Leserin nicht auszuhalten. Es ist dies, wie gesagt, nur ein Beispiel für viele, bei denen die Lektüre des AT in Diskrepanzen führt.

Es gibt selbstverständlich auch ganz andere, dabei aber ähnlich breit gestreute Erfahrungen mit dem AT. Wer zählt die Kinderbibelwochen, in denen Gottes Bogen in den Wolken nachgemalt und Jonas Gesang im Bauch des Fisches nachgesungen wurde? Psalmentexte prägen die Sprache der Liturgie und werden an Krankenbetten gebetet. Die angstlösende und begeisternde Rolle des Wortes von den "Schwertern", die "zu Pflugscharen" (Mi 4,3) werden, ist den meisten von uns wohl noch im Gedächtnis. Die Texte sind dann nicht befremdlich, sondern vertrauenbildend und ermutigend. Sie eröffnen Perspektiven.

\footnotetext{
* Den folgenden Beitrag habe ich - in jeweils modifizierten Fassungen - an der Kirchlichen Hochschule Bethel und an der Augustana-Hochschule Neuendettelsau als Vorlesung gehalten (die Form ist weitgehend beibehalten). Entstanden ist er - nicht nur im technischen Sinne - in München. Historische Perspektive und praktischer Sinn als Konstituenten der Auslegung des AT sind eine Mitgift meines Lehrers Klaus Baltzer. Davon will ich dankbar Zeugnis geben, weshalb der Beitrag auch hier erscheint. Ich würde mich freuen, wenn der Jubilar ihn als eine mögliche Auslegung seines Begriffes der "konsequenten Traditionsgeschichte" wiedererkennen könnte.
} 
Vielleicht kann das Michawort von den Schwertern, die zu Pflugscharen werden sollen, am besten deutlich machen, daß die Diskrepanzen, denen der Leser des Alten Testaments begegnet, zunächst ebendort angelegt sind. Bekanntlich kennt das AT ja auch das "Gegenwort" von den Pflugscharen, die zu Schwertern werden sollen (Joel 4,10). In einund demselben Buch sind neben Worten des Friedens Worte des Krieges und der Gewalt zu lesen. Aber auch der Leser, seine Situation und seine Voraussetzungen, tragen das ihre zum Aufbau der Diskrepanzerfahrungen bei. Wahrscheinlich hätte der Chor in Friedenszeiten weniger Anstoß genommen an den Worten des 2. Psalms, und die Mottete wäre gesungen worden.

Akt und Erlebnis der Lektüre sind geprägt durch ein enges Zusammenspiel zwischen der vorgegebenen Struktur der Texte und dem Leser, seinen Voraussetzungen und Überzeugungen, seiner Phantasie, ja sogar seiner "Tagesform". Erst in diesem Zusammenspiel der Vorgaben des Textes mit der interpretierenden Mitarbeit des Lesers gewinnt der Text seine volle Bedeutung.

Die sogenannte "Rezeptionsästhetik", die sich in diesem Sinne mit dem "Akt des Lesens"1 befaßt, hat inzwischen einen festen Platz in der allgemeinen Literaturwissenschaft; sie gewinnt aber auch zunehmend in der theologischen Exegese an Bedeutung. Der Semiotiker und Romancier Umberto ECO hat jenes Zusammenspiel von Text und Leser auf die knappe, aber prägnante Formel "Lector in fabula"2 gebracht: der Leser in der Geschichte. In Abwandlung jener Formel kann man vom "Lector in Biblia" sprechen ${ }^{3}$.

In der Bibel lesen heißt danach, sich gleichsam in sie hineinbegeben. Was sich dort ereignet, die Lektüre eben, ist keineswegs von allem Anfang an durch Harmonie und Übereinstimmung zwischen den Texten und ihren Lesern geprägt, sondern durch Diskrepanzen. Diskrepanzen sind in den Texten selbst vorgegeben und werden von den Lesern in den Text eingebracht. Manchmal schaukeln sich die text- und die leserbedingten Diskrepanzen gewissermaßen gegenseitig hoch, wie wir dies bei der ungesungenen Mottete beobachtet haben. Für die textbe-

1 So der Titel der für die Rezeptionsästhetik immer noch grundlegenden Monographie von W. ISER, Der Akt des Lesens, Theorie ästhetischer Wirkung, München ${ }^{2} 1984$.

2 Im Titel seines Buches: Lector in fabula, Die Mitarbeit der Interpretation in erzählenden Texten, dtv 4531, München 1990.

${ }^{3}$ So abgewandelt hat ECOs Formel inzwischen auch Eingang in die theologische Literatur gefunden. Die Priorität dabei hat m.W. U.H.J. KÖRTNER, Lector in Biblia, Schriftauslegung zwischen Rezeptionsästhetik und vierfachem Schriftsinn, WuD 21 (1991) 215 233. Auch sonst findet die Rezeptionsästhetik zunehmend Resonanz in der Exegese. Vgl. dazu etwa: C. DOHMEN, Rezeptionsforschung und Glaubensgeschichte; Anstöße für eine neue Annäherung von Exegese und systematischer Theologie, TThZ 96 (1987) 123-134; H. UTZSCHNEIDER, Das hermeneutische Problem der Uneindeutigkeit biblischer Texte dargestellt an Text und Rezeption der Erzählung von Jakob am Jabbok (Gen 32,23-33), EvTh 48 (1988) 182-198; und weitere dort genannte Literatur. 
dingten Diskrepanzen hat die Rezeptionsästhetik die Begriffe "Unbestimmtheitsstellen" und "Leerstellen" geprägt. Es sind dies Momente des Textes, die beim Leser Unsicherheit erzeugen, die ihn ratlos lassen, ja Ärger und Befremden hervorrufen 4 .

Was bleibt einem Leser, der sich derart in die Bibel einbezogen sieht? Er kann vor den Schwierigkeiten und Diskrepanzen kapitulieren, d.h. das Bibelbuch zuklappen und beiseite legen; die nicht-gesungene Mottete ist ein Beispiel für eine solche Kapitulation. Oder aber der Leser kann daran gehen, Orientierungen zu suchen, Brücken zu schlagen über die Leer- und Unbestimmtheitsstellen, und nach Perspektiven Ausschau halten, die über die Diskrepanzen hinausführen. Eben darauf kommt es mir nun an.

Ich möchte an vier ausgewählten Beispielleserinnen und -lesern zeigen, wie gerade aus der Erfahrung und Verarbeitung von Diskrepanzen Perspektiven entstehen können, die die atl. Texte sinnvoll und weiterführend erscheinen lassen. Die vier Beispielleser stehen natürlich nicht für sich allein, sondern repräsentieren, wie ich meine, Typen der Rezeption des AT. In allen vier Typen spielen jeweils spezifische Erfahrungen von Ambivalenz, Diskrepanz und Polarität im Umgang mit den Texten eine Rolle. In allen vier Typen der Rezeption führen solche Diskrepanzerfahrungen dazu, daß sich den Lesern neue und eigenen Perspektiven eröffnen. Ich nenne nun die vier Typen, samt den Perspektiven, die sie jeweils eröffnen:

1. die historisch-literarische Lektüre und die Perspektive des Textes als Ereignis, dargestellt an Hermann Samuel REIMARUS' Lektüre der Schilfmeererzählung (Ex 14),

2. die psychologisch-rhetorische Lektüre und die Perspektive des Menschen-Möglichen, dargestellt an Phyllis TRIBLEs Lektüre der Amnon-Erzählung (2 Sam 13),

3. die moralisch-politische Lektüre und die Perspektive der Parteilichkeit dargestellt an Thomas MANNs Lektüre der Mosegeschichte und des Dekalogs und

4. die theologische Lektüre und die Perspektive der Einheit Gottes dargestellt an einer Lektüre von Hosea 11.

In gewisser Weise erinnern diese vier Idealtypen der Lektüre des AT an die Theorie des "drei- bzw. vierfachen Schriftsinns", die in der Alten Kirche entwickelt wurde und das ganze Mittelalter über in Geltung war. Der Merkvers dieser Theorie, wie er sich etwa in Luthers Galaterbriefvorlesung findet, lautet:

\footnotetext{
4 Zumindest für die neuere Literatur hat die Rezeptionsästhetik zeigen können, daß solche Leer- und Unbestimmtsheitsstellen keineswegs zufällig, sondern von den Autoren bewußt und kunstvoll gesetzt sind.
} 
Líttera gésta docét, quid crédas állegoría, móralís quid agás, quo spéras ánagogía.

Mithin: jede Schriftstelle hat einen vierfachen Sinn: einen wörtlich-historischen, einen allegorisch-dogmatischen, einen moralischen sowie einen eschatologischen, die Zukunft erschließenden Sinn: Der Gedanke, jede Schriftstelle habe einen mehrfachen Sinn, hat wohl seine stärkste Wurzel in der antiken Annahme einer ióóvor $\alpha$, eines verborgenen Sinnes, in den Dichtungen Homers ${ }^{5}$. Auch die Theorie vom vierfachen Schriftsinn ging von der Diskrepanzerfahrung aus. Sie suchte sie $\mathrm{zu}$ beheben, indem sie in den Texten verborgene "Untersinne" wie vergrabene Schätze entdeckte und hob.

Unbeschadet bestehender und durchaus beabsichtigter Analogien unserer "vier Typen der Lektüre" zum "vierfachen Schriftsinn", ist vor allem ein Unterschied grundlegend: Lesende Rezeption sucht nicht nach einem "Untersinn", einer ìnóvor $\alpha$. Vielmehr stellt sie selbst eine Art $\mu \varepsilon \tau \tau^{\prime} v o 1 \alpha$ dar. In der Lektüre nimmt sie Angebote der Texte wahr, ihre Bedeutungen weiter- und neu zu denken.

Nun aber zum ersten Typus:

\section{DIE LITERARISCH-HISTORISCHE LEKTÜRE UND DIE PERSPEKTIVE DES TEXTES ALS EREIGNIS}

Ein historisches Verständnis des AT und der Bibel ist keine Errungenschaft der Neuzeit. Gerade die altkirchlichen und die mittelalterlichen Exegeten waren ja überzeugt: "líttera gésta docét": der Buchstabe lehrt die Ereignisse.

Das Besondere der literarisch - historischen Lektüre des AT ist nun gerade, daß sie den unmittelbaren Zusammenhang von littera und gestum, von Buchstabe und Ereignis, in eine Polarität, zumindest aber in eine unsichere und komplexe Diskrepanz aufgelöst hat. Nicht die Entdeckung, wohl aber die Darstellung und Propagierung dieser Diskrepanz verdanken wir der neuzeitlichen, westeuropäischen Aufklärung, etwa dem holländisch-jüdischen Philosophen Baruch SPINOZA oder

5 Die Theorie von einem mehrfachen Sinn der Schriften Homers wurde in griechischstoischen Kreisen der hellenistischen Zeit besonders gepflegt und dürfte über diesen Weg Eingang sowohl in die jüdische (Philo von Alexandria) als auch die altkirchliche Exegese gefunden haben. Auch in der Homer-Exegese sind diskrepante Leseerfahrungen Auslöser für die Annahme eines mehrfachen Sinnes der Texte gewesen: "Homer wäre jedenfalls gottlos, wenn ers nicht anders meinte" (Herakleitos von Pontus). Vgl. zum Ganzen: E. VON DOBSCHÜTZ, Vom vierfachen Schriftsinn. Die Geschichte einer Theorie; in: Harnack-Ehrung, Beiträge zur Kirchengeschichte, ihrem Lehrer A.v.Harnack zu seinem siebzigsten Geburtstage (7. Mai 1921) dargebracht von einer Reihe seiner Schüler, Leipzig 1921, 1-13, bes. 3 . 
auch Hermann Samuel REIMARUS, gestorben als Professor der orientalischen Sprachen zu Hamburg 1768.

Der letztere hat eine Abhandlung geschrieben, die zu den klassischen Texten der neuzeitlichen Exegese zu rechnen ist. Dieser Text ist niemals unter REIMARUS' Namen erschienen, sondern wurde 1777 posthum als drittes der "Fragmente des Wolfenbüttelschen Ungenannten" von Gotthold Ephraim LESSING herausgegeben": das Fragment "Durchgang der Israeliten durchs rothe Meer". Exemplarisch läßt sich an REIMARUS' Auslegung von Ex 14 die Diskrepanzerfahrung des modernen, historisch orientierten Bibellesers zeigen.

Scharfsinnig, witzig, polemisch, aber durchaus kenntnisreich ${ }^{7}$ bemüht sich REIMARUS darzutun, daß der Durchzug der Israeliten durchs "rothe Meer"8, so wie er in Ex 14 beschrieben wird, nicht stattgefunden haben kann. Er beginnt mit einer Art Paraphrase der Schilfmeer-Erzählung: "Es zogen aus 600000 streitbare Israeliten, gerüstet und in Schlachtordnung ..."9. Der Kenner der Schilfmeer-Erzählung von Ex 14 weiß, daß dort keine Zahl genannt wird. In Ex 12,37 hingegen werden "600000 Mann zu Fuß ohne die Frauen und Kinder" genannt, sowie in Ex 38,26 "603550 Mann von 20 Jahren und darüber". Diese Zahlen setzt REIMARUS in seine Auslegung von Ex 14 ein, und beginnt damit sein Werk als recherchierender Historiker. Er rechnet daraus hoch, wieviel Menschen insgesamt der Zug der Israeliten umfaßt haben mag: "wenigstens 3.000.000"; er vergißt nicht, die Frauen und Kinder, die Alten und Kranken, sowie das Gesinde in Betracht zu ziehen; er fragt, wieviel Vieh eine solche Menschenmenge wohl mit sich geführt haben mag: 300000 Ochsen und Kühe, 600000 Schafe und Ziegen; er errechnet, wieviele Wagen für Futter, Bagage und Gezelt vonnöten gewesen sind: mindestens 6000 . Dann geht er daran, sich die Länge des Zuges vorzustellen: zwischen 60 und 180 deutsche Meilen müsse er betragen haben. Und schließlich vergegenwärtigt er sich das Gelände des Durchzugs. So ist sein Endurteil gut vorbereitet:

"Er (scil. Mose) führet 3,100,000 Menschen ${ }^{10}$ mit Weibern, Kindern, Kran-
ken, Krüppeln, Lahmen, Blinden, Schwangeren, Abgelebten, mit soviel Ge-
zelten und Bagagewagen, vermittels einer Ochsenpost, mit 300000 Ochsen
und 600000 Schafen im Finstern, über Stock und Block, durch Schlamm, Moos,
Sand, Stauden, Klippen, Inseln, Ufer hinunter, Ufer hinauf, viele Meilen
weit, in einer Nachtwache jenseits des Meeres. Sehet; so wenig Verstand

${ }^{6}$ Fragmente des Wolfenbüttelschen Ungenannten, ed. G.E. LESSING, Berlin ${ }^{4} 1835,298 \mathrm{ff}$.

7 Er verweist auf antike und einen zeitgenössischen Geographen.

8 REIMARUS legt offenbar die Septuaginta zugrunde (vgl. Ex 13,18 LXX) oder er identifiziert das Schilfmeer des MT stillschweigend mit dem arabischen Meerbusen.

${ }^{9}$ Fragmente [A.6] 298.

10 REIMARUS rechnet hier aus den Angaben von Num 1,46 hoch. 
und Nachdenken kostet es, Wunder zu machen! so wenig ist auch nöthig, sie zu glauben!"11.

Worin besteht die Methodik des REIMARUS? Sie besteht darin, daß er den Buchstaben des Textes - fast möchte man sagen: gnadenlos - wörtlich nimmt als Darstellung eines Ereignisses. Dabei stellt er implizit fest, daß der Buchstabe das Ereignis nicht vollständig wiedergibt und ergänzt das fehlende, die Leerstellen, teils nach biblischen oder anderen antiken Nachrichten, teils nach seiner eigenen historischen Vorstellungskraft. So zwingt REIMARUS sich und seine Mitleser dazu, sich die biblischen Texte als Ereignisse oder Sachverhalte genau vorzustellen ${ }^{12}$. Im Fragment "Durchgang der Israeliten durchs rothe Meer" trifft er dabei auf eine unauflösbare Diskrepanz zwischen Text und historischer Vorstellung: es ist unter den erzählten und aus der Erzählung anzunehmenden Umständen nicht möglich, eine solche Menge von Menschen in so kurzer Zeit durchs Meer zu führen; kurz: der Durchzug kann so, wie er erzählt wird, nicht stattgefunden haben. Littera und gestum, Text und Ereignis, fallen auseinander.

Soweit die Wahrnehmung der Diskrepanz. Fragen wir nun nach der Perspektive, die aus dieser Wahrnehmung erwächst, so werden wir bei REIMARUS selbst enttäuscht. Dies ist darin begründet, daß er den Text mit einem Interesse liest, das seinem historischen Ansatz im Grunde widerspricht.

Die historische Kritik der Schriften ist ihm nur Mittel zum Zweck; sie soll ihm dazu dienen, das "Göttliche" in den biblischen Schriften zu erkennen - und führt zu einem negativen Ergebnis. Wunder nämlich verdunkeln das Göttliche eher als daß sie es erhellen. Nur allzu leicht lassen sie sich - so REIMARUS - als "aus menschlichem Gehirn erdichtet"13 erweisen.

Deutlicher noch als im dritten, wird im folgenden vierten Fragment, worum es dem aufgeklärten Deisten ${ }^{14}$ REIMARUS geht. Er will zeigen, "daß die Bücher des A.T. nicht geschrieben worden [sind], eine Religion zu offenbaren". Die Religion, das ist - so REIMARUS - "eine übernatürliche seligmachende Religion, welche vor allem eine Erkenntniß von der Unsterblichkeit der Seelen, von der Belohnung und Bestrafung unserer Handlungen in einem zukünftigen ewigen Leben,

\footnotetext{
11 A.a.O. [A.6] 313.

12 An anderer Stelle setzt er Angaben der Opfertora in Vorstellung um: Wie geht es zu an einem Heiligtum, zu dem Tiere verschiedenster Größe getrieben werden, in dem geschlachtet, verbrannt und gegessen wird, an dem kranke Menschen sich den Reinigungszeremonien unterziehen, die die Reinheitstora vorschreibt? - Vgl. 4. Fragment, [A.6] 320ff. 13 A.a.O. [A.6] 313.

14 Vgl. dazu: H. Graf REVENTLOW, Die Auffassung vom AT bei Hermann Samuel Reimarus und Gotthold Ephraim Lessing, EvTh 25 (1965) 427-448, 433.
} 
von der Vereinigung frommer Seelen mit Gott ... erfordert"15. Eine solche Religion offenbart das AT nun in der Tat nicht.

REIMARUS werden seine Fragmente bis heute übel genommen. "Hemmungslos" sei seine Kritik und von "beißender Ironie", bemerkt ein gängiges Standardwerk der Auslegungsgeschichte des AT ${ }^{16}$. Gewiß war REIMARUS - im Gegensatz etwa zu seinem Zeitgenossen Johann Gottfried HERDER - kein Freund des Alten Testaments, und er war - im Gegensatz zu seinem Herausgeber LESSING - alles andere als ein Freund des Judentums ${ }^{17}$. Ein gerechtes Urteil über REIMARUS wird aber beides sehen müssen: sein Verdienst, die Diskrepanzerfahrung der historischen Lektüre des AT aufgewiesen zu haben, und die Tatsache, daß er dabei in der Negation stehengeblieben ist, weil ihn sein theologisches Interesse daran gehindert hat, Perspektiven zu entwickeln. Er hat sich damit zufrieden gegeben, den Text der Schilfmeererzählung als das Machwerk eines unbegabten Wunderdichters zu lesen, der seinen historischen und geographischen Ort nicht am Ort des Ereignisses gehabt habe. Nach eben diesem historischen Ort des Erzählers und der Funktion des Textes an diesem Ort fragte REIMARUS nicht. Genau dies ist aber die Perspektive, die sich aus dem historischen Ansatz ergibt und die in der Folgezeit bis heute die Perspektive der literarisch-historischen Lektüre darstellt: die Relativität der biblischen Texte zu ihren Autoren und ihren ersten Lesern, für die die Texte selbst Ereignisse gewesen sind.

Wir kennen heute die Textelemente, an denen REIMARUS seine Diskrepanzerfahrungen vor allem gemacht hat, als die priesterschriftliche Schicht der Schilfmeergeschichte. Im Topos der Spaltung des Meeres sehen wir den Versuch, geschichtliche und kosmologisch-mythische Wahrnehmung der Wirklichkeit theologisch zu verbinden. Wir lokalisieren diesen Versuch in der Auseinandersetzung Israels mit der Glaubenswelt des Zweistromlandes zur Zeit des babylonischen Exils ${ }^{18}$. Der Text kommt so als Ereignis der Glaubensgeschichte Israels in den Blick.

Der Erkenntnisgewinn dieser Perspektive geht weit über REIMARUS hinaus; er ist aber ohne die konsequente Wahrnehmung der Diskrepanzen zwischen den Texten und den Ereignissen, wie REIMARUS sie vorgedacht hat, nicht zu haben. Ja, das Entdecken von Diskrepanzen in den Texten und zwischen Texten und Ereignissen ist zum Signum der literarisch-historischen Lektüre überhaupt geworden. Insbesondere die sogenannten "Literarkritiker" befinden sich auf einer unentwegten - für

15 A.a.O. [A.6] 314.

16 H.-J. KRAUS, Geschichte der historisch-kritischen Erforschung des Alten Testaments, Neukirchen-Vluyn 21969, 124.

17 Zu REIMARUS Antisemitismus vgl. H. Graf REVENTLOW [A.14] 434.

18 Vgl. etwa J. SCHARBERT, Das "Schilfmeerwunder" in den Texten des AT, in: A. CAQUOT-M.DELCOR (ed.), Melanges bibliques et orientaux en l'honneur de Henri Cazelles, AOAT 212, Neukirchen-Kevelaer 1981, 395-417, 416 f. 
Nicht-Exegeten manchmal schon etwas manisch wirkenden - Suche nach Brüchen und Spannungen in den Texten.

\section{DIE PSYCHOLOGISCH-RHETORISCHE LEKTÜRE UND DIE PERSPEKTIVE DES MENSCHEN-MÖGLICHEN}

Unsere zweite Beispielleserin, die amerikanische Alttestamentlerin und Feministin Phyllis TRIBLE ist, wie die Chorsängerin, von der ich eingangs erzählt habe, eine betroffene Frau: Sie nimmt gewisse atl. Texte wahr als "texts of terror", - so der amerikanische Originaltitel der Publikation TRIBLE's ${ }^{19}$. Ein solcher "Text des Schreckens" ist auch die Erzählung von der Königstochter Tamar (2 Sam 13). Erzählt wird, wie Amnon, ein Sohn Davids, seine Halbschwester Tamar liebgewonnen hat und alles daran setzt, sie zu besitzen. Er stellt sich krank, und arrangiert es, daß Tamar ihn pflegt. Bei dieser Gelegenheit fällt er über sie her und vergewaltigt sie. Amnon wird das Verbrechen mit seinem Tod büssen. Von Tamar aber heißt es: "Sie blieb einsam im Hause ihres Bruders Absalom" (2 Sam 13,20).

Warum liest und erzählt Phyllis TRIBLE gerade diese monströse Geschichte? Wäre es nicht besser, von ihr zu schweigen, oder sie allenfalls als Beispiel für frauenfeindliche Tendenzen des AT zu zitieren?

TRIBLE nennt für ihre Lektüre und ihre Auslegung der Tamar-Geschichte ein sehr persönliches Motiv: "Meine persönliche Entscheidung und verschiedene Zufälle haben mich bewogen, gerade diese Geschichten zu erzählen. Ich hörte, wie eine schwarze Frau sich selbst als Tochter der Hagar bezeichnete, die außerhalb des Bundes stehe; ich sah eine Frau, der man übel mitgespielt hatte, in den Straßen von New York mit einem Schild: 'Mein Name ist Tamar', ... ich besuchte Gottesdienste zum Gedächtnis namenloser Frauen, ich rang mit dem Schweigen der Abwesenheit und dem Widerstand Gottes"20. Phyllis TRIBLE ist betroffen als Theologin und als Frau, nicht etwa nur von den atl. Geschichten, sondern von einer Wirklichkeit, die dem Terror der Geschichten mindestens äquivalent ist. Die außertextliche Diskrepanzerfahrung und die Diskrepanzerfahrung bei der Lektüre entsprechen sich hier also.

Angesichts dieser doppelten Diskrepanzerfahrung ist es nicht nur erstaunlich, daß TRIBLE die Geschichten liest und auslegt, noch erstaunlicher ist, wie sie dies tut. Sie folgt dabei den angelsächsischen Traditionen des "literary"21 bzw. des "rhetorical criticism"22. Zunächst heißt

19 P. TRIBLE, Texts of Terror, Literary-Feminist Readings of the Biblical Narratives, Philadelphia 1984; dt.: "Mein Gott warum hast du mich vergessen?" Frauenschicksale im AT, Gütersloh 1987. Folgende Texte werden dort ausgelegt: Gen 16 und 21; Ri 11 und 19; 2 Sam 13.

${ }^{20}$ P. TRIBLE [A.19] Mein Gott, 16.

${ }^{21} \mathrm{Vgl}$. dazu E.V. MCKNIGHT, The Bible and the reader, An introduction to Literary Criticism, Philadelphia 1985. 
dies, daß sie in ihrer Lektüre penibel auf alle Einzelheiten der literarischen Kunstform achtet. Immer wieder nimmt sich die Leserin Zeit, die Strukturmuster der Erzählung wahrzunehmen und nachzuzeichnen, Wortspiele und Stichwortverbindungen zu notieren. Dabei gehen Betroffenheit und Stilbeschreibung, psychologische Befindlichkeit und sprachliche Analyse Verbindungen ein: Die Darstellung der Vergewaltigung der Tamar durch Amnon in 2 Sam 13 etwa führt TRIBLE so ein: "In diesem zentralen Teil stehen Form und Inhalt in einem fehlerhaften Chiasmus, der den irreparablen Schaden für die Personen zum Ausdruck bringt"23. Analysen des literarischen Stils gehen oft unvermittelt in Charakteristiken der dramatis personae über: So etwa, wenn P. TRIBLE das Gespräch zwischen Amnon und Tamar nach ihrer Vergewaltigung schildert: "Während vor dem Verbrechen vier hebräische Worte für Amnons Begehren gebraucht wurden, ... drücken nun zwei Imperative seinen Gefühlsumschwung aus: Steh auf, geh! $(13,15 \mathrm{c})$. Er nennt sie nicht mehr 'Schwester' ... Statt dessen wiederholt der Imperativ geh (hlk) höhnisch den Befehl, der Tamar zuerst in sein Haus gebracht hatte, als David ihr gebot zu gehen (hlk; 13,7). Diese beschimpfte Frau hört aber ebensowenig auf Amnons Befehl, sich zu entfernen, wie sie in seine Forderung, sich zu ihm zu legen, eingewilligt hatte. Und sie läßt es auch nicht zu, daß Ärger ihren Blick trübt"24.

Worauf es hier ankommt, sind - wie gesagt - die Linien, die TRIBLE immer wieder von den stilistischen und grammatischen zu den emotionalen und personalen Elementen des Textes zieht: Ein Imperativ ist "höhnisch", ein fehlerhafter Chiasmus drückt den "irreparablen Schaden für die Personen" aus. In solchen literarisch-psychologischen Konnexen werden bei TRIBLE die Diskrepanzen der Lese- und der Wirklichkeitserfahrungen darstellbar. TRIBLE folgt darin dem Grundanliegen der Rhetorik: Redekunst und literarische Kunst sind dazu da, Wirkung auf die Vernunft und das Gemüt der Zuhörer, bzw. Leser auszuüben. Zwischen literarischem Stil und psychologischer Wirkung eines Textes besteht - so das Axiom der Rhetorik seit der Antike - ein unmittelbarer Zusammenhang ${ }^{25}$. Die Intensität der Kunstform bewirkt die Intensität der Wahrnehmung des erzählten Geschehens.

22 Vgl. dazu die Programmschrift von J. MUILENBURG, Form Criticism and beyond, JBL 88 (1969) 1-18, neuerdings etwa M. KESSLER, A Methodological Setting for Rhetorical Criticism, in: Art and Meaning: Rhethoric in Biblical Literature, ed. D.J. CLINES, D.L. GUNN, A.J. HAUSER, JSOT SS 19, Sheffield 1982, 1-19 sowie die bei P. TRIBLE, [A.19] Anm. 2 genannten Titel.

23 A.a.O. [A.19] Mein Gott, 70.

24 A.a.O. [A.19] Mein Gott, 75f.

25 Vgl. Ciceros Verständnis der Rhetorik als "seelenwendende Königin". W. JENS, Art. Rhetorik, Reallexikon der Deutschen Literaturgeschichte, III, 432-456, 433. 
TRIBLE geht über diese Wahrnehmung aber noch weit hinaus und damit eröffnet sie die Perspektive der psychologisch-rhetorischen Lektüre: Sie nimmt die Kunstform nicht einfach nur wahr und läßt sich mit ihrer Hilfe in den Bann der Erzählung ziehen. TRIBLE macht die Kunstform bewußt. Diese Bewußtheit ist wichtig. Sie verdichtet sich in TRIBLE's Sicht des Erzählers. Er leuchtet die Erzählung aus, auch in ihren dunkelsten Ecken: Amnon, der Vergewaltiger, schickt kurz vor dem Verbrechen alle Zeugen aus dem Raum: "Obwohl" so kommentiert TRIBLE, "alle Zeugen offensichtlich hinausgehen, bleibt der Erzähler da, sieht, wie das Böse sich entfaltet und berichtet dem Leser, was daraus folgt. Amnons Macht, alle zu verscheuchen, hat seine Grenzen"26. M.a.W.: Eine schreckliche Geschichte, die erzählt wird, bleibt zwar eine schreckliche Geschichte. Aber das Erzählen und noch mehr das bewußte Hören bzw. Lesen bricht - so könnte man sagen - die verdunkelnde Macht des Schreckens; so kann aus eher dumpfer Betroffenheit durch die diskrepanten Wirklichkeiten bewußte Einfühlung und Einsicht werden in das Menschen-Mögliche. Das Verbrechen der Schändung Tamars, sei es die Königstochter in Jerusalem oder die unbekannte Frau in einer Straße New Yorks, ist eine menschliche Möglichkeit. Psychologisch-rhetorische Lektüre erschließt das Menschenmögliche, indem sie ihm Sprache verleiht und die Seele des Lesers durch die Sprache dafür aufschließt27. James MUILENBURG, der Begründer des "rhetorical criti-

26 TRIBLE [A.19] Mein Gott, S. 70f.

27 Es gibt noch weitere Formen, Betroffenheit durch die Lektüre biblischer Texte in eine Perspektive der Einfühlung und der Einsicht in das Menschen-Mögliche umzusetzen. Eine davon kann der dramatische Nachvollzug der Texte, das Bibliodrama, sein. Dies geht etwa aus einem Bericht hervor, den Samuel LÄUCHLI über die "mimetische Bewältigung" der Erzählung von Isaaks Opferung gibt (S. LÄUCHLI, Abraham und Isaak, Einführung in eine mimetische Bewältigung, in: Bibliodrama, ed. Antja KIEHN, S. LÄUCHLI u.a., Stuttgart 1987, 16-43. Gen 22 ist ein klassischer "text of terror", vgl. schon die Auseinandersetzung mit diesem Text bei S. KIEKEGAARD, Furcht und Zittern). Als NichtPsychologe, das will ich ganz unumwunden sagen, kommt mir manches in diesem Bericht ein wenig suspekt vor, so wenn LÄUCHLI vom "mythischen Schock" spricht, der sich der Teilnehmer am Alpha-Prozess des Spieles bemächtige. Was mich aber als Exeget beeindruckt, ist die unermüdliche Durcharbeitung des Textes, die sich im gemeinsamen Lesen, im gegenseitigen Erzählen und vor allem in den Rollenspielen ereignet. Die Intensität der Textwahrnehmung dürfte kaum geringer sein als die, die TRIBLE's "literary criticism" auszeichnet. Die Betroffenheit von dieser Geschichte des Terrors manifestiert sich im Widerstand gegen sie, der sich in den Spielphasen vielfach ausdrückt. Dieser Widerstand ist das polare Element im Prozess der Rezeption. "Warum", so schreibt LĀUCHLI, "erhebt sich solcher Widerstand gegen das Spiel?" und gibt selbst die Antwort: "Weil die Geschichte im Grunde nicht erträglich ist und weil die Analogien, die sofort gefühlten, aber in der Regel kaum akzeptablen Verbindungen zwischen dem Text und meiner Welt, nicht ausgehalten werden können" (a.a.O. 33). Die Perspektive der Einfühlung und der Einsicht ist auch hier deutlich und wohl noch ein Stück weit persönlicher auf den mimetischen Leser hin ausgezogen, soweit, daß die Möglichkeiten der gespielten Erzählung als eigene Möglichkeiten erscheinen. Die Gefahr des dramatischen Verfahrens ist allerdings ganz offensichtlich die, daß es den Leser so stark mit dem Geschehen identifizie- 
cism"28 hat die Sprache der Bibel in Anlehnung an T.S. ELIOT "a raid on the ultimate" genannt: einen Ritt über die Extreme der menschlichen Existenz. Genau dies ist die Perspektive der psychologisch-rhetorischen Lektüre.

\section{DIE MORALISCH - POLITISCHE LEKTÜRE UND DIE PERSPEKTIVE DER PARTEILICHKEIT}

Im Jahre 1943 hat Thomas MANN eine Erzählung veröffentlicht, der er selbst den deutschen Titel "Das Gesetz" gab. Sie war Teil eines Sammelbandes mit den Titel "The ten Commandments, Ten short Novels of Hitler's War against the Moral Code" und trug dort den englischen Titel "Thou shalt have not other Gods before me". In diesem Band haben neben Thomas MANN auch Franz WERFEL, Bruno FRANK und andere geschrieben, jeder zu einem Gebot des Dekalogs. Thomas MANNs Erzählung stand anstelle eines von ihm ursprünglich erbetenen Einleitungsessays.

Den Hintergrund dieses Buches, insbesondere zu seinem erstaunlichen Untertitel "Hitler's war against the moral Code" [Hitlers Krieg gegen das Sittengesetz], erläuterte das Vorwort. Es stammt von einem einstigen Vertrauten des Diktators namens Hermann RAUSCHNING. Er, RAUSCHNING, sei Zeuge eines Gespräches in der Reichskanzlei geworden, in der Hitler und Goebbels wetterten "gegen die Zehn Gebote, das 'teuflische Du sollst, Du sollst nicht', gegen diesen Fluch vom Sinai", diese "Perversion unserer gesundesten Instinkte". "Die Geschichte", so habe Hitler gesagt, "wird unsere Bewegung als die große Befreiung der Menschheit vom Fluch des Berges Sinai erkennen ... Wir kämpfen ... gegen den Fluch der sogenannten Moral, die zum Idol gemacht ist, um die Schwachen gegen die Starken zu schützen"29. Dagegen schrieben Thomas MANN und seine Mitautoren an.

Wir fragen - wie bei Phyllis TRIBLE und Hermann Samuel REIMARUS - zunächst wieder: Wie hat Thomas MANN das AT gelesen?

Die Erzählung hebt an mit einer Charakteristik des Mose und bereits in diesen einleitenden Sätzen formuliert Mann das polare, Diskre-

ren kann, daß er eines gerade nicht mehr erlebt: wie dem Terror des Geschehens die Macht genommen wird. Der Leser bleibt dann Gefangener der Diskrepanz. Ich meine, die Geschichten entfalten ihre Möglichkeit in erster Linie beim Erzählen und Hören, was freilich eine mimetische Bewältigung nicht ausschließt.

${ }^{28}$ So nach J. MUILENBURG [A.22] 18.

${ }^{29}$ K. HAMBURGER, Thomas Manns biblisches Werk, Der Joseph-Roman, Die MosesErzählung "Das Gesetz", München 1981. Thr entnehme ich obige Angaben zur Geschichte der Erzählung; a.a.O. 239. Vgl. auch T. MANN selbst in: Die Entstehung des Doktor Faustus, Roman eines Romans, Frankfurt 1967, 690f. 
panzen entdeckende Grundmuster seiner Rezeption der Moseerzählung:

"Seine (scil. des Mose) Geburt war unordentlich, darum liebte er leidenschaftlich die Ordnung, das Unverbrüchliche, Gebot und Verbot. Er tötete früh im Auflodern, darum wußte er besser als jeder Unerfahrene, daß Töten zwar köstlich, getötet zu haben aber höchst gräßlich ist, und daß du nicht töten sollst. Er war sinnenheiß, darum verlangte es ihn nach dem Geistigen, Reinen und Heiligen, dem Unsichtbaren, denn dieses schien ihm geistlich, heilig und rein" 30 .

Diese Spannung zwischen "naturhaft - zügellos" und "kulturhaftgeistig" bestimmt das Mosebild der Erzählung und die Erzählung als Ganze, die ich nun kurz paraphrasiere:

Von seinen Anlagen und seiner Herkunft her sei Mose ein chaotischer, ungebändigter Naturmensch gewesen, kein hebräischer Findling, sondern das Kind der ägyptischen Königstochter, hervorgegangen aus einer Augenblicksverbindung mit einem jungen hebräischen Sklaven. Am Gottesberg in Midian (Ex 3) sei dem flüchtigen Totschläger dann der bildlose Gott begegnet; diese Begegnung habe in ihm die Leidenschaft für Ordnung, Heiligkeit und Geistigkeit geweckt. Den bildlosen Gott habe er den Israeliten als den Gott ihrer Väter nahebringen wollen und mit ihm Ordnung, Heiligkeit und Geistigkeit. Dies - nicht so sehr das gelobte Land - sei das Ziel des Exodus. Er führt in die Freiheit, den "Raum der Heiligung"31. Dort, örtlich gesprochen: am Horeb, Sinai, in Kadesch $^{32}$, ging Mose daran, die Israeliten im Sinne des bildlosen Gottes zu bearbeiten, wie ein Bildhauer den Block ${ }^{33}$. Dort lehrte er die Israeliten das Recht und die Kultur. Das ging nicht ab ohne Widerstand von seiten der so Bearbeiteten und Belehrten: "Sie hatten", so beschreibt MANN die Gemütslage der Israeliten in der Wüste "zunächst das Gefühl, daß überhaupt vom lieben Leben beinahe nichts überbleibe, wenn man all dies befolgte ..."34 und: "Sie merkten, was es auf sich hatte mit der Unsichtbarkeit Gottes. Es bedeutete eine große Einschränkung ..."35 Am Ende und am Höhepunkt steht die Gabe der Gesetzestafeln am Sinai: Sie sind das "Ewig-Kurzgefaßte, das Bündig-Bindende, Gottes gedrängtes Sittengesetz, ... die Quintessenz des Menschenanstandes"36.

30 T. MANN, Das Gesetz; in DERS.: Die Betrogene und andere Erzählungen, Fischer TB 9107, Frankfurt a.M. 1987, 114.

31 A.a.O. [A.30] 138.

32 Vgl. a.a.O. [A.30] 147. "... man konnte sie gleichsetzen, man konnte den Sinai auch Horeb nennen, und Kadesch hieß, wie es hieß, weil es mit einiger Freiheit gesprochen, zu Füßen des heiligen Berges lag". NB. die hebräisch-deutschen Wortspiele mit "qds" und "heilig".

33 Vgl. a.a.O. [A.30] 158.

34 A.a.O. [A.30] 162.

35 A.a.O. [A.30] 163.

36 A.a.O. [A.30] 176. 
"Nimm sie hin, Vaterblut", läßt Thomas MANN den Mose bei der Übergabe der Tafeln an die Israeliten sagen, "und halte sie heilig in Gottes Zelt, was sie aber besagen, das halte heilig bei dir im Tun und Lassen. Denn das Bündig-Bindende ist es ... und Gott schrieb's in den Stein mit meinem Griffel, lapidar, das $A$ und $O$ des Menschenbenehmens. In eurer Sprache hat er's geschrieben, aber in Sigeln, mit denen man notfalls alle Sprachen der Völker schreiben kann; denn Er ist der Herr allenthalben, darum ist sein das $A B C$, und seine Rede, möge sie auch an dich gerichtet sein, Israel, ist ganz unwillkürlich eine Rede für alle"37. Und Mose fügt hinzu: "... Fluch dem Menschen, der da aufsteht und spricht: 'Sie (die Gebote) gelten nicht mehr.' Fluch ihm, der euch lehrt: 'Auf, und seid ihrer ledig! Lügt, mordet und raubt, hurt, schändet und liefert Vater und Mutter ans Messer ...' Blut wird in Strömen fließen um seiner schwarzen Dummheit willen, Blut, daß die Röte weicht aus den Wangen der Menschheit, aber sie kann nicht anders, gefällt muß der Schurke sein"38! Soweit die Paraphrase.

Zweifellos ist Thomas MANNs Erzählung eine eigenständige Version der Pentateucherzählung. Sie ist aber in vielerlei Hinsicht und nicht nur oberflächlich aus der atl. Vorlage entwickelt. Das Gefälle von einem chaotisch-widerständigen Geschehen hin zu einer geordneten Welt, das T. MANNs Erzählung prägt, nimmt ein Gefälle der biblischen Texte auf, das der gewöhnliche Leser der Bücher Exodus bis Numeri ebenso wahrnehmen kann wie es die exegetische Forschung beschäftigt hat: das Gefälle und die Spannung von den erzählenden zu den gesetzlichen Partien in diesem zentralen Teil des Pentateuchs. Geht es nun um Geschichte oder um Gesetz im Pentateuch? Dies ist eine der zentralen Fragen zu diesen Texten auch für die atl. Forschung ${ }^{39}$. T. MANNs Erzählung greift diese Frage implizit auf und beantwortet sie eindeutig und damit auch einseitig: Es geht um die Geschichte des Gesetzes.

Die Dornbuscherzählung, die Plagengeschichte, der Auszug, alles drängt - so Thomas MANNs Sicht - hin auf das Gesetz als Inbegriff von Recht, Ordnung und Kultur ${ }^{40}$. Und darin enthüllt sich das eigentliche Anliegen und die Perspektive von Thomas MANNs Lektüre der Mosegeschichten. Hitlers unflätiger Angriff auf die Sinaigesetzgebung ist ein

37 A.a.O. [A.30] 189.

38 A.a.O. [A.30] 189f.

39 Vgl. dazu N. LOHFINK, Die Priesterschrift und die Geschichte, in: VTS 29 (1978) 187225.

40 Ein weiteres Element des biblischen Vorlagentextes, das T. MANN breit aufnimmt und ausbaut, ist das Element des Konfliktes zwischen Mose und dem Volk. Die besondere Wendung, die T. MANN diesem Element gibt, ist die Darstellung dieses Konfliktes in der Kategorie des Formens und Bildens: daß Mose - und nicht so sehr Gott - das Volk formt und bildet wie einen rohen Block, ist eine Idee, die - nach MANNs eigenem Bekunden - unter dem Einfluß des Mosebildes H. Heines steht. Vgl. T. MANN [A.29] 690f; K. HAMBURGER [A.29] 250 f. 
Angriff auf die "menschliche Zivilisation" schlechthin41. Er wird als ein Rückfall ins Naturhaft-Chaotische und Anti-Humane entlarvt.

Zweifellos spiegeln sich in einer moralisch-politischen Lektüre auch der Leser, seine Überzeugungen, sein Engagement, seine Parteilichkeit. Der biblische Text wird dabei in gewisser Weise instrumentalisiert und vereinseitigt.

Dies ist an Thomas MANNs Lektüre der Mosegeschichte offensichtlich. Die Unbestimmtheitsstellen des biblischen Textes werden im Sinne dieser Überzeugungen gleichsam bereinigt und ergänzt - so etwa, wenn MANN die Exodusgeschichte als Vor-Geschichte des Gesetzes deutet, wenn er das Gottesvolk in die Wüste, an den Gottesberg ziehen läßt und vom gelobten Land nicht spricht oder wenn er aus der Kürze und Prägnanz des Dekalogs auf dessen Universalität und Allgemeingültigkeit schließt. Diese Sicht des Dekalogs war zugeschnitten auf die universale Dimension des Konfliktes der Welt mit Hitler, wie Thomas MANN ihn sah. In dieser Sicht des Dekalogs war der Fluch begründet, den Thomas MANN dem Mose in den Mund gelegt hat und mit dem er dem Diktator den Fluch zurückgab, den dieser gegen den Sinai zu schleudern gewagt hatte: "... gefällt muß der Schurke sein"!

Man kann und muß fragen 42, ob dieser Gebrauch des Dekalogs textgemäß ist. Im Sinne einer literarisch - historischen Lektüre, die nach den Intentionen der Autoren fragt, ist er es sicher nicht.

Aber auch die Gegenfrage muß erlaubt sein, ob eine moralisch-politische Lektüre, der es um aktuelle, heutige Wirkung, die "viva vox", geht, textgemäß in diesem Sinne überhaupt zu sein vermag. Wenn der biblische Text gegen den Gewalttätigen zugunsten des Schutzlosen gelesen wird, scheint es mir dem Text zumutbar, ungeschützt gelesen zu werden. Dann, aber auch nur dann, ist die Perspektive der Parteilichkeit gerechtfertigt.

\section{DIE THEOLOGISCHE LEKTÜRE UND DIE PERSPEKTIVE DER EINHEIT GOTTES}

Wenn ich mich nun als letztem Typus der Lektüre dem theologischen zuwende, so meine ich "theologisch" in einem ganz einfachen, ja vordergründigen Sinn: "Theologisch" liest die Bibel jeder, der aus ihr etwas über Gott erfahren will.

Die berufsmäßigen Theologinnen und Theologen unter den theologischen Lesern wissen natürlich, daß das so einfach nicht ist. Es ist zwar kein Problem, theologische Aussagen im AT, bzw. der Bibel zu finden, es ist aber ein Problem, daß diese Aussagen nur mit Mühe - wenn

41 T. MANN [A.29] 690. Daß T. MANN den Mose auf dem Sinai nicht nur schreiben läßt, sondern auch gleich noch die Lautschrift erfinden läßt, hebt Internationalität und Universalität seines Ziviliationsverständnisses hervor.

42 Vgl. F. CRÜSEMANN, Bewahrung der Freiheit, Das Thema des Dekalogs in sozialgeschichtlicher Perspektive, München 1983, 2. 
überhaupt - zu einem systematischen, einheitlichen Gottesbild oder Gottesbegriff zusammenzudenken sind. Eine theologische "Mitte" des AT, das "eine Wort hinter den vielen Worten" $43 \mathrm{zu}$ finden, will bisher so recht nicht gelingen.

Man hat dieses Problem als "Verlust der theologischen Einheit" deklarieren und der historisch-kritischen Methode allein aufs Konto setzen wollen ${ }^{44}$. Ich meine aber, daß jede Lektüre, sofern sie sich nur in die Texte hineinwagt und nicht im Panzer irgendeiner Art von Voreingenommenheit durch sie hindurch marschiert, die Einheit nicht vorfindet, sondern sie allenfalls als Perspektive ersehen kann. Auch die theologische Lektüre beginnt, ich hebe hervor: beginnt, mit der Diskrepanzerfahrung.

Dies möchte nun zeigen, indem ich in kurzen Strichen andeute, wie ich einen Text der atl. Prophetie, nämlich Hos 11, theologisch lesen würde.

Gestatten sie mir dazu noch eine kurze, gewissermaßen persönliche Zwischenbemerkung: Wenn ich mich hier in der Reihe der Beispielleser selbst an den Schluß setze, liegt es mir fern, mit Leserinnen und Lesern wie Phyllis TRIBLE, Hermann Samuel REIMARUS oder Thomas MANN in Wettstreit treten zu wollen. Allerdings meine ich, daß es kaum eine Tätigkeit gibt, die weniger hierarchisch ist als das Bibellesen. Im Text sind alle Leser grundsätzlich gleich.

Hier nun, wo ich die Begegnung mit dem atl. Text selbst verantworte, soll dieser Text unmittelbar und nicht nur im Spiegel der Rezeption zu Wort kommen. Dies schließt die Einladung ein, den Text unmittelbar mitzuhören und mitzulesen. Nun also zu Hos 11:

Hos 11 ist eine Gottesrede, und zwar, insgesamt gesehen, eine Rede Gottes an sich selbst. Wir hören also gleichsam Gott über sich selbst und sein Verhältnis zu Israel reden und reflektieren.

(1) Fürwahr, als Israel ein Junge war, da liebte ich ihn, und aus Ägypten hatte ich ihn gerufen als meinen Sohn.

(2) Kaum daß ich sie rief, liefen sie schon weg von mir.

Sie opferten den Baalen, den Götterbildern räucherten sie.

(3) Ich aber hatte Ephraim doch laufen gelehrt,

ich hatte sie an seinen Armen genommen.

Aber sie begriffen nicht, daß ich sie heilte.

(4) An menschlichen Seilen zog ich sie,

mit Stricken der Liebe.

und ich war für sie wie jene, die ihnen das Joch hochheben,

das auf ihrer Backe lastet.

Ich neigte mich ihm zu, ihm zu essen zu geben.

43 W. ZIMMERLI, Rez. Gerhard von Rad, Theologie des AT, Band 1, Die Theologie der geschichtlichen Überlieferungen Israels 1957; Band 2, Die Theologie der prophetischen Überlieferungen Israels 1960; in: VT 13 (1963) 100-111, 105.

44 Vgl. etwa G. EBELING, Was heißt "Biblische Theologie?", in: "Wort und Glaube, Tübingen 1960, 69-89; 83. 
(5) Zurück muß er ins Land Ägypten,

und Assur wird sein König sein,

denn von mir hat er sich abgewandt.

(6) Und es wird tanzen das Schwert in seinen Städten

und wird vernichten und vertilgen.

[...]

(8) Wie kann ich dich dahingeben, Ephraim,

dich ausliefern, Israel?

Wie kann ich dich preisgeben wie Adma,

dich zurichten wie Zeboim?

Verwandelt hat sich über mir mein Herz,

ganz und gar erregt ist meine Reue.

(9) Ich kann meinen glühenden Zorn nicht ausführen.

Ich kann Ephraim nicht wieder verderben.

Denn Gott bin ich und nicht Mensch,

in deiner Mitte ein Heiliger,

ich lasse Zornesglut nicht aufkommen ${ }^{45}$.

[...]

(11) Bebend kehren sie aus Ägypten zurück wie Vögel,

wie Tauben aus dem Lande Assur.

IV

$\mathrm{Zu}$ ihren Häusern lasse ich sie heimkehren,

Spruch Jahwes."

Die Rede hat vier Teile.

Im ersten Teil, der die Verse 1-4 umfaßt, blickt Jahwe zurück auf seine Geschichte mit Israel. Er hat Israel seit der Zeit, als er es aus Ägypten rief, geliebt, es war sein Junge, ja, sein Sohn. Er hat es laufen gelehrt, es gestützt, es gepflegt, es an sich gezogen, es entlastet. Aber Israel hat seine Liebe und Fürsorge nicht erkannt, es lief weg wie ein kleines Kind wegläuft, ohne sich umzudrehen.

Der zweite Teil (V. 5 und 6, vielleicht auch V. 7) blickt in die Gegenwart und in die Zukunft: Israel muß zurück nach Ägypten, Assur wird es beherrschen. Das Schwert wird tanzen in seinen Städten. Das Ende seiner staatlichen Existenz wird angesagt; vor allem aber wird dieser Existenz der theologische Realgrund entzogen. Gott macht die Gabe des Landes, die nach Hosea von Ägypten her datiert, rückgängig46.

Hat Jahwe bis hierher nur über Israel gesprochen, quasi im Selbstgespräch, so spricht er im dritten Teil, den VV. 8 und 9, Israel unmittelbar an: "Wie kann ich dich dahingeben, Ephraim, wie kann ich dich ausliefern, Israel? Wie kann ich dich dahingeben wie Adma, wie kann ich dich zurichten wie Zeboim?" Dann wendet sich Jahwe zunächst

45 Zur Übersetzung vgl. J. JEREMIAS, Der Prophet Hosea, ATD 24,1, Göttingen 1983, 139, Anm. 8.

46 Vgl. dazu H. UTZsChNEIDER, Hosea, Prophet vor dem Ende, Zum Verhältnis von Geschichte und Institution in der atl. Prophetie, OBO 31, Fribourg - Göttingen 1981, 172. 
wieder an sich selbst zurück: "Verwandelt hat sich über mir mein Herz, ganz und gar erregt ist meine Reue. Ich kann meinen glühenden Zorn nicht ausführen. Ich kann Ephraim nicht wiederum verderben. Denn Gott bin ich und nicht Mensch."

Der letzte Teil (im wesentlichen V.11) greift inhaltlich auf den ersten zurück. Wieder kommt Israel aus fremden Ländern, wie ein Vogel,

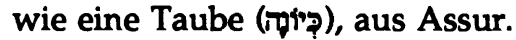

Gott läßt uns hier teilnehmen daran, daß er nicht kann, wie sein Zorn eigentlich will. Wir werden Zeugen, wie Jahwes Herz über ihn hinweg geht, wie das, was er "meine Reue" ('ping) nennt, ihn ganz und gar in Atem hält, so daß er Ephraim nicht vernichten kann. Dabei steht sich offenbar Gott als Gott im Weg, denn wäre er Mensch, die Vernichtung Israels wäre - wie wir wissen - nicht gehemmt gewesen.

Damit macht uns der Text eine Diskrepanz in Gott selbst sichtbar. Ein Widerspruch besteht bereits zum Gottesgedanken der beiden ersten thematischen Komplexe des Textes. Durchaus im Sinne eines prophetischen Gerichtswortes geben sie Anklage und Urteil wieder: Weil Israel Gottes Liebe nicht erwidert und sich anderen Göttern zugewandt hat, wird es real und theologisch vernichtet. Denkt man nur von den VV. 17 her, so ist das ganz in Ordnung. Ein moderner Kommentator schreibt: "Dem Exil aber geht ... ein Blutbad in den Städten Israels voraus. Und das alles ist wohlverdient: sie büßen nur, was sie selbst verschuldet haben ..."47. Es ist nun aber in den beiden folgenden Teilen der Text selbst, der gegen diese Deutung einschreitet: Vielleicht hatte Gott es ja so gewollt. Vielleicht hatte Gott der Gerechtigkeit gegenüber der Liebe den Vorzug geben wollen. Aber er konnte es eben nicht. Nicht weil er schwach geworden wäre, wie ein Mensch schwach wird, konnte er es nicht, sondern weil er Gott ist: Deshalb mußte sich sein Zorn durch seine Liebe überwinden lassen. Und so nimmt der Heilige trotz der Schmähung, die seiner Liebe widerfahren ist, wiederum Wohnung in Israel. Gott ist zu sich selbst in Widerspruch getreten und hat sich dabei selbst überwunden.

Nach dieser "Selbstüberwindung" Gottes ${ }^{48}$ bleibt nichts, wie es ist: Man sieht es im letzten Teil des Textes zuerst an Israel: Nicht mehr getragen und geleitet wie in ägyptischen Kindertagen kehrt es aus dem Exil zurück, sondern zitternd und taumelnd, wie ein Vogel, der dem Sturm entronnen ist. Und auch Gott ist nicht mehr der gleiche: Er ist nicht mehr der All - Eine; er hat sich durch seine Liebe erniedrigen, mit sich selbst entzweien lassen.

Eben damit - und nun kommen wir zur Perspektive jener Diskrepanz - steht die Theologie von Hos 11 auch im Widerspruch zu einem

47 W.RUDOLPH, Hosea, KAT XIII/1, Gütersloh 1966, 216.

48 So gibt J. JEREMIAS a'ơrq wieder, das gewöhnlich mit "Reue" übersetzt wird. Vgl. DERS., Die Reue Gottes, Aspekte atl. Gottesvorstellung, BSt 65, Neukirchen 1975, 46 u.ö. 
Gottesgedanken, der durch die griechische Philosophie mitgeprägt ist und der die Einheit und Unwandelbarkeit Gottes zur Voraussetzung hat. In unserem Jahrhundert wurde dieser Widerspruch zunächst von dem großen jüdische Theologen Abraham J. HESCHEL formulier ${ }^{49}$, und zwar als die prophetische "Theology of Pathos", die Theologie der Leidensfähigkeit Gottes. Jürgen MOLTMANN hat - auch im Anschluß an HESCHEL - seine Lehre von der Theopathie, der Passion Gottes ${ }^{50}$, entwickelt; auch D. SöLLE hat den Gedanken aufgenommen ${ }^{51}$.

Die Lehre von der Theopathie besagt im Kern, daß Gott nicht in ewiger Vollkommenheit und ferner Gerechtigkeit in sich ruht, sondern daß er sich öffnet für ein Anderes. Was ist dies Andere?

Dieses Andere ist zunächst Israel, das - wie schuldhaft auch immer - leidende Israel. Dieses Andere ist aber auch in Gott selbst; Hos 11,8 nennt es seine, Gottes, םיạ, seine, wie man gewöhnlich übersetzt, "Reue": Diese "Reue" Gottes führt dazu, daß Gott, sein Herz wenden und seine Liebe über seinen Zorn und seine Gerechtigkeit die Oberhand gewinnen läßt, daß er sich "selbst überwindet".

Daraus resultiert, wie MOLTMANN darlegt, eine "bipolare Theologie": Gott ist - einerseits - in sich selbst frei und hat sich keinem Geschick unterworfen. Gott hat sich - andererseits - durch sein Pathos, sein Mit-Leid, zugleich im Bund festgelegt. Er thront im Himmel und wohnt zugleich bei den Niedrigen und Demütigen ${ }^{52}$.

MOLTMANN weist zurecht auch auf die jüdische Lehre von der Schechinah, der "Einwohnung Gottes", hin. Auch diese Lehre setzt eine "Selbstunterscheidung" Gottes voraus. In der Schechinah ist Gott in Israel präsent. In ihr leidet er mit Israel Verfolgungen, wandert er mit Israel gefangen ins Exil, empfindet er mit den Märtyrern Todesqualen. Die Wiedervereinigung der göttlichen Schechinah mit der ewigen Herrlichkeit, die Aufhebung der Selbstunterscheidung Gottes wird letztlich erst erreicht, wenn die Erlösung Israels vollendet und die Harmonie der Welten restituiert sein wird 53 .

Die Vorstellung von der Selbstunterscheidung und Selbsterniedrigung Gottes in der Liebe prägt schließlich auch die Lehre vom Leiden Gottes im Leiden Jesu Christi54. Wie die "Reue Gottes" bei Hosea ist das Leiden Gottes in Jesus Christus motiviert im Mit - Leid Gottes für die

\footnotetext{
49 A.J. HeSCHEL, The Prophets (1955), New York 1962.

50 J. MOLTMANN, Trinität und Reich Gottes, Zur Gotteslehre, München, 1980, 36-76. Vgl. schon DERS., Der gekreuzigte Gott, München 1972.

51 D. SŌLLE, Leiden, Stuttgart (1973) ${ }^{8} 1989,56 f f$.

52 Vgl. J. MOLTMANN [A.50] 42.

53 Vgl. a.a.O. [A.50] 43f.

54 Wie die "Reue" Gottes nach Hos 11,8 kann man das Leiden Gottes im Leiden Jesu Christi als einen Vorgang in Gott selbst verstehen. Deshalb hat die Lehre von der Theopathie auch ihren Platz in einer christlichen Trinitätslehre, in deren Rahmen sie MOLTMANN behandelt.
} 
Menschen. Anders als die "Reue Gottes", ist das Leiden Gottes in Jesus Christus ein ganz unmittelbar menschliches, körperliches Leiden. Eben darin geht es über den Gedanken der "Reue Gottes" im atl. Sinne hinaus. In Jesus ist Gottes Leiden noch unmittelbarer, noch radikaler, es nicht nur gedacht oder gesagt, es ist Wirklichkeit.

Ähnlich wie die Einwohnung Gottes in Israel ist das Leiden Gottes in Jesus Christus Ausdruck der Erniedrigung Gottes, und es ist der Anfang des neuen Lebens. So geht die Vorstellung von der Theopathie von einer Diskrepanz aus und ist auf eine zukünftige Vollendung hin angelegt. In dieser Perspektive kann Hos 11 als ein christologischer Text gelesen werden; in dieser Perspektive liegt die Aufhebung der Selbstunterscheidung Gottes und somit die Einheit Gottes, in dieser Perspektive liegt auch die Vollendung des Kosmos.

Diese Perspektive eröffnet sich wiederum nur, wenn man die Diskrepanzen, die der Text in sich selbst und gegenüber unseren theologischen Denkformen aufweist, wahrnimmt, aushält und verarbeitet. Die Einheit der atl. und der biblischen Theologie ist von dieser Voraussetzung her keine Größe, die innerhalb der Texte gegenwärtig und greifbar wäre, sondern sie ist eine Größe außerhalb der biblischen Texte und vielleicht sogar eine Größe außerhalb der Theologie. 


\section{Zum vorliegenden Buch}

Der vorliegende Band ist Klaus Baltzer zum 65. Geburtstag gewidmet. Der Titel, «Konsequente Traditionsgeschichte», ist Klaus Baltzers Programm. Es zielt auf eine Exegese des Alten Testaments, die dessen Texte und Konzepte über Grenzen hinweg verfolgt. In Baltzers Forschung haben altorientalische wie griechische Geschichte und Literatur einen hohen Stellenwert. Die Gegenwartsbedeutung alttestamentlicher Texte und Konzepte liegt ihm am Herzen. Demgemäss enthält dieser Band neben alttestamentlichen Artikeln Beiträge aus dem Bereich des Neuen Testaments, der griechisch-hellenistischen Antike sowie zur Rezeptionsgeschichte des Alten Testaments in der Neuzeit. Auch der praktisch-theologische Aspekt ist vertreten. Mitgearbeitet haben u.a.: Dieter Georgi, Manfred Görg, Baruch Halpern, Jörg Jeremias, Helmut Koester, Norbert Lohfink und Josef Scharbert. 